


\section{Bound 1946}

\section{HARVARD UNIVERSITY}

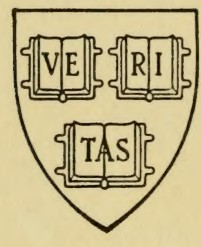

\section{LIBRARY}

OF THE

MUSEUM OF COMPARATIVE ZOÖLOGY

\section{9}





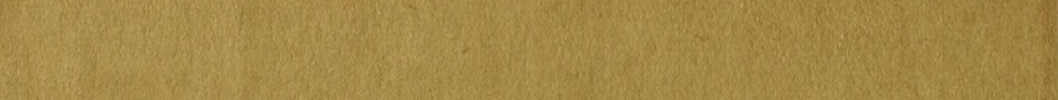

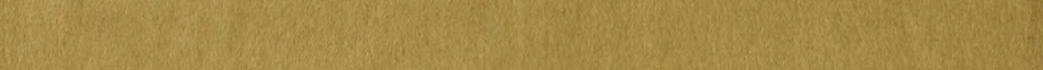

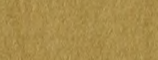

$$
\text { S. }
$$$$
\text { (1) }
$$

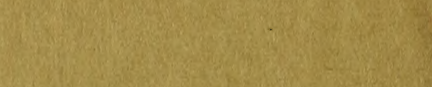

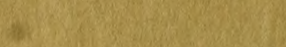

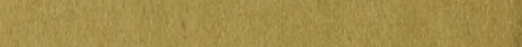

(1)

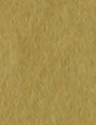

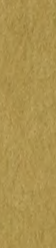
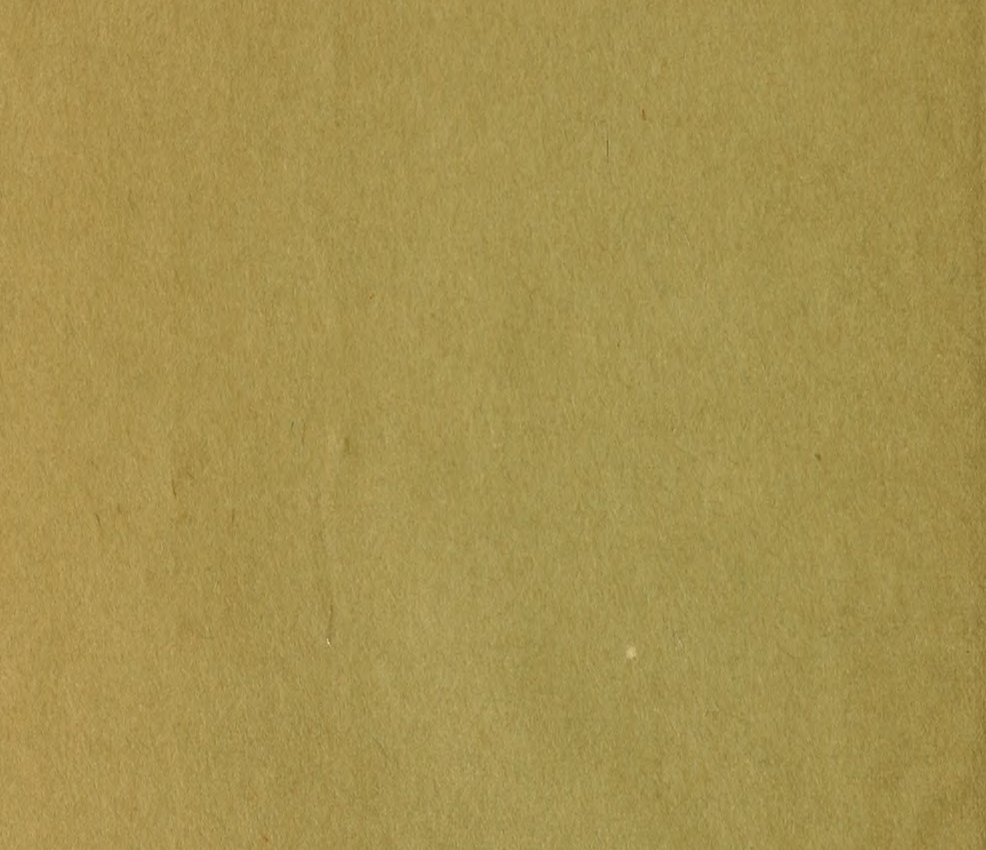

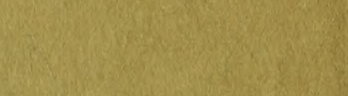

(ex)

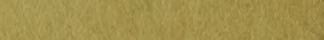

2.

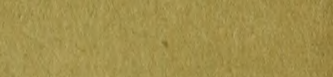

xistix

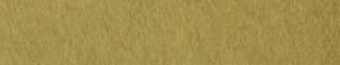

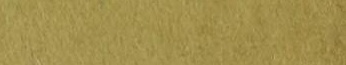

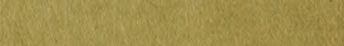

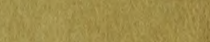

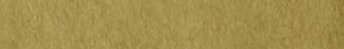

3.

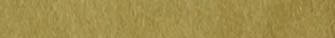

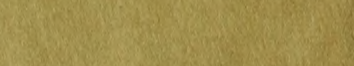
(2)

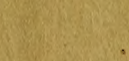

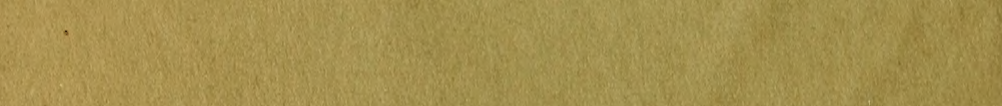

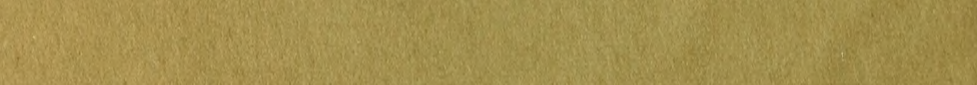

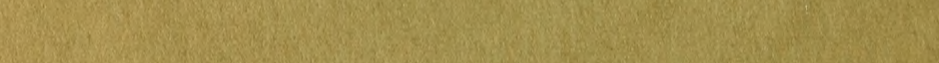

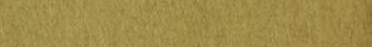
ton (3)

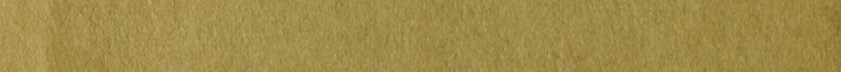

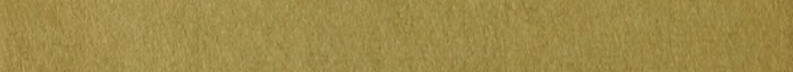
Pla 


\section{.}





\title{
NOV 161928
}

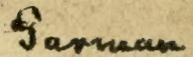

\author{
(Semeinnthige figtematifde
}

\section{Piaturacidoichte}

\section{1,189 Der \\ fif d c $\mathrm{e}$.}

E $\mathfrak{n}$ tworfen

yon

\section{CUarl Cubriftian (15melin,}

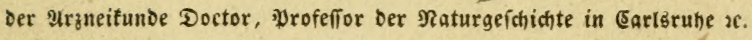

3 weite $\mathfrak{A}$ uggabe.

2RRit 164 มbbilbungen auf 113 \&uџfertafeln.

Mannbeim.

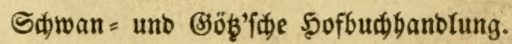

1839.

$$
2.4 .
$$



Dé Kitterg yon \&inné (Amphibia nantes) (d) mimmende 2 mplibien murden nad) (B) ronov, (Souan, Slod) unb andern ju ben Fifden gebracht, inbem ibre Siefen, wie bei Sen fifchen gefafert, jesoch nidte, wie bei sen übriget Filden frei, fonbern an cimem gebogenen, runsen uno röhrenförmicen (Sefäri ohne fnöchernen ßogen angemactifen find, Ginter Dem Sopfe liegen, uno fich an ben Seiten bez Borberleibes surch ein oder mehrere Euftlöcher offnen, bie gemeiniglich feinen beiondern Siefendeckel haben. Die lejtern Battun: gen serfelben haben jedoch fdon wircfliche (Jräten uno Gtrablen in ber Siefenbaut.

Um bie bier yorfommenben fünf $O$ ron $\mathbf{n}$ ! gen ber Fifche und beren (S) attungen oder (5): fd) lechter (genera) zu einer leidtern Ueberficht zu bringen, fano man für nöthig, in ser Einleitung eine gebrängte Befidreibung jeder einjelnen Sinttung soraus geben ju laffen.

Sorz̆üglich $\mathfrak{A n f a ̈ n g e r n ~ u n b ~ a u d b ~ a n b e r t , ~ w e l c h e ~}$ in ber Siefchmindigfeit eine ober bie ansere ober

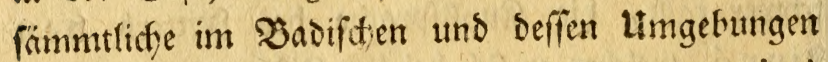
vorfommenten Fif (t): Sattungen und 2 (rten (species) nadficlagen wollen, glauben wir bas Nachfuchen Durd) bie Borbruckung einesa $(t)$ bei ben yaterläns sifden fifden febre exlecthtert ju baben. 
Im bodenfee fins mehrere Sुifhe, welthe nath ifrem verfdiebenen alter mit fefyr verfotebenen Namen belegt werben. Dafin gefört vorjüglich Der Blaufelcten, Drever, Şalbfifh, 2henden, Bangfifd, Stuben, Steuben, J̧euerling, Mandel, (Salmo Wartmanni) ein und serfelbe fifh, melcter untet Siefem গamen bei ben Fifdern bez Sobenfee'z vor: fommt. Jmerften Jafle wird ex Şellerling und Naydel, im zweiten Stuben ober @teu: ben, im britten (s)angfif (h), im vierten $\mathfrak{A}$ hen de $n$, im fünften $\mathcal{S}_{\text {al }}$ f fif (b), im fecheten Dreys ex, und im fiebenten $\mathfrak{b l a}$ ufelchen genennt. Der ebenfalls im Ђobenfee vorfornmende Sigeisfel (h) en,

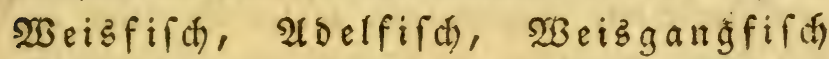
ift eine Abänderung ber groß̧en Maräne (S a lmo Maraena). Deşgleichen mus ber Dafelbft fich befindende Sandfelchen, Kropffeldien,

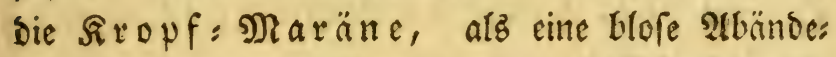
rung der grofen $\mathfrak{R}$ ax äne angefelyen werden.

Fifde, meldye lebendige Sunge jur Siselt brims gen, verbienen alle unfere 2 ufmerffameeit, Dahit gefiört bie $\mathfrak{Y}$ a $\mathfrak{l}$ utter, (Blennius viviparus) Ser $\mathfrak{A}$ ugenroimper, (Blennius superciliosus) und die furinamifde Sd)merle, (Cobitis anableps) meld) lejtere aud nod) weaet inren fonderbaren $\mathfrak{A}$ ugen, weldfe jwei burdbfidtige 


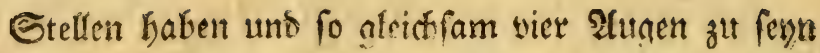
fdeinen, bem Naturforfoter fehr auffallend ift.

Der prafbaud (Silurus Ascita) iff befone

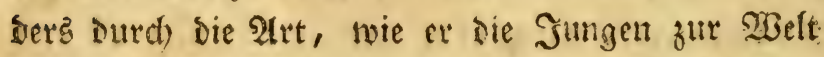
Iringt, äuperft merefmürbig, und bält gleithfam. sas פMittel zmifchen ben lebentig gebährenden un exerlegenten Thieren.

Der Rüfels Rippfifd), (Chaetodon roo stratus) weldher fich in ben oftindiften (Semäffert an sem feudten ufer bes Mecres finbet, nährte fich son Fliegen, welche fich auf bie aus bẹm $\mathfrak{B a f f e r}$ herworragenten Pflansen fefen, auf eine äuberft. auffallente und mercf́nürbige Srt. Er nahet ficts. Ser Fliege biz alf cime Entfernung von vier liz

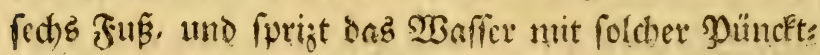

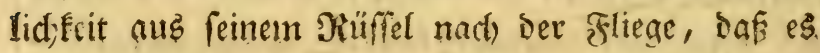
anm nie fellt, felfige ins SWaffer berabjumerfen, um fie zu verfolingen.

Der Sactébad) fen (Sparus Pagrus) wets breitet, fo wie er im Nill cricheint, in Egypten eine allgencine Freuto, intem man butrd) feine Ers.

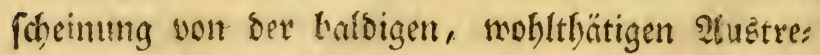
tung biejez fluffes fit) übergengt bält. Saljer bie

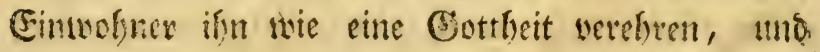
fimer snenge ungeadytet, nid) einch vergelyen, 
mier, Gouan, Pallas, Hermann, Leske, Broussonet, Pennant, la Cepède, Bonnaterre, v. Meidinger uno andere, vorjüglıch aber Blochs Filche, welte allen biahterigen $\mathfrak{W e r c}^{6} \mathrm{en}$

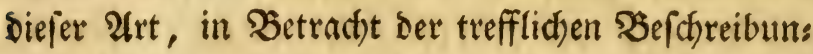
gen, ber vielen eigenen :Beobadjtungen uno natur: getreuen $\mathfrak{A b b i l}$ bungen ben Rang freitig ma(b)en, fo weit fie von uns gebraucht werben fonnten, bes ftens benugt.

\author{
Carloruke, \\ ben 23. November \\ 1816 ,
}




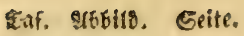

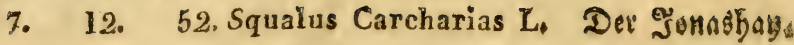
I.e Sq. Requin.

- 13. - - Der offene Madhen.

8. 14. 56. - Pristis L. Der Eägehay. Le Sq。 à Scie.

- 15. - - Der Ropf unb Cẳge von Unter.

9. 16. 59. Chimaera monstrosa L. Der झeers bracte. La Chimère arctique.

10. 17. 61, Acipenser Sturio L. Der Etöbr. L'Acis pènsere Esturgeon.

- 18. - - Der Ĵp fopfon Unter.

11. 19. 69, Lophius piscatorius L. Der grofé frefóds fiig. La Lophie Baudroie.

- 20. - .. Die Baudfoffen.

12. 21. 72. Cyclopterus Lumpus L. Der \&ump. Le Cycloptére Lompe.

13. 22. 75. Balistes Monoceros L. Der Einfgernili Le Baliste Mønocéros.

- 23. 81. Centriscus Scolopax L. Der Edjnepfer, fiíd,. La Bécasse.

14. 24. 84. Pegasus Draconis L. Das Drademperea pfero. Le Pégase Dragon.

- 25. - - von Unten.

15. 26. 86. Syngnathus Acus L. Die Cenabel. Syngnathe aeguille.

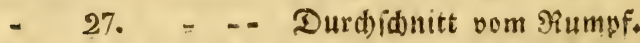

- 28. - . - . - binter bein Zffer

- 29. - - . - - vom Schwank:

- 30. 87.- - Hippocampus L. Das Seepferos den. Syngnathe Hippocampe.

16. 31. 90, Diodon Hystrix L. Der runce Êtadyela fir 
พัก. *66rilo. Seite.

17. 32. 91. Diodon Mola L, Der fowimmente Sopf:

Le Tétrodon Lune.

- 33. 96. Tetrodon ocellatus L. Dev geflecte

Stadelbaut.

- 34. - -. Die obere Seite.

18. 35. 102. Ostracion turritus L. Der Sburmtrăs ger, L'Ostracion Dromadaire.

19. 36. 105. Gymnothorax Heleaa Bl. Die Murene, Le Murénophis Hélène.

20. 37. 108. Muraena Conger L. Der Meer= 2alo La Murène Con

21. 38. 109... Anguilla L. Der zal, La M. Anguille.

22. 39. 111 Gymnotus electricus L. Dev 3itter 2al. Le Gymnote électrique.

23. 40, 115. Trichiurus lepturus L, Der filberfara bige Spighnany, Le Trichiure Lepture.

24. 41. 116, Anarhichas Lupus L Der Seeworf. L'Anarhique Loup.

25. 42. 118, Ammodytes Tobianus L. Der Gando aal. L'Ammodyte appat.

- 43. 119, Ophidium barbatum L* Der \$arta Calangenfifa, L'Ophidie barbu.

26. 44. 120. Stromateus Paru L. Die Gulooecte. Le Stromatée Paru.

27. 45. 122. Xiphias Gladius L. Der ङळwertfild) Le Xiphias Espadon.

- 46. - . Die Sd) Sertortängerung von uns ten.

28. 47. 123. Sternoptyx diaphana. Ser burdfidetige Bruffultenfito. Le Sternoptyx Heszhann, 
ลaf. 246tito. Geite.

28. 48. 123. - - Der Stoyf yon Sorne.

- 49. 125. Leptocephalus Morrisii L. Der geftriz d)elte Banififd. Le Leptocéphale Morrisien.

- Stylephorus chordatus. vid. T. 77. Fig。 108.

29. 50. 128. Callionymus Lyra L. Det grof̧e Spins nenfifa. Le Callionyme Lyre.

- 51. - - Der Siopf von Dient.

30. 52. 131. Uranoscopus scaber L. Dev raube Sternieber. L'Uranoscope rat.

- 53. - - Die obere Geite Des Sopfed.

31. 54. 132. Trachinus Draco L. Dą भुetermăm: (h) La Trachine vive.

32. 55. 134. Gadus Aeglefinus L. Der ๔dellfifi. Le Gade aeglefin.

33. 56. 137... Morhua L. Der Siabeljau. Le Gade Morue.

34. 57. 143. - Lota L. Die Suappe. Le Gade Lote.

35. 58 145. Blennius ocellaris L. Der Mieerpapillor. 36. 59. 150..- viviparus L. Die 2aalmutter. Le Blennie ovovivipare.

- 60.... ฐัunge.

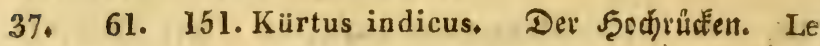
Kurte Blochien.

38. 62. 152. Gymnetrus Hawkenii. Der Şarkenif he Rablafter. Le Gymnètre Hawken.

39. 63. 153. Cepola Taenia L. Der 'Bantfict. Le Cépole Taenia.

40. 64. 155. Echeneis Neucrates L. Der Sdjiffs= Galter. L'echénéis naucrate. - 65. - . Der Ropf uon Dben. 
ఇก.. Mbbit8, Eeite.

41. 66. 157. Coryphaena Hippurus L. Der geffecfte StujEopf. Le Coryphène Hippurus.

42. 67. 164. Macrourus rupestris Bl. Der lang= fhimang. Le Macroure Berglax,

43. 68. 165. Lepidopus argenteus G. Der fitberfar. bige Bjertenfifक. Le Lépidupe Gou anien.

69. - Die 2lfterfiofie.

44. 70. 166. Gobius niger L. Die Meergrundel, Le Gobie noir.

71. 172, Cottus, Scorpius L. Der See= SElos: fion. Le Cotte Scorpion.

45. 72. 175, Scorpaena, Porcus L. Der Eleinịdups pige Dradbentopf.

46. 73. 178. - v volitans L. Der fliegende Dractens Exf. Scorpéne volante,

47. 74. 180, Zeus Vomer L. Der Pflugiळaal. L'Argyréiose Vomer.

48. 75. 186. Pleuronectes Hippoglossus L. Der Şei= ligebut, Le Pleuronecte Flétan.

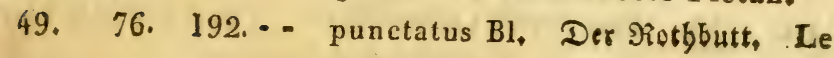
Pl. Targeur,

50. 77. 196. Argus Bl. Der 2ligus. Le Pl. Argus,

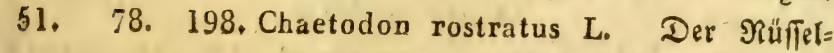
Eliprifí). Chétodon Museau-aloz. gé.

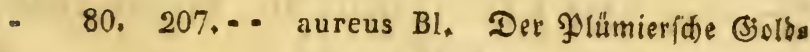
fiic). Le Pornacanthe doré.

52. 79. 204... Imperator L. Der Siàiferfif क. L'Holacanthe Empereur.

53. 81. 209. Eques americanus B1. Der Mitterfif Le Cheralier américaid, 
Taf. 2ribitb. Geite.

54. 82. 210. Sparus aurata L. Der (5olb= istadi) iem. Le Spare Dorade.

- 83. - - Der pfiene Nuno mit వăbnell.

55. 84. 216. - chlorourus Bl. Der grünfó) wänjigs 23radiem. Le Sp. queue-verte:

56. 85. 217. Scarus Croicensis Bl. Der rotbe Pa: pageififid). Le Scare rouge.

57. 86. 218.-. viridis BI. Der grüne spapageififá) Le Sc. verd.

58. 87. 219. Labrus lunaris L. Der violette Rlipp= fifct). Le Croissant.

69. 88. 220,-- Julis L. Der Meeriunfer. La Gi relle.

60. 89. 226. Sciaena nigra Bl, Der Umberfifds L'Umbre.

61. 90. 226. Bodianus Bodianus Bl. Ber Bobiall Le Bodian.

62. 91. 227. Holocentrus Sogo Bl. Der Goge, L'Ho* locentre Sogo.

63. 92. 228. Lutjanus Lutjanus B1. Der Sutjanfifí 64. 93. 231. Perca Lucioperca L. Der Sarider. Le Centropome Sandat.

65. 94. 234..- guttata L. Der \$S(utbaarid). La Sanguinolente,

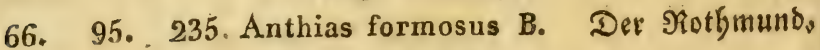
Le Lutjan Écureuil.

67. 96. 236. Johnius Carutta Bl. Der Sarutt Jobns fiid).

68. 97. 237. Epinephelus afer BI, Das afrifanij̄o Stöbange.

69. 98. 238. Gymnocephalus Schraetser Bl. Der Sdrätjer, L'Holocentre Schrabte ser. 
Laf. erbilt, Etite.

90. 99. 239. Gasterosteus aculeatus L. Det gemeinte Stidyling. Le trois Épines.

- 100. 242. Scomber Scomber L. Die Matiele. Le Maquereau.

71. 101. 248,.. Gladius B1. Die Sdwwert: M2aErele

L'Istiophore porte-glaive.

72. 102. 251. Mullus Surmuletus L. Die gelogeftreifte Meerbarbe. Le Surmulet.

73. 103. 253. Trigla cataphracta L. Der gepanzerte Seebabn. Malarmat.

74. 104. 256... volitans L Der fliegende Sees bakn. Pirapède.

75. 105. 257. Ophicephalus punctatus Bl. Der puntes tirte Sd)langenÉpf. L'Ophicephale Karruwey.

- 106. - .- Der Ŝpf von Dber.

76. 107. 258, Lonchurus barbatus Bl. Det Gärtige Ranjetif́cwanj. LeLongure dianème. 77. 108. 127. Stylephorus chordatus Schaw. Der faa benförmige Stielaugenfild,. Le Sty. lephore argenté.

78. 109, 260, Cobitis Anableps L. Die furinamif

Sđmerle. L'Anablèps Surinam.

- 110. - . - Ein Junges.

- 111. 263. - Barbatula L. Die geit. Ed binerte. La Cobite Loche.

- 112. 265,-. fossilis L. Die Calammiðmerte. Le Misgurne fossile.

79. 113. 267. Amia calva L. Der Eable Nafenfaß̧ę: fiif). L'Amie chauve.

80. 114. 268. Silurus militaris L. Der ffeifbartige श્રelb. L'Agénéiose armé.

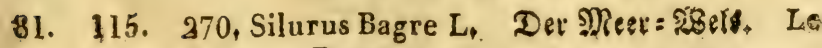
Bagre, 


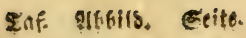

81. 116. 270... Ein Snlnges,

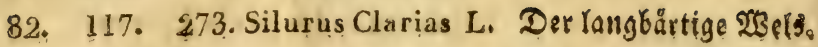
Le Sheilan.

- 118. 275... Ascita L. Der Ylaj6aud), L'Ascite

- 119\% = $=2$ son Uhten.

- $120.12 \mathrm{~T}$ - - Ener.

83. 123. 278. Platystacus cotylephorns Bl, Der Fele Lerriäger. L'Asprède,

- 124. = Der sicpf vell Unten.

84. 125, 280. Platycephalus Spathula B1. Der Sd)auz felplatténf. Le Callionyme indien.

126. - . Der Sdrwan mit ben Siürfen = uno 2ffterferten.

85. 127. 281. Notocanthus Na:us Bi, Ier Naîn= Stacthefrucfen, Le Notacanthe Nezo

86. 128. 283. Loricaria Plecostomus L. Der rungele maulige Şarnifofiił). Le Guagari.

87. 129295 Salna alpinus L. Die Bergforelle. La Bergforelle.

88. 130، 296.-- Salvelinus L. Der Eätbring. La Salveline.

89. 131. 302.-. Thymallus L. Die 2ilide, LOOm= bre de Rivière.

90, 132. 303... Maraena Bl。 Die grȩ́e Maräne, La Marène.

91. 133. 307.-- Wartmanni Bl. Der Blaufelder, L'Ombre bleve.

92. 134. 310... rhombeus L. Der Sägebaudd, Le rhomboide.

- 135, a, - - Dir feilformige Snodjen oor teq Siúckentefle.

- 135.b. . E Eine 3atujidupe, 
Eatf. Nhbits. Esite.

93. 136. 311. Fistularia tabacaria L. Der Tabactz: pfeifenfifd. La Petimbe.

Eine dbănoerung mit

- 137. - .. - . Doppilter @sivaniporife.

- 138. - .. . - gejäbnelter Sdnauje.

94. 139. 312... chinensis L. Der Erompetenfifd. L'Aiquille.

95. 140. 31\%. Esox Belone L. Der Jृornfed)t. Lák Bélone.

- 141. - - Wirbelbeine bes untern Bauded.

96. 142. 319... brasiliensis L. Dev brafilianifde Sedt t. Le petit espadon.

97. 143. 320. Elops Saurus Bl. ऊor guineifde ङi. bechfenfiict). L'Elope Saure.

- 144. 322. Atherina Hepsetus L。 Der Rornäfy: renfiid), Le Joël.

28. 145. 323, Mugil cephalus L. Der 5̧arber. Le Muge.

99. 146. 326. Exocoetus exiliens L* Der Epringer. Le Muge volant.

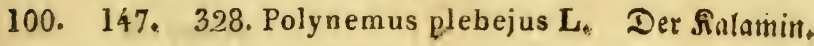
L'Emoi.

101. 148. 330. Clupea Harengus L. Der Seering. Le Hareng.

102. 149. 336... Alosa L. Der Maififid). L'Alose。

- 150. 338.-. Encrasicolus L. Die Sardelle. L'Anchois.

103. 15́l. 339. Pilchardus Bl. Der \$ुildaro. Le Clu. panodon Pilchard.

104. 152. 342. Cyprinus Bárbus L. Die Barbe. Le Barbeau.

105. 153. 349.-- macrolepidotus Bl. Ser Epiegeta Earpfen. Le Cyprin Spéculaire. 


\section{2af. Stbititb. Eeite.}

106. 154. 350. Cyprinus Gobio L* Die STreffe Le Gougon.

- 158. 357... Phoxinus L. Die Elrige. Le Veron.

107. 155. 352... Tinca auratus Bl. Die Bjoldofoleces Le Tanche dorée.

108. 156. 353. -. Carassius Lt Die fiaraufáe. L'Hamburge.

109. 157. 355..- Gibelio L. Der Ģieber. La Gibéle.

110. 159. 358... Leuciscus L. Der Eauben. La Vaudoise.

- 162. 370... bipunctatus BI, Die Strunfe, Le Spirlin.

111. 160. 362... erythrophthalmus L. Das Rot5s: auge. Le Sarve,

- 163. 371. - amarus Bl. Der \$itterling. La Bouvière.

112. 161. 365... Orfus L. Die Dria. L'Orfe.

113. 164. 38\%... auratus $L_{*}$ Der Jolbearpfert. Le Cyprine doré.

geydex. 
tum) kegelförmig (conicum) buckelig (gibbum) mit berooxfebelloem $\mathfrak{B} a u d$ e (ventricosum) fpin. Delfôrmig (fusiforme) Ianzetförmig (lanceolatum.)

TSas die Bebectung Der Fifde betrifft, to find bie meifen mit (S)uwsen verfehen, (corpus squamis tecturs) einige bingegen fino nackend, (corpus nudum) obrie St) upwen und $\mathfrak{S}_{\text {d) }}$ itber, (pisces alepidoti) glat (glabrum, læve) fdlüpfrig, fd) leimig (lubricum, mucosum) ra b), (scabrum) Enopfig (tuberculatum) weidfwargig (papillosum) bartwarzig, (verrucosum) Eleinfta elig, (muricatum) grofit d) elig, (aculeatum) Gorftig, (setaceum). Die Ed)up= wen fino wand, (squamae rotundae, orbiculatae) lángli í) runo, (oblongae) eyförmig, (ovatae) jugefpist, (acutae, acuminatae) abgeftumpft, (truncatae) orey = vier $=f e d) b e c f i g$, (tri - quatuor sexangulatae) am $\mathfrak{R} a n b e$ ganf, (integrae) gefägt, (serratae) geferbt, (crenatae) geftangt, (ciliatae) glatt, (glabrae) ra ub́, (scabrae) fllópfig, (tuberculatae, ftadelin, (aculeatae) gefteift, (striatae) itrablig, (radiatae) Enödern, hart, (osseae) Enorvelartig, (cartilagineae) blâttrig, (lamellosac) ain fïrper feft angewad)fen, (tenaces) leid) $a b f a l l e n d$, (deciduae) geflect, (maculatae) pundt tirt, (punctatae) bandirt, (fasciatae) giob, (amplae, magnae) Elein, (parvae) Eaum fid)tbar, Doer feble Elein, (minimae).

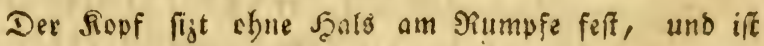
febr verichieden gebrldet. Siad) Der Geffalt, Dem Umfans

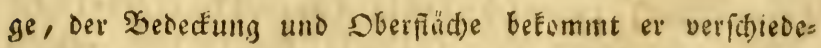
ne Bencunumgen als: $x$ und, getundet, eyförmig, berzförmig, abgefumpft, (truacatum) zulü te 
gefîumpft, (retusum) ơ ugeipigt, (acuminatum,

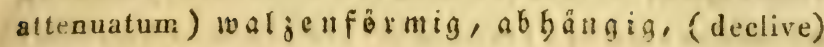
eingebogen. (simum) in einen গüffé vevtăns gert, (rostratum, in rostrum porrectum) ba m mers förmig, (malleiforme) plattoeor ü ớt, (plagopla. teum, depressum) ectig (argulatum) mit einem Sd)ilde bebedt, (cataphractum) bepangert, 10. ricatum) Geidouppt, (squamatum) nacḱt, (nidum) glatt, (glabrum) mit einee fettbaut bedecte, (pingue) weidswargig, (papillosum) bartwarkig, (verrucosum) $x$ ulj lid), (rugosum) erbaben fund tirt, (elevato - punctatum) a (excavato - punctatum) ra: h), (scabrum) gefurtht, (sulcatum) firablich), (radiato - striatum) mit lans gen berfenförmigen znfágen befert, (cirris instructum) mit $\subseteq$ tadeln, (aculeatum) mit fảges förmigen $2 u e r f u r d e n$, (transzerse sulcato-serratum) mit einem Sdirto verfehen, (clypeatum) mit einem $\Re a m m e$ (cristatum).

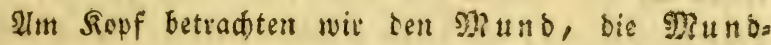
of nung, (os und rictus) we!de in Betrad)t ifrer Rage, Beffalt, Shidtung, und Serbältnif, oft fefre verfdieben find. Die Mundöfnung, (Rictus) ît gewóhnlid rorn

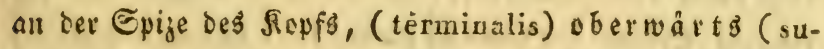
perus) unterwårts, (inferus). Nacb ber Rithtuig ift fie horizontal, (transversus) fencked) $t$, (verticalis) fdief, (obliquus). Eic if genóbnlid mit

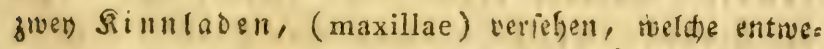
Ler unbedeft, (maxillae nuda) c cer mit Eippen bedect, (labiatae) finto. Die Rippen, (labia find verítieden nach iffrer Eubitan, alö, fleiftig, (car. дosa) băutig, (membranacea) nadi ifra 2(miabl: 
einfach, (simplicia) boppelt (duplicata), naर́t) ifs rev (Geftalt: ganz, (integra) gefpalten, (fisa, bifida) zweylappig, (biloba) fünftheilig, (quinquepartita) am rande gefranj, (ciliata) mit Fublfäoen verfeben, (tentaculata) in einell Săffel verlăugert, (rostrata). Diz Sinnladen

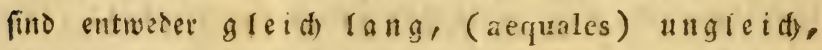
(inaequales) die obere ragt hter tie mintere bervor (mandibula ensiformis) und ift entweder anf beiten Eeten gang, (integra) wie beim Ð d)werofifd), (Xiphias) ober mit fägenförmigen Spizen befezt, (serrata) wie bim Sảgefiich, (Squalus pristis).

Die 3 ing ne ber fil be liegen oft in Den Sinnlaben, aud) in ber Bunge, im (jaumen, unt Siblunbe. Sie fino entweder fpizig, ober aud) ftumpf, abgeruns Det, (rotundati) pfeilformig (sagittati) beweglid) Dber unbelvegli

Die Siemen, Siefen, Siefern, (Branchiae) lienen an ben Seiten bes Rupfs, und befteben aus einer gebogenen Gräte, an deren erbabener Seite, eine aup̃ers

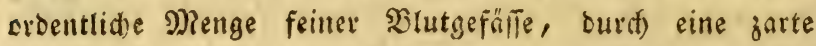
Şmt raufen. 2fn jeber Ceite liegen vier Riefern, bie sten burch einen Snorper, an ben zwey rauken oder ges zăbnten Eleinen (s) a umenÉod)en, (Officula palati) anbängen, uno unten Durd) bie Sieglenbaut mit eils ander verbunden find. Sie find surch die Riefern bedel, (opercula branchialia) bedecte, an weldbert Die Siefenbaut, (membrana branchiostega S.branchialis) bängt, woburd die zwif́then den Fiefendeckelis uno dem Rumpfe befindliche Siefenóf nungen, (apera tura branchialis S. branchiarum) die mit der Şöflung

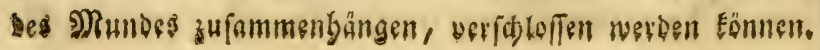


Rermitterft biefar Sheile holen bie Fifthe ?them, intem

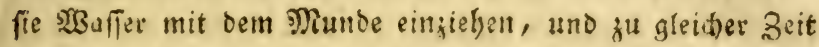
bie Siefenöfnung ourd) die Siefenbant verfdliefen, damit

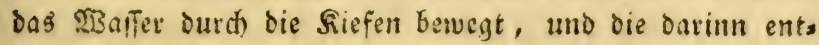

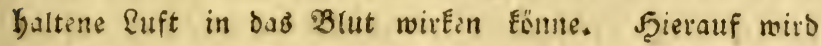

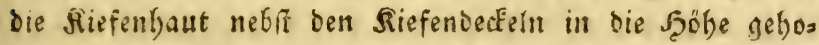

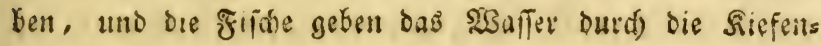
sfnung wieber von fid).

Die Riefendectel fint felten einfach, aus einem Enöhermen Bratte beitefleno (opercula simplicia) gemeia niglic fino fie zuey= oreys oietblättrig, (di-tritetraphylla). Bey den meiften Fifden fino fie $\mathfrak{E}$ nös d) ein, (ossea) bey einigen weith unb biegfam, (mollia, flexilia) mit einer fleifbigen $\mathfrak{g} a$ ut uber= jegen, (caruosa); eben, (laevia) glatt, (glabra) glängeno, (nitida) rauh, (scabra) geftreift, (radiata) fiadig, (aculeata) gemeiniglid) of fne S d) upen, (alepidota) feltener gefinuppt, (squa= mata) bogenförmig, (arcuata) am Nande gezáhnt, (dendata) gefágt, (serrata) géferbt, (crenata) gefrangt, (ciliata) ausgerandet, (emarginata) ganz, (integra) $\mathfrak{x} u n \delta$, (rotundata) eckig, (angulata ) zugefpizt, (acuminata) abgeftumpft, (truncata). Sie fino entweder frey, (libera, patens) feltes nev oben und unten an bie Saaut angewadjen, (adnexa, fraenata).

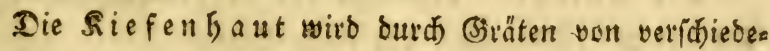
ner 2 ngabl unterfingt, und if entweder gang bon Dem Sies fenbecfel bedecft, (occulta); ober nur balb bedecfit, (semipatens) oder gaur frey, (patens). Die Grảten ber's felten fint biegjam, gefrummt. Bey Befrimmung Det 
(अattungen und Jiten hat ber Ritter von \&inné vorgügs. lid) auf ibre $2($ mabl gefebent.

Die stefenöfnung, sfnet fid) meiftentbeils an ben Seiten. (apertura lateralis) on:t auth zugleich untent in oer seble, gularis) feltener im Geniff, (nuchalis) oier im $\mathfrak{M a}$ aff $\boldsymbol{\|}$. (cervi alis) genen bin, (yectoralis). Bey den meiften fifiten if fie $g e=$ bogen, (arcuata) bey einigen röbrig, (tubulosa) bey) andern egförmig, (ovata).

$\mathfrak{Z}_{i 1}$ den fogenannten Suopelfifden fincet man nec) befonoere $\mathfrak{E}$ uftrögren, (spiracula) ourd) weide

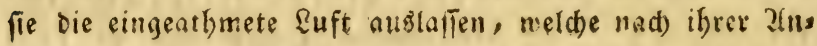
zahl. Sage und Gieftatt veridieden find, Gie ftefnent= wider einjeln, (solitaria) ober es fins mefreve beylam=

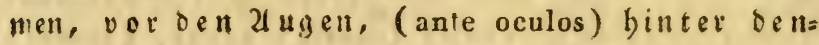
felben, (pone oculos) auf bem Ropfe, an ben Eeiten, im Beniafe, an bev Brutt.

Die 3 unge ber firche ift meiffens unbeneglion, ffumpf

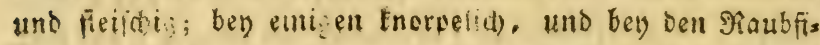
faen mit 3.thien verfehen, um ibre Speife feft zu balten.

Der (3aumen iff entweter glatt, oder $\mathfrak{x} a \mathfrak{u}$, oder mit grefien in mefreren Sieiben febenden Bübnen befejt. In trm binter dem (jaaumen ftefenden Sd)lunde, find ben mefieren flicten, raube oder gezäbrite finodben, auch bey eunigen eine $\int_{\text {ca }} \mathrm{t}$, (membrana palati, veJamen) curdt welde ber Gdluno gefdroflen werben Earn.

De giafenlöder liegen oor ben augen und offnen fia nit ziwa Dimungen auf jeder Eeite.

Die $2 f_{3}$ en liegen gewögnitich an beyben Geiten ziem. Yich in ter Mrtte tes אuffa, (medii); bey einigen im Edeitel, (verticales) cber oben an bell Seiten Des Sopfa, (supremi; bey einigen bidet neben eins 
ander, (vicini); ober nut a uf einer seite des sopfes, (binati). Sie ließzen ber den meiften fifthen blos, bey einigen find fie mit oev innern $2 \mathfrak{A}_{\text {ugended }}$ (membrana nictitans) bedefft; bey wenigen bervor= ragend (protuberantes). Eie fino im Rerbálnis ges

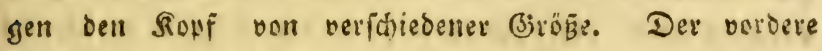
fidtbare Ifeil bes 2lugapfels wirb ber Stern, (Iris) genannt; man unterficheibet darinn, ben sbern, mittlern,

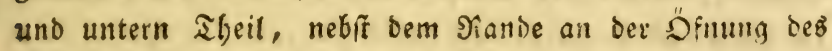
Sterns, (margo pupillaris) und am 2 ugentepife, (margo orbitalis). Bey Beftimmung der arten wirb

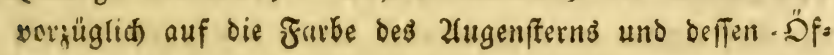
nung gerefn.

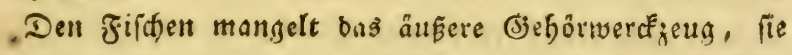
finb aber mit bem innern (jebjorgang ben orey (jiefjör. Enochen, ben bogenförmigen Siohren, welde iid) in cinen

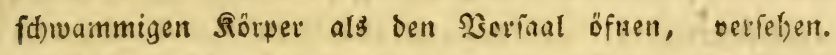
Statt ber Sonnecfe finbet man einen Eleinen Sact mit sinem Eleinen Sinod)en.

Die Reble, (gula) reid)t vont Ente des lnterkies fers bis an bie Bruft. Sie ift flad), (plana) баи t). $i g$, (ventricosa) ge fda âf $t$, (carinata). Die B̧ıuft (thorax) geft von ber Fefle bis an bie Bruffleflen, uno ber $\mathfrak{B} a u d$, (abdomen) von ber Bruif bis zum 2ifter. (Er iff flad), (planum) a ufgetrieben, (tumidum) baud $i g$, (ventricosum) ge $\mathfrak{d}^{\prime \prime} a \mathfrak{i} \mathfrak{f} \mathrm{t}$, (carinatum) ven @duppen gefägt, (serratum). Jer $21 \mathrm{f=}$ ter, (anus) ift feiner Iage nad) veridiebelt, als: $n$ abe a m Gopfe, (anticus prope caput) nabe an Deb Sdh anzflorie, (posticus) wer er liegt mitten am $\mathfrak{B}$ a ude, (medius) doer er ift bey oer féfle, (gularis) oder a $\mathfrak{b}$ be $\mathfrak{B}$ ruff, (pectoralis). 


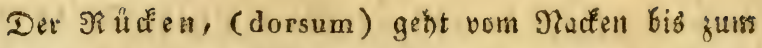
Sáwarige. Er if erbaben, (convexum) gefdälit, (carinatum) bogig, (arcuatum) oder gerabe, (rectum) flach, (planum) gefagt, (serratnm) mit Jurdell und (juben verfeben, (sulcatum excavatum) mit einer, zwey, orey floffen befegt, (mono-di-tripterygium) obe: obne alle flofien, (apterygium. Der Edwanz, (cauda) if ber bintes

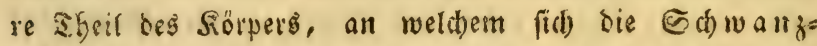
frofle, (pinna caudalis) befindet. Sit er ofne Flofs fe, beist er nad) ber Rumffipradfe, (cauda apterygia).

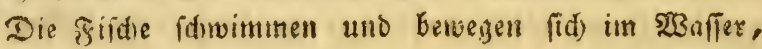
vermitterif ber froffen, (pinnae). Sie beftegen aus berífieoenen burd) eine feine Şaut mit einanber verbunt=

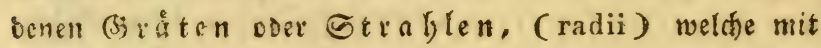

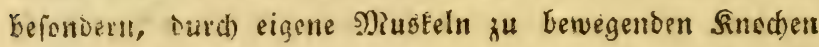
eingetendt fint, uno Dadurd) ausgefipamt uno nad) vers

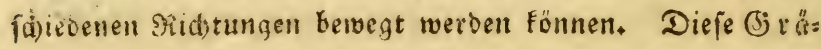
ten find bey vielen fifsten biegfam, uno aus zwey mebeneinander riegenten zufanmengéezt, bie fid an ber Eptze theilen, ( pisces malacopterygii), ober fie fint cillfă, bart, fpizig, (radii spinosi, aculei); Daben baben leztere Flíde, aufer ben Stacheln nocis weidfere Gräten, Desibegen werben ibre frofien zufoms mengefezt, (compositae) und bie erften gleid)föps mig, (simplices) genamt. Fleffen, an welden bie Shaut febr fett iff, beilien fettflolien, (pinna adiposa) in biefen laffen fict) bie Mnenge der Strablen nicht angeben. Şey den übrigen flofien ljingegen werben fie gezáhlt, und bey Beftimmung ber Zabl ser Girablen Die barten von ben weiden unterfidieden. Sinné uno

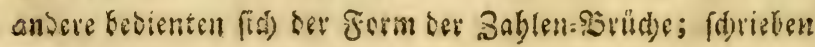


Demnach) in ben Nemter die gange Etraflemangahl einev Fluffe, in ben Bähler hingegen, nue bie Babl ber burten Etrablen biefer Fleffe. So bebentet \& $\mathfrak{B}$, $\frac{1}{2} \frac{2}{5}$, Duß in cirer Floffe usn 25 Etrablen, 12 barte enthalten fino; befänoen fiti) aber auf beiben Seuten ser Flofle barte

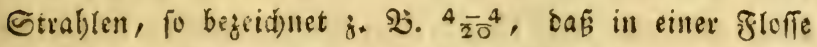
von 20 Strablen, auf jeber Seite fid 4 harte befinden. Diefelte form Dient auh, abandorlidie Etrahten in ih: ren Brenzen anzigeigen, wo $\frac{3}{12}=\frac{4}{15}$, eine floffe von 12 bis i5 Straflen, mit $3-4$ barten $\Xi$ traflen auff einer Seite bezeid)net. Sind floffen, wie bie an Siüften, bey manden gifiden abgefondert: fo bermerEt man yon eis ner jeoen befonders die Etraflen, fo daf man ein Fom tha zwiften jede fezt, wie 12, 19, 17, wo bie erfte Sillténfioffe 12, die zivente 19, bie oritte 17 Etrablen

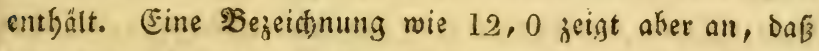
bie erife Flefie 12 Etrablen enthalte, Die zwente aber. eine Fettfleffe ren. Sino in ber Folge bie Strablen:

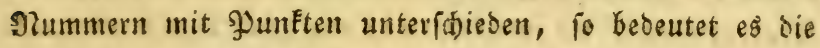

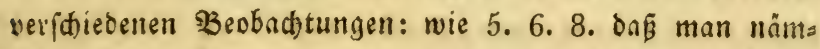
rid) in ciner Flofie, bald 5, bald 6, bald auch 8 Strahs Ien gefundert babe. Sind giuffen= Sd) flefe mit einander verwachjer: fo wirb bie Iutatgabt fänmtliager Strablen, als ob fie eine flofle ausmadten, angegeterl.

Die Floffen werben nad) ifren Stellen an bert Rörs

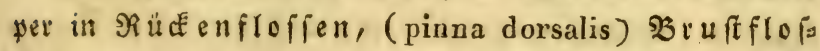
fen, (pinnae pectorales) 23 a udffloffen, (pinnae ventrales) a fterfloffen, (pinna analis) uno in bie

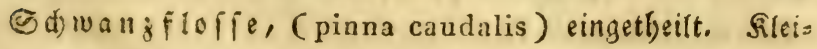

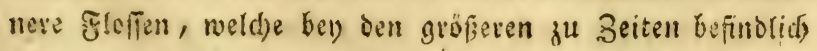
fino, werben, wonn fie wie Eleine Bürdjel gebilbet find, 
büfderförmige, (pinnulae fasciculatae) anbere,

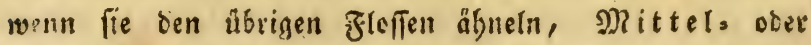
$S B$ aftarb: Floffen, (pinnae spuriae S. mediae) ges nennt. Seice glefie, bat ifren befonbern গiscen, nit

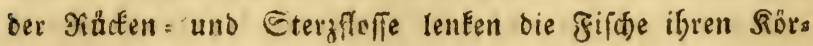

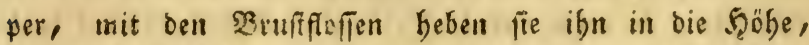
mit ben ausgesreiteten 3 audbfoffen betvegen fie fich in die Siefe, und fehen gleidhfam barauf, und mit bet Sdywanifleffe fteflen fie den \{eib gerabe fort.

Die গü déflofle nimmt entweder die Ränge bes

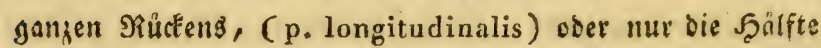
beffelben ein, (semilongitudinalis) ober fie liegt llabe am Sopfe, (occipitalis) ober auf ien (c)ultern, (scapularis) ober in Der Mitte bes Müúfens, (media aequilibris) coev nabe am (Sdwanje, (lumbaris, remota). Sey einigen mangelt fie, (dorsum apterygium), ge= wöhnlid) ftebt nur eine ba, (dorsum monopterygium) mandmal zwey, ( $d$. dipterygium) felten brey, ( $d$. tripterygium) bie meiftens absefondert, (distinctae, ober juweilen verwabien, (coalitae).

Die $\mathfrak{B}$ rufteloffen feblen den $\mathfrak{R}$ urănen, bey bent Bruffid) ilofifde liegen zwey auf jeoer Seite, (geminatae); bev ben ubrigen Fifchen eine, (solitariae). Sie liegen entweder nabe am Siukfen, (supremae) uno fino arbenn oft fo lang als ber Shorper, (longissimae) volatiles); coer fie riegen gemeiniglid) in ber Mitste, (mediae) feitenar nad) unten $z^{u}$, am 3ande ber $\mathfrak{B} r u f t$, (imae, infimae); fie find entweder zugerundet, (rotundate) soer zugefpifat, (acuminatae) ober fid)els förmis, (falcatae).

Die $B a u d$ floffen liegen entweder am Scalfe, vor ben Bruffeffen, (jugulares), ober an bet Bruft, (tho. 
racicae), ober am Scinterleibe, (abdominales); bitt neben einaroer, (vicinae) oder entfernt, (remotae); ober fie find mit cinalloer verwad)fen, (coadunatae, coalitae). Einigen Jifden feblen fie, (apodes) ben den übrigen find aber immer, beren zwey zugegen. Die afterfloffe, Gter ffloffe, bat viel übereinfima

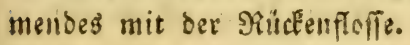

Die Sd want floffe if entweber nach ifier Bittung gleid) abgef(i) niten, (aequalis), ober zugerun= Det, (rotundata), gefpalten, (bifida), oreymal getbeilt, (trifida), a usgefdnitten, (emarginata) unb gewöbnlich eon ben übrigen folfiten abgejonbert, ( di-

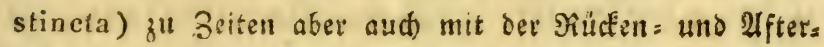
foffe jufammenbangeno, (coalita, annexa).

2lufer biejen mabren floffen liegt nod) bey einigen frifden, binter ber siüctenflofle, eine fleine flofienñlynliche Saut, (pinna adiposa). Swifden Den $\mathfrak{B r u f t}=$ und Baudifoffen find zuveilen einfadbe, gelente borfenfor: mige anbảnge, weldbe ber Fitter oon finné finge:

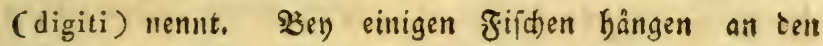
ftad)lidfen (jräten der Flofien biegfame Fajern (ramenta).

Diele Fifde find mit einer eigenen Sd) wimmbla fe (vesica aerea) verfeben, wodurd) lie bas Schwimmen

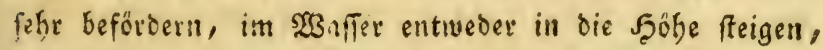
uno fith wieber auf den (sirund deffelban nieberlafien fäns nen. Diefe $S_{\text {d) }}$ simmblaje befteft aus einer feinen gröga tentbeils filberweifen Sqaut, bie burd) einen befondern ( $a=$ nal mit bem Edlund ober Magen in Serbindung ftebt. Sie ift entweder einfach, ober gebeppelt, unb liegt im

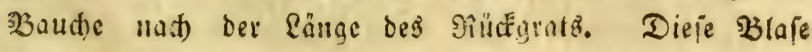
Eonnen bie Filitie nad) Ssistrfubr mit Stiffluft, (Gas azotique) fülen, und dis in Derferstn entgaltene \&uft, 
Eurth bas Bufammenjieben ber Baudamusetn berauss

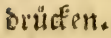

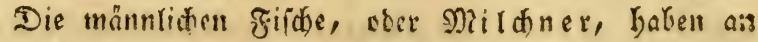

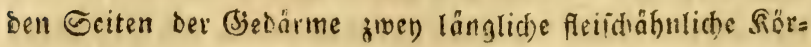
per, bie man bie $\mathfrak{M}^{2}$ ild, (lactes) nenut; bey ben weibs liden Fifichen, Doer. Nognern, liegen an eben bem Orte Die (Everif öcte, (ovaria). Diefe Sheile öfnen fich) in bie Saanblafe, ourd) deren S̈fnung fonwohl die Mild), als Die Ener ausgeleert werben. Die Befrudtung ber Enet oder siugen gefbiebt groffentheils erif alsbenn, nad)bent Das গ̧seibden bie (Fyer von fid) gegeben bat.

Die meiften fird) regen Ever, uno bas gemeiniglich in fehr grefier angahl, fo daf man bey manthent ther eine Mitlion uns in Dem gemeinen fiabelia u gegen neurs SMutionen berfelben altrift. Die Ener ober Siogen find

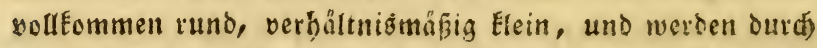

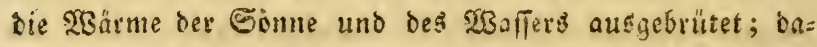

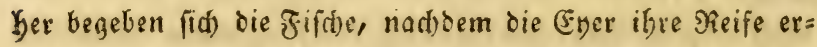
reid)t baben, an bie Lfer, und an fäabere Stellen, wo bie Sennenwárme gróker ift. Ṡey diefen Bügen treffen fie zum Shetl in groper Menge an ben fiuften und llfern ein, und werben von den. Männdisn ober SMildern beglei. tet, welde ibre פMitd fur Befruditung Der (Ever von fir geben. Die Seefifd)e begeten fich zur Raidgeit junt I beil in bie flüfe, welde fie nachber gröftentbeils wiever serlallen.

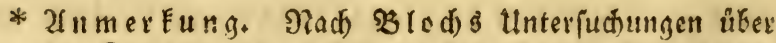
Die farpfentarten, baben die befrudteten Ener berfels ben, zrvifchen Dem Dotter und Dem welfen Sbeile, eine menoformige belle Stelle, weldbe am zwenten $a_{a}$ ge trübe niro, uno einen berveglidten Wuntit jeigt, welder am oritten Sage, eine mit bem Dotter fefts fizende, all bem andern snde freie Mafle barftell. 


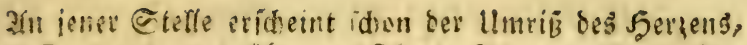
Eeflen uno Der Ütrigen Sbeite Serwegung, weide Dell 4. und 5tell Eag immer beurlicier weroen; antí) Der llmlauf oes Btuteg witb merfbarer. Den 6tit erfocimen die Braten, Den 7ten bie 2fugen, uno ges gen ben 9ten Sag bin burd)Fricht der junge fifid) Dur(b) lebbafteres Sdlagen bas (5y, uno fommt init

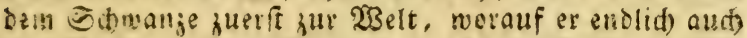
Dell fievf von bem Dotter lesivindet. In Den erfiter

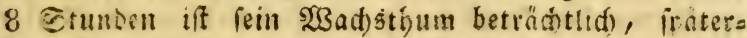
bin ater viel lanafmer. Die Buruffellen entwideln fict) fots am eriten sage, die ubrigen aber fwäter, bie siremen bilden fid erft bey bem fermern sißud) fe.

פlur cinige wenige Fifd)e, wie ber 26ar, (Muraena

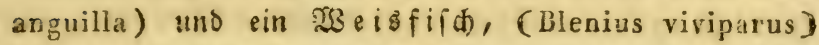
bringen lebendige Siunge zur 532 elt. Sormutblid) finbet

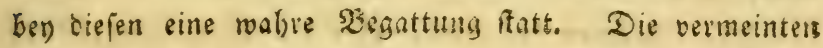

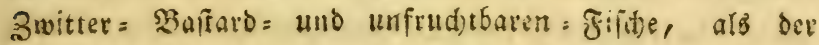
Zwitterefafe, ber Baftards Sarpfe, und un $f r u$ d) $t b$ a re $\mathfrak{T} a r p f e$, fhemen blos zu Den शRifgsebutten ju geböoren.

Die meifen fiid) balten fid) im 5 Peer auf, (marini).

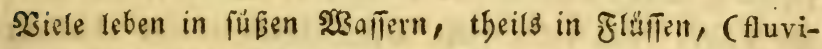
atiles) theils in frebenden (jemáffern, (lacustres), Mef). reve berfelben, und vorgüglid die Siaubfidie geben Des

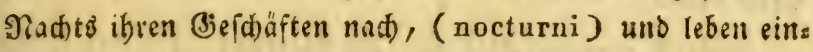
fam, (solitarii) fanwimmen aud) öfters in ber Slefe, obes auf bem Soben bes 2 Safferd; andere bingegen fudfen ifre Nabrung am Tage, (diurni) fofwimmen mebr in bes Seöhe des $\mathfrak{x a f f e r s , ~ u n d ~ l e b e n ~ n i d ) ~ f e l t e n ~ b a u f e n w e i f e ~ b e i s ~}$ fammen (gregarii).

Nebrere Fildhe erreiden ein bobes after, unb eine

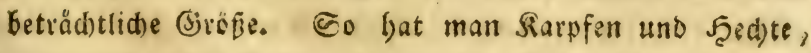

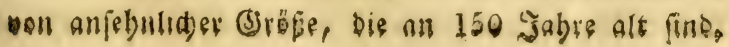




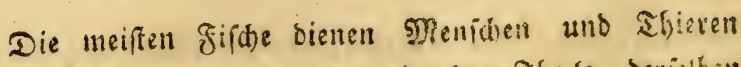
jur Nabrung, aud) werben einielne Thente berielben

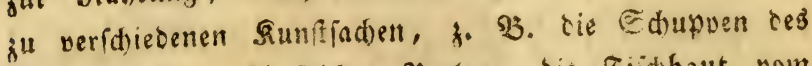

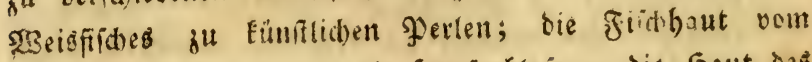
Feden und Sqayen, - die Sraufenblaie - die Saaut oes Eägefiches fum Ciblenloder, Der Ifyran ber Seringe unb anderer Fifice jum Brennen u. Q. gl. benurgt. Eie gewefnen fid reid) an jeden Scimmeleftrid), weil fie in bem Elemente, werimen fie leben, ein iffer Natur ans gemeffenes Slima finden. So ift Der Rarpfen in seds land, Engeland, DämematE und Edweben, ber Etels

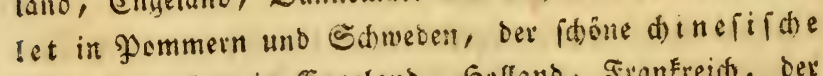
(30 old Eapfen in Engelano, Soullano, GranEreid), Dex Sd)weiz, uno in unfern Sifeingegenhen naturalifït worden,

Das Saerietzen ber Fijhe ift ein wichtiger Ciegenftano fer Eantwirtbid)aft, bev alle :efergigung verbient. Das zu Dienen vorzüglich Eleine Eeen, Teide, ober Wreiber, welde am fidjerften mit' befiudteten Siggen befest werven. Sorzüglid) gebeiben bie Fifá)e in folden Eeen ober Seichen,

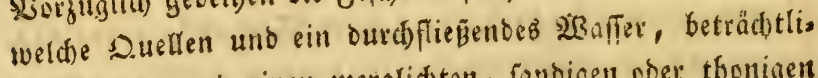
d) Tiefen, unb einen merglid)ten, fandigen oder thonigen mit Siräuter bewad)fenen (siruno, und babey ein flacbeg Ulfer babell.

2'iußzerft mannigfaltig find bie Sorrid)tungen bes Fifá.

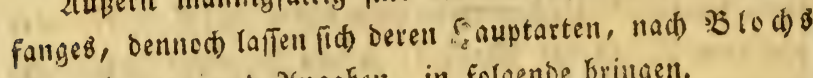
Benennungen und angaben, in folgende bringen.

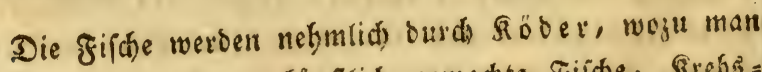

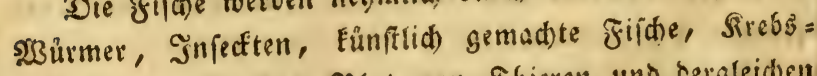
uno Mufdelfdaalen, Blut von Sbieren uno bergleid)en

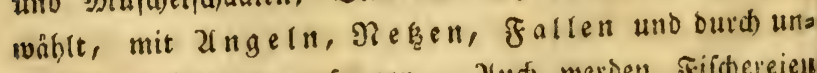
mittelbare నobtung gefangen. 2tud) werien Fifdereielt 


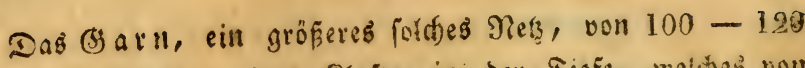
Slafter Rănge unb 6 slafter in ber इiefe, weltheb von 8 Menfden in 2 Machin gezogen wirt. Man beoient fith Deffetben vorgüglid) untex bem (Eife. 5.) Das (5) rog garn, befîn Flüget unter jener Sänge an 12 Slafter tief, uno Der Eact an 10 bis: 12 Slafter Iang iff. Silan bedient

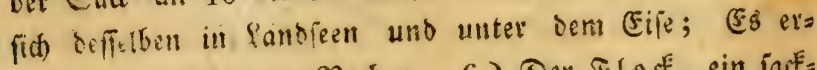

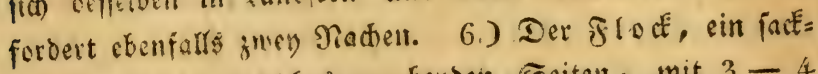
formiges Net3, we!ches all beyden Seiten, mit $3-4$ Slafter langen baftenen Striffen sder Rieifen veriebell if́. Cs: wiro an ber einen Eeire an einen quer gegen bas

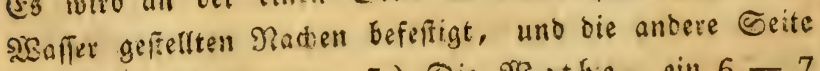
mit Eteinen beidwert. 7.) Die 23 atbe, ein $6-7$

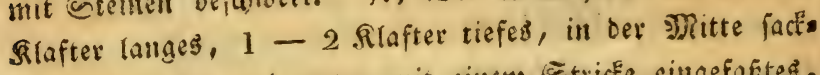
förmiges, oben unto unten mit cincm Etricfe cingefaEtes. und mit Yingen verfehenes, an Den Setten aber mit

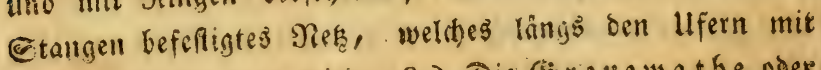
Crricten fortgezogen wirb. 8.) Die (si ra ue wa the poes

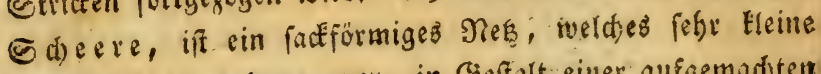
פiafiden bat, uno an zwey, in Beftalt einer aufgemadjtent Sdeere, ubber einander gelegten Stangen befeftigt iff. Da Durd) Diefe Sorrichtung Die Eleinften Filihe, unb bie jat:

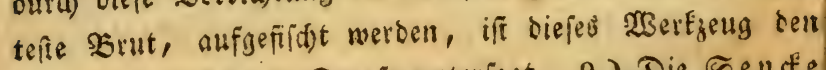
Fifithern bei fanwerex Strafe unteriagt. 9) Die Sente

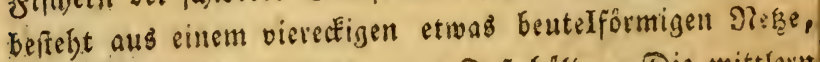
jeldes auf jeber Seeite $6-8$ Suß bält. Die mittlern Mafthen find enger, als bie nad) Dem Nanbe zu. Die Seiten werben mit einem ftarken Dinthaben eingefap̃t, uno bie Ecten an ben vier Enben zweier Stangen befeftigt, regtere bindet man Ereuzweife uber einanoer, uno an Des Sterle, wo fie fid Ercuzen, nod an eitte oritte nad) $I$ ms

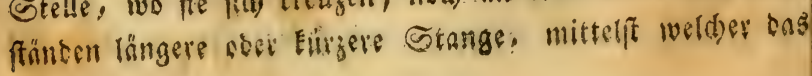




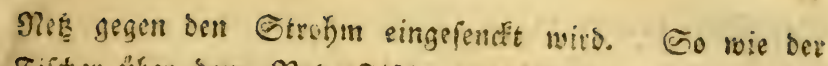

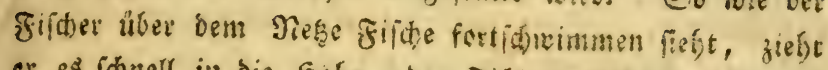

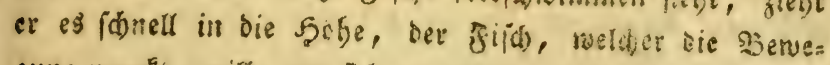

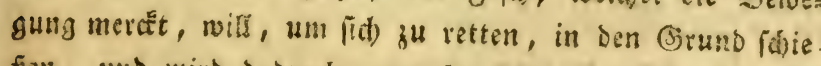
Bell, und wito boourd um fo fidserer gefangen. 10.) Der Samen ift ein tiefer, rundes und an einer (sober

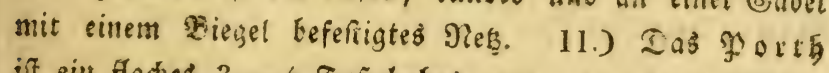

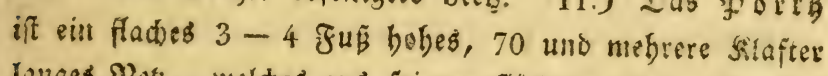

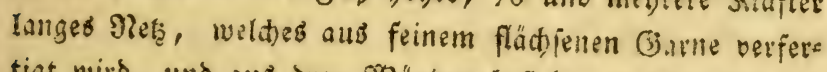

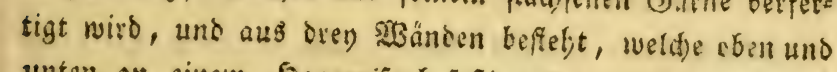
unten an einem fraarreife befertigt fint. Die Miafiten Deffelben find an bell beiben äuffrm swanben $6-8$, an Den mittern aber $1-2$ görrig. Es nirb in Gefralt cines Dremects aufgeftell, uno werben bie aus Dem Sdilfe (coer Bielage) aufgetriebenen fifóe in foldges binein gea trieben.

Die fallen = Fifdereien, wo dis Fifise varmittelf eines Söber's in Befillter, wer auch in פef̧e geloct rerden, find oon verfobizdener Einrichtung. 3u ben vor: guglid)fen gebören, 1.) dar 26 alfang, ein gitterförmiges Bebaltnifa, in weldges das bineinfräbmende 23 affer den

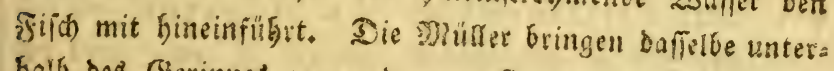
balb bes (3erimes an, und wenu fie sas Jreifithts wieber jufersen: fo Eömnen fie den $2 a$ al mic leidter Mihbe aus Dem fang berausnefmen. 2) Die গRenfen, an beiben Enden fpistg zugefende şebälter, roelde man in ber Mitte mit einem Siöber verfiebt. Dutch die S̈finungen

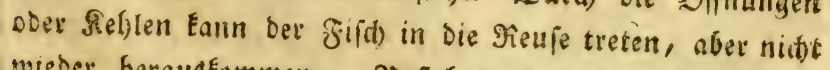
sweder berausfommen. Seftelgen fie aus einem Nebe, sveldes mit bölgernen $\mathfrak{B}$ ügern ausgefpannt uno in Der Strobm ober Gee gefendft if, fo beiñen fie Gasureus

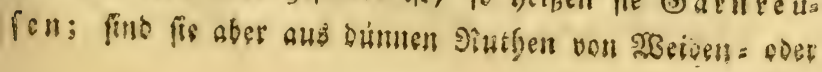


Nabeiforge zufummen gefledten: fo werben fie 50 fgress fen geinint. Sene verbindet man bistweiten nod) mit mefreren Sammen, Damit Eefonders farce Fifáse bei biefen Durajgangen fich befier abfonbern, unb für bie neus erit in ben vorbern Sianmern spiaz entifeben Eann. 2ibutiche Neufen werben aud) bei nem Durdffuffe ber -25ebre angelegt.

Getótet werben bie Fifde mit eifernen Babeln, Opres ren, oder aud Şarputen.

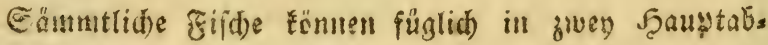
theilungen gebrad)t werbell, beren erfe 2lotbeilung bie Enorpelartigen gif́pe nebft benen entbült, weldie ents weder Eeine Silefendecter, oder Eeine Siefentgaut befisen, uno von bem sitter o on Einné ju ben forwimmenten amplibien gerewnet wurben. Die sweite abtheitung bes greift fämmetiche fifdle, weld)e mit wafren Siefendecteln und siemenfaut begabt fint.

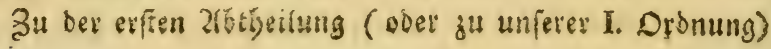
geböen:

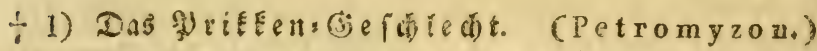

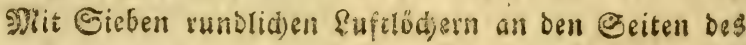
ßoiderteífeg.

3) Dab Salstiemenfifd)= (f)efd) ledt. (Synbranchus.)

llnter bem Sorberleibe nur cine cing̊ge Riemenôffnung mit einer fedigftrafligen Siemenbaut bedect. Sbne Siuft und Bamdfofien.

3) Das Doppelfarefieman. (Stefd) fed)t. (Sphas gebranchus.) 


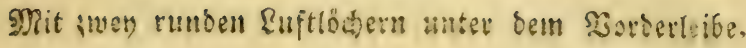
ofne flefien.

4) Da bauclemenfifd). (jeftiect. (Gastrobranchus.)

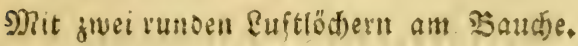

5) Das Tioden=(अeid!ed)t. (Raja.)

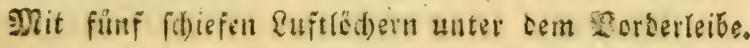

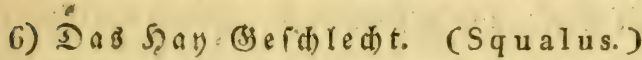

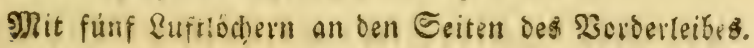

7) Das Meeroraden= (jeid)ledt. (Chima era.)

Mit ennem viettbeiligen \&uftrod)e auf jeber Seite bes Dorberleibez.

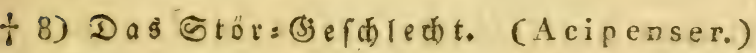

Mit cinfachen, an ben Easeiten fitzenden langlidben Siemenöfinungen, jabnlefem unterwårtb geriojtetem,

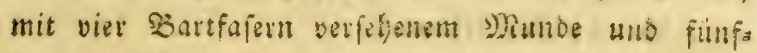
Eantigem Siörper.

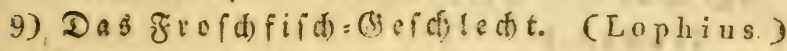

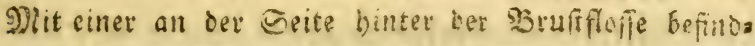
liden Siemenoffrnung, jwey Bsad)floflen und gejabna tem Munde.

10) Das Snotenfif́: (3) efdr(ed) (Cyclop. terus.)

Sit zuammengewadionen, einen Shito bitbenden Saudflefien, vier Etrablen in oer Siemenbaut.

11) Das 5ornfifक, (अiefकledt. (Balistes.)

Mit einfader, eine Sdäufe biloenier Saudhfloffe, wirb sbne Siemendecter, 


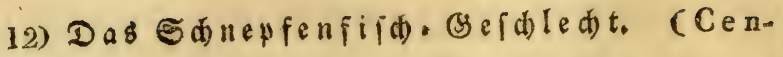
triscus.)

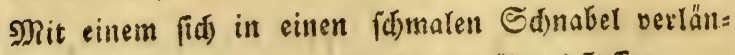
gernoem fiopfe, und verwadfenen saudfofien.

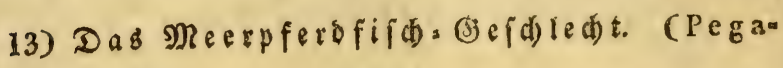
su s.)

5git einem fid in einen bünnen Iangen siuffel endis genden Sopfe und gepanzertem geglieberten sionrper.

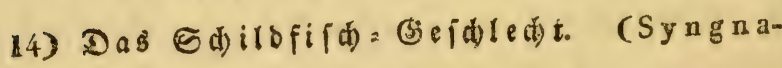
thus.)

ghit einem fin in einen langen Edhnabel enbigenten Sopfe, gabntejem slumbe, gepangertem uno geglie: Dertam Sôrper. Die Baudfoflen felylen.

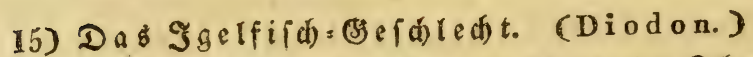

Mit berucrragenden, getbeilten, fich in eine Sdynets De entigenden Sinnlaben, ftadtichem Sörper. Die Ђaudfloffen feblen.

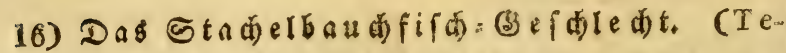
trodon.)

S) Rit berborragenden gerbeilten, fid) in eine Sd)neide endigenden Sinnlaben, weitem runblidbem init Stas deln befejtem Baudie. Die Baudflojfen feblen.

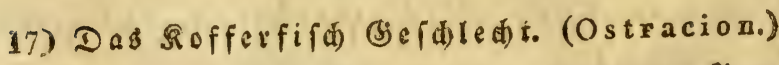
2)it einem in fedsectige Chiloer abgetbeiltem Pans ger, Eeilformigen etwas fitumpfen orangegetben Zäbs nen in ben Simuladen. Die Baudfloffen feblen.

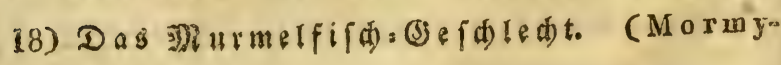
Ius.) 
Mnit einftrubriger Siementaut, 3ăhnen, weldhe an Der Epizęe eingefdunitten fino, uno fouppigem Siörper.

19) Dab Sagloruftfifd)= (jefid) ledt. (Gymnothorax.)

SMit Eduupentefem Sörper, fdimaler nad) ber Ränge geridteter Siemenoffnung, gegahntem Munbe. Dhs ne Brufflotien.

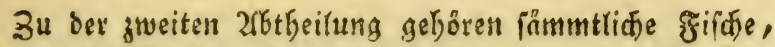
welde mit $\mathfrak{R}$ iemendedern und $\mathfrak{S}$ iemenlyat verfes ben find. Cie werben oon $\mathfrak{s}$ inné nad) ber Begentwart

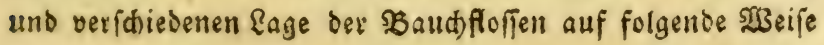
eingetbeilt, in:

I.) Fifte ofne bauthfloffen. (Pisces apodes.)

Dafin gefören (Die Fifite unferer 1I. Dronung.)

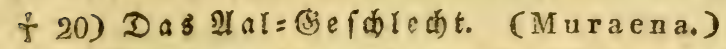

Nit Siemenöfinung bei ben \$ruffrfoffent. Die after=

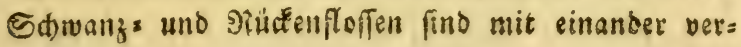
wadfen.

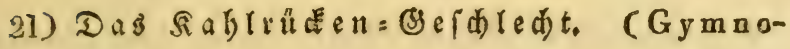
t us.)

Mit glattem flofienlofem Näben und fin in eine Sanneibe endigender 2aud)e.

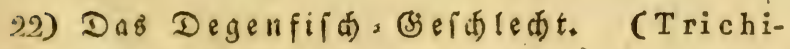
urus.)

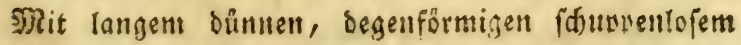
Sörper, an deffen shücen nur eine greffe ferbt.

23) Das đeenolf. (3efd) (ed)t. (Anarhichas.) 


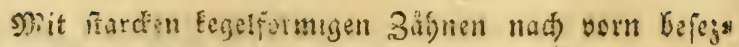
ten Simniaden.

24) Das esondaal (3efolect. (Ammodytes) Der Sivf tif icmater als der Simmpf, Die Dbers linge tit geosplets, bie untere Simmade lauft in eine Eprtze nus. Der sgluno ift jabntos.

25) Das (s (b) langenfifd): (3)efd)ledt. COphi. d i u m.)

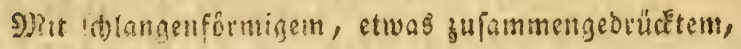
weich)(o)uppigem Siorper.

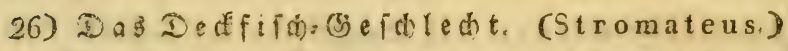

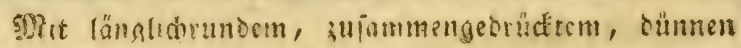
(d)tüprigem Förper un gabelförnitgem êdwwange.

27) Das Cowerofifó (jefdledt. (Xiphias.) mit vertangertem fónertörmigem Dberfiefer.

28) Das B̧ruftartenfifd)s(3efd)led)t. (Sternoptyx.)

Siti bünnen, Greitem, zufammengebrútem, fhuss fentefem Särper, unb Eielformiger, zu beiben @ei: ten gefalteter Bruft.

29) Das Banofif(t)= (sefd)(ed)t. (Leptoce. phalus.)

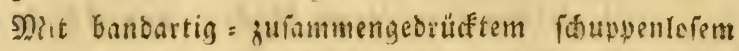

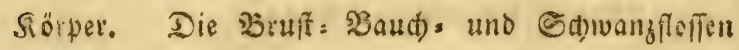
feblen.

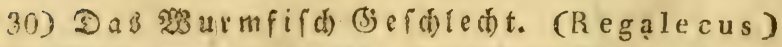
git wurnartigen Sörwer. Der Sispf verlangert

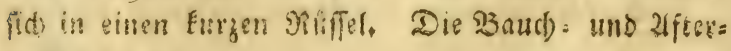
floffen febien. 


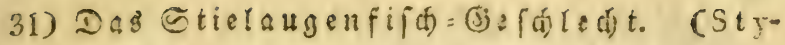
lephorus.)

Die augen ffefhen auf breiten, Ditur, nahe baifa!n= menfebenten Gtieten.

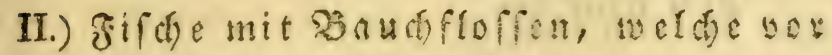
ben Soruffloffen feben.

$$
\text { (Pisces jugulares.) }
$$

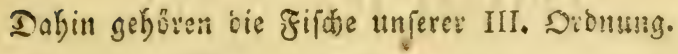

32) Das Epinnenfifa) (jefdredt, (Calliony us.)

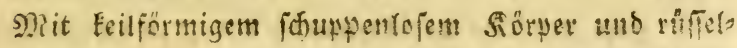
formigen Siopfe. Der BacfenEnocten endigt fict in einen Dreifpigigen, getrümmten Stnder.

33) Das Sternfeber = (5ieflect) (Vtanos copus.)

Die Zugen riegen im Sheite?. 2fm thnterEicfel fit eine Sartfajel. Det Muno iff fotief.

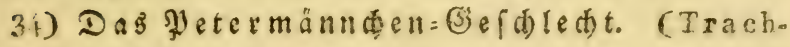
inus.)

Mit gerägten Packen, uns Siemendecteln. Der after feft wabe an Der Situft.

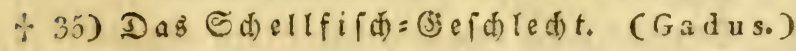

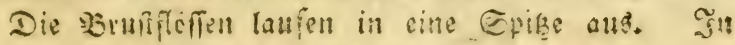
fämutlid)en ofoffun find bie Strablest weich.

36) Das Sdreimfifd)= (s) f bledt. (BIen. ni us.)

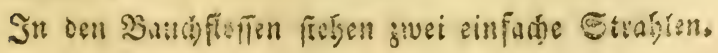




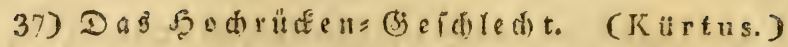
Sitt erbabenem Rhaten uno langerförmigem Sorver.

38) Das Siablafters Gefoled)t. (Gymne(r $\mathbf{r}$ s.)

Sbrie a terflefier.

III.) Fifore mit ssaudfloffen, getabe unter den 9 tuffloffen.

\section{( $P$ isces thoracici.)}

Dabin getjöen bie Fुfaje unferer IV. Dronung.

39) Das sienenfif $d)=(5)(d)$ led)t. (Cepola.) Mit aufwärts geridhtetem Siunde, uno fduppentofem bůnem riemenformigen Sörper.

40) Das Saugefifds=(Seid) (ect). (Echeneis.) Dev Sopf if mit einem ovalell, von Suerfurden begeidineten Saugidirlbe verieben.

41) Sa Doraden=(jefdredt. (Coryphaena,) Dit breitem, ftumpfen, ftark abfähingen Sopfe unb gologlänjenden Sduppen.

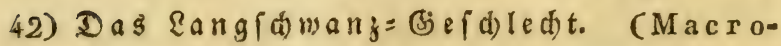
u r us.)

Mit langem bünne auglaufendem Schwange. Die

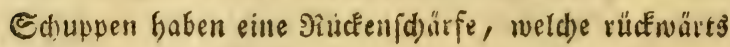
gefachelt iff.

43) Das (jertenfi pus.)

Mit fortupuentoiem regenförmigen Söper, uno wei, ter pishelförmiger Giemenöfinung. 
44) Das (3) ruber = (5ield)led)t. (Gobius.) Mit Baudflefien, werd)e in (Sieftalt eines sritters zufammengerwad) fen find.

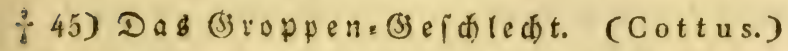

Det ourn abgerundete, mit Stad)eln bejejte Sepf ift breiter als ber fiorper.

46) Das Dradentopf = Giefdredt. (Scorpaena.)

Der unförmige, grofie, ftumpie, 伍uppentofe Sopf ifr mit Stadeln und Japern bejezt.

47) Das Epiegelfif $(b)(3) f d$ led t. (Zeus.) Mit grefiem abjüllfigem Sopfe und gewölbter Dber:

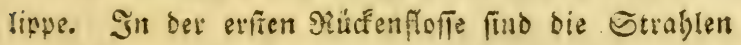
mit Gaarartigen fortfäken verlängert.

48) Jas (5)orten.(jefdretit. (Pleuronectes.)

Die 2tugen liegen, ganz nabe beifammen, auf einer Eeite Des Siopfa.

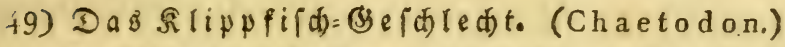
Die 3ăfne find Gerfenartig, gleid)lang, beneglich, unb ftehen bidgt beifammen. IIn ber giületen = uno afterfiofie fieben Stadben.

50) Das Sitterfifd):(jef(d) (ed) t. (Eques.) In Den Simnladen fteben mebrere Sieiben Eleine: 3ăbue. Der foumale förper ift gebandirt. Die

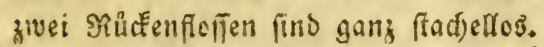

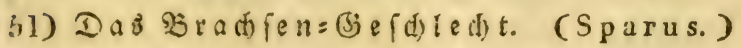
Mit cmfachen Ripwen, ftarten S্Scrberzäbnen und

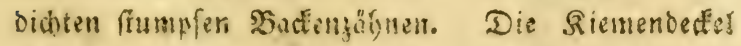

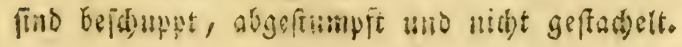


52) Do Sapagevfif Eext ber Bibne ragen die Enôtemen Sinnladen Gerocr, welo idbuartig geferbt fint.

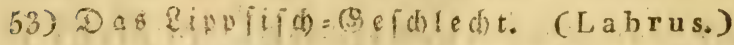
Shit felforigen, alifiewnrionen, faltigen Rippen, uns bederfen RinvenEnoden.

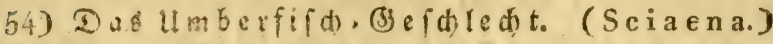
Der Suf if mit Soruppen bejazt. Die Sduppen

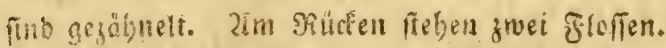

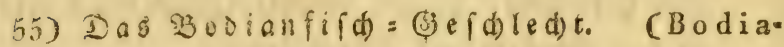
nus.)

Die Siemenoectel find ungezăfnelt, mit Couppen uno Gtadith verieben.

56) Das Sogefifd)= (3)efoledt. (Holocentrus.)

Dic Siemenoeder find mit Gauppen bedectet, gejálys nelt, und mit etobell verfeben.

57) Das \&utianfifd)= (sefd) led)t. (Lutianus.) Dit varbere SGeil bes Sopjo ift foluppentos. Die

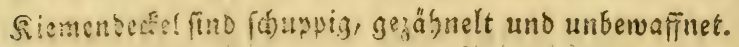
+58) Das baarfd =(3efd) (ect)t. (Perca.)

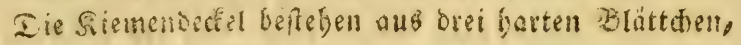
Davan bas ebarfe gegahbnelt oder gefänt ift. Die Simmbten find mit ungleid)en fpirgigen und getrums ten Zäbuen bewafnet.

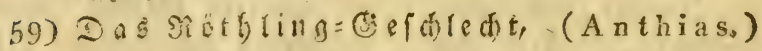

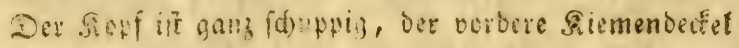

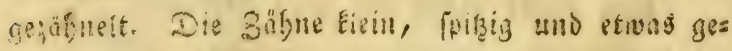
Erimt:

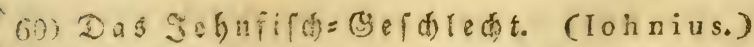
De: Sopf gan mit Gdumben betect. Die Riemems

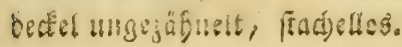




\section{Pisces.}

6i) Dos g lódaugenfifd)=(5iefd)redt. (Epine phelus.)

Der Sopf ganj mit Edupwen befegt. Der norbere Siementecter geşấfnelt, Der bintere mat Gtahela berezt.

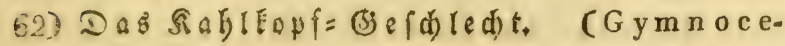
phalus.)

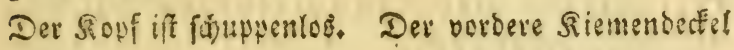
gezăbnelt.

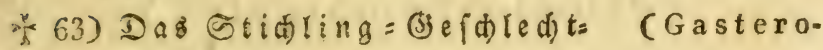
steus.)

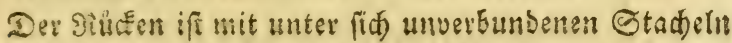
befejt.

64) Das SRatielen=(3efdred)t. $\quad($ Scomber.)

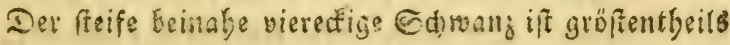
mit vielen Eleinen $\mathfrak{B a f t a r o f t o f f e n ~ b e f e g t . ~}$

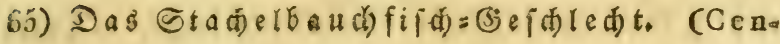
trogaster.)

Die viet crfien Strablen Der Şaud)flofien find ftad) clig.

66) Das Miecrbarben=(5efd)(ed)t. (Mullus.) Der sörper if mit grofen, reidt abfallenden Sdup: pen bedect. Die Sätrenflffe ift gebappert, uno er fieve mit Stactein verfefen.

67) Daв Geebabn= (jefGled)t. (Trigla.)

Tieben ben SBuffftefien friben afgefonderte geglieberte

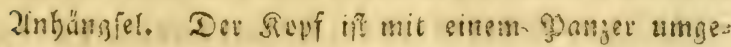

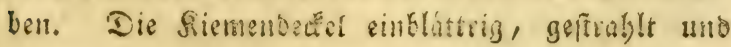
fradielig.

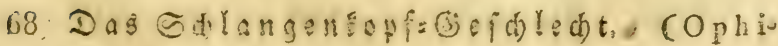
cephalus. 3 
Der Sonf iff (d)langenåhnlid), mit unglrid)förmigen Shupren bededt. Der Server gefteett.

69) Das Sanzetfawanz= (Sefd)ledt. (Lonchurus.)

Die Sowanzflofie lanzetformig. Sie Baudfofien getrennt. Ser Sörper geftrect.

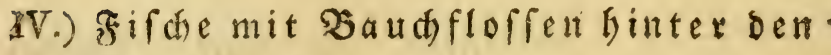
XSuftifloren.

( $P$ isces Abdominales.)

Sabin gefüren bie Flibe unferer V. Dronung.

* 70) Das Samerlen=(3) eidledt. (Cobitis.) Der Sörper länglich, faft ven gleider Breite, follei= mig, mit letcht abfallenden (G)uppert. Sgodliegende 2uges. Die Sirfendecfel einblätrig, unten fait ans (a)liefeno.

71) Das Nafenfaferfifd) (3efdledt. (Amia.) Mit Enodigem, fhuppenlofen, rauben unb mit $\mathfrak{N a}=$ then ourdjogenen fopfe, unb zwer fafern an bee 9iaje.

72) Das 2els=(3efdle d). (Silurus.)

Der gropie brette Sepf iff zufammengebrüclt und fó up: penlog. Der geftrecte Sörper zufammengedrüct. Die erften Gtrablen der গRüfen a uno Bruffloffen fino fảgefôrmig eingeîchnitten.

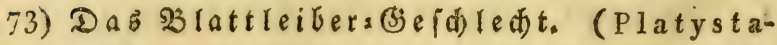
cus.)

Der Mund ftebt unterwärts und ift mit Bartfafern

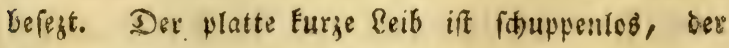

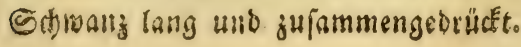




\section{Pisces.}

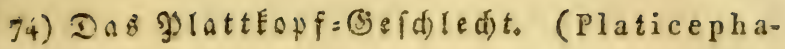
lus)

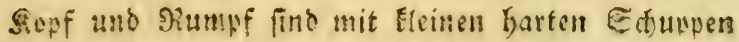
betect. Die Satidflefien ftefen fefe weit ausein= anber, unb weit Ginter ben כruftfifien.

75) Das Stad)errúaten= (jefdredt. (Notac a n thus.)

Der Börner if

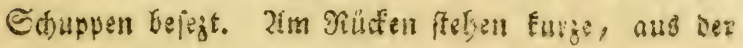
Saut Eaum bervorragende Stachelt.

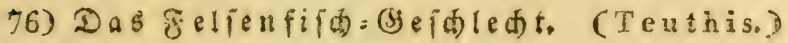
In beiben Sinntaden ftoft eine einjelne Sieife gleid)

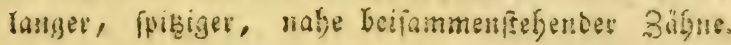

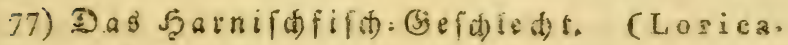
ria.)

Der Sonther ift mit einem Hanzat bebefic.

+78) Das Galm=(jeid)ledt. (Salmo.)

Die bintere औutenfeffe if bäutig uno obne Ctrabs len (eine Fettflofie).

79) Das pieifens (3) [ f Der Sopf gebt in einell langen röbrenförnigen Sils fel, Der an der Epitze mit Sinnladen berfegen ift.

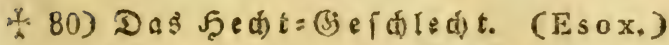

Die untere Rimnlabe ift meiftens langer als bie obere und getupfert.

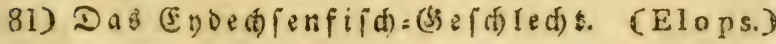
Der Souf it glatt. Die Siemenbaut bat bueifig und mefrere Strablen.

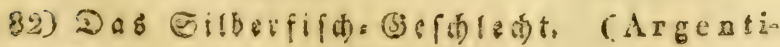
na, ) 
Dor Gopf if Ereit. Die Etim niebergebrüft. Die Simnlaben gleid) lang. Der dfter fiffít nabe am (Ed)wanje.

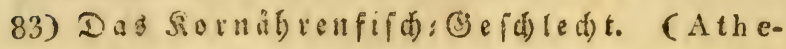
rina.)

Der sêtuer fomal, Elein, mit oünnen filberglän:ens Den Solumpen belegt. Son jeber Beite teg̉ Rupfs

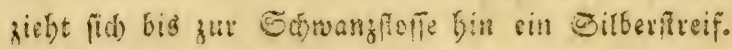
84) Das Deevaícen. (jeld) ledt. (Nugil.)

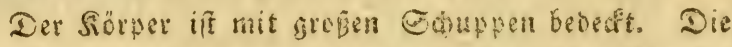

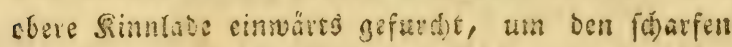
Fanb Der untein aufanebmen.

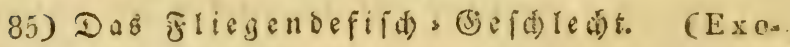
coet us.)

Qange zum finge eingericitete SBufifforfen, bie bis

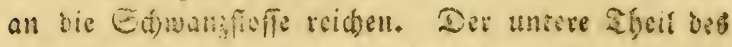
gobelförmigen Cónwanges längar als ber tEere.

86) Das fingerfifds= (jefdredid. (Polyuemus.)

Lluter oer Sefre fitsen zu beiden Geiten freiliegenos, ungegliederte, borfitenartige Strablen.

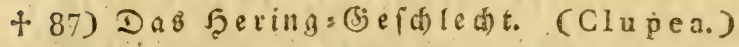

Der an ben Ceiten zufammengebrüdte Siopf bat sberwăts eine nad)enförmige Bertiafung. Die Coduppen am Waudbe bilben einen fdarfen Sand, unb freben fógeförmig bervor.

† 88) Das Sarpfen= (5efid) 1 ed)t. (Cyprinus.) Bäbne binter ben Siefern in cinem befonbern ges borenen Silleden, und in bem Siaumen eill rauber Sinoden. 
bat, die faicf oar bemienigen äufern Suftowe liegt, mit metdem fie zufammentgangt. SPitten burd) biefe Sungen= focke geft eine Siobre, bie fid in ben Ed)eitel offuet,

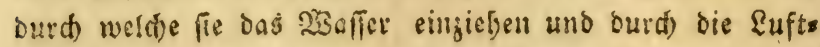
löter wieber beraudblafen. Der Mund, womit fie ans fougen, if oben långer alş unten. Die Săbne oben etwas gefrummt, bohl, unten breit, mit einem fleifobigen Rande umaeben, orangenfarbig. Die Zunge Galbmonbförmig mit

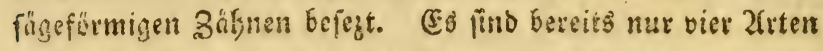
betant, bie in Ftuffen uno Meeren vorEammen.

+ 1) Die Rampretens grice. Die Ramprete. le Petromyzon Lamproie. La Cepède hist. nat, de Poissons I. p. 1 pl. 1. f. I. Lamproie marbrée. Bonnaterre Encyclop. methodique 1. 1. 1. pl. 1. f. I. Petromyzon marinus. Linn. Bloch Fifdie Deutfalanos III. 38, $t, 77$. (III. p. 49. t.77.)

(Tab, 1. Fig, 1.2.)

Im sjunde fig. 2. freben gengen jwangig Reifen 3ábne.

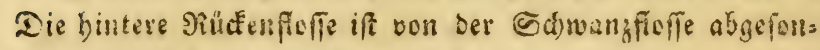
Dert. Siücell und Seiten find fămurgig olivengrün,

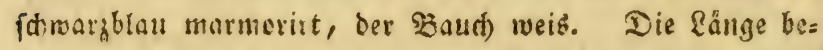

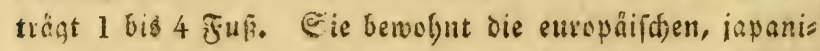
(d)en uns fitoamerifanifacn झgeere, Foment im Jrubjabe in Die Ellbe, Die Doer, ten Rhbein, Necfer und andere

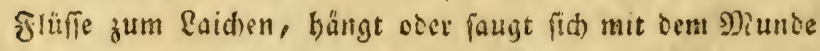
fert an andere Sörper, Dafer ber Siame Lamprete, Eteinleater, Steinfauger. Die Nabrung belfeft in

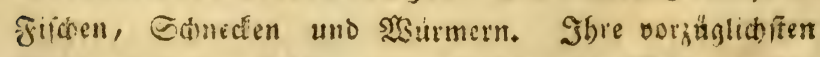

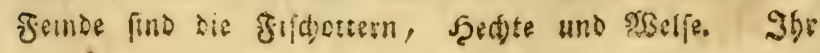




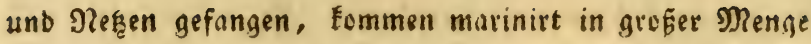
aus bem preufifden in ien Scanbel. Sin Gommer find lie

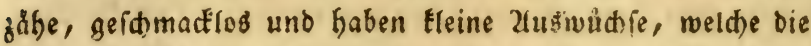

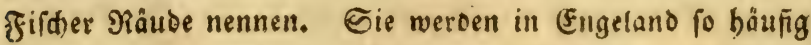

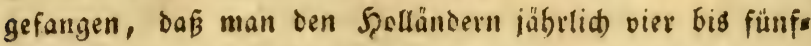
mal bunberttaufeno Stüc zum Rabeljau= unb Steinbutten: fang verEuafet, und bunderttaufend geben in ciefer 216fitst nad) Şarvid). In Sarland werben im Senner im 23aus. Eenfonen flute, wo fie viel sröfer als in antern fitulfen fino, eine Menne mit פieżen, aus bin im Elfe gebaues nen $23 u b n e n$ gefangen, it Sdnee gepadít uno weit vers fendet.

+ 3) Die Siefenpriáe. Le Petromyzon Lamproyon. La Cepéde I. p. 26. pl 2. f. 1. La mproie branchiale. Bonnaterre I. n. 3. pl. 1. f. 3. Petromyzon branchialis, Linn. Bloch. Fifac Deutfal, III, p. 45. t. 78, f, 2. (III. 58. $t .78, f, 2$.

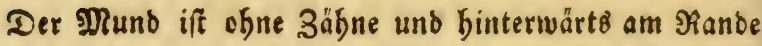

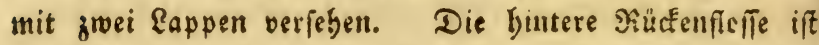

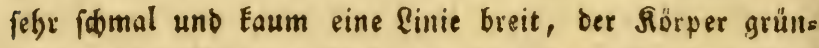
licb) an ben Seiten getblich, am Baucbe weif. Die \&äns ge betrågt 6 - 7 30 I. Sie bewobnt bie mebreften flüffe

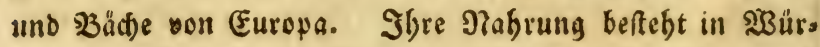
mern und Infecten. MRan finbet fie febr oft in ben zum গioffen ober Mazeriten in bie $\mathfrak{B}$ ñd)e oder Flüffe bineinges legten flachsbündeln, in welden fie fiid) nid)t felten ver= bergen und Damit aus Dem $\mathfrak{W B}_{\mathrm{f}} \mathrm{fer}$ gezogen werden. Sie werben mit Şamen und SReufen gefangen und bie und ba gefreist, alld) zum Söobr an bie fifd)angel benuzt. 
Die Eurge Rüctentioffe und range dfterfloffe fliefien mit Der Єdwangficfe zufainmen. Unter bem Borberleibe frebt

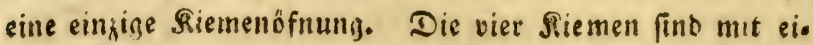
ner fechsfftabligen Siemenhaut bedectit. Es fino beveits 4 -5 veridiedene 2trten beEannt.

1) Der marmorirte ḩalbiemenfif.) (Synbranche marbrée.) L'Unibranchaperture marbrée. Cepède v. p. 658. Synbranchus marmoreus. Blsch austandidate Fiinde IX. 87, t. 418.

$$
\text { (Tab, 3. Fìg. 4.) }
$$

Der Börper if buncéel olivenfarbig, an ben Feitent und bem sauche grủngelb, violett marmoriut, mit bicker, Iecferer Fraut bedecft. Der frovf ift oben gewöltbt, an sent Ceiten zufammengebrürt, unten flad). Der weite Mund mit vielen Misiben Eegelförmiger, Fleiner Zââne beję̧t. 3unge und Baumen fint glatt. Die Eippen einfad), fleto fdig. Die Nafentöther ftehen nabe an ben blauen 2lugen. Die Seitenlinie ift in ber Mitte. Er if aus Surinam

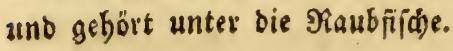

III. Das Doppelfalstiemen: (5) efdedt. Sphagebranchus.

Unter bem Sorberleibe ftehen zwei Riemenöfrinungen, bie nach vier Riemen auf ieber Seite führen. Der Kônver if glatt, idmal, wurmförmig, fiduppenlos und olgne alle florten.

1) Die fanaberlepfige Dopperbarbieme. La Collibranche. Sphagebranchus reo 
stratus. Bloch, atsl. Fifthe, IX, p, 88, tab. 419. fig. 2.

(Tab. 2. Fig. 5. 6.)

De: Sicpf endigt fith in eine fumpfe, fornabelartige Spite. Der Sglund ift an ber untern Seite. Die Sinna laben find mit fieben Eleinen Zăbnen veriefen. Der Förs per if wurmförmig, fouppentos und obne alle floffen. (E) fommt in Doftinoien vor.

\section{Das Baudfiemenfifd = (Befdletbt. Gastrobranchus.}

IIm 3 :aud)e ftehen zwei Eleine runbe Riemenóffnumgen unb eine rôbrige D̈fnung am Mentue. Der sörper ift nurmförmig, follupfrig. Zunge, luggen und Najentödher fehten. Zn beiben Seiten geht vom Sispfe bis zum Stbwange

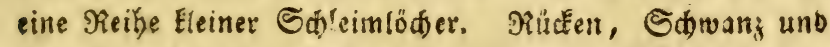
Ufterforfe find Eurz, fieffen in cinander unb baben weidhe, feine in ciner biden Syaut liegende Stadeln. Sechs blas fenartige Siemen liejels auf jeber Seite.

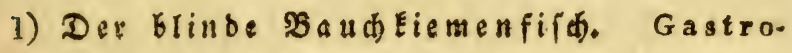
branche Aveugle. Cepède. 1. p.524. Gastrobranchus eoecus. B(ed) aust. fif de $1 X .6 \%$ t. 413. Myxina glutinosa. Linn. Mus. Adolph. Frid. 91. t. 9. f. 4.

\section{(Tab. 4. Fig. 7.)}

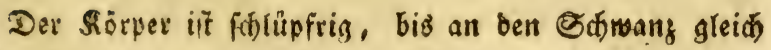
biake, blaulid), an ben Seiten tüt'flid, ain Bauche weis.

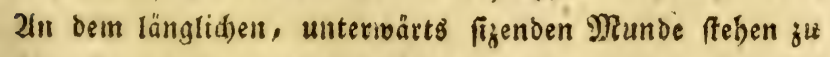
jeber Grite jwei, und oberwartts vier Bartfajern. Swifcen 
rez̧tern it eine röbrenförmine S̈frnung, burd) welbe bet

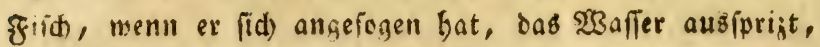
und welthe surd eine eigene Slappe verfdloffen werden

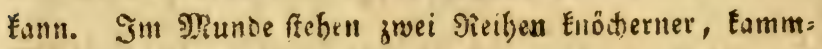
artiger 3ăhne. Zlm Baumell ift eine faltige Şaut unb binter ifgr ein rüđfwảrts gebogener 3abn. Die fänge be= trägt gegen 10 3oll. (E. Fommt in Dännemart, Norwe= gen unt Sdweden im Mreere vor. Seine Nabrung beftebs auz fif(t)en, (tn weld)e er fid) anfaugt, fid) mit bem bacten. förnigen Zahne im (jaumen feifgält, und mit ben Eamm.

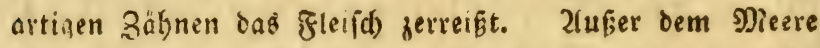
bleibt or nidat 4 Etunden an Reben, uno bält man ibn

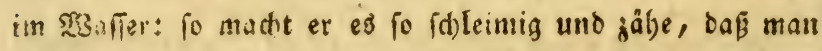
Jäoen baven zieken, uno andere birreingetaudte Sörper fardf Damit überlegen Eann.

* Xume Eung. Salm, welther ifn anf feiner Reife

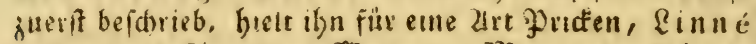
uno andere fuir einen $\mathfrak{B u r m}$. Nooeer, abili: ga a ro, weld lejterer ifn genauer unterfuch te und gers gliecerre, febten inn nebft 2 lo d) mit allem Niedtet un. ter Doe Fijuty.

\section{Dab Roden: (Sefdedt. Raja.}

Lluter bem Rerberleibe liegen an jeber Eeite fünf $\mathcal{E} u$ t: röđer. Ser Sörper if breit, Düne, platt, rautenförmig, zugefpitzt. Der Miund ftebt in oie D.uere unterwårts, uno if sid, mit frikzigen ober ftumpfen Bähnen bejejt. Die सugen fino zut Şalfte mit einer J̧aut ükerzogen uno Reben oferwärts. Die Nafenlöder fino über Dem Sjunte in eis ner breiten furde. Şinter ben 2fugen if ein balbmonbs formiges $\Omega_{i}($ ), von weldhem eitte Doffrung nad) Dem Miunde und enie jweite nad) ben fliemen geht. Die nach dem 
Nunbe Gin mit einer Rlappe verfolefien finb. Die Ries mendecfel find burd) eine f̧aut an die Bruft befeftigt. Die 3unge if breit, Eurz unb ylatt. Der 2lfter liegt am Bjrunbe bes bủnnen langen, meiffentlfeils ftadecliden, mit

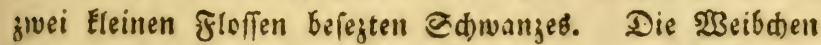

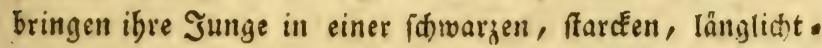
viereffigen Şülle, weld) in vier lange f̧ồrner ober Piancêt aus̆läuft, bie unter beın Namen Seétüfien, Seemà us fe (mures marini) betannt fino, zur ææelt. Sie grbeıt biefelben vom Mai bis 2(uguff von fict. Die $23 e i b d) e n$ fino viel größ̄er als bie Männden, und baben eine bopwelte Mutterideibe, aud) fintet bei ifnen eine Ueberfruditung (Superfoecundatio) ftatt. She 2ufenthalt find blos die Meere. Bon biefem biefoledte fino bereits gegen 20 vers fatiebene afrten befaunt, weldje nadh ifren Bäfnen von Linné beftimmt werden.

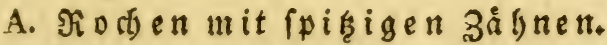

1) Der Bitterrode. Srampfrode. La Raje Torpille. La Cepède I. p. 82. pl. 6. fig. I. Bonnaterre. 2. n. 1. pl. 2. f. 5. R a j a Torpedo. Linn. Blod ausl. Fiidde I, 44. t. 122. und III, 118. (I. 59. t. 122.)

$$
\text { (Tab. 4. Fig. 8.) }
$$

Der Förper ift gang ofne Stacheln ober fonftigan Es. babenkeiten, glatt, graubraun ober röthfict), ž Zeiten mit

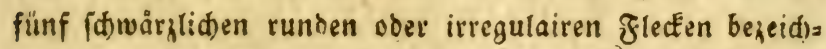

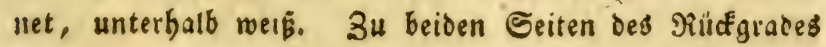

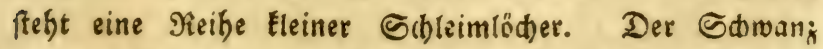
ift zu beiben Seiten gejकärft. Die j:vei Eleinen Miüúen. floffen laufen bis zun @dwange. Die Sdiwanglefte if 


\section{0 - Sierte Elaffe. Fifde.}

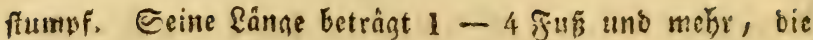

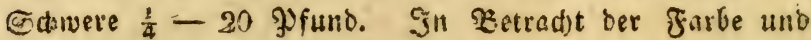

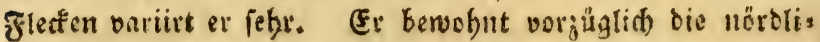
d) n Meere von (Europa, bas mitteliänoifde Meer und fins bet fid) auch am perfiften Mieerbufen. Ceine Nabrunis beftebt in Eleinen fiid)en. Ias Fieijo) if (d)leimig, weids

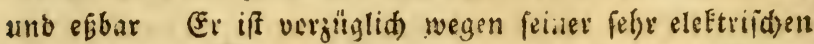

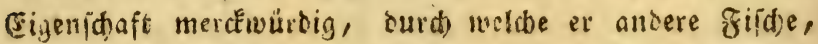
bie ifm nake fommen, betäubt, unb auch Sienfiden unb andern Sfieren, tie ifn unmittelfar ofer mittelbar burb feiter berủfren, electrifdhe Sotåge mittbetlt. Die mit Diefer Sraft veriehenen Igeile liegen ju beioen Eeiten fei.

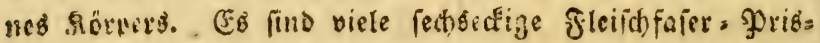
men, bur(b) weld)e siefe \$3itcung bervorgebractit wirb, uno

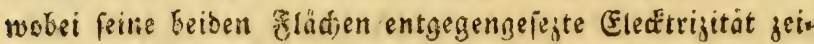

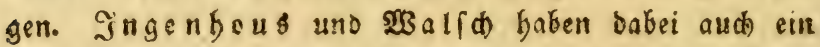
Rut), wie bei Entlobung einer leibener Flajde, beobachtet.

* 2rnmertung. San Aristoteles fdreibt, bie= fer Jifuh for, weun er im Eante liegt, bie uber ifm beridhionmention fiche betäuben, uno in biefem 3u: falloe fid ther bemadtigen. Siad) Droscoribes foll er bie (stieberictmeraen beben, menn er an bent leidenden Iheil gehatten wiro, mas nun in neuert Seiten bie mit ber Elestricttät, und oer galvanifiben Eăule, gemadten Erfabrungen fattfam Keftätigen.

2) Der (G) att: Rod)e. La Raje Batis. Cepède I. p. 35. Raje coliart. Bonnaterre. 2. n. 2. pl. 2. f. 6. R a a B at is. Linn. Blod) Fild e Deutid)l. III. 54: t, 79. (III. 69, t. 79.)

Der Sôn ger, afograu, ju Sciren fonnarigeflectit, unterba!b weib,

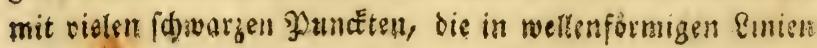




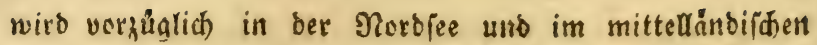
gneere angetroffen, aud) auf biefelbe 2lrt wie ber vorige gefangen uno verfpeigt. Das gleifo) ift reniger idmact. baft.

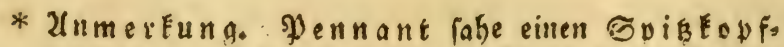

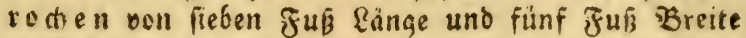
ausfidien. Gowobl vor biejer, als ber vorhergeben= ten Zirt werben in Engeland die Sungen fo lange Jungfernrochen (Maids) genannt, bis fie ibe (Geid)led)t fortzupflanjen anjangen.

4) Der Spieger = Rode. La Raje Miralet. Cepède 1. p. 75. Miraillet. Bonnaterre. 3. n. 4. Raja Miraletus. Linn.

răcfen und Baud) find glatt. 2fn ben 2(ugen ftebell Stacheln. Der Sabwank if mit einer brelfachen reibe

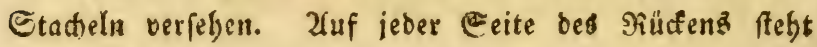
ein greficr, augenförmiger, violetter, fhwarz eingefaptes Flecf noer Spiegel. Die \&änge betrảgt $\frac{3}{4}$ bie Breite $\frac{1}{2}$ Jü. Er Esmmt im mittelänoijden Meere vor uno ift als Speije wenig gead)tet.

5) Der Dorn= Rode. La Raje Ronce. Cepéde 1. p. 79. pl. 5. fig. 1. 2. 3. Bonnaterre 4. n. 11. pl. 4. f. 11. R a ja Rubus. Blo(t) Fi(d)e Deutid)! III. 67. t. 83. 84. (III. 85. t. 84.) Linn, Syst, nat. ed. Gmel. p. 1507.

Der Siúfen if mit einer, ber lange Sdbwant abet mit orei アieifgen Stadbeln befezt. Der Siörper gelblid, braungeflecft, unterbalb weifß. Neben ben Baud $=$ und dfferfoffen bajen die Männden befonbere, berunterbän=

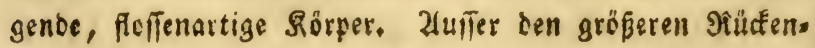




\section{Drontug. P isces.}

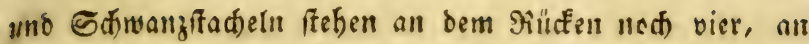
ben Zugen fect)s, an ber Pafe zwei und an ben Piscfens floffen mefrere Miciben Eleintere, wie an ber ăbrigen Dbers fladue eine Menge feine Stadjeln. Die Zlugen ftehen febr.

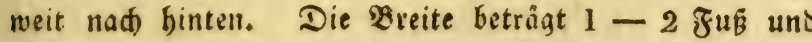
mehr. Er bewobnt vorzüglid) bie Norbjee, die übrigen eurepaiifden Neere, uno wiro geipeiśt.

* 2 um andern Rodentarten werben allerlei gefünffelte Figurent uno Menfrefitäten verfertigt, bie bei ben ältern Ed)riftîfellern, z. B3. Bellon, allorevano, (3) Bs nex und sonften theils als folde abgebildet und ero Eannt, thenls als getreue Beidnungen monftrofer, coer wunberbarer Shiere geliefert wurben.

\section{B. Nioden mit fitupfen}

6) Der Nagel= Rode. La Raje Boucléc. Cepéde 1. p. 128. Bonnaterre 4. n. 10. pl. 3. f. 9. R a j a clavata. Linn. Blod ßrifde Deutichl. III. 65. t. 83. (III. 82, t. 83.)

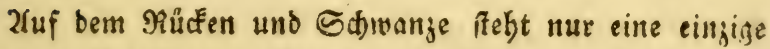
Nieife nagelförmiger, Enotiger, gefrümmter Stadjeln. 2(m übrigen Sôtper und den Seiten bes Sdwwanzes fint Eleine Gtadeln. Der förper ift braun, mit vielent runden, wei,

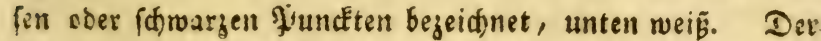

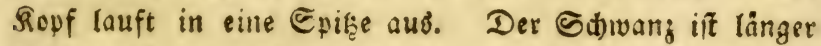
sls ber Förper, gegen das Ende mit einer bäutigen Jiofle

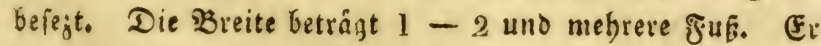
bewefnt bie Nersfee und anbere eurepailithe Meere, but

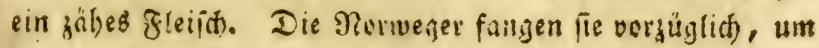

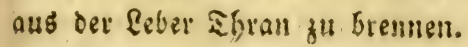




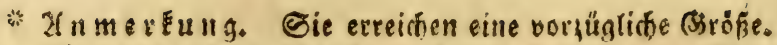
Fontoppioan fareibt in feiner Sifforie oen Rore wegen, man babe im Sabr 1634 ofnneit der Jntel (5 t. Chrifto bel bermittelf Sarounen einen ges fangen, ber 12 ₹uß lang uno 10 Fuß breit war unઠ wouon bie Reber allein uon 10 Matrofen mit vieler Datube fortgefdafft werden founte.

7) Der rorer= Rode. Der Meerabler. La Raje Aigle. Cepède 1. p. 104. Bonnaterre 4. n. 8 pl, 4. n. 8, f. 10. Raja Aquila. Lina. şlod Fiịd)e Deutid)I. III, 59, t. 81. (III, 75, t. 81.)

?n bem borftenartigen Sdwwange ftebt eine Flofie unb ein fägeförmiger Stacher. Der Sörper ift glatt, mit

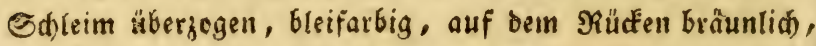
an ben Seiten olinenfarbig, unten weíf. Die faaut bick und lederartig. Der Sopf entigt fich in eine Eurge ftumpfe Spirse. Die 2lugen fieben auf einem tnoxpliden Eylinder: weit bernos, baben einen folwarzen Stern und gelben Ring.

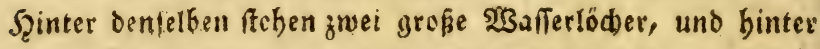
diefen in ber Dritte eine und feitwärts fünf (Erböbungen. Die פiafentôd)er liegen in bie Duere, find ourch eiue fnorplide Sdeibervand getrennt, mit einer ftarcfen Saut bebecft, die $i_{n}$ ber Miste ourd ein Bano befeftigt iff. Die \&ange bea

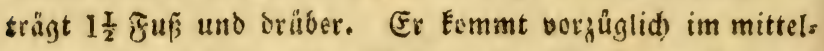
räntifben Meere, feltener in ber Merbfee vor. Das fletich) iff gábe uno wening geadtet. Die Reber bingegen wirb als eine DelEatelie fü: die Safe(n gefucht. Die Fifder bauen, aus $f u r d$ t von jeinem Sdwanfifad)el verlegt zu werben. Denferten logleid) ab, wie fie ibn gefangen baben.

* IrnmerEung. Ce Eann mit bem fipizisen Ctaded febr ftacc vertumben. Mantimal ift ber Stachel ab. gebroden. 3u Zeiten findet man alid) weldbe init zrea 
Stacheln ; Denn ba mad) ber Beobatitung ded Dr. $\mathfrak{B}$ as fter otefer Fiid) ben Gtadsel iafbrlich wedfeit: fo trifft et fich ju Beiten, dafi cer neue bervertomme, menn ber alte nad) nicht abgerworfen ift. Die Stainburger

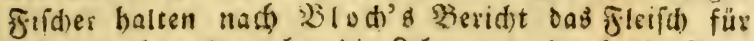
gifug, gebrauden aber bie Leber, um burd die Eens nennarme ein Del aus ibl ju jieben, weldes fie in Der (Jid)t benuken.

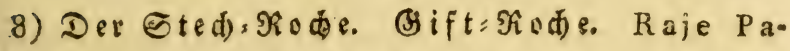
stenaque. Cepéde 1.p. 114. Bonnaterre 3.n. 7. pl. 2. f. 8. Raja Pastinaca. Linn. Slod Filíde Deutid)!. III 62. t. 82. (III. 79, t. 82.)

( Tab. 5. Fig. 9.)

In bem foffentsien, Eorfenartigen Edwanze ffebt ein fägeförmiger Gracbel. Dit Storper if glatt, mis Solleim itbergogen Dir Siopf luuft in eine kurge Evige aus. Die

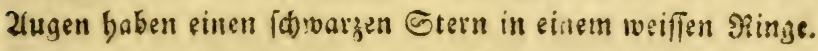
2luf ber obern Geite ift er am Bütrab und an den floffen braun, und iswiißhen biefen slivenfärbig. Die untere Geite ift weif. Die \$audfifofien feblen wie bei ber vorbergebens ben 2rit. Die Squwere betrảgt $2-12$ Pfund. Er Eemmt in Dem eutopäifden, rotben und inbifden गeere vor. Daร Fleifh) ift zăbe uno wenig geachtet. Die Erber bingegen if

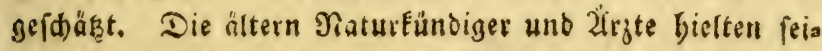
nen Stadiel für febr giftig, weldbes er aber niant if, obns eradtet 23 unden Durd) ib̆n wegen feine: fägenartigen feers vorragungen von üteln folgen fegn Eonnen. Ei bient biss

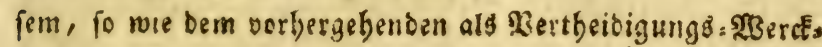
zeug, aud) zur Berwunoung ber fofifde, suf rolde ex Jago madt. Die Snoianer bebienen lïh auch feiner Etas d)eln zน गुFeilew.

* If n mex $\mathfrak{E} u n g$. Man fintet a Zeiten aud welde mit zwei Etadjeln, bie einige Siacustoricher fallolid fins 
eine befonbere 2frt, unb $\mathbb{R}$ inné als eine 2ffart unter bem Nainen Raja Pastinaca Altavela, be= fabrieben baben.

* 2fnmerEung. Die Giriechen und Siömer madten

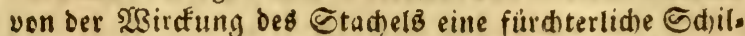
berung. Zf rian und Plinius fhreiben, dafs wenn ein lebendiges (5eíchenf damit verwundet witrde, es obne ßettung verlebren jege. Erfferer eriublet, oaf ein Dieb, welder einen bergleiden silid) in Der Mei= unng, baf es ein Sdolle gewefen, gefteblen, roll bemfelben verlejt worden, uno forleid) teot neben ibm liegen aeblieben wäre. Sa fogat foll nad) Zillian Der gröfe un gefundeffe Baum abiferben: wenn er mit clefem Gtachel geriz̧t wirb, unt nad) $D$ puian fol fein (sift Felien veriebren tönnen. Daber bat man vermutblich aud Dem Echn ber گitcé bieien Gtadel als einen Dold mitgegeben, womit er feillen sater, ben Uly fieg fidter ums feten bringen wür: be. Divfioribes bielt hingegen fein (sijt forn für heilbar. Die Sapanefer halten fegar ben Etadel für Das fitherfte Iglittel wiber ben Sd)langenbib̈, wenn fie bie 23 unbe damit beftreiden, fie tragen ifnn hu bie: fem Ence, nad) $\mathfrak{N}$ ämpfers Ingabe in feiner গieife nad) Sapan, immer bei fid), nur inüffe er, wenn er ciefe Gruft äuffern foll, von einem lebendigen গiod)en abgej()nitten (et)n.

VI. Da\& Şay: Sefdledt. Squalus.

Fünf Euftloder an jeber Seite bes Sorderteibes. Der Sörtper länglid), faft walgenförmig, fhuppenlos, gröftens theils mit ganz theinen rauben Etadteln veriehen, welde

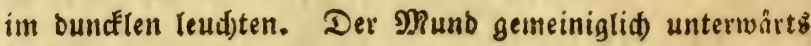
in bie Suete, bei einigen nad der \&änge und bei bem See, enget vorne am Ranbe. Die Zäbne ftehen in mefreren

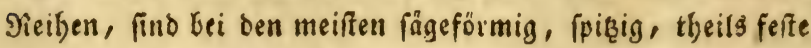
und theits beweglid). Şinter den längriden, halbbedeckten

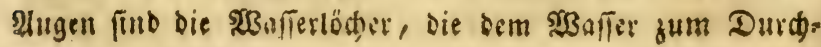


gange fowoff aus bem शhunbe als aus ben Riemen bienen, uno nur bei sinigen 2frten ghänjlitit) feblen. Die reifen Ener baben eine åhnlid)e vierectige fęüfle, wie bie ber roden. Die Sungen entwiffern fih ous sem (E) in ber

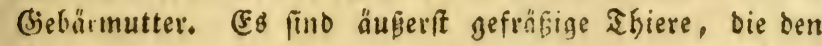
Sd)rffen gern nadffolgen, um bie todten über 3 ord gea worfenen Rörper aufzufangen. Sie bervobnen vorküglid Den füsliden und nördlid)en Deean. Daf gleifch ift bart

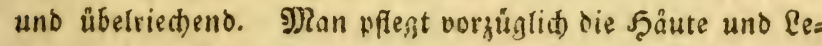
bern, jene als Reber und zum peliren, dieje fum Ifran ju

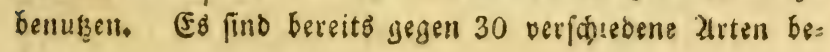
Eannt.

1) Der ifabelffarbene 5any. Le Squale Isabelle. Cepéde 1. p. 255, Chien de mer is abelle. Broussonet. mem. de l'Acadernie des sciences, 1780. Bonnaterre 6. n. 1. Squalus Is a bell a. Linn. syst, nat, ed. Gmelin, p. 1489.

Der Sörper ift ijabelfarben, fawwarzseffecte unten fidmukgig weił. Der אepf ftumpf, breit und Eurz. Die

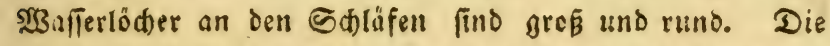
Tilufenfleffen faft vierectig unb bie zweite ber affterfiofie entgegengeregt. Die fehr groffen Bruffeffien entifehen bei Dem britten Ruftlodse. Die Bandflofien find abgefonbert anb laufen nach binten fwizig zu. Die Seitenlinie fteht

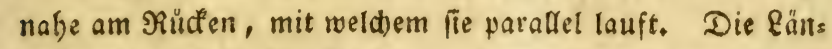

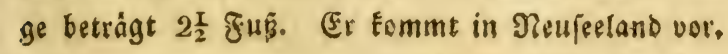

2) Der Squndв̆ay. Der getiegerte 5̧ay. Le Squale Rousette. Cepède 1. p. 221. Chien de mer roussette, Bonnaterre, 6. n. 2, pl, 


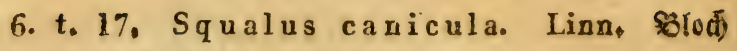
audi Fiide 1. 16. t. 112.

Der Förper ift lang, fdimal, an beiben Enben yon Len Seiten zufammengebrücft, röthlid) braun, rotbbraun geflect, unten weis. Dex Siopf Elein, die Sonnauze Eur. Şinter belt 2lugen fteben bie \$Bafferlöber. Die Baud). flefien futb von einander abgefondert uno die erfte Rücfen. fisfe freft binter ignen, bie andere Eleine aber, gerabe

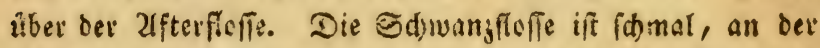

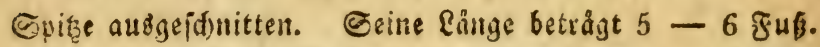
Ev bewoínt faft alle Mleere in ben gemäffigten unb bitfent Gjegraben, gebont unter die åuperft gefräfigen Taubtbiere, rueduegen er bie Ediffe verfolgt und alles auffängt, was

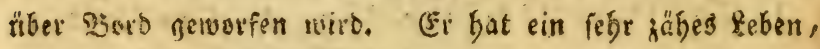
fo daf ber Siumpf, nadisem man den Sopf und ben (Edwang bavsn gebauen, uno die Eingemeide berausgerif

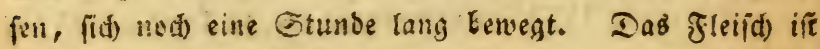
zâke unठ unfamacthaft. Der Ebran wilb benuzt. Die Sgaut wirb bei f̧olzarbeiten fum syoliven gebraudst. (Ex wirb an grefen mit faiten Etriden befeptigten Sgadien gefanger.

3) Der Eleingeflecte Şay. Der Eleine

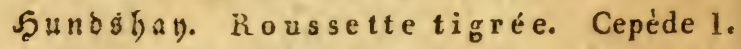

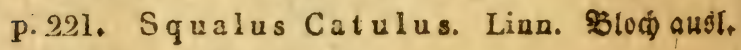
Fisabe. I. 21. t. 114.

Der Sörper ift geflectet, bräunliá) an ben Seiten rütb: (id), unten weis. Der Sopf grof und bie balbourchfictige Schnauge lănger als bei ber vorbergebenien 2l't. Die 2luz gell find balbbededt unb baben weife Sterne. Sinter ben:

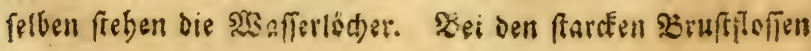




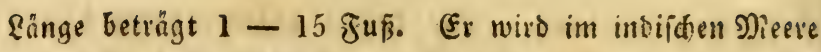
angetroffen. Seine গabrung beftebt aus Muid)eln uno Srebfen.

5) Der Meerfaubay. Sagenbay. Le Squale Milandre. Cepéde 1.p. 237. Chien de mer Milandre. Bonnaterre. 7. n. 4 p, 6. f, 16.

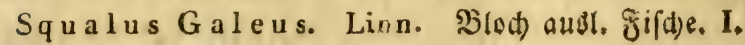
31. t. 118. (I. 42. t. 118.)

Der länglidrunde Förper if grau, unten Geller. Die

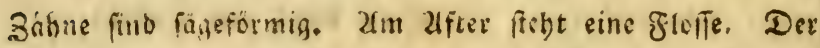
vorne zujammengedritcte Fopf endigt fich in eine ftumpfe

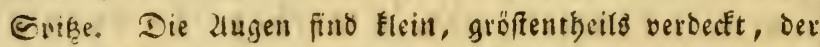
Etern iff phwarz, Der alugenring weí, und binter oem=

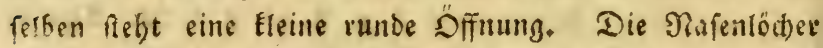
fieben über bem Siunde und find mit einer Sgaut bes

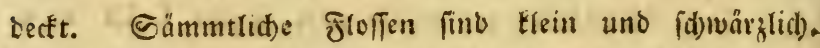
Der Sd)wang bat beinabe die fänge bes übrigen fiörpers. Die Ränge beträgt über 3 uno mehrere $5 u$. Er erreidt

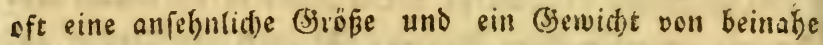
100 Pfunden. Scin 2lufenthalt if vorzughtid das -mittel= lândifde Nicer, feltence die Norbfee. Er if åuferit ges fräß̈ig, verfd)lingt fogar Stücte von foll, wenn fie mit Fett befanmizt finto, und it ber gemeinfte im mittellän, Difden Meere, wo er ben Sdiffen nachfoigt.

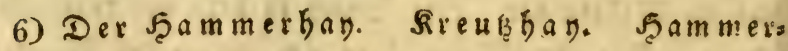
fifd). LeSquale marteau. Cepéde 1.p. 256. pl. 8. f, 3. Chiende mer marteau. Bonnaterre 9. n. 11. pl. 6. f. 15. Squalus $\mathrm{Z}$ y gaena.

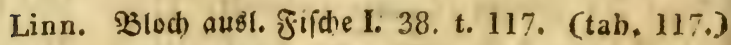
(5 $\quad(\mathrm{Tab}, 6 . \mathrm{Fig}, 10,11$. 


\section{Sronumg. Pisces.}

(Ev if von allen vitrigen 2frten fogleid) ourd) peinen breiten in bie D.uere mit dem Sörper verbundenen Gan: merförmigen Sopf ju unteritheiben. 2un den Enten beflets ben fehen bie grefien, nad) unten geridteten, berborftes benten 2fugen mit einem fowwargen Sterne und einem geltfarbigen 2lugentinge. Die Munsóffnung fteft nad) unten gegen Dem Siumpfe bin, und if begenförmig. Ier Siöper ift geftrectit, rund, eben grau, unten weip. Die Şaut rauf. Die Fleffen baben alle einen monoförmigent

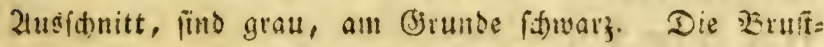
fleten izen unterwärts. Die Baudflefien find getrent,

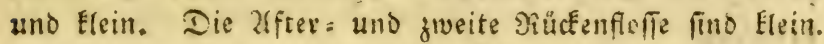

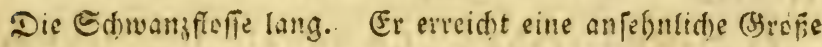
uno ein Bjevidjt von $4-500$ PJfuncen, bewabut oug

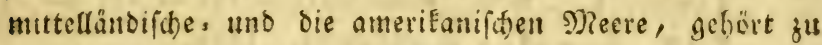
Den farcen Siaubrilden, welde fogar Mienjolen anfullen.

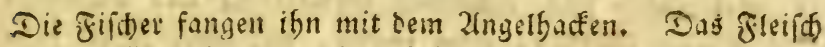
ift zạbe unb übelriedento.

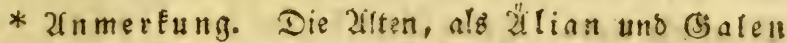

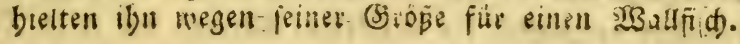

7) Der blaue f̧ay. Le Squale glauque. Cepéde 1. p. 213. pl. 9. f. 1. Bounaterre 9. n. 15. pl. 7. f. 22. Squalus glaucus. Linn.

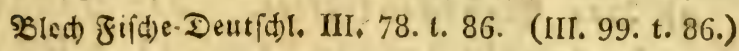

Der Fopf if obne Şaffertóder. Dónmeit ber Ẽdwang=

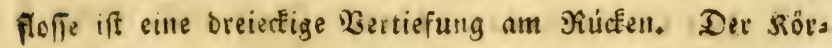
per ift runt, glatt, am æiücten uno an ben Seiten blau,

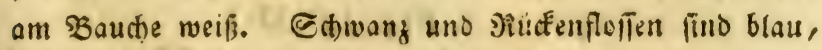
Saud) uno Bruffloffen oben blau, unten weißß, Die 2ffters foffen weip. De: Sispf ift bon sben uno unten zujams 
mengedrüft, die গlafe lang. Die Zugen baben èinen

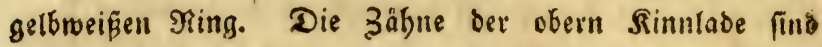
fägeförmig, in ber untern lăngev, fđumäler und ungefügt. Die Rånge beträgt $2 \frac{T}{2}$ bis 14 unb mebrere fub. Er bes fafit alle Neere, vorzüglich aber die Dft, und Norbfee,

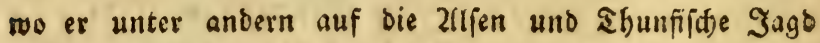
madt. Das fleifh ift bart, jâbe und übelried)end. Die Reber wird für eine wablidmedfende Epeife gehalten. Ee ift äuBerft Eübn uno foll fogar Menichen anfalten. Mair fincet in ben Sotuefucten: Sammlungen unter bem Namen verffeinerte $\mathfrak{D}$ ogelzungen (glossopetrae) Die Zngne Deflelben.

8) Der Kiefenbay. Le Squale trésgrand. Cepède 1.p. 209. Bonnaterre. 10. n. 18, pl, \% f. 19. Squalus maximus. Linn.

Die 3ähne fino fämmtlid) Eegelförmig uno ungefägt. Der Siörper iff blau, grün melirt, mit einer jäben raus ben Şaut bebecft. Die vorbere Rücfenflofle grof́, die 2lfterfloffe Elein. Geine \&ănge betrảgt $26-40$ Juß. E:

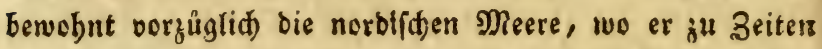

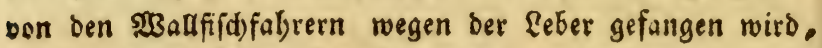
aนs welder fie Sbran bereitell. Ev foll Eleime Sallfifo ganz verfdlingen.

9) Der Menfdenfreffer. Der Jonab̧ay. Le Squale Requin. Cepéde 1. p. 169.pl. 8. f. 1. Bonnaterre 10. n. 19. t. 7. f. 20. SquaI us Carcharias, Linn. \$(ดd) augil. Fi(d)e. I. 41. t, 119, (I. 45, t, 119.)

$$
\text { ( Tab. 7. Fig. 12, 13.) }
$$

(Ex ift von grauer Farbe, und zeichnet fic) vorzúglict burd) feimen breiten sücfen aus. Dor Rörper ift geftrectits, 


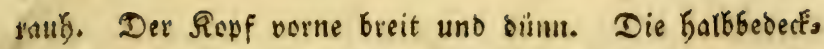
ten 2lugen baben einen ¡dwargen Stem in einem peegrüs

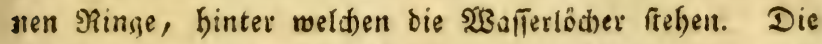
Slundorffnung Fig. 13. ift feffe weit und mit vielen Reithen

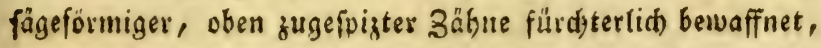
you weldien bie norderen Mieifen feffe, bie bintern aber beweglid find. Die 3unge if furz, bid, breit uno knorps

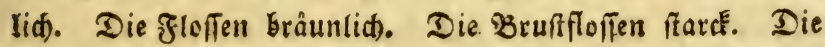

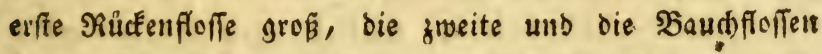
flein. Die Sthwangforfe lang. Die 2 ffterflefte mangelt.

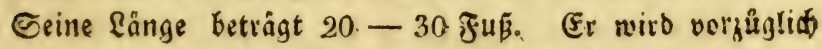
in mitteländifकen Mreere unb faft in aften Begenben bes groben 2 seltmeers angetreffen, wo er fid getwöbntich in

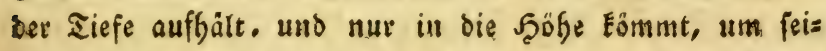
nen Saunger zu fitten. Zun ben Ufern exid)eint er nur bein Serforgen feine\& Raubes, aber wenn er feinem grös ffen feinde, Dem sootfifide. (Physeter macrocephalus

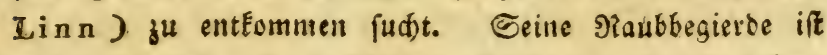
auperorbentlich. (Er veridstingt alle Shiere, fowobl rebens sig, als toot, verfolgt ver;üglidi) den STeitbutt (Pleuronectes Hippoglossus Linn, ) ben Sabelian, das (Ties falb unb ben Ifunfifd). Den Meniden fïllt er all, wo ex ifn erhafden Eann, zieht baher ben Sdiffen nad, wo ex Menfकen, weldhe in daz $23 a f f e r$ fallen, ober toot über Borb geworfen werden, fogleid verfidlingt, baber er ben Namen Mienfdenfreffer befommen bat. Die unges

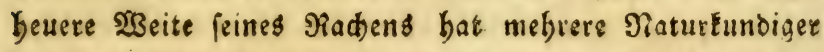

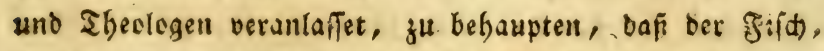
der ben $\mathfrak{J}$ cnas verfolungen babe, biefer gewefen. fery,

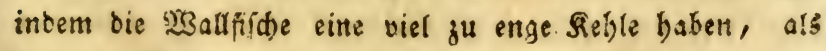

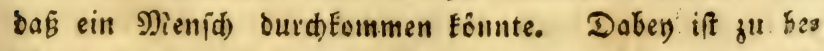

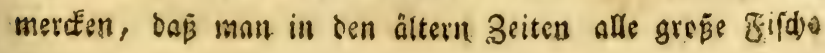


23alnfiche nannte. Faft in allen Befdrcibungen von Ges: reifen lefen war die traurigiten (5iefchidten von biefem Fis fire. Sa no elet verfichert, man babe im sagen cines. bei Miarfeille gefangenen Flídes einen ganjen gebarnifitent

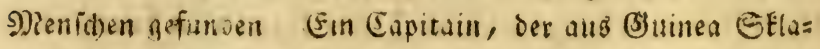
ben auf femem Edoffe hatte, uno wabrnabm, dafi die E(t)warjen besbalb den Gelbftmerd ausubten, weil fie glaubten, fie ftünden bei ben ifigen wieder auf, wollte fie

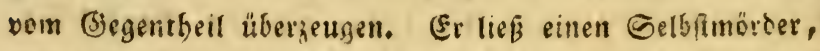
nachoem er ifm die Beine batte feftsinoen laffen, in oie See werien, uno shnerachtet er mit möglichfier (sefachin= bigfeit wiedse berausigezonen werten forte, fo batte ifn ein

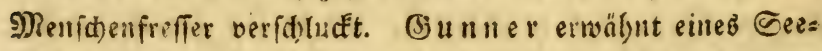

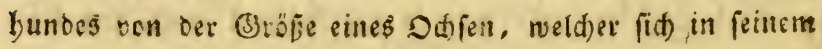
Siagen kefuneen. Stgre Bjefräbigkent geft fo weit, bafi fie auch ibrer eijenen aft nidjt fbonen. Ein Sappe, ber eitrent faayfi is gefangen butte, befeftigte foldhell all feineal Sabn,

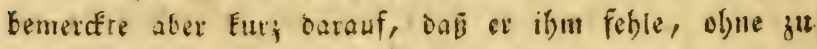
milien we ar orum gefsmmen fey. 2118 ar aber nidjtange nadber einen grësern fing: To fano ex in beffen Mlagen feinen britobinen Say wieser. Man Eam fid) feiner aber auch leid)t bemáchrigen, wenu man fida) nur mit entem ftal: Een Şarfen, der an einer jwei Fllin langen eifernen Sette beferfigt if, rerieben bat, woran ex, ba er einen anuserft

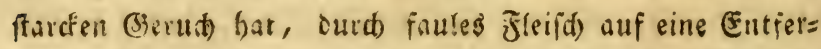

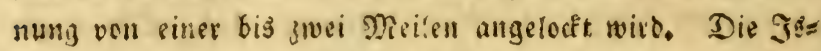
län er wfizen ei: en G.uf mit fautem fleifobe, ster einen Eevbunts Siopf, all ibren Şaction ju bindent uno ifren

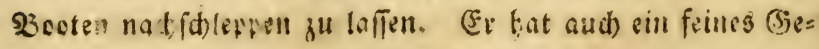
b̈ri, went er, wens er Mienjiden laut zufammenforedsen

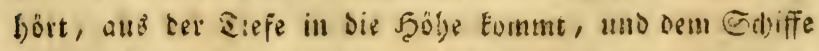
fii) ju niberen pflegt: baber bie Grönlänber, wimn fie mit 
ifren Nadien, die fie aus Geefundsfeffen verfertigen, auf tiefe Gtellen Eommen, jid) gang ftitle verbatten, weil tie

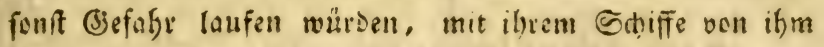
gefreffen zुน werden. Es if übrigens fonterbar anzhliehen, wie ber Menia), ber fith vor biejem llngeheuer fonit fo fehe

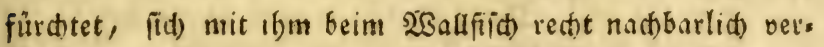
trågt: benu iniem jener biefen von cben plindert, fo bet/= fen bieje ifm Stuture aus bem \&eibe. Sit er gefangen, fudt) ex fid) burch augerorbentliffe Sprünge zu befreien. Sind feine Berfuche frudttes, fo übergiebt ex fid) vor

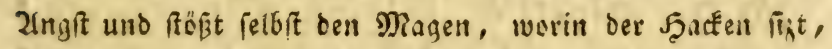
heraus. So fürdterlid) er allen 2 Bafierthieren iff, fo Eamr

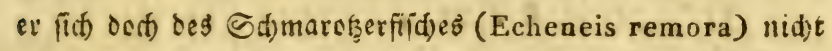
erwebren, ber fith ifm anbängt und mit ifm die Neere

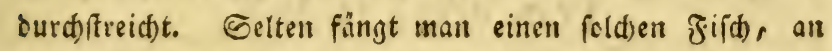

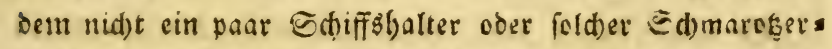

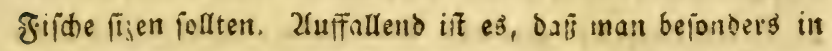
bellien (begenbeat faft allegeit ben Rootsmann (Gasterosteus Ductor. Linn.) in einer gewififen (Entfernung oor ifm ber fodmimmen fieft. Er hat unter aflen Şayfifichen dus (d)macthaftefte Fleifd. Es befteft aus jweierlei Eanen, wooon das åullere roth uni zart, bas innere aber weis unb

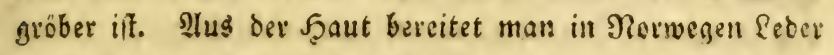

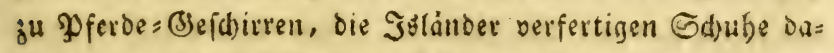
raus. Zius ber Reber wiro Shran gemadit. Die hie unt sa vorfommenden folliten 3ăbne bicfes zifides wurden vor Beiten für verffeinerte Sallangenjungen (Glossopetrae) sefammelt.

UnmerEung. Ohnweit Mördburn am Botenf: fano id vor einigen Jabren in einan feinen Eandges rölle febre viele tleine uno grobe Bägne, die bizlite forche angebouren und unter andern emen, bet beinalse 
fünf framsinfiche 3oll rang, am (3runde nier 3oll breit, und einen 3oll biat ift, Das (3avisht beffelben beträgt

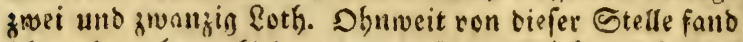
id) ned) melgere fleinere unb gröfsere Siuncfentuirbe!bei= ne, bie vermuthlit) aud) ku biefem Fifithe getören, roeven ons groffe utber fünf $30 \mathrm{ll}$ breit, uno gegen swei 3oll bute iff. Diefe Grücfe bradte id in Das (Siros: herzogl. Maturalien = Cabinet zu Carlorube. 2lus ber

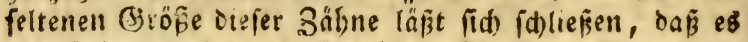
vor Beiten nod) ungleid grépere Sbiere biefer 21ut ges geben babe.

10) Der Sảgefif́. Sägen Scie. Cepède 1.p. 286. pl 8. f. 4. Bonnaterre 11. n. 21. pl. 8. f. 24. Squalus Pristis. Linn.

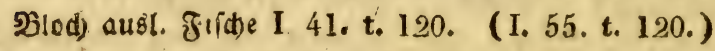
(Tab. 8. Fig. 14. 15.)

Ěr unterfabeiset fid fogleid) von allen uีbrigen 2frten burch ben langen, glatten, Fnöd)ernen, fdwerbförmigen, auf beiden Geiten gezábnten Fürlel, in w:Id)en ber Sopf ousliuft, ber mit einer glatten leberartigen Şaut überzo= gen iff. Der fiörper ift geffrect,t, bie Şaut glatt. Sin̈efen

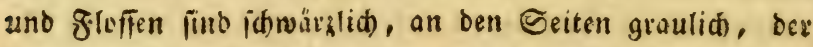
3au(t) weir. Der Siopf vorme flad). Die 2ugen grob

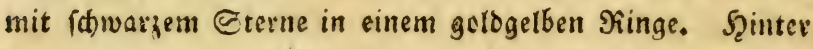

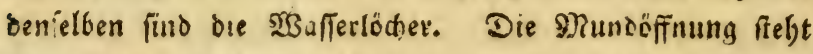
bie 2 uere, uno beibe Sinnlaben fino mit getörnten 3ăbnen befez̧t. Fig 15. Die Ufterfloffe feblt. Die Ränge beträgt ûber 15. Die ber Săge $2-5$ ₹uß̧. Ex bewobnt die nördfichen uns fürameriEanifhen Meere. Bei Şgland, Spiţbergen, und Birënland tummeln fie fiit) mit ben Wallfilden berum, weldhe fie mit ifrer Săge am Baudbe verlezen, die ifnen ols verjüglides \$jertbeidigungs = Mittel bient. Bei einem ungebobrnen Sägefich iff oas Sdywerot nod) weid unt 
12) Der Meerengel. Der Engelbay. Mod) en= Gay. Rrötenbay. Le Squale Ange. Cepede I. p. 293. pl. 12, f. 1. Bonnaterre 12, n.28, pl. 5. f. 14. Squalus Squatina, Linn. Blod) ausl.

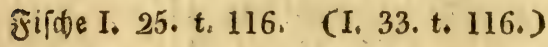

Er mad)t gleidjiam ben lltergang ven ben গodjen ju ben Şayen uno ift fefre leiditt an feinem nach) unten jufams mengebriaten Sionper zu erEennen. Der Sopf iff flach uno

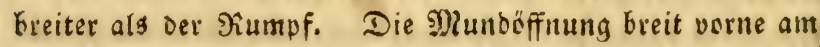
Sopfe. Die Najenlöd)er fino mit cirrer Şaut bebecft, die fic) in swei Bartfafern entigt. Die Zugen find flein uno Der feegrüne Stern ift mit einem gelben Ringe umgebent. Şinter ifnen freben zroei balbmondö̈rmige Wafferlöder. 3 u den Seiten fino 5 halbmonoförmige \&uftloder. Der Sorper if werbalb grau, von Eleinen Erummen, nach bem

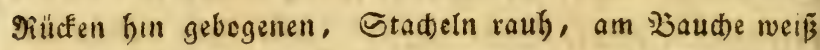
uno dafelbit bis an ben Sd)wang glatt. Die Bruftifuffen

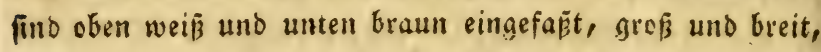
flügelartig, Daher bermutblict) ber Raine Seeengel ents ftanden. Sie Baudtfleffen länghth) und weif́; bie 2 Miưfens flofien Elein unb lizgen am Sdhwange. Die Ed)wangflofie if jenctred)t uno hat einen Éleinen, balbmonoförmigen 21

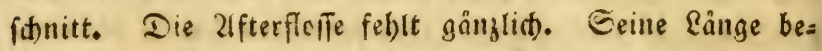

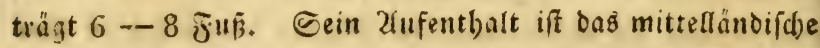

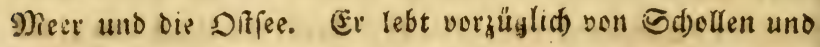

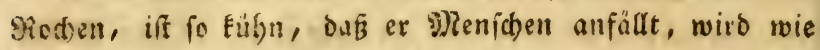
Die übrigen atrten surch ein Stücf Jleif(h) am Ingelbacfen gefangen. Sein fleifd) ift jube uno unf(tmacthaft. 2lu\& be: Saut verfertigen Die Eirten den fañnfien Cbagrin, welder vorginglid) ju Ubrgebåufen verbraudt wiro. 
VII. Das Serafen= oder Meeroraden: (J) $f($ d) $(e d)$ t. Chimaera. Linn.

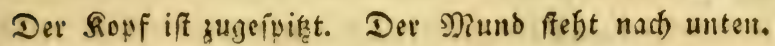

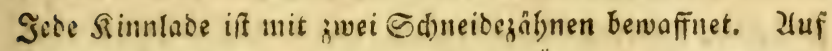
jeber Seite, nad) unten, ift nur eine D̈ffnung zum 2tthems, bolent. Der störper ift geftrecft, uno mit cinem Stadjet nuf dem siüten verféten. Der Sdwwanz länger als ber

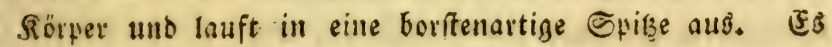
fiiro bereits nur jovei Zliten betannt, weld)e voin Siaube leben.

1) Die nórolide Eceratte. Der Meeraffe. Der M. Meerbrathe. La Chimère aretique. Cepède I. p. 392.p1. 19. f. 1, Roi des Harengs du Nord. Bonnaterre 13. n. 1. pl. 8. f. 25 . Chimaera monstrosa. Linn. Mus. Ad. Fridr. 1. 53. t. 25. SBlod ausl. zifide. I. 61. t. 124. (J. 85. t. 124.)

$$
\text { (Tab, 9. Fig, 16.) }
$$

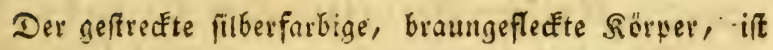
von beioen Seiten jufammengebrürft. Der Sopf längliđ mit vielen flemen Goheinüfinungen. Die sbere Sippe ift getheilt und an jebem Munowindel fieft ein bervorragen= Der Rapwen. Die grofên Zlugen baben einent meergrünen Etern in einem weiffen Singe. Zluf Dem Sopfe fteht bei Dem Månnden eine Gafer, an welder ein Eleiner Büfdel bängt. llber und unter bein Iluge fteht eine gefrummte Emie, bie fid) mit ber Seitmlinie, reld)e boin Siopfe bis zum Ende des Edtwanzeg fortiauft, vereinigt. Der Ét)wanz ift faft noth einmal fo lang als bes fintper und lanit in eis

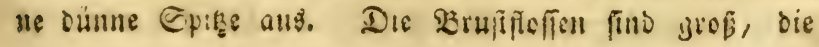




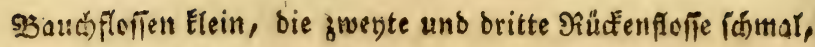
bie erfte breifantig, an einem ftarcéen nad) binten gejäbnel= telt Etad) befeftigt. Sämmtlid) zroffen find braun. Bei bem 2lfter liegen bie gedoppelten 3eugungzglieder beiber (5es

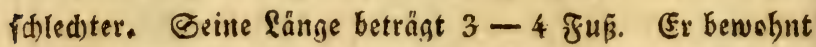
ธas Noromeer, lebt vorzüglid) von Seefternen uno Srebfon.

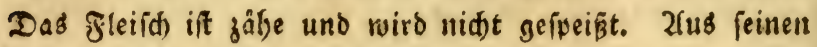
Eyem backen die Norweger Pfannentuchen und aus bem Borftenförmigen Sheil bes Sdwanjes, wenn fie ifn getroct: net baben, mad)en fie Pfeiffenraumer. Die Seber binben

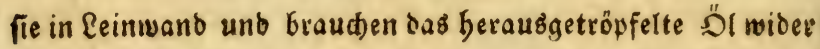

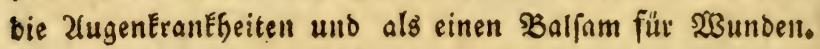

* InuerEung. Einné gab ifm. ben शlamen Chimaera, wegen feiner auffallenten unb fonberbaren Bieftalt. Hesiodus gab biefen Famen einem mon ftrôfen \$biere mit einem Dradenfámangu. Roi des

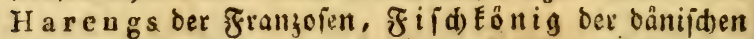
sauern, wegen feines fonderbaren Supfaieraths. Det शame (seedra it) e gebort eigentlich nid)t biefem gi= fale, fondern bem Pegasus Draconis Linn.

2) Die fúblide Secratte. Der Seebahn. La Chimère antarctique. Cepède I, p. 400. Le Roi des Harengs du Sud. Bonnaterre 14. n. 2. Le poiss on co q. Molina hist. nat. de Chili. 207. Chimaera Callorhychus. Linn.

Zuf bem Sonfe figt ein Enorpelartiger Samm, welder fid) einen balben Zoll bod) über bie Dberlippe erffredt. Det

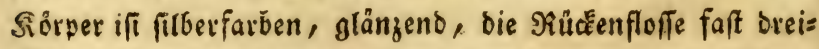
eafig mit eincm langen Stad)el verbunten. Die affere fioffen fino geboppelt. Der Sdiwang ift blattartig unb mit

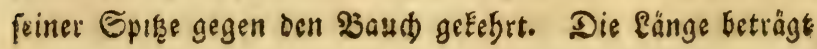


gelben Ringe haber. Die Riemeneffnung if grof uno its: Decfel beftebt aus einem nach allets Geiten geitrablten כ̇lätt(d)en mit einem bâutigen Rande. Der Bauch ift ge= rade, breit und weiß̧. Die Bruftfoffe iff am Biunbe mangefarben, am Sanbe fawarg. In ibr find 30, in Der 3 audflofie 25 , in ber 2 fter und Sdmanjfolf 24 und in ber Siücfenflofle 38 Etrablen. Geine fänge betringt 5

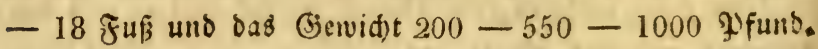
Er wiro allentbalben im Diean, in ber Norb, uno Ditfee, in mittelländifden, fdwwargen uno rotben Neere, nus welden er in bie Srröme uno Flülfe gebt, angetroffen. Bei uns wirb ex nid)t felten im गibeinitrom gefangen. Fe wiro vor:üglıd an ven Sutiften, wenn et auf antere fijide Jago mad)t, ober in Flüffen uno Strómen, worinn er

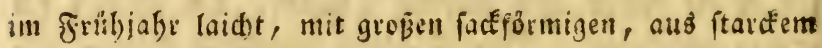
Binbfaven verfertigten Nokgen gefangen, auf bem Mleete

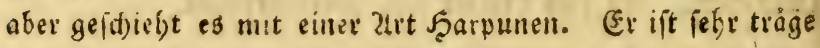

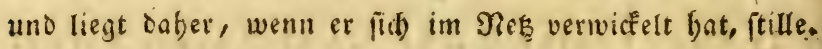
Die Fifder befefrigen ifll alsbann burd) einen bur(t) bert Mund und bie Riemen gegogenen Strick, womit fie ifn am Sdiffe anbinden und fortfubren. In bem Sdwwanj bat et

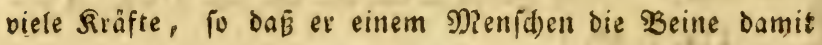
enrigrei fallagen Eann. Ser ftärfite Fang bes Sröhrs ge= fdieht im Senner mit faacken unter dem (Sije, weil er zull biefer Jabreşzeit einen ungleich böberen \$serth als im Sommer bat. Dlueradtet fie gegen ben Winter aus bent Etrömen wieber in bagr Meer wandern: fo bleibt bod) aud) ein groper Sbeil in ben Strömen zurthe und überwintert bafelbit. Das Jleifd) ber jungen Stóbre if́t fett, lüplid, woblid)mectenb, uno bat mit bem Sialbfrif(t)e einige 2̈ifn= lid)eeit. (5) wirb theils frifd, theils cingejaljen und mart= nirt, gefpeipt. Frifd) wirb eร aus bem Salgwafler, geEedt 
legt worben, in Eleine Säcfe von Reinwand eingeb̆nnoen uno gepreft wiro ( Rufiijd) Meschechnaja Ikra). Mnu pflegt ben Caviar entweder auf গ̧rob zu effen, oder ifn als

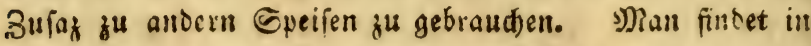

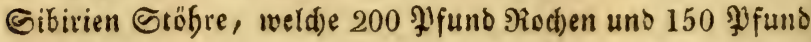
Mita) gebell. Son ber Mild) wirb aud) Durd Fo(t)en eit bod)gelbes, woblid)medenties öl abgefondert, welches bei geringer Siälte gerinnt, jut Bacfwerć an Speifen gebraud)t unb im Sommer eingefalgen wirb. 2lud wiro ber Mlagen

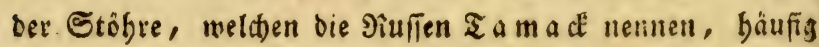
geipeifít. Ferner wirb nid)t nut vom \$̧aujen = Stöhr, fon= bern aud) von biefem, vorzuglid) aus ber Sd)wimmblafe, ser fifdleim soer bie 5̧a ufonblafe gemadt. Die Sd) wimmblafer werden gewaid) an, an ber \&uft getrecfnet,

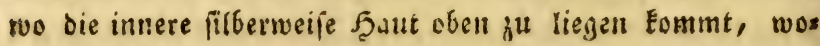

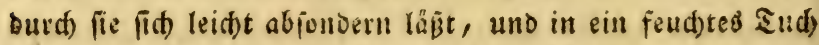
geid)lagen wirb. Sie wirb naciber aufgerollt und etwas getrokinet, aldbonn an Fäben aufgebängt unb im Sd)atten völlig getroctuet. Diefe Sraufenblafe gefört mit au ben bes

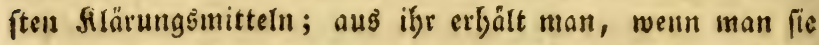
mit Canbelgucter f(j)meljt uno ju einem gelven ourd)fid)ti=

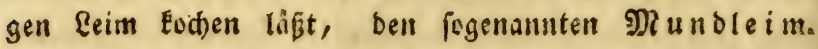
2fud) mit 3 ramttwein giebt fie einen fefr binbenden Leim. womit man Steine, Şorzellan uno Silas wieberum Fittets Fann. Man bebient fid) ifrer au(b) zu Şerfertigung be: unåd)ten Perten.

* InmerEung. Die Stöbre variiren vorghủglid in

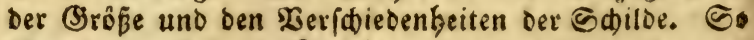
faeint ber Sdip: Stöbr. Le Schype. Bonnaterre 16. n. 3. A cipenser Schypa. Guldenstädt nov. Comment. Petrop. XVI. 532. S (d) ips

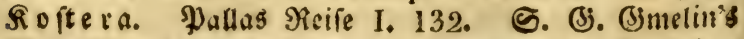
Reife IL, 259., weicher in Der X̧solga angetreffen wird, 
geben fie fid) vom Miecre in bie Fluffe. Jhte Nafrung bes

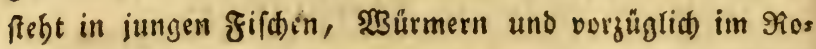
gen bes తtöbrs uno f̧aufens, Denen er in biefer 2lbfidt)

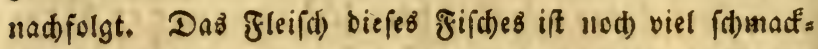
bafter, zårter unb angenefmer als vom Stỏbr. Daber wurben weldje von bem Sönige in \$rellen, in bell Stabts gräben von Cüftrin und theils in einen grofien See unweit Etettin eingeferet; in legterem find fie nod) vorfanden und pflanzen fid aud barinn fort. Friebrid) lfte Fönig in

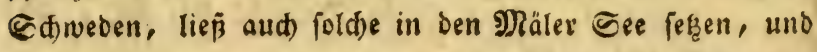

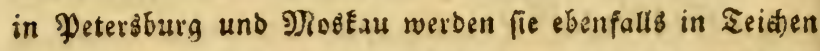
gebalten, wojelbft fie bei auB̈erordentlidjen Gielegenbeiten auf bie Safel Eommen. In Siuflanto wirb altc) ber গogen zu Caviar benuzt, melder, on er ben vom Stöbr an Güte weit übertrifft, an ben Sofof geliefert wirb. Sie werden in

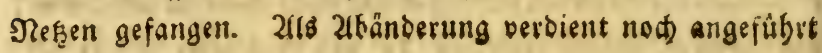
วน werben:

2) Der Saik= Steriets Stỏhs. Serutiuga. Sepedjin इagebud I. 156. t. 10. f. 1. 2. भallas Reifen I. 131. Sentuge. S. (5. (3melin' \$icipe I. 42. Le Seuruga, Bornaterre 17. n. 5 .

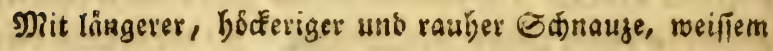

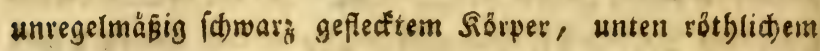
mit Sternden befeztem Sopfe. Xuf bem riüfen ftefr 12 - 16 Sdilbe, auf ben Seiten $30-37$, am \$Baนde 10 - 12 und an bem Sabwanje nod zwei einjelne. Seine

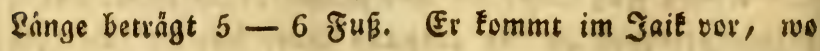
er mit Nex̧en gefangen wirb, uno wegen feines angenefs

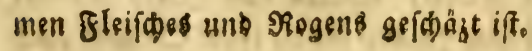




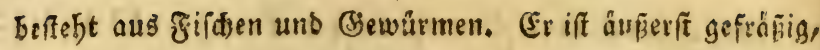
peridblingt audh, wie ber アitter von Pallas verfidert, junge Geekälber, wilde Enten, Scolguvert, Schilf,

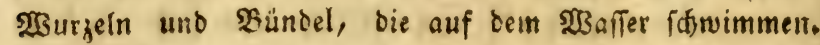
Mach vollbrachtem Raid)geidåfte geht er wieber illb Meer. Im nerbif Febrt ein grofier Ibeil Derfe!ben nieber in bie

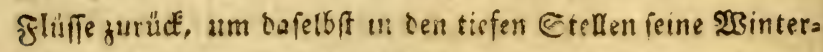

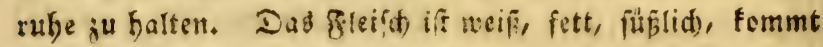
an Befamad bem fialsperict) nabe uno wirb aud eben wie Dirfes zur Eprelje zubereitet; jedod) wirb ber aroffe Iyeit eingefalgen verbralid)t. Sorgüglid) wid)tig ift ber fang oev Şaufen für bie Ruflell, ba fie mit bem barnus verfertig= ten Caviat und ber Sุa

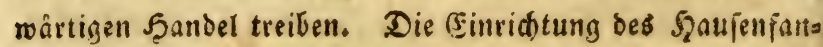

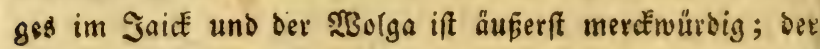

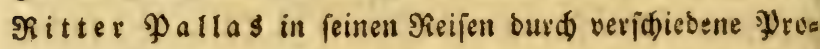

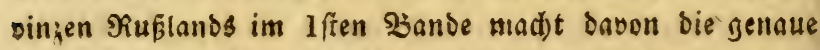
soefdreibung. Er gefdielst in befondern Fifdwebren, io

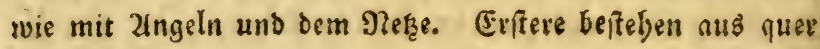

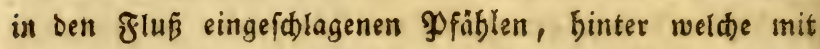
Steinen angefüllte Sörbe gebradt, vorneber aber Sanmern angebracht find, in weldyen fich die fifije fangen. In diefen Rammern liegt ein oberwärt mit Stricfen gehaltes

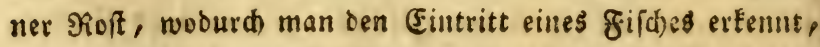
and die Gaatbür alg̈benn verfhliefien Eann. Der Sioft lâjt fid mit ben gefangenen firdhen Geraufwinden. Bei biefen Webren if nod die Einridtung getroffen, baß́ Der gefane gene Fifch felbit Das Serabfallen des (Satters veranla fist und baburd) auch eine (Jjlocfe in Bervegung fezt. 2(ufierdem bedies nen (id) nect) die aftrafanifhen fifcher ber Backnełe, weld)er Fang gewobulid mit dreibundert und mebreren E(t)iffen ge= fofiebt, wo nach oerberiger Grille die Fifde mit groficm 
Rärmen aufgeidendit werben. afub) werben fie mit bes Brunbfdnur gefangen. Die J̧aut ber Şaufen wiro ausa

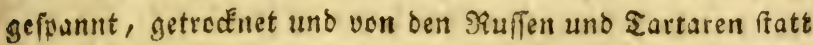

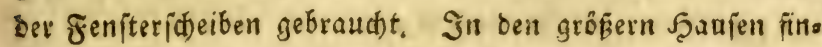
bet man ju Zeiten einen weiffen @etein von der (Brốpe ein nes Şüfnereryes, ber unter Dem Namen bes belugenta fiteing befannt ift. Es liegt derferbe innerbalb der Nies ren in einem א̧ăutchen, unb eร werden ifm bejonbere Şeilftå̆fte zugejörieben.

\section{Daz frofdfifds ober Seeteufel: Se:}

$$
\text { (d) ledit. Lophius. Linn. }
$$

Die Bruffloffen find mit einem ellenbegenábntiden Berencte verfefen. Deresiopf ift nach unten zufammenges brúctt, ber Munb mit vieten lleinen fwig̨igen Zähnen bes fe;t. Die Zugen fiken am Stheiter. Die Kiemenöffnung ift an ber Seite binter ber Brufffleffe befindlids. Der 2 ff ter liegt in ber 9刃itte bes Siörpers. Die Şaut if bünn, fduppentos und locker. 2lim Rumpfe fint fieben glofien, ols zivei Bruft: und \$audfloffen, eine 2(fter: Sd)wang =

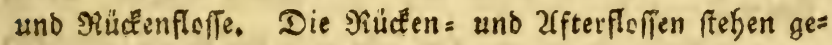
gen einander üfer unb beibe shnweit bem Sd)wanke. Sie batten fid int Meere auf, pflanzen fid) burd Eyer fort

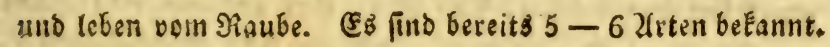

1) Der grobe frofdfifd. Der Geeteufer. Der Seewolf. La Lophie Baudroie. Cepède I. p. 304. pl, 13. f. 1. Bonnaterre 14. n. I. pl. 8. f. 26. Lophius piscatorius. Linn.

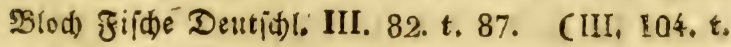
87.)

(Tab. 11, Fig. 19. 20:) 
Ev unterícheidet lid fogleid burd) feinen ungebenern grefien Sopf, welcher breiter als ber Sorper iff. Der rum be weit herverragende Unterfiefer if mit zwei, ber obere aber mit brei Sieiben langer, runder, fptB̧iget ßăbne bes fegt, wovon bie binterften bie gröften und cimbantts benegs lidi) finc. Der (saumen uno bie breite, Eurie und bicfe Zunge find elenfalls mit Bähnen befęt. İn Ghlunie fizen zwei lange mit viaten fpiģigen Zäbnen verfebene Snos

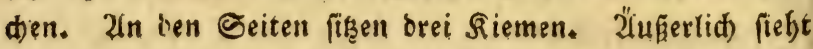
man weder Tajen: nod Gebörlōcher; Dagegen find im Dbers Fiefer givei Sertiefungen, weldhe vermuthlich bie Ctelle bers felben vertreten. SBor ben 2fugen liegen zwei lange borms artige Borfien und auber biefen nod vter bergleid)en auf bem Rücfen. 2lm Siopfe unb Rumpfe firgen all ber oberen fläd)e einige Stadieln uno am Fanbe ber untern viele fleis ne, wurmartige 2Inbängfel, bie gleithreit von einanber ents fernt find. Sie obere Seite ift brăunlia), bie untere weißs. Die Kiemenöffnung fizt bid)t unten an bet Bruffloffe. Die Siemenbaut ift bün, erftrecft fich über bie ganze breite

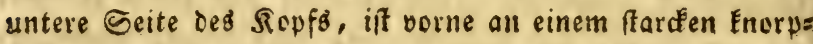
ridjen Sogen befertigt und wird nuf beiben Eeiten, wo fie

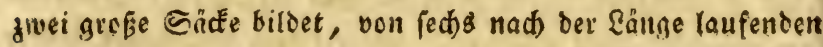
grobien, runden Strablen unterftüzt. Dic Baudfloften figen unter ben Bruffifoflen, find Eurs, fteif und wie eine Sanb geffaltet Fig. 20., womit er fid an fefte Sörper antlams mern Eanu. In ber 3rufffofle find 24, in Der Baud). flofle 5, in ber xfterfloffe 13, in oer Edimanzfoffe 8,

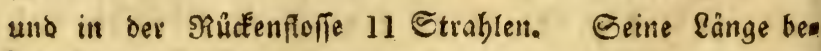
trågt 2-7 รuß̧. (Fi bewobnt die europâifden Meere, wo er fich gröftentbeils im Seetang unter Slippen unb an

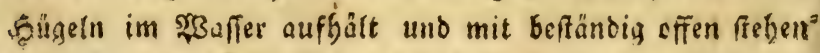
dent Runde liegt. Eeine פabrung beftebt vergüglid in 


\section{Sำแแg. Pisces.}

Fif

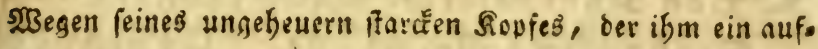
fallenbes uno furdttbares 2fnfehen giebt, heiǵt er vermuthlich Seteufel, ob er gleidy wentg. Sababen anridten fann.

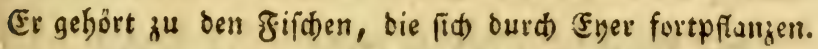
Das gleifh) ift weid uno foll wie bas vom srofde fdimerfen.

2) Der gehörnte frofdfifd. Der Eingorn= tellfel. Die Seflederma \&. La Lophie Vespertilion. Cepéde I. p. 315. La ChauveSouris. Bounaterre 14, n, 2, pl. 9. f. 27. Lophius Vespertilio. Linn. SIlod ausl. Fifite I. 11, t. 110. (I, 13, t, 110,)

Der Supf lauft in ein laniges fpirgiges f̧orn aus. In Der $\mathfrak{B}$ rufffoffe find 13, in ber $\mathfrak{B}$ audgfloffe 5 , in ber afters forfe 6 uns in Der Sd)wang = und Riutenflefie 9 Strablen.

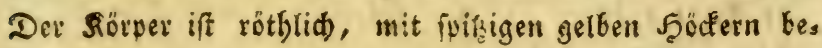
fejt, weld)e napfförmig und geîtrahlt fint. Die $\mathfrak{2}$ (ugen fint

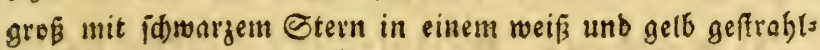
tem Ninge. Der Eleine MRunb fteft unterwårts uno beibe Sinnlaben finto mit einer Reibe Eleiner fpiß̨iger Bäljne. vers feben. liber ben Nafentöbeen fteft eine bornartige Zajer,

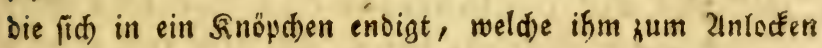
ser Fifde bient. Die $\mathfrak{B a u d f f l e f i e n}$ ftellen gleidfam bie Sorberpfoten vor, fizen nảber beifammen alo bie Bzrufftof fen, wetche bie Stelle ber Şinterpfoten vertreten, Tez̧tere baben cin ellenbogenartiges Belencée. Die Riemenôfinum gen fino Elein, halbmenoförmig, binter ben Brufffoffen.

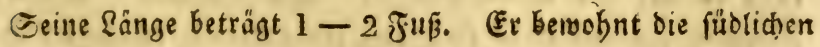
Meere von Zfınerifa, wo er gevoôhnlid in einem şinterfalt

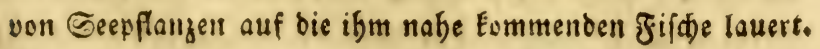

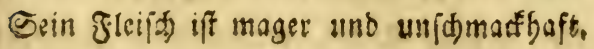




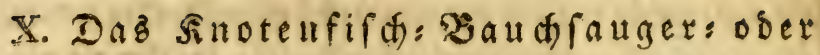
Eechaafen: Befaledt. Cyclopterus. Linn.

Die Baudbforfen find in Geftalt eines Birctels zufaus mengewad) fen uno bilden einen Swilb. Der Sörper iff

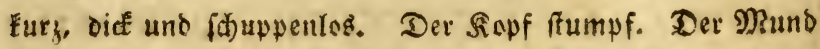
ôfintet fich vorwårts. Die Sinnlaien fino mit Eleinen fipiz̧i= gen 3ăhnen berwaffnet. Die 3unge Eurz unto bict. Die Siemenôffnung Elein an der Eeite liegent. Der Kiiemens Decét befteht aus einem SBlättden, unter weldhem auf jes ber Setre vier Siemen verborgen liegen. Der Miumpf iff

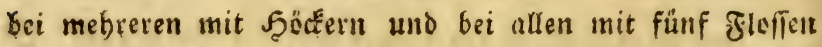
gum Sd)wimmen und zivei zum feft balten verfehen. Sie

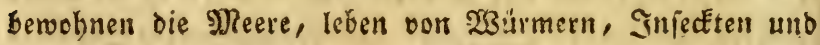
Der Brut anderer Fifdie. (F) fino bereit 8 $8-10$ vere foiedene Zfreen beEanut.

1) Der Eump. Seebolr. Seebaale. Le Cycloptère Lompe. CepèdelI. p. 52. pl. 3. f. 1. Le Bouclier Lompe. Bonuaterre 26. n. 1. pl. 20, f. 63 Cyclopterus Lumpus. Linn. $B$ led ঔi(d)e Deutfdíl. III. 103.t. 90. (III. 131, t. 90.)

( Tab. 12. Fig. 21.)

Der Eurge Sopf bat eine breite Gtirn. Die Napens

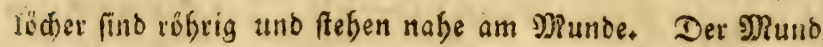
ift weit uno bat ftarcfe Sippen. Die Sinntaden und bie

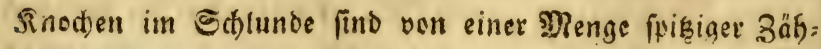
ne raub. Die Mlugen baben einen fowwarijen Stern it

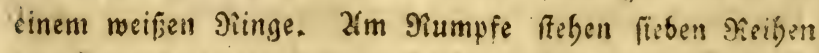
borter, geftrablter, fpigiger Szöcter, weven eine Sieife atm 
gitufent unb brei auf jeber Seite figen. Der Rauten ift folvarg und idneideformig. Die Seiten grau, breit. Der $\mathfrak{B a u d}$ fefre weit und breit, orangefarben voer grau, Worwåts an ber Şruft liegt ein breites, rundez Sdild,

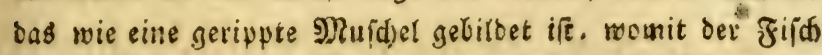

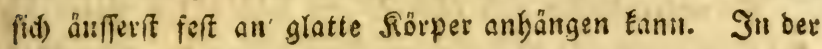
Boruffleffe fisto 20, in ber Saudifoffe 6, in ber 2ffters flete 12 uno in ber Siúctenflofte 10 Strablen. Eeine

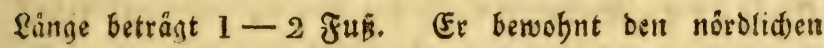
Deean, bie Noro = und Dfftee. Şălt fid meiftens binter

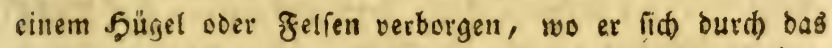
unter Der Siruft befindidas Edillo an Eteine ober Felien an=

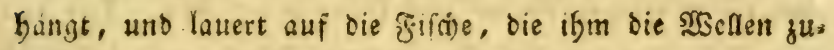

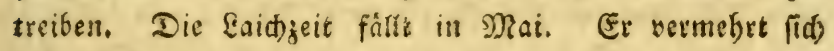

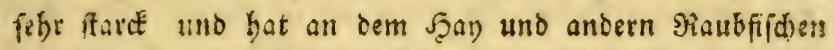
snäd)tige Frinde, aud) an ben Fifdottern. Sein fleifa if wentg geadtet, wito aber benned in Sslant theils frifich genuffen, theils eirgefalzen.

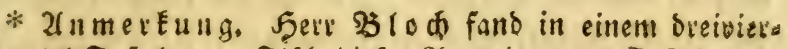

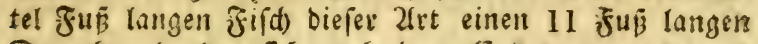
Darmsanal, ber fid nad bem Ende erweiterte uno

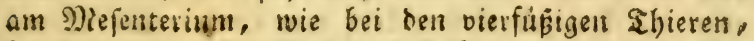
befeftigt war. Der zlufang beffelben war mit fechs 2ins bängiên ungeben, veldhe nidht, wie bei andern ở. jithen, einfach, fonbern fich in 3meige uno biefe wieder in andere theilten, fo oaß ifgre 2 (ngahl auf 40 ftieg, sweláne 2-3 3oll gré́ waren, bie ganze Ränge dera

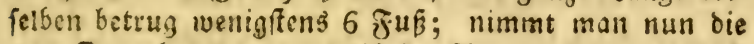

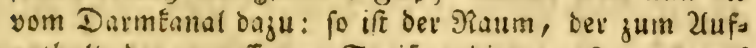
enthalt der genoffenen Speisen Dienet, $6-7$ mal größer, a! der ganje fióper: eine bei den Fifden ganz ungerwöbntițe Erideeinung.

2) Der tingfrofizge Sutenfifd. Sartifd.

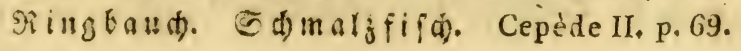


Le Bouclier Liparis. Bonnaterre $27 . n$, 5. pl 20. f. 67. Cyclopterus Liparis. Linn.

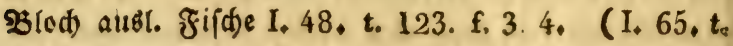
123. f. 3. 4.)

Er unterjabibet fïh fogleid) an feinen bis unter bie

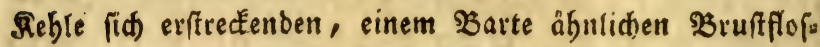
fen, in weldjen 34 Strablen fino. Der Sörper if $\mathfrak{g}^{e}=$

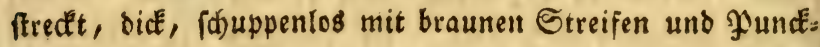
tell geziert uno mit cinem zăben Sd)leim überzogen. Der Sopf ift Eur, ftumpf, flad), breit uno gelb. Der গiulifen uno bie gloflen braun, bie Seiten gelb, ber Baudi) weiß. 2In ber Dberlippe liegen jwei Eleine 3 Bartfafern. Die 2lu. gen finb Flein, an ben Seiten beim Sdeitel, fie baben cis nen fohwargen Stern, in einem gelben Ringe. Der Siles mendectel ift glatt, runb und vermittelft ber Riemenbaut am Siumpfe angewad)fen. Die Siemenoffnung eng; bie Siemen Elein, auf jeber Seite 4. Die Eeitenlinie lauft initten über ben Sörper. Der saud ift bervorftebeno. Der gange Sörper ift it ciner bünnen, Iofen Saut, wie in einer Blafe eingebuallt. Sảmmtliche frofien find lang, nur bie Sdyanzflefien Eurz und rund. Die Saudfleffer fint in einem ßinge zufammengewad) fen, womit er fid) an anbere Siörper feft anfaugen Eann. In ber Siemen. haut liegen 7 , in ben verwad) fenen Bauthfloflen zuammen 12 , in ber 2fferflofte 33, in ber Sdwanjflofie 10 uno

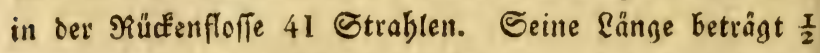
bis $1 \frac{\pi}{2} \mathfrak{J} u \tilde{B}$. Er wirb in ber Nerdpee, bejonbers in bex

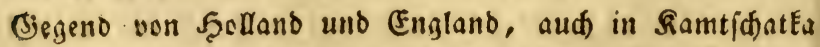
angetroffen und geft aud in bie benad)barten Flüfe. \$hre \&aidjeit fált in Februar. Sie nåbren fid von Elemen

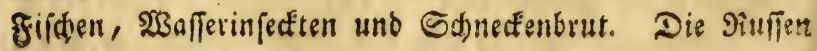


balten ibn fủr giftig. Sein fdleimiges, fettes, übel=

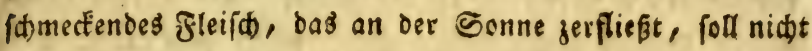
einmal von ben şunden gefreffen werben.

XI. Dab̉ Şornfifd: (Sefd)ledt. Balisa tes. Linn.

Der Sörper ift nebft Dem Sopfe von beiben Seiten zu= farmmengebrüct, mit Eleinen rauken Stacheln befejt. Die Nundoffnung if eng und beibe Sinnladen find mit 3äbnen befegt. Die Riemenöfnung ift idmal und ftefet böber als

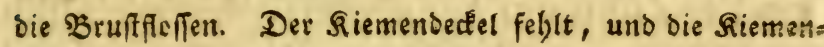
haut, weldse verborgen liegt, if mit zwei Enorplimten

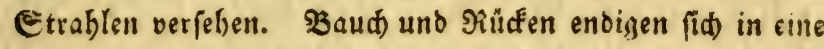
(5d)neibe, auf ienem fteben zmei Floffer, bavon bie vorbere bei einigen ibren Sis zmifhen ben 2lugen bat und alsbenn nur aus einem Stad)el befteft. Unter ber Şaut bes Bau. des liegt ein fturcéer Snod)en, ber mit feinem Enoe als berfelben bervorra, und von Eleinen Stadeln raub ift. Sis gebören z̆ ben fieifdfreffenden Ibieren. Die mebreften werden für giftig gebalten.

1) Der Einfornfifd. Le Baliste Monocé ros. Cepéde 1. 386. pl. 17. f. 3. Bonnaterre 17. n. 1. pl. 10, f. 34 . Balistes Monoceros. Linn. Blod) ausl. Filde II. 12, t. 147. (II. P. 186. t. 147.)

(Tab, 13. Fig. 22.)

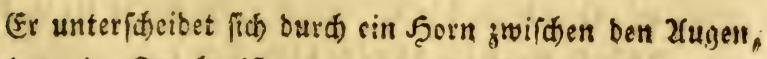
wetches ein Strabl iff, ber bie erfe Rücfenfieffe vorffeât uno burch bie alfterfioffe, in welder 51 Ctrabien find. In ber Bruffleffe liegen 15, in ber Sdquanjfoffe 12 und in 
ber jweiten গRüčenfloffe 48 Strablen. Der Sörper ift von Beiben Seiten zu[ammengebrücft, bủnn und raub), grau unb braun marmoritt. Der Siopf grof, bie Mundoffnung Hein. Die untere Sinnlabe länger als bie sbere und beibe mit 8 , am उrunbe breitell, in eine Spif̧e audlaufenden 3äbnen verfefen. Die Sippen fino berweglid. Die nabe am 2 Birbel fabenben 2lugen baben einen fobrargen Stern in einem gelben ringe. Sor ben Uugen fiebt man zwei länglidbe Ŝfinungen, welche wabrideinlich zu ben (jertucto

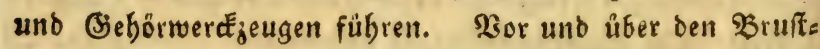
floffen fteft bie fdmale Siemenoffnung. Sämmtlithe Flof fen baben eine gelte Farbe und nur bie Sd)wangfleffe bat orei braune Ctreifen. Seine Rảnge betrangt $1-1 \frac{1}{2} \mathfrak{F} u \tilde{B}$. (Ex bewabnt bie afiatifden uns fübamerifanifonen Mleere, wo er von ber Brut ber arebfe uno ben spolywen lebt. In China und Carolina ift eine $2 b_{a n n}$ berung, auf ber man fowarge, rothe uno blaue, ben dinefifden Budfitaben äbn: ride flecte findet. Der Sd)want if gegact. Das Sern hinter ben 2lugen gerade in bie Sëbe ftebend. Seine \&änge betrăgt 3 子ुü. Shie Nabrung beffeht in Corallen uno sgiufdeln. Şr fleifo foll nach Catedby History of Carolina Vol. II. Tab. 19, giftig feyn.

2) Ber Baudgabelbornfifd. Der zroiftades ridte Şornfifd). Le Baliste à deux piquans. Cepéde I.p. 355. Bonnaterre 20.n. 14 . pl. 11. f. 36. Balistes biacule atus. Linn. ed. Gmel. p. 1465. ஒ(od) audl. Fifde II. p. 17. $t_{4}$ 148. f. 2: (II. 192, t, 148, f. 2.)

Er. Gat jwei lange auf beiben Seiten gezn̆hnelte Sta. delu am Baude, weidje bie Stelle ber Saudffoffen ver= 
Qänge. Die Munsöfrnung Elein. liber ben Sippen fiellt ein blauer Streifen und vier anbers dergleidhen über uno brei unter bem 2iuge. Die Ritemenaffnung liegt grwifden Der Brufffeffe und der lezten blauten $Q$ inie. Son ber Mund= siffnung an, bis zur erften blauen Sinie fteht ein rötblicter Streifen. Die Geiten fintoben braun und unten weif= getb, son ber Mitte derfelben Taufon binter ber Baruffifoffe vier braune Bănber am $\mathfrak{B}$ auct)e binunter. Unter bem Baud ffebt ein ftard er gegacter Ctrabl und binter bems fetben verfdiebene Spikgen, welde man gleidjam für eune §aud)forfe balten Eann. Die Seitentinie feblt. Die \&lofs fen find Eurg. Die Etrablen in ber erffen SRüteen, und Daudfforfe frad)elidtt unb einfad), bie in bent übrigen gro/s fen weid) uno vielgweigigt. Soer erfte Strabl in ber

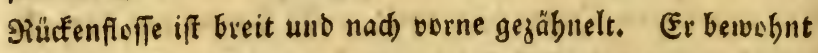
Das indifide und rotbe Meer, lebt von Sivebsbrut unb bat ein unidmact baftes gleif

4) Das alte 23 eif. Le Bal iste vieille. Cepède I. p. 337. Bonnaterre 19. n. 9. B alistes

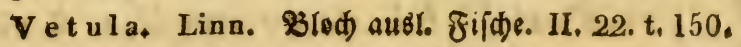
(II. 198, t. 150.)

(E. bat nur eine cinzige Saudfflefie uns in ber erften

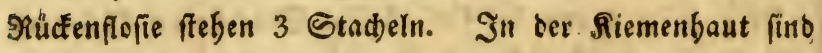
2, in ber Bruffloffe 12, in ber afterflefie 28 , in ber

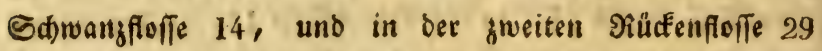
Etrablent. Eit ift breit, bünn und rauh. Die Siemen, affnung Elein. Beibe Rinnlaben finto mit Goneibejäbnen befejt. Die Sippen fino ftarte uno blau eingefaßst. Ifn Den SBacten ftelyen 2, unter bern Zfuge 3, und üter bemfetben 8 blaue Etreifen; Iegtere fobeinen aud einem 21ugs 
floffe 21 , in ber Sd)wanffoffe 12, unb in bev grweitest rückenflofie 24 Gtrablen. (Fr if von beiben Seiten zu= fammengebrủct. Die Dberfảche if mit Eleinen rauben

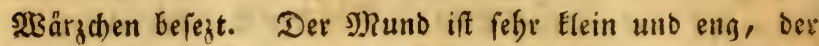
fd)warke 2lugenffern von einem feegrünen Ringe umgeben.

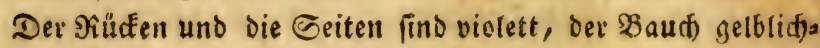
weí;; Der Sinod)en am Saud fehr fark uno rauh; zwifden diefem und dem 2ffter vertreten einige Stadjeln bie Stelle Der Baudfleffe. Die erffe Rüctenfloffe bat einen langen unb ftarcfen nad) voine gezâfnelten uno einen oünnen und Euzen Strafl. Die zweite rüctenfloffe nebft der zifter= uno Sd)wanifoffe fino grefi. rejtere uno dic Schwanzflefie gelb. 2uf ber Bzruft, sithe = und Edjwamzfloffe freben

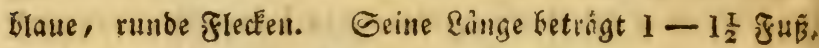
Ei berwobnt die ameritanifd)en Meere.

6) Der (d) alze 5oornfifi. Le Baliste sil lonné. Cepède I. p. 370, pl. 18. f. 1. Bonnaterre $19, n, 10, \mathrm{pl}, 12 \mathrm{f}, 39$. Baliste noir. Renard. poiss. I, 26, t, 17, f, 96, Bal is tes rin-

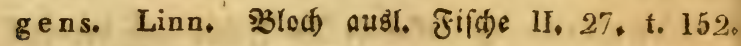
f. 2. (II, 205, t. 152, f. 2.)

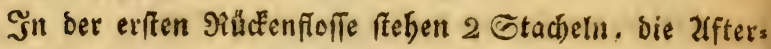
foffe iff fomal. Sn ber Bruftfoffe find 16, in ber 2ffte: flofe 32, in Der Sdmangfoffe 13, uno in ber zweiten Stü. Eenfloffe 33 Etrablen. Der Siorper ift fow 2ffter = und zweiten Siúcfenfloffe ftebt ein blauer Etreif. Die Manooffnung ift weiter alz an Den ủbrigen 2rten. Die obere finnlabe ftelft vor Der untern etwas hervor und beibe finb mit breiten Băbnen verfeben. Die runben 2u. gen baben einen fdroargen. Stern in sinem weipen 9ïnge; 


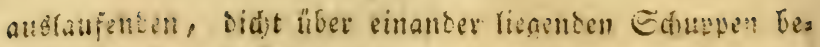

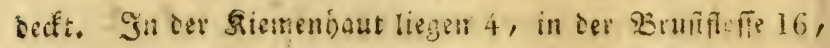

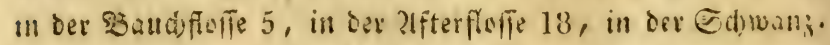

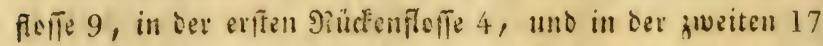
Etrablen. Der Senf if cún etwas breit, anto enoigt fici in eine nad) sben gll gebogene sis sre, an teren Enie cie

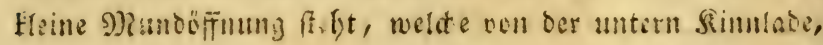

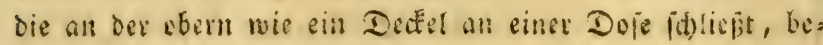

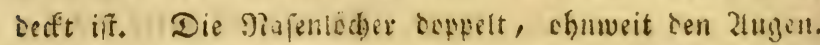

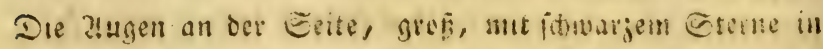
einem braprothen Simge. Der Sirmenoectel beftelt aus ch nem Blättd)en, Die Siemenofinnng î̃ weit. Die Sẹtea Ianfen cben mo unten in eine $\mathbb{E}$ dureibe aus, bie sobere if

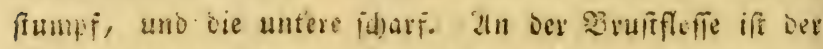

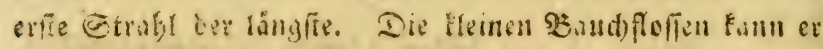
in einer binter Denjelben liegenden Enodecnen furd)e vers

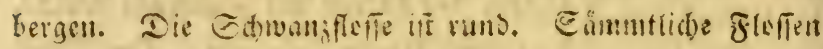
finb grau. Seine lange betrigt gegen eine Spanur. Ev wiro im initteilambifden Miecre sugitrufien, bat ein jartes

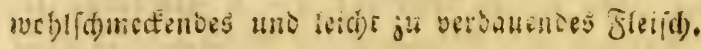

3) Dex Mefierfif́. Der Sdiroers Mefrets fifd. Cepèdell.p. 88. Le Centrisque cuirassé. Bonnaterre 30, n, 1.pl,21. f. 68 . Centriscus scutatus. Linn. B(od) aug̣t. そifid)e I. 57. t. 123, ᄃ, 2, (I. 80, t. 123, f. 2.)

Ier Sörfer ift mit glatten, Ditft an einanter gefügten, gorbglämzenoan Sd)ilben bededt. In ber Birufflofle fino 11, in ber Bauchfelfe 5, in ber ?fferfleffe 13, in bes Gdwnutleffe 12, in oer exfen siufenfiefie 3 , uno in ber zweiten 11 Strablen. Der Sopf iff langlid)t und lauft in 


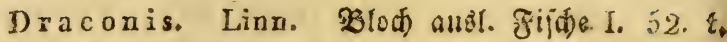
109. f. 1. 2. (I. 70. t. 109. f. 1. 2.)

(Tab. 14. Fig. 24. 25.)

Der Sörper if breit and sreiectig. Die Brafflefie bat

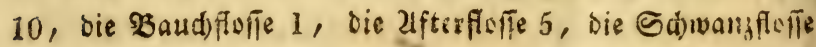

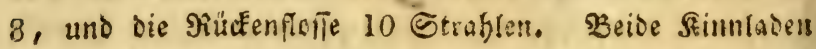
find mit febr Eleinen Bähnen befegt. Die Siemenéf Elein, monoförmig. Die auf ben Seiten liegenden afugen fino bervorrageno und baben einen idroargen Gtern in cis nem gelben গRinge. Der গRumpf ift cberwants mit verfdies Denen geftrablten Sëdfern befest; Die untere Geite Greit, mit einer in ber Mitte Rebenien Erbabenbeit, ats wricber bie Baudfiffien entipringen. Dir vierecfige Sdiwalid bat adjt an oell Geiten böckerige Sabiloer. Die Brunofarbe ift Glaulid)t und die feöcfer braun. Jede \$aud)fioffe befrebt aus einem eingigen langen Etrahl, Degigreinen einem uber

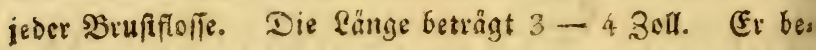

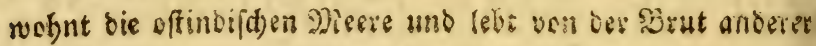
Sectbiere.

2) Der Sóntuimex. Le Pégase Spatule; Cepède II. p. 85. Bonnaterre 33. 1. 3. pl. 22. f. 78. Pegasus natans. Linn. \$loct) autl. Fif(t) 1.53, t, 121, f. 3. 4. (I. 73, t, 121, f, 3. 4.).

Der Sörper ift lang unb vierectig. Son ber Sruffifelf feten 9 , in ber Baudfloffe 1 , in ber 2lfterfoffe 5 , in bet Edwangfloffe 8 , in ber Siuctenfloffe 5 Strablen. Del Sörper ift vorne breit, binten fd)mal, mit Grbilden bebect', obell ge!bbraun, unten tocí̄. Der Sopf flać), Eur's, Greit

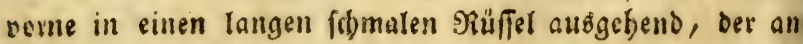

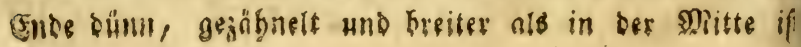


tetragonus. Thunberg, act. Lund. J. 301.t. f, f 1.2. Linn. ed. Gmel. p. 1453. Syngnathus

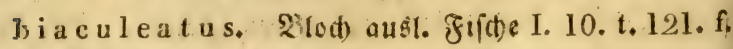
1. 2. (1.11, t. 121, f. 1, 2.)

Der Sörper ift vierecfig. Luber ben 2 fugen regen zmei Etadeln. Die Riemenbaut bat 2, Die Simutrite 21,

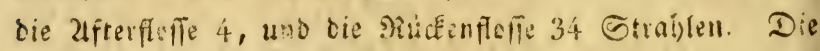
Sd)nauge ift lang; die Zfugen flem mit fitwarzem Eterne

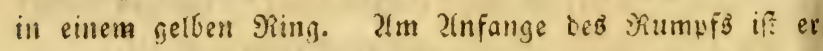

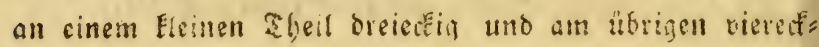
i. Der getfe unt braungeflecte Baud) iff breit, Der Sithken fidmal, bie Sriren braun, die Fiofien gart uno gelblich. 2luf dem Siumpfe fient man auf jedem Echilde

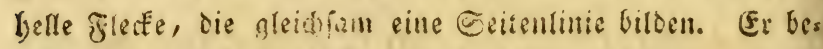
wobnt bie oftindifúen Mreere.

2) Die Seenabel. Die Sicmpets. Le Syngnathe aiguille. Cepede II. p. 39. pl. 2. f. 1. Bonnaterre 31.n.2 pl.21. f. 71 , Syngnathis a cus. Linn. Ş(ct) Fif(t)e Diutit)l. 111, 113, t. 91. f. 2 (III. 144, t. 91, f. 2.)

$$
\text { ( Tab. 15. Fig. 26. 27. 28. 29.) }
$$

Der Siumpf it fitbenedin, Fig. 27. unb am Sthwan= je fiebt eine Flofie. Sn der Siemengaut find 2 , in ber

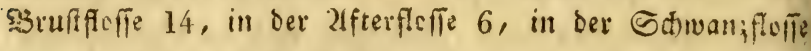
10 und in ber Siủcfenflofie 36 Straflen. Ser Siumpf bat 20 mo Der fedtectige Sd)wanz 43 Sdhilde; an beiden fino braune, breite Streifen fichtbar, we!che mit meifigelb: riche!l abiwed)ielir. San den idjarfen Sianten Fig. 27. fies Ken 2 ain Siürefen, eine auf jeder Geite, 2 am 3zuthe, unb rie flebente in Der Mitte. Seine Păage Enangt 2 


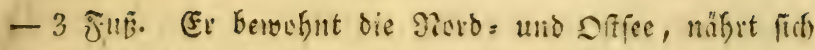

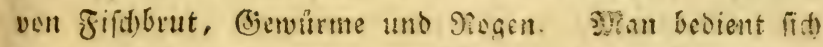
feirer und ber übrigen afrten beim Jiidfang jum Sioper.

3) Die Meeriulange. Der Sdrangen. Stild= fifd). Cepéde II. p. 48. Syngnathus Ophidion. Linn. B(ed) Fifit) Deutidit. HII. 115. t. 91. f. 3. (III. 146. t. 91. f. 3.)

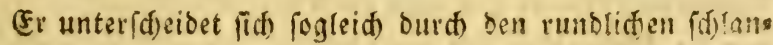
gemartigen, in Getencfe getbeilten, grüntiden Sö̀per. G̈n

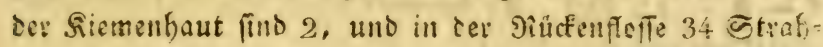
Ien. 2(m Miumpfe fieft man auf ben Eepiten einige (d)wad) Sianten, 4 blaue untertresthene Sinien, victe Singe, wie

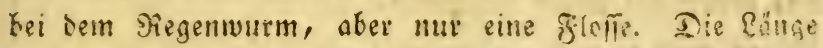

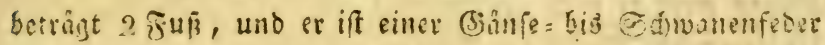
Did. Eein Zufenthalt if bie Rerts, uno Difie, wo ex juilden Eeepflanjen lebt.

i) Dag Eepperoben. Le Syngnathe Hippocampe. Cepéde II. p. 42. pl, 2, f. 2. Bonnaterre 31.n. 7. Syngnathus Hippocampus, Linn. 33 (od) aus!. Fifie I. 6. t. 109. f. 3. (I. 7. t. 109. f. 3.)

$$
\text { ( Tab. 15. Fig. 30.) }
$$

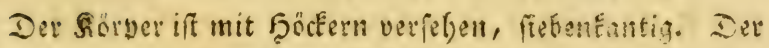

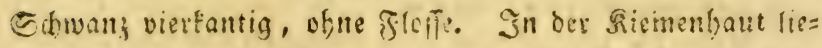
gen 2, in ber Bruffictie 17, in ber ?! frotfolle 4 , uno in Misucenflofte 20 Etrablen. Der Sopf it grep, und cie

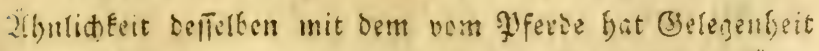
ju jeiner Benennung gegebert. Fe betummt aber biefe 2ibn= lide Eeit erif nad) dem Sode, intem ar Eein 26bjerben den 


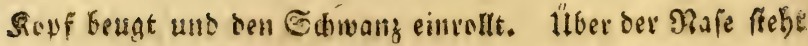
eine, hber ten zlugen aber vier Enodherne Erbobungen, bic fit) in frofirn endigen. Iie grefien 2 (nygen baben einess fdmaren Ctern in cinem fi bernen গinge. Der Riemendecte? if grej geftrohlk, angerachien. Die fiemenefrnung engo Der Baud ragt hervor un enoigt fid in eme gezacte

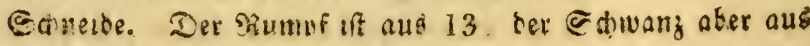
35 Eduloen zufarmenaefegt Der braune Räfen und bie

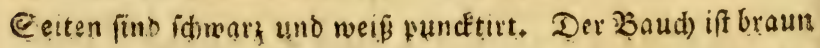
uno die Flonten find zart uno rötylich. Eseine \&änge betrågt

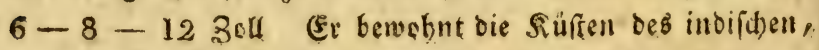
norrifonen und mittedantioifhen Mieeres uno lebt ven Eleinen 25afferinfectert. Die 2titen rübmten ifn als ein vorguglis thes Şeilmittel wioer verfdiedene Firanfheiten uno in Dale matien wirb er nod) gegenwårtig als eill Sceilmittel gegen. Die geronmene Mild ber frauen gebraudit.

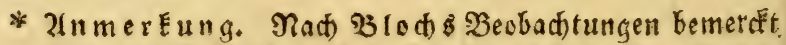
man im Frubiabr, oafi fid) bie Sdilibe ber Nadel= fifte unterwârts am Schwanke, bitht binter bam $21 \mathrm{f}=$ ter, auseinander geben, uno indem fre fith auf beiben Seiten emporbeben, fo biloen fie znei parallel laufen=

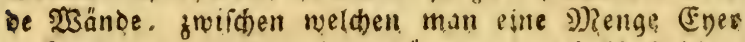
wahrnimm, dic ill ciner bünnen gemeinfdaftlidsen 23lafe einnethlefien find. Diefe SBlafe mito ven bem Sact, weld)er ben renen umgiebt, gebilbet, unto wers ben oie Jungen hier eben fo, wie beim $\mathfrak{P} / a z b a u d$ ) (Silurus Ascita Lin n.) entwicfelt. 2(ud) in Diejem Falle fommen fie mit ben lebencig gebäbrenten finer: velfijchen überein; nup mit bem llnteridhied, bas bei biefen bie abgerifienen Eyer innerhalb des Unterleibes, bei ben unfrigen after aufferbalb ceffelben auggebrütet roerben. Seierim fint fie den Sirebfen ähnlich, welde bei ifrem gepanjerten Förper die Eyer unter dem

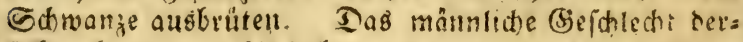

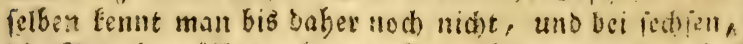

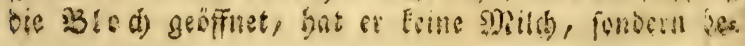




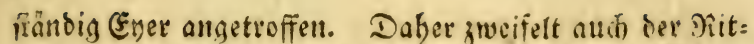
ter von Pallas, Dafi, es in biefem (Bieidfled)te Mlänn= deen gäbe, unb in allen ben vielen, sie er unterfidute, bemercfite er bie $3 \mathfrak{B l a f e}$ mit lebenbigen Jungen angefült.

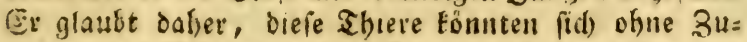

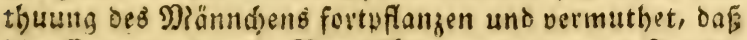
bie (Erreugung und Servolfénmmenung neuer Frud)t:

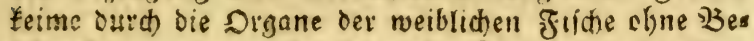
Yebunt von einer männliden Siraft, ourd) eine forts Dauerende Rebenswirctung bewerdiffelfigt werde; wie

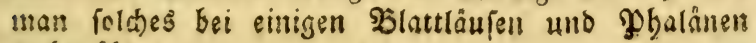
waด̆เnåbme.

XV. Das Jgelfifd: oder Stachelfifd: (3) efaledt. Diodon. Linn.

Die Simntaben futo hervertagento mo getheitt, und ens șigen fid in eine Sdunibe, Die ftatt ber 3ăbne dient. Der runbe coer längliçte Sörper ift mit langen, farcken, weis unb 他warggeflefften Stadeln befejt. Sie endigen

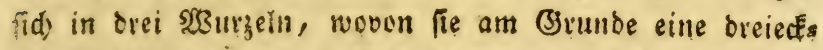
ige (beffalt babeil und find bis an bie Epiß̧e mit der

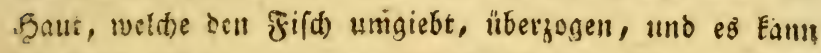

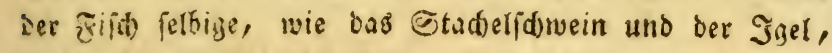

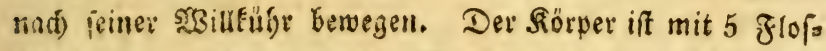
fen bejęt, wobon 2 an ber $\mathfrak{B r u f f}$, eine am Rukcten, zif = ter unt Sdwwanje fijen. Sie werten am SBorgebürge ber

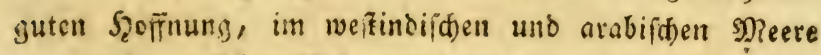
angetroffen. SGre Nabpung beftebt in Jifwen, Sirebjen uno Mufdein.

1) Der lange Etadifelfida. Le Diodon Atino ga. Cepede II. p. 3. Diodon Atinga. Linn.

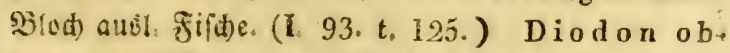

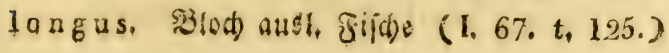


De: Sörper if länglicht. S̈ ber 3rufiffolfe fino 21 , in ser afferfloffe 17, in ter estunnffofte 10, und in ber Sincenflute 14 Errablen. Der Sors ift Flein, oben breit, unt inwentig mit einem farcken Snorpel veriffen. Die Maienledier fino empad), röhrenförmin und fteben zwifhen

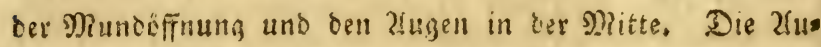
gen fino greis, haben einen ichroargen Ctern in einem gelben ringe. Die Etadjeln uno ber ganje אörper fino mit fowar:

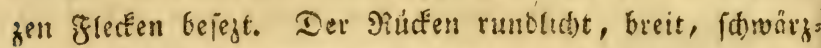

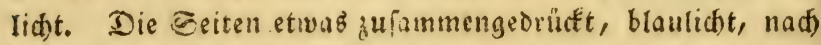

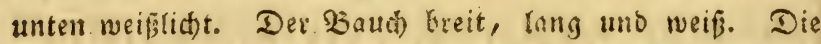

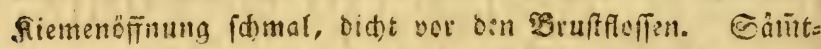

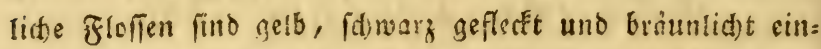
gefäit. Eeine Eänge beträgt $1-1 \frac{1}{2}$ Fuf. Er berwobint ba 2aorgebirge der buten Soffinm uno die amerifonifoben gReere, wo ex fid) an den llfern auffält, um Sirebfe und

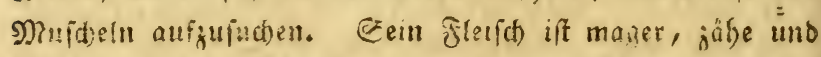
wenig gearbtat. Die Saut, weld)e den Sôtwer ungiebt, iff fehi Gart, unter berfelfan befindet. fith sine andere,

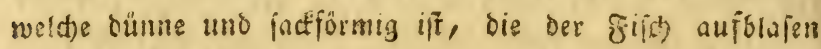
Eanir.

2) Der runde Stadiffíd. Sugelfifa. Le Diodon Orbe. Cepedell.p. 16. Diodon

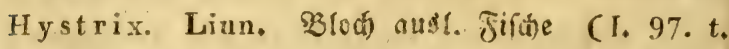
126.) Diodon rotundus. Biod) ausl. Fifde I. 69. t. 126.

\section{( $\mathrm{Tab}, 16 . \mathrm{Fig} .31$.}

Det Server if rundidit uno bidt mit Stadeln bes fegt. Sin bev Buffiffle find 22, in ber 2fiterfoffe 12,

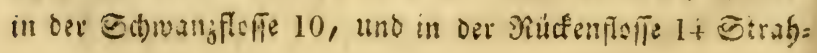


Ien. Die Etadieln find an ben Eeiten linner, ara an

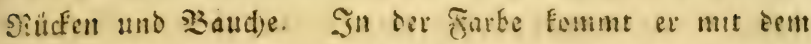

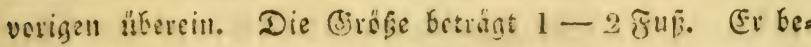
molnt die amerifanifdin uno das rotbe Meer. In Bes

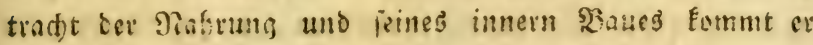
mit dem vorbergebenden übrecin. Eein Fung if ein be,

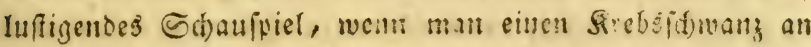
rie 2lngel fitidt: fo finter er fid) bart inbei ein, weil er fid) aber oor ber Edunur füd)ter, fo geft ex eine 3eit lang um bie 2fngel berum, endia veriut er mit Bebuts

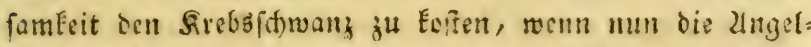

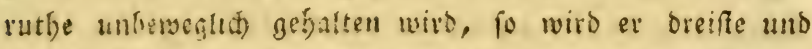

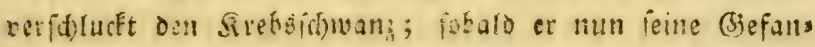

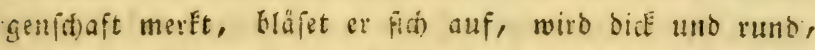

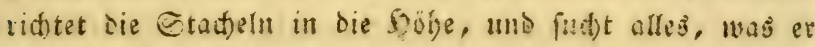
erreid)en Eam, ku verwunben. Eiefter, dais all fein Sefrreben verachens ift, fo legt en die Gradieln nieder. (Ev bebient fith rarnuf einer andern \&if, dructe die Blafe jufanmen, und forijt jugleid) mit ber \&uft bas eingefogene

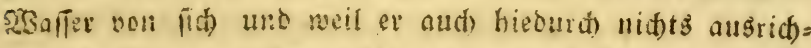
tet, fo fingt (i) fid) anfo neue an aufjublajen und mit feimen Etache!n zn oreben.

3) Der fonimmende Sinf. Der Grumpfifto Der fdeibenformige ggerfifd. Le Tétrodon Lune. Cepéde I. p. 509. pl. 22. f. 2. Dio don Mola. Linn. erl. Gmêl p. 1452. Pallas spic. Zool. 8.p. 39.t. 4. f. 7. B̈lod) augl. Firitte (I. 103. t. 128.) I. 75. t. 128. Tetrod on Mo1a. Linn.

(Tab, 17. Fig. 32.) 


\section{5ुterte croffe. Fifde.}

(Ev unterf(h)eibet fid) von bon ůtrigen arten fogleidg burci) feinen bieiten, oben und unten in cine Sodnetve ouslauten en, raub anzufubienten foryer, und dell abges

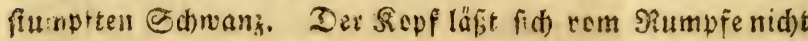
suntrifdeiden. Die beiven enthöbten, in ber solitte gebos genen Sinntaden gleid)en oen Edunbel eines toggels. Dié gुroßen alugen baben enen forwarzen Gtern in einem weipis gelben Siinge. Der Siüfen bat eine graue unb bie Geiten

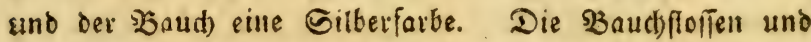
bie Seitentinien feblen. Die Eleinen Bruffterfen baben bei ibm eine gank atbere Middutung als bei ben übrigen Fifhen, inbem fie nid)t wie gemóbnlid) perpendikutar, fonbern bori=

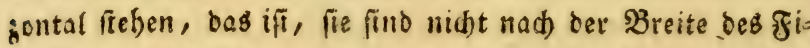
fdes, fondern nad) befien Länge am Siumpfe Kefoitigt. Die siücéen = unb 2lfterffeffe find lang, figen am Enbe des Sörs

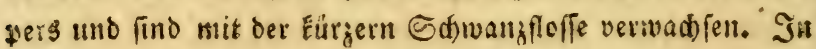
Der SBuffictie fino 13, in ber lffterflefie 16, in ber

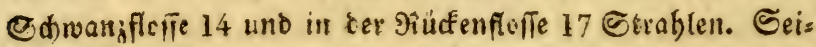

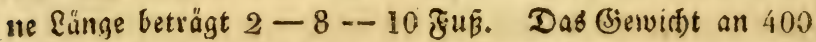
- 500 \$pfund. Er bewobut cas mittelländifde Meer, bie

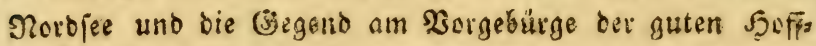
suung. Sein gleifh ift fehr weiß̄, bat einen thranigen

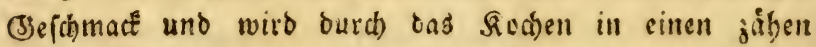

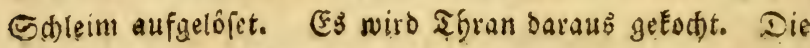
Eeber wird geppriß̄t.

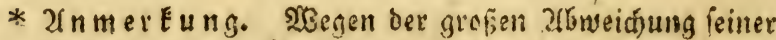

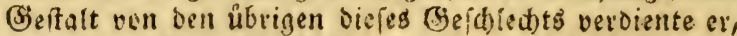

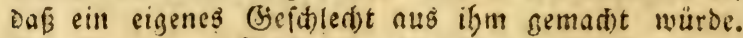
Der Mitter yon lintié bradjte ilbn unter Tetrodon, wobin er aber nidjt gehören Eamm. Bs metin befielte

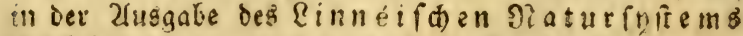
ifgn bei Tetrodon und toieberfolte ifn bei Diodon. 
XVI. Das Stad)elbaud): (5) (d) ( trodon. Limu.

Die Enüdernen finarfen Ginulaten fino an ber Spige getheilt und bervorffetgend. Etutt der Sduppen ftebers

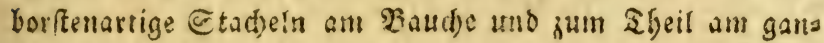

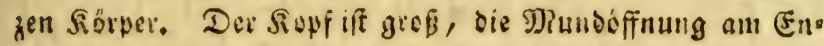
be befleltben Elein, bie Sippen biff, bie 3unge Eurg init Fleis

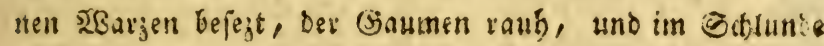
fieken jwei beweg!idge, rafpelartige Rnodien. Die zlugers

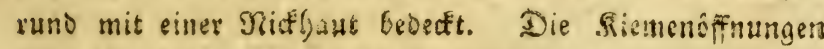
cinfad), id)ma!, Eurg. Die Siementeckel Elein, aus einem Enerplidten Bbättd)en beftebeno. Cie baven 5 Jroffen,

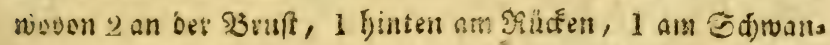

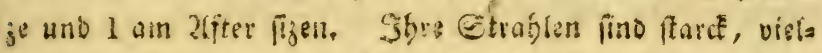

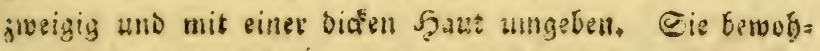

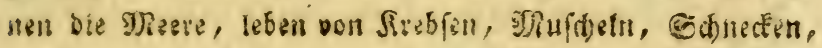

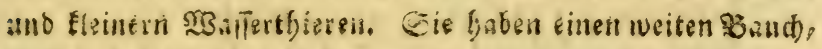

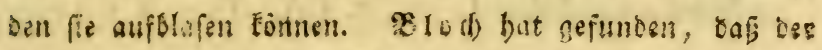

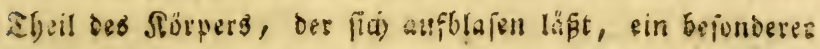

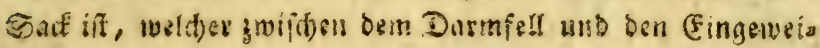
Den liegt, und oun der innern Şaut bes erftern gețiloet wiro.

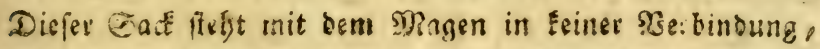

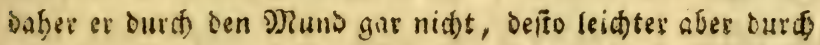
Die Siemenüffung aufgeßlajen merten Eonnte. (\$5 fiul bereits gegen 12 verifictedene Zirten betannt.

1) Der ऽ roquet. Cepède I. p, 477. Tettrodon tes-

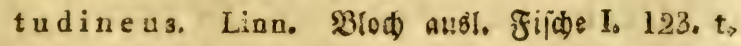
139. (I. 160. t. 139.)

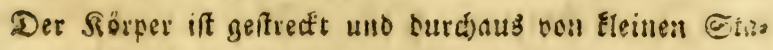

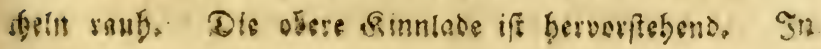




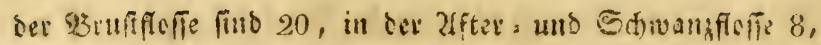
uno in ber siudenfoffe 10 Strahlen. Der Jisuf ift fehe gropi, oben breit, vorne abichuinig uno ftump; die Whunds

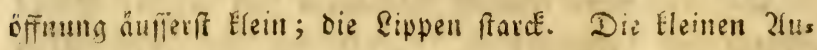
gen baben cinen idwarzen Stern unb einen rotben Sing.

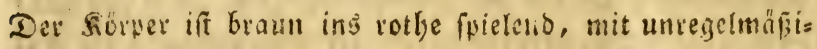
gen Rängeitreifen von blauer uno brauner Jarke abmed gs:

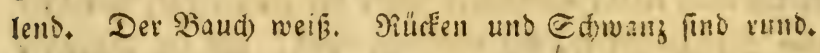
Sömmtliche Strab!en fino rôthlich mit brautner (Finfaffunis.

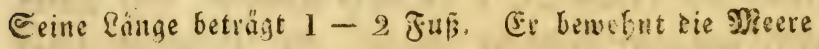

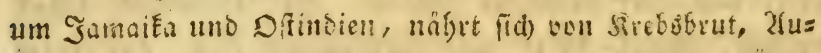

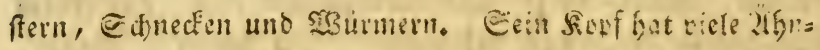

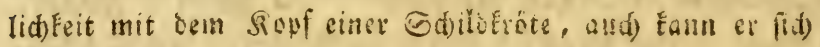
wie cine Sirote aufolajen, Ouber jeil Siame.

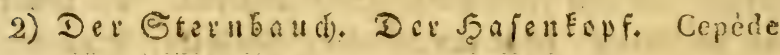
I. p. 495. Tetrodon Iagocephalus. Linis. SBled) aแt. Filite I. 126. t. 140. (1.163.t. 140.)

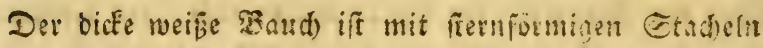

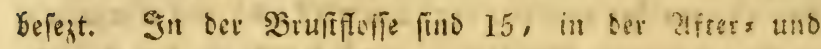

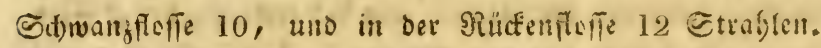
Der Ropf ift länglid)t, Die Mlunsoffnunis fét) Elein und bie beiben Simntaben gleid) lang. Die limgen oval mit

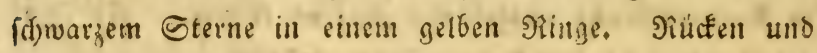
Sd)wang fint runo. Die Steme find an Saube in 20 bogenförmige Seilgen georonet, jeber wirb ven einem Gras

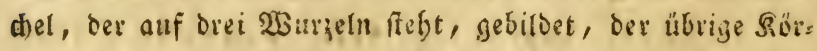
yer ift glatt, ber Siumpf gelb. 2lm Siutét uno, ter Sduangflefe find veridiedene braune D.uerftreifen und am Saudbe veraleichen runde Fleffe. Gảmmtlidje filstien find getb uno Duncfel eingefopit. Seine Rninge biträgt 1 - 2 
4) Der gefledte Gtadelbaud. Tetrodur

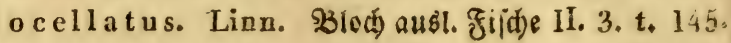
(I. 176. t. 145.)

(Tab, 17. Fig. 33. 34i)

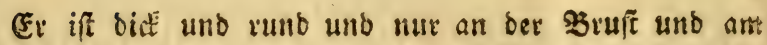
Sauche mit Gtacheln bejezt. Zuf rem rumber, glatten,

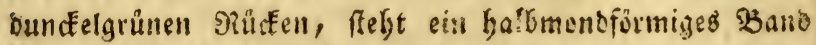

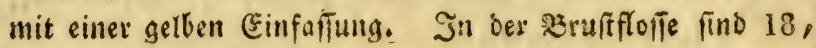
in ber 2afterfoffe 12, in ber Cowangferfe 8 , und in bes

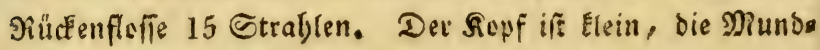
offinung rund, beibe fimmaben von gleiciser Sănge. Die Jugen fino flein, ofne Nițbaut, baben einen fotwarger Stern in einem gorofarbenen SRing?. Die Sirmenöfnung ift balbmonoförmig. Die Eeitentinie lauft mit bem Situctest parallet. Der Salwang ift Eurg, glatt uno rmo. Cäints

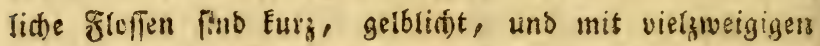

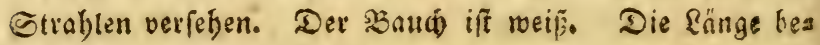
trägt $\frac{x}{2}-1$ FuF. Er beworgnt die füfen (jewáfler vers

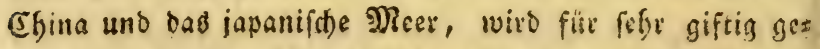

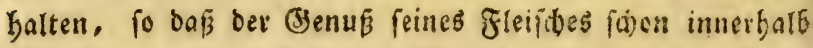
groet Stunben oen Sod nad) fid) ziehen fod; Daber if ber SoetEauf beffelben verboten. 2luper biefer giebt es in Japan nod) mebrete giftige arten.

5) Der Seetrónfer. Der Bortige Rugelfifá. Le Tétrodon hérissé, Cepéde 1. p. $48 \%$. Tetrod on hispid us. Linn. Bloch ausil. Fild 11. 130. t. 142. (1. 168, t. 142.)

Der $\mathfrak{B a u c h}$ if bervoritebend. Die Stirne flach. In ber Bruffloffe fino 18 , in ber 2ffter = uno Sdwanzfoffe 10, unb in ber Rứenfloffe 9 Strablen. Der bräunlidbe 
gemeinfibaftrichen bor)len (s)ans, ber fid) verbintet uno modurd) bie (Ener einen 2 lusgm finden. Sie 2 maght Dii Ener war grof̈, fie batten eine Drangefarbe und waten uon der (jrópe des Seirfefaamens.

7) Der eletrifáe Stadififa. Cepède I: p. 507. Tetrodon electricus. Linn. ed, Gmel. 1445. Peterson. act. angl. 76. 2. p. 382 t. 13.

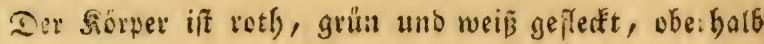
bramn, anten meergiun, an den Geitent gelb. Gämmtl=

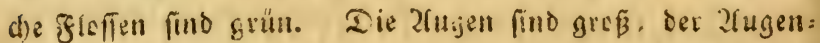

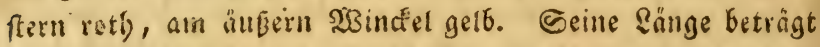

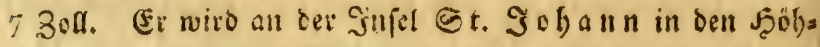
fungen bar Sotallen: Sitefe gefunden, und bat bie Eigena

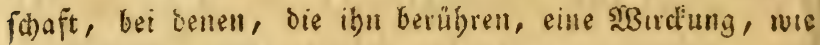
die von einem eletrifden Sdylage, Gervorghtringen.

XVII. Da Es Seinfifh: Soffer: ofer Pan zerfifal: (j)efálecilt. Ostracion. Linn.

Cämmtlide bieber gebörige fifice baben eine barte Edhate voer \$anjer, worimen ifr Särper, Der Edwans

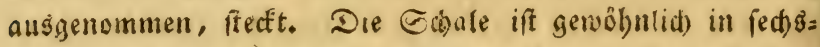
ectige Sdjilder abgetheilt, weld)e mit Elermen gुgerlen befejt, mit fternförmigen Sigurkl gejient, Doer mit einem feinen Neţe überzogen find. Der Sopf if abjhüfig, der Miuno Flein und öffnet fiit) viorwärts. In jeder Simulade ftehen $10-14$ Keifförmige, etivas frumpfe, srangengelbe Bähne. Die Rippen fino beneglid) und rotb. Die Bunge Eurz, glatt und unberveglitid. Die 2lugen fteben am Sdbeirel nahe beifammen, und werben ourd) einen bervorragenten Enöhernen গiand geiduht. Die Najenlöd)er liegen obus weit ben lugen, find flein, länglidt), Gald cinfad), bald 


\section{Dronng. P isces.}

boupelt. Der Siemendecfel ift Elem, Geweglid, uno be=

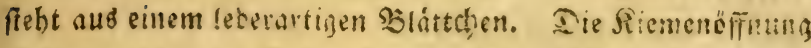
ift lang, idmal, flect) gebogen. Der Rüuden bei sinigen f(d)arf unb begenformig, bet andern breit unb flad) und nut

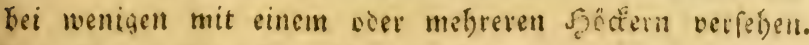

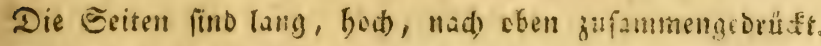

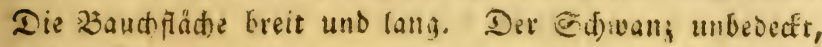
glatt und berveglith. Eetrentinir, Eduppen uno Die Baud)= floffen fegien. Sie gebärent iu ben fleifitfreffenden I!ie=

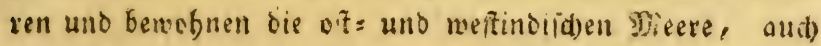

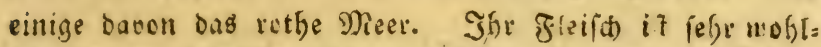

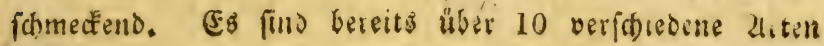
befannt.

1) Der breieckige Sofferfild. Das fad at: rofe Dreieff. L'Ostracion triangulaire. Cepède I. p. 444. pl. 20 f. 2. Coffre triangulaire. Bonnaterre. Ostracion triqueter. Linn. S164) aust. Jifid) I. 99. t. 130. (I. 134, t. 130.)

Der braunrothe Sörper if breiectig, Itadellog, die

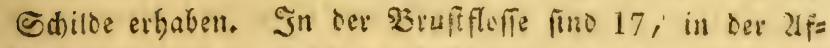

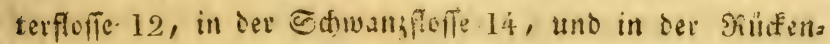

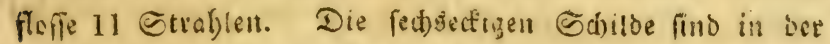

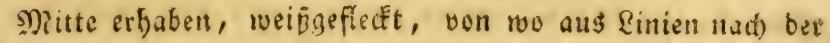
Seripherie laufen, Die mit Elemen झerlen beftrent fint. Die zugen Gaven einen fdwargen Gotern in einein weigent Singe, welder von sinem gelben umgeben wir'. Die glsi=

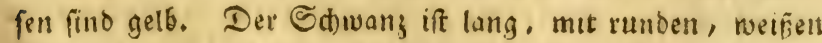

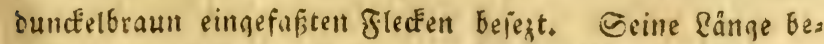

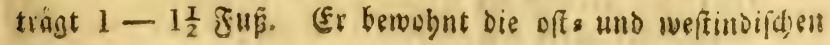




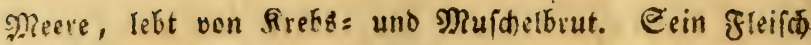

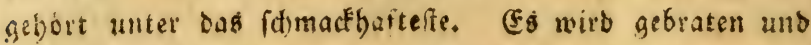

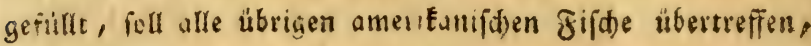
unt daber in bobem Sreife iteben.

2) Das̊ gepertte Dreiect. L'Ostracton tria gone. Cepède I. p. 465. Coffre triangulaire tuberculé. Bonnaterre. Ostracion trigonus. Linn. Sloc) augl Fifide I. 110, t. 135. ( I. 147, t, 135.).

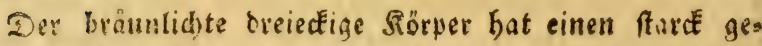
wölbten Sivicfen. Bei bem 2lfter freben grwei gefurchte Etas

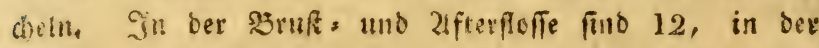

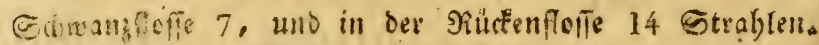

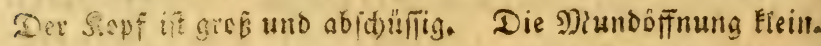
Sie were Entublade mit 10, und bie untere mit 8 bithe beiranmen ftehonden בabnen bewnfinct. Die 2ugen fino

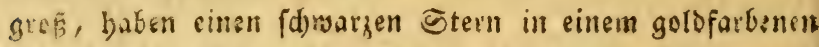

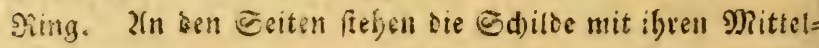
puncten unb am Saudje mit ifren アänibern bervor. Eie find mit Rinien, auf benen ftarfe Perten fteben, befezt. Cåmmiliche Eloffen find gelb mit blaulid)ter Einfalfung.

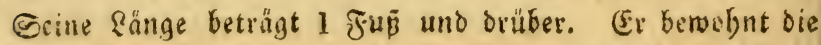
indifden s)eere, wirb vorzüg(id) um die 2intillen unb bei

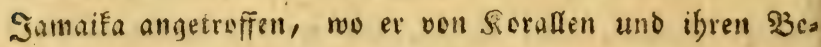
wobnern lebt. Er foll, wenn ar gefangen wirb, wie eir

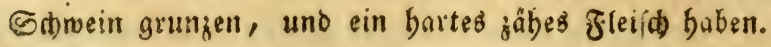

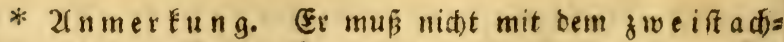
lid)ten Dreiecf, Ostracion bicaudalis

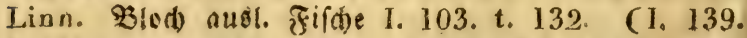
t. 132.) verwedfelt werden, welcher fid) bon ifm uns terid)eidet burd) Den geflecteten dieterfigen mit zrei Stan 


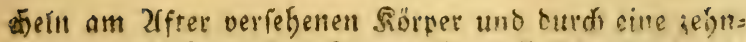

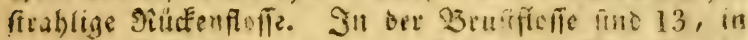

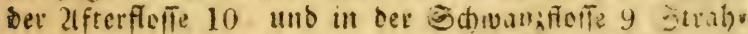

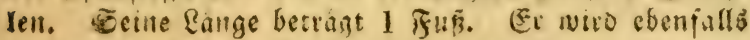

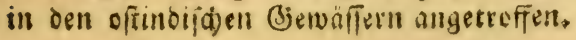

8) Das viethorrige ober vierfadelitte Dreiect. L'Ostracion quatre-aiguillons. Cepéde I. p. 468 Ostracion quatri-corn is, Linn. Blod autl, fiidje l. 108, t, 134. (I. 144. t. 134.)

Der breieckige Rouper ift mit gwei feormern doe: Sta thein am Sopfe uno binter bem 2liter befezt, In der 3rmits floffe fint 6 , in ber afterfoffe 8 , in oer E⿱

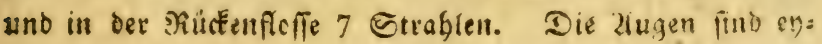
runb unb baben ennen bunfelblauen Gtern in einem gelfent Singe. Die Edilde fino rauf. Der Siorper ift rötllid)= braun, mit braunen länglidten Flecten bejcidnet. I'et Sd)wam und bie Floffen fint getb, erfiever lang unb

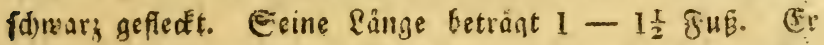

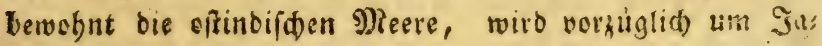
maifa, Guinea uno an ben antiflidjen Snieln gejuncent. Eein 8leifd wirb nid)t geadtet.

4) Das vierfórnige Siered. Dev. Eeefier. L’Ostracion quadrangulaire, Cepedc!.p. 470. Ostracion cornutus. Linn. 2(0d) aแร์. Jiiłe I. 105, t. 133. (I. 141. t. 133.)

Der Förper ift vieredfig. Lan Sopfe ftehen 2 lange J̧ërner uno ebon foviel chnweit bem afret, welde fimant= lid) am Girunde fein gefurbet fino. In ber simiffoff: fins 11, in bev afterfloffe 9, in ber Gibuangfaffe 10, und is 


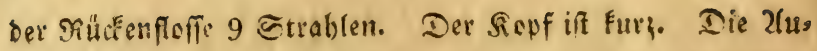
gen gros mit foblwarkem Gtern in einem gelbaünen Sins

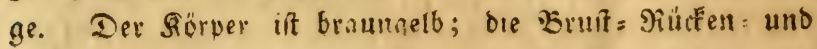
2lfterfloffen gelblidit, ire Gownarifloffe braun mit einer bletten oundein Finfufiung, und ciefe fowobl, als ber

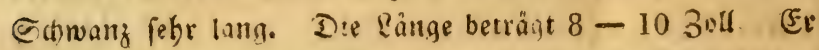

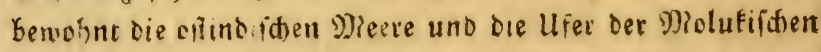
Infein. Seill jleifd if bart nnd zonbe und fitwer zu vet: bauen.

5) Der viereçige $\mathfrak{b}$ hrmtråger. Der trâger. L'Ostracion Dromadaire. Cepède I. p. 470. Ostracion turritus, Linn.

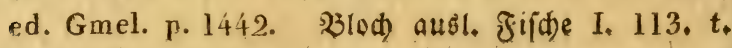
136. (I. 150.t. 136.)

\section{( $\mathrm{Tab}, 18 . \mathrm{Fig}, 35$.}

Der Sïrper if vierectiq und auf bem Sillcten fteft ein

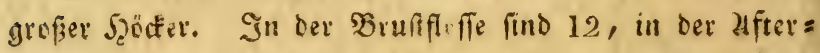
Edwangs und Siacfenflefle, in jecer 10 Strablen. Der Sopf if grefi, abfdulfig, Der suno etwaz bervorftebent. Die obere Simnlade mit 12 uno die uncere mit 8 3ăbnen

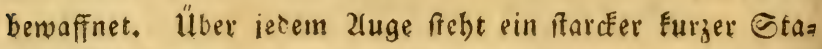
del. Die 2lugen baben einen fdwarzen Stern in eirem gold: fnibenen अing. Die Riemenóffnung ift weit, uno bie Sies menbaut mit einem Etrabl verfeben. Dev Niücfen fteigt zu beisen Geiten in die Sabe, uno bat in ber פitte einen breiten frishernen SPöckex, ber in eine idarfe, nad) binten zu gefrummte Epibe auslauft. 2ln ieder Seite des Baus d) gelbgrau, bie und da braun gefledt. Die Schilde mit er: fabenon finien, wie init einem शeke Überzogen. Des 
Sdiwang if braun uno bie fiofien grau. Eeine Range

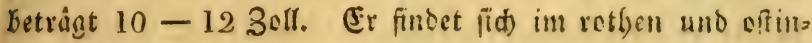
Difchen Meere, vorgügltid) băufig um bie moluccifiden Int: feln, bat ein jăber barteł fleifd).

6) Der Nafenbeillfild. L'Ostracion Museau-alongé, Coffre a bec. Bonnaterre. Ostracion Nasus. \$̉lod) ausil. Fiifte 1, 118, t. 138, (I. 155, t. 138, )

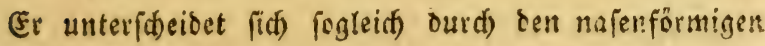

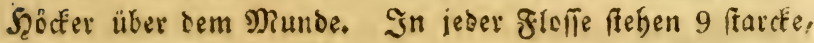

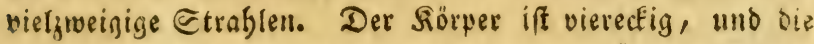
vier Geiten baben beinabe gleidge \$zreite. Ulber bie Mitte ser obern Geite lauft eine bervorftefenoe Rinie ber Ränge

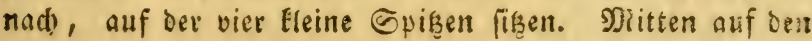
Sdilden fefte ein rother runber flecte, ber aus Eleinent syerlen zufammengefejt ift. Die Zlugen finto gré, uns baben einen fowwargen Gtern in einem grüngelben ringe. In ber ebern Finnlabe fint 14, und in ber untern 1?

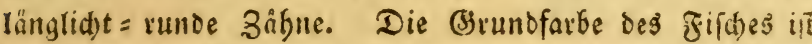
grau, bie ber Finffen röthlidt, uno Edwwans uno Repf mit einigen braunen Flecten gez̧eidgnet. Ceine Ränge bes trăgt $1-2$ ₹ur. Fr wiro an Der Miunbung Des git? und itn $\mathfrak{R i t}$ felbft angetroffen.

\section{Daร Murmelfifd = (Gefdifedt. Mormyrus. Linn. ed. Gmel.}

Der Sopf ift glatt. Dev Unterfiefer länge: als der obere. In beiten Simnladen ftefjen mefrere an der Grifte

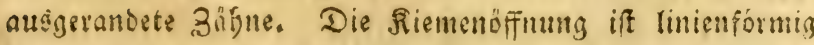
obne Decfel, Die Siemengaut bat nur einen Strabl, 


\section{TO4.}

\section{Biente EInffe. Fifde.}

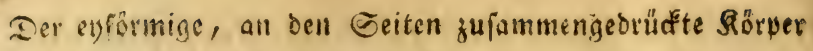
if mit runoen Gdunven bebecft. Sanon find 9 2frten bea Eanut, Die fammtlich im Fil vortommen.

1) Der Sonutum Mirmelfift. Le Mormyre K a n numé. La Cepède V. p. 621. Bonnaterre 184. n. 3. Mormyrus Kannume. Linn. ed. Gmel, p. 1440. Forsk. Faun. arab, p. 75. ne 111.

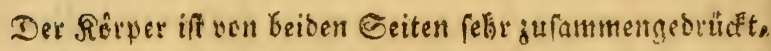
weiflicht. Die ßuxcfenfleffe ift in juei ftumpfe Rappen ges theilt, von der balten fänge bes forperg. In ter shirciens

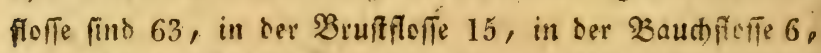
in ser 21fterfoffe 17 und in der Somwanjoffe 20 Strablen. Die Ceitentinie rauft getabe auf der smitte ber Eeitur. Er wirb im Mill gefunden.

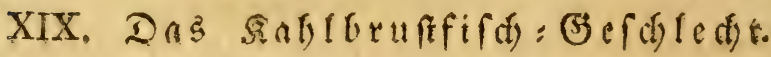 Gymnathorax.}

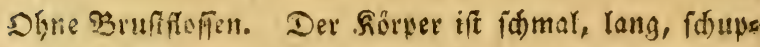
tenlos, foleining uno bunt. Die Riemeneffnung fomal,

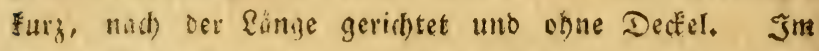

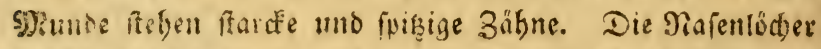

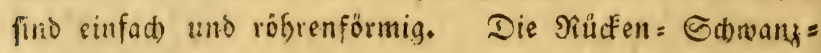
uns liferficfie mit ciner gemeinidaftlidgen Saut verwads) fen, ifie Etrablen fins weith und zart, und Eonnell we:

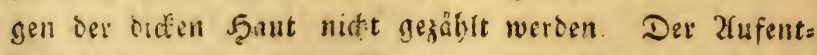
balt biefer zifide if im speere, aus weldsem fie fith zu

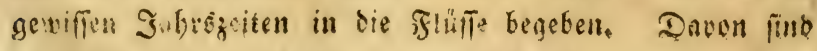
beritb $8-9$ verfobicdene zrten betannt. 


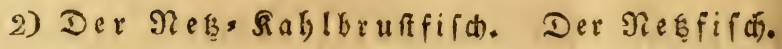
Gymnothorax reticulaire. Gymnothorax reticularis. Bloch. augl. Fijide IX, p. 85. tab. 416 .

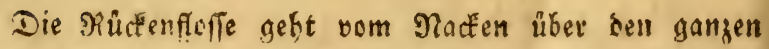
Siumpf Des̊ Fifches, Deffen Rörper nekgförmig geflect ift. Sopf uno 9) Rnocff̈nung fino Elein. Die 2lugen baben einen blauen Stern in einem fdumalen, weisen Ninge.

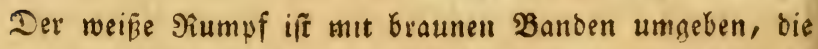
nut am rücten und Bauche fidtbar find, indem fie an Den Seiten burd) die neģörmige Flecke bebeckt werden. Der 2lfter ift nod einmal fo weit vom Sopfe, als von bet Sommangfofie entfernt. Ex fommt bei Iranguebar nor. 
1) Der Natter.Zal. Der bunte 2 al. L'O. phisure Ophis. Cepède II. p. 196. Murae n a Ophis. Linn. Bloth ausl. Fijpe II. 35. t. 154. (I. 216. t. 154.)

Det förper if fiflannenábulid), auf weifem (S)runt Iuncel gefieft, uno ber Eatrwan; chne froflen. In ber

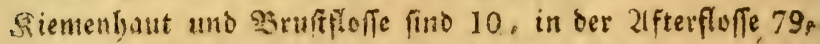

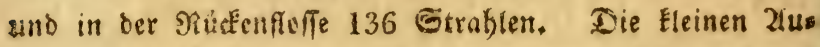
gen baben einen fomarzen Stern in einem filberfarbenen

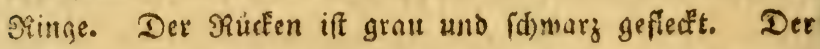
Ed)mans endigt fich in eine ftumpfe Spirge. Die Seitena Junce ftelyt in ber Mitte, uni ift mit weipen Spuncten

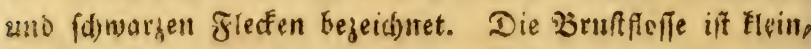
unb unter berfeiben ftebt eine Eleine Sienenöfinung. Die Siscécenflofie fängt binter dem fiopfe an uno. entigt fid

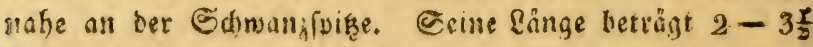
Jun. Cer bencbnt die oftindifaten Meere. liber feine

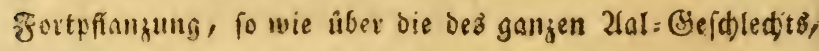
weî́ man wenig guverlälitiges.

2) Der Meer, 2lal, La Murène Congre. Cepéde II. p. 268. Muraena Conger. Linn. 3lod autl. Fitide II. 37. t. 155. (I, 218.t. 155.) ( $\mathrm{Tab}, 20 . \mathrm{Fig} .37$.

Die Xfter = Comang = und Rüfenflefie find mit eins ante: vernadjen. Die Seitentinie ift weip. In ber Sies menbaut fino 10, in ber Bruffloffe 19 und in ber ver

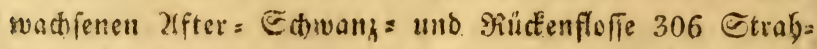
ten. Der foldangenartige sobrper ift voin গtudell an bis

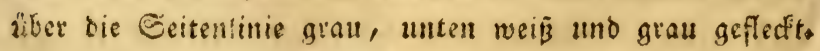

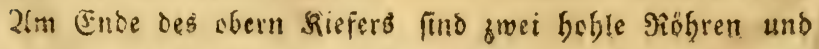
bid)t all oen zlugen zwei sertiefungen, Die 2lugen fino 


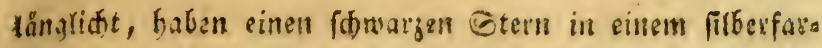

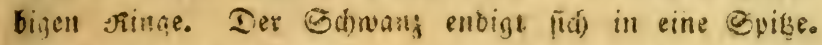

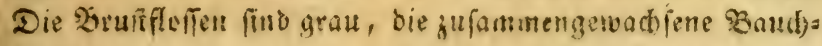
Rü

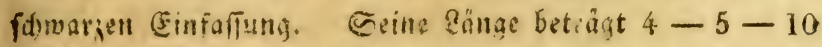

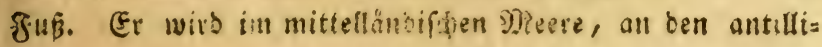

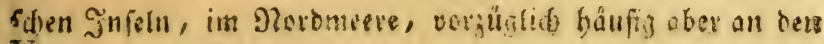
$\mathrm{X}_{\text {iffen won (Englano gefunden. }}$ bleiben groffentbeils im eer, bed) balten fie fich aud) an ben Nisnoungen und dfern ber frifie anf, une man finket eine Mienge junges Meeraale in Dem Flü Geevern in England, wo fie in

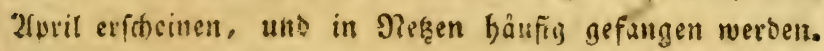

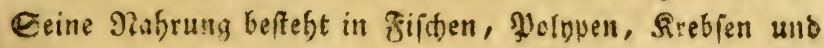

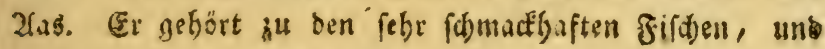
bat ein weifos zarte fyleiin.

4 3) Der gemeine 2ral. La Murène Anguille. Cepéde II. p. 226. M u raena Anguilla. Linn.

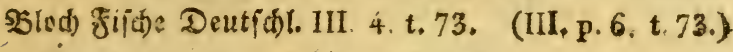
r. Meidinger. Pisc, Austr, tab: 31 .

\section{(Tab. 21. Fig. 38, )}

Die untere Simmlabe fteht über bie offere etruas bervor, Der fdlangenartige fdlüpfrige $\Re^{\circ}$ rper if in fotlammigem

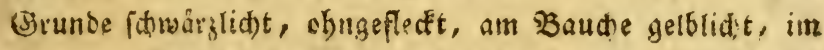
fandigen Girunbe bingegen grünlidft: braun, am Bauthe fitberfarben. In ber אiemenbaut find 10, in Der $B$ ruffe

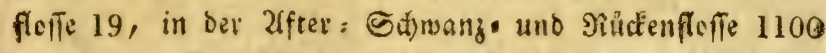

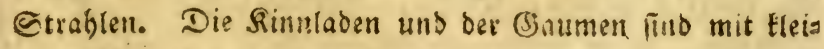
nen Bäbnen befęt. Die Eleinen 2lugen baben einen. fdwar=

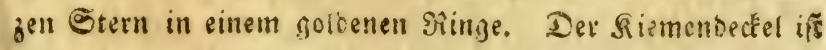
mittelft einer Şaut ant Siumpf verwad)ien. Die Eleine Slies menöfnung if balkmonoformig, und fetht bidst an ber 
93rufffloffe. Die Seitenlinie lauft gerade und bat weine

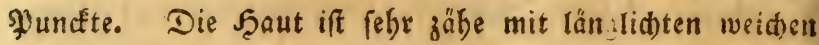
(G)uppen bedecft, weld)e nur am troctenen 2lal fidhtbar find. Siücfen = und afterfioffen find lang uno fdmal; erfere if

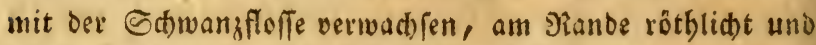
Ieztere weip. Die sruftioffen find Elein, runo uno voit einer etwas hellern Garbe alz oer Sïrper. Ceine Rñna

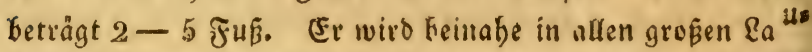
peeen, Irid)en und Flüffen Europens angetroffen, begi ${ }^{\text {en }}$

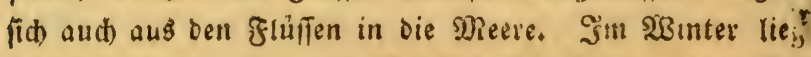
ex im Sd)lamm in ganjen (5eferfichaften beifummen. Sei= ne פabrung beffebt aus Infeften, Sצümern uno aus sem 2lafe; voraủglid liebt ex ben rogen anberer fis ide, gebet. Daber biefem in ber Lainzeit nach, uno tyut Daburd) Der Bermefrung ber übrigen Fifd)arten einell gros Ben 2lbbrud); aud) liebt er bie grimen (Erbjen, benen er, wenn fie md)t weit vom llfer gebaut werben, nad)gebn forf.

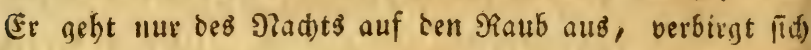
ain Sage im Sd) (amm, worinn er (iid) tief eingräbt, uns feine Sanner mit zuei S̈frnungen verfieht, Damit er, wenn eine verftopft wird, curd) bie andere einen 2 (usizang finde. Die 2frt feiner Saernebrung Eennt man ebenfalls ned) nicht genau. Sieuere Deobadtungen fezen es aber nun faft auper Zweifel, dẫ er zu ben lebendig gebăbrenden fis

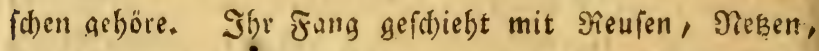
alarfoffen und oer (jouncfanur; aud) werben fie mit Spies fen unter bem Eife, wo fie in Mienge beifammen liegen,

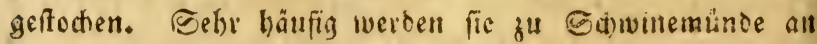
ber Ditfee, uno in verfdiebenen (jiegenden an ber Docr ge= fanizen, unb in grober Menije nad) Berlin, Gadjen und Sd)lefien verfihrt. Sie merben thells frifh, theils ges săudbert, theils eingefaljen verfperbt, baben ein lajmadfbaf 
(d)warzen Ste:n in einem gelben Ringe. Die breite Bunge. uno ber Baumen find voller Sisarzen. 2lm Siörpar fteben

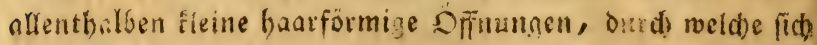

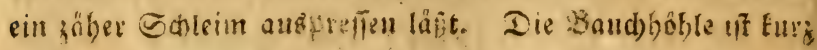

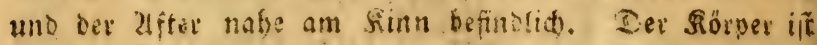

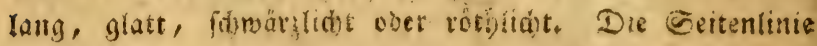

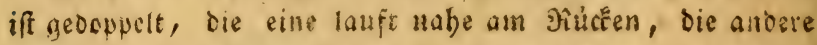
nabe an ber dufrerfoffe fort. Die Bruftiofien find Eleit,

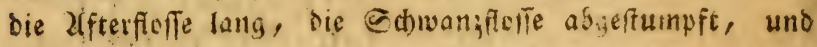
alle brei mit weiden einfacten strablen verfeben, bereas 2 lingabl fich aber wegen ber fie umgetenden iften $5 a$ at nidit beftimmen läbt. Seine Ränge betränt $1 \frac{1}{2}$ bis über 5

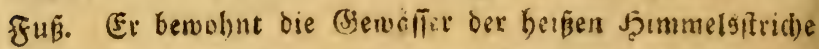
von Buinea, Gurnam, Caysnne, Steru uno die afitfanis

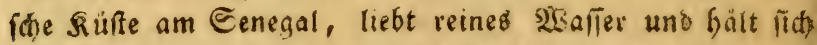
Daber an fireinigten Seeufern und den Miundungen ber fluffe nuf, ven wo aus er in bie fFlüffe und die bamit verbunies nen Seeen geht. (Er näbrt fid) von frifden, Infecten unt

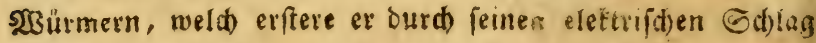
betäubt soer tootet. Sein fileifo if fett und fomatryaft mo wiro gefweist. Ex verurjatt, wenn man ibn beribrt, cine bem eleftriiben Salage ăbnlitite Empfintung wie ber

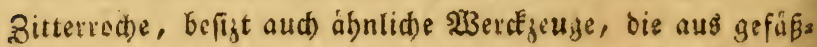
uno nervenreichen Ђăuten befteben, uno vie ganze \&änge Des Ed)wanger einnefmen. Seine elettrifhe (Figenid)aft wurbe zuerft von Эi ider im Sabr 1671, weldher von Der Syarifer ZfEadnie ju matbematbifichen Beobachtungen nad). Conesne gefdicft wurbe, entbectt, ber einer 2falart gedencft, welche fowobl beim unmittelbaren, als mittelbaren Berübs

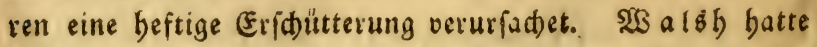

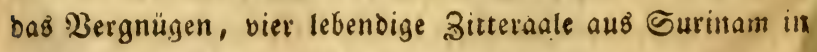
Eondon zน erbalten, Şbm gelang es zuerft, den eleftrijden 
snenbout find 5 , in ber Bruifiofie 10, und in ber 2lfters flefe 230 Ėtrablen. Die fibr Elenten 2lugen baken einen fawarien Eiern in einem fibernen Binge. Ier firmens Decfe! beitebt aus einem arsfien kno flernen Lifärtchen. Die 3auchboble ift Eurh, Dex lfiter eng uno obumeit sem Siopfe. Die Cettenlmie gebt vom Sopfe in gerader Miditung zun

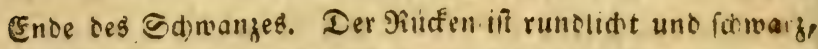
sie Geiten unt der Baudh braumrötblid)t, brsun geflecft. Die beiden Bruffleffen fino Eurg, bie am Mifter fethr lang; Sie buben insgefammt eine bräunlid)te Farbe uno einfache Etrablen. Seine \&ănge beträgt $1-2$ Fuв. Er bewobnt

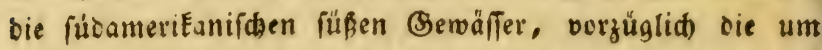

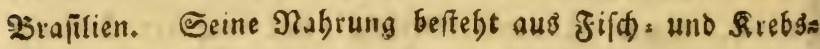
brut. Das fleija) ift id)mactbaft.

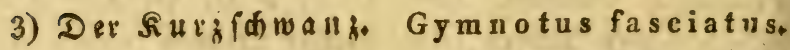
Linn.ed Gmel p. 1137. Bled au\$1. Fif dife H. 61. t. 157.f. 1. (I, 248, t, 157. f, 1 )

Er unterfdeibet fid von bem bribergebenden pogleids burd) Den Eurgen fid in eine Spike enbigenten Sdwall. uno ourd ben bervoritebenden Unterfiefer. In der Riemen:

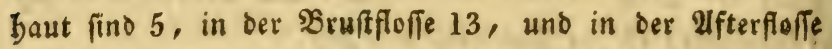
123 Strablen. Die Grundfarbe bes Fifacs ift bellgelb mit wellenförmigen \&inien, bie bei einigen braun, bei andern

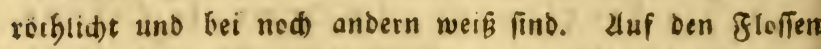
ftehen viele Eleine Fundte. Er wiro mit tem vorbergehens ben in ben flufien und ftebenden (semäffern oon Brafilien gefunden, und bat ein woblid)mectenbes glelíd. 


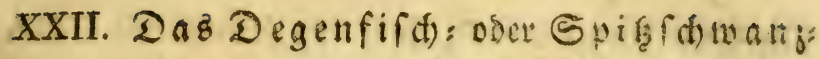
fifd): (sefdled)t. Trichiurus. Linn.

Der Rorver if lang, bůn, begenförmia, forundentus,

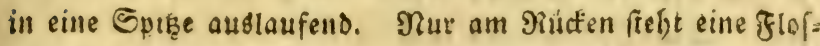
fe. Der Souf ift lang, von beiben Eeiten zufammenges

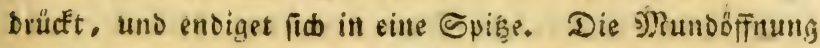
ift weit uno betie ßinntaden finto mit beweglidten 3ábnen won ungleidier länge beiejt. Die zlugen grefß. Die Sie: menëffnung weit, uno ser Siemerdictel befielgt aus einem einkigen Bllartchen. Die Eeitenlinie if getabe unb det

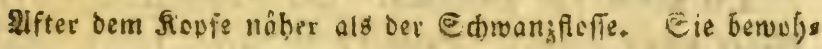

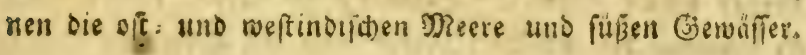

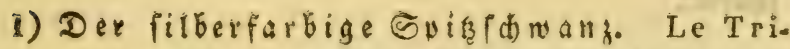
chiure Lepture. Cepède II. p. 182. pl. 7. f. 1. Trichiurus lepturus. Linn. B!cki aus!s Fif

(Tab, 23. Fig. 40 )

Der. Unterfiefer ftefft über ben oberen beroor. Die Sinnladen find mit langen und Eurzen Bähnen bewaffinet. In Der Siemenbaut find 7, in ber Brufferfie 11, uns in

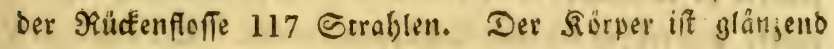
filberfarben. Die zlugen ftefen nabe am Echeitel, uno bas ben einen fdrwargen Etern in einem goldenell Siinge, wels der nad ber innern Geite eine weiñe Einfaffung bat. Die Siemenêfinnung if weit, bie siemenbaut hat fieben frumme

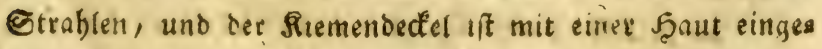

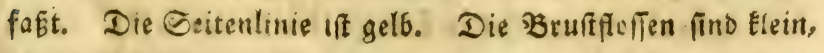
bie Rilutenfleffe lang. Şinter bem Ilfter fethen ftatt eines Sleffe vifle Eleirie, weit auseinander ftehende Stadjeln. 
Die Sănge betrågt $2-3 \frac{1}{4}$ \&uß̄. Er berobnt bie Secel;

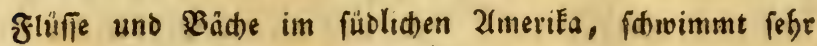

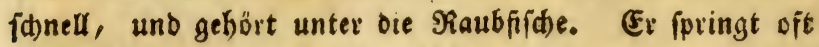

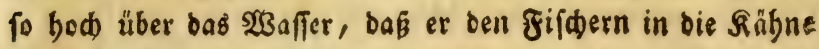

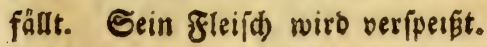

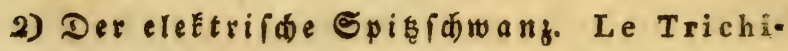
ure électrique. Cepéde II. p. 188. Trichiurus indicus. Lian, Klein, miss, pise, IV, 52, n. 2. t. 12.7 .

Die Siefer find gleidlang. Die Zähne flein. Der Särper braun geflectit. Seine fänge beträgt $1-2$ F Er bewobnt bie indijd)en Meere unb bat elettrifde Eigens idaften.

XXIII. Daв Seewolf: Şefdled t. An are hichas. Linn.

Beibe Rinnlaben find vorn mit ftarden Fegelfärmigen Zåknen befegt. Der Sopf ift abgeftumpft, bie Mundöffo nung weit, bie 2lugen grof́, bie Siemenśffnung weit und in ber Stiemenbaut find 6 ftarte Enöderne Strablen. Der Särper ift langlidt, von beiben Seiten jufammengebrüat't, glatt, mit feinen hünnen Søuppen bebectt. Eie berwobnen

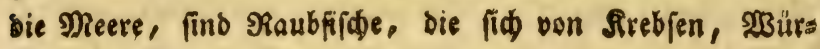
mern unb gilden nåbren.

1) Der Seeworf. L'Anarhique Loup. Cepéde Il. p. 300. pl, 9. fig. 2. Anarhichas Lupus. Linn. Flod Fifde Deutíl. III. 18. $t, 74$, (U, 25. t. 74.)

(Tab. 24, Fig, 41.) 
Die 3åkne fint fnödern. Die Siementgaut bat 6, Die xirulfferfe 20, bie lifterfleffe 46, bie Sdivanifloffe 16, uno die эtúctenfloffe 74 Strablen Der Repf ftaref. Die Munboffnung weit, bie Sippen ftard, bie Rinntaden bor= wårts mit langen auseinanber ftehenben Zđdgnen bewaffinet, Bie in einander eingreifen, bie Seiten und ber Gasunen mit Eaffä̧ägnen beíegt und ber Miund wie bei den vierfüs figen Zbieren bejoaffen. Die Bunge ift Eur', ftumpf unb glatt; Das 2luge länglidet mit idnwargem Stern in eis

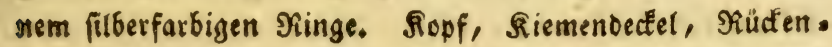

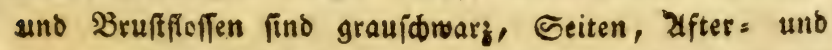
Schwamgloffe fablfarbig, ber Bauch weiflidt. Zn bent

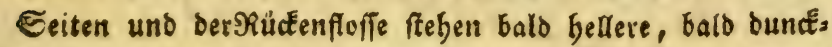
gere, nach ber Bruft laufende glecte. Die Jaaut, weld) Den Förper umgiebt, ift glatt unb mit bünnen aus einan= Der fitehenden Sdjuppen belegt. Seine Rånge betriagt 3

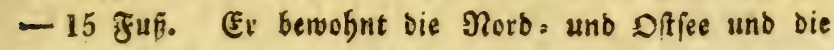
mordifaten Meere, wo er fid gewöbnttd in ber Tiefe aufo

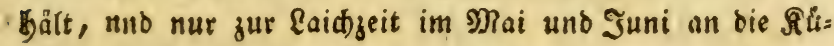
ften Eommt, um feine Eyer, weldse fo grós wie Erbjen finb, an Ceegewådje abzulejen, fried)t faft wie ein Zlal,

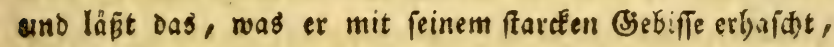

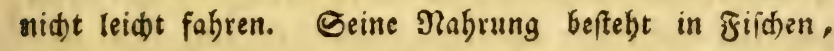
Rrebjen, Şummern, Sirabben, Muidjeln und Sdnecten; beren Gdaalen er leidft zermalmet. Gein vorzüglichifer

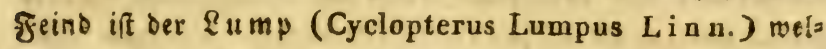
der ibn im Nacken pact.t. Sie verten vorgügli mit epeeren, aud mit Netzen gefangen. Shro gleifh wirb von ben Grôntåndern fowchl frifd, als getròctnet gegeffern. Deß Zellę bebienen fie fich zu Beuteln, um barinn igre

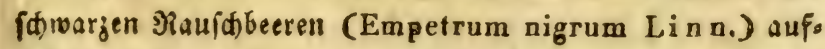
zubervabren. Die fogenanten Sötenfâtine, (Lapides 
Buffonites) Buffoniten, furo blo bie forfiten उäbne biefer Jifabe.

XXIV. Daz Sandaal ober Sandfifh: (b) $e$ d led led. Ammodytes Linn.

Der fiörver if fdlanE, aalformig. Die Shuppen Elein, weid), zart und leidt abfallend, Die Sdwanzfleffe abgez fondert. Der länglidite, von ben Seiten zufammenge= brüfte Sopf tif jomiler, als ber গRumpf. Die Dberlippe ift gedoppelt, die untere Sinnlade lauft in eine Spize aus. Der Miuno iff zabnlos uno im Sdlunoe fizen zwei lảnglid’s te raube Sinoden. In Der fiementaut find 7 Strablen. Davon jino bisher nux eine eingige art befannt.

1) Dep Sandaal. Sanofift). Lammodyte appat. Cepède II, p. 274.pl.8. fig 1. A mmodytes Tobianus. Linn, Blod fifde Deutidy 111. 24. 4. 75. f. 2. (IJI. 32, t. 75.)

$$
\text { ( } \mathrm{T} \text { a b } 25, \mathrm{Fig} \text {. 42.) }
$$

Die untere Sirntade lauft in eine Spiz̧e aus̆. In dek S2ruffleffe fino 12, in ber 2lfterpuffe 28, in Der Sdmwang flente 16, uno in Der Siüstentifie 60 Strablen. Die Sies inensffnung if weit. Die fiemenbectel beffeben aus vier slattchen. Die zlujen fino flein uno baben einen fdwar: zen Etern in cinem filberfurbigen Ringe. Zluf bem ruts

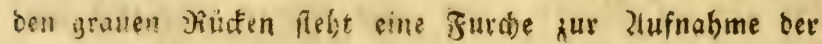

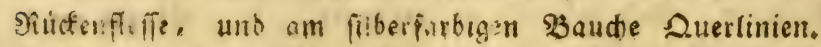
Die eiten fino fiberfarbon. Der lifter ift nabe am Edwanjents. Die Seitenlinie bat cine gerabe Ridtung

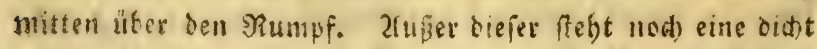
ain Sibiten, Hno cine unten am Baude. Die Sd)wanj= 
fleffe ift gabelförmig. Er bewolnt bie nördlid)en europåif)en Meere, wo ex fich an ben Ufern eirten balben Fufis tief in Sand eingrảbt, fich mebrentbeilß im (jorunce oufhált, uno nur felten in bie Säbe Fommt. Seine Nabruug befteft in Eeegenürmen. Er laid)t im Mai, und feit feune Fiter an ben Ulein im Eand ab. Das Jleifi) it mager, uno wirb von den (jrönländern fowabl frif́), als getrocénet, gegeffen.

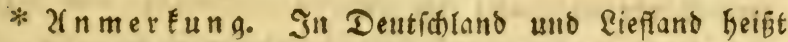

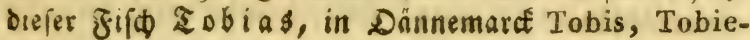
sea.

\section{Das Sdlangenfifth: Sefdledt. Ophidium. Linn.}

Der Sörper ift fallangenformig, von beiben Eaiten ets waร zufaminengedrüctt, mit weidhen zarten Edtuppen bes freut. Der Sopf if Elein, fduppenles, uno in den Rinn. laben find Eleine 3ähne. Die Siemenóffnung iff weit. İn Der Siemenhaut liegen 7 Etrablen. Eo find bereits 5 vers fdiedene arten befannt.

1) Der Barts Sdlangenfifd. Der Graus bart. L'Ophidie barbu. Cepéde II. p. 279. pl. 8. fig. 2. Ophidium barbatum. Linn.

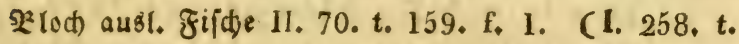
159, f. I.)

$$
\text { (Ta b. 25. Fig. 43.) }
$$

Ex hat am Unterfiefer 4 Bartfajern. In ber Riemen= Gaut ino 7, in ber Bruffflefie 17, in ber lffer: Gdwang.

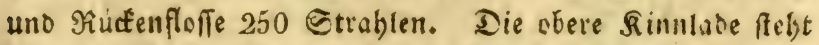
über bie untere beroor, bie stepen fino faref. In ben 
Sinnlaben, im (Saumen und Sd)lunde ftefen Hele Eleine Săbne. Die 2lugen bahen einen fowarjen Stern in einem

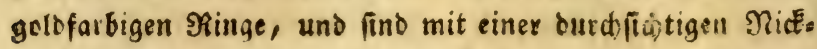

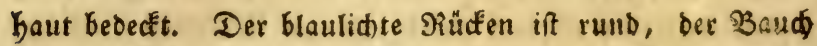

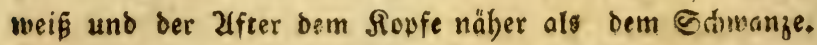

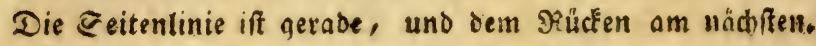
Die Bruffeffin fino flein, am Birunde braun uno nach

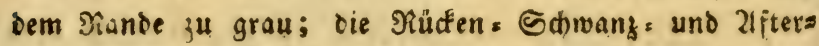
floffe laufen in einander, fino i申mal, weiß uno mit eine: fadwarien Einfaffung umgeben. Eeine \&änge betrånt 12 -

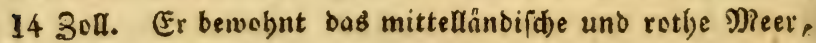

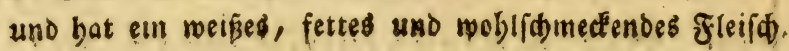

\section{Das Dedefifd): B̧efdidedt. Stro-} mateus. Linn.

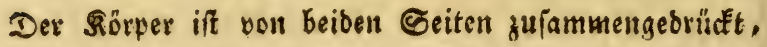

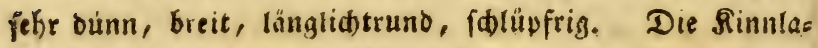
Den find gleidlang, mat Żăfnen bejezt. Der Muno Elein, Die Rippen ftaice. Die fiemenoffrnung weit. Die Seitene Yinie gerade Der Sdywall gabelformig. E़s find bereits. vier arten betannt.

1) Die Cioldoede. Le Stromatée Paru, Cepède II. p. 319. Stromateus Paru, Lina. \$lod aust. Jifde II. p. 75. t. 160. (I. 265. t. 160,)

( Tab, 26, Fig. 44.)

Der Pấrper bat Eeine Streifen und ift mit zarten Eleis nen Eduppen, bie leiabt abfallen, bedect. In ber Sies mentaut fino 2, in ber Brufffoile 24, in ber zifterficfie

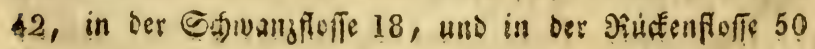




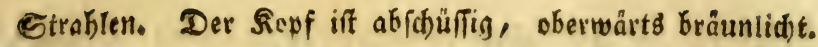
Die 2lusen find grof́, haben einen fhwargen Etern, bex in einer weisen uno gelben boppelten Einfarfung ftebt. Der Siemendectel beftẹt auß einem einz̧igen slâttchen, bas mit einer bünnen Şaut umgeben iff. Die Seitenlinie ift breit unb filberfarben. Die Seiten glänzen oberwårt's wie Bold

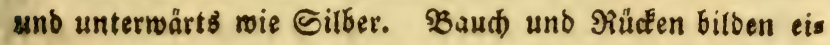
nen Bogen, und ber 2rfter ift bem Munbe năber alb ocm

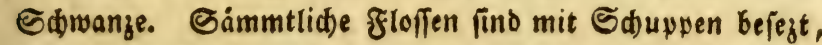

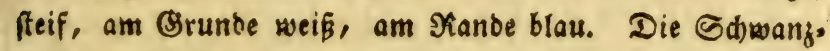
forfe ift ftarte gabelförmig. Seine \&ảnge betrng $5-6$ 30oll. Ere Eommt in Brafiltien uno Eranquebar vor, lebt von \$ürmern uno Eleinen zifdaen, uno bat ein weiEts, zartes, (đ)mat'baftes Fleif币.

2) Die Silberbete. Stromateus argenteus, જlod) ausl. Fiíde IX, 92. t. 421 .

Der Sốrper ift fitberweiß̄, von Kellgtångenden, Eleinen, leidtt abfallenden Edhupben. Die gabelförmige Edwangs floffe bat gleid) lange Spiz̧en. In ber Riemenbaut fund 9,

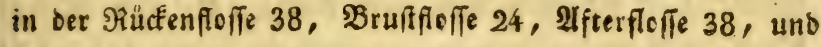
in bey Sobmangfefie 19 Strablen. Beine Ränge beträgt

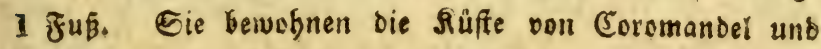
Ceslon, wo fie unter bem Namen ga a mpel betannt fino, und baben eill zartes, woblidmedtendes gleifd).

* UnmerEung. Brod hat aud nod einen grauen und fowargen Dect fifd t. 420 unb 422 ebenfalls von Coromandel und (Cenlen beítrieben uno abgebils bet, bie elenfalls uitter bem Namen $\mathfrak{p a m p e l}$ da. Dafelbft betannt find, und gefpeifist werben. 
122 Bierte Elaffe. Fifde.

XXVII. Daz Shmerotfifd: (3)efdedt.

$$
\text { Xiphias. Linn. }
$$

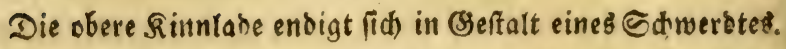
Der Muno ift zafnlos. Der אörper pintelförmig, in ber Neitte ftarc und an beiten Enden fitmal, glatt, und mit einer bủnne॥ Şaut bebectit. Der Sdjwang endigt fid in eine lichelförmige glofle.

1) Der ๔điderbtfifd. Le Xiphias Espadon. Cepède II. p. 289. pl. 9. fig. 1. Xiphias Gladius. Linn. SBlod \&i ide Deutfdl. III. 28, t, 76. (III, 37. t. 76.)

$$
\text { ( T a b. 27. Fig. 45. 46.) }
$$

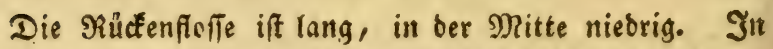
Der Siementaut find 7, in ber Bruffleffe 17, in ber 2ffters fleffe 18 , in ber Sdwanzforfe 26 , uno in ber Rüctenflofie 42 Strablen. Der Sopf ift abichüfia, die Mundéffnung meit, und bie untere Finntade endigt fid) in eine Sprize, fo mie die cbere in eine fdwer otförmige Berlanngerung. Das Edherbe if oon oben und unten flad, auf beiben Seiten fdarf, und lauft vorne in eme ftumpfe Gpikge aus. Die 3unge if frei uno ftark, und im Munde fiehen einige vaube Sneden. Die alugen fteben bervor, uno haben eio nen fimarzen Stern in einem reiß̈grüntioten \$ringe. Die Siemensffnung ift weit. Der Riemendectel beftehet aus zwer Blättden. Sopf uno Sdwerdt fino ftablblau, ber. SRứen viclett, Saudb unb Seiten unter ber Emie mels.

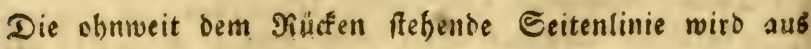

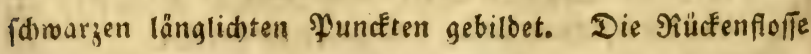

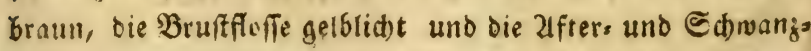

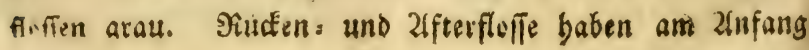




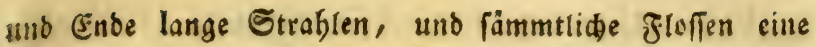
fidelförmige, bie ๔đwwanzfoffe aber eine halbmondförmige Beitalt. Seine \&änge betrågt 4-20 8ußs, uno er miegt

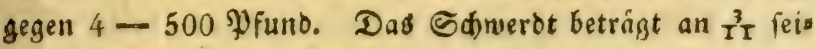

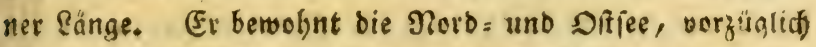

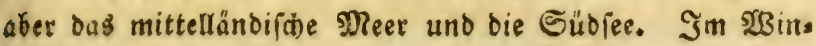
ter balten fie fid in ber Eiefe ber. bohen See auf, und zies

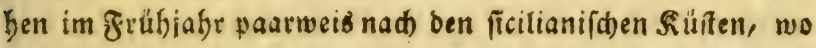
jie im Mai und Juni ifree Ener im Brounde abfexen. SGre Nafrung befteft in Seegewádjen, Fifiden uno ßBümern. Das Sdwerdt bient ifnen als trefflides 3 entheibigungs a \$ittel. Sie werden mit Şarwunen gefangen. Şhr Gleifd), bejonbers bie \$Baud): und Sddwangftucfe werben gegefien, unt die eingejaljenten zlofien unter bem Namen Callo vers Eauft unb gefpeißst.

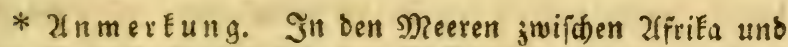

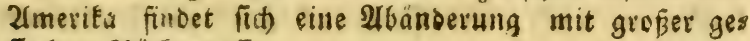
flectter গǘtenfloffe,

XXVIII. Das $\mathfrak{B}$ ruftfaltenfif(b) (Sefd) ledt) Sternoptyx. Linn. ed, Gmel. p. 1130.

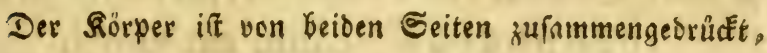
idjuppentos, von Eielförmigen, an beiber Eeiten gefalteter Bruffennoden, ber Bauch ourdfiddtig, ber Siopf fumpfo Der Mi un fendiredt in bie Şobe geridtet. Die 3äbne Tefre Elem, Seine Siemenbaut.

1) Der ourdfidtige $B$ ruftaltenfifo. Le Sternoptyx Hermann. La Cepède V. p. 613. Sternoptyx diaphana. Sermann. Naturs forif. XVI. p. 8, t. 1. f, 1. 2 .

( $\mathrm{Tab}, 28 . \mathrm{Fig}$, 47. 48.) 
2n bem Unterfiefer fteben in ber Mitte 4 Garbereiafors. mige Bertiefungen, welä) burd) eine Sdjärfe abgefonbert fino; 3 ăbnlide fteben unter ber fiemenöfinung. Die Xugen find grof und gelb, Die 3unge bick und raub. Die 10 Faltell an ben Seiten bes Bruffench)ens laufen in ber

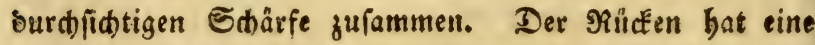
geboppelte Sdjấrfe, weld)e gegen die Nafenlöd)er bin auss einander lauft, uno ift bei ber Rüffenfloffe böcterig. Die Eeitentinie feflt. Die effige Rrümmung bes $\mathfrak{B a u d b e s}$ ift binterwårts breifad) ausgefdnitten, uno burd) eine burdy fid)tige Şaut mit ber bur(b)ithtigen, geglieberten Baudb= gråte, auf weld)er bie Zffterfloffe fizt, verwachfen. Die

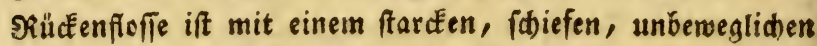
Stachel verwadjen, vor weldem fiá) eine am Rande febe fein gezabnte Şaut befinbet. Der Sioprer ift grünlidbt = Eraun, unten unb an ben Eeiten filberfarben. Die \$3rufts froflen fino gelb. Die Sdwwanifluffe ift greifwaltig uno bat 40 Strablen. Die ganje länge biejes fifdhes betrảgt a 3oll. (5r ift auș Jmerita,

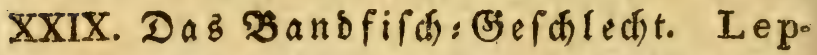
'tocephalus. Linn. ed. Gmel.

Der Sörper ift fauppenlog, wie ein Banb gुulammen.

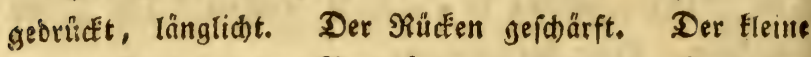
fadmale Sopf hat eine Bertiefung am Sheitel. In beiben Siefern ftetgen febr Eleine Bäbne. Die Kiemenoffnung frelft theils an ben Seiten, theils unter. Die siemenbaut ift

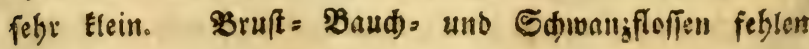
gånuglid. 


\section{Dัธนแแ. Pisces.}

1) Der geftridelte $\mathfrak{B a n d f i f d . ~ L e ~ L e p t o c e ́ - ~}$ phale Morrisien. Cepéde II. p. 143.pl. 3. fig. 2. Leptocephalus Morrisii. Linn. ed, Gmel. p. 1150. Gronovii Zooph, n, 410. t. 13. f.

3. Morris. Brit. Zool. 3. p. 125.

( $\mathrm{T}$ ab. 28, Fig. 49.)

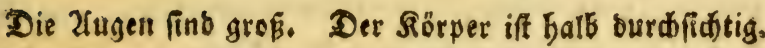
zluf ieber Seite ftehen vier \&inien, weld)e mit paralleten, in 2 Bincteln zुน

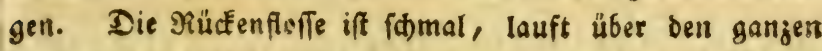

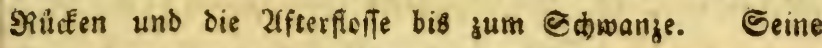

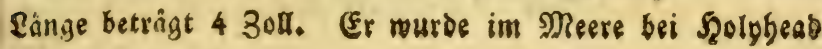
in England gefunden.

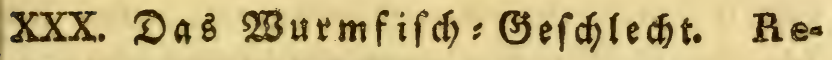
galecus.

Der Sörper if wurmartig mit etwas rauben Striders befegt. Der mit 5-6 Enöd)ernen Blättchen bejegte Siopf

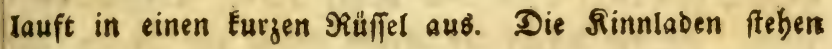
bervor, und baben pfriemenförmige Zăbne. Die ßienens Decét find vielblättrig. Die Riemenbaut if $4-5$ ftrablig ano bie Riemenóffnung bogenförmig. \$Baud = und 2fftera flofien feblen.

3) Der Fafer.æurmfifo. Le Régalec Glesne。 Cepède 1I. p. 215. Regalecus Glesne. Aga canii icon, Jer. natural. fasc, J. 5. Havaiae 1772 fol. 
Ser Tontwer ift filberfartien, an bem binteren Sbeif mif brei braunen Duerbinben begeidnet, ber פiuno runo. auf bem Edeitel find 8 Etrablen, welche faif aleid lang fino,

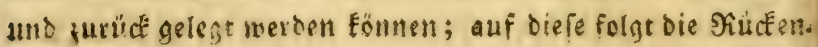
finfle, waide fid mit ier Edmanaffofle verbindet. Sie Bruffisten fine felor Elem, who unter ibnen entftehen bie

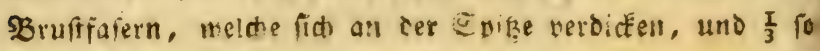
Iang, als ber obruer fino. Sie tanue beträgt $10-12$ 3ิoll. Cie bewubnen die nöblid)en Ig?ere.

XXXI. Das Stielaunenfifd: (5efđ́led)t. Stylephorus.

Der Rörper if lang, riemenförmig, zufammensebrilctét, unb wiro gegen den Edwant immer fimäler. Der kepf geht in eine fannabelformige Schnauze alts, welde mit bem Şintertheil beß Siepfs ourd eine biegfame lederartige Galte verbunben ift, burdh welche bie Edhnaze fo vers längert werben Eamm, baß̄ ber Muno aufwärt's fteft, uno

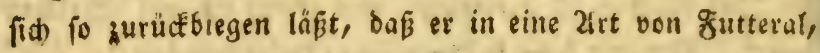
weldes ber obere Sheil vom Ropfe bilbet, aufgenommens wirb. Zin ber Epize bes Ropfs ftehen die Zlugen aus walzenförmigen, Eurzzen, Dicfen, nahe beijammenftebenden Etielen. Zn beiben Seiten unter bern sapfe fẹt ein balbfreisförmiger, nach vorne burd) ben bäutigen Riemens

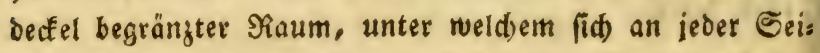
te brei Sgaar fleine Siemen befinden. Die Brufflofien

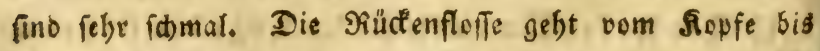

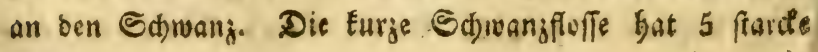
Strablen. 


\section{Dิธกnng, P isces.}

1) Der fabenformige Etielaugenfifa. Le Styléphore argenté. La Cepède v. p. 617. Stylephorus chordatus. Shaw. of the Lin. aean Society. Lond. 1791. I. 90. t. 6.

(Tab, 77. Fig. 108.)

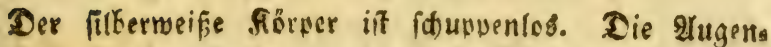
ftiele, die 巨dnnu;e, die Fleffen und ber fehr lange fas Denformige fortfats am Edmange fint beabraun. Iis

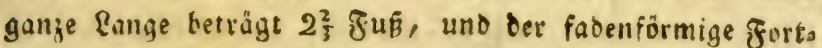

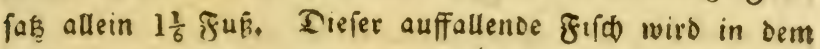
sofitundifchen Mieere gefunden, wo er zwotiden Den Innjeln Cuba uno Martinique aufgefídt nurde. 


\section{III. $D \mathfrak{v} \mathfrak{n}$ u $\mathfrak{n}$ g.}

Sifde mit $\mathfrak{B a u d f l o f f e n}$ an ber Geble yor ben Srufffloffen. Pisces Ju-

$$
\text { gulares. }
$$

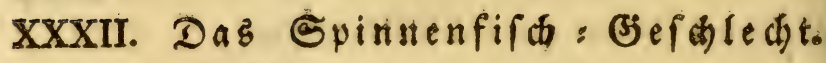
Callionymus. Linn.

Der Sörper if faft Eeilförmig, fohuppenlos. Der Sopf

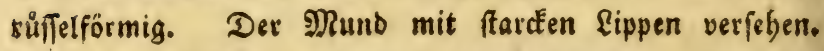
Die Zugen fethen am Sdjeitel nabe beifanmen. Der §ies

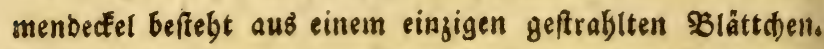
Die Siemenöfnung ift im Beniff, flein unb röbrenförmig. Der Badenfneden endigt fid in einen breifpisigen ges

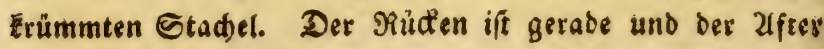
Dem Sopfe näber als bem sauche. Sie haben 8 glefien, wovon 2 an ber Siehle, 2 an ber Bruft unb bem Siücten,

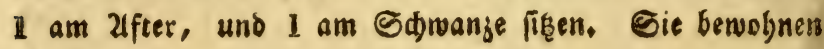
bie Meere.

1) Des grope Spinnenfifक. Der fliegende Spinnenfifd. Le Callyonyme Lyre. Cepède 1I. p. 329. pl. 10. fig. 1. Callion ymus Lyra.

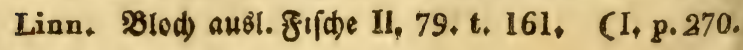
8. 161.)

( $\left.\mathrm{Tab}, 29, \mathrm{Fig} .50,5 \mathrm{l}_{\mathrm{p}}\right)$ 
(E) unteriabeibet fid) von bem vorfbergebenden burd) 4

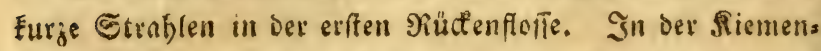
baut find 6 , in ber 3 iruffloffe 19 , in der \$aubfioffe 6 , in Der 2lfterficfle 9 , in oet Stbwaniferfe 10, in ber erften Rüctenfiffe 4, uno in Der jweiten 9 Strahler. Sepf uri

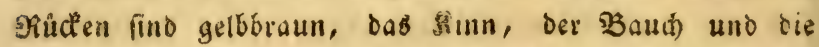
Seiten filberfarben. Sängs bem Mücten ftebt eine Furche. 3wifden bem Repfe und der erffen Riüfenflefie fiebt man vier fleine D̈ffnungen, Davon bie zwei vorbern im গxBind: Des Riementectelo uno bie jwei bintern beim anfang Der

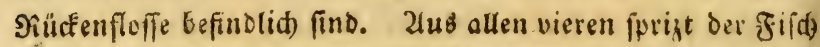

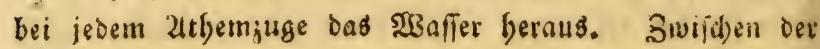
Faum fithtbaren Geitenlinie und bem 3 aud be fteft ein gels Eer, geidlungelter Streifen. Die Farben fino bei thm und ber vorbergebenden 2frt unbeftänoig. Sruits und lifterfl.ie fino grünlid)t, bie 3 aud)fofolle gelb mit grünen Strablel.

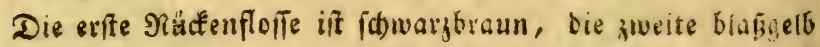
mit bundelgetben uno bie runde $\subseteq$ d)wanjfeffe mit grüniels ben und braunen Streifen beriegen. Die Etrablen in ber

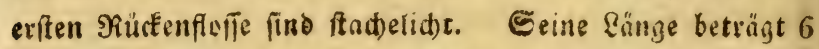

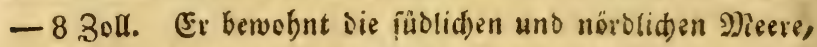

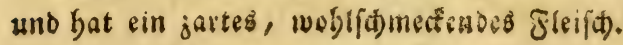

\section{Das Sternieber: Siefdedt.} Uranoscopus. Linn.

Simerbalb bem Munbe am linterfiefer figt eine Bartfas fer. Der Supf ift niebergebrüft, grej und roub. Die alugen ftebn ain Sdbeitel bid)t beifammen. Det fliemens beckel endigt fid) in einen ftarufen Etad)er. Die Siemen= offnung if weit. Die Riemenbaut bat fünf Strablen. Der länglidte, geiduppte Siöper if mit 8 glcffen werfeben, woo 
yon 2 an ber Réle, eben fo vier an Der Bruft und dem Pitufen, 1 obnwett dem 2lfter, und 1 am Edjwanje fïgen. Der 2 ffter if mitten am $\mathfrak{B}_{a}$ at.

1) Der raube Sternieher. L'Uranoscope rat. Cepéde II, p. 347, pl, 11. fig. 1. Uranoscopus scaber. Linn, S. N. - Bloch, aแต๋t. Fíf dife p. 90. tab, 163. (II, 5. tab, 163.)

( $\mathrm{T} \mathrm{ab}, 30$. Fig, 52,53,)

Der Sopf ift grof́, vierEantig, mit vielen Eleinen, raßs=

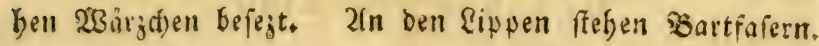
Der Shund sffinet fid nad) obert. Die zlugen feben am Ed)eiter, neben einander, ragen berwor, uno baben einen [dwargen Stem in einem gelben Эinge. Swifhen den Xus

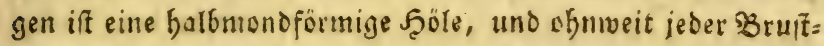

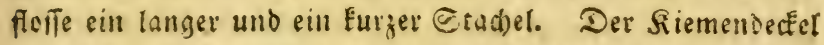

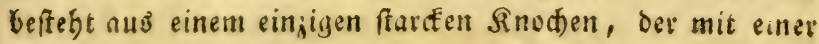
breiten, gegähnelten Şaut umgeben ift, unb bie verborgene Riemenbaut if tnit fünf gefrümmten Snoden verjegen. Der Siumpf ift mit fefre Eleinen S(t)uppen bejejt, und bis an

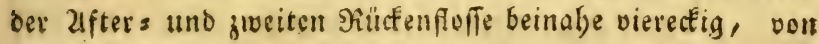

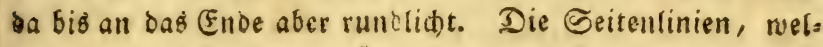
de aus Eleinen runden D̈ர̄nungen beftehen, nebmen am

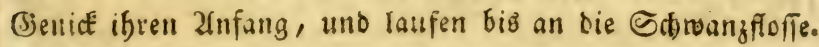
Der Piúcken ift braun, an den Seiten grau, der Banud

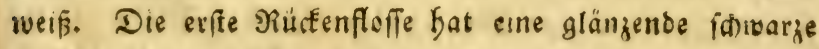
Jarbe unb Enöberne Strablen. Die Strahlen in ben übris gen flofien find weich und von gelber Farbe. In ber Kie. menbaut find 5, in ber פBrufflefie 17, in Der Baud)ferfe 6, in ber 2rfterfloffe 13, in Der Edwangfoffe 12, in bes erften Rüffenfleffe 4, unb in ber zmeiten 14 Strablen, 


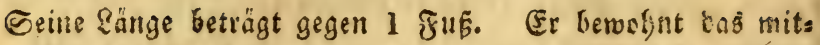

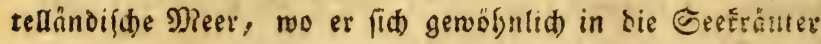
varbirgt, und die kleinen Fifde Dur(b) feine Bartfafern an=

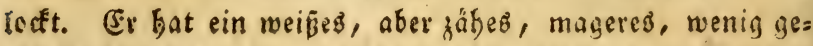
achtetes fleifa. Weil bie 2lugen Fig. 53, bei bieiem fiide ganz gerate in die Soobe geridset fino: To baben ifu

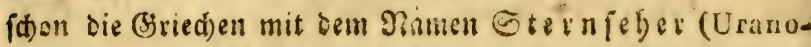
scopus ) belegt.

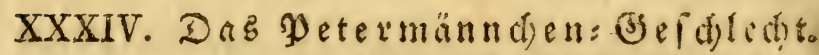
Trachinas. Linn.

Der Sörper ift lang geftrent, auf beiden Seiten ffarce

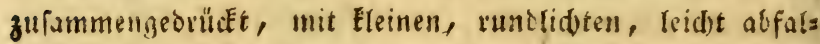
lenden Gduppen befezit. Der Siopf ift Elein, jujamments gedrückt, uno mit Snoten uno Stad)eln befezt, ber Nacken auf beiben Seiten gefügt. Die Simnlaben fins ungleia, und baben fpiz̨ige zurüfgebogene 3ăfne. Die Siemens Decfel fino oreiblättrig, uno ain untern slatte gefägt. Die

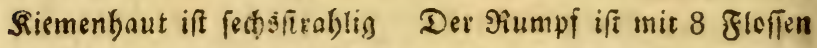
verfeben, wovon am SRüfen, an ber Bruft, uno bem Bautbe 2, uno ain 2after uno Sdfwanze 1 befindlid find.

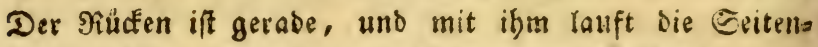
linie parallel. Der after feft nabe all Der Brutt.

1) Das Эुetermånnden. La Trachine vive. Cepède 1i. p. 354. pl. 11. fig. 2. Trachinus

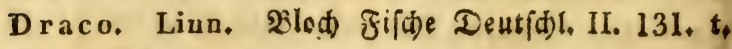
61. (II, 178. t. 61.)

( $\mathrm{T}$ a b. 31. Fig. 54.)

Der Unterfiefer ftebt bervor, und in ber erften গRúcfens floffe fino 5 Strablen. Sn der Siemenbaut riegen 6 , in 
Ber Bruffifolfe 15, in ber Bautfloffe 6 , in ber afterficfie 25, in ber Sd)wanffleffe 15, und in ber zweiten Mirfent flole 24 Strabien. Der Muno if weit, unb bie untere Sinnlade bat eine Siid)tung oon unten nad) cber. Die

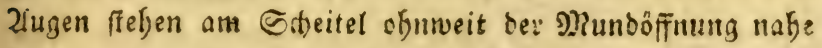
beifammen. Der Zlugenfern iff ifjwar stit getbem unb

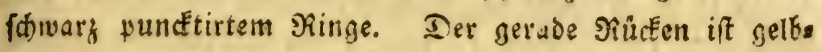
brami, bie Eeiten unter ber Sinie uno ber Sbauch filbe?: farben mit idjiefen brăunlidten Sinien begeid)net. Die ers

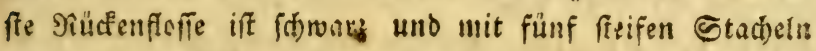

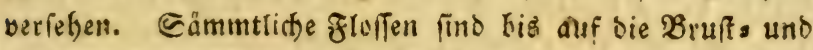

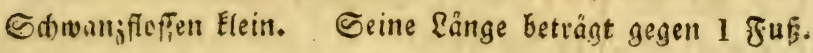

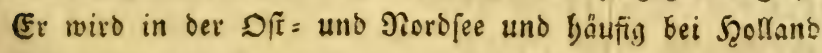
uno Deffriérlano, aud) in mittellândifd)en und andern Meesell angetroffen, wo er im Sumi jur Eaidjeit an bie flad)en Eteden fommat. Eein Fleija) if geidiăst. Da Diefe rifide leicht mit ibren Siurfenfuffen = Stad)eln vers wunden Eönnen, die für giftig seffalten nurben: fo if es

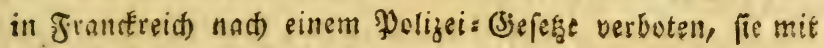
Den Etad)eln zul verEaufer.

\section{Das Swelfifd: Gefdedt. Ga. dus. Linn.}

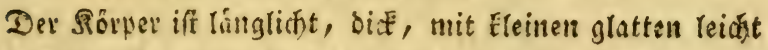
abfallenten Ëduppen beserti, unb auf beiben Eeiten et:

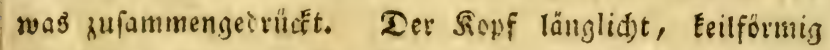
mit breiter Ctim. Die Wunoffnnung if weit, und brite

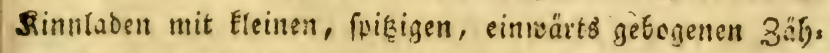
nen bejegt, unt bie untere bei einigen mit Bartfafern ver= fehen. Die 3unge breit uno glatt, ber Gaumen von Eleis

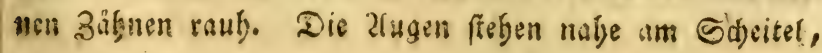


find gró́ und mit einer Nickgaut bedectit. Die Siemen: offinung if gres. Der Siemendecfer ebenfalls gros, und aus iree Blätthen iufammengefezt, Daoen bas unterfte mit eincr Saut eingefajit ift. Die Riemenbaut if fark und

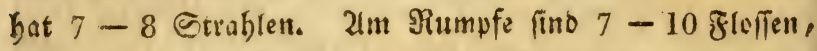
bavon 2 an ser 33ruif, 2 an ber Sehle und binter Dem affer, 1 am chwallie, uno 3 am Rüten fißzen. Die

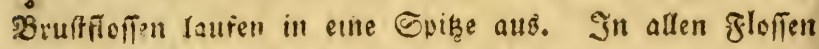
fino ore Srrublen weid). Der after ffeht beinabe in ber

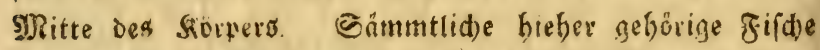
fino, bis alf Die Suavpe, Bewofner ber Neere und ges ben nidht lesde in ore flüffe. (Fs find bereits über 20 verfóledene atren betannt.

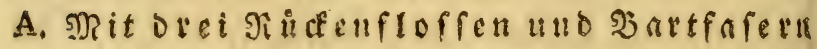
an $\mathfrak{R}$ unDe.

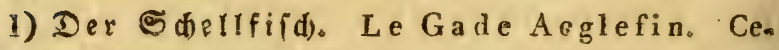
pède 11. p. 397. Gadus Aeglefinus, Linn. SBloch Fifd)e Deutid) II. 138. t. 62. (II. 188. 62.)

(Ta b. 32, Fig. 55.)

Ifm Simn fteht nur eine einzige Bartfafer, und bie Seitenlinie if fdwary. In ber Siemenhaut fino 7 , in

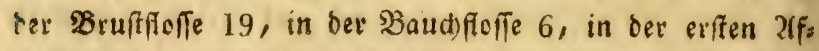
terfloffe 22 , in ber zweiten 21 , in ber Sdwanifloffe 27, in ber erften SRüfenfloffe 16, in ber gweiten 20 und in ber britten 19 Strablen. Der Sopf ift Eeilförmig, die obere Sinnlade länger als bie untere. Die 2tugen find greß̈, baben einen fowaizen Sten in cinem filberfarbigen Sing. Der Sillten ift weniz gefogen, bräunlid)t, ditf. Die Seis 
ten unb ber biffe Şaud) fint fitberfarten, unb bie Seiten.

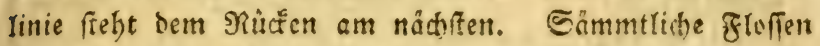

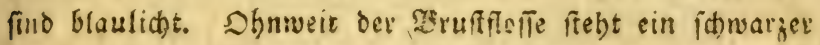

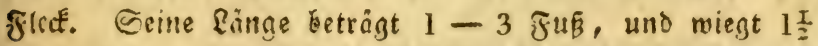

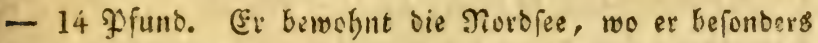
im Saerbft in groferer Menge gefangen wirb. Man fincet ifn aud) um Şotland, Diffrieglant und im Sanal, am bäufigften aber um England, wo er in ganzen Sd)aaren! erideint, und gevöbntid) eine Shiffe nad) ber antern bes fuchet. Sic erfheinen offers in fo greser Menge, baß brei sifither in einem Miaum von einer englifhen Mreile zwe mat bes Sages ibre Böte bamit anfüllen. Sie fint sakger

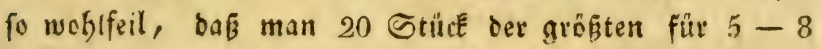

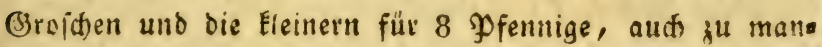
wer Zeit für bie Saâlfte biefés Preifes einEaufen Eann. Die gröpten fieft man gewölntion vem Noveenber bis in Sanuat. Som Januar bis in Mlai Eummen die Elcinem

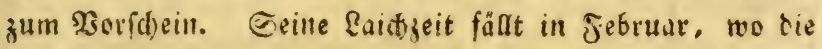
צrBeibden in ganzen Sdharen ifren Raidy an Seeftäutern abfergen, werauf fid) bie Månnden eingeln einfinten, und die Eier befrudten. Shre Talgrung befteft in Geenuirs

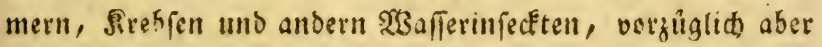
in Sheringen, von welden fie Den Sommer hinourd) Fehs

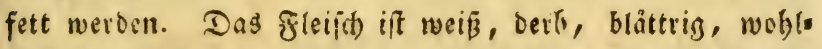
fd)mecfento und leid)t zu verdausen. (Er wirb vorgüglich mit Birunoidgnủren gefangent. Diz Broôntänder greifen lie mit

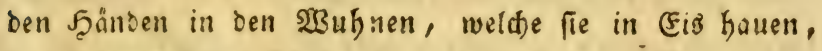
wojelbit bie Fifdue fid baufentweife einfinden. "Sie werden

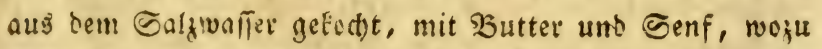

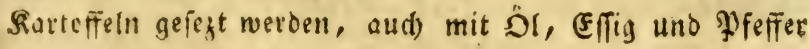
oose mit einer zufternbrûlye verfpeifet. 
2) Der Dorfti. Le Gade Callarias. Cepéte. II. p. 409. Gadus Callarias. Linn. Bloct)

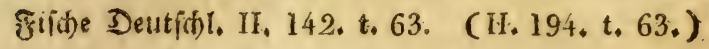

Die Geitenlinie if breit, se ogen uno geflect. Sn bes

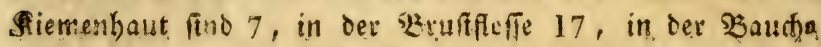

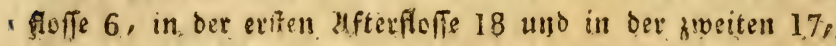

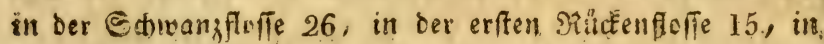
ser jweiten 16 uno in sav oritten 18 Straflen. Der fopf ift grau, hraun ober fobmargheflect. Die sbere Sinnlabe

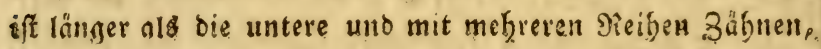
bie untera aber, an meldher eine Bartfajer befindic), nut. mit einer Sreibe 3âbne verieben. Die Zugen fints runb,

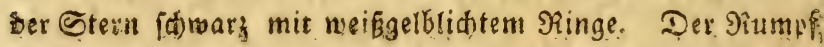
ifit grau, bis an ben Bauth braun çer tôtb́lid)t geffecft. Der ßauch dick, weif uno broun gejprengt, bei einigens.

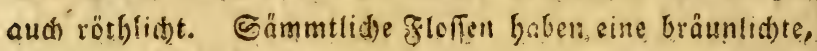

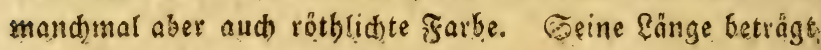
1-4 Juf. Er findet fít) im baltifden Meere und in ber Solfee, und Eommt fo weit in die Jtüfe alg felbige nech

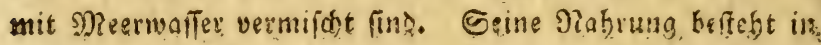
Fifden, Snfedien uno $2 B u r m e n$. (5r wirb in Buthen an

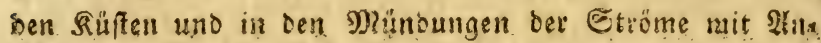
gelid)nüren undo Neģen sefangen. Seine Raicbzeit fälrt in.

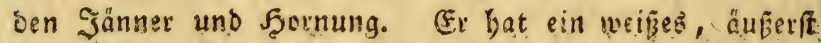

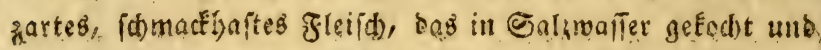
mit Şenf und brauner Şutter, qud) mit Effig, Sitronens. făture, Saumér und SPfeffer, oder gebraten verfpeiñt wirb.

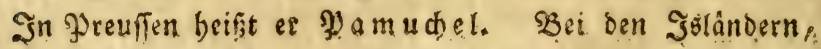
Die ifn einfalgen und trodfnen, sittel ing.

3) Der Rabelicu. Der Stockfifd. Der \&aba berball, Der zold. Der Rrippfifd. Le 
III. Siftutng. Pisces.

Gade Morue. Cepéde II p. 369. Gadus M or-

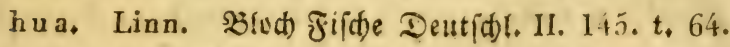
(III. 199. t. 64.)

( $\mathrm{Tab}, 33$, Fig. 56.)

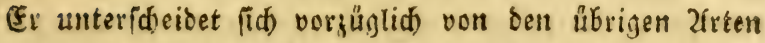
Burd die groffern Sduppen. In Der Riementaut find 7 , in ber Brufffoffe 16, in ber Bauchfoffe 6, in ber erfen Zifterfurfe 17, in ber zweiten 16, in ber Sdiwanzforfe 30 , in ber erften 9iủutenfoffe 15, in ber zroeiten 19 und in ber Dritten 21 Strablen. Der Sapf, Rüken uno dic Seiten find grau und mit gelblidten Flecken befprengt, bei now) jungen Fifichen biefer Zrt, wenn fie fid auf Ferfengruno

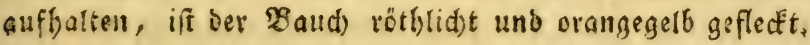
Iie Minnobffung ift gref, bie obere Rinnlabe hervorfes

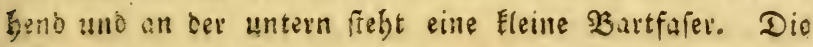
Zlugen baben forwarje Sterne in einem getflid)en Singe

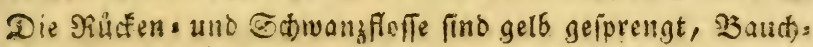

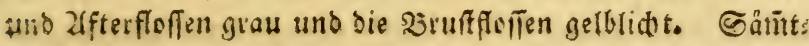
tide Strahlen find meid). Der 2 ffer fiţet dem Ropfe ná= Ger als dem @ifivanje. Seine Länge betrảgt $2-3-5$

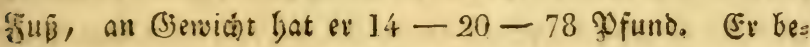

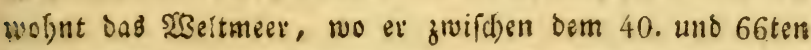

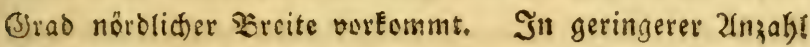

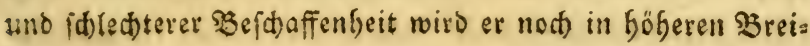

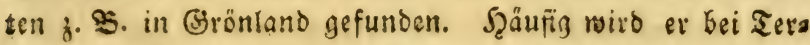
reneuve, Capreton, Neujdottlano, Neuenglano, an ben

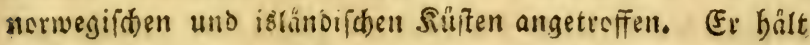
fí) gewốfnlid) in ben Siefen bes hohen Meeres auf, uno fornmt zur \&aidgeit, welde in Englano vom Satmer bis.

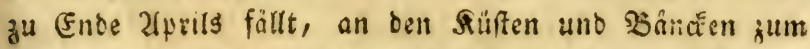

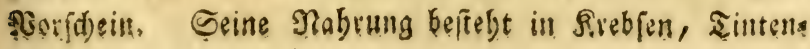


firden, ferinnen turb andern Fifhen. Fr vertauet n̈uferfe fanerl, uno entlediat fid) ber unverbaulidien Dinge ourd)s

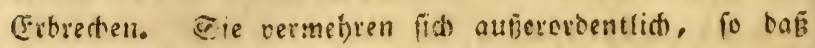
Q e u venbỏck in einem mittelmäfigen Siabeljau 9,34.4000 Eyer zăhlte. Cie marian eimen fehr beträdtliden unb ein. trág!ıdien bjeasmiano der greỉen frifdereien aus. 3u bies fen Frfiserren Eammen die Süutentenohner mit Böten, tie andern Matisnen aber, wie die Marmảnner, Sänen, (E) veren, Sgutander, frlangejell, Englünter, u. a. in Sohiffen von $60-120$ Tomen. Lluper ben norbiothen (j) genden tuberbaupt, wobin bieje Sationen Sobiffe fenten,

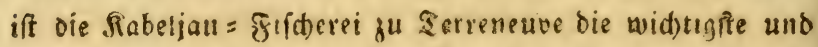

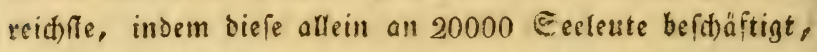
uno in Dem Sahr 1763 Den nordamerifaniichen Rolenien aII 4,928250 গithlr. eintug. Sie werien mit zingelionul= rell oder Eted)nezen gefangen, und zwat mit ienen nath ber Ratdjeit, indem fie wâfrento biejer auf Elinen ßöber fallen. Die Sdnüre finb entrweber (3iund = cier eigentli.

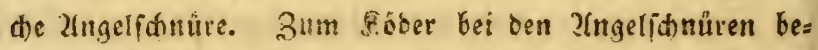
rient man fich ber Seringe und anberer Fifde, bes verbor= berren f̧leifhes auf ben Schiffen, Der Muicheln uno Rrebje, und da fie gerne auf gin̆nzente Dinge fallen, bängt man

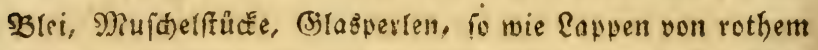
Sudie an. Sie merden in ben Geeftioten an ben Rüften frifd gefpeift. Die größte Nienge wiro aber ourd befons bere 3ubereitungen für ben Sandel zugeridtet. SRan bflegt fie, nacherm ifnen bie föpfe abgebauen, uno bie Fin= geweide berausgenommen werden, zut trecknen, it weldem 3uftande fie Sto df fif he, (Morue en hreton) oder eins zufa!qen, wo fie Eabberbane, $\mathfrak{B}$ old (Morue frais)

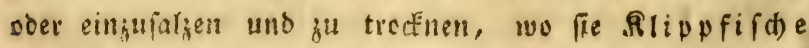
(Morue seche) genent werden. Die Söpfe, weldbe bei 
jenen B̉ereitungen übrig bleiben, werben von den Sătån,

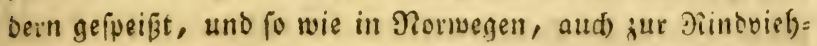
Fistterung verwendet. Die Reber wirb z̆u Thran benuzht.

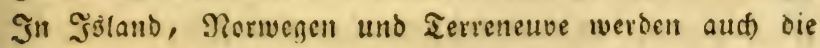
Ed)wimmblafent diefer Jifde als Şaufenbla fe benuzt. Die Sabeliau. Sungen werben gill Serreneuve als eine ver-

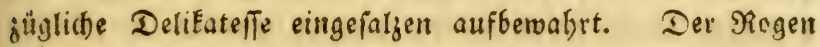
wirb in Norwegen eingefalzen, unb in Eleinen Fäfifern an bie Sollänber, ₹ranzofen unt Spanier, als Föber zum Sarbellen, und andern giffffange verkauft.

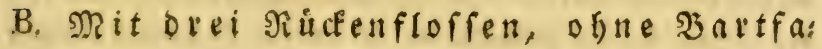 fern am Munde.}

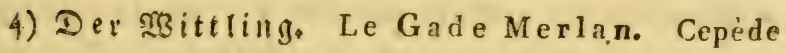
11. p. 424. Gadus Merlanchus. Linn. Slod Silithe Dentfol. II. 161. t. 65. (II. p. 221, t. 65.)

Der Dberfiefer ift Gerverftegent, Der UnterEiefer ofne Sourtfafer, Der אơrper filberfarben. In ber Riemenfaut

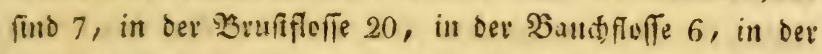
erffen afferflente 30 , in ber giveiten 20 , in Der Edwwall

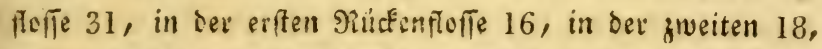
uno in ber britten 19 Strablen. (F) bat einen geftreffen, mit Eleinell, runten, bünnen, filberfarbigen $\left.\mathcal{S}_{d}\right)$ uppen $b_{e}=$ Dectren Sö̈rper. Der Repf lauft in eine Spiz̧e aus. Die Zlugen fino runo und baben einen groben fotwargen Stern in einem filberfarbigen ßinge. Die obere Kinntade if mit mefreren Sieilgen Bübnen befejt, bavon bie vorbern bie längften jint, und die untere nur mit einer Reithe verjeffen.

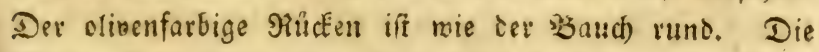
Geiten find ein menig zufammengedrủft, unb ber affer feeft dem Sippfe năber ald bem Sdrwange. Die Seitens 


\section{I40 Tierte Elaffe Fifhe.}

linie if gerabe. Beim Znfange der Sruffeffen ffeht eing

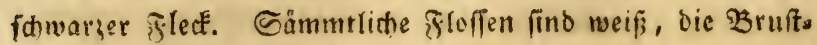
uno Schwanflofie ausnenommen, weld)e eine fdowanglidje

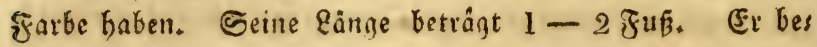
robnt bie oft und Siorblee, unb ift voriuglid) biufig an

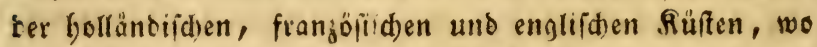
er fid) im (3runde bes Meeres aufbält und fich von Eleinen Sirbjen, 2̧urmern uno jungen Fifhen näbrt. Eie werden mit ber (Srunofonur gefangen. Der ftäcfite Sang geid)iebt an bell franjöfifit)en Sühen vom Dezember bis in Februar, alt ben bollándifanen aber in ben Sommermonaten. In ben brittichen Süfell eridheint er in gangen Eshaacell, bie 3 englifde Meilen rang uno $1 \frac{1}{2}$ breit find. Sn ber Beit, wo er bell Sceringen nact)gebt uno fiă) von jungen Jaeringen märtet, iff er am fettefren uno idmactbafteftell. Dlan ipei= fet ifn aus dem Salzwaffer getod)t, entweder wie ben Sdells firib ober mit einer fogenanntent weiß̄en Brübe, weld)e aus Eafur, frifither Butter, etwas Miebl uno Muśatenblumen gubereitet wiro, aud) wito er bäufig gebraten. Er wirb aud) getrocfinet, widurch er aber vieles an (3) zichmack vers liert, unb baber alob Schiffóplt gebraucht wirb.

5) Dex Söhler. Der Seblmund. Gadus car. bonarius. Linn. B(cd) Fild)e Deut(d)t. II. 164a t. 66. (11. 226. t. 66.)

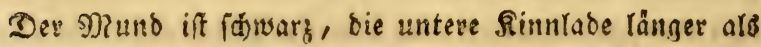
bie obcre. Die Eeitentinie ift geraic und weiß. In des Siemenbaut find 7, in ber 23 rufffoffe 21 , in ber $23 a u d$ ) fiffe 6 , in ber erfiten 2 fterfleffe 25 , in ber zweiten 20 , in

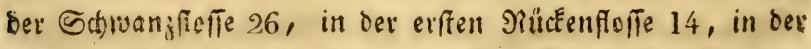
froiten 19, uno in bet oritten 20 Stroblen. Der Riemen; 


\section{Droung. Pisces.}

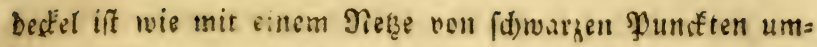

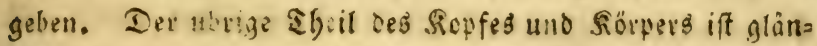

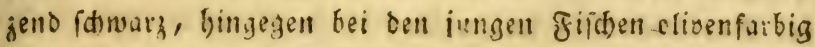
ober bräuntıdt. Der alugenring if meis und auf iecer

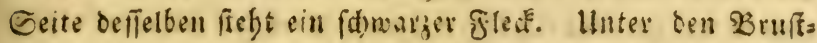

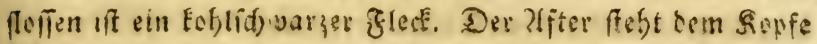

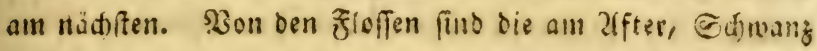

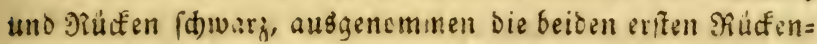
fleilen, welde, fo wie bie Brufffoffen, am Brumbe olivens

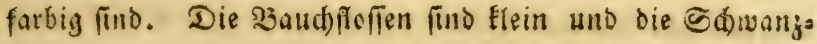

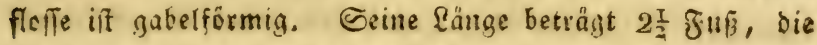

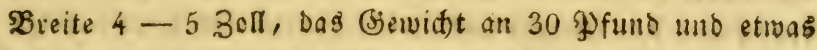

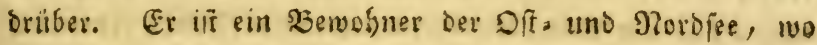

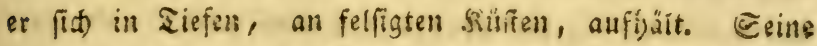

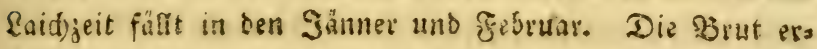

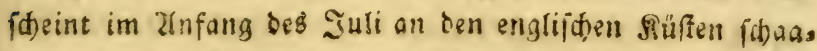
venweife, uno bat alsoamn bie länge bon $1 \frac{1}{2} 30$ h, im 2 rus galut aber von 3 3ull uno brüber. Sie werben in biefer Zeit mit ber angefrulte, unb wenn fie on fladje Stellen geras t)en, aud) mit einem feinen Neb̧e in greferer Menge gefons

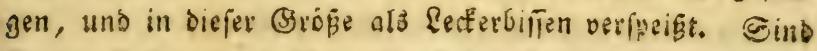

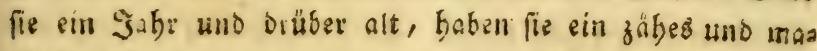
geres Fleifit, uns geben eime Speife für Den gemsinas Mann, werden aud), weil fie frifh nid)t geju(t) merben, wiz der אabeljau zu Stueffifa) und Rabberban zubereitet,

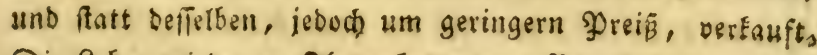
Die Seber wirb zum Ifran brennen aufbewabrt.

\section{Nit z'}

6) Der leng. Le Gade Molve. Cepède it. po

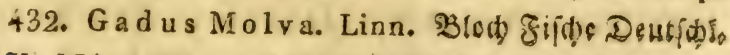
II, 174. 5. 69, (UI, 24l, t. 69.) 


\section{I42 Wierte Elaffe. Fifde.}

Der DberEiefer ift Gervorftebend, und auf bem Sillten fteben nur zwei floffen. In ber Riemenbaut fino 7, in

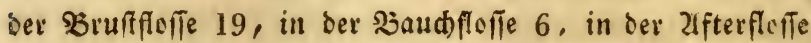

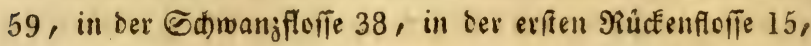
uno in ber zweiten 63 Straflen. Er ift Der famälefte uno

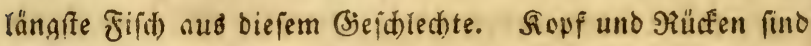
braun. Die longlidten 2fugen haben einen fdwwargen Stem in einem weißßen SRinge, in weld)em ein gelbgrüner flect ftebt. Der Mitmpf iff fdmal, lang und rund, an Den Gei= ten getblid)t unb am Băache fdmukgig weißß. Die Seitens

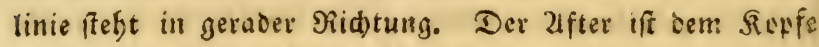
etwas näber. Bruft = unb Siücenflotien fino graujabarz, leztere find am Ende mit einem fá)warzen flect bejeichnet, ben man auch an ber grauen 2literflofie fieht, unb biefe

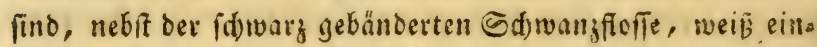
gefaît. Seine fänge beträgt $4-7$ Juß. Er bewobnt Den nörblichen Dcean und befonbers die Nerdfee, wo e?

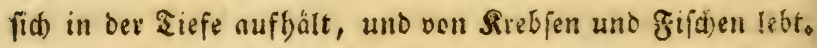
Seine Raidjjeit fălt in Juni, wo er feine Evyer an bie Sิce= kräuter ablegt. (Ex bat ein febl woblfidmectendes gleifd), befonders vom Februal bis in 9)ai, zu weldber Beit er bem Sabeljau vorgezogen wirb. (Er if nad) Dem F̧ering und Rabeliau wegen feiner grofien Menge für bie Şandiung mebreres Nationen am widtigften, witb wie der Rabeliau zu \&abberdan und Slippfiid) bereitet, uno if auf weiten Geereifen bauerbafter, als ber vom Sabeliau. 2lus ben

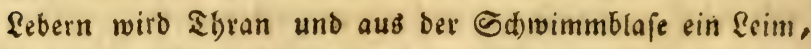
welder ber Saujenblafe Habe fommt, bereitet. Sie werben mit Sirunofdnüren gefangen.

† 7) Die Suappe. 2ialquappe. Truf́e. Oiuf folfe, Le Gade Lote. Cepède II. p. 435. 
Gadus Lota, Linn, Bbled firitie Deutfdr. II. 177. t. 70. (II. 246. to 70.) v. Meidinger, Pisc. Austr, tab. 8.

$$
\text { (Tab. 34. Pig. 57.) }
$$

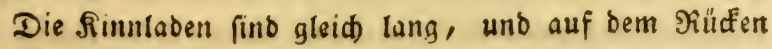
fiteben 2 Jielfen. In der Sitemenbaut find 7, in Der

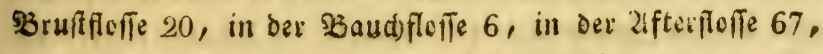

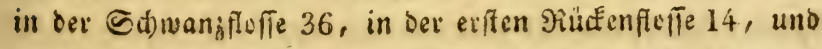
in oer żmeiten 68 Strablen. Der Seopf if gref́, breit und nac) unten zuศammengeorüuft. Die Munbéfinnung groß̂.

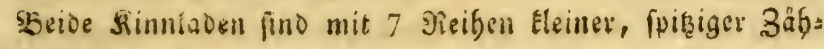
ne befegt. Die untere Stinntade ift mit $1-2$ Dartfajern befejt. Die fleinen alugen fteben auf der Seite uno babun sinen blaulid)ten Gtern in einem gelben গiinge. Die Sie=

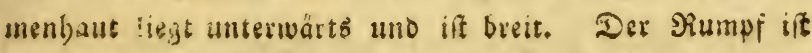

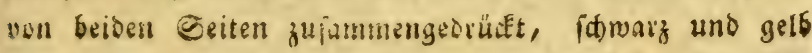
marmorirt, oder braun mit blap̧zelfen flecten, mit einem Sd) leim úberzagen, mo init Eleinen, weithen und bünnen Sdjuppen beirutt. Die Geitenlinie if gerade, Der Baud

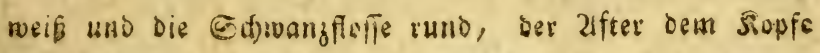

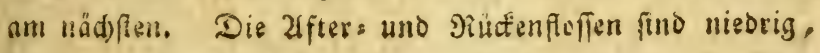
lanty uno eben fo wie der übrige Görper marmorirt Sore

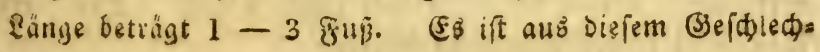

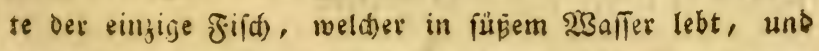
grwar fowobl in glúffen als Sanofeeen. (E) ift nidft nus

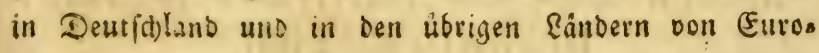
pa, fondern aud) in Difindien anjutreffen, (ieft vorjüglid reines $23 a$ jer, uno verfecát fiich in ben tiefen steillen unter Die Şöblungen ber Steine oder in (Bruben, und lauert auf

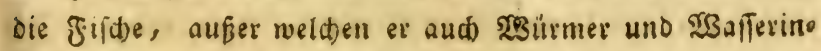

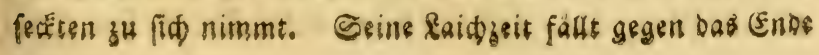




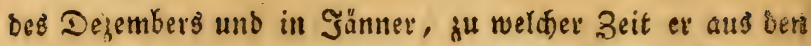
tiefell Etellen ber Geepll an bie flachen Drten in bett Flup fen fid) begiebt. . (5x vermebrt fid) febr ftarcf, bat ein weis

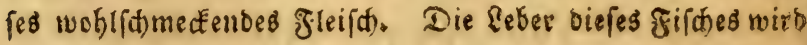
fur ein gan; vorzüglither Eecferbiflen gebalten. Diefelbe its pin Bras nebangen und auf ben warmen Dfen ober in bie Sonne geftellt, giebt ein S̈r, weld)e von ben älteften bis auf unjere Beiten als ein würtames Mittel wieber bis Flerten der Sornbaut gebalten wurbe.

D. Sit eingelter Siufenflofle.

8) Der Iorǵ二. Le Blennie Torsk. Cepéde If, p. 508. Le Torsk. Bonnaterre 51. n. 25. pl 87. f. 362. Gadus Torsk. Pennant. brit.Zool, III. 203. n. 89 .

Der Sörper ift braun, an ben Seiten getblicbt, unters

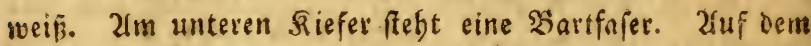

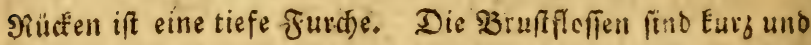

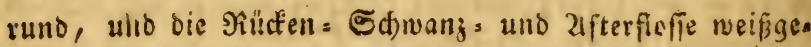

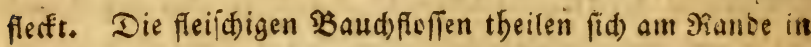
vier Rappen. - Die Siemenbaut bat 5, Die Bruft?olfe 8, S3auchflufe 1, Die Rükenfleffe 31 und bie afterfluffe 21 Strablen. Seine fänge beträgt gegen 2 f̈ü. Der $2 u$ f entbalt ift in ben mordidfen Meeren.

- XXXVI. Daz ઉdleimfifd: (Jefdrledt. Blennius. Linn.

In Den Baudfofifen felten suei cinfache Strablen. Dev Sopf ift Elein, glatt, zufammengedrüct t, unb bei vers fdiedenen mit Eammartigen Satvorragungen befegt. Die

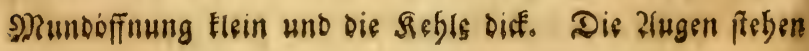


ant Scheitel, ragen bervor, uno fint mit einer Nickfaut bebecfit. Die Riemenberfel find bič, und befteben aus 2 פIlättchen, Die Sitemenbaut liegt frei, unb bat $4-$ ?

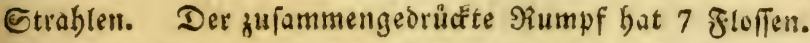

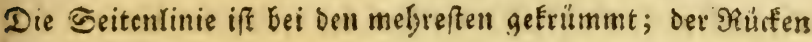
gerabe, und nur mit einer langen gloffe beję̧t. Die Bruft= forfen fino runolid)t; bie 2ffterforfe if niebrig und lang, unb bie am Sdimanze rundlicht. Der 2 fter fteft beinafe in ber Mitte des Körpers. Sie finb, bis auf einige wes nige, Meerbewobner, bie von ber $\mathfrak{B r u t}$ anberer Fifite,

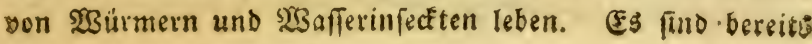
gegen 20 veribiedene Zrten befaunt.

A. Nit einem Ramme a lf bem Sopfe

1) Der Meerpanillon. Blentius ocellatis, sBlod) ausit. ₹ifite II, 112, t, 167. f, 1. (II. 31, t. 167. f, 1.)

\section{(Tab. 35. Fig. 58.)}

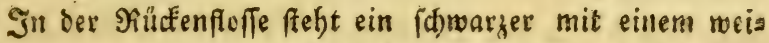

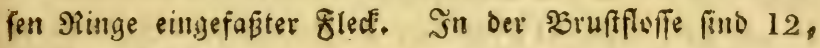

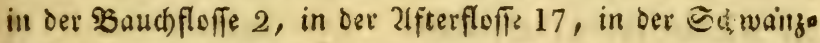
forfe 11 und in ber 9iüfenfloffe 25 Strablen. Der kopf

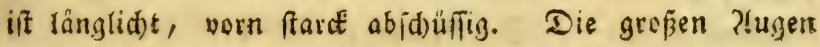
freben weit bervar, und baben einen fownargen Stern in

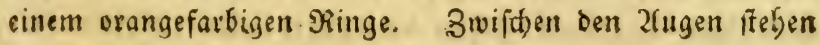
2 einfacte lange Strablen. Beibe Rinnladen fint von gleis

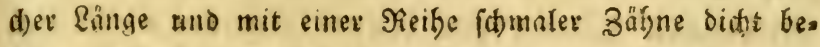
fegt. Der Siemendectel befteht aus einem einfachen Silâtts

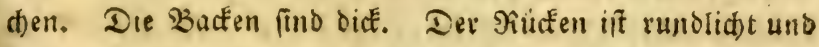
blautid)t. Der 9iumpf it fduppentos, Der Baud) Eurz uno berit. Der after bem Ropfe náber als bern Edwanze. 


\section{I46 Bierte Erafie. Fifde.}

Die Geitenlinie obnweit bem Siücte. Der Sióner if fd)musig grün oder bellblau mit olivenfarbigen Streifen. Die Brufffleffe ift grof3, runb, und bat, fo wie bie Gitmang. fleffe gabelförmige (Strahlen. Die Baudflofle ift zrueifrab: lidht. Die sîucfentloffe v!ivenfarbig mit blauen Flecten uno Sounften beiprengt, vorn uno binten hod) und in ier MJitte nietrig, Der erfe Etrabl berfe!ben iff fétr lang. Ecine

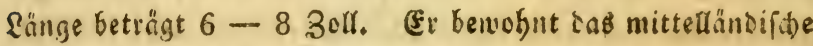
Meer, bält fich ain $\mathfrak{l}$ fer zwiftien ben filippen und Cees pflanzen auf, uno lebt von. Sirebs. und Mifdhelbrut, bat cill mageres, menig geactetes fleifक.

2) Der Meerfirfd. Der Diffbalt. Le Blem nie Gattorugine. Cepède II. p. 168. Blennius $\mathrm{G}$ att orugine. Linn. SBlod) autl. Fija) II. 115. t. 167, f. 2. (Il, 34. t, 167, f, 2.)

Zwifhen ben 2lugen und im (5) Ganbförmige, Eleine, vielzweigige Fafern. In ber תiement

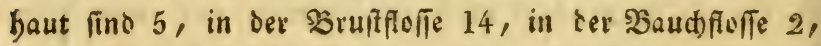
in Der afterfloffe 21, in Der Sdbwanfitife 12, und in Der アRücfenfloffe 31 Etrablen. Die 2lugen fieben fard berwor, baben einell făwarzen mit einem rötbidten Singe umgebenen Stern. Die Sinnlaben fino von gleid)er Rănge

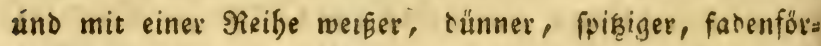
miger uno bienjamer 3äbne bewaffnet. Die Bactin find Dicf. Der siumpi if auf beiben Eeiten zufammengebrüft, mit braunen Gtrelfen uno Dunçleren flecten marmorit.

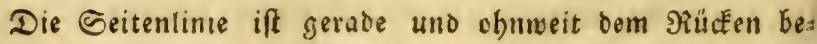
findlid). Der Sauch if Eurj, grau, uno Der 2lfter nid)t weit yon rem Siopfe entfernt. Gámmtlide Floffen fino gelblidt und baten einfodue Strablen. Die Siütenforfe 


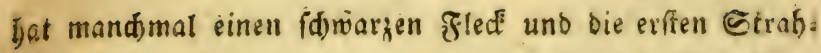
Ien berfelben find fachelictht, bie leztern aber fehr lang. Die Garben bei biefem gifale andern fehr a 5 , Denn man findet welde, beren Flecte olivenfarbig unb blau eingefaf́t fint. Seine Sänge beträgt $6-8$ Zoll. Er: berobnt bas

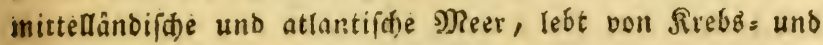

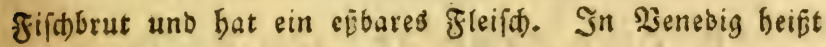
er Gattorugine. Er variirt: Mitt blos bandförmigen Fas Fern über ben 2lugen; 'Mit 3 Faferth thber irbem 2fuge, unb 6 auf jeber Seite Des Echeitels; Mit 4 gezühntens

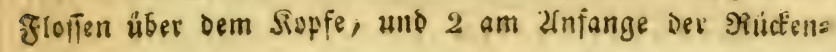
folie:

3) Der 2ugenwimper. Le Blennie sourcila leux. Cepéde II. p. 470 Blennius super-

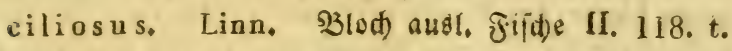
168. (II, 38, t, 168 )

2fn jebem 2lugengliebe ftebt eine Eleine berabbängentoe, an ber Spişe breipaltige gaper. Die Seitenitinie ift in einen Sogen getrummt. In ber Siemenbaut find 6, in ber Brufffoffe 14, in ber Buแdffefie 2 , in ber 2lfterfiolie

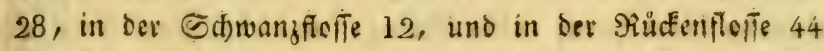
Strablen. Der Sioiper ift langgeffrectit, etrans jufammen= gebrücft, Eleinf(d)uppig, gelblidit uno fatön reth geffect. Der Sopf ift Elein, dick uni faluppenlos. Die grobien 2tugen baben einen fdwargen Gtern in einem fllberfardis

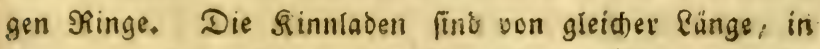
ber oberen findet fid eine Reibe größ̄erer nuseinander ftes benter uno binter berfelben viele Siciben Eleiner, fpişiger 3ấbne. Der after liegt bern Mande naber als bem Edwange, Die Strablen in ser Siütenfoffe find bis auf 
Die 5 Iesten frad)elid. Die erfte Millefenfloffe wirb an bes

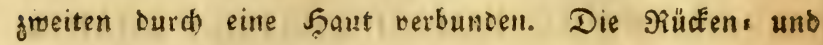
2lfterfleffe find mit rotben flecten geziert. Seine fänge Beträgr 5-7 3ิoll. Err miro in Snoien angetreffen, nåbrt.

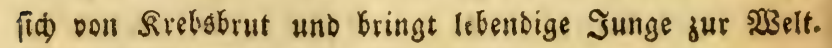

B. Dhne samm auf bem Ropfe.

4) Die Mierlerde. Der Gs rundels Shleima fifh. Le Blennie Pholis. Cepéde II. p 489. Blennius Pholis. Linn. SB(od) Fijche Dertid)l. II. $184 . t$. 71, f, 2. (II. $255, t, 71, f, 2$ )

Die Naienlöber find röbrenförmig und gezact. Dis -bere Rinnlade if länger als die untere. Die Seitenlinie mad)t binter ben 3 rufffloffen eine Beugung. Sn ber אiea

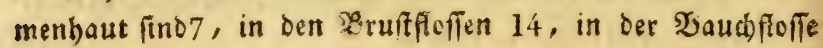
2 , in ber afterfoffe 19, in ber Sabwanjfleffe 10, uns is

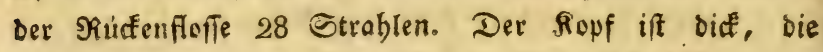

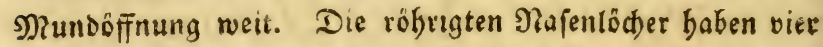
- Gaiern, bie grofien I

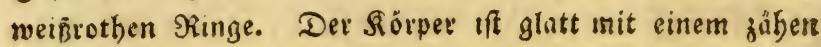

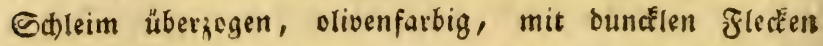
marmorirt, bet einigen mit blauen Sinien bezeidnet. Die lange Rưtenfloffe ift in ber Mritte gleidffam geibeilt. Såintlid)e Strablen find fefr bič und ftark. Şbre Sånge beträgt $6-7$ 3oll. Sie bewohnt bie Norbfee und bns mittellänoifde ख)eer, wo fie fich am Ufer und in ben Miüra Dungen der Flüffe zwilden den Steinen und dem Eeegraje aufbät, näbrt fid von ber Brut bet fifche unb firebfe, uno bat wie alle Sd)leimfifhe ein febr zäbes \&eben. Das trocfene zábe gleifch wird nid)t gendist. 
5) Der 2 sutterfifd). Le Blennie Gunnel. Cepède II. p. 503. Blennius Gunnellus.

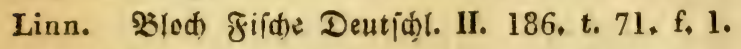
(II. 259.t. 71. f. 1.)

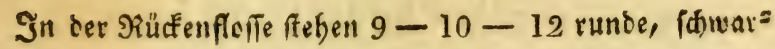

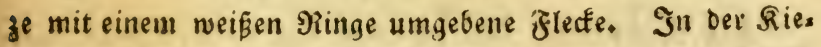

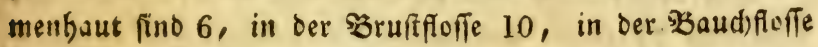
2 , in ber 2lfterfloffe 41 Strablen, bavon die erften betien

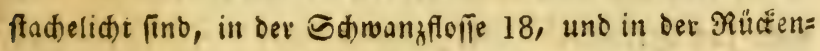

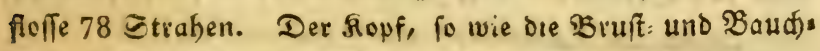
flofie if febr tlein, ber Sörper auf ben Seitell farte zuiam=

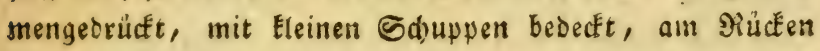
uno ben Eeiten graugelb, braun oder olivenfarbia, mik

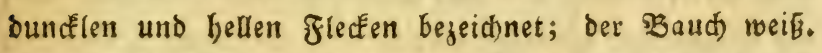
Der Mund if Elein, die untere Rinnlabe gefrummt uno Gervorftebeno, uno jede mit einet Eleinen Teibe rplagiger Zånne befęt. Die Eleinen 2lugen baben einen füwarzent Stern in einem weifen Minge. Die Seitenlinie ift Faun fichtbar und lauft gerabe über bie Mitte bes Rörperģ. Der zffer ift bem Sopfe etras näber als ber Sdirwangfiffe. Der Rücfen if fóarf, bie Etrablen in oer langen uno fdmalen Siucenfloffe find ftadelidt und ragen bor ber Buis

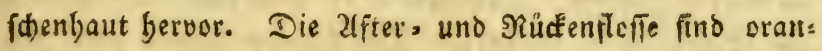
genfarbig und erffere am Girunde braun geflect. Die Siücen: uno Eifwanjfloffe fino getb uno bie Şaud)forfen

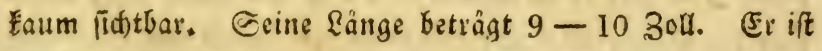
sin Sewohner des Nordmeers und der Diffee, wo ex fid Dhnveit ben Ufern in ben Seetrảutern aufhált, uno fitc

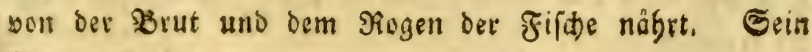

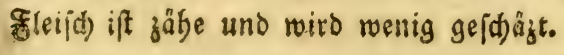


6) Die $\mathfrak{A}$ almuttel. Le Blennie ovoviviparę Cepède Il, p. 496. Blennius viviparus. Linn. Slcch Filiche Deutid)l. 11, 188, t. 72. (11, 262, t. 72 )

$$
\text { (Tab. 36. Fig. 59. 60.) }
$$

Die Nofentöher fino röbrenförmig. S̈ Der Sientents. baut fino 7, in ber Bruffloffe 20, in ber $\mathfrak{B}$ assdflofie 2 .

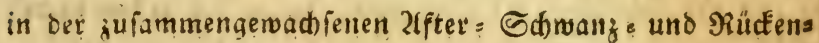
floffe 148 Grrablen. Der Sopf ift Elein. Die obere Sinn. rabe länger als biẹ untere, unọ beide mit Eleinett Bábnent bewafinet. Die länglidten 2lugen baben einen fdwargen

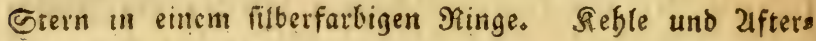
fiolie fino orangefarbia, uno der übrige gan id)lüpfrige §örs yer if gelb uno (d) warg geflect t, uno mit fleinen langltd)ten

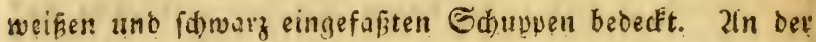

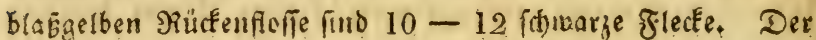
Bauch iff Eurz, bervorftebeno, uno oer after weit. Sämmts ride Grrablen in ten Flofien finb weids. Die Seitentinie if gerade an ber Mitte bes Rôrpers, Eaum fidtbar. Shre

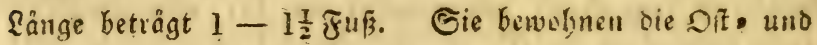
Nerofee, wo fie fid) in Mecreggrunde aufbalten uno von

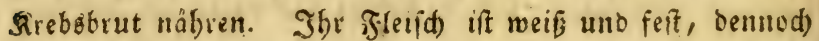
als Speife menig geadytę. Die Biräen merben beim Sc: d)en grün. Cie tringen retendige Junge zur 2Belt, fig. 60 . Deren 2-300 it ifrem difen Baud) enthaften fillo. 3ut

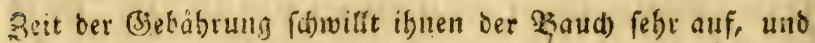
wenu man alsoenn nur menig batan orüct to fommt ein

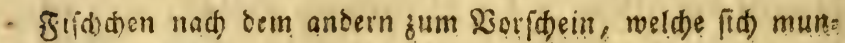
ser bewegen. 
XXXVII. Das Şod)r

Kürtus. \$lod). Linn. ed. Gmel.

Der Rôrper ift lanzetförmig, unten unb oben gefdärft.

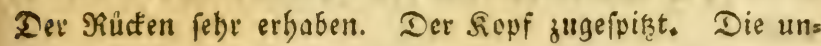
tere Sinnlabe långer als bie obere, und beide mit Eleinen Săbnen verfehen. Etatt des Riementeckels ift er mit eis

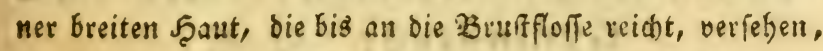
unter welder bie Siementhaut, bie nur 2 Strablen bat, vers borgen liegt. CEs ift nut eine eingige afrt betannt.

1) Der f̧०drủfen. Le Kurte Blochien. Cepède 11. p. 517. Kürtus indicus. Şlod) ausil. Fifide 1I, 122. t. 169. (II. 42, t. 169.)

(Tab. 37, Fig.61.)

Der Görper ift breit, Eurg, binn uno ftatt ber Ed)ups pen mit zarten Silberblättchen befezt, welche bermapien an

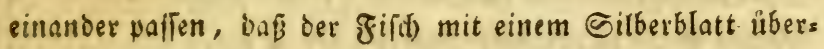
jogen žu feyn fdeint. Die gropen Zlugen baben einen fdowargen Stern in einem ßinge, ber oben blau und unten

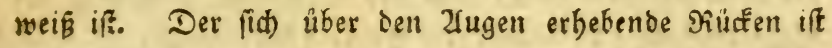

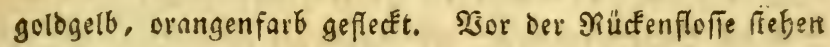
4 fdwarze grlecte. Die Seiten und ber Bauch find golds. farben. Die Eeitentinie fangt über ber Brufffferfe an, unt lauft gerabe nact ber Mitte ber Sdwanzfloffe. Der Bauct)

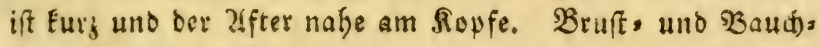

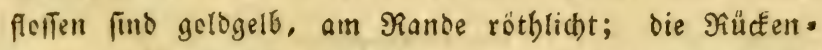

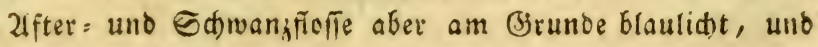
nad) bein গiunde zu gelb. Sämmtlide Straflen find gabets

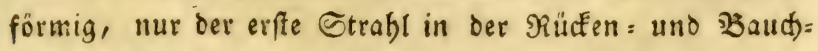
flefle ift hart, und die beiden erffen in ber afferfarfe find ftadjelid)t. In Der Brufffolfe fino 13, in oer Baud)forfe 
I52 Tiexte Elaffe. Fifde.

6, in ber 2ffterfoffe 32 , in ber Sdwangfleffe 18 , und in

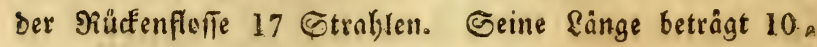
bie Breite etwas über 4 Zoll. Er ift ein Berwobner ber

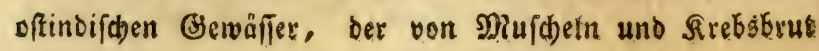
tebt.

\section{DaE Sablafter: Befdled to}

\section{Gymnetrus. らלloct.}

Der Särper ift olgne afterfioffer

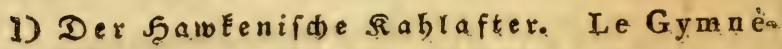
tre Hawken. La Cepède III. p. 280. Gymnetrus Hawkenii. Blod) autrl. Filfo IX, 95. t. 423.

(Tab. 38. Fig. 62)

Der Särper ift fdwerbförmig, die Riemenöfnung weit. Die \$autcfoffen fint zrweiftrablid)t, und jeber Strabl theilt (iid) am Enbe in mebrere Sweige, Die in einer beciten Şaut

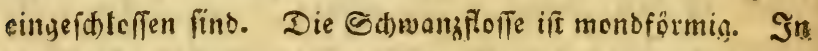

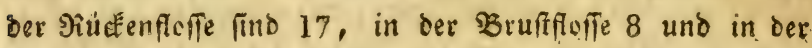

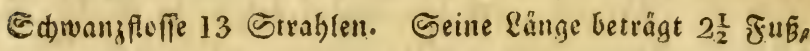
und die Breite 10 3ol. Er wurbe im offindifden \$Reere obnueit (5joa gefangen und wag 10 . \$fund. 


\section{IV. $\mathfrak{D} \mathfrak{d} \mathfrak{n} \mathfrak{n} \mathfrak{n}$.}

Fifde mit baudfloffengerabe unter ben Bruffloffen. Pisces Thoracici.

XXXIX. Das Şandfifds ober baz Rie: menfifd: : Befdledt. Cepola. Linn.

Der Sopf ift rundlift, son beiben Seiten zulammen:

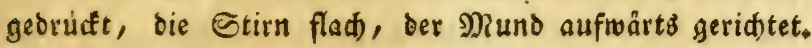
Die 3ăbne find pipişig, gefrummt, und ftehen in beiden Sinnladen in einer einfacten oder geboppelten Reife. Dee Sörper if iffuppentes, lang, fodmal, bün und bantoförmig.

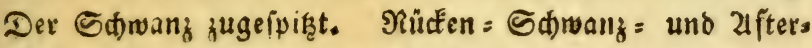
forfe fino mit einander verwad)fert. Es entbålt nur weuige Zlten, bie im mittellåndifden Meere leben, und z̆ Den

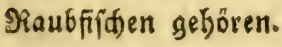

1) Der Bandfifd. Le Cépole Taenia. Ces pède II. p. 526. Cepola Taenia. Linn. Sblod

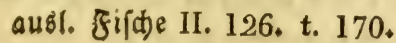

( $\mathrm{Tab}$, 39. Fig. 63.)

Der Ropf ift abgeffumpft, In ber Riemenbaut finb 6,

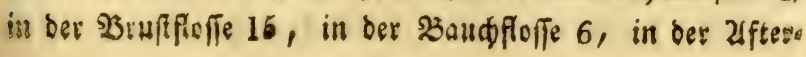




\section{I54 2 ierte}

flofie 60 , in ber Sdivanjforfe 10, uno in ber Rưdenfloffe 66 Strablen. Seibe Rinnlaben, wovon bie untere über Die obere hervorftebt, filio init einer boppelten Reibe fpisis ger auseinanter ftebenber Zăbne berwaffinet. Die groben Ilugen Gaben einen fotwarzen Stern in einem filberfarbigen mit blau gemirhten Sringe. Die Riemenöfnung ift weit, ber Siemendecfel befteft aus einem einzigen $B$ lättdjen. Der Siumpf entigt fid) oben und unten in eine Sdoneide. Die Seiten fino ftarc zufammengebrůc nad). oem Sdwange zu. Der Saud) ift fo turz, baß er faum bie \&ange bes Ropfes ůbertrift. Die Seitenlinie ift gerabe. Der Slopf filberfarben, rótblid)t gewäffert, ber

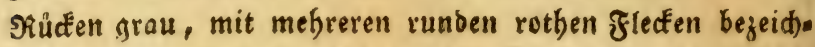
net. Seiten und Baud) finb filberfarben, bie Floffen rotb,

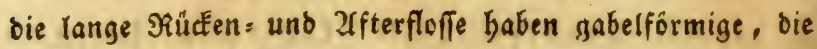
übrigen aber vielgmeigige Strablen. Bruft: uno Baud)= floffen find febr Elein und bie Sd)wanffloffe ift in ber Mitte

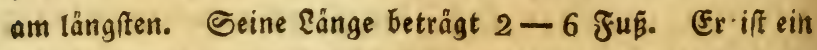

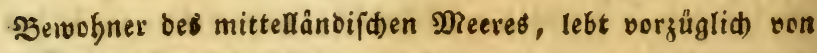
刃uideIn unb Rrebsbrut, unb wiro wegen feines wenigen Jleiphes nid)t geadtet.

\section{Das Sailsfifd: oder Saugefifdy: (Jefd) ledt. Echeneis. Linn.}

Der Sopf ift breiter als ber Sörper, oben flach und mit einem ovalen, geranbeten unb von Duerfurden gezăhs nelten Shillo bedect't. Die untere Sinnlade ift länger als̆ bie obere uno beide fino mit Fleinen Zähnen befezt. Der

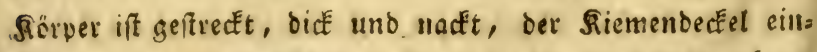
blăttrig, bie Riemenbaut $9-10$ ftrablig. Sie bewobnat 


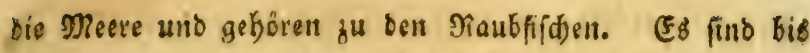
jejt nur einige Zuten bavon be Eamut.

1) Der ङ diffegalter. Der gröe Saugefifक. L'échénéis na ucrate. La Cepède 1II. p. 162。 Echeneis Neucrates. . Linn. Bloch ausl. Fis fide II. 131, t, 171, (II. 53, t. 171.)

(Tab. 40, Fig. 64.65.)

Die Edinwangloffe ift abgerunbet. In ber Siementaut find 9, in ser Bruffloffe 20, in ber Baudbfleffe 4, is Der 2ffterfloffe 35, in ber Echwangfleffe 18, und in ber 9iusfenfluffe 40 Strablen. Im Sepfidbilbe liegen 22-24 D.uertinien. Die 2lugen fint Elein uno baben einen idwwars

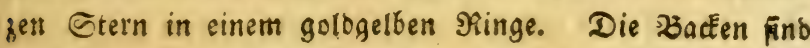
fleifhigt und filberfarben. Die Şaut ift fouppentos unb

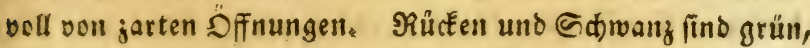
bie Seiten unter ber weifen, geraben Seitenlinie nebft dem Baude reiß. Sämmtlide sloffen, nur bie am Sdywanze aukgenommen, baken einen gelben Grrund und eine breite violette Einfaffung. Die $\mathfrak{B r u f t}=$ und $\mathfrak{B}$ audffoffen fino

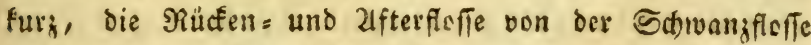

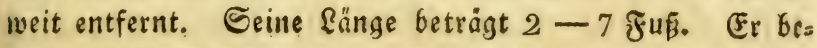
wolgnt fait alle Meere, fowohl ber Ealten, als ber heísen und gemäifigten Bjegenden, lebt ven Mafdeln unb Sirebfert

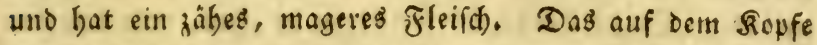
befinblicte Sadilo wirb yon mebreren in bie S.uere gefgender rauben Rinien gebildet, unb von einer nach ber \&änge laus: fenten burdfidnitten. SBetrad)tet man biè fe raube Einie burd) ein Sudblas : fo nimint man wabr, baj fie aus laus, ter Burfen zufammeniefezt iff; wenn ber ziif́) nun feinen shopf gegen cinen rauken doer mit feinen Söd)ern berféfeners 


\section{I56 Siexte Elaffe. Fifde。}

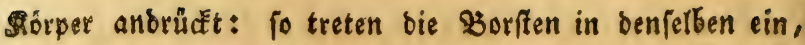

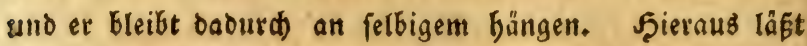

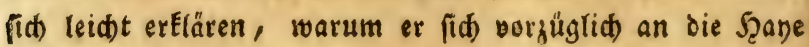
feitzufezen pflegt. Die alten glaubten, er tônne bie Şdiffe aufbalten, was aber ganz ungegründet ifr.

2) Der Unfauger. Der lleine Saugefifd. La Cepède III. p. 147. Echeneis Remora. Linn. 210 172.)

Ev unterfdeibet fid fogleid) von bem vorkergegenden burd feine halbmondförmige Sd)wallgfoffe. Sn Der Sies stentaut find 9, in ber Brufffeffe 22, in ber Saudfloffe 4 , in ber aftero und Sdiwanififfie 20 , unb in ber Siüftena forfe 21 Strablen. Sm Kopfídilbe liegen $17-18$ Suer.

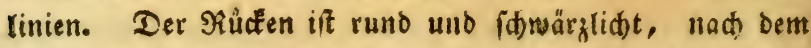

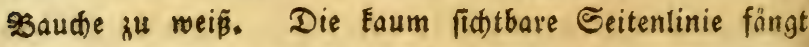
am (jenice an, madt am Ende der $\mathfrak{B r u f f}$ foffe eine $\mathfrak{B e u}$

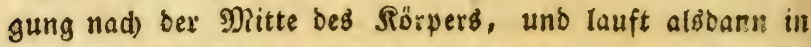

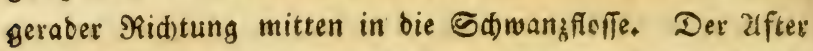
liegt ber Sd)manjforfe am nädffen. Die $\mathfrak{B}$ rufts unb $\mathfrak{B}$ aud(b)= fleffen find tury, eritere nebit ber 2 ffter = und Sdiwanjferfe im (3runbe grau, uno am Ranbe braun; fämmlide Strahs. Ien find weid), vielgweigigt unt won einer siffen f̧aut ums

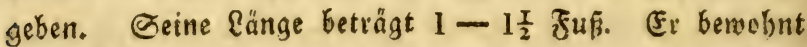

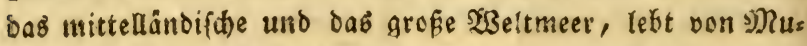

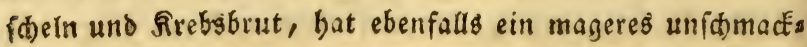
baftes gleif's; baingt fid an bie Shiffe, befonder's aber an bie Şayfifade, an denen man gewöbntid mebrere ber. felbent ziggleid finvet. 
XII. Das Stuffopf: oder Doraden: SP: (d) led)t. Coryphaena. Linn.

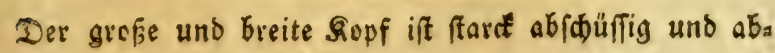

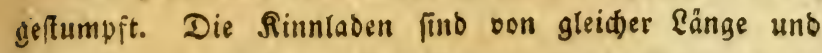
mit Bălmen bewaffnet. Der Soêrper ift mit Sduppen $b_{e_{3}}$ fe;t, faref und an ben Seiten zufainmengebrüaft. Des Rumpf ift mit 7 glofien befęt, baven bie am Rücten jefgs lang iff. Die meiften 2 ltrten, beren bereits gegeri 20 bes Eannt uno gröftentbeils Bewobner ber Mieere find, babers gotoglänzende ভđdupper.

1) Der geflette StukE onf. Die gemeins Dorabe. Le Coryphène Hippurus. La Cepède III. p. 178. Coryphaena Hippurus,

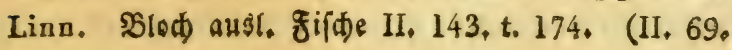
t. 174.)

\section{(T a b. 41, Fig. 66.)}

In ber 2rfterfloffe find 25 Strablen. In ber siements Gaut liegen 7, in ber Bruftefleffe 16, in ber Baudfloffe 6,

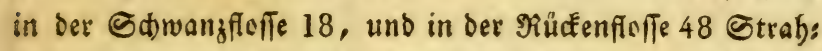
len. Der אopf ift oben blau, an ben Geiten grünlidt, nad) unten filberfarben. Die Zfugen baben einen fdwars zen Stern, Der von einer weínen linie und einem oran, gefarbigen stinge umgeben wird. Die gleid)langen Finna laben fino mit 4 Reiben Eleiner, fpişiger nađ) binten getrüunter Bălgne bewaffnet. Die Riemenôfinung iff weit uno die fiemenbaut liegt unter bem aนs einem

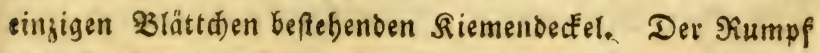
iff geftreckt, unb mit zarten Sdappen befejt, an ben Seia

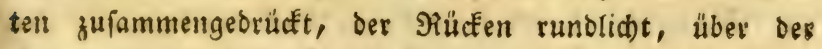
Eeitentmic meergrün mit orangefarbigen flecten befprengई uno unter derjelben filberfarfig, Dis Eestentinis if gels? 


\section{SBierte Eraffe Fifde.}

madt an Enbe ber Bruffiffen eine Reuguing und laufk

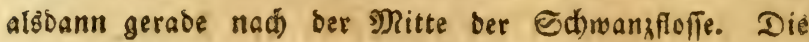
Straflen in ber lantgen sRütfenfloffe fino gelb uno bie 3wifhenbaut if blau. Die Sd)wank, Şruft, un๖ Baud) floffen find am Brunde bellbraun unb übrigens gelb, uno Die Sd)manifofle bat eine grünlid)te (Emfaffung. Seine Långe betrảgt 4-5 ₹Fuß̧. Er berwobnt bas mittellänoi=

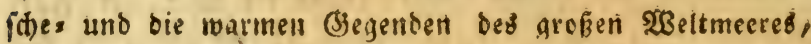
ift äufierft gefräß̧ig, verfolgt vorğ bie ifm butd) ben Eurzen Flug über bas๋ গ̇alier zu entnebent

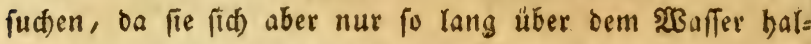
ten Ëonnen, alş ifre jloffen ná find, fo lauert jener mit aufgefpertem riadien, um fie, fobalo fie fïh steder ins

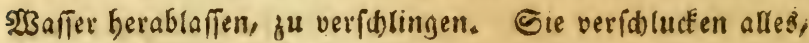
เพaร ifnen vorfommt, und verfolgen bie' Schiffe, um bas? was aus bertfelben weggewerfen wirb, aufiufangen; fo fanb ber פ⿹ater $\mathfrak{O}$ I Magen des Fifajes, Den er zerglieberte, wevon ber grö̈te 5 3oll lang war. Ex wirft, fo lange or in feinem Eles meate iff, einen trefflid) idoonen (jologlang oon fid, wirb Daber von ben Sdiffern (5)oldfifi) (Dorado) gez sennt. Gein fleifo if febr wohlidumedend. Er roirb art báufigiten im Seetbft, als in feiner Raid)zeit gefangen, wo ex fid) ben felfigten Ufern nábert, um jeine Ėyer abjufeżen. Diefer Fifa) büpfet bisweilen in ber Jgöbe eitrer Slafter aus bem פeere in bie $\mathfrak{\text { Iuft. }}$

2) Der Meerpfau. Die গ̧fa Dorase. Le Coryphène Plumier. La Cepède III. p. 201. Linn. ed, Gmelin 1191. Coryphaena Plü-

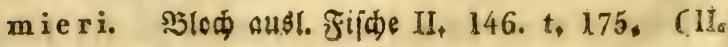
73, t. 175.) 
In bar zlfterfiffe ftehen 55 Strablen. In ber Riez

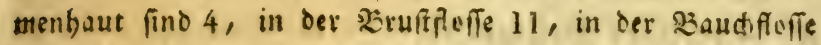
6, in Der Sdmaniflelfo 16, uno in ber Rücfenflefle 77 Strablen. Der Rovf ift länglidte, oben breit, fduppens los und braun, über ben Ilugen gelb und an ben Geiten filberfarben. Die sinnlaben gleidlang uno mit fartefen fisizigen Zăhnen befęt. Die 2lugen baben einen fotwargen Stern, ber mit einer weif̧en finie und einem rothen ßinge umgeben ift, zu beiden Geiten berfelben ftehen blaue @trabs.

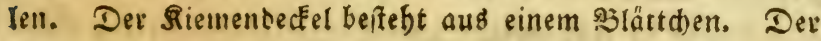
Sërper ift geftrectit, mit Eleinen Sduppen bededt, der

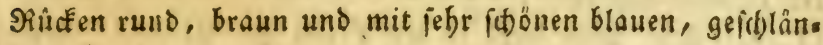
geiten, fotmalen Jleffen gejiert. Die Seiten fint golde uno ber Bauch filberfarben, lezterer if Eurz uno ber Zlftes

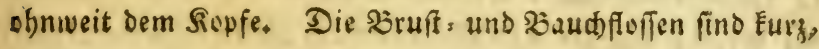
am Brunde gelb, am গiande grau und baben viergmeigige

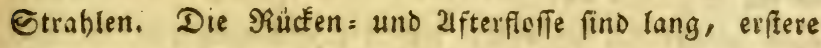
ift violett unb leģtere blä̈gelb, beibe baben einfache Straf: Ien. Die Sdwwanffoffe ift oben und unten gelb, in ber Mitte röthlidft und am Rande blau, ifre @trablen fint vielzweigig, wovon bie in ber MRitte Eur; uno bie an ben

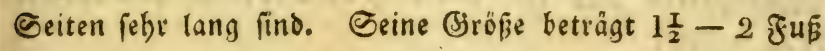

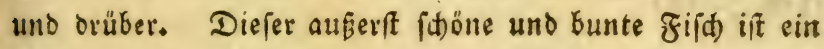

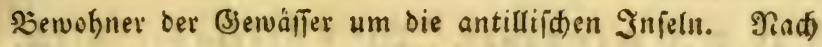

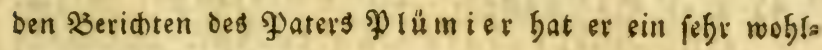

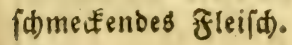

3) Der blaue Stusctopf. Le Coryphéne bleu. La Cepéde III. p. 200. Coryphaena coeru. le a. ßlod) aust. Fiffde II. 148.t. 176. (II. 75 。 t. 176.) Novacula coerulea. Catesby hist. of Carolin. It, p. 18, t. 18. 


\section{I60 Wierte Elaffe. Fifde.}

(5r unterfacidet (id) fogleid) burci) bie blaue farbe, wos mit er burchaus ülergegen iff. S̊n ber אiemenbaut fino 4,

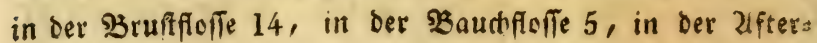
floffe 11, und in der Sdwanz: uno भüctenfloffe 19 Strabs

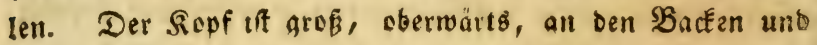
Siementedfel mit Sduppen beię̧t. Die gropen runden $\mathfrak{X}_{\text {us }}$ gen baben einen fawwarzen Stern, der von einer weifen Sinie und einem gelben গinge umgeben wirb. Der Sies menbecfel befteht aus einem eingigen $\mathfrak{B l a ̈ t t ( t ) e n ~ u n d ~ d i e ~ \Re i e s ~}$

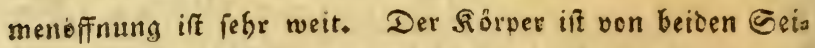

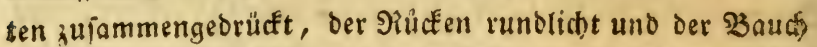
fónarf. Der 2lfter liegt in ber Mitte Des Sörpers. Die

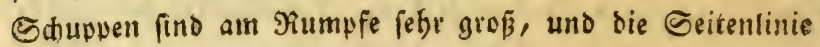

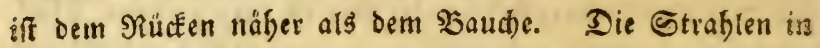
ber $3 r u f t=$ Rauds, unb Sdwanjlleffe find vielgmeigig, die

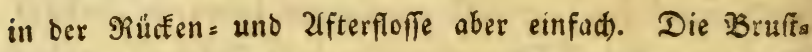
flofie endigt fich) in eine, und bie Shwanjfloffe in swei

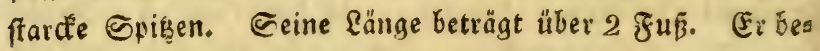
wobnt bie amerifanifden Meere. (Eatesby fand ibu be: ben bahamifaen Injeln uno in ben Meeren zwifben ben

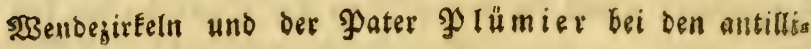
phen Inieln.

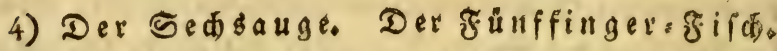
L'Hémiptéron ote cinq-t a ches. La Cepède III. p. 215. Coryphaena pendadactyla.

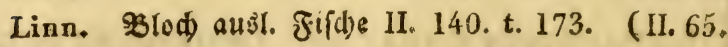
t. 173.)

Die Sanamflefte ift gerabe, unb in ber গähenfoffe find 21 Strablet. In der Sitemenbaut liegen 4, in ber

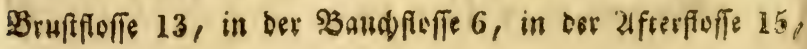




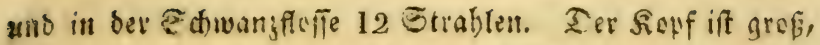

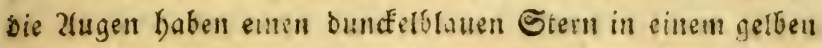
Siinge. Oberwärts if der fovf braun und verwerts isegt an Der (d)arfen Sante ieffiben ein Dundelbraume: Streijen, De:

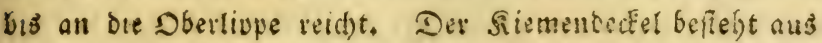

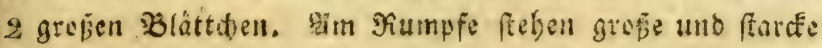

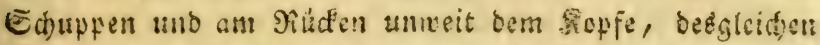
am Baude 5 zrecte. Son jenen if ber erfte runo, ber grocite oval, beibe baven einen forwargen Gramb, ber ven einer getfen \&inie ungeben iff. Die ûbrigen ơei fuio lângs rifft, Glau, bie am Baud)e runb, Hein, van gleider Fars be. Der פlufen if braun, Die Eesten und ber Sauth fino

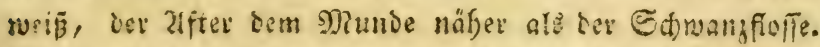
Die Ecitenlinie foft nabe an Sitcten uno wiro ofmueit

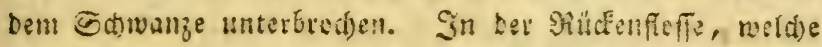
gleid) binter ben zugen anfängt, fint bie evffen 9 Strafo

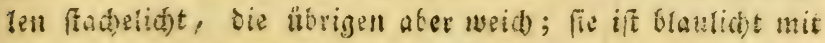

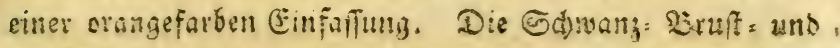
Baudufinfin fino am Brunte orange, am giante violets Hno baben vielgweigige Etrablen; an erferer firghn auz

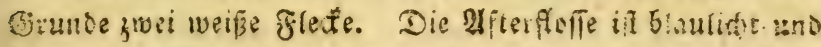

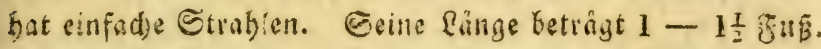

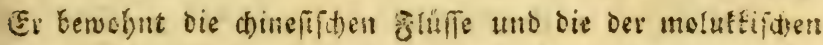

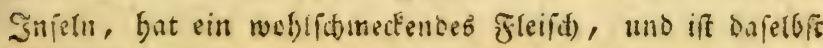

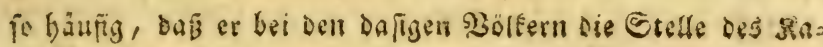
Getjanes vertritt.

5) Der Binden=Stutapf. Die Binden: Do. rabe. Le Coryphène ondé. La Cepède lir. p. 196. Coryhaena fasciolata. Pallas spic. Zool. VIII, 23. t. 3. f. 2. Linn, ed. Gmel, 1193. 
Dir Fonf if Fegelförmin abigeftumwit, am Edicitelplatt.

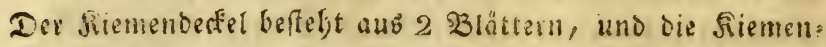

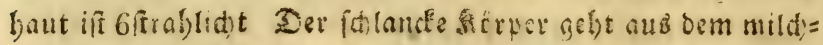
weifen ins filberweige, uno it mit gelbbrantulichten, bin uno niecer a (d) wurdenben Suerbinden bezeidnet. Sie Geitentinie ferigt gegen Den Sepf Gin aufwarts. Der zfter liegt in ber yjit=

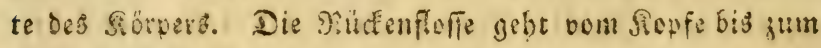
Edimanje, wito nad) binten etwas böber und bat $5+$ Strab) len, welde parmeife mit der Swifdenisaut weif uno braun abiosdie(n. In ren Stuffleffen liegen 19, in ben Baubs frofien.5 und in ber bräunlid)t geftreiften 2fiterfloffe 37 Etraglen. Die tiefgeffaltene Edwaniflofie bat 17 Etrab)

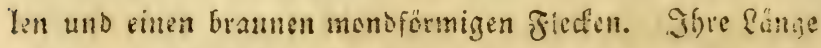

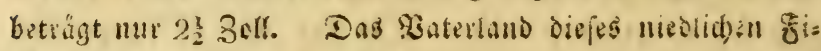
(d)es ift amboina.

6) Der Seger. Etuftenf. Dia Segeloonde. L'Oligopode vêlifère. CepédeTr. p. 512. Coryphaena velifera. Pallas Spic. Zool, VIII. - 19. t. 3. f. 1. Linn. ed, Gmel, 1193.

Der Sepf ift iufammengedridt, ftumf abgermot, ber Muno liegt aufwärto uno if tief gefpalten. Der un: tere Siefer bat 2, ber obere eine Sieige fpitziger gefrümm= ter Săbne. Sie Siemenbaut if fiebenfrabsiat)t. Der foup= fig grau:filberfarbige, jufanmengebribłte, dünme Sicrper iff an jeocr Eeite mit 11 Reiben gaofer geftreifter, breiectia get an ber Epize tief geferbter Edouppen befezt, weldhe am Grunde mit einem gegen bell Sispf zurücF̈gebogenen Etachel verfeben find. Sole äuberft bobe Siüdemflefle fängt am Sopfe ail, unb gebt in einem SBgen bis zum Sobwanje, 


\section{Sierte Elafile. Fild e. \\ Coryphaena rupestris, Linn, ed, Gmel, p. 1195.}

( $\mathrm{Tab}, 42, \mathrm{Fig}, 67$. )

In bev Siemenbant find 6 , in Dev \$̇uffiofie 19, in

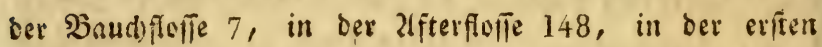
Siückenfoffe 11, unb in Der jweiten $12+$ Strablen. Ser Sopf if grof́, nad) oben breit und enbiget fid) in eine ftumpfe Spise. Boie sbere fimalabe (tel)t vor ber untern Gerver, uno tiefe if mit einer lanen Santifaler verfeben.

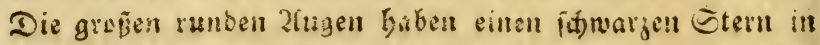
einem fitberfarbigen Minge. Der fiöper if filberfartent

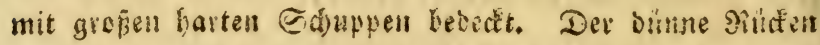
uno bie floffen find grau, ber Şaut) Eurz uno breit, die

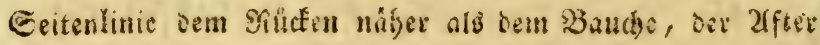
bem Siopfe nabe. Der erfte Strabl in oer eriten Siülfeils floffe ift ftarte, lang und an Dem vorbern Siunte gezăh:

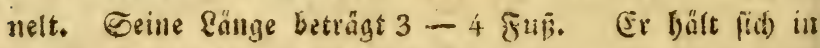

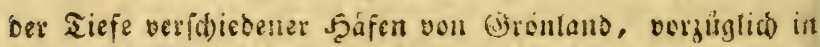
Dem Sgafen von IunnubliorbiE, auf. Writo mit

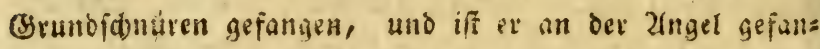

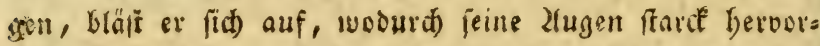

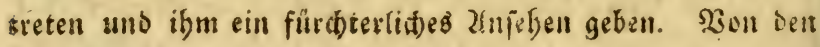
Gröntändern wiro er als eine Selitatefle verfpeift, und

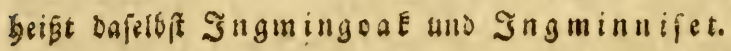

XIIII. Das Gertenfifd: (Sefd) (ed)t. Lepidopus. Gouan.

Der Sörper if fdoppenlos, begenförmig, zufamment gebrüct, na(t) binten zugefpizt. Der nacte fonf ift auf Dem गacten gefdürft, Die Rimnladen zugefpizt, die untere 


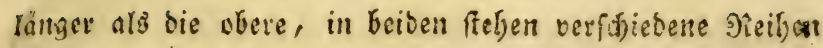

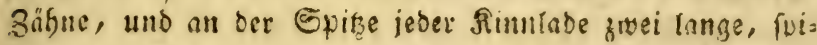
jige und an ben Geiren ber oberen now ein eimgeiner län

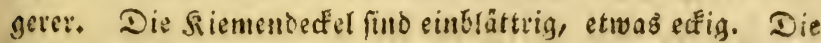

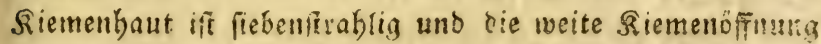
fiidelfürmig; Daven ift biş jezt nur eine einzige afrt be Eannt.

1) Der firberfarbige Bsertenfirs. Le Lépidope. Gouanien. Cepède II, p. 520. La Jarretière. Bonnaterre 58. pl, 87. f, 364. Lepidopus argenteus. Gouan Genera piscium p. 185.t. 1.f. 4 .

(Tab, 43, Fig. 68 69.)

Der Sïrmer ift glatt, glangent, filberfarben. Die gros Een sualen 2fugen fins mit einer Nitefhaut bedeckt. Die

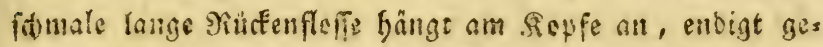

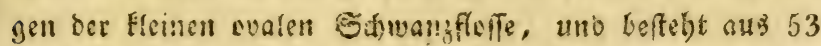

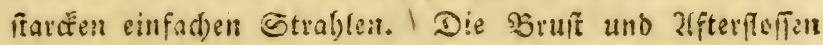
fino fent tlein. Seine Range beträgt 8-10 3oll. Er wiro in nittellnoifden MReet gefunben.

XLIV. Da (5) Unbel: oder Tud terfifd: (j)efdledt)t. Gobius. Linn.

Die Sauchiteften find in Geftalt einer Tute, wher eis

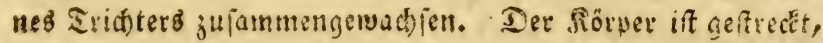

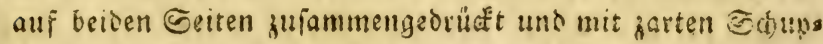
pen befegt. Der Sopf iff Elein, balb vour oben nad) unten,

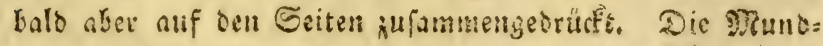

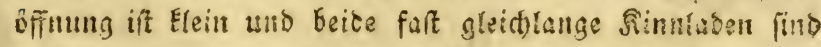
mit Fleinen, gerasen, fwişigen Bühnen verfegen. Smifdent

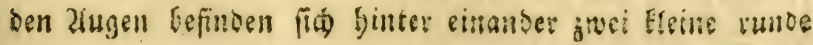


Sifnungen. Sn ber Siemenbaut find $4-5$ Straflen.

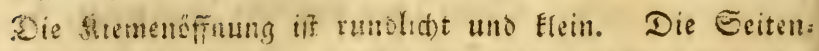
linie lauft geraoe, mitten nber den Sörper. Das Enbe bes

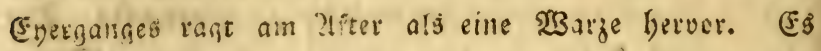
fins bereits etluche 20 veriatrevene 2frten befant, die fida

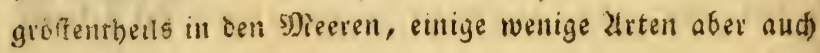
iil Den fruffen aufbaiten.

1) Dic Sieergrunder. Le Gobie noir. Cepéde II. p 568. Gobius niger Linn. B(tod Fifale Deutid)t, II, 5. t, 38, f, 2. 3. (II, 8.t. 38 . f. 2. 3.)

(Tab. 44, Fig. 70.)

Der Sörper ift weif́, fobargbraun unb gelb geflectet.

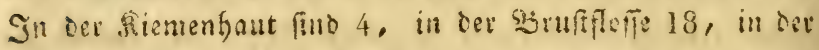
Saudfloffe 10, in Der lifrerflofie 12, in oer Ed)wanjflefie

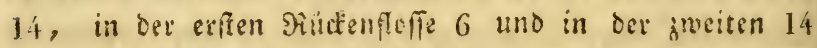
Etrablen. Det Sörper iff Eeifformig, am Sepfe dick, ber Sopf nach unten zufammengedücft, oer auf ben Eeiten jujammengedriafte Siumpf nad) Desn Eatuanje

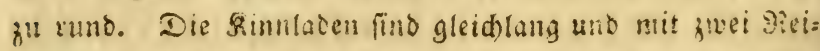

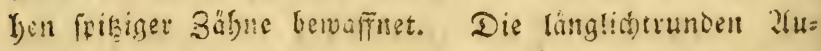
gen baben einen fohmargen Etern in cinem filberfarbenen

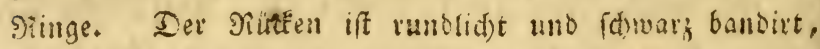
bie Ceitenlinie unmerckbar. Der breite Saud) gelb, det 2lfter in ter 9jitte beș Sörpers, mit fómarbraunen wiid gerben SJunten und flecten ganz bejpiengt. Die Joffen find graublau uno mit Eleinen fowargen Fleffen ge= itert. Die Etrablen in oer siuken = uno afterfoffe fino sinfad, in sen übrign aber getfeilt und fümmnlid) weid) bis auf bie in bev erften shitfenfleffe, weldbe etwas biater 


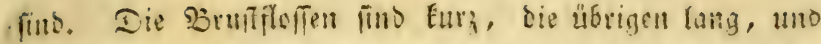

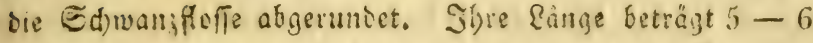

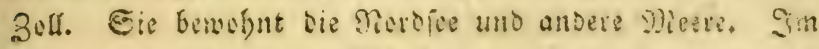

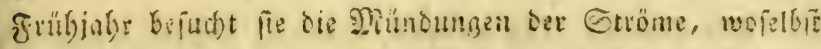

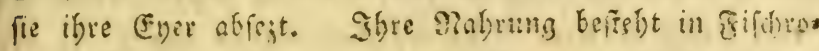

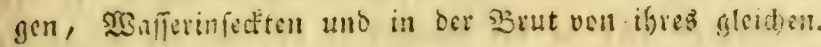

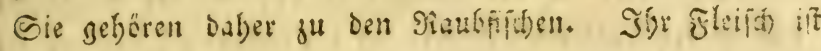
woblid)mectino.

2) Die Braugrunber. L,e Gobie Jozo. Cepéde II. p. 557. Gobius.Jozo. Linn. SBlod) ङifte Deuticil. III. 168. t. 107. f. 3. (III. 214. t 107 . f. 3.)

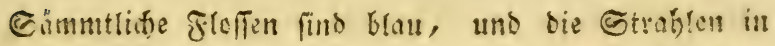

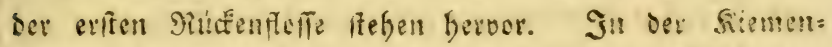

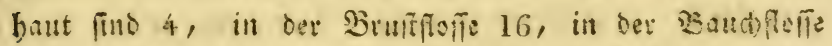

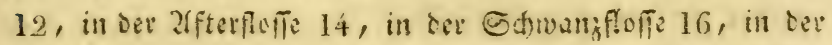
erffen Piuldienfoffe 6 , uno in ber jweiten 14 Srrablen. Der

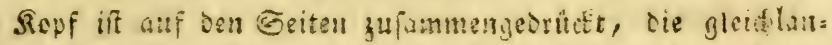

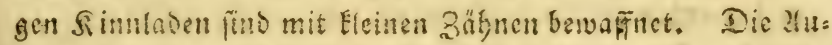
gen baban cinen fidwakgen Etern in cinam weigan simge. Der Situten if runo, brann, flads gebogen, tie Eciten

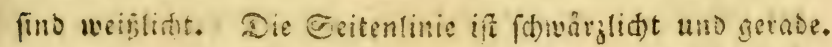
Eeime Eange betrïgt 4-6 3orf. Er bewolgnt sie Firro=

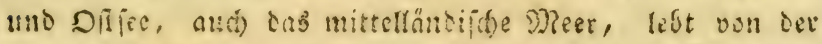
Brut Ser Strabsen, Miujdeln uno Bifite. Ceine Eyer peit

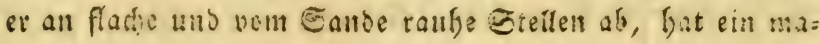

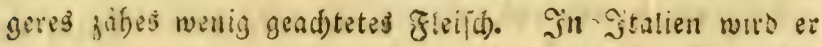
J o z o getient.

3) Die Rangettgrunder. Le Gobie Lancéolé. Cepède II. p. 545. pl, 15, f. I, Gobius 1:a a- 
ce olatus. Silcth Fithe Deutithl. II. 8. 4. 38. f. ?. 6. (II. 12. 138 f. 1. 3.) Gobius oceanicus. Pall. spic Zool. VIII. p. 4 .

Die Gdinanifloffe it? Ereit, länglicht zugefpignt und wie cine Eanze aefraltet In ber friemenbaut fins 5 , in bet Bruffente 16, in her Baubfoffe 11 , in ber 2lfterfleffe

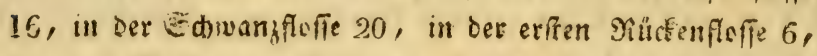

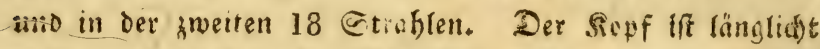
uno vorne abgefumpft. Die Riefern fins gleid)lang. Die bid)t beifarmen febenden 2fugen baben einen fobmarient Gtern in einem geldenen ringe. Die Bacfen find flans

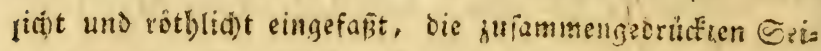
ten beflgelb. Der Millfen ift runo, branunlicht. Die Eeis

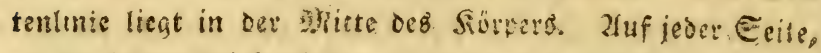

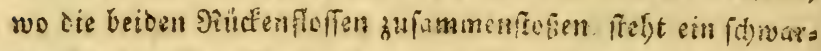

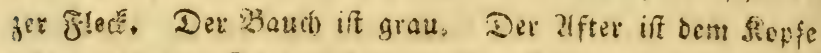

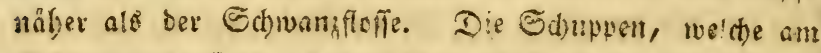
Ed)wanjestoe fizen, fino grëber als bie gegen oem sisple. Die Srufflobe if gerb uno blau eingefabt. Die Cotrabran in ber erfen Diälienflefle ragen weit beroes, find lang uno weich. Die Gdmangforfe ift am Grunoe grüngelb uno am Rande viclett, Die Rónge betrảgt $5-7$ 3oll. Gir fin.

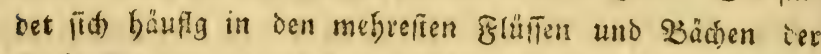

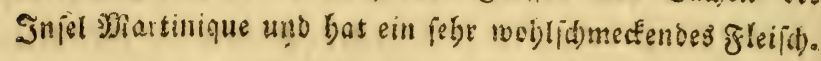

4) Die geaugte (3) runbel. Le Gobie awaou. Cepéde I\%. p. 566. Gobius ocellaris, Brourssonet ichthyol. dec. I, n. 2, t. 2, - Linn, ed. Gmel. 1204.

Die obere simnlade fatget über die untere berwor: dic

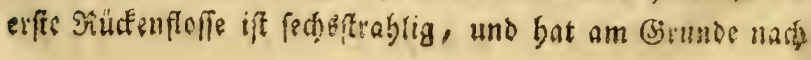




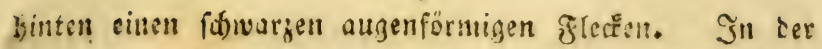

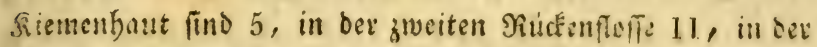
Sòruffuffe 16 , in ber Baudfeffe 6 , in ber afterfoffe 11 , uno in Der Sdwaraflerie 22 Errablent. Der Sopf if

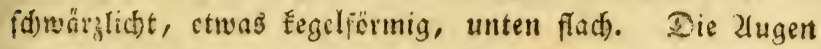
baben einen braulidfen Etern. Do: §örper iufanmenge. orücf́t, lanzotförmig, olivenfarb, buncfelid)wary gewäffert, unten Glautiof unb mit binterwákts gefranhten Echuppen

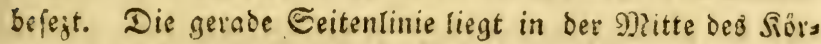

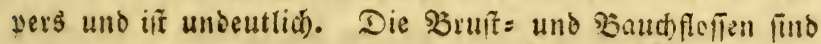

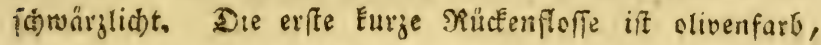

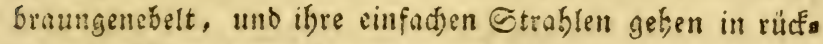

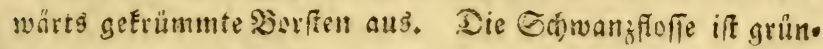
lidit und eyruns. Cie bewobnt die Båthe ber Injel Dtas Geiti.

\section{Dดร (5) Linn.}

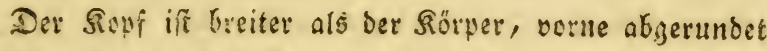
und mit Studeln berezt. Die 2lagen frefen ain Sdeitel,

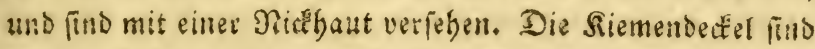
gros unb bei cinigen gejăbnelt. In ber Siemenfaut lits gen 6 Strahlen. Der Siôrper ift långlitft runb, veroünnt (iid) gegen Den S(d)wanz und if fiatt ber Sofuppen mit

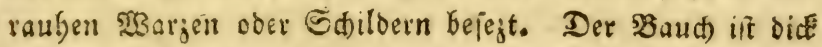
uno der zifter be: den melgreffeit dem supfe năber als Dem Shthange. Die Ceitentinie if gerade. EFs find bea reits ÜEer 12 verfchiebene arten befaunt, Die fämmtlida bis auf eine, şeivofner ber szeere fins. 
1) Der Cetnuider. Der gefanjerte Broppe. L'Aspidophore armé. La Cepéde III. p. 222. Cottus cataphractus. Linn. Blod) (Jic)e steutal.1.15. t. 39 f. 3.4. (II. 22.t.39. f. 2.)

Der Sörper if mit adt Tieifen Enöd)erner Sdhirber be= bect, the thm eme scteckige Bieftalt neben. In Der Sie= menhaut fino 6 , in ien sirmiffefen 15 , in ben Baudfiof= foll 3, in oer zifterflofie 6, in oer edumantinfe 10, in Der erifen Näukenfle Der Sovf if breit, nad) unten jufammengedrüct uno mit viefen Bartfaiern und Etadeln verieben. Die sbere Kinn.

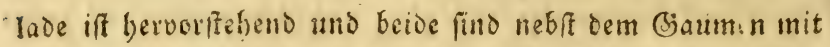
mefyeren Sietben Eleiner und fwitgiger Zäbne bewaffret. Die Dunvofinung fieft unterbalt, und ift monofórmig. 2n bet

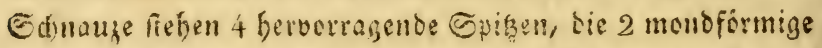

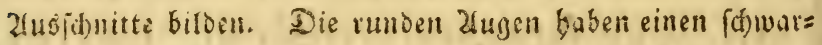
gen Etem in cinem gerben Ringe. Der Siủexen unb die Eeiten find biaun uno mit $3-4$ fduarzen flecten verfe=

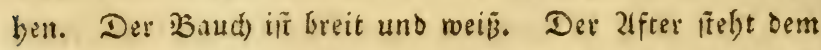
Sicufe năher a!ß̧ Dem Gibwanje. Die Eeitenlinie lauft ge= rade, mitten über ben Siorper. Die Brufffoffe if grö, runtolid)t, weif̈grau unb mit Eleinen fd)wargen flecken bes perengt. Die Boudffiefen fino idtmal unb lang. Die If: terffrife if vom 2lfter weit entfernt, ftebt oer smeiten Situcenflofie gegenüber uno if an Cirunbe fowwarg. Die (e) d)

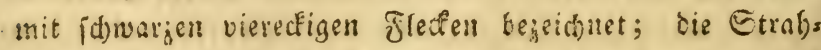
ren in ber exfen groffe feben wie etadfefu heruor. Geis ne Eânge bitringt $5-6$ 3oll. Cir bewohnt die glordo fee und wirb bänifg juifden ben Eteinen im Eanbe an ben

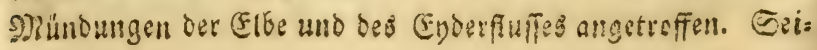




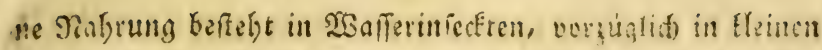

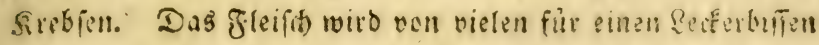
gehalten. Die Raidjeit fint in Mnai, wo er peine (Evar shmueit der llfer jwijden den Stemen abjejt.

2) Der $\mathfrak{B}$ rummer. Le Cotte grognant. La Cepède III. p. 232. Cottus grunniens. Linn. SBled) aus่l. Fildie II. 157. t. 179. (II. 87. t 179.)

Der Sörper ift glatt, und am Unterfiefer rijen viele Sartfajern. In ber Fiementaut find 6 , in der פruffletie 22, in ber Baudffoffe 4, in ber 2ffterfloffe 16, in der Ed)wanjflefie 11 , in ber erifen siüffenfferte 3 , und in der gueiten 20 Etraflen. Der Sopf if gros uno breit, non won nad) unten jujammengedrüt t. Die untere simnlate

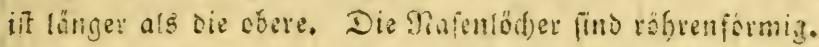
Die Eleinen Zurgen babell einen fotwargen Erern in einem

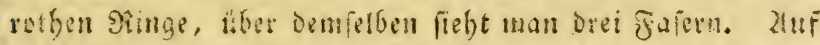

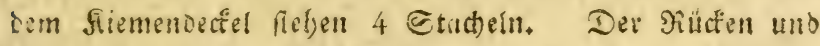
Siepf find braun, bie Seiten weif und bratm matmorirt. Dor Baud) if Ello, und ber affer liegt beinabe in oer

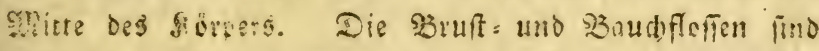

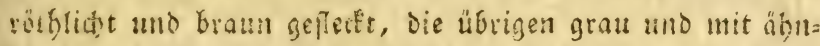

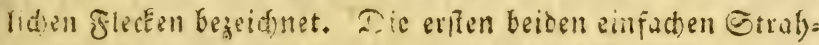

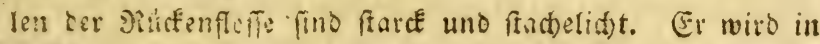
Dit: und siseffindian angetreffen unb gefört idu Den fleifd)=

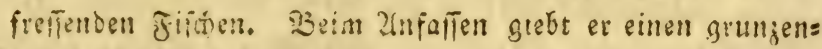

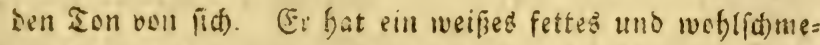
cfentes fleift, bingegen wiro bie Reber für fo giftig gebal,

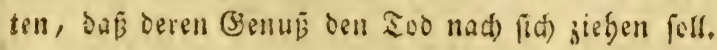

3) Der Seefcorpion. Die Donnerfüte. Le Cotte Scorpion, La Cepèdelli, p. 286. Coto 


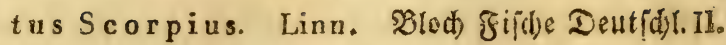
18. $t, 40$. (II. 25, t. 40.)

(Tab. 44. Fig. 71.)

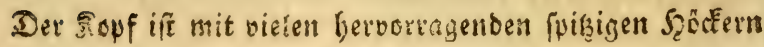

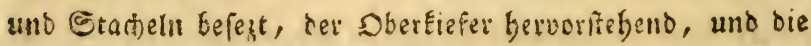
Etrablen in be: Sruffeffe einfach. In ber Riemenbaut

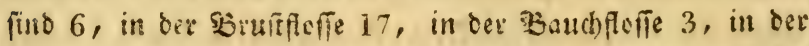

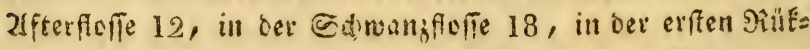
Fenflofte 10 uno in ber zweiten 16 Strablen. Die vielen Jeöcfer und bie Etacheln an ben B̈ackenEneden geben dem Sepfe eine vielecfige (jeftalt. Bwei von diefen Grad)e!n fijen vor bell 2fugen und find beweglidi), uns auf jeocr Seite 3 - 4, bie unberveglid) fint. Die Muncoffnung ift fefr weit. Sie Simnlncen funo mit einer Menge furfiger Żăhne befajt. Die grofen länglidtumben atugen baben einen fatwaryen Stem in einem weibgelben Singe. Sie Sinodien Der Zlugenboblen ragen oben farck Gervor, und bitoen eine

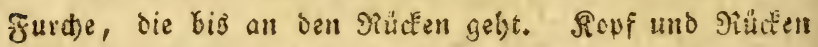

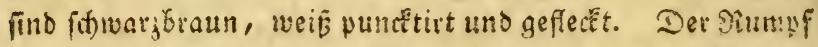

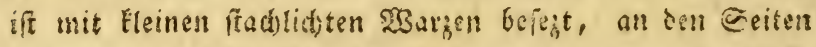

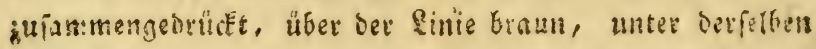
aber weif́ marmorit. Dor Baun ift bick, breit, bei dem

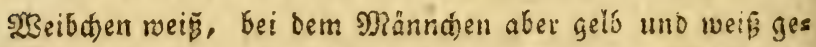

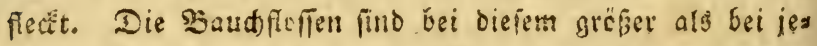
nem. Der affer frebt in Der Mritte des Bauches. Die Etraklen in Den Bruffaften fino an ben Gpitsen weich, wangefarben, dic Baud)foffen lang, unb bie Edsmanjfoffe

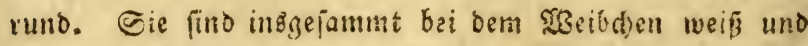
fdwarz geftreift, bei bem Dannaben bimgegen fino die

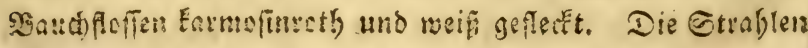
fino bis auf die in ene Oofwangfolfe ungetbeitt. Geime 


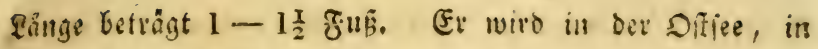

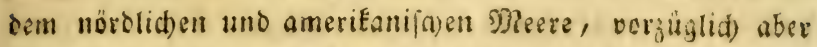

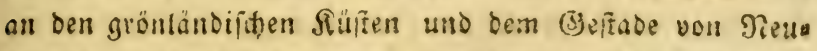

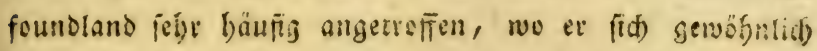
in Der Tiefe aufbălt, uno mur alsbenn in bie Jä̆le fommt,

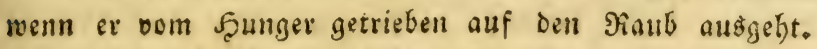

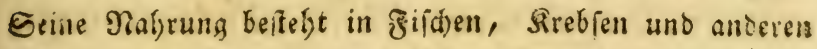
Seetbieren. Seine Raiđzeit fält in Dejember uno Januar, wo er feine Ever in Mienge jwifden ien Seetang abjeht. Ev giebt beim SSerúl)ren einen murrenden \&aut von fid),

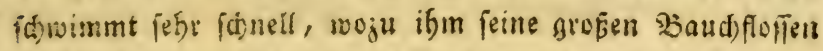

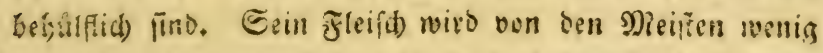

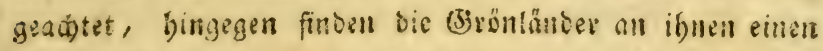

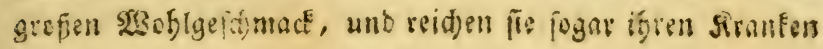
als eine gefunde Epribe bar.

-4) Der Rautepf. Der Roppe. Der Rauls baifd. Der Difkopf. Le Cotte Chabot. La Cepéde III, p. 252. Cottus Gobio. Linn. B(sd) Fifite Deutifit. II. 12. t. 39. f. 1.2. (II. 17 . t. 39, f, 1.) v. Meidinger, Pisc, Austr, tah, $1 \%$

2lit iebem Sirmendectel fiefgen 2 Erumme Stacheln. S13 ber Siemeribaut finto 4, itt Der $\mathfrak{B r}$ ruffifoffe 14, in ber

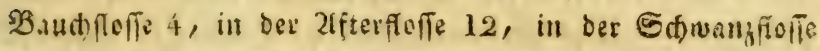
12, in Der erfiten 3tünfenfloffo 7 und in Der zweiten 17 Strag.

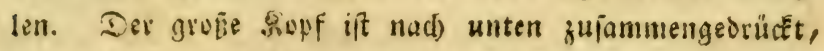
vorn fibmäler als binten und bilbet auf jeder Seite einen

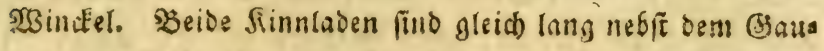

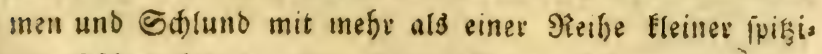

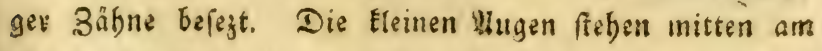
Solfo unb baben einen fonwargen Stern in einem getfess 
Singe. Die Siementedter beftebn nur aus eincm eingigent

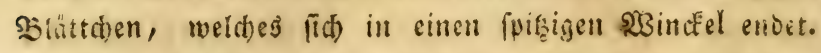
Der Эiumpf wirb nad) bem Sd)rwange ilu aflmälig bünner, ift an oen Seiten etwas zufammengeorüct, und mit sinem

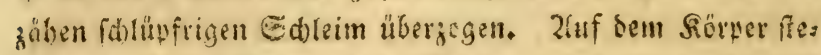

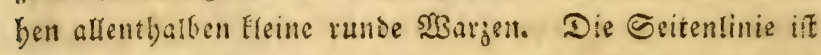

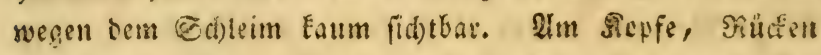
und an ben Seiten sberbalb ber Rinte ift er braun uno

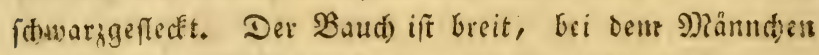
graia, bei dem Wrseibatin bingegen ganz weiñ; aut) unte:

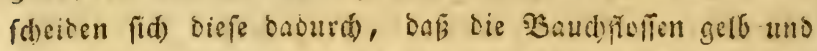

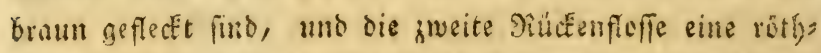
(id)te Einfanmug bat. Der 2lfter ftebt mitten am Storper,

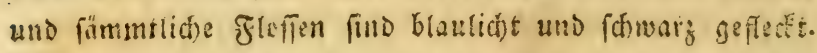

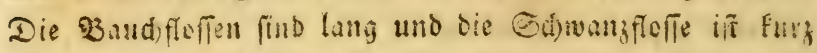
und rund. Eeme Gröbe beträgt $4-5-8$ 3all. Erwis

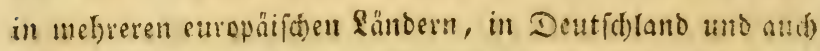
in ben Mifeungegenten im Saoijden, in Sdiwaben, in

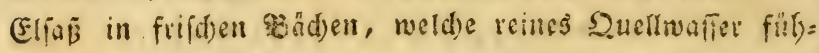
ren und einen fteinigen (5)und baben, angetroffen, beneat

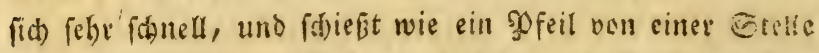

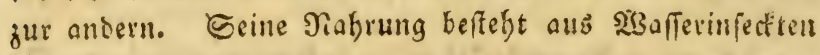
uno Brut anterer filide. 2fn ben forellen uno Sechtent

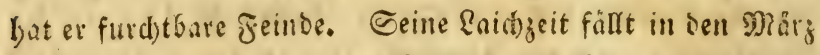
uno 2lprit, wo er fid gewöbnlich in föblungen aufbät, welche das Waffer unter ben gref̃en Cieinen verurfactit. Gein freif̣) ift mobrfameckend uno geiumo, uno nimmt beim Sochen eine rötblid)te Farbe an. Man fecht ibn ges

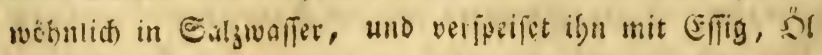
und Pfefrer. 
farbe if braun, bie Seiten find oberwärts fdwarz geflect, und nad) unten weís. Der \$auá) und die Floffen rôtbrić)t,

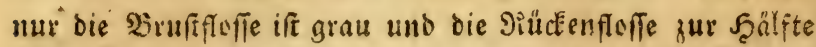

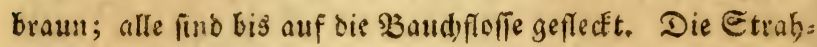
len in ben şruffloffen find gelb und fhwarg geflectit. Sit ber langen Siüdenfoffe find 12 frarde nad) binten ge Erüuma te Etacheln. In der Waudflute if ein, uno in ber affer= fleffe find 3 Etad)ell. Esine Sånge beträgt 1 Fubi. (E: ift ein Sewobner bes mittellanbifiden giteeres und des Die=

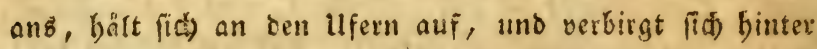

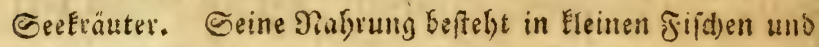

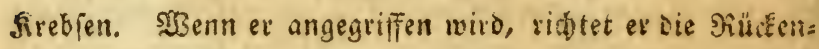
foffe in sie 5oóne, uno verwunder badurci) mit feinen Cta=

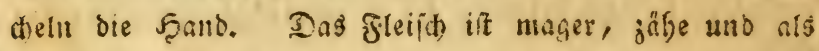

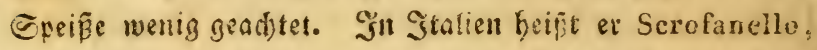
in Garbinien Scorpina. Die ditten birlten frine Cots: deln für giftig.

2) Dergrofí) d)eriau. Scorpaena scrofa. Linn. Bféf aนร1. Fifde 11l. 10, t. 182, (11, 100. 1. 182.)

Die Souppen fund grop̉. Die untere Sinnlabe, cie Bacfen und die Seitentinie find mit Fafern befezt. Int ser Siemenhaut fino 6 , in bet Brufffoffe 19, in ber Baudifleffe 6 , in ber 2tfterforfe 8 , in ber Sabanzfoffe 12 ,

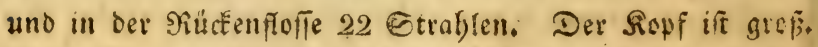
Seide fimuladen find oon gleidber Sänge uno mit megreven Sieiben furgiger nach binten getrummter Bübne befejt. Die 2urgen baben einen fohrargen Gtern in einem gelbliditer uno rölblichten singe. Zn jebem bervorrabencen 2fugen. rande fteben brei Gtadjeli uno eine farde Fafer. Zhm 


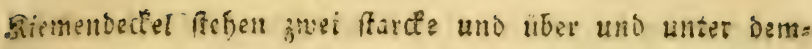

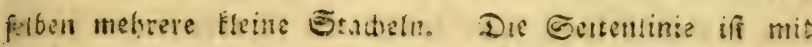
Eleinen Fafern beiegt. Der bisuch if lang, unt ber zlfter vom Sonfe weiter als vom Sdhwange entfernt. Die Birunds farbe ift braunrotly ins weik̉e fwieleno uno braun geflects.

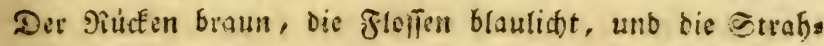

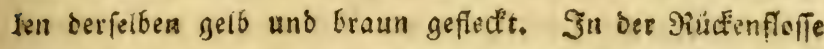
find 12 , in ber afferflotie 3 uno in Der Baudyletie 1 far, der nach) binten gebogener Etect)e!. Seine Räng: beträgt

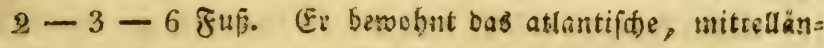

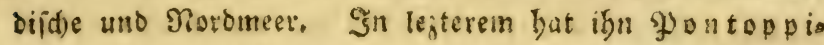
ban in ber Bröbe con 3-4 Elfen gofunioen, welde fän= ge er in ben anberen Meeren nidjt erreițt. Seine $\mathfrak{N a b}_{\text {s }}$

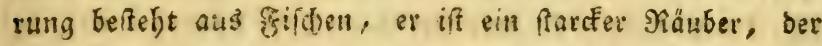
fogut aud) Ecevëget verfülingt. In Ştalien wirb er ges

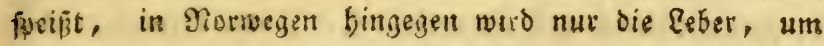

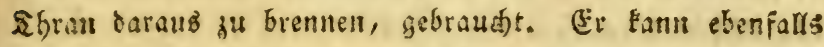

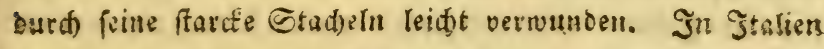
bzipit er Scrofano, in Cardinien Scorpena.

3) Der 3 a uberfifor. Der fónpentofe Ders dientopf. La Scorpene horrible. Cepéde 11. p. 580. pl. 17. fig. 2. - III. p. 261. Scot. paena horrida. Linn. Bloch ausi. Eifde IIr. 15. t. 183. (II. 10.6. t. 183.)

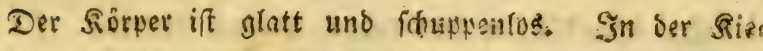

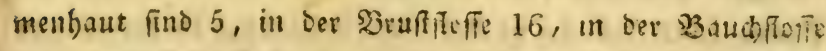

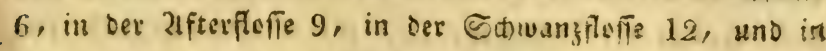
Der Siuckenflutie 20 Gtrablen Der grobe ßopf if mit vielen Syötfern, Stadeln uno Bertisiungen befezt. Dbers

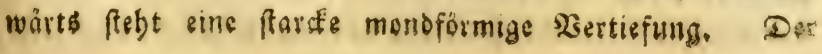


Muno offnet fíd) oberwårts uno iff weit. Die untere Simn labe bat die (bieftalt eines J̧ufeifens, ift oben rund, böfese rigt, uno enbigt fild unten in 2 Evisen; bas Cbarnier if unten an Der siemenoffunng, uno fdhest bie Unters Einnlabe an bie sbere, mie ber Decfer an eitner Dofe; beibe find mit vielen Eleinen 3ähnen befegt. 2or jebem

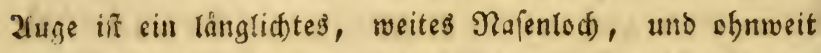
Der Oberlippe fino 2 runblid)te frafern. Die fefre fleinen 2lugen baben einen fowmargen Stern in cinem getben গin= ge; unter bemfelben fiebt eine ftarcte Sertiefung Sopf,

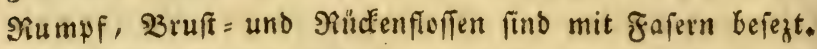
ভåmmtliche flotien baben eine bicke Şaut und fartfe

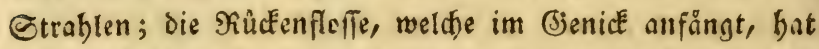
13, Die 2ffterfoffe 3, uno bie Baudfleffe 1 ftarfen Ctrabl, Die übrigen Gtrablen fino gabelfürmig. Dex ganze fiorper

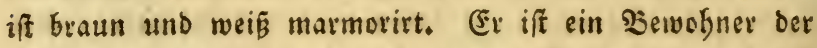

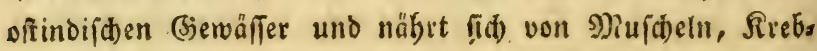
fen uno fifden. Wegen feiner wunberbaren und nuffal= Ienden (jeftalt gaben ifm bie Deutid)en den Tiamen Sau= berfifd.

4) Der fliegende Drachentonf. La Scorpène volante. Cepède II. p. 580. pl. 17. fig. 3. III. p. 289. S corpaena volitans, Linn. SBlod aนร์. Fif́che 1II, 18. t. 184, (II, 109. t, 184.)

$$
\text { ( } \mathrm{T} \text { a b. 46. Pig. 73.) }
$$

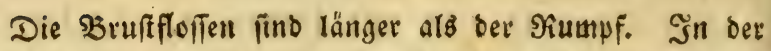
Siemenbaut find 6 , in ber 3 ruftfoffe 14 , in ber Baudib)

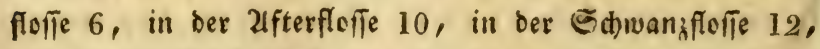

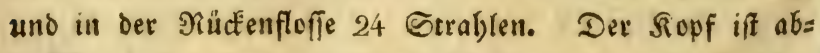
fdüfig, vorn breit, auf ben Getten jufammengebrückt, mit verfdiebenen Stadbell uno mit vielen zacfigten fafern, 


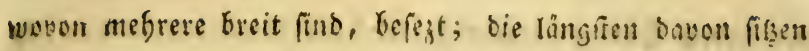
wher ben 2rugen uno die breitefien nahe am 23 incfel des

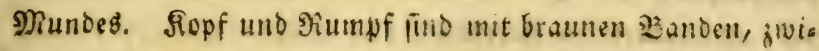
(千)en weld)en stangefarbene uno weipe Sinien ab́wed)feln, gegiert. Die Simnladen finto von gleither Ränge uns mit vielen Fieiben Eleiner fpiziger Băfne befejt. Die zlugen baben einen id)warjen Etern in einem weifen blau= uno fdiwargeftrablten Sing. Der Siemendecfel endigt fib in einen fpiţigen SSSintel und if mit febr Eleinen Sdjuppen befejt. Der গiumpf if mit Eleinen Sduppen bedecft. Die Eeitentinic if aus vielen Eurzen berverfefenden Sinten und

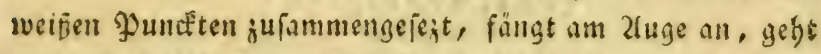
nad) bem Siüden unb enbigt fid) in Der Mitte cer Sodyuang=

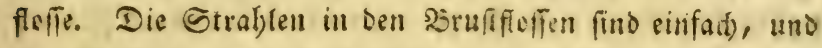

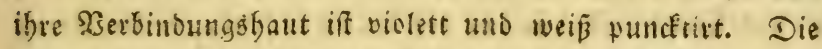
erften 12 Strablen in ber 9iuctéffeffe find ftochelid)t, braun unb geth gefledt, unten mit einer buneflen Şaut verbumben uno cben frei. Sin den Baudffleffen ift ber erfe Strabl bart und einfa(d), bie andern weid) und gabelfärmin; in ber 2lfterfleffe find bie 3 erften Etrablen fiadjeridet, die thbrigen

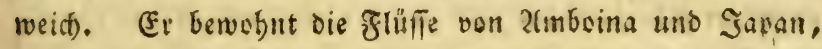
in welden er jesed nur felten zum Sorridein Eommt, lest von ber siut anverer fifde, bat ein weises, derbes und

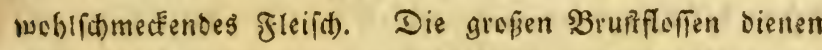
ibm, um fich, wenn er von feinen feinden verfolgt wiro,

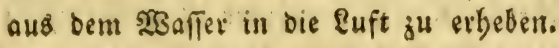

\section{Das Spiegelfifd: (5efdrectit.}

\section{Zeus. Linn.}

Der Gouf ift von beiden Seiten zulammengebrüct, vorn

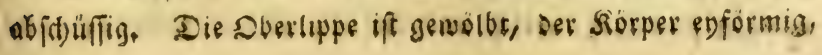


ouf beiben Eeiten zafammengebrüct, bünn, Gecit uno wie

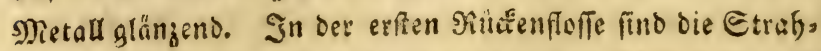
Ien mit baarartigen fortfäsen verlängert. (E\& fint bereity

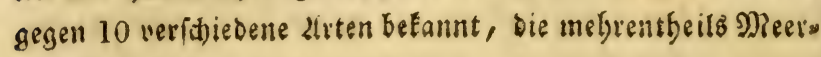
bewofiner find.

1) Ser Pflugf́ą. Der Cilberfifd. L'Ar* gyréiose Vomer, La Cepède IV. p. 567.

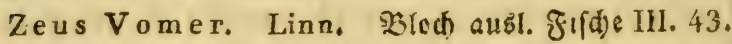
t. 193. f. 2. (II. 138. t. 193. f. 2.

$$
\text { ( } \mathrm{T} \mathrm{a} \mathrm{b} \text {. 47. Fig. 74.) }
$$

Der queite Strabl in ber Rüctens und afterfleffe über. treffen den Rumpf an \&änge. Sn ber Riemenbaut find 7 , in oer Baruffloffe 18, in ber Baudiffoffe 6 , in ber 2ffters flofie 22 , in ber Sdjwanzfoffe 19 und in ber siüctenflofie 31 Eitrablen. Der Sörper if breit, Dünn uno fatupenlos, Der Sopf famal und lang. Beibe Sinnlaben, woven bie untere bie längfte ift, find mit febr Eleinen ppiz̧igen ßăbnen befest. Die runben ajugen baben einen fdwarzen Stern in einem filberfarbigen von einetn rotben umgebenen アinge.

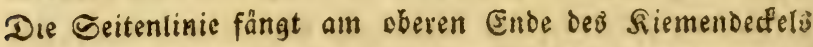
an, bilbet eimen Bogen nath Dem Rabken zu ullo verliert fid in ber Mitte ber Săwangfteffe. Der 2ffter liezt bill= ter ben langen und fd)malen $\mathfrak{B}$ audffiffen und bie 2 Sia. deln find vor ber alfterfloffe. Der Sörper ift in Brafilien filberfarben, ins blaue fpielend, in Norwegen biutgegen fpielet er ins purpurfarbene. Gämmtlide floffen find lang

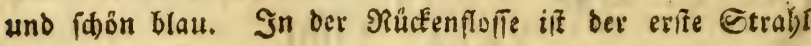
ftachelid)t, ber 2. 3. 4. und 5 te fint lang, ber 6. 7. 8. und 9te Eurg und fachelidit, Der lote ift wiebel lang und Dis äbrigen find Eurg, weid) und an Den Enden getfeilt; bice 


\section{Dronแng, Pisces. I8I}

felbe Sefhaffenbeit Gaben bie Etrahlen dev afferfloffe, nut Det erfte ift Itaúd)elid)t; die Errablen in der Bruft, und Baud)fluffe theilen fid in viele Zweige. $230 n$ gebad)ten 4 Etad)eln fino 2 vor ber Fiucétl = uno ebell fo ouel oor oer 2fiterflofie befindlich. Eeine Range betrågt $5-6$ Joll. Ex bewohnt bie brafitianifhen und norwegifiten Meere, lefit von Mu[deln unb Sirebsbrut, bat nur wenig zleifa, bas aber, forosbl gefod)t sis gebraten, woblfdimecteno ift.

2) Dep rifige Spiegelfị́, Le Zée rusé. La Cepède IV. p. 572. Zeus Insidiator. Lina. ed. Gmel. 1221. Bloch ausi. హiid)e III. 41, t. 192. f. 2. 3. (II, 135, t, 192. f. 2. 3.)

Die Mundöffnung ift Elcin. In ber Siementaut find

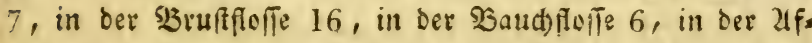

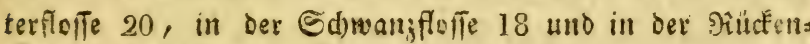
folle 2+ Gtrable!. Er ift wentgex breit als bie übrinen

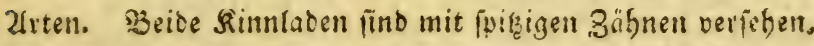
Die 2lugen baben eiren fllberfarbigen ing gelbe ipielenten

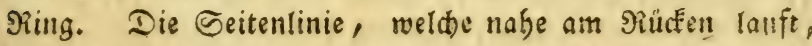

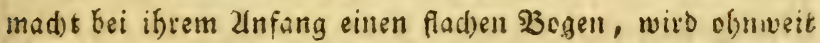

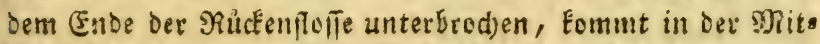
te Des Sơwanjes wieber zum 2sorfacin und verliert fith in beflen flofle. Der 2rfter ftebt bidt binter ben Eleinen Baud)fiffen, bei benell ber vierte Grrabl frachelicht ifi. Die Eeiten find filberfarben und mit vielen fdwargen fुunces

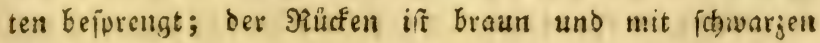

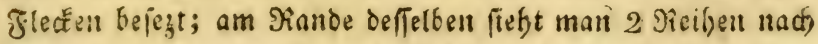
Ginten zu gefogene Etacteln uno ;wijhen biefen eine Jur: de jur zufnabme ber Flolle. In ter গilufenflefie lino die

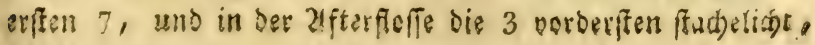


sie übrigen aber waits unb an den Enten getheilt; bie Exablen in ber $B$ ut = uno Etwantleffe fino in viele

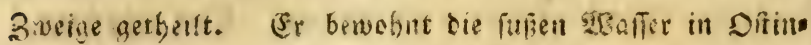
bizn, näbrt fid) oon Snjecten ourci) Sift auf eıne ganj eiges ne 2irt, wexu ifin fem eigener SMechanis̆mus bient. Der

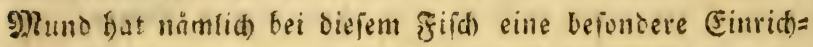
tunig: bie untre fimnlade, welche gerabe aufiteht, bat ibr Bielente in sem ssindel beim 2lnfang des sinns; fafit man biefelfe an, un ben giuno zu offnen, fo beugt ex lid) vors

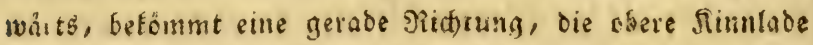
ziehet fid) beraus, unb eş entifebet basurd) eine töbrenföra mige Camause; bie gluntofinung, bie bisber obell ant Sowfe war, iff jezt in Der 93itte Defleltien; ziebet nun ber grific) on Doertinnlabe ein, fo folgt itge die untere nach und

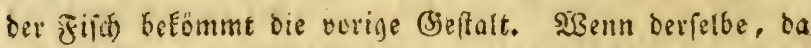

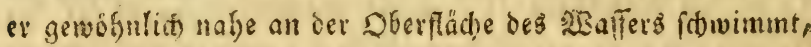
die TSalfermúfen uno anbere Infecten an den Lifern ober

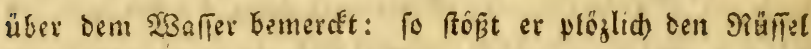
bervor, fprijt bas burdi) bie Siemen eingefogene $\mathfrak{X}$ affer auf bie Infecften und indem fie damit berunter fullen, bafchet ex ile. Se bat ein fettes und febr wohliamedenoes Fleifo, weldes ftatt ber Sduwen mit einer bünnen Şaut, bie wie en Silberblutt argifieht, umgeben iff. Man fängt ifn forvoht mit bem פetze, als mit ber angel, wenn leztere mit einem fliegenden Snfect verfeben wirb.

3) Der Gonnenfifd. Der Meeridmist. Der (5t. Weterfifd. Le Zée Forgeron. La Cepède IV. p. 577. Z e us Faber. Linn. B(od) Fifde Desutichl, II, 24, t, 41. (II. 33, t, 41.)

Sie 2lfterflofle ift boppert. In ber Sismenbaut find 7 , in bev Siuffente 12, in ber Bauchfoffe 9, in Der exfen 
afferflefie 5, in Der zweiten 21 , in ber Sdinamiforie 13 ,

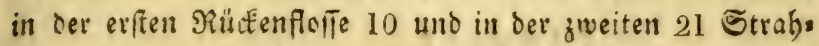
Ien. Der Sopf if greś und bie Mundóffnung weit. Die - bere Simntabe fteft vor ber untern weit hervor und oek

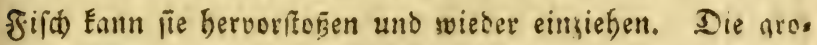
fent Zlugen baben einen fifwargen Stern in einem Betfen Sinnge. Die Bacten und Seiten furb glänghend grün s get5.

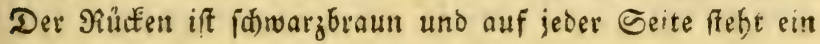
fidwarzbrauner Fieff. 2(n ben St)ulterEnoden fiefen 2 Epitzen berver, nämlich eine Eür'jere, weldte nach bein

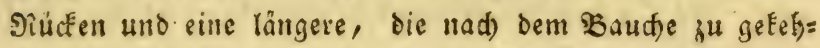
ret iff. Die Seitentinie entipringt binter bem Ziuge, lauft

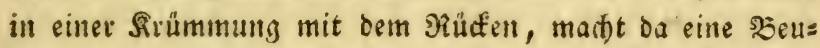
gung und verliert fid in ber Mitte ber Sdwwanffolfe. Der

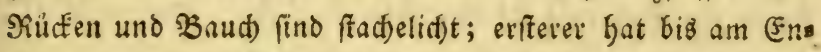
De ber zweiten Rüctenflofle nur eine Reibe einfacter, von ba an aber bis an bie Sdywangforfe eine Mieife boppelter

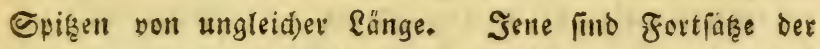

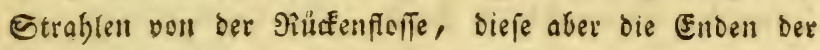

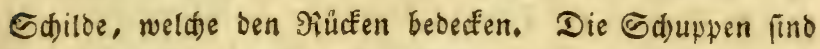
Elein unb bünne. Die Brufteflefen Eurs, rundlidtet, graut sno getb singefafit und wie bie Strablen Der Baudffloflen vielfrafligt. Die Strablen ber erffen afterfeffe geben in

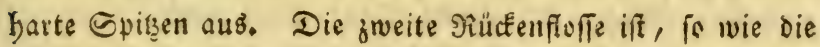
jueite 2ffterfolle, grau uno in beiden find bie etrablen einfad). Die runbe Sdmanzfelle ift getb geftrahtt. Sei=

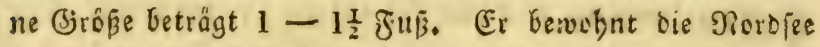

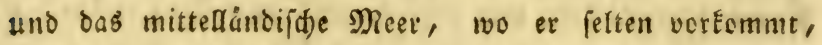

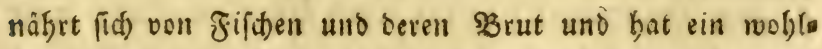
fotmerfentes gleifó). (Ex if in FranEreid) su(t) unter bem Namen La Dorée, St. Pierre, in Statien Pesce san Piedro, Citula, Rotula, uno in Dalmatien Fabro betumt. 


\section{Das Sdbollen: (5efthlectit. Pleua}

\section{ronectes. Linn.}

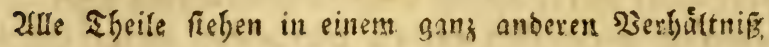

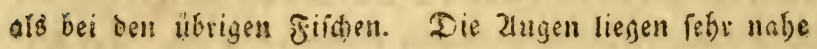
beijammen, auf einer Geite Dee Sicpfes, woven gewobntids.

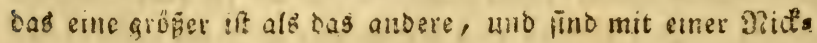

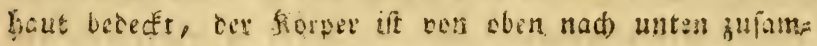
snengeoritct uno flad), bie chere glade ein wenig erhafers unb von sunther Garbe, bie untere aber gall; platt unb weis. SRüaten und Baud geten in ciuc idnetioformige (Gea

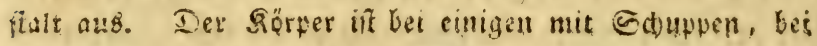
anseren mit Stacheln befekt. Der flopf if Elein, ber Sjumb Bitoet einen $30 g e t$. Die Simnlaten find von ungleider:

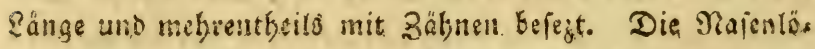

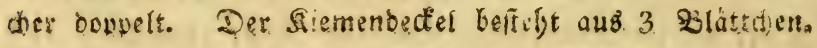
Die Sismentgaut ift 4-7frablicht. Die Seitentinie iff ber einigen glatt, bei anderen fingegen mit Staheln bejejte Der 2lfter liegt nabe an Siepfe. Eie liegen melfrentbeils. in Desn (3runbe des Meeres ifitre, wo fie ifren Sorper bis an bell Siopf im Ganbe verifecten. Sie bewegen fith auds sidft in ciner geraben, fonbern in einer fdhiefen gitistung

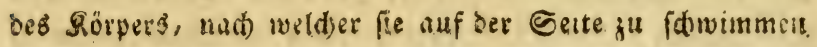
fdeinen. Şsegen des Mangels der Șdinimmblaje Eônuer

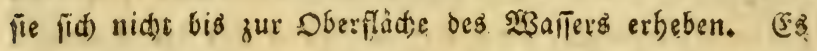

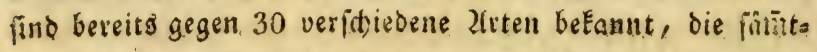
liá) NRecrbewubner find unto pon andern Igieren reben. Des Fitter von finne und andere, wie aud $\mathfrak{B}$ (od) theilers,

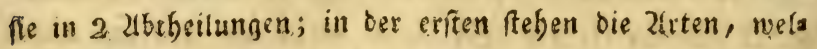
d)e bie zlugen auf der red)ten. Seite, in ber jweiten aber die, welthe bie dugen auf ber timeten Scite baben. Ulm nun tichs

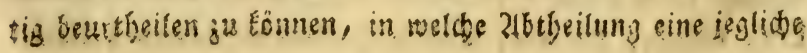


2(rt biefer gifăde geföre, baif man fie nur auf bie flad)e Qeite legen, da denn die zlugen auf ter erhabenen erfdeiz

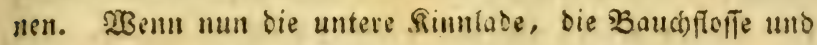
ber after zu ung gerid)tet find uno dann bie Zfugen unferer redten Seite gegentiber ftehen, fo fagt man, ber Fifd bat Die Zlugen auf ber rebten èceite, freben fie aber unjereq

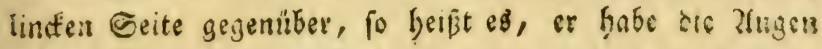
wuf ber lincten Eeite.

A. Siectitugige Schollen, mit oen Atugen auf Derechten Seite.

1) Die $3 e b r a=\subseteq d$ delle. Die banbirte 3 ung: Le Pleuronecte Zèbre. La Cepéde IV. P. 643. Pleuronectes Z ebra. Linn. ed, Gmel,

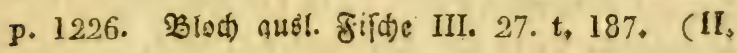
119. t. 187.)

Soicle braune Suterkande ain geîrectéten zungenförmis

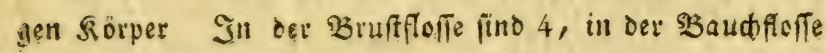
$\hat{\sigma}$, in ber 2ifrerforfe 48, in ber Edwwangfleffe 10 uno in

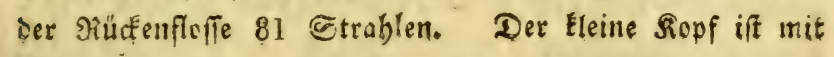
Sahuppen bejegt. Die Sinntabell, von welden bie obere Sie längfte ift, find mit fiviģigen Zăhnnen bewaffnet. Die febr fleinen alugen baben einen punftartigen fodwargen Etern in einem meergrünen গing. Der গiumpf if miq gejäbnten Schuppen bedrett. Die Seitenlinie lauft geraie

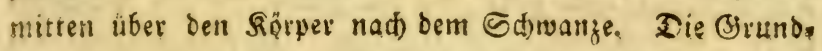
farbe der oberen Geite ift an ben Manndern bråuntiobt, in icr Mitte weiß mit braunen Querbanten, bie parweife

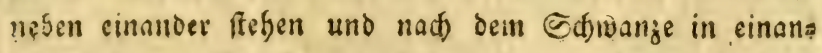
Der laufen. Die flefien find gelb uno braun bantirt, Die Straflen in fämmtliden floffen einfad, auß̧er beneis

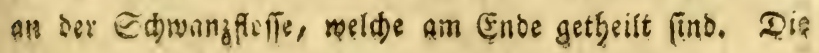




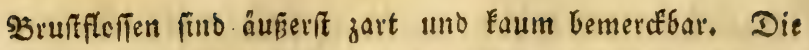
Siücen = und 2fferflefie mit Der Sd)wangfloffe verbunden uno nimmt erftere an ber Dberlippe iffen 2fnfang. (F) bewobnt bie offindijchen Meere, left vermuthlid, wie bie übrigen 2rten, von Muideln uno Srebsbrut und bat sin wobliomectendes Fleir.

2) Der Şeiligebut. Die 5̧eirigebut=S币olle. Le Pleuronecte Flétan. La Cepéde IV. p. 601. Pleuronectes Hippoglossus. Linn.

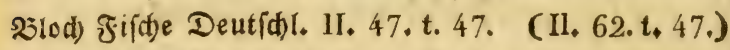
( $\mathrm{T}$ a b. 48. Fig. 75.)

Die Sdwanflorfe bat einen monbförmigen 2(usfonitt. In dex Siementbaut find 7 , in der Bruftfoffe 15 , in Der

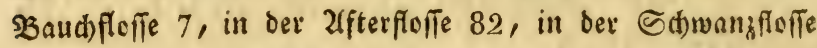
16, uno in bet Bückenfleffe 107 Strablen. Der Sepf ift Fiein, bie Mundojīnung meit. Bcibe Sinnlaben, rovon bie véere beweglid) ift, fino mit vielen langen, fpirzigen, getirummten uno von einander abitebenden 3äbnen befekt. Die bidht beifammen ftebenden zugen find grefi und baben einen fowwargen Stern in einem weipen Singe. Die obere Seite ift leberfarbig, zll 3eiten fdowärlid)t, bie untere weif. Seibe Geiten finb mit länglidhtrunben, weid)en Sd)uppen bebecft. Die Seitenlinie mad)t an Der Bruft einen $\mathfrak{B}$ ogen uno gebt von da gerabe bis zur Sd)wang= floffe. Die Bruftflefe ift länglidt. Er Eommt wegen ber monbförmigen Sdwangfoffe, ber Freiten Riemenbaut, bem geftrecften unb fieifdigten Förper mebr mit ben übrigen Fifchen überein, als irgend eine andere Sdjollenart. 2in (jrổe übertrifit er fait alle andere Geefifde, indem mant weldhe ż $2-3-400$ Pfunden antrifft. In গlorwegent werden fie fo grof gefunden, dafi ein cingiger berfelben 
ein ganjes Soot kebectet, unb ven feinem Fुleifale $1-2$ Tunnen angefüflet werben. Fr benobnt ben nöroliden

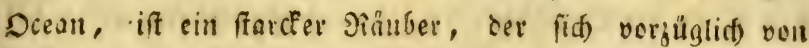
Dichen, Sdellfictien, Sirbjen uno bem an ben Felien băngencen Sechaajen (Cyclopierus Lumpus. L.), ber

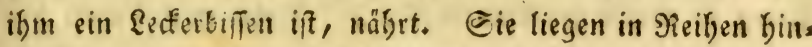
ter eitandes auf dem Meeresgrunde unb lauern mit aufges fiertem Rachen auf bie vorberfhwimmenten Eeetbiere. (5x roird mit bem Stadjel und an ber 2lngel gefannen,

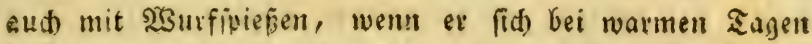
auf cie Gandobance ciev fladbe Gtellen des Meeres bes giebt. Sein fsleifd) iff fett und thranigt, es wird volt ben (Srönländern fowohl frifd) als getrod́net verfpeiŝt; aud) verjefien fie die Şaut uno bie Reber. Die Magenbaut gefraudjen fie ftatt ber Fenfferfdeiten. In کdweden,

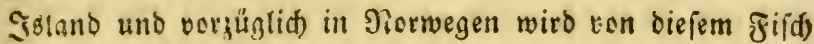
Ser befannte Sa ff und Siócf el gemad)t. Sener ift nid)t\$ onber's, als bie flollen mit ber baran figenden fetten $\mathcal{F}_{\text {gaut; }}$ Diefer aber, bie nach ber \&ange gefdnittene Stücfe bes fet, ten fleifcheş; alle bieje Stûffe werden mit Salzeingerie= bent auf Stangen geftecft und an ber \&uft getroctnet; aud) pöfelt mant biefelben ein, ba lie an Biefdmact ben 5ering übertreffen follen. In Salland und in Şamburg wirb ons Fleific) olejes Fifices an ben gemeinen Miann für einen ges

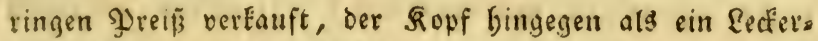
biffen theuer bejablt. Sie Eaichen im frübjabr uno pejent ibie Ẽyer an ben Miecrufern zroijden ben Eteinen ab.

3) Die gemeine (क) Pleuronecie Plie. La Cepède IV. p. 628. Pleuronectes Platessa. Linn. Bloci) Fifde Deutid)!, II. 31. t. 42. (II, 42. t. 42. ) 


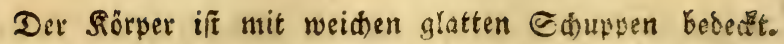

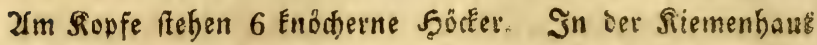
fino 6 , in Der 3 ruffroffe 12 , in oer Baudflofie 6 , in bes

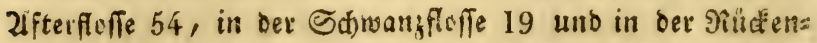
floffe 68 Strablen. Sie 2ugen baben cinen blautidten Stern in einem gelbgrunen Sing. F̧inter den 21ugen lie: gent bie 6 faöffer, bavon cer erfe ber gröbte ift. Der Siös= per if auf ber Dberfeite braun und afdgrau marmorirt, ouf ber untern weí uno fo, wie bie Siuffen = und 2lfters flefie, mit runben, orangefarbelten flecten beiegt. Die Seitenlinie lauft gerabe, mitten über ben Sïrper. Die

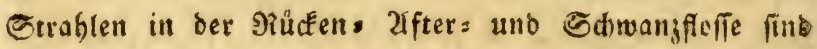
länger als bie 5aut, weldhe fie unter einanber verbinbet; bie lejtere iff lang und am Slunde mit Shuwven befeght.

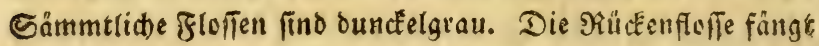
über bem 2luge an. 2̧or ber afferfloffe fteft ein farcfer

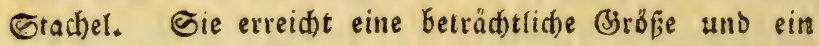
Gewidt von 15 - 16 Pfunder. Sie ift ein 3 Bewohnes ber Nord = uno Ditfee, wo fie fid) in (irunbe aufbält und

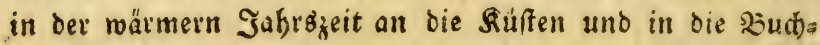
ten, nach Strômen uno Slüflen binkegiebt. Ş̧re Siabs rung find Eleine Fifche, Mufheln und Gonnetentrut. Die Eaidjzeit fält it den Februar und Märg, wo fie ifre Eyer

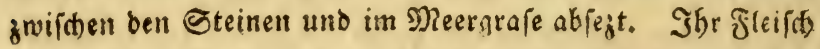
if febr famathaft, unb vorgüglia) beliebt if bas ven groficer Sdollen, weldes fefter und fetter ift, al\$ baร von bers Eleinern. Gie werben frifh, ober an ber Euft getroctinet, verpeifft. Die größere 2rt wiro elienfalls getrectnet und

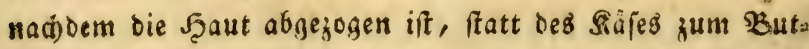
terbiod gegeffen. Sie werten gefangen, mit der Grunb: f(b)ur, an welche man fifthe befeftigt, ober aud ourch bas bas fogenannte 2 uttited en, indem bei bellem Sonnesty 


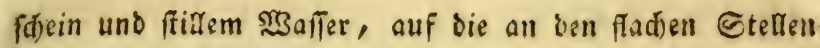
liegenden Sdtodfen, ein B̈lei mit einem Eifen von 4 Eprigen

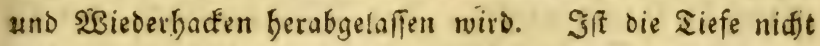

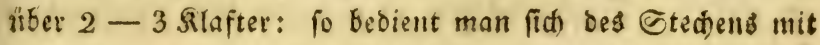
siner Stange, an weldher ienes Eifen befeffigt ift.

4) Der Flunder. Flonber. Die Butte. Le Pleuronecte Flez, La Cepède IV. p. 633. Pleuronectes Flesus. Linn. Bloch) Jifiche Deutfdjl. II, 39, t. 44. (1I, 52. t. 44)

Zuf Der Dberfeite frehen eine Menge fleiner Stachein, welde ibre Oberfäd) raub madten. 2fn ber Seitenlinie

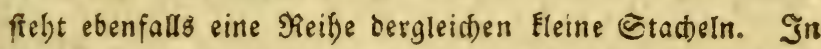

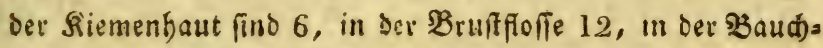
floffe 6 , in Der ?ffterforfe 44 , in Der Sdimanzforfe 16 uno

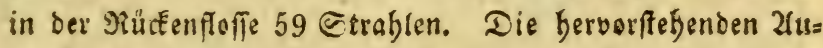
gen babeft einen fówarzen Etern in einem getben ßinge. Die sbere Seite if buncieibraun und burch olivenfarbige, grüngelbe und fक̆warge Elerfe unterbrođinen. Die untere

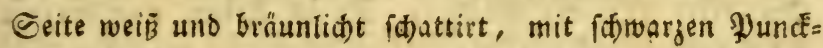
ten befprengt. Beibe Seiten find mit dünnen, länglititen

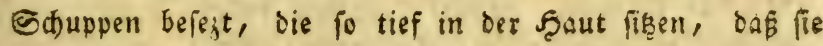
taum fintbar find. Die Floffen find beáunticht uno bie

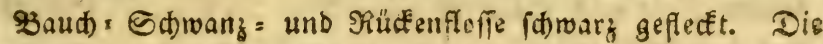

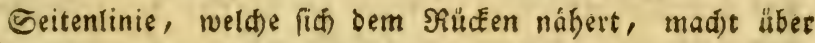
Der $\mathfrak{B r u f f f l o f f e}$ eine 2 Beugung und verliert fid) mitten in bes

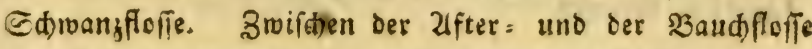

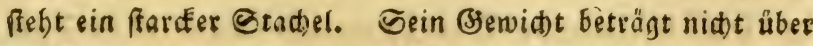
6 Pfund. (Er wird in ber Nords und Diffee angetroffen uno begiebt fich im Frübiabr an Dte Ufer und in die Miüns Sungen der Gtröme, wirb eben fo, roie per vorbergebents 
gefangen und gefpeif́t. In Engelono begiebt er fï) wzit in bie Flufe binein, wo er eine bellere Forbe und ein weis

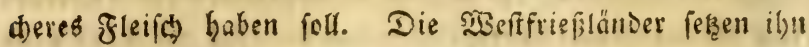
in Seide. In Francfeici) ift er unter Dem פamen Hez betannt.

5) Die (5labree, Sliefde. Le Pleuronecte Limande. La Cepède IV. p. 621. Pleuronectes Limanda. Linn. Bloch Fijde Deutid)l. II. 45. t. 46, (II. 59. t. 46.)

Die Bübne find ftumpf uno Elein. Die Sduppen ges zăbnelt, raub unb bart. Die Seitenlinie bilcet bei ifrem 2lnfang einin Bogen. In Der Siemenbaut find 5 , in Der

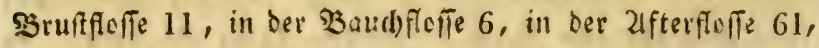
in ber Sdwanzfoffe 15 und in ber 9ưdenflefle 75 Strabs= Ien. Die sbere Ecite ift getb, bie untere weif. Die ßnn. laben fiub von gletofer fange. Die hervorragenden Zugen baben eitren fohwargen Gtem in einem goldfarbenten ringe. Gåmmtlidie Flofien baben auf ber oberen Eeite eine braun= gelbe, bie Sd)wanjfleffe bingegen eine sunckelbraune garbe. 2Im 2ffter ftebt ein Stad)el. Er ift fleiner und feltenti als bie vorkergebende 2lit und ebenfalls ein Bewebner ber Dit = und Norbjee. Seine Nahrung beftebt in 2 Sümern

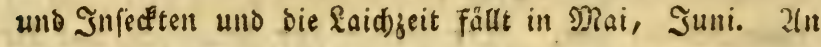
feinem (jefdmad ubertrifft biefer Fild bie gemeine Sd) unb ben Flunber, wirb übrigens auf biefelbe art gefangen uno veripeifit. Sn frandfeid) if er unter dem গiamen Limande befannt.

6) Die 3unge. Die 3 ungenidolle. Die Sole. Le Pleuronete Sole. La Cepède IV. p 623. Pleuronectes Solea. Linn. Blolit) Filde Deutid) II. 42. t, 45, (II. $56, t, 45$.) 
Der Fổrper if länglid)t, raub, bie obere Sinntabe hers vorfethent. In Der Kiemenbaut fint 6 , in ber Bruffflofle 10, in ber Baudffoffe 6, in ber 2lfterfeffe 65 , in ber

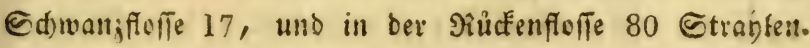
Der Fourper if zungenartig seffaltet, faft breimal fo lang als breit. Die obere und untere Seite find mit Éteinen, barten, gezăbnelten, rauben Sdupwen bebectit. Sene if olivenfarbig. Die obere Sinnlabe ift mondförmig ausges fofnitten und bie untere allein mit mefreren Sieifen fefs

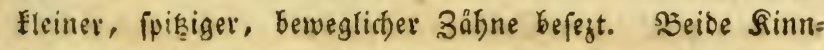
laben find auf ber untern Seite mit fehr vielen Eleinen weişen Bartfajern verfiken. Die weniger nahe beifammens frebenden 21ugen baben einen blauen Stern in einem getben

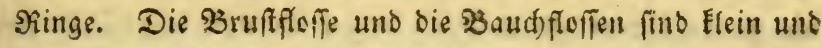
iene fdrwarz eingefä̈t; unter ben lejtern ffelyt ber affeer Didft am Sopfe uno an biefem ein Eurzer ftarffer Stad)et. Sâmmtliche flofien find oben ofivenfarbig unb unten weiß̈.

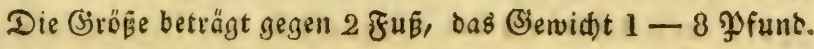

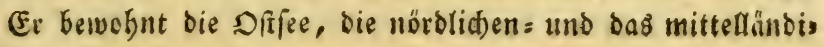
fife Meer, lebt von den Eyern und Der Brut anderer Fis

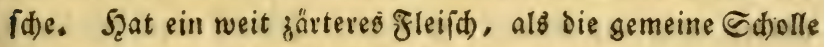
und witb eben fo wie biefe gefangen und verfweişt. In Zlabien if er unter bem Namen Samakmusi ( Mo ofe fifd) ) Tefanut.

B. Eindésagige Sthollen, mit ben 2 ugen auf oer linden Seite.

7) Die Dopperrinie. L'Achire deux-lignes. La Cepéde IV. p. 663. Pleronectus bilineat u s. Linn, ed, Gmel. p. 1235. S3lod) aน81. Fi: idje III, 29, $t, 188$, (II. 121, $t, 188$.) 
2rm Sörper ftehen 2 paraliellaufende Eeitentinien, wo. son bie eine did)t am Rücfen und Die andere mitten am Sïrper. Die Brufffoffe feblt. In Der fiemenbaut fins 4, in ber 2lifter = Sd)wang sno Siüclenfiffe 174 Ctrablen:

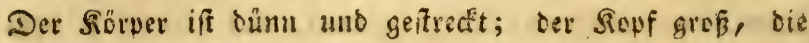
Mundoffnung Flein und balbmon förmig. Selbe Sinnlas Den find mit Eleinen fumpfen Zälynen befezt. Die Eleinen 2lugen baben einen weisen Stern in einets feegrünen unb weiken Singe. Sopf und Siumpf find mit Eleinen rundiit)

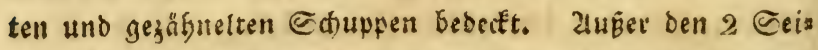
tenlinien (ieht man nod) 2 in bie Duere gerid)tet, Davust bie eine an ber untern \&ippe anfängt, am Siemendectel eis ne Beugung mact), und fïb in oie Seitenlinie verliert; Die jweite nimmt gleid) Darunter an ber nämlichen Seitan: linie ifren 2lnfang, mo lauft quer über ben fija nath oer wbern bia. Sämmtlid)e flofien fino braun uno baben cills fadte Etrablen. Die গiúckenflolle, welche sen Siopf un: giebt, verfiert fid mit ber afterfoffe in bie Sobwankfoffe. Der 2ffter ftebt bet ber Ricmenöfinung. Die sbere Este ift nach ben Siändern zal braun uno in bể פritte gelo, bie

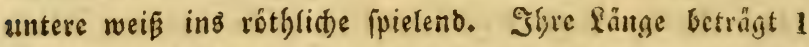

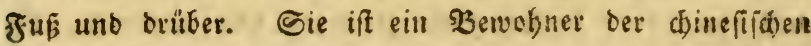
Meere, und bat wabridbeintic) ein wobliđumectenoes steifa.

8) Der Notbitt. Le Pleuronecte targeur。 La Cepéde IV. p. 652. Pl e uron e ctes pun st a tus. SBloch ausi. Jifite III. 31. t. 189, (Il 123, $t, 189$.

( $\mathrm{Tab} .49 . \mathrm{Fig}, 76$.

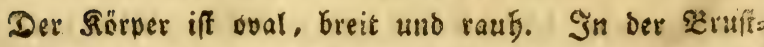
Toffe find 11 , in ber 3 aud)foffe 6 , in bev afterfloffe 68 , 


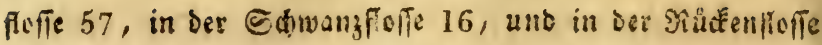
71 Strablen. Det breite Fopf ift Elein, bie Mluneöfinung weit und bogenformig. Die untere Sinnlace fieht etwas beroct, beide find mit mefreten $\Re$ seiben Eleiner, fpisiger 3ăbne befezt, und fönnen vor = und rüriwart bewegt wera ben. Die Augen baben einen idwwarzen Stem in einem weiben Singe. Die S(t)uppen finto långltht uno weid).

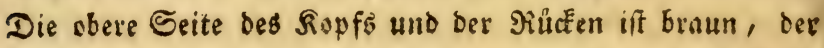
গumpf braun und gelblidt marmorirt, bie untere Seite weiß. Die Seitenlinie madt nabe am Sopfe einen Bogen und tauft nachber gerabe mitten über ben Sörper weg. Die Jlefien fino braun, weiß uno gelb marmorirt. Die Miüteles flofie fängt bidbt am Dberktefer an, und endigt fich an bee (Sd)waniffoffe, weld)e lang und etwas abgerunbet ift. $2 \mathrm{~mm}$ 2lfter fiel)t man Exinen Stadhel. (Er erreid)t eine anjebnlis d)e Gröbe uno if nebft Dem Steinbutt ber freiteife im ganzen (jefdled)te, wird als ber gemeinfte allentbalben in Det Nordee angetroffen, wo er lich im (Firunde aufbalt, und fommt von ba bâufiger als die übrigen 2frten in den Elbftrom binauf, baber nennen ibn bie Samburger ben (5) Ib. butt. Er if wie oie gemeine Sd)olle ein fardier Paub: fiid), uno wirb auf eben bie 2trt, und zrwar am băufigften im Şerbite gefangen und eben fo veripeigt. In Siom un enedig ift ex unter bem Namen Rhombo betannt.

30) Der Steinbutt. Dotnbut. Le Pleuro. necte turbot. La Cepéde IV.p. 645. Pleu= ronectes maximus. Linn. 'Slod Fifide Deutfकl. II. 53. t. 49. (II. 70. t. 49.)

Der Siörver if mit Eleinen Enödernen Erböbungen bes fezt. In Der Siemenbaut find 7, in Der \$ruftiole 10, 


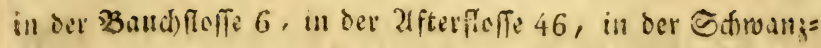

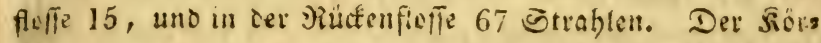
per iff lunglidtermo, auf der oberen Sette braun und getb marmerirt, und auf der untern wets mit braunen flectent. Die Säoter auf Der obern Seite find weit gré̈er als bie auf ber untern, und fcite find mit jorten búnnen 3 djuppen belegt. Der אopf ift brit lino raul). Die grofien Zlugen baben einen meerglunen Etern in einem braunen פinge. Die untere אumniace it berverrageno, uno beibe find mit

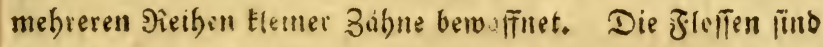

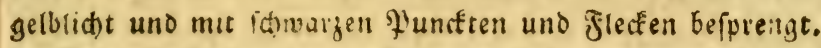
Die Geitenlinie lauft gegen der Bruft bin in einen Begent, von da gerade mitten uber ben sórper weg. Er erreidft

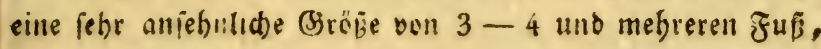
und ein Bsewidt von $20-30$ Pfund, if ein Bewebs: ner ber Noro = und Dffee, und des mittelläncifden Mees res. Der Sang, ber vor jügltid mit oer angelidnur gefdieft,

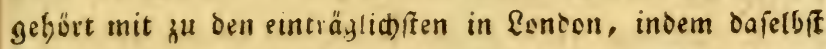
jährlid) an 30,000 N) fund ju Marcte gebradjt werder.

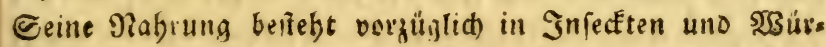

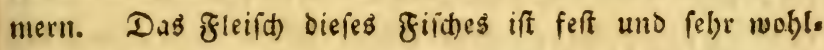
fdimectend. Err ift in Frandfreich) und Engelano unter Dem Namen Turbot befannt.

11) Der linde Stadelfiundex. Der Statít. butt. Le Pleuronecte moineau. La Ce- pedeIV.p.652. Pleuronectes Passer. Linn. Blod Jifide Deutidl. 11.57. t. 50. (II. 74 t. 50.)

Der Kopf und bie Seirenlinie nad) bem אopfe gu fiind ftadtelidt. In ber אutemenbaut uno Baudflofie find 6 , in

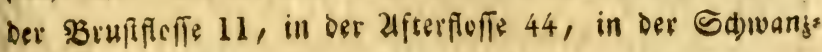


I96 Sierte Staffe. Fif

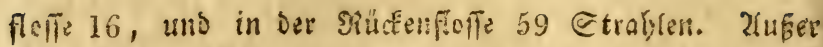
Dem sopfe und der Eeitmintie if aud Der (J)rund Der Strablent in ber Siübens unb Ifferfolfe init Enöcternens (Erböfungen, auf welden viele Stacheln ferehen, veriehen; Der übrige Sheil bes Sörwerg bingegen if auf ber Dbers fläh) glatt. Die obere Seite if grau und gelb marmos

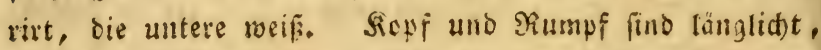
Die untere Sinnlabe bervorftebent, unb beibe mit Fleiness 3ăbnen berafinhet. Die bid)t beifanmen frefienoen flemen 2lugen baben einen grüngeiblidten Etern in einam weibbraunen Эiinge. Seide Geiten find mit fleinen tünners Esthuppen bedecft.o. Die Eeitenlinie bat beinahe eine ges rabe Siddtung. Die gloffen find gellitidit und braun ges

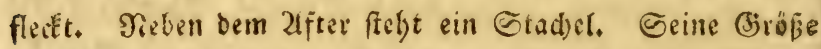

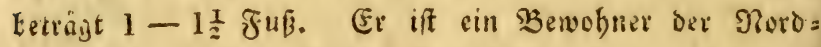
uno Diffee. Eein jeilid ift woblfitmectend und etwas härter als bas bes flunbers. (Ex wiro auf eben bie 2art, wie die übrigen biefes Gefdledts gefanjen uns veripeißt, unb von viefen mit ben Jlunver fälíd)lich für sinerlei fiid)

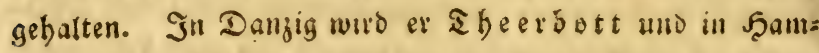
burg Struffoutt, und wegen feimen Zugen auf bee

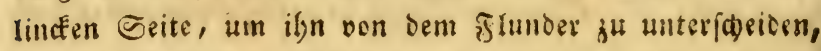
aud) verÉbrter Elb butt genanist.

12) Der argus. Le Pleuronecte Argus. La Cepède IV. p. 652. Pleuronectes Argus,

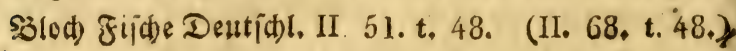
(Tab. 50, Fig. 77.)

Der Säoner ift mit bal6monoförmigen blauen glectên befegt. In ber Brufferffe find 10, in ier Saudfferfe 8,

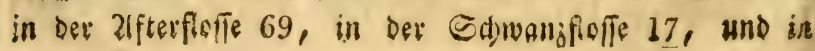




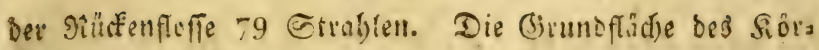
perb if weis. Die idjönen Flecte fint bellgetb mit brau= nen Puncten bejprengt, bellblau in einem ganzen Birčer,

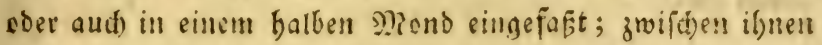

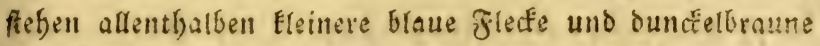
Sunctéte. Die etwas weit ocn cinander alyêtehenden 2 hu= gen baben einen blauen Gtern in einem weişen und brau=

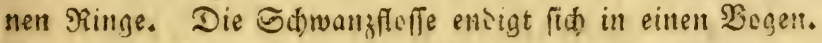

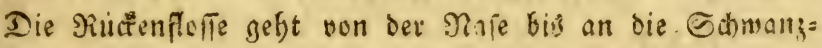
floffe. Beide Seiten fint mit Eleinen veidfen Schuppen befegt. Die Eeitentinie madjt über Der Brufffeffe eine geugung, uno lauft von da getrabe mitten über Den $\mathbb{S}_{00}$

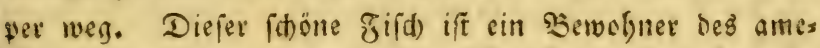

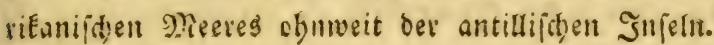

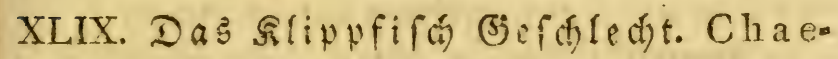
todón. Linn.

Der Sopf und sie Miundoffinung fint Etein, die Sips

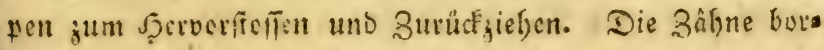

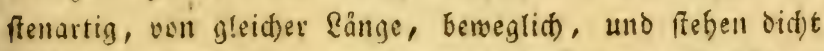

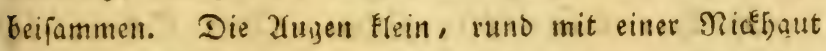
verfében. Die Nafentoldter soppett unt Elein. Die Sies menfaut bat 3 und mefrere Straflen. Bei einigen ftebe am Bacfenthatien obntiveit Dem Miunse oder am Stemen= Deckel ein Etadgel. Der Förper if breit, bum und ven

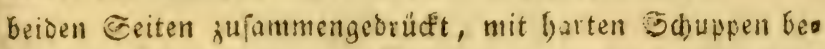
Decft, uno bei ben mefreften mit Suerbunben geziert.

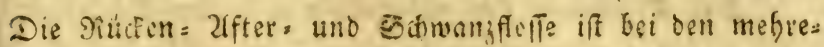
ften fieif und mit Ghupper bejegt. Bei allen find in ber

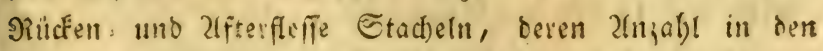

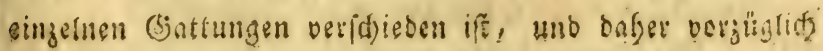




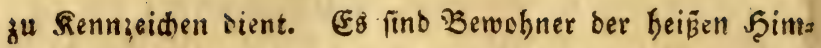
metsitrithe, beren bereits uber 60 verideiedene Arten bess Eanut find.

1) Der Bogen. Rlipufifd. Der sogenfila. Le Pomacanthe arqué. La Cepède IV. p. 521. Chaetodon arcuatus. Linn. Sled alaf. Fild)e III. 76. t. 201, f,2. (II, 176, t. 201. f. 2.)

2fuf rem braunen Sörper liegen 5 bogenförmine weife Bánder. Sn der Siemenbaut find 6 , in oer $\$ 3$ ruffiffie 14 ,

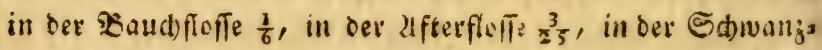
flofle 14, und in ber Rüctenflofie ${ }_{4}^{9}$ Strablen. Son bell 5 weik̂en Bândern ungiebt das̉ erifte den Miund, bas lejre

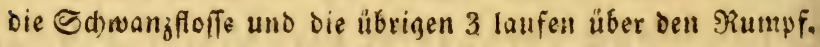
21m Siemendecfel ftebt ein Strabel. Die Beitenlinie bes fteft aนช่ weifen Punč́ten. Seine \&änge beträgt $4-7$ 3cll. Er Gemobgnt bie brafitianifit)en Meere, uno ift bas felbft unter bem ఇanien Guaperva befunnt.

2) Der Rúffelelippifd. Der Spribif́. Der Sdnabelfifd. I.e Chétadon museau-a longé. La Cepède IV.p. 486. Chaetodon rostratus. Lina. Blich augl. Jijide III. 78. t. 202. f. 1. (II. 129 t. 202, f. I.

(Tab. 51. Fig. 78.)

Die Sinnladen find röbrenförmig. 2fm গiücfen fteft ein elnfacher eingefáter fowwarzer Flect. In ber Bruits

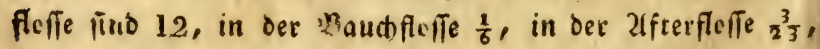
in ber Sdwanzfloffe 15, uno in ber Ruafentioffe $\frac{2}{3}$ Sirab. ren. Die alugen baben einen fdunaren Stern in emem 
gelben Silng, ber zum Sheil voll einem braunen über bas 2luge laufenden sanbe bebecfit iff. Die bogenformige Seis

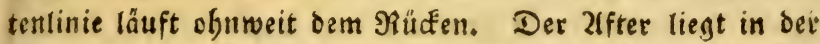

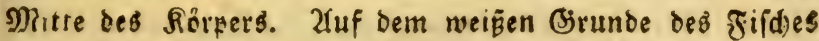
feben braune Rängelinien und 5 nad) ber Breite laufende şinber, movon bie lez̧teren weiß̄ eingefaß̈t fino. 2/n

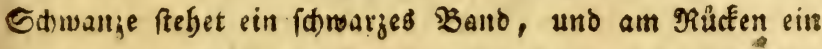
gleid)farbiger Flect, weldhe von einer weipen Sinie umgeber

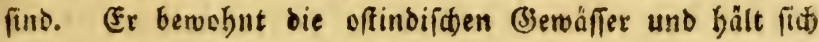
all ben feidten Ufern bes Meeres auf, und gruar in Den (je. genden, wo fid) bie flüfe in bas Mreet ergieften. Diejer

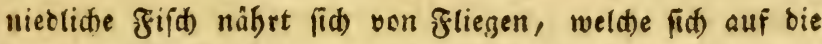

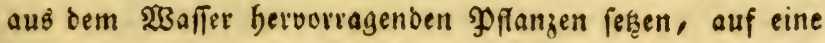
ganz befondere 21:t. (Ex nabet fid) ber Fliege bis auf eine

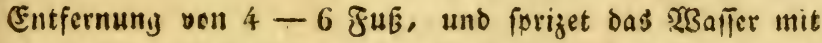

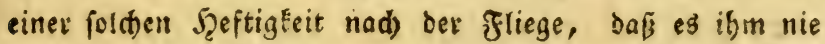

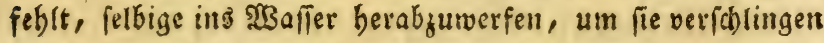
ż E⿱丷三nen. Die Sornebmett auf mebreren ofitinbifden Ins

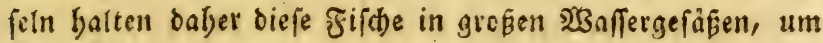
fiț an ify:er Jago, bie fie auf die Jliegen maden, zu era

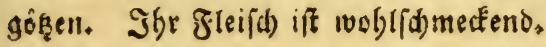

3) Der Pelfer. Der fd wärzlidte Rlippfif́. L'A canthure noiraud La Cepède IV. p. 548. Chatodon nigricans. Linn. Bled) ausl. fildae III. 82. t. 203. (11. 184. t. 203.)

Die Bäfne find ansgebacter, und bei ber gabelförmigen Sdywaniflofie fiebt ein Ctadel. In ber siemenbaut fino 4 , in ber Buffioffe 18, in ber 3audbfleffe $\frac{1}{6}$, in ber 21fs

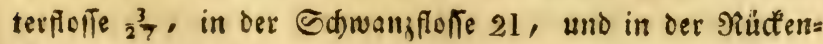
foffe $\frac{9}{36}$ Sirahlent. Der ä̈rper iff fleifdigter als vet ben 


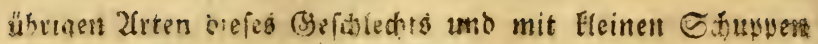

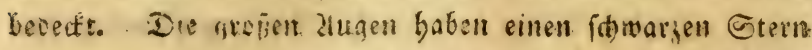

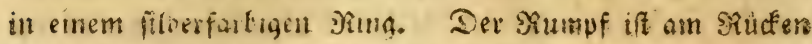
fotinurlact, auf ben Eeiten braun und nach bem Baude

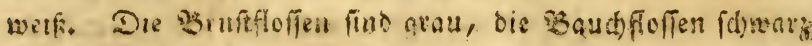
unb beide mit melareulizzn Grrabten verféfen. Die afretz

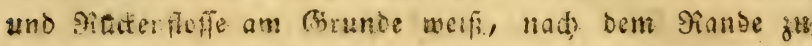

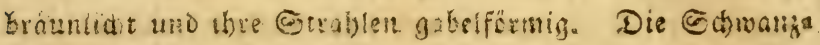
fleffe wethgrau m vielgneigigen Etrablen, woom bie äus

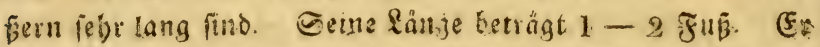

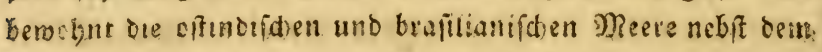
sothen Sher, leEt von SRujheln uno Sirebstrut, uno bat:

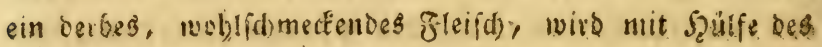
Sactens ader bes Netzes gefangen.

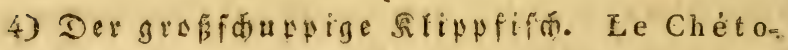
don grande-écaille. La Cepéde IV.p.478. Chaetodon macrolepidotus. Linn. $R$ lod aust. Fif f. 1 )

2luf bem filberweifen, grofichuppigen Söper fteben 2

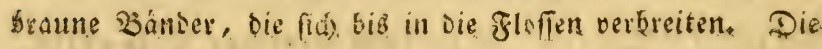
Sommantleffe it gerabe, uno ber vierte Strabl in bet

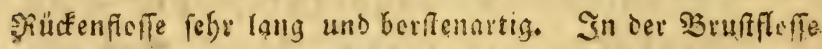
fino 16, in oer Baudefoffe $\frac{x}{6}$, in ber 2lfterflufte $\frac{3}{2} \frac{3}{4}$, in oes

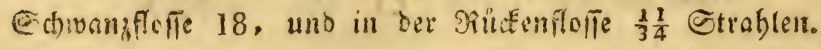
Die ktunen baben einen fownarzen Stern in einem blaulid)s fen Singe; vor und über benfetben fleht man einen braunen Flect. Die Seitentinie macht einen Boaen. Der 2ifte.

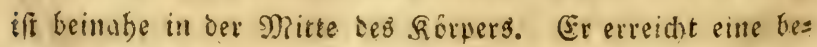

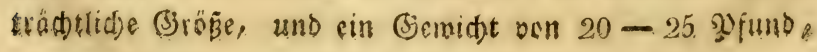


uns bat ein fettes fefre fumadifaftes Fleifa. Sei ben Sgornandern beint ex Safelvifa), (j) roote Iafelvifd).

5) Der $21 \mathfrak{i g u s}$ Silippfifd. Le Chétodon Ar. gus, La Cepède IV.p. 478. Chaetodon Ar.

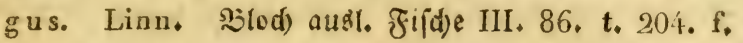
I- (II, 189, t. 204. f. 1.)

Der Förper ift breit uno geffedt. In ber afferflefle lieigen 4 Etad)eln. In Der Sliemenbaut find 4 , in Der

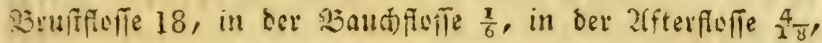

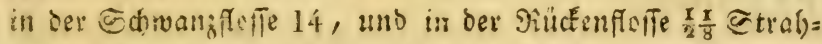
Iell. Der Sîmpi if beinabe vierechigt, ber 2lugenfern (i) wars mit cinem goldfarbenen গing umgeten. Die Sei= tentinie madt einen Bogen. Der 2(fter ift beinabe in ber Mitte Des Gôrpers. Die Beiten fino fowwarbraun

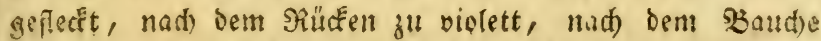

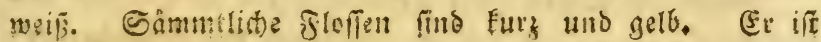

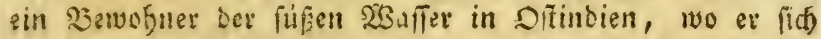
gewöbnlid) in moraftigen (jegnenden aufigirt, uno fich bas

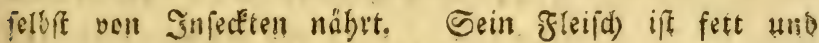
ivobridumectens,

6) Det bandirte Srippfifid. Chaetodon stri-

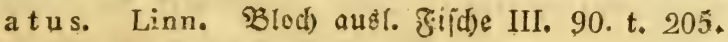
f. 1. (II. 193, t.' 205 , f. 1.)

Der Göpre if braun geväntert, sie Cohwangforfe rumbriche In ber riukenflefie freben 12 Srad)eln. In ber Brufflefie find 16, in ber Baudhane $\frac{1}{6}$, in Der 21 fo

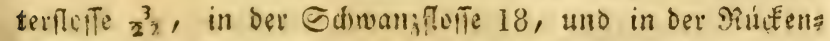
flefle $\frac{1}{3} \frac{2}{3}$ कtrablen Der Eleme Souf ift mit gresien Shups pen bedeft. Dev Mand ill eine Erbnauge verlängert. 
Die stofien zlugen baben einen fómarzen Etern in einet

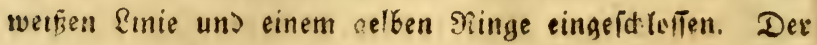
3trer fitebt naber ain Sopfe a!b am Ediwanice. Die Girundarbe des fildes ift gels. Die Schurven babers eine bell. uno die Floffen eine oundfelbraune Finfaliung. Die Bruttfoffe allen Ift Durdhgångig braun. Die gelbe Grunbfarbe des Fifhes wird outh) bie 4 breiten, idnary. biaunen Querbanbe erbögt. Er ift ein Dewobner ber oft= indifaen Meere, hat cin febl wohliamectinbes Fleifh uno

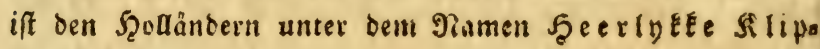
vif(t) beEaint.

7) Der Sclbatenfif́. Le Chétodon bridé. La Cepéde IV. p. 489. Chaetodon capistratus. Linn. Bloch ausl. Fifite III. 92. t. 205, fo 2. (II, 195, t. 205, f. 2.)

Durh) bie 2lugen zieft ein fahwarges, von cirem gels ban ringe umgebenes Bano. Obnweit ber Sd)wanjflefle

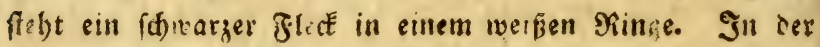
Siemenbaut find 5 , in ber Brufflefte 14, in ber $\mathfrak{B a u d )}$ flofle $\frac{r}{6}$, in ber 2Afterforie $\frac{3}{9}^{\frac{3}{9}}$, in ber Edwangfolfe 16,

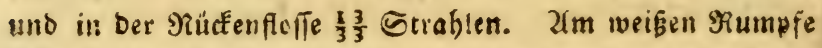
fteben grape Sduppen und gegen einancer laufende bralls ne Einien; Die oberen laufen vom Rüfen gezen ben Sopf, uno die andern vom Saudbe eben babin uno fitfen in tes Sitte zufammen. Beim anfange der Sobwangfeffe ftebt

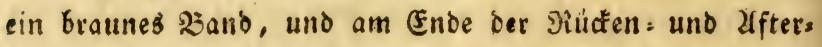
flofis eine braune Einfaffung. Der Sirmendecfel, besggleis

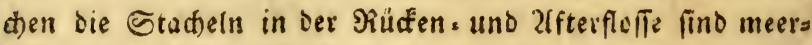
grün, Die übrigen fleffen gelblidi)t. Seine (Srö̈̈e beträgt

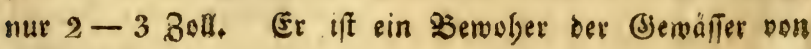
SamaiEa. 


\section{IV. $\supset \mathfrak{i}\|\sharp\|$ g. Pisces.}

8) Der Sdwármer. Chaetodonvagabundus.

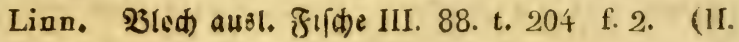
t. 204. f. 2 )

Der Runo röhrenförmig. Üter bie Zlugen zieft ein

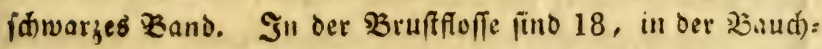
Forfe $\frac{x}{6}$, in der 2ffterfloffe $2^{3}$. in ber Sdivanzflote 14, uno

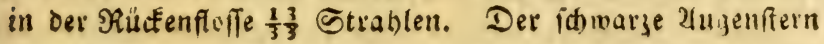

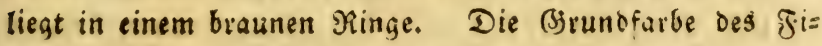
fdes ift gelb. 2lm Ento bes Siumbfes uno in ver Mitte

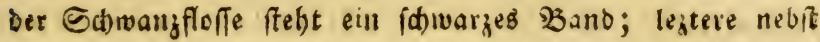

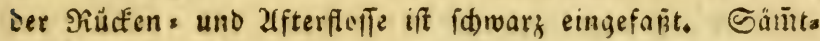

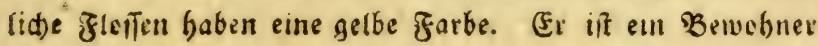
ber efirindifden Biewáfer und bat eill fettes, derbes, wohts fitmertendes zleirch. In Franctreich wiro er le Vagabond; in Jrolland Doutuing gy rins, Douming f̧erteo Bin, 多rincefie z $\mathfrak{B}$ if

9) Der $2 B u n b a r z t . \quad$ L'Acanthure chirurgi e n. La Cepède IV. p. 548. Linn. ed. Gmel. p. 1259. Chaetodon Chirurgus. Blud ausl. Fıid)e III. 99. t. 208. (1I. 204. t 208.)

$21 m$ Sobwanģe ein langetförmiger Stahel. In ber

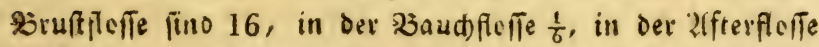
$\frac{3}{2} \sigma$, in ber Sdiwangflefte 16 uno in ber siuctenforte $\frac{1}{4} \frac{4}{6}$ Ctrablen. Der אupf if gref, bie obere fimmlace if ore läng te. Die 2lugen baben einen fatwarzen Siern, ber bon einer weífen \&unie und einem getben. Ninge umgeben

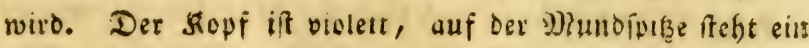

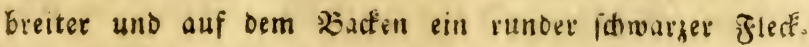

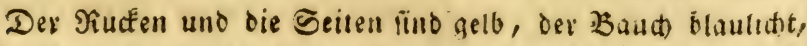

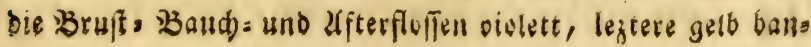




\section{Salerte Eraffe Fifde.}

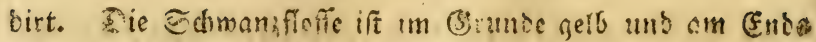
biclett uno ore rufuentelfe aelb unb viclett marmorit.

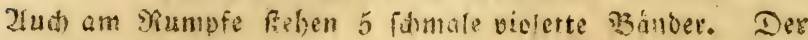

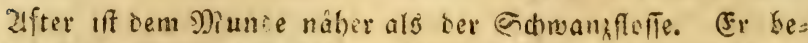
wobnt bie (Jienaffer ber antullffien Jnfeln uns hat ein wobl=

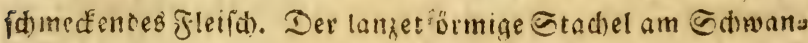
ge bat (3)elegenbeit jur Senennung oiefes Tijdes gegeben.

10) Der Saiferfif́. L'Holacanthe Empereur. La Cepède IV.p. 533 pl. 12. Linn. ed. Gmel. p. 1255. Chaet od on Imperator.

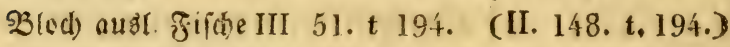
( $\mathrm{T}$ a b. 52, Fig. 79.)

litfer Den getben Sörner laufen nad) ber Sänge hin blaue

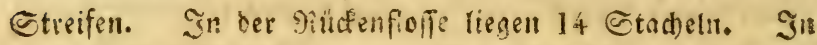
ber Brufficfie fint 18, in oer 23 auchfleffe $\frac{x}{6}$, in ser 2lfter:

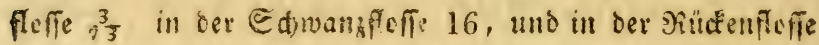

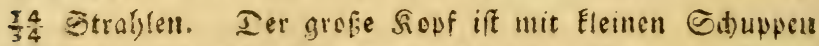

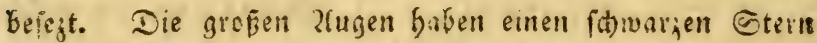
in efnem srongefartigen Singe, um weldhen ein blaucr, bogenförmiger Srreifen fidtbat ift. Det Soufenfnotien iff blau eingefüt unb mit einem frarden Gtad)el verfeben. Dev Siemendectel befrebt aus znei slätchen, Davon allf einem jeten ein Slauer Streif. Diz Geitentinie madt am Enve

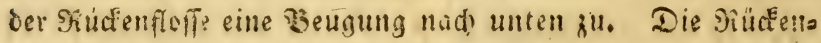
uno zifterfferfen find oiff, fieif und abgerundet; legtere

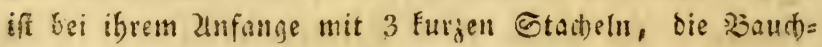

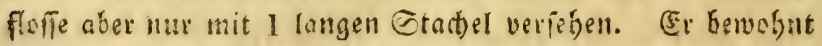
sie jopanifhen Jiecre, uno if unter affen effouren indifiten

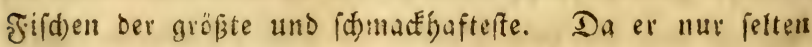
gefangen wirb, ffeft er in einem fefr boben Wreife, und

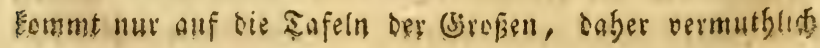


peine benemung bei ben Sollunbern ber Japan $S_{e}$ is jer, (oer אaifer bon Japan).

11) Der moruktifte berzog. Der geftreifte Silippfifd. L'Holacanthe Duc. La Cepède IV: p. 533. Chatetodon Dux. Linn, ed. Greel. p. 1255. Chaetodon fasciatus. B(od) aublo Fiide III. 53, t. 195. (II 150, t. 195.)

Der weife Sörper ift mit neun blanen uno braun eina Befabten Suerbandan amgeten. In àt Brufffelle find 16,

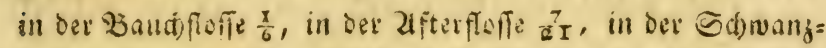

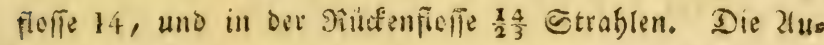

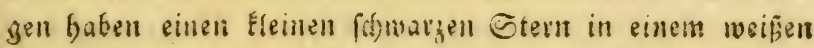

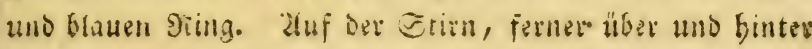
Den 2lugen finto ótaue Streifan. Der Bactentnoden if gejäbnelt uno endigt fid) in einen ftarden Stad)el. Die

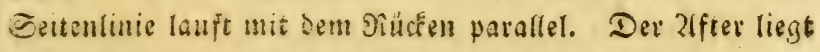

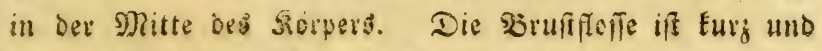
suntolid). Geine fänge bettägt 7-10 Zoll. Er if ein

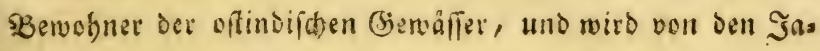
pantur vermuthlid) wegen Der fibönten Sande feergog,

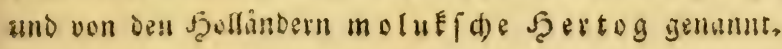

12) Der a ditbandige Flippfifd. Le Chéto. don huit-bandes. La Cepéde IV. p. 489. Chat odon oct of ascidtus. Blod ausil. Firide III. p. 113, t. 215. f. 1. (II. 220. t. 215, f. 1.)

2luf bem weiḡen ins violette fpielenden Förper ftefen

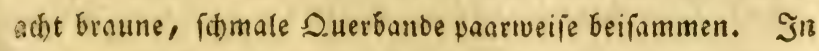

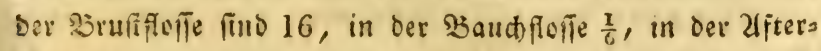

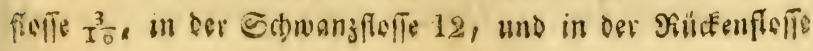


$\frac{1}{2} \frac{1}{8}$ Strablen. Sämmtliche Floffen fint Eurz und am (Sjuns be bräunlicht. Die Jitutens und afterflefie baben eine braune, ore übrigen einc gráue Einfafiung. Die breite Geitenlinie madht einen fladen Ṡogen. Der 2lfter ftebt in Det Mirte des Gïrpers. Seine Ränge beträgt $4-530$ ll. (Ex: Eommt ebenfalls in oen oftintríd)en (biewäflern vor.

13) Der Ring = Rlippifd. L'Holacanthe a n ne a u. La Cepède IV. p. 533. Linn. ed. Gmel. p. 1262. Chatodon annullaris. Blody aนsi. Filde III. 114. t. 215. f, 2. (II, p. 221. $t$. 215. f. 2.)

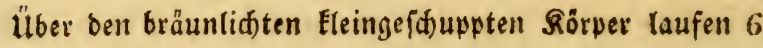
etwas getrünte bellblaue Streifen ber \&änge nad). Dhn: weit bem Sepfe Reft auf Der Geitenlinie ein bellblauer গiing. In der Bruffleffe fino 16 , in ber Bauchfoffe $\frac{\pi}{6}$, in Der affer:

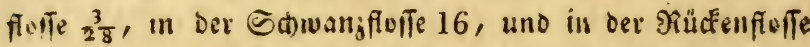
$\frac{1}{4} \frac{4}{1}$ Sotrablen. Ser Riemendedel befteht aus 2 Biättden, wovon baş vordere gezälnelt und mit einem Stad)el verfes ben itr. Der llfter liegt in ber Mritte des Jörpers. Die

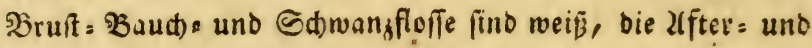
Puctenfisfe idwarboun; bie erftere ift runb und mit ei= nem bellblauen Bande verfeben, unb leztere lauft in eine Spize aus. Seine Sänge betrangt $4-6$ 3oll. Diefer nieolude uno idöne fild if ein Belvobner ber oftindifden Meere. Die Scllander nennen ibn Douwing Marquis, cambodische Pampusvisch.

14) Der Plúmieride (5)olbfif́. Le Pomacanthe doré. La Cepède IV. p. 521. Linn. ed. Gmelin p. 1254, Chaetodon a ureus. 


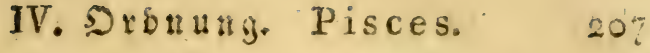

3lid) nusl. Fitite III. 49. t. 193. f. 1. (II. 146.t. 193. f. 1.)

$$
\text { ( } \mathrm{Tab} \text {.51. Fig 80.) }
$$

Ser oyale mit barten negáfneiten Sd)upwen befegte Sör,

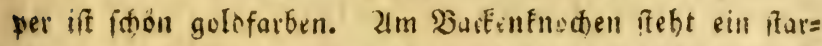

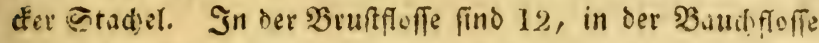

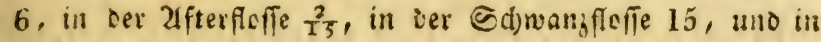
Der Siudfenflofie $\frac{x}{4}$ Strablen. Die augen baten einen fd)war;en Stern in einem röthlidten Siinge. Der Riemens

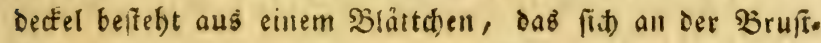
flofte in eine Spise endigt. Die Seitenlinie madt) einen flad)en Segen. Sie Floffin find am Grunde gelb und an

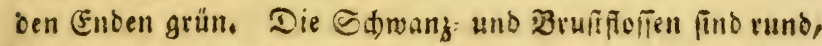
Due utbrigen fichelförmig. Diefer prachioulle $\mathbb{E} i f h$ if ein Sewobner der (jewäfler ber antillifhen Infeln, wo ex zu= erft von dem şater Ş เ

15) Der fdwarge Rlippfifh. Le Pomacanthe Paru. La Cepède IV. p. 521. Chaetodon

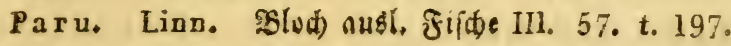
(II. 154. t. 197.)

Der Sörper ift mit greßjen fónargen Sdhuppen be. fegt, Die eine gelblichte Einfalfung baben. In ber アilita Eenfloffe fteben 10, und in ber afterflofie 5 Etadielir. In Der Siruiffolle find 14, in ber saudffoffe 6 , uns in Der Sdranzflofie 15 Strablen. Die untere Sunnlade ftebt vol ber oberell beroor. Die kleinen 2ugen baben einen fawargen Stern in einem goldiarbenen ßinge. Ser Ries

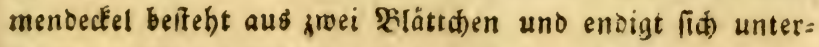

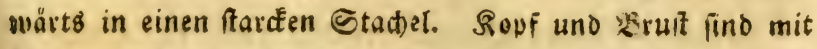

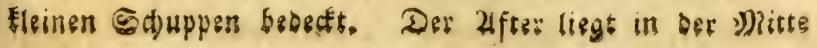




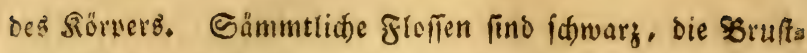

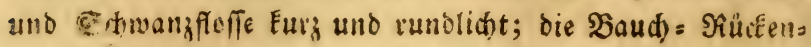
uno afferfofle lang uno fiefelförmig. Seine \&änge beträn 10 - 16 3ull. Er bewobnt Die Meere von Brafitien uno

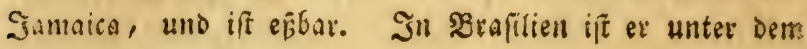
Damen Paru betannt.

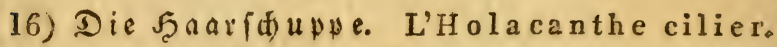
La Cepède IV.p. 533. Ch a tod on ciliaris. Linn. SBled) aนst. Fifd)e III. 111, t. 214. (II, 218. t. 214.)

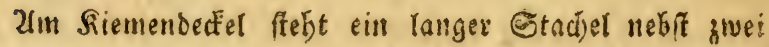
Fleineren. Die Siänoer Der Schuppen fino mit Gaarförmia gen Einien befegt. In ber Sirmellóaut find 6 , in ber Druiffleffe 20 , in ber Bauchfoffe $\frac{x}{6}$, in ber 2lfterfolfe $\frac{3}{2}$, in ber (S)wanjfoffe 16, und in ber Siütenfoffe $\frac{x}{3} \frac{4}{5}$ Strabs

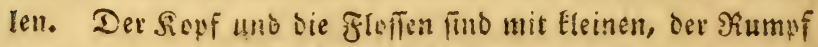
: aber-mit grefien Eddupen bedect. Die 2lugen baben eis nen fdwarzen, Stern in eitrem weifen ins rotbe fpierenden siing. Zn bem bunckelgrauen SRüčén fteber vor ber Fleffe befle!ben ein finwarger ring. Die Geiten fino gran, die Floflen grau uno braun eingefafit, ber $\mathfrak{B}$ nud) filberweif. Die Geitentinie lauft mit bern গücken in gleidförmiger Dichtung. Der 2lfter ift in Der Mitte bes sërpers. Die after = uno গiücfenflefle find febr lang. Er bewolgnt die vitindifden Gewatier.

L. Das Ritterfifd: (Sefdifledt. , Eques. Bloch.

Diefes Gefdledt unterfaciset fid) von bem vorferge= Genden vorzüglid) Durd mebrere Seifen Eleiner Sábne in 


\section{2ro :Bierte Elaffe. Fifde.}

Fiementerfel und die Bruft und bas oritte fängt an bet

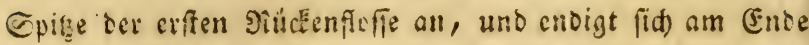

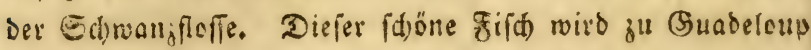
uno in Carclina gefunden. Die Engelände: nennen ifn

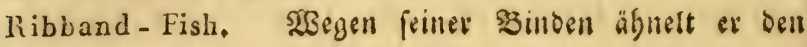
Rliptfild)en.

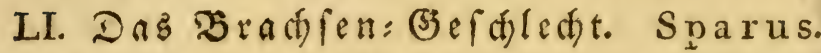
Linn.

Der Sopf if eyrund, abfhüfig. Die fimnlaben fino mehrent́feilos von ungleitber Ränge. Die sorber: voer Eeci.

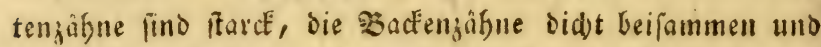
ftumpf, die Siemendectir melgrentheils dreiblättrig, abges frumyft und unbewaffiret. Die Sicmengaut 5-6itralglid)t. Dev Rump eysuno = langlidt, von ben Seiten jufammen= georüt und gefouppt. Die Ceiteninie nad) binten ges

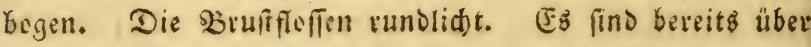
60 verid)iedene Arten betannt, die fämmtlid) Deerbewobner fino.

A. Nit cinem fob aron fled bezeichnete.

1) Der (3oldoradiem. Der Golbrafím. Le Spare Dorade. La Cepéde IV,p.57. Sparus a r a ta. Linn. B(od) ausl. Fijd) V. 52.t. 266.

\section{(Tab. 54. Fig. 82.83.)}

In jeber Finnlabe fteben 6 Edneidegäbne. In tar Siemenbaut find 6 , in ber Bruffteffe 16 , in ber Baud)= flofie $\frac{x}{6}$, in ber 2ifrerflefie $x^{3}$, in oer Edowangflefte 17 , uno in ber গiuctenfoffe $\frac{1}{2} \frac{x}{5}$ Etrablen. Der souf if zufam= mengeoruft, abjauffrg uno bis auf bie Siemendectel foups 


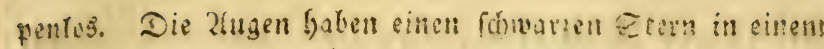

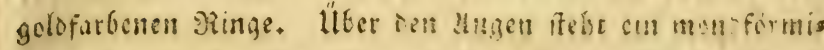

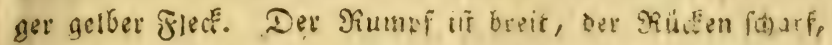

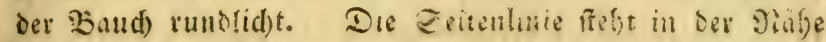
be silutcens, uno bilcet einen flab) pen find weid) unb glatt. Die Jiutentente befteht aแร 11 einfaden, barten, uns cus 14 weidten unb gofelformigen, bie 2lfterfloffe aนs 3 einfacten barten und 12 weidi)en gabels formigen Etrablen. Die Gtrablen in bon übrizen freffen find viergweigig, und nu: ber erfe in ber Sauth]lefe it bart. Der britte Strab! in Der Bruffrteñe bat ben britten Sheil ber Ränge bes zanzen Rörpers. Sepf, Эumpf urd

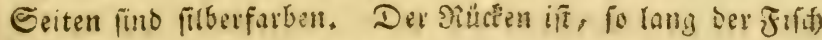

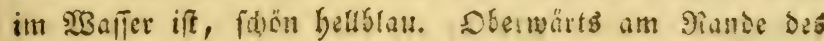

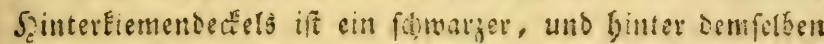

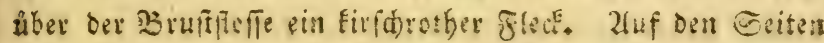

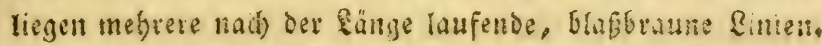

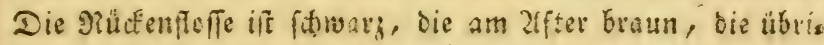

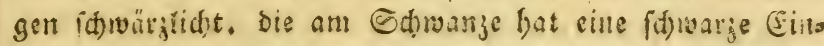
fallung, uno if gabelförmig. Der 2ffrer liegt der Stwang= fleffe nâfer, als bem Sopfe. Eeine Range beträgt $1-2$

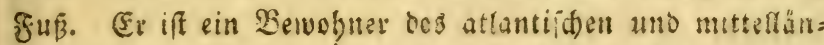
bijd)en Meeris, fo wie au(t) ber Norofee; năgrt fít) von

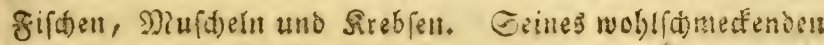

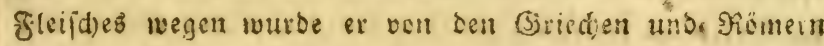
allen andern fifden vorgezegen. Sn frantreid wiro er

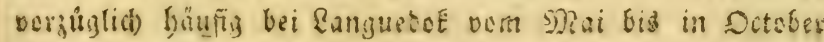
in Pietzen soer auch au kinget gefonigen. Mian fintet thon aud Dafelbft in ben mit bem Mgeere verbuntenen Sianalent mo Ranefeen, wo er aewobnlid) felgr fett wiro; aud foll er in ben হeidien von Gardinten vorfonmen Die bintern

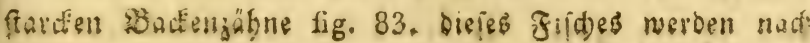




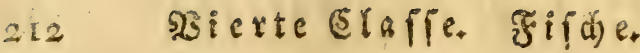

(2) ubamel aIs Srötenfteine gefät und verEaft. 2fuf

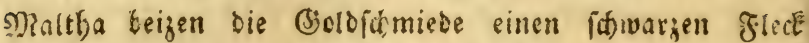

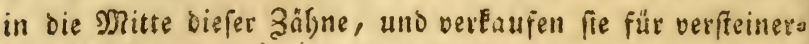
te Sd)langenaugen, beren man fid) als 2tmulete bebient.

2) Der ciseiffraffem. Ser bandite $\mathfrak{B}$ ra fem. Le Spare Sargue. LaCepéde IV p. 76. Spa rus Sargus, Linn. Sled) aแvi. ßif(t) V' p. 36, t. 264 .

In jeder finnlabe feben 8 Căneibes uns 2 গivifen

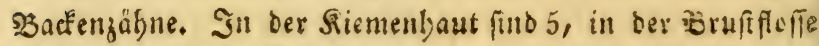
16 , in ber Baud) floffe $\frac{x}{6}$, in ber afterfolfe $\frac{3}{17}$, in ber Edjrangfteîe 22, uno in ber Siückenfloffe $\frac{1}{2} \frac{x}{5}$ E troblen. Die Edincibejäbne find am Piande breit und am Grunbe idomal, binter ibnen ftefgen eine Menge Eurger Zăfne. Dag Mafenbein if lang und die boypelten গafentöber fteban febe bicht an ben 2fugen. Die grónen idjwargen 2fugen babert einen fabarzen Etem in einem filberfarbenen গiage. Des

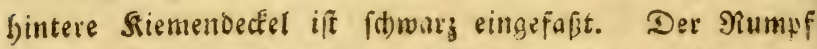

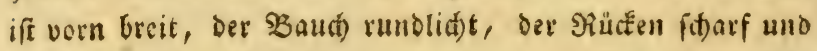
gebogen. Die Eseitentinie iff \{dwary. Der $21 \mathrm{fter}$ lebt swifben bem Sopfe uno Dem Sd)wange in ber Mitte. Über Den filberweifien Sörper zieben gelbe Eängelinien, und nad) ber Szreite if berịlbe fohwarz gebannoert. Das Benicf uno

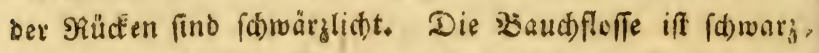

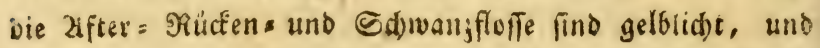

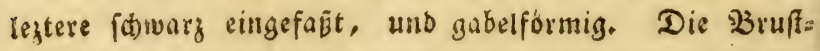
floffe if febr lang, welches ven dem verlängerten 4ten bis 6ten Stralst fommt, bieje find vierjweigig, Die übrigen gabelfórmig, uno nur ber erfte einfach. Geine Ränge bes

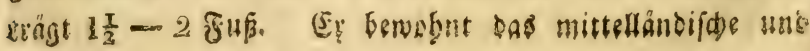


Eotfe Meer, wie aud) Den Dcean, wo er vorzhglidid an ben Hfern angetruffen wird. Seine Pafrung belieht in Fis

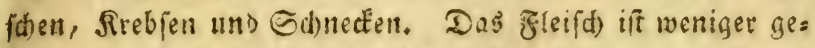
fäazjt, als das vom Bjolobraffem. Er wiro mit bem Bjarm,

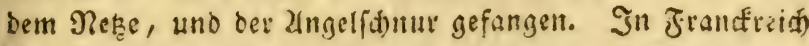
ift ex unter bem Namen Sargo, Sargue, Sar, Sarguet, Sarg, in Statien und Garbinien Sargo, unb in Dalmatien Pagaro befannt.

\section{B. Siotbe.}

3) Der Eprif̧radfen. Le Spare trompeur. La Cepéde IV. p. 120. Le Filou. Bonnaterre 103. n, 35. pl. 49. f 189. Sparus Insidiator. Pallas spic. Zool, VIII. 41, to 5. f. 1, Linn, ed. Gmel. p. 1273 .

Die Siefern find grveitheilid), uno jebe hat in ber Mitte 2 Eegelfôrmige, grö̈ere Zåbure. Der Mund läft fich in eine lange Möbre vertangern. Der Särper if reth und an

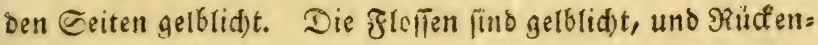
nebit 2fferfofle mit Eleinen grünlidten Binben begeidgnet, uno auf beibent Geiten mit harbfanģetförmizen Sdquppert

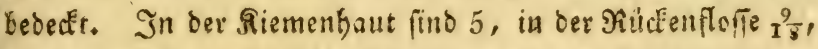
in ber 3ruffloffe 11, in ber 3autefeffe 6, in ber lifter= Forfe $x^{3}$, uno in oer Ediwangfoffe 11 Strablen. Der S.)wang ift etwas gabefförmig. Seine Qänge betrågt gegen 10 3ofl. Er ift cin Bewolnner der Givañffer bott Sumatra, lebt von Snfecten, weldee er mit dem Miüfifel, we ber ober

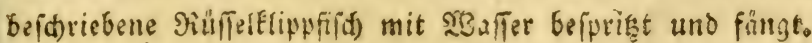

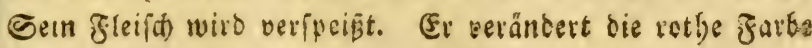
uach bem ミode in eine braune, 
4) Der Eadḱbad) fem. Der Satfioffer. Le Pagre. Bonnaterre 99: n. 13. pl. 49. f. 186. La Cepède IV, p. 85. S parus Pagrus. Linn.

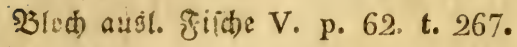

Der binterife etrabl der sublen. und afterffefle ift in entet fenat eingehutat, womit auth ber Grund ber wers

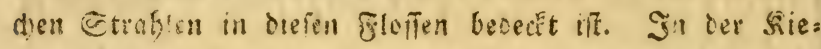
menbaut lino 6 , in der Bruffinte 15, in ber Bauthoffe

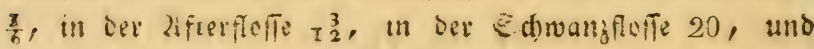

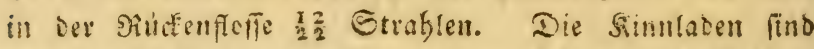
gleidulang, uno vorne mit einer bidit fefentsen Pieibe Flei=

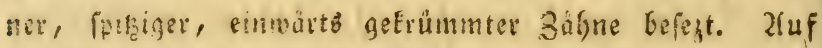
ben Eeiten legen 2 Dieifon abgermbeter Batengăbne. Die grefzen Zna?n baben enen idwarjen Ctern in einem fil

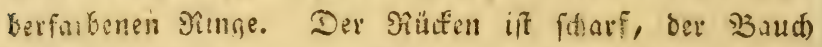
rmatidt, ber after tem Eobunje nafer als bem Sopfe. Die Gieffan laufen in eine, uno mu bie am Gombanje in 2 Sontsu aub. Die Grundfarbe des Fifctes ift roth ins gelbe flielent, oer Baud flterfarben, die floffen rotb), on ben Eeiten mit gerben Eängetinten bejetthet.

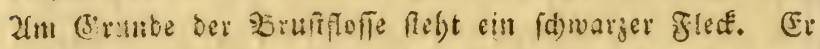

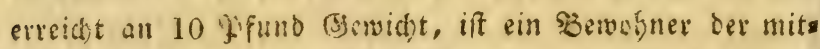
teínohoirithen uno atiantifden Meere wno ber Marefee, von wo aus er fid) nadi) ben Siünoungen Der Fruffen begiebt. Ceine Erfobemm! im Nal, auf weld)e diefer Fluß Balb anşzutreten pflegt, vertereitet in Egynten eine allgemeine Sreute, raber bie Cinwohnet denlelben als eine Gisttbeit verebren und feiner Menge ungeadtet Eeinen eingigen vers jefren. Geine Tafrumb befreft in Edwänmen, Sdals thieren, Grebien uno Dintenfifiden. Das freifd ift feft,

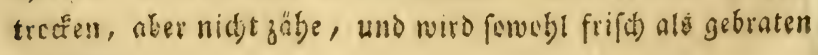
verfpeift. 


\section{Siefterifte.}

5) Der gorditreifige Bablem. Dor (5) Dorbo ftrib. Le Spare Sa upe. La Cepéde IV. p. 97. Sparus Salpa, Linn. SBlod) auț. Efif(t) V. 44.t. 265 .

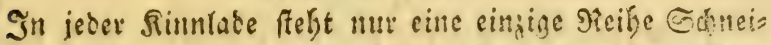
bejábne. In ber Riementaut fno 6, in der BinfRente

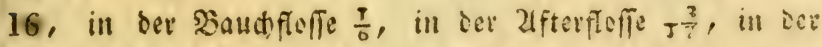

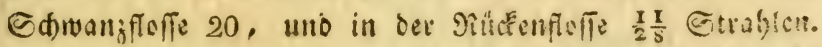

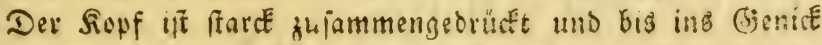
fa)uppenlez. Die Sinnladen fimb von ungleider Ränge. Die zugen bafen einen fidwargen Stern in einem roth und gelb fpielenden Ringe. Der Baand) if lang und runts=

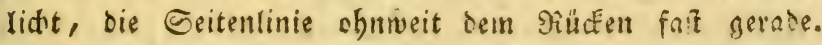
Die Souppen finto grế uno glatt. Der Militen if fitarf,

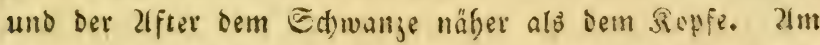
Girunde ber Brufiffeffe feht ein fdiwarger glects, ber enfe Strabl in berfetben iff Eurg und einfad), ser sweite, orits te und vierte vielgweigig und pifre lang, Die übrizen adts jueigig. Son lez̧terer zart fint auth bie Strablen in ber Bautifleffe, woron jebcá) ber erffe bart if. Die lifters

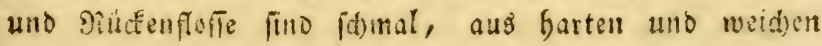
Etrablen zufammengelezt: erîtere hat 3 und leztere 11

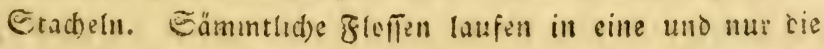

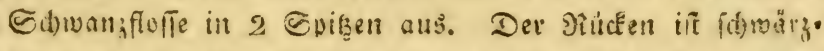

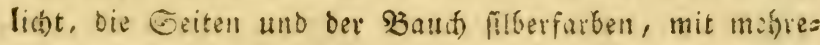

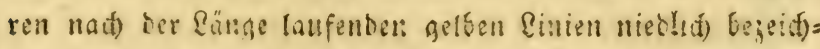
net. Die freflen fino grau uno bräuntide eingefast. Gris

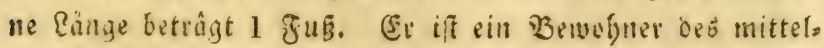

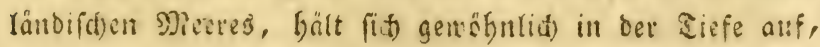
ano Exmmt in Setrber an sie feid)ten Steflen, un ju 


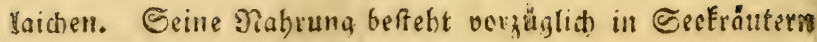

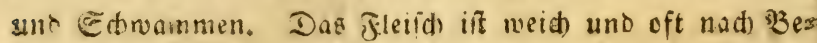

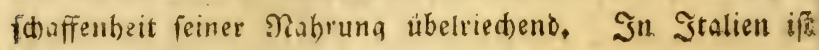
or unter bem Namen Salpa betannt.

\section{SHute.}

6) Der grunf fowand. Le Spare queve-verte. La Cepéde IV. p. 163. Sparus chlorourus. Şlods ausl. Fifde $\mathrm{V}$ 24. 1. 260.

$$
\text { ( } \mathrm{T} \text { a b } 55 . \mathrm{Fig} .84 \text { ) }
$$

Die Eeirentinie if unterbronken, und bie $\mathfrak{B}$ autheffe lauft in eme lange Embe aug. Sin ber Siemenbaut fint

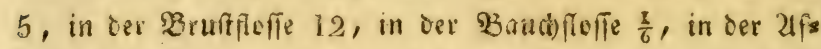

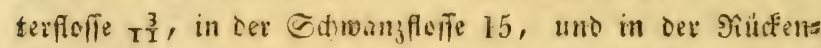

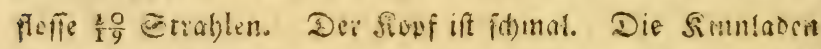
fino oon greid)er Eänge, nno wie alle übrigen firsed)en, bie Sackenjähne ausgenommen, grün; in beiben fino 2 binters

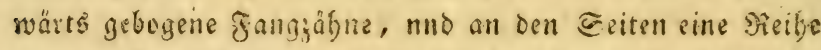
Furjer etwas von einaried enternter, Fegelfö:miger Bnbne. Die augen baben einen fatwargen Grem in einem rothen Singe. Der Siumpf if fegr oumn, uno binterwäts fait eben fo breit als vern. Die Geitenline, bie nur einen Daumen weit vom silicken entfernt ift, enoigt fith on befs fen Jleffe, nib eine anoere witio ocr Mitute der afterfleffe gegentiber fidtbat. Der $21 f$ fer ftégt bem Sd)wange nábar als Dem Fopfe. Dia Sduppen find breit und oủn. Die weid)en Etrablen enoigen fich in 4 Srigen, unb bie barten soér Stad)eln fint mit einer meichen fafer verfeben. Dia Brundfarbe des gifdes ilt grün und am Saumpfe ins gelbe fafleno, Die Bruffleffen find getb, die butigen duntek 


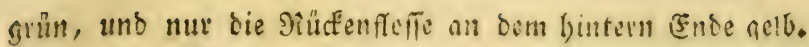

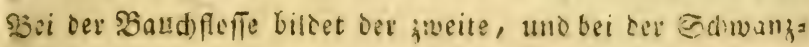

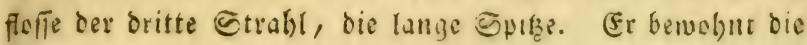
Meere von Japan uno Et. Domingo. Die Jatlander nens nen ibn ben grünen รুapageififd.

LII. Daz papageififd : (Jefdbledit. Scarus. Linn.

Die Rimntaten find Geruerifefend, fie baten ftatt der 3ăbne einen Enedrigen, zabuig geferbten গiand. Die Jites

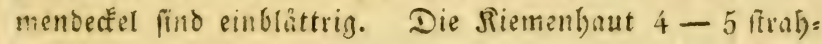

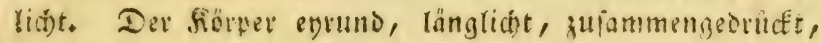
mit lofern @duppen befajt. Die Eeitenlinie einzeln, ooer

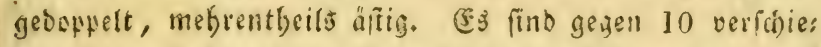
bene Zfren befannt, bie fümntlich in ben Meeren ongctrof= fen werben, uno fit) von Givefen und Miufifeln nábren.

1) Derrothe syapageififa. Le Scare rouge. La Cepède IV. p. 17. Scarus Croicensis, glod) ausl. Jifite IV. 27, t. 221.

\section{( T a b. 56, Fig. 85.)}

Die Sd)wanffolte iff abgermbet. In ber Riemenfaut find 4, in ber Bruffoffe 12, in ber Baudjfleffe $\frac{1}{6}$, in der

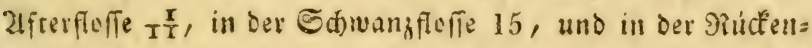

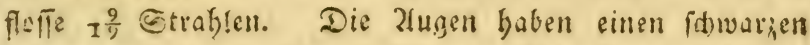
Etern in einem goldenen 9iinge. Die Bsundfarbe deg Firdes ift reth uno fpielt burdi) die glänjende Ellberfarbe. Der Baud) ift weis. Die Efferien fino Elein, Die Eduppen groer, dün, fein geffrablt. Die Ceitentinie füngt bet ders

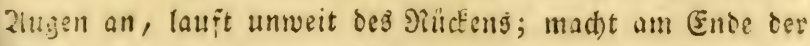

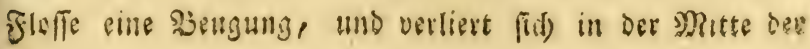


Gdwamzfoffe. Zuf jeber Solumpe, über bie fie weglauft,

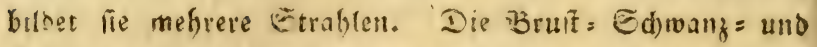
2xaudfloffen find am (5runde gelb und am গance grau. 2im Grunde der Sauchforfe lient ein Enödcrner Znbang.

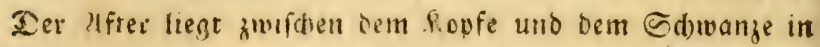
Der Mitre. In jeden oer 9 Stacheln in oer Siüctenfloffe feft eine Faier. Er iff ein Bewsbner ber ofts uno weit= indijden Meere.

2) Der grủne Papageififó). Le Scare verd, La Cepède'IV. p. 17. Scarus viridis. Bloch Quริl. ₹ịd)e IV. 29, t. 222.

(Tab. 57. Fig. 86.)

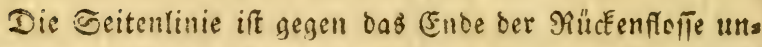
ferbroden. In Der Riementaut fino 4, in ber Brafteffe 14, in ber Baudfeffe $G_{1}$, in ber diterfoffe $x^{2}$, in oer Sdhwanffolfe 13, und in ber গiücenflefie zo Strablent. Die Sdwangfifle if gerabe und hat grüne vielgweigigte Etrafien, Daven bie bitien am Enbe am längiten find. Die Echupen fino rund, geitrablt und grün eingefafit. Die Eleinen zlugen baben einen fobwargen Gtern in einem

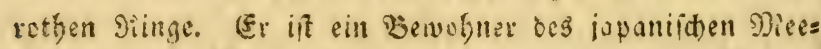
rest, wo er in Mienge vorbanden, und unter bem Namen Cacatoea yoe betaunt iif.

\section{Da's Rippfifd: (5)efdect. Labrus.}

Die Ripren fins fleiforig, farce aufgewerfen, faltig,

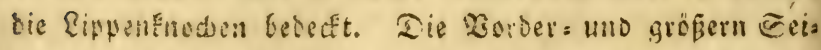

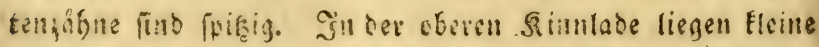

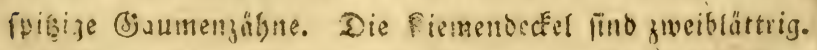

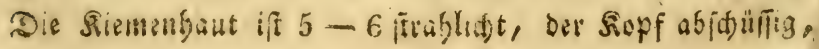




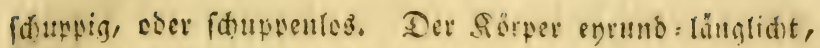

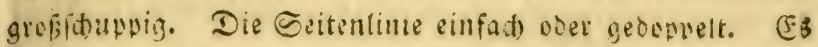
find über bundert verfotedene arten befannt, die fámmt= (iif) Meerberushner fint.

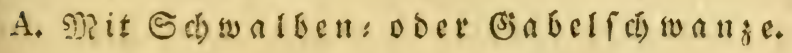

1) Der violette Rippfifd. Le Croissant. Bonnaterre 106. n. 6. pl. 51. f. 196. Labrus I unaris. Linn. Błod augl. Fifde V. 127, t. 281. (Tab. 58. Fig. 87.)

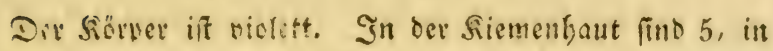

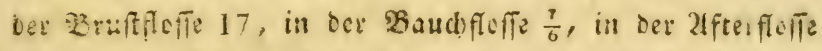

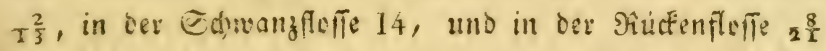
Etrahlen. Der Sepf if flein, zufammengedrüut, fdup. pentus und mit vielen Gtheimaffinurgen verfeben. Die Eleitren Zlugen Gaben emen blauen Sten in cinem fitberfar: benen Siinge, und fint mit einer פicffgaut verfegen. Ser

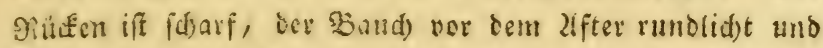
Ginter semielben forfor. Der zifter if sem Sopfe näher

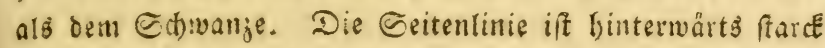
getrümmt, uno giebt auf jeber Edinpe 2 Eeitenäfte ab.

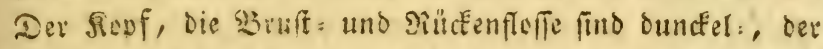

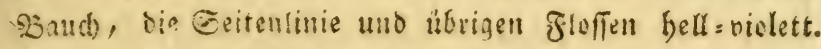

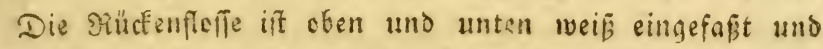

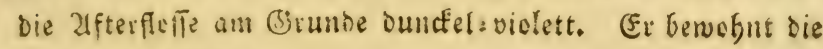
qufindiffen MRere.

2) Der grüne Eippfift. Le Labreverd. La Cepéde III. p. 526. Labrus viridis. Blect) ausl. Fificte V. 129. t. 282.

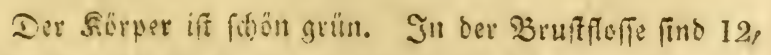

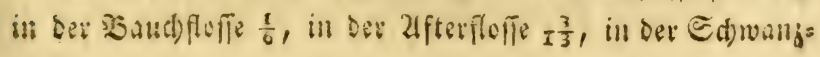


forfe 14, und in cer Siubenfleffe 8 Strablet. Der Eleis ne juimmengeorutite Sopf if fidupwenles. Die 2fugen baben einen fow warken Stem in einem goldfarbenen Ringe. Der Siunipf iff id)mal, zhufammengedrücft, von grofien, glatten, getben und grün eingefafiten Gduwpen bedecf́t.

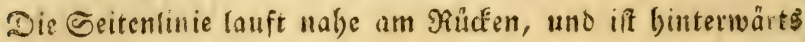
gebogen. Der 2lfter fteft in oer Mitte bes fiorpers. Die Jiffen find bis auf bie an Solwange fitmal. Der Sopf if Sräuntiont uno grün geffreift. Die fiftefen fino gelb uno grün eingefaf̧t. (Fe bewehnt bas japanifhe Meer, und

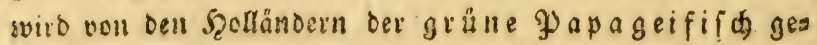
zennt.

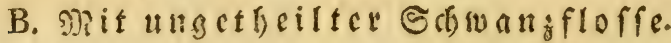

\section{a.) Mit foupenlofem Ropfe.}

3) Der Meeriuner. Der Segentogen= Linpa fifd). La Girelle. Bonnaterre 106. n. 16. pl. 52. t. 199. La Cepède III. p. 492. Labrus Julis. Linn. Bloch ausl. Fifale V. 141. t. 287, f. 1. ( $\mathrm{T}$ a b. 59. Fig. 88.)

In ben Geiten ber fänge nad) ftebt eill gegateftet (Etrid). In ber Siemenbaut fint 6, in ber Bruffeffe 14,

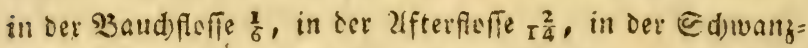

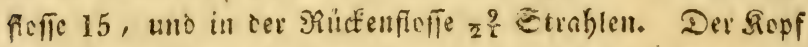
if zufammengedrifft, fohupwenles. Die Zlugen baben eis

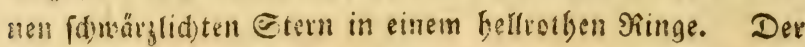

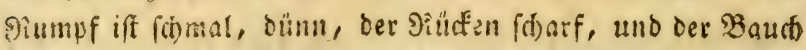
funclidt, ber after dem Săbuange näber als dem Sopfe. Die Ceitentinie if binterwants farce gebogen, uno auf ies ber Gurppe in 2 Sibgren fittbat. Die Sduppen fino

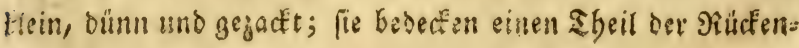


巨d)

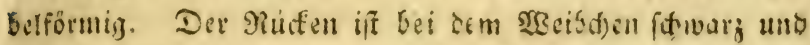
bei dem S)äumden grün. 2im (janidê fảngt ein orangefar: Bener gejacter Strid) an, uno geft bis in sie S(fwanz= floffe. Fin anterer von blater Farbe nimmt an ber Miund.

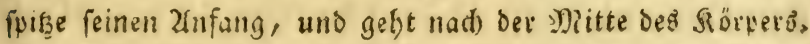
Der ubrige Sbeil von ben Seiten, ingleichen ber $\mathfrak{B}_{3}$ at)

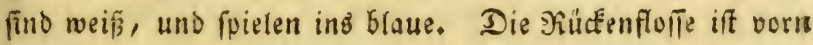

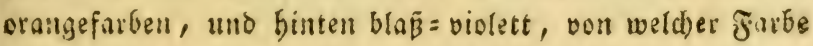
aut) die ufbrigen fleffen find. Diefe aufiallenden fobonen Farben und Beidinungen baben ju feimen Benennungen Juncex, Negenbogenfif selle, J̧ungfer, Gielegentbeit gegełen. Srine \&ange bis

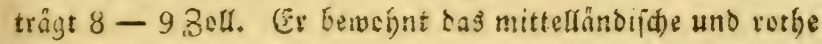
Dieer, lebt voil Sdjecten uno Fij(b) brut, uno laid)t im

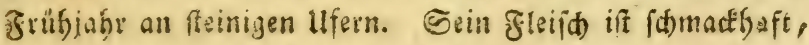
suirb gefad)t uns gebraten verfpeipit. In Sarbinien if er unter bem 5iamen Zigurella, in Schllan Jonckervisch, in Eitgelano Sea-Junkerlin befannt.

\section{b.) S)it fitupigem Ropfe.}

4) Der lutbe Rippfif́. Le triple tâch e. Bonnatcre. Labrus carneus, \$B(sd) suif, Fiīd)e VI. 3. t. 289.

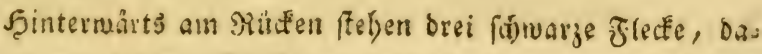
uen 2 am bintern Sbeile ber Jillfens uno eine: Diht an

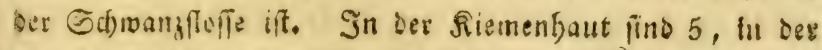

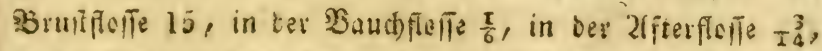

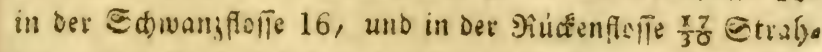

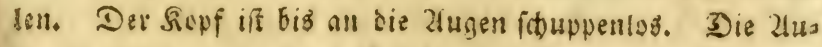

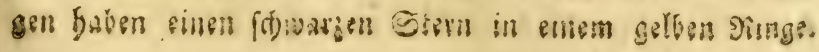




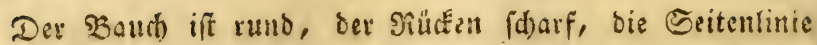

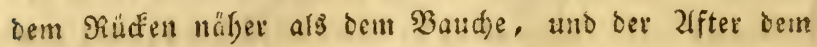

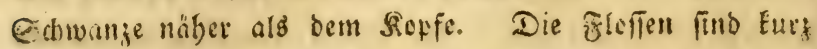
und abgerunbet. Die harten Etrablen find afle bis auf ben am פaudje mit einer weichen faper werfeben. Die

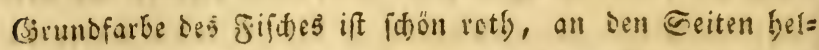
ler. Er iftein SBewobner der normegifden (Jewâlfer, uno

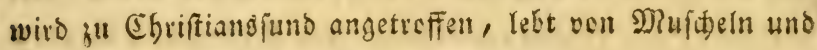
Sduecken. Sein Flaifd) if id)madibaft.

\section{NRit monoformigem $S$ ch wanje.}

5) Der sorfenfloffer. Le Trichopode trichoptère. La Cepéde III. p. 129. Le Crin. Bonnaterre 106. n. 8. pl. 99. f. 406. La brus trich opterus. Pall, spic.Zool. 8. p. 45, Linn.

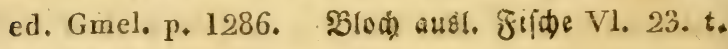
295. f, 2 .

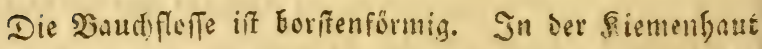

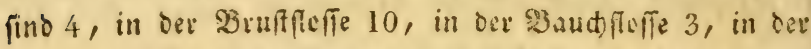

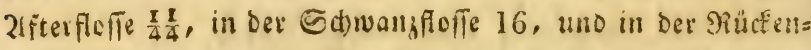
flofle I $_{4}^{7}$ Grrablen. Die 2lugen baben eimen fowargen Ctern in einem galdfarbenen Siinge. Ser Stumpf if breit, sunn, nim siluce vorwärts runb, binterwärt und am

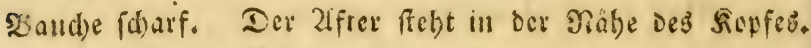
2luf ben Eciten freht ein länglid)ter, uno bicht an De: Gd)wanifloffe ein runder, fd)warger flect. Die Eeitenlinie madit gegen bas Cinoe ber Brutffalle eine farde seugung bts nad) Det imitte Des Forpers. Die Schupen fino febr Flein, Gart und gezäbnelt. Sie Furie 9iüctentleffe bat 7 batte uno eben fo vial weide gabelfermige uns die 2lfier= flufe 11 barte uno 33 meide Strablen. Ser lange Etrab̧t 


\section{Drontng. P isces.}

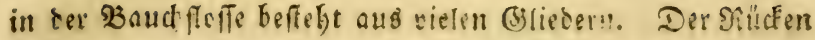

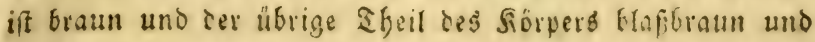
Durcfel marmorirt. Die 2lfterfleffe ift jum Sbeil uno bie Ed)wanffeffe buchans gelb giffect. Er bewohnt bie japas nifden (jewáffer, no er lkan Marate Djantan, Pangay und Capirat genannt wirb.

LIV. Das llmberfifd: (Jefdiledt. Scia en a. Linn.

Der Sopf ift mit Sduppen befezt. Die Sduppen fitsen fert, und fins gezähnett. Der vortere אiementecter ift gegágnelt. Die Bügne find rafpelartig. Die Siemenfaut bat 6 Strablen. ZIm Siü Der ganz getremut, QDer vermittelif einer bünnen J̧aut zus=

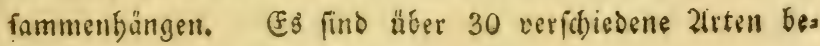
fannt, oie fämmtliđ Miereşbewobuer find.

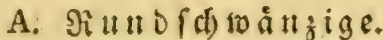

1) Der gemeine umberfifi. Der Sowarzo umber. Le Sciène umbre. La Cepède IV. p. 314. L'Umbre. Bonnaterre 119. n. 1. Sciaene Umbra. Linn. Sciaena nigra,

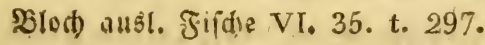

$$
\text { (Tab. 60. Fig. 89.) }
$$

In ber fowarien afterfoffe liegen 2 Stadieln, ven welden ber vorderife fehr Eurg und der hintere lang iff. In

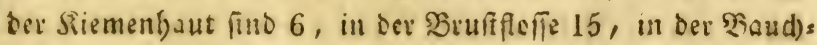
Toefle $\frac{1}{6}$, in ber afterfleffe $\frac{2}{2}$, in ber Ediwanjferfe 19, in

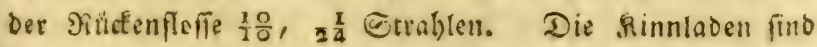

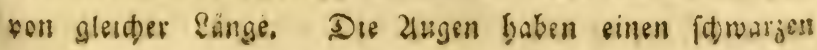


Etern in eine:n bundfelrotben Singe. 2im Gintern Ries mencectel ftebell 2 Stadheln. Der Siumpf if mit bunnen uno fein nezâbuelten Eduppen bebecfr. Die Eeitenlnie

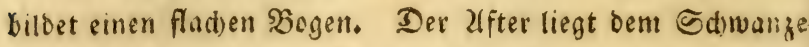
näher als bem Sopfe. Der Siücfen it f(f)warz, ber runbe Band) fllberfarben. Die Seiten fino mit vielen Fleinen fhwargen Suncten befprengt. Sammetiche fleffen, bie fd)warzen Siücfenfeffen auggenommen, fint ain Sirunde gelt, fonit aber folwarg. Seine Länge beträgt 10-12 Boll.

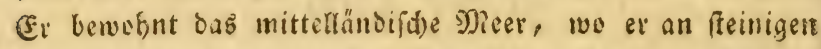
and fandigen (j)egenten fid bänfig leben läfit, von Sanek= Fen uno Siujcheln lebt, uno feine Eyer im Şerbite givifden

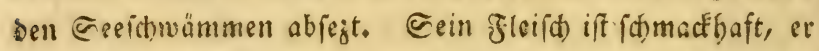
wiro baber aud) marinirt unb eingefalgen verfenoet. In Stalien if er unter bem Namen Corvo de Fortiera, is Garbinien Umbrina, in Frnncficit) Corp und Durdo bes Eannt.

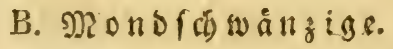

2) Der Bartumberfifd. La Persèque Uma bre. La Cepède IV. p. 414. Le Corp. Bonnaterre 121, n. 9. pl.53,f.203. S cia ena cirrosa. Linn. Bloch auछl. Filide VI. 46. t. 300.

$2 \mathrm{~m}$ Simme ift cine Bartfufer. Die cbere Rinnlabe fiebt vor der untern berwor. In ber fiemenbaut fino 5 , in ber

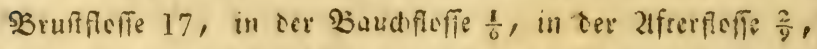

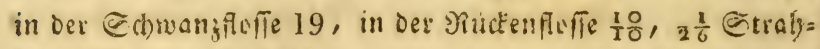
len Ser Sowf it id)uwpig, julammengedrüte uno lauft in eme frumpfe Grige aus. Die lugen baben emen fdumar: zen Elern in einem filberfarbenen Ninge. Der butcre Siemendeckel ift mit emem Stadbl verifben. Der Siumpf 
nur 2-3 barte Etrablen finbet. Eี find über 10 vers

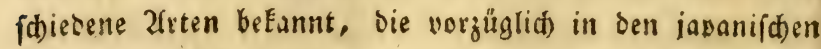
unb brafilianifden Meeren angetreffen werden und gröftens theils mit fdönen farben prangen.

1) Der Bodian. Le Bodian Bloch. La Cepède

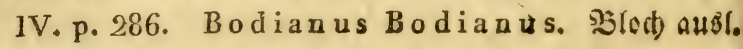
Fifde IV. $33, t .223$.

( $\mathrm{Ta}$ b, 61, Fig. S0.)

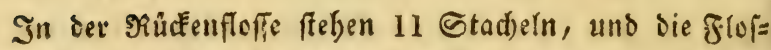

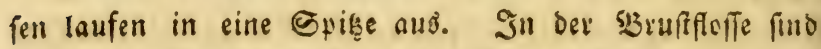
13, in ber Baudafloffe $\frac{1}{6}$, in ber Sd)wangfloffe 15, uno in Der riüfenflefie $\frac{x}{2} \frac{x}{2}$ Strablen. Der Kleine Repf endigt fid) in eine ftumpre Spize. Die Rimnladen find gleidjlang, und mit mebreren Sicifen feilförmiger Băhne befejt. Die Sorderreifen enthalten auf ieber Erite yorn 2 farcfe und binten viele Eleine Bágne. Die etwas bervorfétenden zlugen baben einen fowarzen Stern in einem weizen unb rotben Ringe. Der vordere Fiemendectel endigt fid in ei=

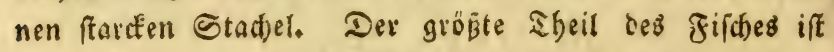
goldarbis, und bie Sduppen find toth eingefaizt. Dev

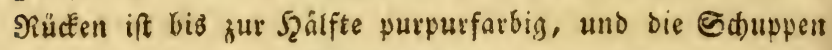
find blau eingefapt. Die Brult: und Baudfleffen purpurs farbig, bie Zlfterfloffe in ber Mitte gelb; bie Shwang= fleffe gabelförmig und rotb eingefaß̧t. Die গücfenflofie am Znfang purpurfarbig, bann roth unb am Ende golb. farbig. Er erreiotit die Srößße unfers Sarpfens, bewobnt Die brafilianifaben Meere, uno bat ein febr fdumactionfter Fleifd. Die \$Portugiefen in Srafilien nennen ifn Pudi. ano uno Bodiano vermelho, die bafigen Einwobner Ai. pimixira und Tetimixira, 
IV. $\supseteq$ roung. P isces.

LVI. Das Sogofifd: (Sefditcdit. Holo. centrus. Bloch.

Die Siemendeckel fino mit Êduwpen befę̧t, gezäbnelt unb bewaffnet. Im übrigen Fommen fie mit bem verigen

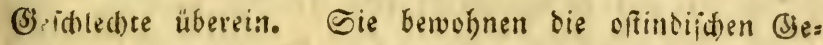
wáffer, uno emige baven bie Süften von Zlfrifa und 2lmes rifa. Es find über 20 verfádiedene Zfrten befannt, die

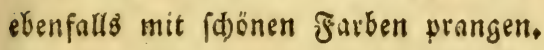

1) Der Sogo. L'Holocentre Sogo. La Cepède IV. p. 347. Holocentrus Sogo. Bloth auţ. Jif be IV. 61. t. 232.

( Tab,62. Fig. 91 )

In ber Baudfllefie ftehen 8 Strablen. In ber Sies menfaut fino 8 , in Der $\mathfrak{s}$ rufffeffe 17 , in Der alferfleffe $x_{4}^{4}$, in ber Edivanzforfe $\frac{1}{2} \frac{9}{9}$, uno in ber giủdenfefie $\frac{1}{2} \frac{1}{7}$ Etrablen. Sopf und Miumpf fino an ben Eeiten zulana mengeorúfft, jener vorn abidúfilig, und biefer beinahe wie ein länglictes Siereck geftaltet. Der Sthwang nimms auf cinmal $a b$, unb geht in gleidjer $\mathfrak{b r e i t e ~ b i ß ̧ ~ z u ~ f e i n e r ~}$ groffe. Beibe Sinnlasen uno die Bjaumen fino mat fege Eleinen fpitzigen Zäbnen bidt) befęt. Die großen, berbors ftefenden 2 tugen baben einen fdyargen Stern in einem fil bernen und gelben গinge. Zwifa)en betoen 2kugen frebt ftatt ber Solupen eine Furdhe am Solitel. 2lm vordern Siemendectel ift 1 uno am bintern find 2 Stadjeln. Dis ganze Siörper ift mit greßen, barten, ferfítsenoen, am

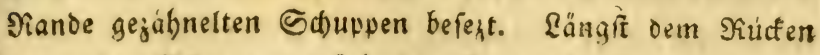
ragen die Ed)uppen auf betoen Seiten herver, und bilden

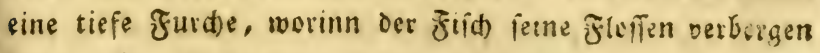
Fann, Die Seitenlunie madht eınen fladjen Bugen. Den 


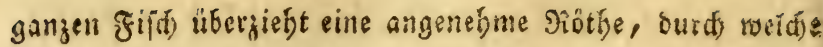
Der Silberg!anj Der Săuppen Durd)idimmert, uno beide Farben werben burd) belfgelbe Einien lilterbrod)en. (Ev Eommt in allen MReeren vor, and ift wegen frinem weišn,

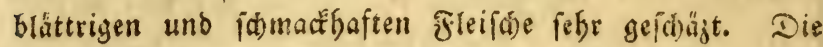
2ffrifaner nennen ifn Sogo. Den nemlid)en Samen bat er aud) in Deutialand.

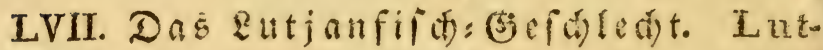
janus. Silocí.

Die Siemendecfel find (d) pypig, gezülinelt und unberwaff= net. Der verbere Sheil des Siopfes if fít)uppentos. Die mebrefren baven einen jugefpisten Eleinen 9anund uno einen bunten Sörper, der vou ziemliá) groj̄en Sduppen bedecft iff. Sie prangen mit föonen Fnben; Emmen im übrigen mit ben Sarfásen (Perca) übercin. (Es find bereit\& gegen

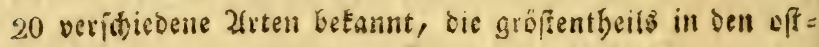
und wefrindifben 2Recren angetreffen werben.

1) Der Rutianfifh. Lutjanus Lutjanus, รlod) ausl. Fifide IV. 107. t. 245.

( $\mathrm{T}$ a b. 63. Fig. 92.)

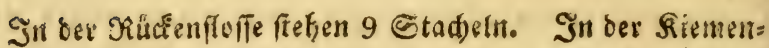
Gaut fino 6 , in Der 2 rufffoffe 17 , in ber \$audffolfe $\frac{1}{6}$, in Der Ifferfloffe $x^{3}$, in ber Schwangfloffe 18, und in ber Rürefenflofle $2 \frac{2}{3}$ Strablen. Dic untere Rinnlabe febt vor Der oberen bervor, in beiben if eine Sietbe Eurger einwärt gebogener 3äbne. In ber Dberkinnlabe vorn auf jeber Eeite ein frarcker $3 a$ b) n, unb innerfyalb derfelben, fo wie

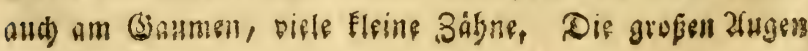


IV. p. 399. Bonnaterre 126, n. 1 pl. 53, f. 204. Perca fluviatilis. Linn. SEled Fifiche Deutíd)l. 11. 66. t. 52. (II. 87.t.52.) v. Meidinger. Pisc, Austr. t. 5 .

In Der afterforfe riegen 11 . Straflent, in ber Fiements baut 7 , in ver Brutififie 14, in der Baudfloffe 5 , in ber

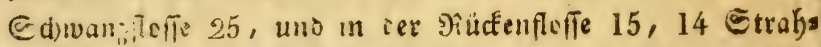
Ien. Setoe frunniaden find gletch lang und mit Eleinen ipis gigen Zabnen bewaffnet. Der (Saumen uno Sd)lund finb an verfactedenen Gtellen mit kleinen fpiz̧igen Bägnen befegt. Die grefen llugen baben einen fdwargen Stern in einem blauen unenoig gelb eingefafiten Singe. Der Baud) if Greit uno weifi. Der after fieht oer Sd)wanjfeffe näber, als Dem Siovfe. Dic Bruftifeffen find röthltcht, bie Baud)a 2ffer: uno Sdwanifolfen bedroth, und bie beiden Siuckena floffen violett; Dre erftere bat am Enbe einen fobwarzen Flect. Ere berochnt bie füfen, ftefgenden und flieffenden

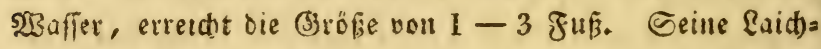
zetr faft in 2furil und Mai. Er wiro mit bem 2lngel, dem

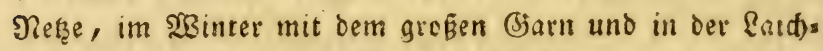
zeit mit einem bejondern Refze, weld es $\mathfrak{S} a$ at $f$ d) nef ges nemit witb, gefangent. Sein Fleifo ift won gutem (Jes. ia)macf. Zus ben Saarfhbauten wirb ein Eeim bereitet, Der bie Şaufentafe an Feftigfeit weit übertrifft. Etatt ber Sdwimmblafe ift eine über bas Siuftrat quergefpannte Şaut.

+ 2) Der 3ander, Sallber, Sechtbanríd, Ganbbarrid). Le Centropome Sandat. La Cépède IV.p 255. Le Sandat. Bonnaterre 126. n, 2. pl. 53, f, 205, Perca Lucioperca, 


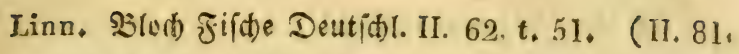
11. 1, t. 51.) v. Meidinger. Pisc, Austr. t. I.

(Tab. 64. Pig. 93.)

Sn ber 2ffterffoffe liegen 14 Strahten. In ber Sies menbaut 7 , in ber : Bruffieffe 15 , in ber Bautffoffe 7 , in ber Sd)wanjfleffe 22, in ber Sivtenfleffe 14, 23 trals= ren. Die obere Sinnlade fefft etwas über bie untere ber: vor, uno beibe find mit grofen unt Eleinern Bäbnen bes waffnet. Die 2lugen baben einen fiswarzblauen Etern, welder mit einem braunrotben Ringe umgeben iff. Die

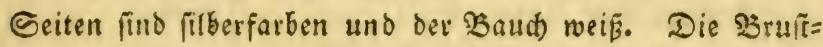

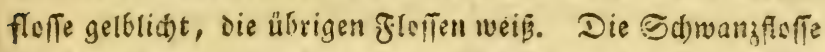

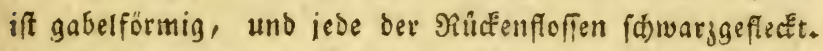
Er if wegen feines geftrecteten Sörpers uno ber frarcen

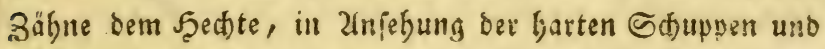

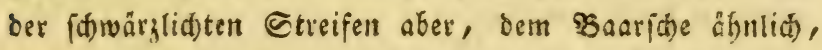

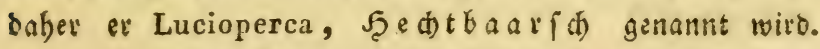

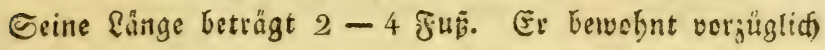
จie jüßen, reinen, tiefen europäifgen Gecen, die mit eis

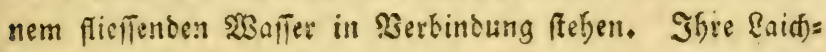
Zeit fâlt in 2(pril uno Rlai. $2 \mathfrak{O} 10$ G) fand in cinem 3 pfüns Digen Fifitie an 380,640 Enyer. Sie werben mit dem Bars

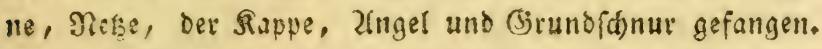
Das gleifd) iff idmactefaft, uno wito frifí), gefargen uno gernudgert verpeiß̄t.

3) Der Streber. Etreber: Szaaff. Ffeifert. Le Diptérodon apron. La Cepéde IV. p. 170. Lapron. Bonnaterre 126. n. 3. pl.54. f。 206 Perca asper. Linn. Bind) giide Deutidit. III. 175. t. 107, f. 1, 2. (ग.Ad)trag 123. t. 107, f, 1. 2.) 
In Der Siemenbaut find 7 , in bes Brufffelie 13, in

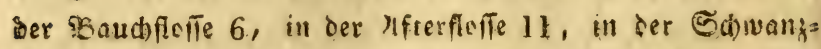
floffe 18, uno in ber গiúcenfefie 8,13 Gtrablen. Die

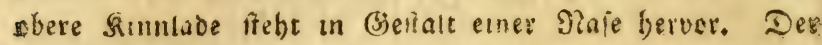
Sopf if beeit, oer Dinno ofjnet fich unten, if flein uno yalomenoformig. Die Zabne fino Eaun fistbtbar. Die ?lus gen baben einen fdwargen Gien nad emen weifen Ming

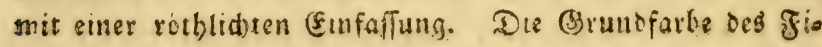

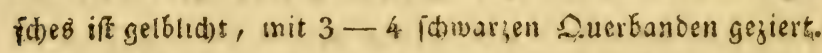

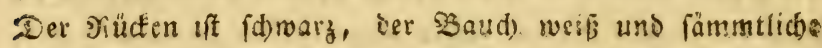
Steffen finto blafigelb. Der Sörper if nacl) ber gabelfärmis

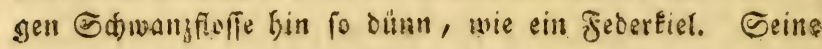
Rånge beträgt $6-8$ 3oll. (F) Fummt in Frantreid) in Der

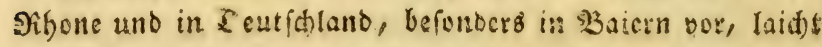

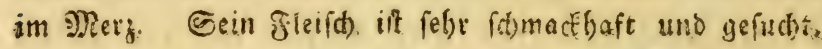

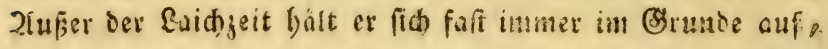
Daher er auber berfeleen nur im 23inter unter bem Eifo gefaugen wirt.

4) Der Bingel. 3ingelbaarif. Le Diptérou don Zingel. La Cepéde IV. p. 170. Le Zina gel. Bonnaterre 126. n. 4. pl. 54, f. 207. Pe ra

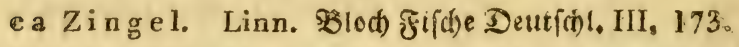
t. 106. (III. 219, t, 106.) vo Meidinger. Pisc Austr. tab. 4.

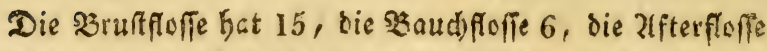

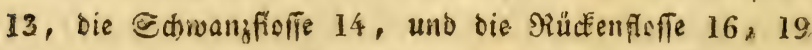
Strablen. Der DberEiefer ffebt in Geffalt einer Mafe über Dell untern hervor. Der weite Mand öffnet fich unterwontts. Die Kinnlaben uno Der Gaumen fint mit vielen, frisigen Zäbnen befozt. Die zugen baúen einen fdywargen etera 
in einem gefblichten Minnge. Die Brunbfarbe bes Jifices

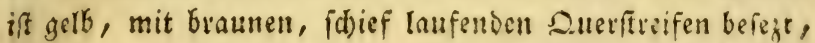
zwifden weld)en einige branne Glecten freben, ber sGaud)

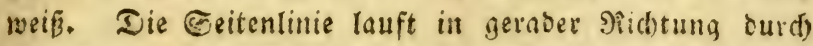
den Sộtper, Die Etraflen in ben floffen find getb. Die

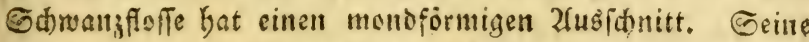
Sonnge betringt 12 - 14 3oll. Er Eommt im fitolict)en

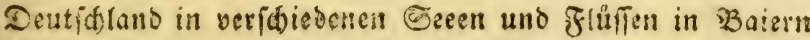

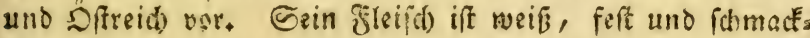
baft. Man plegt ifn mit ber 2lngel, und in bet \&aidy.

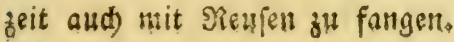

B. N2 it eitreltier Ructenfloffe.

5) Der Salltraarfd. L'Holocentre Post. La Cepéde IV.p. 357. Le Post. Bonnaterre 134. n, 44. pl. 57. f. 220. Perca cernua. Linn. \$3lod) Fiide Deutít. II. 74, t. 53. f. 2. (II, 97. t. 53. f. 2.) v. Meidinger. Pisc. Austr. tab. 3.

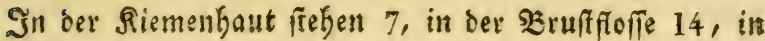
ser Baudfleffe 6, in ber 21fterfferfe 7, in ber Ed)wang floffe 17, uno in ber siutenforfe 15, 12 Strablen. Dew

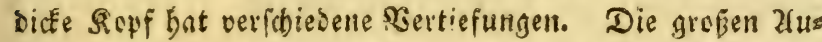
gen baben einen Brauen Gtern mit einem Brauten Ming und mit einem getben Flect. Die Siuntaben find von gleider Qånge. Der Munb und Gaumen fino mit Eleinen, fwikg

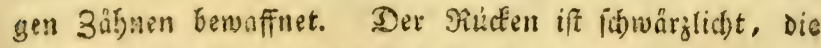

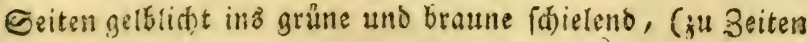

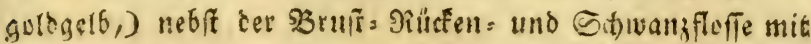

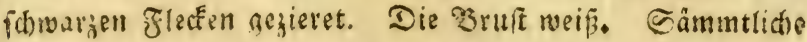
Slefion find gelblidt. Die Sd)waniflefie mondförmigo

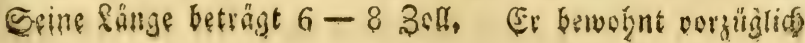




\section{23ierte çaffe. Fifde.}

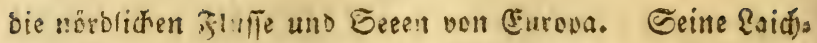

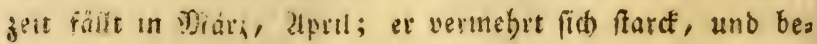

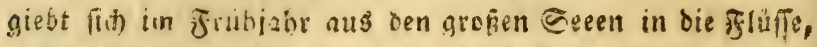

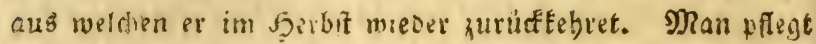

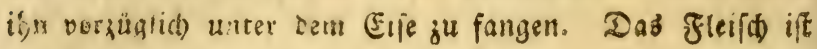
gart und woblidimectend.

6) Dex $\mathfrak{B}$ (utbaarfd. La Sanguinolente. Bonnaterre 130, n. 25. pl. 56. f. 215. Perca guttal a. Linn. Blech ausl. Fif (j) VI. 89.t, 312. Catesby Carol. II, 14. t. 14. f. I.

( Ta b. 65. Fig. 94.)

In ber Soruftifelfe find 10 , in ber 3audfinfle $\frac{x}{6}$, in

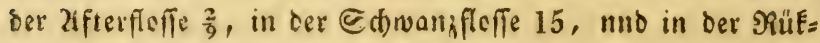
Eenflofie $x \frac{2}{9}$ Strablen. Der Sopf ift grob̉ uno bis an bie Siemenderfel fehuppenlob. Die Mrunböfinung weit. Die Sinntuben gleid) lang, mit fpişigen Bäbnen bewaffnet. Die länglia) $t=$ runben 2 lugen baben einen fowarjen Stern in

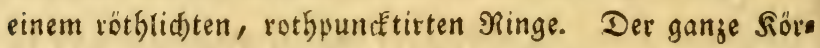
yer ift roth, mit ouncfelrothen flecten geziert. Die Sthups

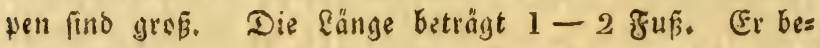
wobnt bie oft s und wefrindifonen (jewanfiet, uno bat ein (4)mathaftes F(eifa).

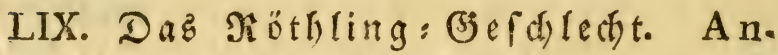
thias. Şlod).

Der Souf if gans fónppig, ber Sorberkiementecter gegälynelt. Die 3ăbne Elein, fikiz̧ig uno etwas gétrümmt.

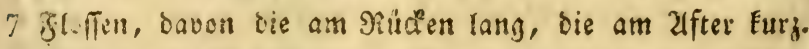
Die Soduppen find bart, gezăhnelt und prangen mit ben

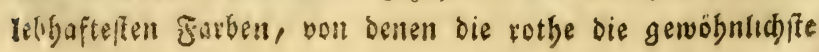


iff. Gie find beinahe alfe serwohner der off = unt weft!ns difden Benâffer, uno über 10 verfofiedene 2frten befannt.

1) Der Sióthling. Le Lutjan Anthias. La pède IV.p. 197. Labre barbier. Bonnaterre 105. n. 3. Labrus Anthias. Linn. Anthi-

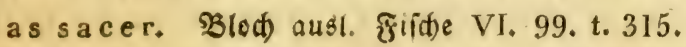

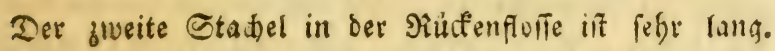
In ber Siementaut liegen 5 , in der $\mathfrak{B}$ uffifolfe 14 , in Der

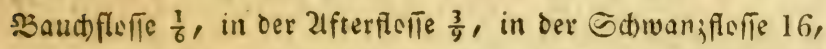

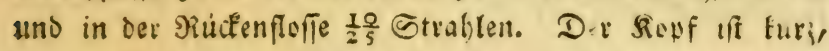

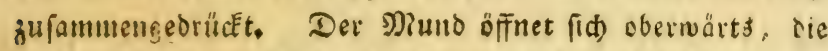
antere Siluntade feeft vor ber olveren etwas hervar, uno

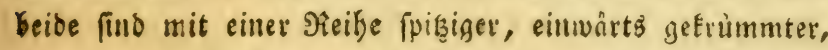
yon einander entfernter Zäbne bejegt, uno de 3 viliden= ráume mit Eurzen, nadeliôrmizen, bidft ancinander f̈eben=

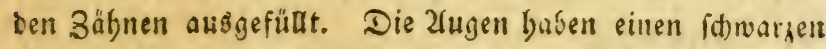
Stern in einem gelogelben singe. Die Eeitenlinie it

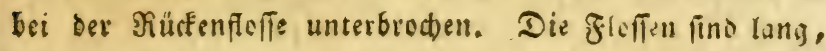
und laufen in eine Gpişe aus. Durd) Die barten lilbers farbenen Souppen fieilt eine angentefme blafirethe ồarbe.

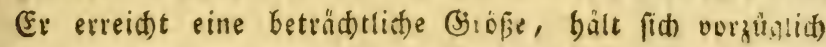

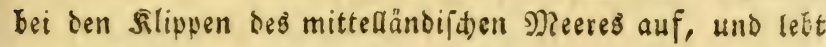
von Sdanttbierén uno ziíden.

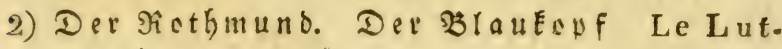
jan Écureuil. La Cepède IV p. 205. L'Écureuil, Bonnaterre 135, t. 57, f. 221. Perca formosa. Linn. Anthias formosus. B(od) auçl. Fiide VI: 122. t. 323. Catesby Carol, II. p. 6. t. 6. f. 1 .

( Tab, 66. Fig, 95, ) 


\section{Biexte Elafie. Fif}

In ber Giemenbaut liegen 5 , in der $\mathfrak{B}$ runtffeffe 16 ,

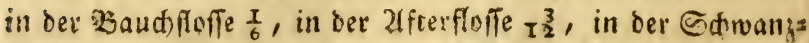
forfe 17, und in ber siúctenflofie $\frac{1}{2} \frac{2}{9}$ Strablen. Die Miunts

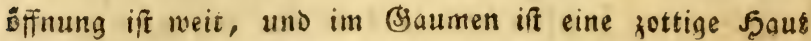
fidtbar. Die Simnladen find gleid)lang. Der vorbere Ries menbecel ift nur wenig gejäbnelt und ber bintere glatt. Der breite Görper bat gelbe, braun eingefaß̄te Sduppen unb blaule Rangenftreifen, reldbe eine fhmale braune (Einfaf fung baben. Die glerien find getb, die afterfloffe fteif une

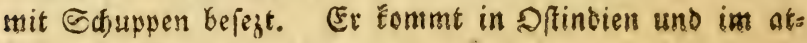
Iantifden Noeere vor.

LX. Das Solnfifd: (3) ef(d) (5)t. Johnius. Slod).

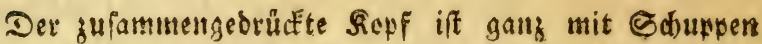
betect. Die Siemendectel fint zungezăfnelt uno ftachellos, ser vortere fdimal, ber bintere breit. Die Fiemenbaut it bebectit und fünffitrabliçt. Die Siefern find mit Eleis.

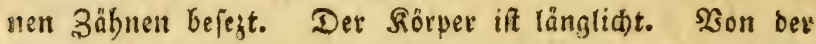

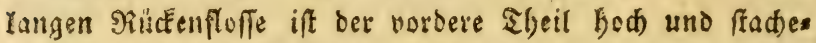
ridat. SBlod bat 2 ?trten befdrieben, bie aus Der Bes getio bon sranqueb̆ar Esmmen follen.

1) Dex Rarutt: Sobnfifd. Johnius Carut.

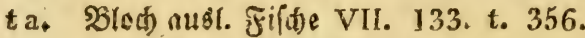

(Tab. 67. Fig. 96.)

Der DberÉefer ift Gervorftebent. In ber Riemenbaut fint 5 , in Der Bruffiofte 16 , in ber Baudjfoffe $\frac{1}{6}$, in der 2ifterfloffe $\frac{2}{3}$, in Der Sthwanzfoffe 18, und in ber গiücten. flefle $\frac{x}{4}$ O Etrablen. Der abgerundete Sopf if zulammen= geoviaft, unb ganj mit Gd)uppen belegt. In ben Simsa 
Syeite. Die Seitenlinie fein, uno binterwärtb nad) unten

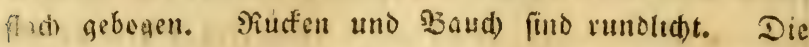
Gownen Elein, bart uno gejabnelt. Die farbe ift am Situken Dunctel und an ben Seiten und Dein Baud)e bells braur. Eämmtiche Fleffen find abgerundet. Die Gla= shiln ifarcf. Die Bruitfolle ift fdwe elgelb und bie Saud)=

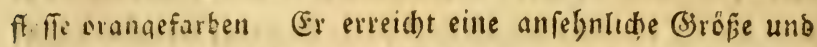
bolt idd) an oer Süfite von Guinea auf, bat ein weifes (d) madthafted Fleifd).

LXII. Das Sahlfopf : (Befhled)t. Gymnocephalus. $\mathfrak{J l o d}$.

Ser Ropf iff ifhuppentog. Der vordere Fiemendecter

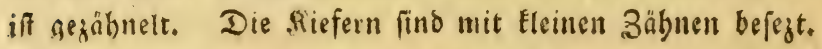
f̧ievon find nut etliche Zfrten befannt.

1) Der Gdinatier. L'Holocentre Schraitser. La Cepéde IV. p. 347. Le Schraitser. Bon. naterre 134. n, 45. Perca Schraetser. Linn.

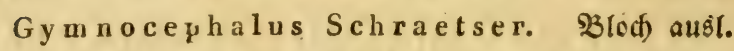
Fiiche Vll, 26, t. 332, f, 1. v, Meidinger. Pisc, Aust. tab. 2.

$$
\text { (Tab, 69. Fig. 98.) }
$$

In ber Siemenhaut fino 6 , in Der Brufffleffe 14-16, in oer Bauchlefie $\frac{1}{6}$, in Der Afterflufe $\frac{2}{7-9}$, in ber Eawanificfie $15-18$ uno in ber Siuckenflofie $\frac{18}{20-32}$ Etrabien. Ier soof bat oben etme Bertlefung und if fowari netupfett. Der Dberfiefer länger als oer untere, Der Niuno flem, ore stupen fletidug. Die Augen baben sinell gelben Gtern. Ser Siorper tif geftrecte, gelblicht, Init 3 id)warzen nac) Der Eange laufenden Emien Durd)zogen, 


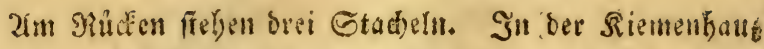

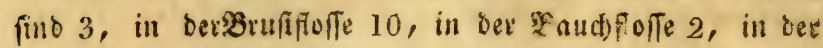

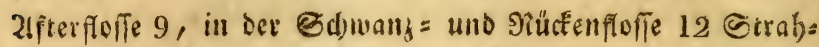
leil. Die berworftebenden 2fugen baben einen fdwarzert Erern in einem filberfarbenen Minge. Der ximendeder if grobi und fo wie bie Geiten fiberfarbig. Sei einigen bat die Sichle und die Sirult eine fásone rotbe farbe. 2in Der Bruft find 2, am Baudfe 1, und auf jeder Geite 13 Sobilde, uno eine beroorftehente gefaltete Saaut. Die Eeitenlinie gebt sben lăngs ben Edilben fort, if raub.

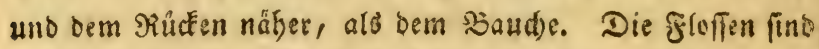
gelblicht, bie am Zaudbe beffeben aus einem ftatden, auf betoen Seiten gezăbrielten Ctadbel und aus einem weid)en Eurzen Strabl.. In oer Siủcen = und 2ifterfloffe ift seb

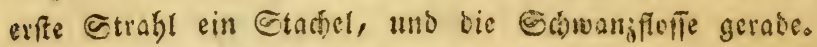

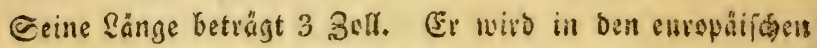

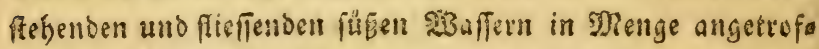

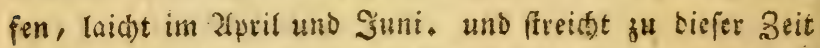
aud) aus ben Eeen in bie flïfe. Seine Nabrung beftefte

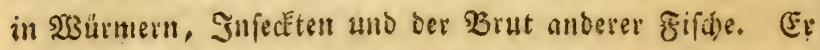

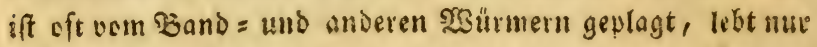
$2-3$ Jabie, wirb nid)t won Mienfiten gefpeiff. $250 \mathrm{er}$ bäufin gefangen wiro, wie bei Danjig, wirb er zum Ifyrans fieben ober aud) an anbern Drten, zum Süngen ber Żaker,

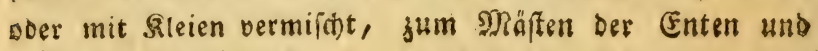
Det Schiveine verwendet.

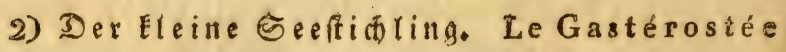
épinochette. La Cepède III. 1. 396. L'Epinoche. Bonnaterie. Gasterosteus pungitius. Linn. Blod) Fifole Deutid) 11. 82, t. 53. f. 4. (II. 108. $t, 53 . f .4$,) 


\section{Sอธกแแg. Pisces.}

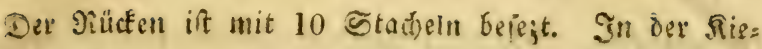
smenbaut fino 3 , in ber 23 ruffinfe 10 , in Der Saudferfe 1, in ber 2lifter: unb Edmantaflefe 13 Etrahten. Der

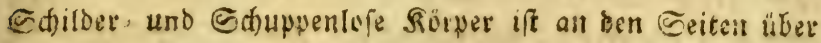
Ser Sinie getb, unter berfetben aber und am Bauthe fils berfarben. Die Baudfiflête befteft nur aủ einem einj̧ gen Etadtel, und bei ber 2lfterfoffe ift ber erfte Etrahl

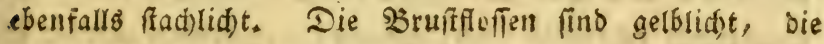

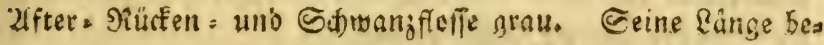

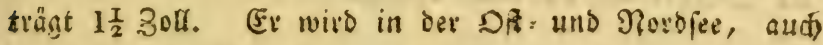
in alten Ranbfeeen unb Safen, wetare mit dem Meere in Szerbinbung fteben, gefunden. Sie balten fid in Şaufen bei einander auf, begeben ind) im Frübjabe in bie Miuns

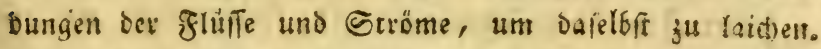

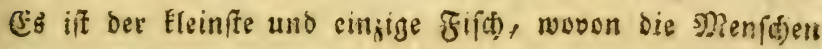
weinen (jegraud) madjen.

3) Der grobe Seftiding. Der Dornfif Le Gastérostée Spinachie. La Cepéde III. p. 296. Le Quinze-épines. Bonnaterre. Gasterosteus Spinachia. Linn. Biody giiche Deutifi)l. II, 84. t. 53. f. 1. (II. 111, t. 53. f. 1.).

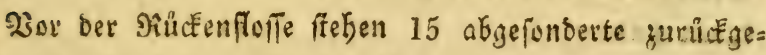
Fruimmte Gtacheln. In ber ßiementyaut fino 3 , in ber Soruiflofie 10, in ber Bauchloffe 2 , in Der afterforfe

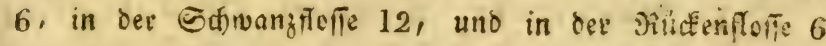
Ctrablen. Der Sowf if ıöbrenformig. der Serper gefrectit, fünfectig, ber Sdbwanz platt gebrǚt Die untere ßinns labe fagt vor ber oberen hervor. Die alugen baken einen

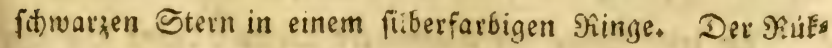
fen uno bie Seiten babell eine Sliven - uno Der Şaud eme 
Silberfarbe. Die Centenlitile iff fdarf, erbaben, aus vies Ien braunen finien jujammengefejt, uno am Bauche ftebt auf jeder Selte ein langes, id)maleș, bervorftehendeb Sdild. (er erreid)t bie (jiröfe von 6--7 3cll, finoet fid fowobl in ber Dit = als Nordee, lebt von Nogen, Fiidbrut, SWümern und Snfecften. Sie werden von armen \&euren

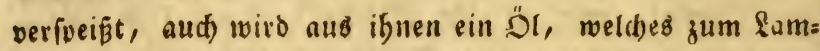
penbrennell gebrau(t)t wirb, getod)t, Deß̧gleidden werden fie als Dünger auf Die Zücker benujt.

\section{Das Mafrelen: (Befd) ledt. Scomber.}

Der Sopf ift zufammengedrüft, Elein, glatt, mit $a b=$ faüfîlaer gefdärfter Stirn. Die faft gleid) langen Sinn= Jaden fino mit fpişigen Zäfnen bewaffuet. Der Sörper ift non ben Geiten zufammengebrüćt, mit Eleinen Sdup= pen bedect. Der fteife uno beinabe vierestige Sdywanz ift bei sen mebreften mit vielen Eleinen 2 affartfeffen be: fegt. Die Kiemenbaut hat 7 Strablen. Son sen 8 Flofs fen figen an het Bruft, Dem Bauch und গiucfen 2, am

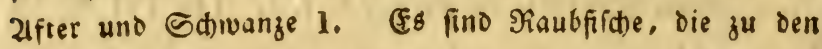
Berobneri der Meere gebören, wovon gegen 40 Urten be: Ealint find.

1) Die gemeine Matrele. La Cepède III. p. 24. Le Maquereau. Bonnaterre 138. n. 1. pl. 58. f. 227. S comber S comber. Linn. Blod) Fis fabe Deut foll. II 88. t. 54. (II 117, t. 54.)

( $\mathrm{T}$ a b. 70. Fig. 100.)

21n jeber Seite bes Samanzes fteben 5 Fleine Baftarts freffen, In ber sorufflofie find 20, in Der Baudfloffe 6, 


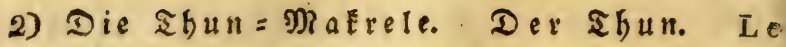
Scombre Thon. La Cepède II. p. 605. Le Thon. Bonnaterre 139. n. 5. pl, 58. n. 228. Scomber Thynnus. Linn. Blot) Firde Deutichl. II. 95. t. 55. (II. 125, t, 55.)

Die Eeitenlinie iff nlatt unb ofnmeit bem Sopfe ger Exummt. In oer Brufffofle find 22, in oer :Bauchflofle 6, in bee 2lfterfiofle 13, in oer Edwanzfloffe 25, und in oev Rücfenfoffe 15, 12 Strablen. Die Mundeffnung ift weit. Der Unterfiefer fiebt vor bem oberen bervor. Die grofien aus gen baben einen fawarjen Stern in einem fillerfarbigen mit

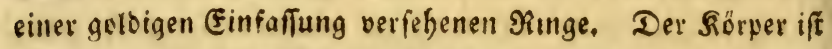
fpindelförmig, am Rumpfe Dick und ain STopfe unb Sd)ronje

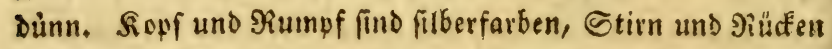
fablblau. Der Shwwang if sierectig oben und unten mit 7 - 11 Baftartfoffen, und auf ben Geiten mit einer ets was beroorftehenben Saut in Gieftalt einer zetıfloffe befejt. Die Fleffen find an Der Siruif lang, am \$audbe Eurg. Jelle baben eine gelblide und diefe sine graue Farbe. Die ers

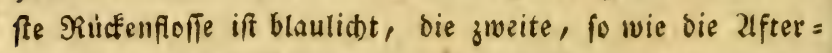
uno Saltartfoffen gelblidt. Die Sthwanzflefe graufdwarg

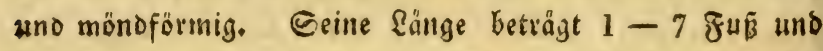
barüber, das (jewidht $7-500$ ßfunb. Sie bewebnen bie europáif́cen, afrifanifaen, jüblich=afiatifaen und ameris Eanifacn Meere. Sm Mai uno Juni laid)en fie im Meere und an beffen Ruftell. Sie zieben in greken Cd)aaren in

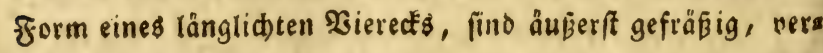
folgen Szeringe uno Maktrelen. Şbie feinde find die Şayz filche, voriuglid) aber der Sd)werdtfifd. Gie werden mit farden (3runofdnutren, die mit vielen angeln verfeben (und, gefangen, vorgüglich aber mut einem grofen factefors: 
migen Neşe, weld)es in Francfleid unter bem Namen Marorag und in Sicitien Tonnaro betannt ift; fo bald nur ber erffe voin 3uge in buffetbe hineingeräth, forgen

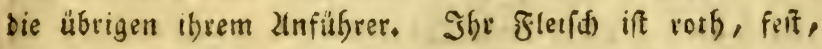
fehr nabrfaft, iem Salbfeifhe an (jefichmact äbntit). Sie werben frifit), eingejalyen unto martmirt geipeist, und vors

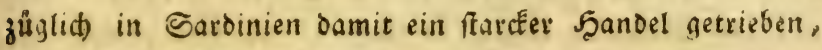
wo br gang leffr bortheilfaft if, uno zu den allgememen SolEsbeluffigungen gebört, und mit allertei Solennuráten bes gangen wird.

3) Der Stö́fer. Die Baftart=MaErele. Le Caranx Trachure. La Cepède III.p. 60. Le Gascon. Bennaterre 140, n. 10. pl 58. f. 230. -Scomber Trachurus. Linn. Blod) Flíd) Deutifl. II. 104. t. 56. (iI, 138.t. 56.)

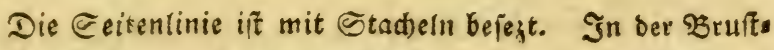
flofie find 20 , in ber Baudflefte 6 , in ber 21fterflete $\frac{2}{3}$.

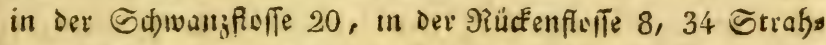

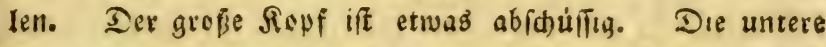
Situnlade länger alş bie obere, nad) oben geEtümmt, und

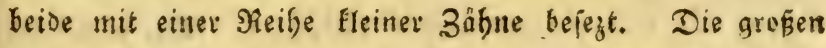
2(ugen baben einen fdrwarzen Stern und emen fillberfarties

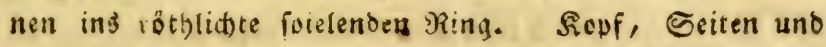
Bauch fint fitberfarben, Etirne uno эäcfen grünblau. Der Sörper if geftrect und von beiden Seiten bufammenges brüct. Die Sentenlinie if mit 68 Şatliben bejezt, welde wie Dadzieget au einanter liegen, deren jebes in ber

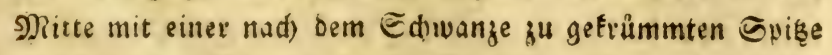

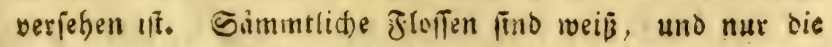

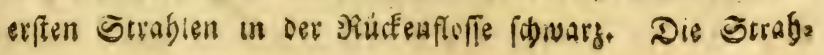




\section{6 รierte ĔInffe. Fifde.}

fen in ber erften rücfenfloffe und die beiben exften in ber zifterfloffe fino ftadgelid)t, bie übrigen weidt. Die Sdmank= forfe menoförmig. Şhre Rănge betrâgt $1-2$ Fuß̧. Sie bewobnen bie Norb, uno Ditiee nebit bem mittellandiften

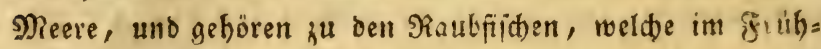
jubr an ben MReeres s \$eftaben baufenweife erideinen, uno mit ben Makrelen forwobl in Neţen, als mit 21 ngefn ges fangen weiben. Slor Fleifd ift weniger zart unj fett, als Das der MaErelen, wiro aber benned) frifd, gebraten, eino gefaljen und aud) marinirt veripeīît.

4) Die Roots = Matele. Der footgmant. Le Centronote Pilote, La Cepéde IlI. p. 311. Le Pilote. Bonnaterre 136. n. 2, pl. 57. fig. 223. Gaster osteus Ductor, Linn, Scom-

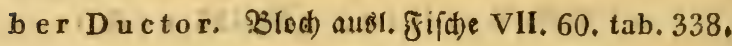

Der Sörper ift bandirt, mit 4 fieiffebenden Stacheln

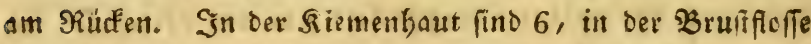
15 , in ser Baudfleffe $\frac{1}{6}$, in ber afterflofie $\frac{x}{16}$, in bet

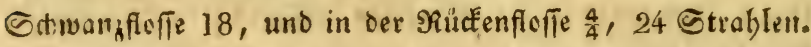
Der geitreckte Blaue, unten weipe Sörper if mit $4-6$ Blauen und weipen Duerbinden bezeidnet. Der $R$ opf $z u=$ fammengebrüct unઠ bis auf oie Siemendecter fa)upenlos. Die Sinnlaben gleidh lang mit Eleinen 3ăhnes beregt. Die

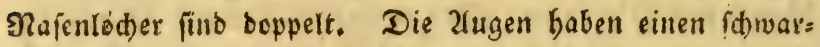
sen Stein in einem gelben singe. Die Siementecter fino abgerunbet, bie Riemenoffnung weit und bie Riementyut ganz bebecfit. Die Seitenlunie biegt fith naib oben uno berliert fich in ser Mitte ber 巨dwansfofle. Cämmtlide Ctrablen finb weid), bie in ter Siuléen: und afterfleffe ein= fab, in ber 3ruffloffe gabelformig und in bert ubrtgen 
viergimeigig. Bruft: unt Bauchfleffen fint grau, Xfter s und Riuckenfoffen blaulidht, Die Sothwangferfe ail Brunde und in ber Mritte fhwars und an Enoe werk. Seine

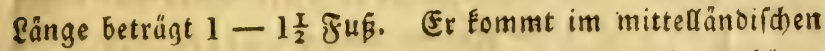

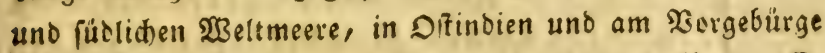

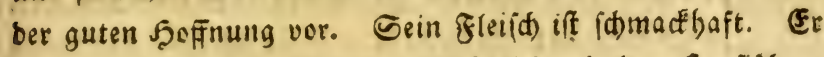

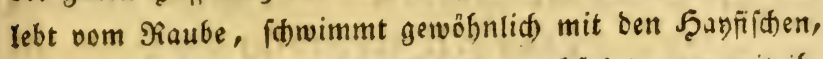
in beren Befenfidaft er ben Sdiffen nadfolgt, um mit it)= nen das aufäufangen, was̆ auş den Sdbifien gerworfen wirb.

3) Die Beutelaugen= MaErele. Scomber Crumenophthalmus. Bloch ausl, Fische VIr. p. 77, tab. 343 .

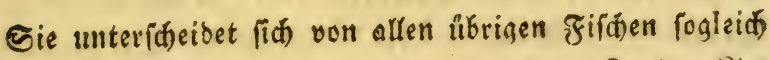
ourch bie beutelförmige Şaut um die 2lugen. In ber Ries menbaut fino 6, in ber Bruffloffe 20, in ber $\mathfrak{B a u c h f l e f f e}$ $\frac{I}{6}$, in ber 2iftertleffe $\frac{2}{2}, 27$, in ber Edjwanzfleffe 18 , in

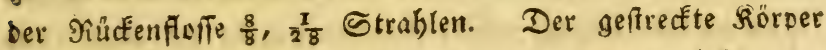

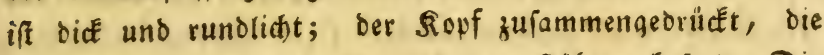
Sinnlaben mit febr Eleinen, fpiz̨igen Zähnen befę̧t. Die Nafentöt)er boppelt. Die Riemenefffnung weit. Die Sies menbaut bebecft. Die Eeitenlinie if beinabe gernbe unb

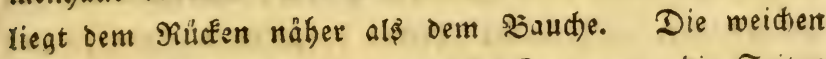
Strablen fino vielznetgig; Die gletien grau, oie Seitern

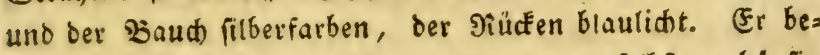
wohnt die afrifaniiden Sủften: Meere, wofelbit er häuffis in ber Besegento ven Acara vorfommt. Ђat ein weifes fet= tes, wohlịmectentes छleifo,. Sermuthlid) Eann or ferne

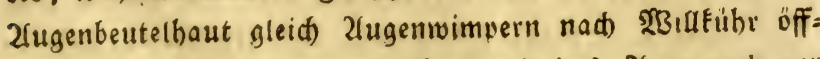
sen und fallefien, um zu fefjen und das 2luge aud vor

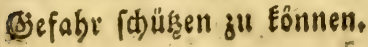


6) Die Sdwerts = MaErele. L'Istiophore porte-glaive. La Cepéde III. p. 375. Voi. lie r. Broussonet Mem. de L'Acas. de Paris. 1786. p 450. pl. 7. - Rozier. Journ, de Phys. ann. 1786. p. 18. - S c om ber gladius. Bloch, ดน81. Jia ithe VII. p. 81 tah. 345.

(Tab, 7l, Fig. 101,)

Die obere finnlabe velthager fick in einen langen, fhiverdformigen Ednabel, die untere hat biefelbe Batloung, it aber um viermal Eürier, als bre sbere. Beite Sinnlas Den nebft sem çaumen find mit Eleiten Zåbuen bejegt. In ser Siementaut find 7 , in ber 98 ruffloffe 15 , in bev

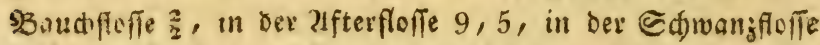

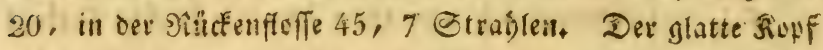

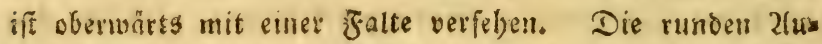
gen baben eirren fduargen Stern uno einen fitberjurbenen Fing. Die einfaden robrenförnigen Majenlödjer fteber bidt an ben 2unen. Die Siemenoffnung if weit, und

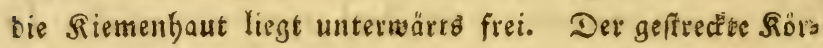
per ift orc mit barten länglidten Sáuppen verfeben, wels

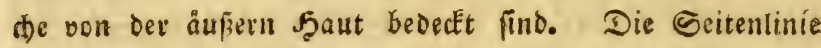
bildet bei iftem 2llfange eillen 2 ogen, und lauft alsoann gerabe aus. 2fn beiben Ceiten bes duwanzes fiebt eine

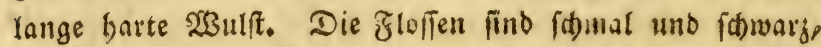

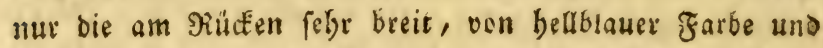
idbwary geflect. Die Baubliofle beftebet aus 2 breiten, langen und gefrummten Sned)en. Sie Etrablen in der boben siückenflefie find bis auf bie 3 lejtern gabalformig.

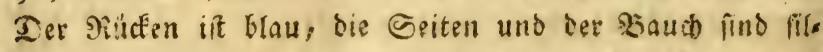
berfarten. Gie erreldt eine keträdthate (hióbe von 9

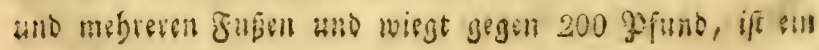




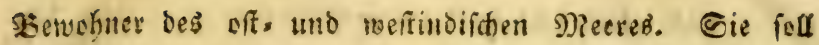
nidit nur Seethiere, fondern aud) Mienfiden unb Sd)tfe angresfon; and finter man nid)t felten Gridfe von ifrum Sdiwerote in ben Sdiffien ftecten. Sd)on von ferne er= fennt man fie im bohen Neere, an igrer über baffelbe bervorragenben shüfenfeffe; debiwegen fie Voili e r (Sego (er) genennt wirb. Shre Nahrung befteft in Giiden, bie

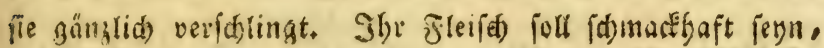

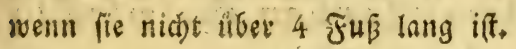

\section{Daz Stadelbaudifd): (5ef ble th t.} Centrogaster. Linn.

Der Sopf zufanmengebrückt, glatt. Die Riemenfaut

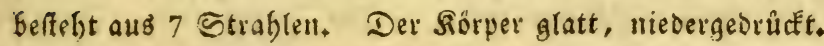

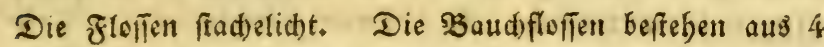
fprigigen Stad)ein und 6 weidsen Strablen. EB fint 4 Ilrten beEannt, Die ž den Meerbewobnern gebören.

1) Der Satterfadelbaud. Le Caesio poulain. La Cepéde III. p. 90. S combre la petite jumont. Bonnaterre 141.n. 14. - Centrogaster Equula. Linn. ed. Gmel. p. 1337.

Die Stirn bat 2 vorrvårţ̉ jufammentaufende, Enteçis

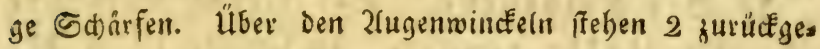
fefrte Stad)eltr. Die 2ugenfterme find weiß. Die Ober" lippe ift berweglict), bie Bálne borftenförmig. Sie vordern Si iemenblätter unterwärtş gefägt. Die anfänglich) gerabe Seitentinie freigt in oie Sröbe uno gegen den Sdbwang

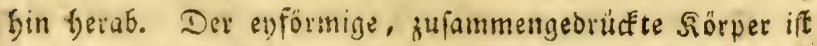
mit feimen Miberfarbenen Soduppen belegt. Die Baudgo 
floffen find oberwåts mit einem 2tnbange von einer lan= zetförmigen Şaut, vor biefer mit einer gleid) breitell f(d)wies lichten, Encchigen Bertiefung, un nor biefer mit einem

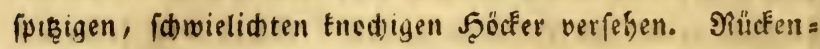
uno afterfoffe laufon bis zum Sinwanze, beffen Fliffe gueilappiy if. Seine Ränge beträgt obngefäbr 5 3olls Er bewobnt bas rotbe Meer.

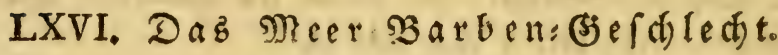

\section{Mullus. Linn.}

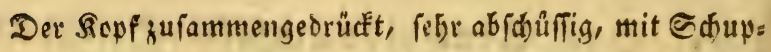
pen besecft. Die alugen länglicht, am Sdbeitel nabe beifammenftebeno, mit einer গicthaut verfeben. Die Najen. löher tlein, geboppelt. Siefen und (jaumen mit vielen ganz Eleinen Zähnen befełt. Die Junge Eurg, famal, glatt uno unbeweglid). Die fdmale Siemenbaut breifrafy. rid)t. Die Siemendectel befseben aus 3 fein geftreiften salăts tern. Die Siemenóffnung måżig groß̉. Der geffrecfte run= de Sörper ift mit großien leidt abfallenden Sduppen be= fezt. Die Siúfenfloffe ift geboppelt, uno erffere mit Sta= deln verieken. (Fs find Meerkemobner, die fid) vorzüglic von ber Brut allberer ßif́de uno von Eeeträutern nábren. Man Eennt baven über 9 verfobiebene arten.

1) Der Rotbbarbe. Der fleine Rotbbart. Le Mulle rouget. La Cepède III. p 385 . Bonnaterre 143. n. 1.pl. 59. fig. 232. Mullus barbatus. Linn, Bloch, augl. ङijate VII. p. 98. tab. 348. fig. 2 .

Der Sopf abgeftumpfit. 2fn ber untern . Finnlabe ffeken. 2 lange Sartfafern. In ber Siemenbant find 3 , in ber 
filberfarbenten Эäinge umgebenen Stern. Die Riemenöfnung weit, die Siemenhaut fomal. Sopf und Sörper fino rotly uno bie gologelben Streifer lizen nur auf ber Dbertiathe ber Sd)uppert. Sanmilide Floffen fino gelb. Die Strabo ren ber vordern Tiutenfloffen fino bart un einfac, die übris

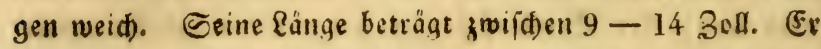
Eommt in ber Noro. uno Ditiee, im mittelländifden Neere.

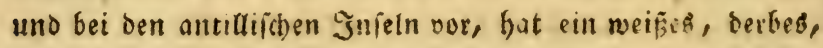

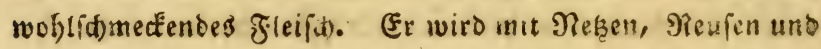
ber Inger gefangen. Er frano bei Den (Mrtedien uno $\Re 0$ a

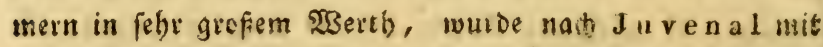
fo viel Giltber begablt, alš et folwer war. Raifer Tiberius lieg nach Senela einen folden vierpfünoigen Fifd, ber ifin gefdendt rurbe, vertaufen, weldber bem Octavius für 5000 Seftertient nid) zu thener war, und zu Derfelben Zeit wurden orei andere mit 30,000 Seftertien, (nach) unjerm (selo faft 1000 Mieid)othaler) bejablt. Nad) Sarto wat er den Tömern in ifren fild befáltern wegen feiner fdönen zarben eine Jugenweibe. - Gie liejen fie aud) nach SeneEa bei ibien Gaftmalen in Den Şänden abfterben, um fid) an ber Beränderung der Farben, die

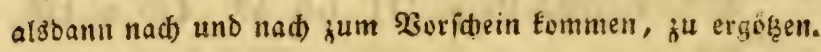
(Daber Nihil eo expirante formosius, nihil Mullo sapidius, romanorum itaque in eo summa gulae insania - testibus Plinio, Seneca, Horatio, Juvenali et Martiali.)

LXVII. Das Seehahn: Befdredt. Trigo la. Linn.

Neben ben Brufffifien abgejenberte, geglieberte Znhyängs fer. Der grobe Sopf if gepanzert. Die alugen gró, 
runb, nabe am Stheitel ffehend. Die Munceffnung weit. Sinnladen und Baaumen mit fikizinen Zähnen veífel)en. Die פaiens Эiobren gedoppelt. Die Siiemenóffunng weit. Die Siemenopctel einolattria, geitrablt uno fradblidt. Die Riemenbaut $7-8$ frablicht. Der Sörper feilformig, Elein= geichuppt. Der Riüfen gerabe mit einer all beiben Seiten

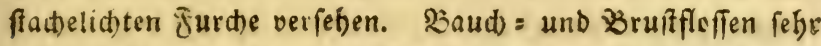

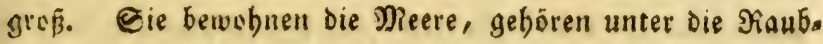
fifde, ven welaben gegen 20 2rten befannt find.

1) Der gepanzerte Geebabn. Der (5abels fi đ. Le Péristédion Malarmat. La Cepède III. p. 369. M a la rmat. Bonnaterre 145. a. 1. pl. 59. fig. 234. Trigla cataphracta, Linn. Bloch aubl. Fif che VII. p. 105. tab. 349,

( $\mathrm{Tab}, 73 . \mathrm{Fig}$ 103.)

Der Sörper ift gebarnifht. Sn ber Riemenbaut find 7, in Der Bruiffulfe 12, in Der Bauchloffe 6, in bev aftere fleffe 20, in ber Sdwoaniflefie 13, und in ber riuckenfloffe 7 , 26 Strablen. (Er hat fratt Der Sd)uppen rautenförmige Edilde, bie fint in ber Mitte in eine Satheibe erböhen und fid) in nad) binten geridjtete Jaaden endigen. Sie bilien 8 fdarfe Santen und eben fo vial furchen uno gebeil daber

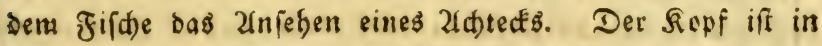
einen viereffigen Sineden gebüllt. Die obere Sinnlabe en. sigt fith in 2 lange Sinoden, bie eine gabelformige Beftalt

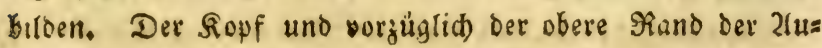
genböble fino mit Stad)eln befezt. 2fm Sinme fino 4 turze ano 3 lange $B$ artfajern, beren leztere fict) in nebrere 3weige theilell. Die Jugen baben einen idwarzen Gtern mit blaus

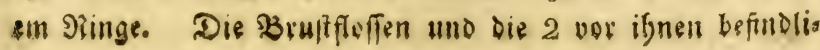




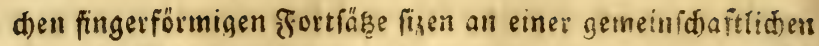
Şaut. Die Baudhfoffen fino grau uno die Brufffofien fd)wary. Die Strablen in ben affer: uno Sithicenfloffen

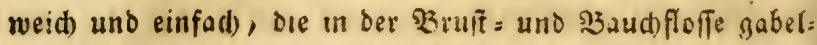
formig, bie in ber Echroanflefie vieraweigig, uno bie in

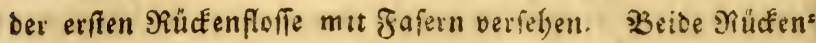
floffen bängen burd eine gemeinid)aftliche 5 ?aut zufammen. Diefe uno Die afterfloften fino rotb, Der übrige Siorper if

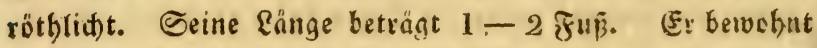
bas mittefländifd)e und oftindif(be ) Neer, bat ein mageres uno barter Fleifd.

2) Der rotbe Seebahn. Le Trigle Grondin. La Cepède III. p. 358. Le Perlon. Bonnaterre 146 n. 5. pl. 60. fig. 237. Trigla Cuculus, Linn. Bloch Fifde Deutid)l. II. p. 124. tab. 59. (II. p. 166. tah, 59,)

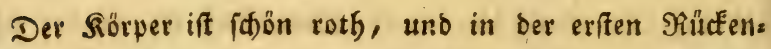
forfe ift ein fowarzer flect. In Der Siemenbaut fino 7, in ber $\mathfrak{B r u f f f e f f e} 10$, in ber $\mathfrak{B a u d}$ fioffe 6 , in cer afterfiffe

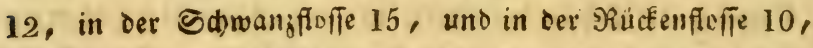

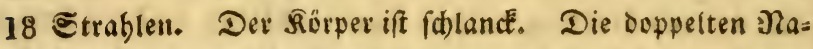
fenlöder fiteben nabe am Munde. Der idwarze 2lugeniftern if mit einem filberfarberten Sinıje umgeben. Sücten uno Seiten find roth und mit weifent Punffen befprengt, ber Saud filberfarben und ber ganze Siórper fleinfotupyig. Die Sertentinic beitebt aus itarden, breiten, filberfarbigen,

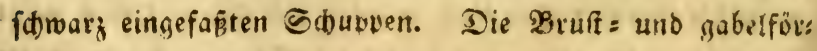
mige Sdmanaflefe fino rëtblidt, bie Baud: = uno after.

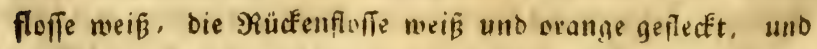
bie Seiten roth. Seime Range betrigt $8-10$ 3oll. Er 


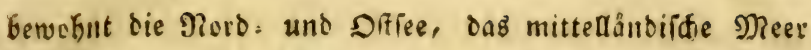

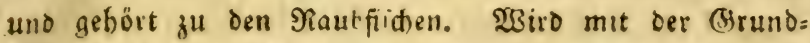

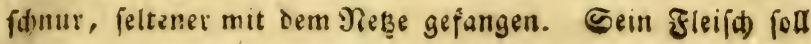
berb" uno idmatfouft pern.

3) Der Satwalben= Seebahn. Die Seeforwals be. L'Hirondelle de mer. La Cepède III. p 353 Bonnaterre 146. n. 7. pl, 60. fig. 238.

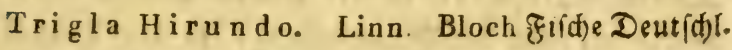
II. p. 126, tab. 60, (II. p. 169, tab, 60.)

Die Brufffoffe iff eben fo lang als breit. In ber Sies menhaut ind 7, in der Brufflofie 10, in ber Baudfleffe 6, in ber IIfterfente 14, in oer Edwangferfe 16, in ber

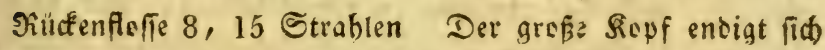
vorn uno hinten in Eurire Spizen. Die fhwarzen 2ugen= fterne fino mit einem filtberfarbenen, ins rothe fojielenden ßinge umgeben. Der Siörper if mit Eleinen Sduppen benectit. Siúcfen und Seiten fino braun ins viclette fipies reno, oer Baud) fliberfarben. Die Brufffloffen fino vios

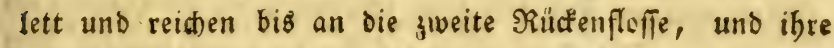
Strablen entigen fid, wie bie ber Baudjfleffen in 4

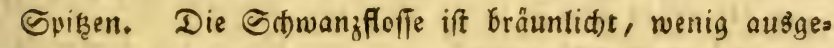
fanitten, unb hat viergmeigige Straflen. Die übrigen Flofien fino meí, und baben einfadbe uno meithe Strab.

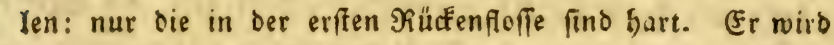
2-3 Ffund fdwer, benobht die Norb, und Dffee, und fommt aud) einzeln im mittellandifchen Meere oor. (Jjes bört k Gen Bruffflofien fehr idnell. WBiro mit ber Brundidnur

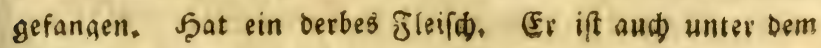
Samen Sinurb a bn betannt, 
4) Der friegende Seebabn. Le Dactylopa tére pir apède. La Cepéde III, p. 326. Pi* raped e. Bonnaterre 147. n. 12. pl. 61. fig. 239. Trigla volitans. Linn. Bloch aนชิเ. Jiflue VII, p. 115. tab. 351 .

$$
\text { (Tab. 74. Fig. 104.) }
$$

Die Siruffleffe ift fo lang wie ser Siumpr. In ses Siemenbaut fino 7, in Der Eleinen Bufffloffe 6, in De: grofen 20 , in ber Baubfloffe $\frac{1}{6}$, in ber 2ffrerfaffe 11 , in oer Schwaniflefie 12, uno in oer গiückenflofle 6,8 Etrablen. Der turge, ins violette fpielende Siopf fted in einer vieteffigen fnöthernen Saufle, bie fith in 4 lange Stadeln enoigt. Die Nunoeffinung ift weit, die obere Simnlade ftebt vor ber unteren etwas beroor, und betde fino mit Eleinen Jieitgen mégrever pertenförmigen Búlyue bewaffuet. Die 2 ugen baben cinen forwargen Stern mit

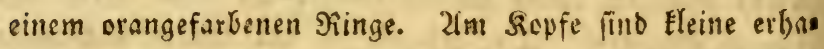

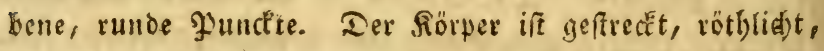
Der S3auch flad), mit rautenförmigen Edutwen befest, bie Seiteniduppen find mit einer fdarfen Ririe ber Ränge nad) verfeben. Die Rüctenfloffen ftén weit aureinander und vor Der erften fint 2 lange sorfien. Eämmtlide Strab) len find weid) und cinfact), und mur bie in oer Gdwang= floffe gabelförmig. Die erfte Shüuen = uno bie Sdywang=

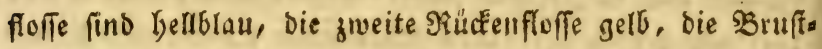
floflen olivenfarbig uno alle blau geflect. J̧hre Ränge bes

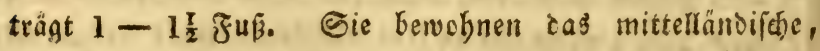

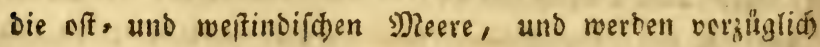
båufig bei bem 20rgeburge der guten Satînung angetrof= fen. Shre Nabrung beftebt in Muforein, Sdjecten uns Sirebfen, bie fie mit ifren pertenformigen Bübnen jermats 


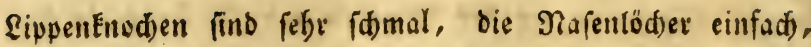
röbrenförmig, Didht an ben 2(ugen. Die zhugen flein, nabe an ber Mundöffnung, iffe fowarger Stern bat einen

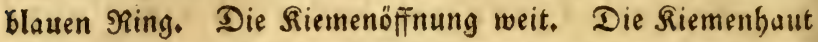
liegt verborgen. Der Baudb ift Fur. Die Seitentinie

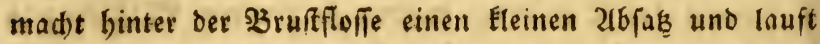

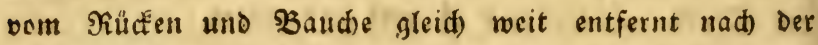
Sdwanzforfe. Die $\mathfrak{B} r u \mathfrak{t}=$ unb Baudfieflen find Eurz und abgerundet, fämmtlidbe Strablen weid) und viergweis gig. Die Brunbfarbe Diefes fifdes if fodmuţig wein, bie

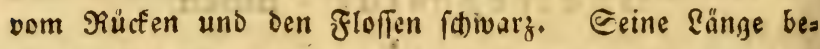

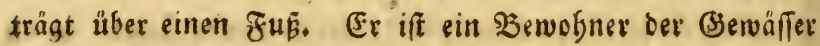

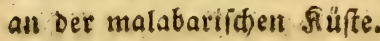

* In nerEung. Die ziweite 2fre iff ber geftreifte Edlangentopf. Ophicephalus striatus. Bloch VII. tab. 359. pag. 14l. Die fidi) Durd) Die braunen Streifen, bie man fowehl am গiumpfe, als an einigen slofien wabznimint, unterfdeibet. Die

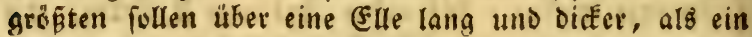

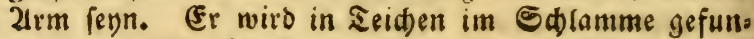
ben, uno ift efpar.

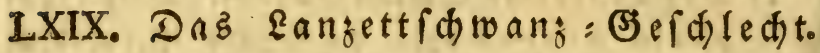
Lonchurus. Bloch.

Die Sd)wanzflofe langettförmig, bie Baudfloffen ges trennt. Der Sörper geftrecft, mit weichen und glatten (s)uppen befegt, und mit 8 Flofien verfegen.

1) Der bårtige Eanzettíñang. La Lonchure dianème. La CepédelII. p. 414 Lone churus barbatus. Bloch ausl. Fifide VII. pag. 144, tab. 360 .

(T ab. 76, Fig. 107.) 


\section{Dํ $\mathfrak{n} \mathfrak{n} \mathfrak{g}$.}

Baudfloffer. Pisces Abdominales. Mit Saudffloffen binter Den Sbruffloffen.

LXX. Das Sdmerlen: Şefdled)t. Cobitis. Linn.

Der Repf Elein, länglid)t, fduppenlos. Die Zuggen boct) am Sopfe fistent. Der Nacten flat. Die Riemens

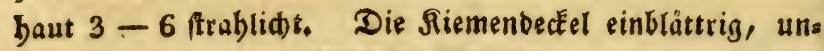
ten feft anjidließend. Der geflectite und geftreifte Sörper faft gleidbreit, zum \$heil walzenförmig, idieimig, mit fernen, reidt abfallenden Sdduppen. Der ßiücten gerwbe unit einer gloffe, Die Geitentinie Enum fidtbar.

1) Die Surinamifale Sqmerle. Der Bier: auge. L'Anablèps Surinam. La CepèdeV. p. 26. Le Gros-yeux. Bonnaterre 148, n. I. pl, 67. fig. 240. Cobit is Anableps. Linn. Anableps tetrophthalmus. Bloch autl. Fis ife Vill. 7. tab. 361 .

$$
\text { (Tab. 78. Fig. 109. 110.) }
$$

Die 2lugen hod) beroorftebenb, 2 Bartfajern am Mun= 6e. In der aiemenbaut fin 5, in der Bipftiofle 22, in 


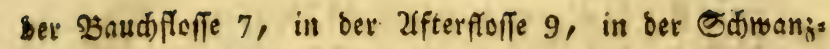
foffe 19, un in ber Rüćenfleffe 7 Strahlen. Der Repf niebergebrüct, vorne abgeftumpft, ber obere Siefer lánger als ber untere, unto beibe nebft ber Zunge uno dem Baus men mit Eleinen Zăbnen verfefen. Dir গlafenlód)er einfad)

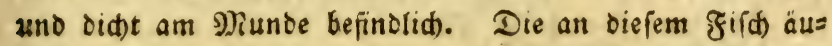
berft mercfwüroigen 2ugen *) baben 2 burdfichtige Stellen

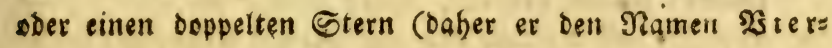
euge bat). Der Rörper if obell jufammengebrüatt, bins terwärts walzenförmig. Zn ben Seiten fiteben 5 nad ber

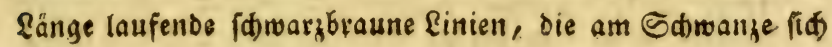

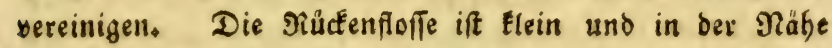
bes Sdwanages. Sämmtlidje Strablen fino weich uno vieliweigig, nut die erften find einfad). 2luģer ben 2lugen

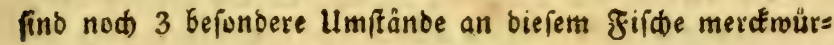
big. **) (Ex bewolgnt bie glüfîe von Surinam, if $6-10$ 3oll lang, vermefort fid ftart, bringt lebentige Sunge zur 23elt uno wirb ven ben bortigen Einwebnern gefpeist.

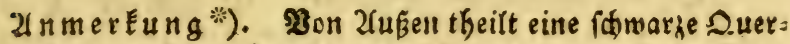
binbe auf ber Şornbaut bas luge in 2 ungleide Ster, ne ober \$upillen. Inwentig theilt eine Berlangerung ber aberbaut (Tunica choroidea) und ber Den Fiiden eigenen Silberbaut, (Tunica arge $n$ tea) die gupille von vorn uno ginten in 2 Theile.

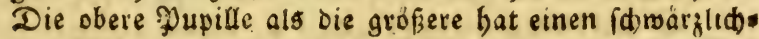
tell গing, in weldeen bie Silberbaut auf biefer Seis

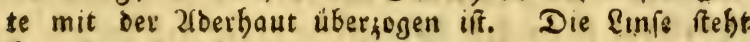
Gier Der Şornbaut mit ber Eugelförmigen Dberfäathe fefe nabe. Die untere Eleinere SPupille bat etnen fils berfarbigen Sing, in weldem ber obere Piand ber ver. lângerten Silberbaut fo wenig als ber untere अiand Derfelben, mit ber adorbaut bebecf́t iff. Zun diefer liegt bie Eleinere Duerfläche oer finfe. Züüerdem aber if

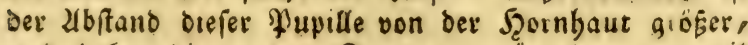
amb baber bie untere Sammer gerăuniger uno mis 
mehr zeuditigfeeiten angefüt als bie obere. Die birne formige Sinfe liegt in Der Suere, uno ber fpibigere Shell derfeiben madit die $\mathbb{E}$ infe beg klemen runden Sterns, Dre tuqoliunde Sherfladbe aber bie Rinfe bes gröern eyrunden Sterns aus - f. Bloch a. a. D.

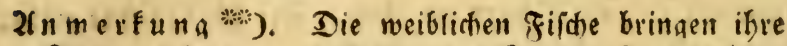
Jungen lebenda zur Welt; Die Miutter ift ein düns båutiger grober Eact, der in 2 Eicte getbeit zu feyn fdeunt, movon her eine etwas länger als ber andere

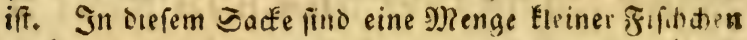
entholten, ravon ein jedes in einer belendern rünnelt uno ou:difidtigen fhaut etngefdloffen ti einev nethen runcen siugel ober Ditter. fig. 110. Eerner if bie ltrteriferfe bet dem Manniten anders

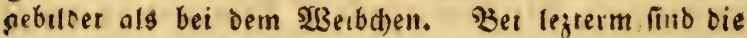
9 Strahlen, wornus fie quiammengeje;t tit, leid)t iu etfennen; bet erferm aber fino nur 3 zi fehen - und bie vibrigen find mit ciner $\Re$ iöbre, die ein Bundel aus= madten, in einer Saut gebüllt, mit Schuppen bedecf́t unt rem Särper abifeḩeno. Fig. 109. Wrenn man bie Saut non oiefem Bundel forgrältig ablöf: io Esmmen bie Durm verifeft geweienen 6 Etrablen und bie eben erwäbnte Rôbre gum Rorichem. In siefe Möbre er. gief̂t fich forvehl ber Saamen, als auch ber Starn. Iies bereifet fomeht bas anfdiwellen oer Saamen. bläsden, als ber Saarngänge, wenn man \&uft in bie Siohve lås̆t.

WBir Eennen zwar nod einine Sduppenfilche, die les benoig gebabren, nemlid in Eureva bie $\mathfrak{l l}_{\text {a }} \mathrm{Im}$ ut tes (Blennius viviparus. Lin n.) und im Morgenlande ben al genwimper, allein bei vieien bat nod Nies mans einen Milder entdecf́t. Natürliderwetfe fällt eillem jeben ber Bisdancfe ein, 16 bei unferm Fride eine croentliche Begattung fatt finte, oder ob dif zortpflunisung ourd) sie blof̉e lnnäherung oer Reu= gungetheile wie berm $\Re$ od en bewirft werde. MRis ift bas erftere beswegen wabricheinlich, weil bie Männs d)ell mit ber erwäbnten 3öbre verjeben fint. $B(0$ d)

a. a. D. 
$\div$ 2) Die gemeine Edmerle. Die Brunder. Grủnoling. Barts (S) runbel. Le Cobite Loche. La Cepède V p. 8. Franche-Barb otte. Bonnaterre 148. n. 2. pl. 61. fig. 241 . - Cobitis Barbatula. Linn. Bloch Fifíde Deutidfl. I. p. 224 tab. 31. fig. 3. (I. p. 284. tab. 31. fig. 3.) v. Meidinger. Pisc. Austr, t. 18.

(T a b, 87, Fig. 111)

Der Roof unberwaffinet, 6 Bartfafern am Nunde. Su Der Siemenbaut find 3, in ber Bruftioffe 10, in ber Bauds:

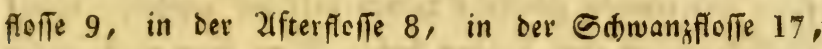

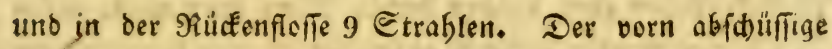
Sopf endigt find in eine frumpfe Spif̧e. Der Dberfiejer fefeft vor bem untern heroor. Der Munb iff zalnulos, bie Mundöffnung nebft dem 2luge Elein. Der Förper runo, grau unb weiß marmorirt, mit Eleinen Sduppen bebect't. Die gerabe Seitenlinie lauft bom Rispfe zwifhen bem

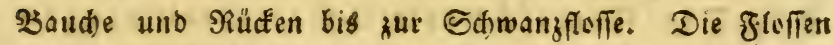

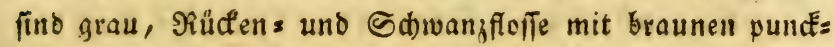
tirten Sinien befezt. Sie wirb nur 3-4 Zoal lang, Fommt băufig in Eleinen mit einem Eiefigten, İeinigten Girunb vers

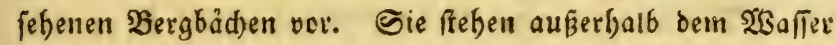
fogleid) ab. Das zarte Fleifo biejer Fifhe übertrifft das

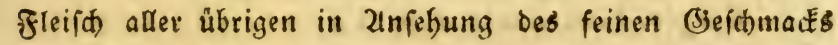
wett, bejonders in den Monaten November bis Mai, unb iff febr teidt zu verdauen. Shie Nabrung befteft in 2 Süla

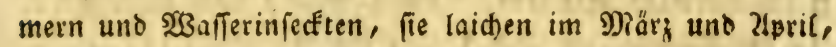

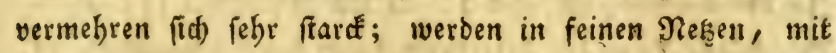
ser Gencfe uno ben গieujen gefangen, ber angenehme (sea fdimact biefer fiifde wiro oaburd) ned) mehr erböbt, wente man fie fogletch als fie aus bem Warfer Eommen, in 2 Sein 
Dobr 3) Mild akfferben läğt. Man pflegt fie in Sarzwaffer

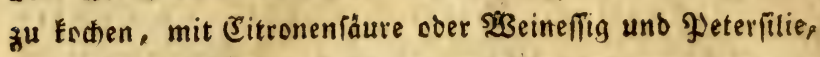
ofer mit einer 3 utterbrithe zu recht zu madell, aud) zil

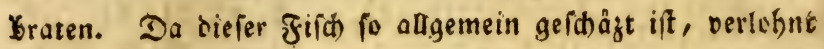
fids wobf ber \$übe, in jenen Bäben, wo er vortsmmt, eigene of $r$ unbelgruben anjulegen, bagu wercen Gtelten gemähtt, die einen fteinigen Girund baben uno immer fri= fdes Dueflwaffer erbalten. Dieje Bruben müfien 3 Fuf tief, 6-8 \&uf in ber Sange haben uno balb fo breit

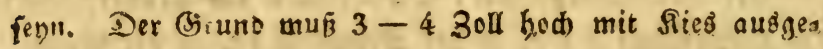
fült unb eintgen grofen Steinen verfehen werben, bamit er Gelegenbeit zum Raiden babe. Mlan thut webl, meks sere folder (Bruben zugleid anz̧ulegen, baven bie eitre zum Etreidben, Die andere zum Finfegen ber פrut und bie brita

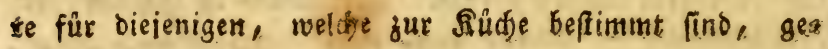
Graudt wivg.

43) Die Steinf́mexte. Dex Steinpitger. Steinbeifer. Greingrundol. Ee Cobite Taenia. La Cepède V. p. 8. La Loche. Bona naterre 148. n. 3. pl. 61. fig. 242. Cobitis

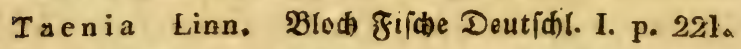
tab. 31. fig. 2. (I. 280. tab. 31. fig. 2.) v. Meidinger. Pisc. Austr. tab. 32.

Su beiben Seiten bes Sepfs ofnneit ben Zugen fteben. 2 gabelförmige Stad)eln. 2lm Munbe fizen 6 Bartfafern. In Der Sirmengaut fino 3 , in ber Srutflefte 11, in see Baud)folfe 7, in ber Xfferflefe 9, in oer Edwanjflefte 17,

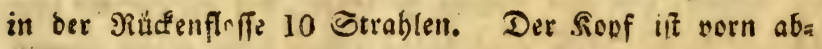
foulfig, auf ben ऊettell ebell fo wie be: Förper zujarnmens gebrüćt und mit braunen furien gegiert. Die ?lugen fino 


\section{V. \ัธนแกg. Pisces.}

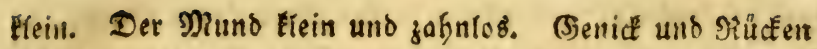
find braun, unt bie Brundfarbe Der Geiten blä̧aelb, auf welden fich) 4 Pieigen brauner glecte uno gyunctite von un,

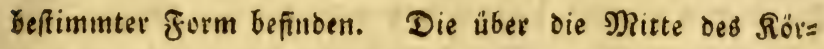
yers weglaufente Seitentinie ift Eaum fiddtbar. Der gan je Rörper if mit einem Sdleim überzegen, unter weld)em Eleine feine Sdukpen liegen. Bruft, 2ffter , und Sdbwang.

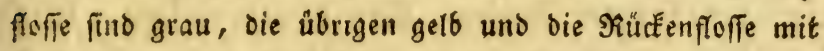

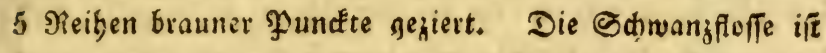

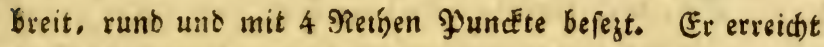

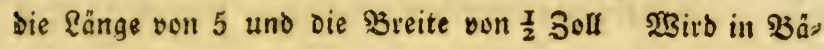
den und glüffen gefunden, wo er fidh gewöfntid) unter bels

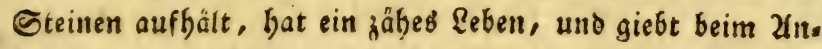
grcifen einen eben folden pfeifenden gaut oon fid als ber Ed)lammpigat. Seine Nafrung befteht in $23 u$ urmern,

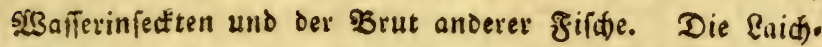
żeit fâllt in 2lpril uno Mai. Eer hat ein mageres uno zäa

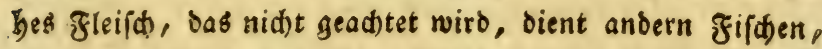

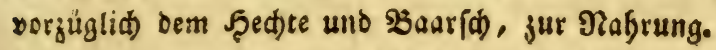

+ 4) Die Sdlammidmerle. Der Salammpiz= ger. Le Misgurne fossile. La Cepède V.p. 17. Le Misgurn. Bonnaterre 149. n. 4. pl. 61 fig. 243. Cobitis fossilis. Liun. Blodf Jifúfe Deutidfr. I. p. 216. tab, 31. fig. 1. (I. p. 275. tab, 31. fig. 1.)

$$
\text { (Tab. 78. Fig. 112.) }
$$

Xin Munbe fiefen 10 Bartfafern, yon welden 6 ate ber Gerverffefentien Dbers und 4 an ber Unterlippe find. In ber 5 iementyaut fins 4 , in ber Brufferffe 11 , in ber

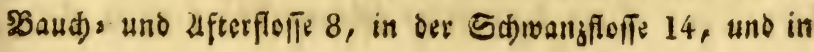




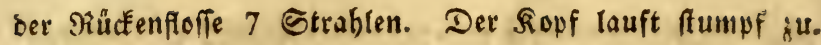
Die Mundoffinung ift lânglidłt. Sebe Sinnlabe mit 12 Eleinen fpigigen 3ägnen befegt, bavon ber 3te, fte thib 5 te ver ben übrigen bervorftehen und oben mit einem Sinöt: d)en verfeben furb. Die Rafentödjer fteben bidyt an bent Zugen. Die Zugen baben einen famarzen Stern in eis nem golbgelben Singe. Bacten uno Siemenbaut fino gelb mit oundfelbraunen flecfen. Daş Ģnilfe iff breit. über ben idwarzen Rörwer laufen ber \&änge nach gelfe unb braune Streifen, bie bin und ba geflecti jint. Der orans

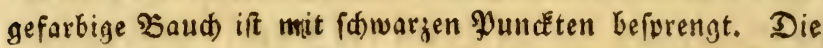

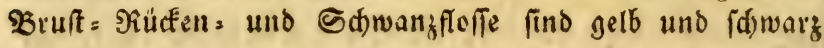

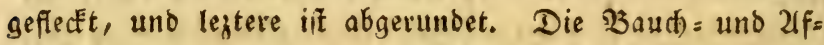
terflofie find gelb, und jene fieht ber গüctenfleffe beinabe gerabe gegenüber. Der ganje Rôrper if in einem Sd)leim eingebüll, unter weldem Eleine Eaum merćlid)e Sd)up= yen liegert. Fr exreid)t eine länge von 10-12 3oll;

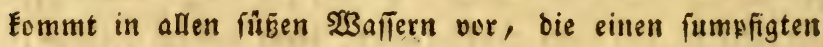
- Der moraftigen Girunb baben; verbirgt fid im $233 i n t e r$, wie ber 2fal, im Sdlamm, au\& bem er im Frühjabr her. borkommt, und feinen \&aid) an bell Pflanjen abfezt. Seis ne Nabrung beftebt in \$̋̈rmern, Infecften, Fifdbrut unb fetter Froc. Er bat ein rebr zähes Reben; Eommt bei einem bevorftehenden (3iewitter voin Brunde in bie Scöbe, uno ift febr unrubig. Ere Eann baber ftatt eines Wetterglafes bienen, wenn man ifn in ein mit Fluß . Doer Regenwaffer, und ein weniq fetter Froe verfebenes (Blas fęt; wofelbit er allezeit 24 Stunden vor cintritt eines Sturms oder Berwitters unrubig wirb, Das $\mathfrak{S}_{\text {afler }}$ trübt, uno in bemfelben auf = und abwärts fteigt, Da el bingegen bei ftiller 233 tterung mefrentbeils rubig auf ber Eroe liegt. Man Eann einen folden Sifd beinabe Jabe 


\section{Dxonung. Pisces.}

und Iage im Bimmer erbalten, wenn er nur im Sommer zweimal, unt im $\mathfrak{3}$ Binter einmal in oer $\mathfrak{W}_{3}$ eche mit fris

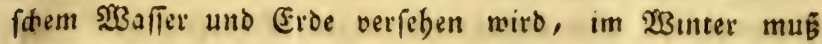
ifm eill gebeiztes Simmer und jwar ene Stelle nabe ame Jenfter antyerviefen werben. Sein von Befdomat mobes ridtes babei weides und iüfies fleif́) wirb wenig gead)

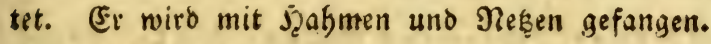

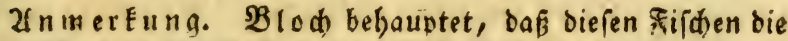
Sd)wimmblate mangle. Soneider aber in Artedi Synops. Pisc. 3. fagt, daß́ lie Enöhern, mit ber orits ten und vierten ßippe verwadjen, inwendig aber mit Sุâuten auģgefletbet [er.

LXXI. Daz Nafenfaferfifd: (5efdledt. Amia. Linn. ed. Gmel. p. 1352.

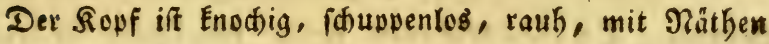
burdzogen. Siefer und Baaumen fint mit ipigigen, ges Drängt ftehenten Zăbnen bewaffnet. Zuf ber Nafe fiekent 2 Eajern (Cirri). Die . Niemenbaut bat 12 Strablen. Der Rörper ift mit Sduppen befegt. Man Eernt bisher nur eine entrige Zfrt.

1) Dex Éhle Nafenfaferfifa. L'A mie chave. La Cepède V.p. 43. La tête-nue. Bonnaterre 149 pl. 99. fig. 408. Amia calva, Linn.ed. Gmel.

$$
\text { (Tab. 79. Fig, I13) }
$$

Zn ber Seffle ftehen 2 idjildoformige Sinodren, weldhe yon der Mitte aus geftrahlt find. Die Riemendectet find fnodia, fitumpf. In ber Riemenl)aut feten 12, in ver

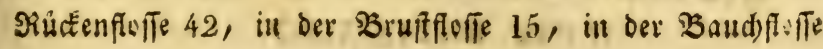


7 , in ber 2ffterflefie 10, und in ber Sdwanjfote 20 Strabs. Ien. Der Söper ift runblid)t bie Seitentiaie gerabe; bieSebwangferfe abgerundet mit einem fowwarzell flect am

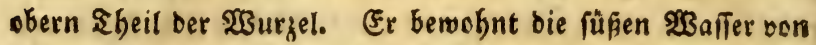
Carolina, wofelbft er wegen feines moderigen (5)ejdmacts felten verfpeifit wirt.

* UnmerEng. (5) ronovo Bjattung Amia. (Zoo. phyl. 80.) ift von biefer verfichieden. Bonnatere's abbiloung ift nad) einem exemplar aus bem sarifer Mupeun.

LXXII. Das $\mathfrak{B e l}$ : (J)

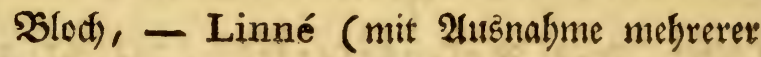
Arten.

Dex grofé breite Sopf ift zufammengebrůct und unges \{ajuppt. Die Mundöffnung weit, bie Sippen biơ uns nebit ben Siefern feilenartig gezabnt. Die Eurge 3unge ift bid uno glatt. Die 2lugen finto Eleir. Die Siemenbaut beffeft aus 2-16 Strablen. Der Sorrper ift geftrectet, zu[ammengebrüaft, mit Sd)eim überzogen. Der erfte

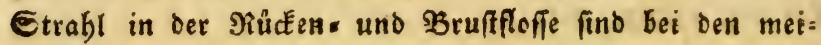

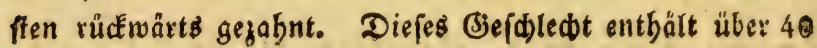
2rten.

a.) Dhne \$artfafern.

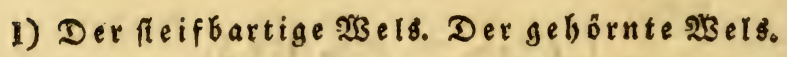
L'A généiose armé. La Cepède V. p. 133. L'armé. Bonnaterre 151. n. 8. Silurus mili ta ri s. Linn. Bloch ausl. ફifide VIII. pag. 19. kab. 362.

( a b. 80. Fig. 114, ) 


\section{Sronung. Pisces.}

3wey gerabe auffitehente Şörner mit Garten getrůnms sen Spizen auf bem Sopfe. In ber Riementaut find 9, in Der Bruffloffe 16, in Der Baudffeffe 8, in ber aflers feffe 35 , in ber Sd)wanjfloffe 24, und in ber Riüfenfleffe I, 0 Etrablen, Dek groß̧e Ropf ift flact) und oünn. Die Minnobffinung weit. Die fimnlaben g!eid) lang Die Mas Fentöd)er einfarb), röbrenförmig, bidt an den Şörnern bes findlid). Die Zlugen bid)t am Munbe, baben einen rothers enformigen Etern, ber in einem fifwarzen Ringe ftebt. Der אopf nebit Dem übrigen Sörper werben von einer lea Derartigen, buncfelgrünen, an ben Seiten etwaz lid)tern Saut umgeben. Die Rüúfenflofie ftebt ganz nabe am Siopfe, und ift mit einem langen bičé und Enödbernen Stas del berwaffinet, an weld)em die übrigen Strablen befeftigt find, ex felbft aber ift am Brinde mit einem Bselencte, in

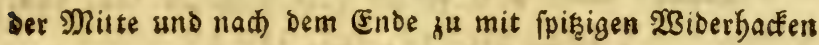
verjefen. Die Seitenlinie an ber Mitte bes Riourpers ges Poblångelt, mit vielen Eurjen Seitenröbren. Såmmtlide Sloffen baben metde und vielgmeigige Strablen. Die Sdwanifloffe ift mondförmig. Seine Eänge betrăgt $1 \frac{t}{2}$

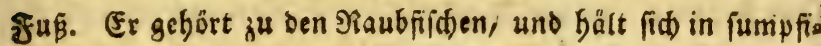

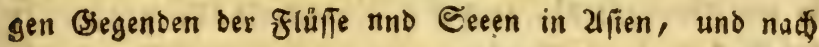
\$lod in Surinam auf, Sein fleifh ift zábe uno mager,

2) Der ungebörnte 2 els. L'Agénéiose désa rmé. La Cepéde V.p. 133. Le Désarmé. Bonnaterre p. 151. n, 9. Silurus inermis. Linn. Bloch ausil, fsif de VIII. 22. tàb. 363.

Der Ropf ofhne Sôrner. Sn ber Riementaat find 10, in ber Bruiffoffe 14, in ber Baudffoffe 7, in ber afters

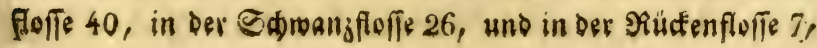


0 Straflen. Die Mafenlödser fiǹ töhrenfôrmig. Die Zius gen baben einen fowwarzen Etern mit einem blauen अing. Der Baud) ift oiff urb breit. I ie Geitenlinie liegr bem

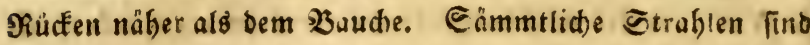
weich) uno bis auf ben erften otelgueigig. Die Grundfarbe

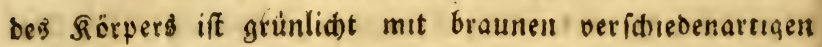

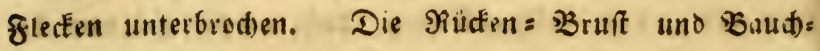
floffen fino braun, bie übrigen grau. Er berobnt bie sluffe von Suriham.

\section{b.) NR it vier Bartfafern.}

3) Der Meers $\mathfrak{B e l}$. Le Pimélode Bagre. La Cepède V. p 98. Le Bagre. Bounaterre 154. n 20. pl.63. fig 253. Silurus Bagre. Linn, Bloch ausl. Fiiche VIII pag, 26, tab, 365. ( T a b. 81. Pig. 115. 116.)

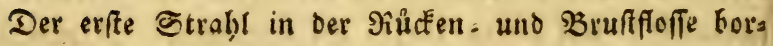
ftenartig uno febr lang; aud) in oer Edimanjfolfe fiebr auf ieber Eeite ein verlangerter Strabl. SIn oer Siemen: baut liegen 6 , in ber Brufficffe $\frac{1}{1} z$, in ber Bautbfleffe 8 , in ber afterflefie 24, in ber Sd)wanjfleffe 18, und in ber Rüdenfloffe $\frac{1}{8}, 0$ Strablen. Dir flache Sopf if soril abo gerundet und oberwärts mit einer länglid)ten nad) binten

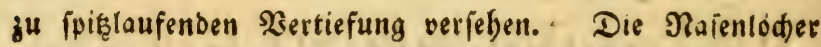
fino doupelt. Der Dberftefer ift långer ald ber untere. Die 2 Bartfajern an ben Munowincfeln fino lang uno flad, bie 2 andern am Sinne fino Furg, runo und weiś. Die längs lid)ten Zugen baben einen fow warjen Stern in einem rötf.

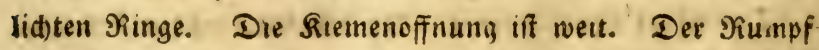
zufammengebrüft. Der Baud) it breit, filberfarbig, bes, gleid)en die Getten, bei welayen eine blaue garbe burdb: 


\section{Sำ $\mathfrak{u n g}$. Pisces.}

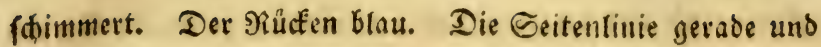
in ber Mitte bes Rumpfes. Die Floffen finb blaulid)t, baben vielgweigige Etrahlen, uno nur bia erffen finto einfact. Der an ber Bruftfoffe ili breit, an beiben Eeiten gezăb= nelt und am Brtunbe in Sdlülielbein eingefügt. Der ain

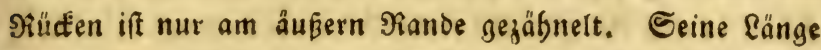

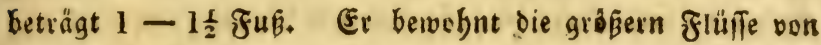

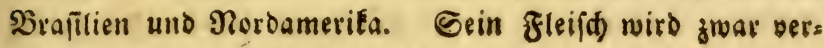
fpecist, if aber unidomadthaft,

\section{c.) Mit fed}

4) Der gemeine $\mathfrak{B}$ els. Le Silure Glanis, La Cepède V. p. 59. Le Mal, Bonnaterre 150. n. 2. pl. 61. fig. 244. Silurus Glanis. Linu. Bloch rifide Deutid)t. I. p. 242. tab. 34. (I. p. 309. tab. 34.) v, Meidinger. Pisc, Aust. tab. 9.

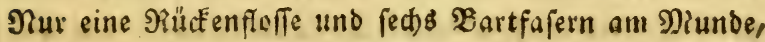
Daven bie an Der Dberlippe die längften find. In der Rie= menbaut find 16, in ber Brufferffe 18, in ber Bauds floffe 13, in ber 2fterfloffe 90, in ber Sdjwanjfleffe 17, uno in der Riuctenflofie 5 Strablen. Der Sopf if idaufer.

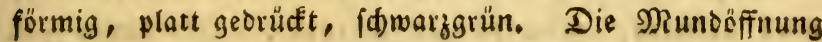
febre gros. Die bogenförmigen Sinulaben, wovon bie un= tere etwas bervorfteht, find mit einer Menge Eleiner 3ăbne befejt. Im Siad)en find 4 hervorfebende mit Eleinen ge=

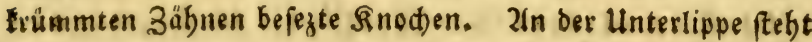
zu jeber Seite eine länglid)te glatte $\mathfrak{B e r t i e f u n g . ~ D i e ~ r u n s ~}$ Den Nafenlöct)er fteben zwifden den beiden länyffen Bárts fajern, uno hinter benfelben Die Eleinen Zlugen mit einem

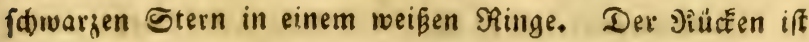
sund und von grünfd)warger Zarbe, ber Diffe und lange 
Sörper ift mit ungleidfförmigen fáwär; lifteten Flecten bes fezt. Der Bouch ift Eur, breit, weif̧̧elb. Die brufts floffen find am Birunie und Enbe blaulidst und in Der Mitte gelb, ifferfer sitrabl ift ftarct, Enödern und nach

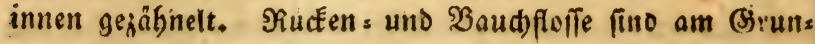
be gelb, an ben Epizen blaulid)t. Die lange 2lfrerfloffe

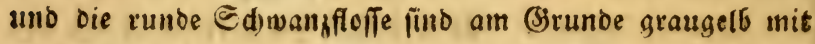
violetter Einfafiung. Exr ift nebft dem Şaufen ber gróB̄te

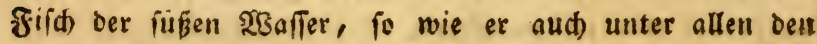
grêkten Sopf uno weiteftell Rachen bat. Fe erreid) eine

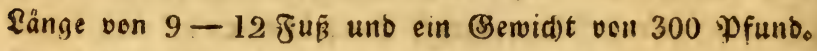
Sie bewobnen die größ̧етn Flüfe von Europa, die Donau - und im Drient ben शill, fettener die Diffee. Bebörent zu ben febr trâgen Raubfifáen, balten fich gemöbntids paniweife beijammen. Sm Frübiab́re fommen fie jur Said)

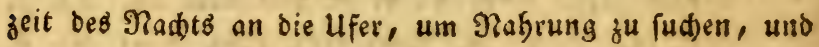

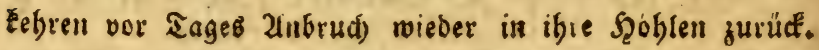
Cie fobwimmen febr langjam, uno fommen nur bei (jies

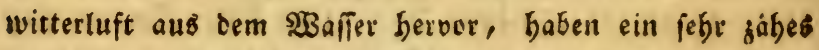
\&eben. Sie werden grö́ftentheils mit oer 2ungel, bem Speer, uno nut felten, da fie in Rödern liegen, mit Dem

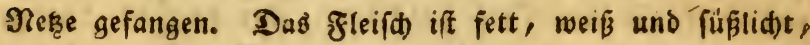
wiro gefotten, gebraten uno marinirt. Şbr bicfeg fell wird mit ber Fetthaut an ber Donau all ber \&uft getroct. net, uno als Spect benuzt.

5) Der elétrif́c électrique. La Cepède V.p. 91. Le Tremble ur. Bonnaterre 156. n. 26. pl. 62. fig. 245. Sil urus electricus. Linn. ed. Gmel. p. 1354. Broussonet. Mem, de l'Acad, Roy. de Paris, 1782 . Rozier. observ. sur la Physique, 1785, 
Bruffifofe 11, in ber Bondifofie 7, in berafterfiofie 11,

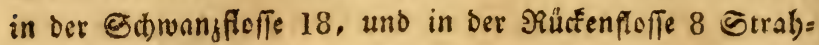
rest. Der vornen breite Ropf bat eine gré̃e Mundöff= nung. Die sbere Sinnlabe fteft etwas berver, uno beibe finb nebî bem (Saumell mit Eleinen fwiß̨igen Zăbnen be= fezt. Die länglid)t s runden 2rugen baben einen fduargen Stern in einem goldenen Ringe. Der Siemendedel bes fébt aus einem Blåttchen. De: গiüten ift bis an bie riücenfleffe fdarf, nebft bem breiten Bienicfe mit einem frödernen Gdilde bedect, uns mit 2 Ftoffen verfeber. Die Sciten find zufarmengebrüct; Der Baud if furz, diá uno breit. Die obnnweit Dem Bienicke anfangende Seis tenlinie if in ber Mitte etwas unterwarts gebogen, uno endint fich in ber Matte ber Edwanjfofle. Sämmtlide Floffen nebit bem Siücen und ben Geiten fino von grau=

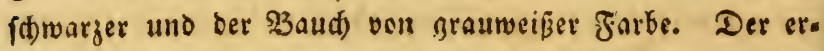
fte Strabl in ben Eleinen SBuffioflen if Enöbern und auf beiden Seiten fägeförmig. 2(ud) ift bei mebreren ber erfte Strafl in ber SBaudfleffe gezălyne!t. Dic alfter: und Fett= foffe fteben einanber gegenuber, unb baben einen mono= förmigen 2iugfonitt. Die Sdywantlofte enbigt fid in 2 lange ungleid)e Spizen. $2(n$ Der grofien Siüfenfloffe ift Der zweite Strafl auf beiben Seiten gezåbnelt. Er er= reid)t bie Range ven $12-15$, und bie SBreite von $3-4$ 30ll, und bewobnt bie Fluffe von Burinam und Brafilien, wirb aud im Nil angetreffen. Nad) Şaffelquift foll

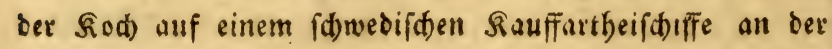
253 unde vom Gtad)el ber Brufflefle biefes fifides gefto:

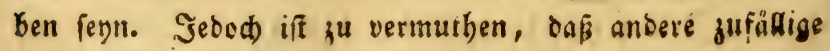
Urjachen brebei 2intheil gebabt baben. 


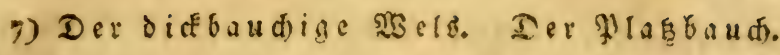
Le Pimélode Ascite. La Cepède V. p. 102. L'Ascite. Bonnaterre 154. n. 21. pl. 63 fig. 254. Silurus Ascita. Linn. Bloch filite Deutictl. I. 249. tab 35. f.g. $3-7$. (I. p. 318 . tab. 35. fig. $3-7$.

( $\mathrm{T}$ a b. 82. Fig. 118.119. 120.121.122.)

6 Bartfafern am Munbe, movon 2 an ber Dberfippe unb 4 am Sinne ftehen, 18 Strablen in ber afterflofie. In ber Brufflefie find 13, in ber Bauchfeffe 6, in ber

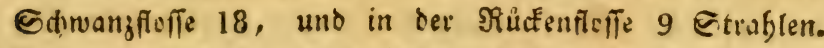
Der etivas erbabene Fleine Sepf ift fumpf. Die seppele ten Najenlöcher fikgen gaur vorus. In ben Bruftelfen iff ser erfte Ctrafl fwitzig. Die Baudffleffen fino Eleiner als bie afterflorfe. Die Sdywaniflefe ift gabelfömin und von ber Siücenfolle der erfte Êtrabl unterwảtş bart und oben weidt. Der ritter voll Rinné giebt die Rănge diefes

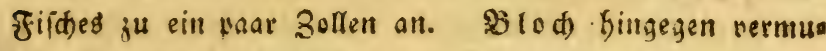
thet aus be: felbit Secbadteten Gröfie ser Eyer, Daß ber

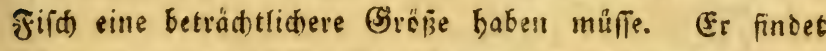

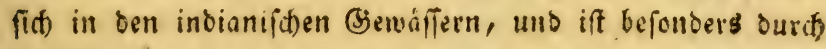
bie 2frt, wie er bie Jungen gebiert, merckivürbig, naw welcher er zwifden den leliendigs gुebährenden uns eyers regenden Tfieren das Mittel bålt. Eeine Evyer fig. 120.

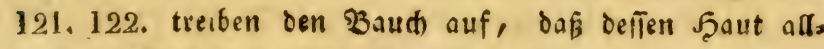
mahlig ounne wirb, unt aufulazt, wo bas von Dem Enera freck abseriffene (E) vor oie D̈finung tritt. Diefe (Fner beftefen aus einer Dúnnen f̧aut uno Den Dorter, jwifden welchen ber Einbryo liegt, weltiter ourch (sefafis aus peis nem গajuel mit ifm zufanmenbängt. Nad) feiner weitern Zuablidung zerreipt ber Embryo Die jaut Des Drtters. 
anb juvar bein Sopfe, Breibt vermittelft bea Dutters fo lange an ber Mutter bangen, bis foldjer verzebrt iff, wo er alsbann bünne genugg gewarben, un ourd) bie ミsauctisfï nung Eommen zu fonmen. Siaum iff Defer fort, folgt iffu fogleich ein anderes (E) vor bie S̈f̈nung - uno wem bie

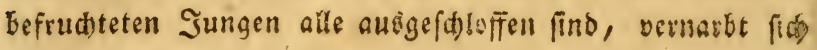
Der şauth wieder. *j

*) Zf unerE ung. 2(us biefer fonderbaren Fortpflans zungeart erbellet, oafi, diefer fith nicht ju den leben= Dig gebäbrenten geredinet werben fonne, weil ber Ems Eryo nid)t rermittelft ber Pabelf(u) un und oes 9)jutter: Euchens feine Pivisum aus ben Gäften ber Miutter befommt, fondem nuts bem. Dotter, weil bie Eints wicklung befferben nicht wie bei jenten innerballs Des

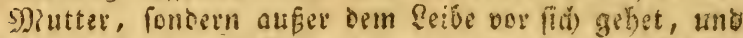
weil ber iunge ₹ifh nioht wie anbere iunge. Shiere volfemmen (Foetus) fondern unoarfémmen ( $\mathrm{Em}$ bryo) entwickelt zut sißeit tommt. 3is oen Ëyerles genten aber Eann er audh niots geredunt werden, weil

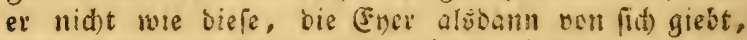
wemn fie ibre gelgörige seife erfalten baben, uno weil Der (Embruo nid)t in (Fy, fonborn nuferbalb beflelben

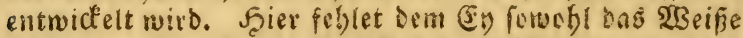
(albumen) als auch bie n̊up̃ere Sullle, worim ber zarte Embryo bie ku feiner (Entwiskilung nöthige \$Bes wegung, obne Nad)tbeil feines beinabe fdleimigen Sö́pers, cerridten Eam. (3) bat Daber Die Sintur sicfe zu feiner Entwidelung unembehrlichen Sheile auf

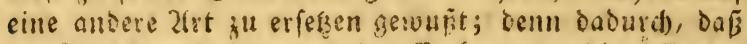
Der Bauch aufreiñt, uno ber (Embryo oor bie Sffnung zh liegen Eemmt, Fann er fich in Dem ifn umgebenden

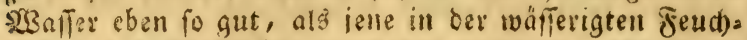

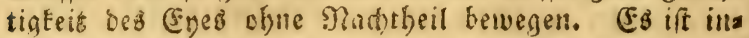
Defien oiejer fififd nitht oer eingzige, walder auf pine von ber gewóbnlichen fo abreiciente zlet flith fortpflanzt: Denn fo baben unfere eurováifie Seenade!n (Syngnatus) binter Dem Siabefled) äuberlid) einen Enct, Ier, Hatiem bie jungen shiere ibre schorige 


\section{2 I}

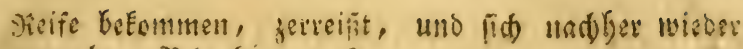
vernarbt. 3 lod $a, a, D$.

\section{d.) Jit $a$ d $t$ Sbatfafe $n$.}

3) Der Frofd = Şelb. Le Macroptéronote Grenouiller. La Cepède V. p. 85. Le Grenouiller. Bonnaterre 151, n. 6. Silurus Batrachus. Linn. Bloch ausl, Sifige VIII. 44, tab. 370. fig. 1.

Die Sillefen = und afterfterie rang. In bir Riemenfaut

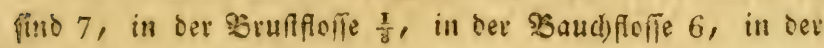

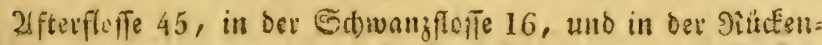
flofie 67 Strabsen. Der flache vorne abgeftumpfte siopf iff ouf com sisirber mit 2 sertiefungen veriegen, wousn die vorbere länglid)t unb bie Gintere runb iff. Die Sippen fint Dicf. Der Dberfiefer lânger als Der untere, uno beide Simutaben nebft bent (jaumen find gleid) einer geile rauts. Die 8 siartfafern fretyen nabe am șintel pantweife bei= fammen und bie an ber Defertippe find bie biffifen. Die

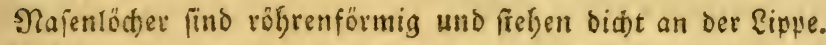
Die Eleinen Zlugen baben einen Glauen Gtern in einem

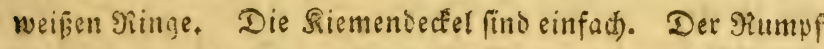

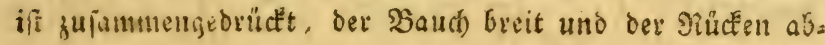
gerunier. Die Eeitentinie liegt in ber Mitte. Der evfte Etrabl in Der an ber Siemenöfnung firenden Bz:uit: fletie ift feif uno gegábnett, bie thbrigen Etrablen fino

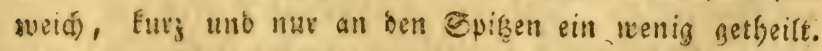

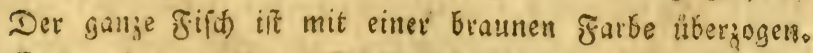

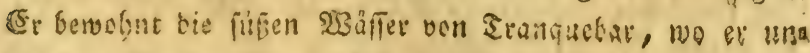
eer ben Sinmen Toeli betamit iff. 


\section{Ia plattleiber: (B)efdiled)t. Platystacus. Bloch.}

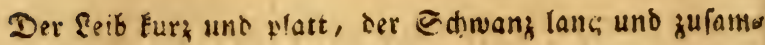

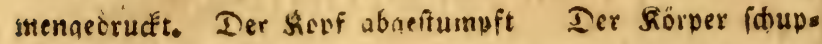
penles. Die obere Rinnlare sor ber untern bervorfehello. Der Muno, welcher fich untermärt offnet, if mit sart

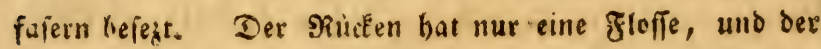
erfte Strabl in der Bzruffluffe ift fieif, ftarf, gezäbnelt, uno madr mit bem Edlutelbeine ein Gelent. Sie ma

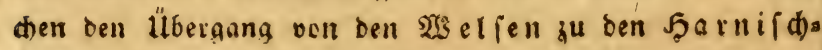
fifd)en, (Loricaria). Eg find Davon 4 2rten betannt.

1) Der Gellerträger. Der rauhe Welb. L'Asprède. Bonnaterre pl. 62. fig. 246. Platyst a cus cotyley horus. 54. tab, 372.

( $\mathrm{T}$ ab. 83. Fig. 123. 124)

6 Bartfafern om Miunbe, und tellerartige Saugewals Sen am Baude. Son erftern fteben 2 bieite am Ende ber Dberlippe unb 4 fdmale paarweife am Sinne. Einige ber Baudwarzen lizgen ganz flac) auf ber Şaut, andere auf Eurzen ober längern Stielen. Fig, 124. Sin ber Sies menbaut fins 6 , in ber Bruffloffe $\frac{1}{8}$, in ber $\mathfrak{B a u d}$ floffe 6, in Der 2ffterfofie 56, in Der Sotwaniflefie 9, und in

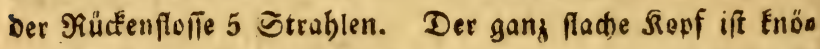
dern mit eiller bünnen Şaut übergogen und fo wie ber Sörs per fduppenlos. Der ocrbere Ibeil des Repfes bat in dee Mitte eine långlid)te $\mathfrak{B}$ erticfung und binter berfelben gebt

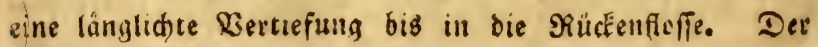
Sioff und der gange übrige Siorper if oben mit Elemen rBäjden bejejt, bie an ben Seiten bes Sduwanjes der 


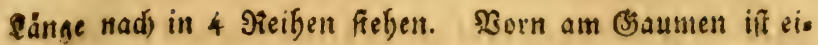
ne fottige Scaut, welde mit ber Unterlippe bie Miundêff: nung veridlieg̈s. Die ftarde Sberlippe enbigt fid an ben Geiten in eine Bartfajer. Die פiafentỏder, ven denen die vo:bern röhrenförmig fino, boppett uno bintereinander îtes benb. Die Éleinen mit ber gemeinfidaftliden Şaut bedect. ten 2lugen baben einen weifen Stern in einem fowarzen

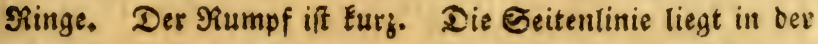

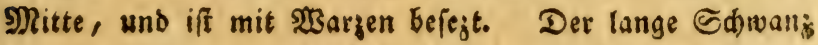
if an ben Seiten gufammengebrüct', oben figarf unt un॰ ten runblicht. Die Etrablen in Der langen afterfloffe finb

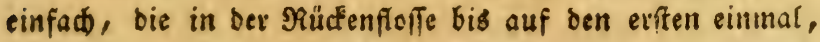
unb bie in ben übrigen flofien zweinal getheilt. Der erfte Strabl in bet Baudfloffe ift breit, an beiben Seiten ge= zact't, am Bjrunbe mit einem Betencke verféten und lănger als bie ůbrigen Strablent. CFine braune Earbe überģieft

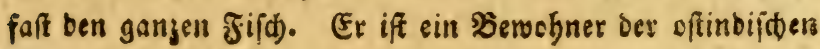
श्äbifier.

" zumerlung. Det gitter von Einné hat biefen giíd nebit bem (b) lattleibe Platystacus laevi s. Bloch VIII, p. 58. welder fitt 6, 8 Bartfae fern ain Miunde wnd cine lange Zfferflofie bat, unter Silurus Aspredo beforieben, aud fino beibe un:

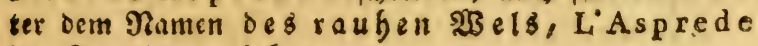
Der Eranjofen, beÉannt.

LXXIV. Das plattfopf: (efdledt. Platycephalus. Bloch.

Der Sorper plattgeorüat'. Die Baudflofien fefo weit

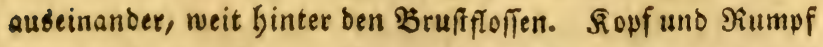
find mit Eleinen barten Sdappen bedecț. Şieven fino 2 alrten Befannt. 
1) Der Sdaufinlatténf. Le Callionyme indien. Bonnaterre, Callionymus indicus. Linn. Platycephalus spathulas Bloch auvil fiche IX. 97. t. 424.

( $\mathrm{Tab}$. 84. Fig. 125. 126.)

Der ishatelförnige Repf if abgermot. Die Seitem Vinie shne cradein. In der Sirmenbaut find 7 , in des

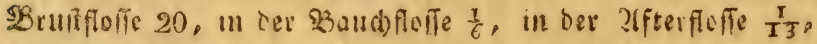
in cer Edowanifleffe 13, und in ber Siuckenfleffe $\frac{7}{7}, \frac{1}{1}$ Strabjen. (5r bat Fleine barte uno gejäbnelte Eิф)upen,

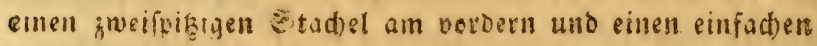
am bintern Sirmendectel. Die Sirmenófinnng ift weit.

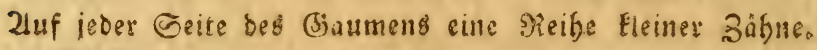
Die rasben Simnlaben baben einen bervorfehenden Untera Fiefer. Einfadbe Siafentëder. Eänglia)te auf oer Dberfiad) res Repfs figende dugen uno nad) der Eänge laufende jd)male Ealien. Er bewohnt bie Fुaffer von Iranquebar.

* anmeréng Die zweite 21rt: Den $r$ a Slatteof (Platycephalus scaber) bat

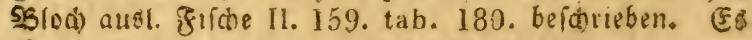
ift oer Cattus scaber. Linn. Le Raboteux. Bonnaterre 67, n. 6 . deflen linglioter sterf mit 4

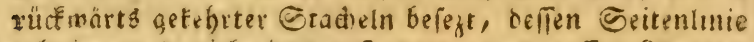

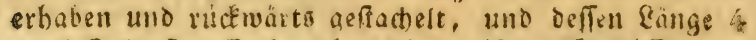
-5 3oll uf. (E⿱

\section{Das Stad)efrü den: (5efdiledtot. Notocanthus. Bloch.}

Surze aus ber Saut Faum herverragende Stathe!n am Shititer. Der Siorper iff fitmal und burd)aus mit fegh Eleinen-weidsen Sdappen befezt, 


\section{Dronulu, Pisces. $\quad 281$}

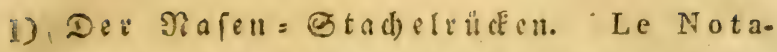
canthe Nez. La Cepède V. p. 292. Noto. c a thus Nasus. Bloch aนs̆l, Jifche IX, p. 113. tab, 431 ,

(Tab. 85, Fig. 127.)

Der Gopf endigt fid) in eine mafenformige frumpie Gpi-

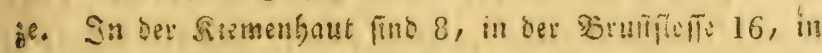

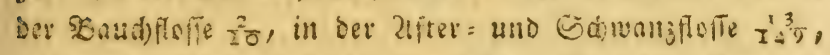

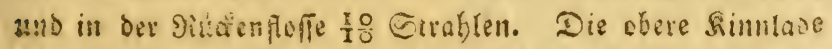
ift langer nls Die untere, Geibe fino rafpelformig bewaffnet

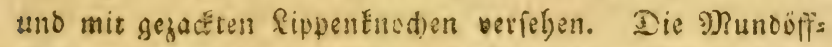
ift Elein. Der fáwarge Zügentïen in einem filberfarbigen sringe. Die Majenläber boppelt. Die Fiemendecfel glatt uno bie Fiemenöfrung weit. @tatt einet Siüfenfloffe hat er 10 Euge ftarde nad) binten ju gefogene Stad)eln, oas von ein jeber mit einer gemeinfohnftlichen Saut, wie mit einer Sobeide, "Iberzogen if. Die Geitentinie lauft nabe am Diüten biu. Die zfferfteffe ift mit ber $\Xi$ drwanifoffe ver: wad)fen, jene bat 13 Eurje Stact)enn. Die Baudffreffe bat jwei Eurze Etwdoln. Der Sơrper if grau ins Eilber fpieleno und ain Tiücken braun geflect. Seime Sånge be: trågt $1 \frac{1}{2}-2 \frac{1}{2}\{u \tilde{b}$. Er Eummt in Ditinbien vor, wo er aus bem Meer in bie fluffe ftreid)t. Sein Fleifd) foll fefts fchmactbaft fejn.

LXXVI. Das Felfenfif(t): (sefdiftet. Teuthis. Linn.

Det Sopr it va!n eturas abgeinumft. Die Siemens

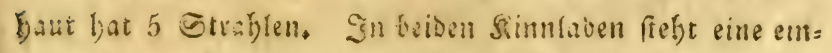

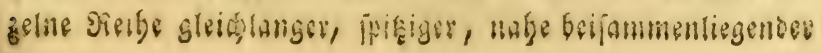


3ähne. Der Siörver if evrunos lanzetförmig, zujammen, georucfit und mit Soluppen bebectit.

1) Der geffachelte Ferfenfifo. L'Acanthure 'g'heuthis. La CepedeIV. p.548. Le Papou. Bonnaterre 156.n. 1. pl. 64, fig. 358. Teuthis Hep a tus. Linn. Seba Mus. III. tab. 33. fig. 4. Catesby Carol. 11. 10: tab. 1. fig. 1. Gronov. Zooph. 353.

3u beiben Seiten des Eobwanzes ftebt ein ftarder bes

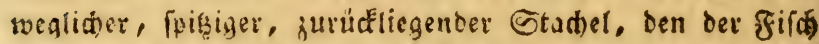
aufrudten uno wieder in eine furebe niederlegen Eann. In

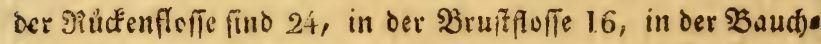
flofle 5 , uno in Der difterflofie 26 Strablen. Der Sörper

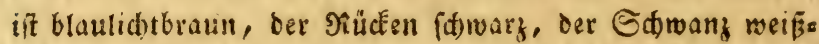
ridbt und fowary marmorit. Die Floffen find bodblau. Die Geitenlinie Eaum fintbar. Er beweónt die Giewáffe: yon Carclina uno 2tmboina.

* In merEung. Die Seba und Catesbyiden abbits oungen fdeinen 2 verifhiedene fifiche vorifuftellen, da

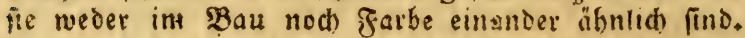
Gronov in feinem Zoophylacium fiellet diefelben twae auch als einetlei Zrten zufammen ouf, uns giebt bie

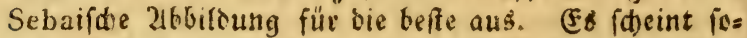
gar, bafis Seba, Catesby und Gronov, ieder cine antere zat vor fid nebabt babe. Denn bie Flof. ren, Errablen und zarbe berfelben follen alfo befinof= fen feyn:

Mad) Gronov: in ber Sïufenflofie 9 Stadtein und 25 Etrablen, in der Bruffente 16 Strablen, u ber Sauthelfe 1 Gtad)el und 4 Gtrablen, in ber $21 \mathrm{~F}=$ rerfluffe 3 Gtudueln uno 26 Strablen. Die Sdbwan: fiffe menoförmig auggzidnitten. Die Farbe bräun. lidt. - Nach Seba: in ber sillcenfleffe 3 Gtadeln ant 20 etroblen, in ber somffleffe undeutlit), in bev 


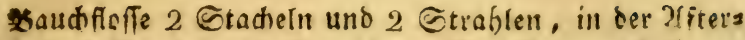

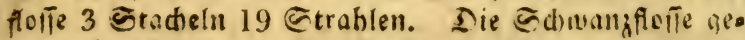
lace abgeidnitzen. Die Farbe grauichwar, melpiglb, fdrwar mit gelb gemifidst. - Naci Catesby: in Der Siücfenflefie 26 Srrablen. Die Brufffolfen undeut= lith, und in tief fizend, bie Bauchflofie fehlt, in oes afterficle 22 Strablen, die Sdhuanjfoñe mentförmig ausgeidnitten. Die 5arbe bellblau Die bewenlithen Stadein an beisen Seiten bes Sdrwanzez fino an bev $\mathrm{Se}$ baithen Zeidnuni und dem Ronfe a $u=$ unt an ber $\mathrm{C}$ a tes by iden nach bem Sdjwanje ju geridtet.

LXXVII. Das Şatnifdfif(t): (5) Loricaria. Linn.

Der glatte Kopf ift niebergebrủaft, unb oberwärts in eis nen Finochen gehüllt. Die Enerplititen Sinnlaben find aus Berbal6 von einer breiten Szaut umgeben. Der Mund fteft unterwärts, oder auф yorwårts. Die Riemenbeffel fino cinblättrig. Die Riemenbaut hat 4 Strablell. Der אiör= yer ift mit einem Manjer bebectt. Şievon Eennt man 5 Jirten.

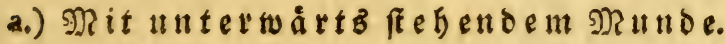

1) Der runzelmaulige Şarnifdfifd. L'Hypostome Guacari. La Cepède V. p. 145. Le Gu a cari. Bonnaterre 158, n. 2. pl. 65. fig. 260. Loricaria Plecostomus. Linn. Bloch aนฮ่. Fifithe VIII. 69. tab. 374 .

$$
\text { (Tab. 86. Fig. 128.) }
$$

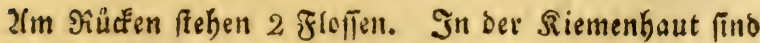
4 , in ber Brufffeffe $\frac{x}{7}$, in ber Baudiffolfe $\frac{7}{6}$, in ber afters

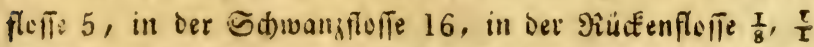

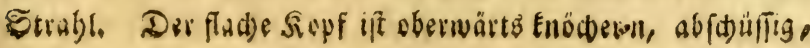




\section{Siterteclaffe. Fifde.}

raul), unterwints becit, gerabe, glatt uno weid). Die sgunsoffnung ftebt in Die Duere, iff Elein. Die Sinnta= ben fino mit einer Siteibe borftuartiger Zăbne bewafinnet. Die untere finpe î̃ maing uno an jeder Seite mit einer Surtfaier verfeben. Die Siafentöder fino einfach. Die Lugen buben einen föwargen Germ in einem grülithten Simge. Die rauken Edilde fino in Der Mitte gefielt. Xuf jeser-Gerte liegen 4 Siriben folder Sdulde. Die Stoffen fino lang, ibre Etrablen rauh uno vierzweigig.

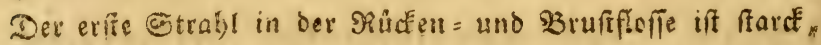

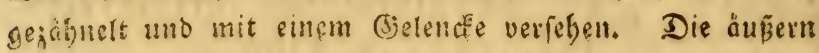
Ctrablen be: Golwanglofie find lang, bei cinigen find bie beren, bei anoern bie unteren am längfter. Der Röper if orangefurben, ber Baud) weifflid)t. Die Floffen von

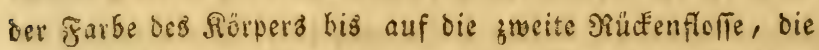
an ifferm bästigen Sigeile fowwarg iff. Sglan bemerdt über: all bato grofiere bato Eleinere runde flesten. Er bewohnt

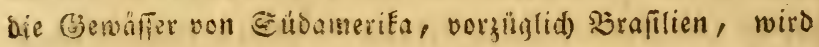
fowohl getwot als auth gebraten verfpeifit, natboem ifm vorker bie Garte Gonate if reggenommen worden.

b.) SR? it vor (4) a Cataphractus. Bloch.

2) Ser gerippte \$aruif fif cote. La Cepède V.p.117. Le Silure cote. Bonnaterre 155. n. 22. pl. 64. fig. 253. Silurus costatus. Linn, Cataphactus costatus. Bloch aușl. Jifd)e VIII. 32, t, 376, (Loricaria costata)

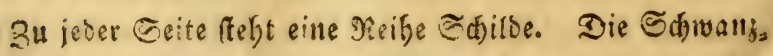
freffe if monoförmig. In ber Siemenbaut find 5 , in ber

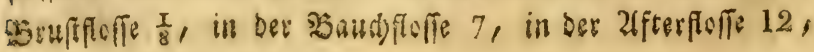




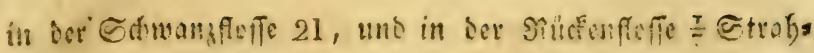
Ien. Die 2 an ber Sberlipe befindiuten sontiajem fint langer, und bie 4 am Stime fibrger ats ber sonf. Die Zugen hafen einen formangen Gtem in einem asten פinge. Sete Seite if mit 34 fdumaten Edjitten Estectt,

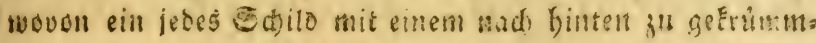

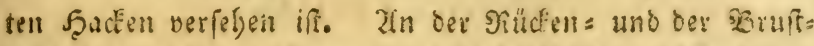
forle bildat ber erfe Etrabl cinen langen erwas gefiummten,

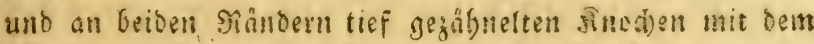

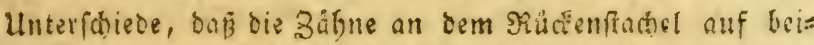
Dea Eeiten nath oben, bei Den an Der Burffreffe Gingegen

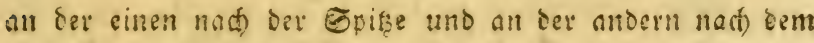

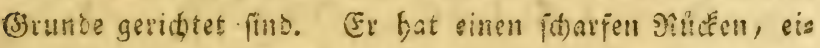
nen breiten und weidjen Banud), und zurummengestude

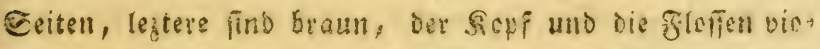

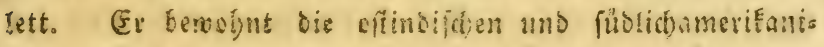

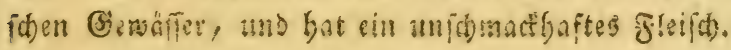

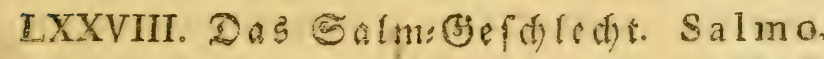
Linn.

Ber glatte fajupkentofe Sopf if un sen Seiten gufans

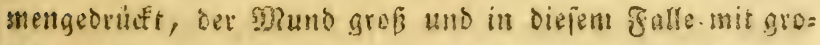

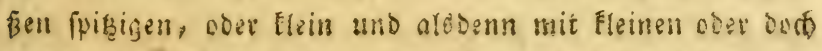
nut Eurzen Zăgnen befejt. Die Sicmenberfel find Dreigrät:

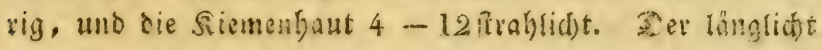

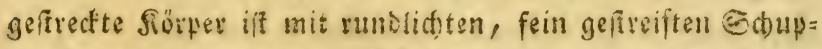

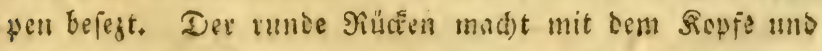
Schlwanje beinate eine gerabe finie. Die Seitentinie,

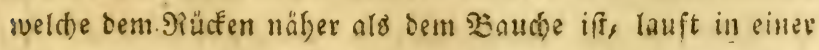

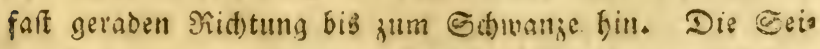

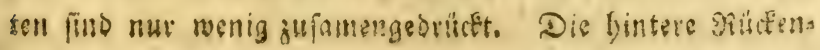


floffe if eine fettflefie und die Baudfofien find vielfirabs lidt. Daven find uber fectgig 2lrten befannt, weld)e zu ibrer leid)tern liberfid)t fugglich in folgende 4 abtbellungen gebradt werbell:

A. Forellen: Salme. Forellen: Mit gefleftent Solper. Truttae.

+ 1) Der gemeine Sarm. Der gemeine fads. Le Saumon \& Le Becard. Bonnaterre 158. n. 1. pl. 65. fig 261, - pl.65. fig. 262. La Cepèdc V. p. 159. Sal mo Salar. Linn. Blod Fifde Deutidsl. I. p. 128. t. 20. - III. 146. t. 98. (I. 162. t. 20.) (Fin weiblid)er Şifd). III. 185. t. 98. (Fin männlid)er ₹ifið). Der Şactenlad)s).

Der DberEiefer if etwas bervorffebeno. In der zifter= fleffe find 13 Strablen. Der Unterfiefer lauft bei bem ans.

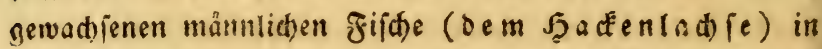
cinen fumrfen Sacten aus, welder in eine Berticfung bes Dberfiefers einfaß̄t. In ber Siemenbaut fino 12, in ber Brufteffe 14, in ber Baudfleffe 10, in ber Edwanjflefie 21, unb in bev Stüfenflefie 14 Strablen. Der Sionf if

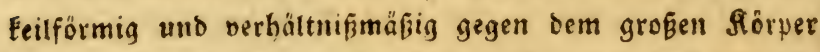
flein. Die Sinnlaben, die beiben Seiten bes Gaumens, des Sकluntes und die Zunge find mit Bäbnen verfeben. Die fleinen 2lugen baben einen fdwarzen Stein in einem filberfarbigen simge. Die beicen Zlugenwinctel find gelb. Der Situten if fdowarz. Die Eeiten fino über Der Sinie blauliaht, und unter Derielben filberfarbig und gh $^{\text {Seitent }}$ mit grouen flecten befęt. Sauch uno selgle baben eine gelbröiblidte, bie אiemenbaut eine gelbe uno bie Brufficife nad tein Rande bin eme blanlidite Farbe. Baud = uno

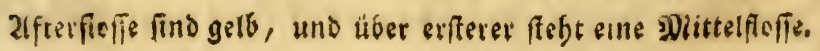


borzhglich auth in ben sibein formmt, ant fettefren. (S)

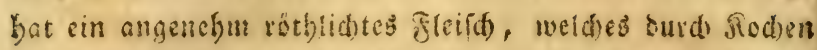

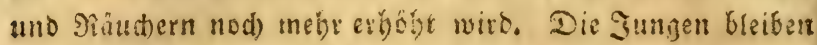

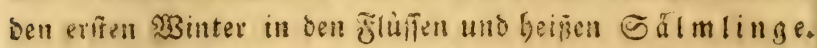
Sim folgenten Gabre aber begeben fie fich) autis in bie See. Man pflegt ify in Entywaffer gefotten, marinirt, einges falgen und gerähthert z̆l verfpeipen. Der Salmenfang wiro Gäufiz om Dibeine, in Engelano, Norwegen und Sdiweden betrieben. Dian bedient fíd biejut groger frarfer 3iefneşe,

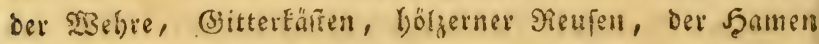

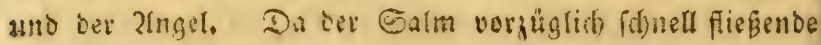

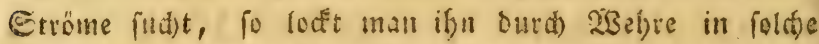
Stuffe, woljin or fenfis nidt temmen whitbe. Die Gitters

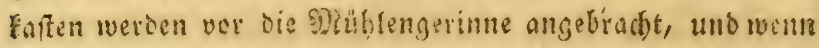
Der Golm in folde bineintritt, if et burd) Sarablaffen der Beidüre nefangen. S3it Şamen fängt man ifn an-fols den felfigen thlasen, wo er antsuruben pfegt. Zlud) wiro

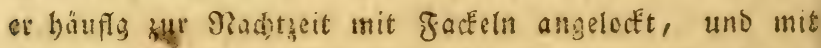
Epeeren gentrden. Der Galm bat vorgüglidje Geinte an

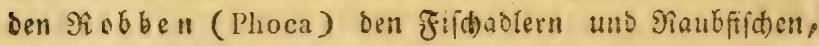

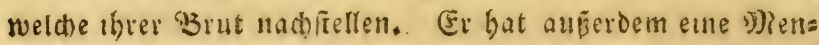

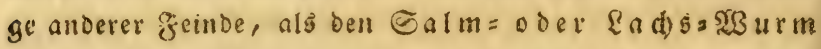
(Lernaea salmonea) verítiebene siefenfǘze, wie ben Monoculus salmoneus uno piscinus,

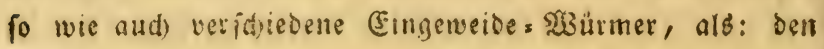
Echinorhynchus Salmonis, sublobatus uno quadrirostris. Ascaris Truttae, Cucullarius lacustris uni Salaris, Fasciola varia uno Farionis, Taenia nodulosa Salmonis u. a. -

* In neré un q. Tiad) Deli us uno anberer Beobad)=

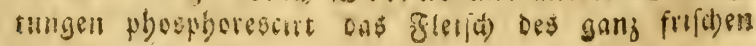


Carmes mit eitrem weifblaulidten Sidfe, weldes fid aud an antere förper bringen lapit.

In dell giheingegenden befommen forwofl bie mănns.

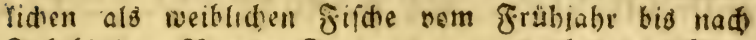

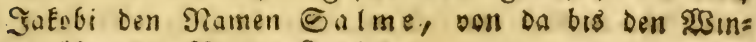
ter über ben ?amen $\&$ a $\mathbf{6} 8$.

† 2) Der Fheinandens ober Jrandens Forels len: Sarm。 Der Rbeinanden, Sllanden。 Le Salmon Illanken. La Cepéde V. p. 182 , La Truite Sa umonée, Bonnaterre 165. n 11. Salmo lacustiris. Linn. Bloch Fríce Deutic). III. 180. (III. 227.) Salmo III a nca* Wartmann. in Edrift. Der Berl. (E)fellí(). Naturf. freunce IV. P. 55. Salino Salar $\beta$. Illa a ca. Linn, S, N. ed. Gmel, p, 1365 .

Êr fommt bem gemeinen Salmé nake, unb unterfideis

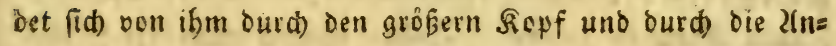
jaht Der Etrablen, in ber Riemenbaut und in ben Flcifen. In der Siemenbaut find 10 , in ber

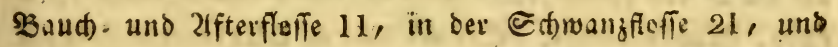
in der Siüfenflefie 12 Strahten. Sn beiden Sinntaden fte: ben nađ) einwărtş getrümmte, fivişige und meit berveglide 3ähne, womit auch (Jaumen, Siaden und Bunge verieben fint. Der untere Siefer lauft forsen im grweiten Jahe in

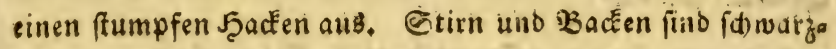

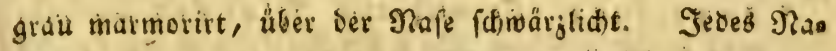
fenlod) ift init einer bäutigen 223 ano in 2 Sheile getbetle. Die rebre grểen Zlugen baben einen fobwarzen Stern in eis

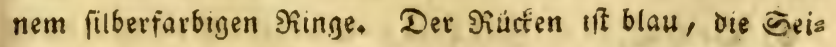
ten bis an bie Emie bin bellblau und unter derietben filbers farben. Sgill und wieber, befonders gegen ben tywange 
zu, fieben verlängerte, unglichförmige, đđ)warge Flecten, Die in feinem bellen Felbe fteben. 2/m ganzen Sörper find weber rotbe Flecten, nod) Puncfte zu feben. Die Siluffins unb $S$ dwanaferfe fino blau, die übrigen aber grau obne Flecfen. Ser Sd)wang ift faraufelformig und mit einem geringen 2lusid)nitt verfehen, und endigt fid) meiftens in ets nen fidwargen Gaum. Die Jettloffe ift grof́, ftard uno bicf, graulid)t und nur an ber ăuperfên Seite fdwårzlidt. Sie erreid)en ein (jewidt von $30-45$ Pfund. Er bewobnt

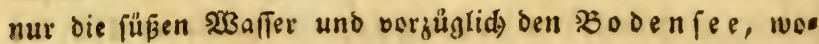
felbit er aud) unter bem Namen See $=$ Salm, See $=$ Balm. Forelle befannt iff. (E) begiebt fid ill 21pril

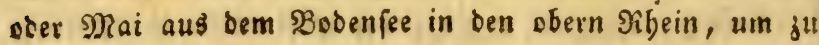
laiden, und Esmmt im Şerbft wieder zurüc. Den গ⿰冫士口: ter bringt er in ber Siefe des geoad)ten Seees zu, no Eeis ner weder zu fangen, nod) zu feben ift, und läfit fict) bis (s)angfif d) (Salmo Wartmanni) bebagen, Denen ex grofien Gchaben zufügt. Daber pflegen aud) die Fifcher

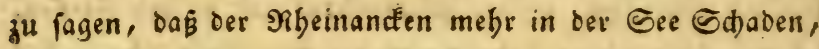
als burd) ben fang feines fonft Eoftbaren und tbeuern Fleis

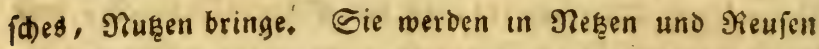
gefangen. Sab famactbaftes weistötblidtes fleijh ift fefr

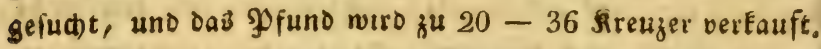
(Er foll fid) aud) in ben füpen $\mathfrak{3 a f f e r n ~ v o n ~ \Re o r w e g e n ~ u n o ~}$ Sibirien finben.

* Unmer fung. Er roirb aud) Grrancfen genennt, well er fich aus Dem Sibein bei gelokuta in Den Dajelbif borbeiflieffenden Fluß $\$ 11$ begiebt.

3) Der Silberaforellens Salm. Der Silbers Iadb. Le Sal mone Schieffermuller. La Cepède V.p, 187. Lue Saumon argenté. Bon- 
Erlwarge grecten an sopf uno siumpf, ben sioucis

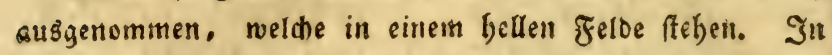
Der dfterflifie ftehen eilf Strahlen. In ber Kitemenbaut fino 12, in ber Brufterfe 14, in ber sautbloffe 10, in Der Sdiwangflofie 20, uno in der Rüctenflotie 14 (entrablen, Ię̧tere ftebt dem Siopfe náber als die Saudd)= fleffe, uno über biefer if eine Mrittelfolfe fidtbar. De: Eleine אopf if Keilförmig, sie אinnlaben fino gleidh rang

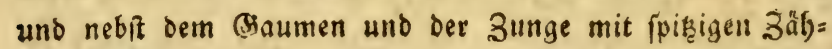
nen befejt Tiafe und Stirn fino fdwarz. Die Eleinen Zlugen baben einen fdwwarzen Stern in einem fitferfarbigen

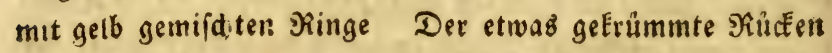
und bie faft gerabe Seitenlinie baben eine fdwarge, bie Beiten eine ins violette fallende, ber Baud) und bie Seth= Ie aber eine meife garbe. Die grefien baben vietgmeigis ge Strablen und eine graue Earbe, bie Sd)want = und

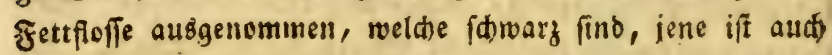
Diel breiter, als bei bem $\mathfrak{L a d b}_{\text {s, }}$ uno bat nur einen gerins

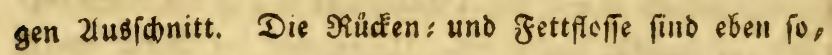
wie ber Sörper mit fdwargen runden flecten gegiert, nue ftehen diefe nidjt wie iene in einem betlen felde. Sie erreid)t eine Sddwere von 8-10 \$funb, unठ wirb über

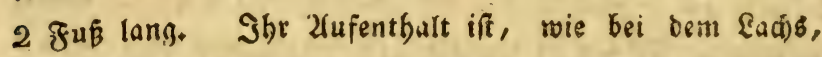
medfellnweife in Meeren uno glüfien, in welde fie gleidf,

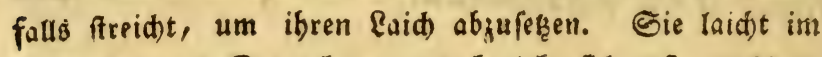
November uno Dezember, uno begiebt fïli erff, nachbem

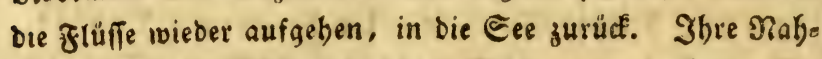

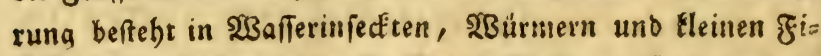
fden. Gie rebt idnell flieffendes গ্Saffer auf einem fans bigen uno kiefigen (Grunde, bat ein weiēröthfichtes woflo

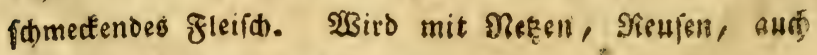
mit Brund = Angein gefangen, 
* If Bevbactung im Sinftern in einem heten Sirade. Die leud)tende Materie bat iffen Sift in bem Sd deime.

5) Die gemeine Forelle. Die Badforelfe. Seichforelle. Le Salmone Truite. La Cepède V.p. 189. Le Fario. Bonnaterre 160 。 n. 7. pl. 56. fig. 266. Salmo Fario. Linn. Bloch Fifde Deutid/al. 148. t. 22. (I. 188. t. 22.) v. Meidinger, Pisc. Ausir, tab. 20.

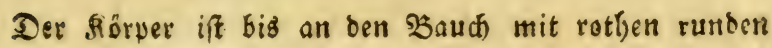
Flecten, weld)e in einem bunden Riveife freben, betectits In oer afterfleffe find 11 Strablen. In ber . Riemenhaut uno in ber Bruffeffe 10, in ber Baucffloffe 13, in ver

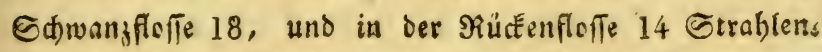
Der Sopf iff in $\mathfrak{B}$ ergleid)ung mit ben übrigen Zfrten giems

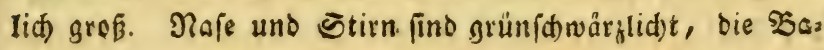
déen gelb mit grủn vermifđts. Der zfugenffern iff f(d)wark

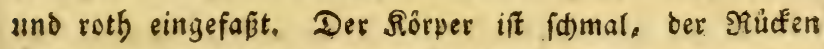

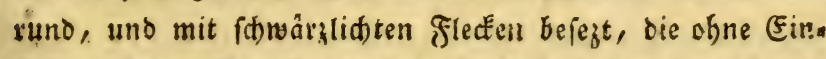
faffung find. Die Seiten find eberbalb der geraden formars aen Sinie grủngelb, unterbalb berfelben geldfarbig, am

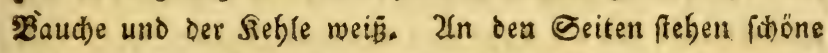
rothe runoe flecten in einem blaulidten ajerbe. Die $\mathfrak{B}$ rufta

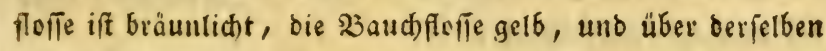
sine Eleine Mittelfoufe. Die 2afterflofie ift an ben exfen lângfên Ctrablen purpurfarbig, unb all ben übrigen graus gelblid)t. Die Gdwantiflefie ift gelbfdwarz getitreift, an ben enden abgeftumpft, uno in ber Mitte mit einem Eleis nen 2lusichnitt verfében. Die settfefle gelb init einer braus

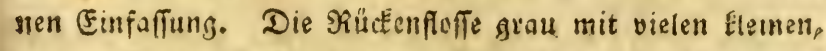

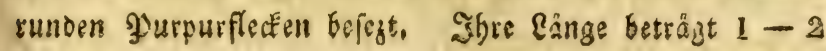


そuF, bas (अervidht $2-3$, feltener $8-12$ Pfunb. Sie liebt bie fanellfieffenden reinen $\mathfrak{B e r g}$ s $\mathfrak{B a ̉ h t e ~ u n d ~ f l u ̈ f e ~ v o n ~}$ fteinigem (3runde, geboirt zu ben Raubfifden. Sie werden

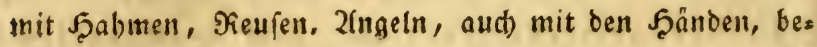
fonbers zur laicheit, weld)e in September und Sctober fält, unter ben Eteinen gefangen. Şbr Jleijd ift febr (d) martbaft uno vorgüglid) gefdảzt, baber pfegt man autb befondere forellens Seiche in mem id)attigen Sbale, Das reine Sueflen bat, anjulegen.

t Eine 2lbảnberung ber $\mathfrak{E} e i d$ forelte ift bie $\mathfrak{3}$ ald ober Steinforelle. Die braune Forelle. La Truite brune. Bonnaterre 160. n. 7. pl. 66. fig. 267. Salmo Fario sylvaticus. Bloch Fifdje Deutid)I. I. 157.t. 23. (I. 198. t. 23.)

Sie ift Gram, bat einen grốzern Soyf von fowar braua

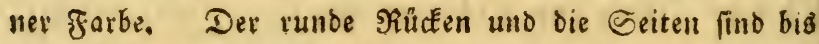
an bie Rinie braun und nebft bein Sopfe mit violetten Fles afen befezt, uno unterwärts berfelben fino fie weişgelblid)t snit rotben Stepfen, bie in einem weizen Ringe in einem braunen Felde fieben. Die Sdwanfloffe if breiter und bat einige Strablen mebr. Shr 2lufentbalt if ebenfalls in ben

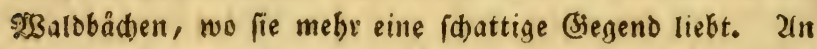

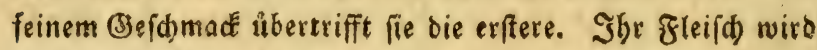
bei bem Sioden rỏtblid)t.

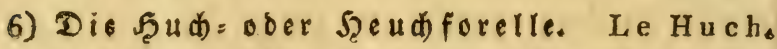
Bonnaterre 160. n. 8. pl. 66. n, 268. La Cepède V. p. 210. Salmo Hucho. Linn. Bloch filide Deut \{d). III. 152.t. 100. (III 193. t. 100.)

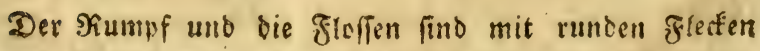
befezt. Sn bes Siemenbaut find 12, in ber Brufffeffe 17, 


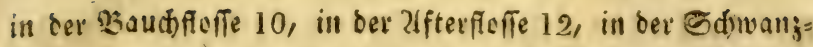
flefte 16, und in ber riücenflefie 13 Gtrablen. Der Siopf Jauft in eine Spitze aนs, Die obere Sinnlabe fteht etwas bersur. In jedet derfelben ftebt 1, im Saaumen und auf Der Zunge aber 2 reiben fpirziger Zäbne. Der oben braus ne Sepf ift an bir Reble uns auf ben Bacfen filberfarbig, und an ben Seiten fpielt Durth den filberfarbigen (jirund sine rôtblid)te farbe. Die gernobe Cettenlinie ift fonntal. 2fn ber Baudflofie ffeft ein anbängfel. Der Sdwanz if sabelförmig. Sämmtlid)e floften baben einell gelblidtent (jirund. Sie erreidt eine Rånge von $4-5$ FuE Binvidt ven $40-70$ Pfunden, bewohnt bie Dsnau und

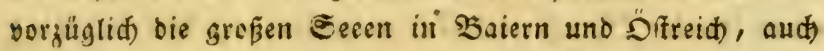
verfdiedene flüfe in Rufland und Sibirien, lebt bom

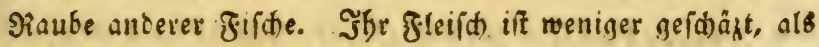
bas ber übrigen forellenarten. Sie werben mit ber 2lngel uno mit bem grofen Garne gefangen.

† 7) Die atpen = Forelle. Die Bergforelle. La Bergforelle. Bonnaterre 162. n, 16. pl. 67. fig. 272. La Cepéde V. p. 203. Salmo alpinus. Linn. Bloch fifche Deutidt. III. 158. t. 104. (III, 200, t. 104.) v. Meidinger. Pisc. Austr. tab. 19.

(Tab. 87. Fig. 129.)

Siele fowwarge, rothe uno filberfarbige Fleine flectent und Punckte, bie mit cinigen gologelben vermifat finto, welche fämmtlid) ofne Einforlung. Die Cdwwangflefte ift gerabe. In ber Sruffloffe fint 14, in ber Baudffoffe 6. 810 , in ber Xfferflofi 11. 12, in ber Sdwanzfolfe 16.

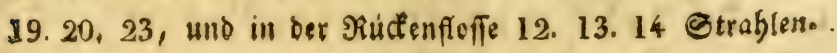


Der Sobf entigt fich in eille ftumpfe Spize. Der fábivars. ze Augenftern if mit einem fllkerfarbinen গinge und eines golbenen finie eingefafit. Backen unb Siemenbecter fint.

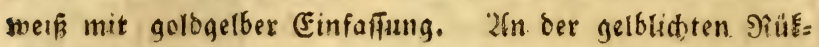

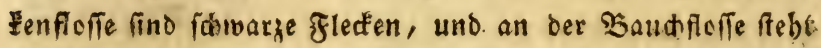

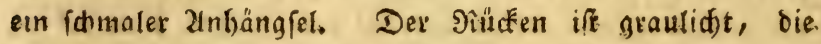
Seitenlinie gerace, der Baud) weißs. Sämmtlide froffen, fino. bie ßiuctenfleffe ausgenommen, rötblidit, und bie. Fettfleffe am Sande roth. Gie erreidht eine Sd)were von. 10. Ffunben, und bewohnt bie böbern Seeen ber Soltweis.

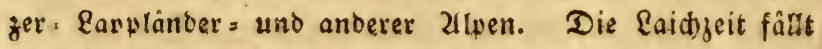
in Februar, uno feine Rogen legt er ohnweit ben liferit in.

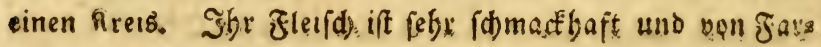
be rötblicht.

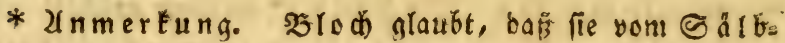
fing ( $S$ alm o Salvelinus) mobt veridieden fetp

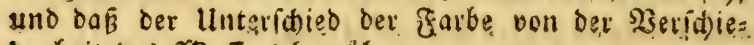
Denbeit des 2 SBaflers berrủbre.

+ 8) Der Sălbriag. Der Galuelin. (roóthele.) Le Salmone Salveline. La Cepède V. p. 210. La Salveline. Bonnaterre 162, n. P7. pl. 67. fig. 273. La Salmarine 163.n. 18. Salmo. Salvelinus. Lian. Bloch §ifde Deutín! III. 149. t. 99. (III. 189. t. 99.) v. Meidinger, Pisc. Austr. tab, 22 .

( $\mathrm{T}$ a b. 88, Fig. 130.)

In ber rotben Baud) = und afterfofle ift ber erife fias. fe Ctrabl weis. In der Riemenbaut fint 10, in oet

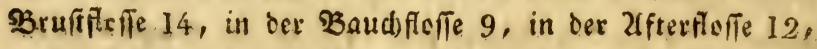

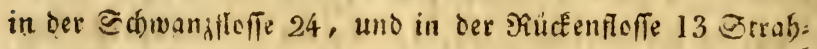
4en. Der Ropf ift an ben Ģeiten zujammengedruct, uno 


\section{V. โอธกแนส. Pisces.}

Sie Niunsoffnung weit. Beibe Simnladen find meb/t ser

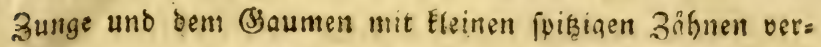

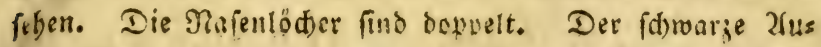

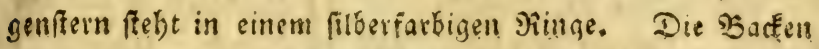
amb der Siemendectel fint filberfarben. Der Souf ift ubeve

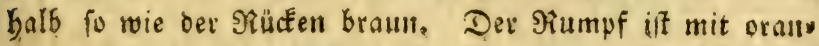

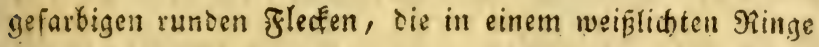
frethen, befegt. Die zarte Seitentinie lauft an ber Mitte Degs Sörpers. Die Grundfarbe ber Seiten ift weif und bes Bauch s crangefarben, zu Zeiten nad) ber Berjádieden,

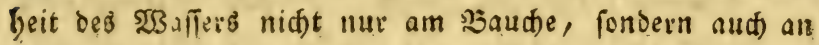
Den Geiten feuerroth. Die Bruffforfen find reth, an Der

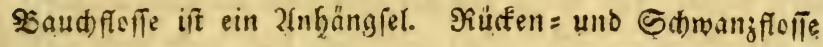
Broun und rejtere gabelfọrmig. Sein Bienidtt beträgt 2 10 Pfunde. Fr findet fid bejonders in ben Seeen, welde innerbatb ben wan SalzGurg zwilden D̈ffreid) uno Steier: marék gegen Ungarn gelegenen Bebürgein vorkommen, wie

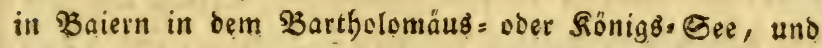
in Dैftreid) in oem Traunfee, im פobenfee bei überlingen,

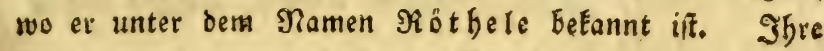
- Eaidjeit geft vom DEtofer in Senner. Sie werden mit ber Sappe uno aud) mit ber 2ungel gefangen, baben einere anaenebmen Biefdumaté, und werben gefotten und gebraten seripeißit.

* 2fnmerung. Bloch hărt ben Särbring uno uno Salmarin (Salmo Salmarinus Linn.) für einen unt denfelben Fifd), ba fid Fein wefentidides? Hnteridaied oon beiden angeben lạ̈t.

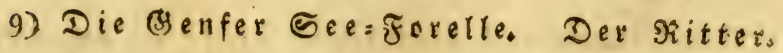
Der ît thling. L'H umble Chevalier. Bon. gatęrre 164, n, 21, pl, 68. fig. 274. La Cepéde. 
V. p. 210. Salmo Umbla. Linn. Bloch fis fabe Deutift). III. 154.t. 101. (III. 195, t, 101.)

Der Sörper ift shne Fleffer. 11 Gtrablen in ber affe

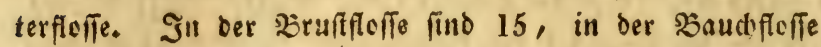

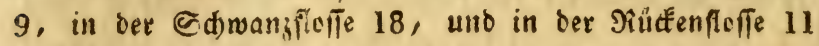
Strablell. Der Sepf ift Elein uno von beiden Finnladen ift bie obere bie langfte; in biefer ift eine boppelte, in je.

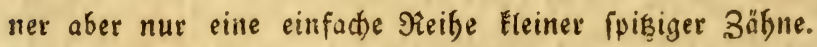

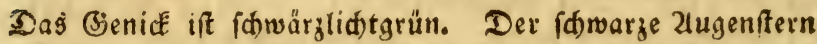

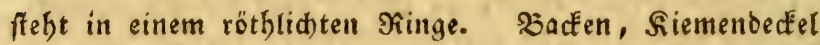

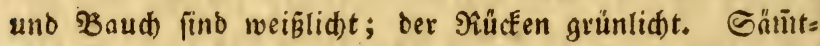
lidbe flofien find furz, grủngelblidit unt oie Sdwanjflofle ift gabelförmig. Die Sduppen fino febr Elein uno zart. Die Seitenlinie bat eine gerade Ridtung. Sie find ge=

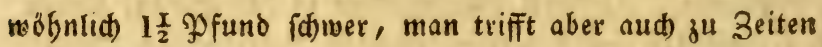
einen von 15 Pfunden. Sie Eummen bảufig in bem Siell.

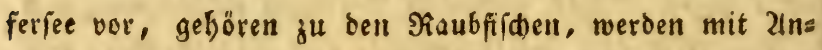
geln uno Nef̧en ofnweit den Ufern gefangen, uno babelt eil fefre zartes, wohliamectendes Fleifd, weid)es ourdbs Roden rötblidt wird.

B. Stinte ober SnIme, beren Siuctens uno Ifs terfloffe cinnonber gegenúber ftehen. (Osmeri.)

10) Der Stint. Der SRogenftint. L'Éperlan. Bonnaterre 164. n. 23. pl. 68. fig. 276. La Cepède V. p. 231. Salmo Eperlanus, Linn. Bloch Fifकe Deutfdl. I. 179, t. 28. f. 2. (I. 226. t. 28. f. 2.)

Der Unterfiefer ift bervorragens und in ber afterficfie fteben 17 Strahlen. In ber Siemenbaut fino 7, in ser

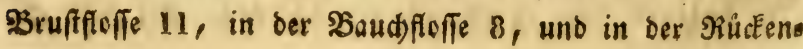




\section{Sצronng. Pisces.}

Aefle 11 Struflen. Der Eleine Souf endigt fide in eine Rumpfe Griţe. Die grofien alugen baben eillen fdwar: gen Germ in einem firberfarbigen ins blaue fipielenden Fitto ge. Der gef́rummte Unterfiefer uno der gerabe Dberfics fer und Baaumen find mit Eleinen nad innen gefrümunten Záfhen bewaffinet. Der Sörper ift etwas fipindelförmig,

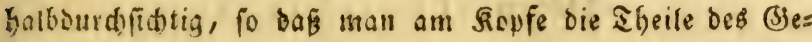

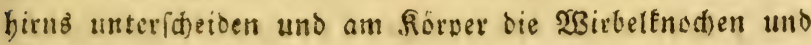

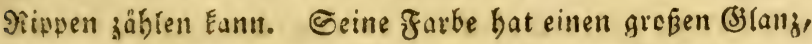
ber grün, blau unb weis fpielt, auf einem Silbergrunde.

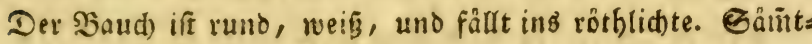
lide Fivfien find grau unb bie am Sdiwanģe gabelförmig. Die Gettferfe frefgt oer affeeffoffe gegenuber. Geine Răn= ge beträgt 3-5 3all. Ex Gerwobnt die europáifonen füken

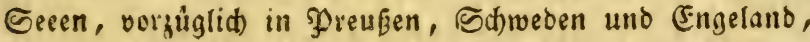
verbreitet einen fehr miorigen, ftinçenden (jerud), bafer ex audh an manden Drten bell Namen Still df fifd er, balten hat. Dennod) werden fie fowohl gefotten als ges braten veripeißß̈t. Man fängt fie in engmajdigen Barmen.

\section{Zlis eine 2abänderung gefört biefer:}

Der Seeffint. Salmo Eperlano-marinus. Bloch Fiifde Deutid)l. I. 182, t. 28. f. 1. (I. 229. t. 28, f, l.)

Mit Differm und lanngerm $10-13-20$ 3oll Vangen

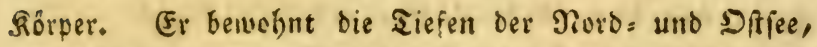
uno tritt vom November bis Senner an bie Süften uno in bie Ströme, und laifft im Mårz, wo er in grốzerer Menge in bie Flüfie ftreidt, und gefangen wirb. In Şreufien wiro er, fo wie der Eleine Stint, auf luftic

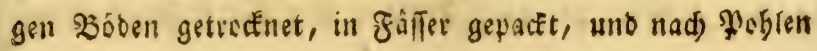


verfentet. Fr witb vorługltob vom şering= Fadens 223 uนm (Gordius Harengum) geplagt, bie gewobntict)

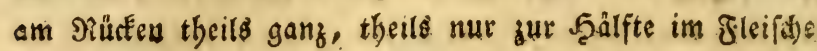
firen.

C. $\mathfrak{a}$ éć) 3ె̊̊l)nen. (Coregoni.)

11) Der Sdritel. Le Lavaret. La Cepede V. p. 245. Salmo Lavaretus, Linn. Bloch Fiifde Deutíd, I. 163, t. 25. (I. 206, t. 25.)

Der DberEiefer ift in Geftalt einer Nafe bervorftebend. III Der Riemenbaut find 8, in ber Brufteffe 15 , in ber Ssaudfrofle 12, in ber 21fterfloffe 14, in Der St)wangs floffe20, unb in ber Rabenfloffe 15 Strablen. Der Repf ift gegen ben langen und bicten Förper nur Elein, Eeilförs mig uno bis an die 2lugen balboutditittig. Die Stirn breit, abfdüfitg uno gelblidt. Der bervorffebende Dbers. Fiefer enbigt fith in eine ftumpfe, weidse und fleifhige Splaze oon fawarier Farbe. Der zabnlofe Eleine Mund offinet fid unterwárts in bie S.uere. Der fdiwarge 2(1/s genfitern frebt in einem fllberfarbigen Minge. Solfen uno Silemenbedel fpielen aus dem gelblict)ten ing blaue. Der runbe Siutcen if́t blaugrau. Die Seiten bis an Die Sinic blaulidt, unterbalf berfelbell ermas gelb und am Saude fitberfarbig, Die gerade Seitentinie if mit 45 Эुunciten

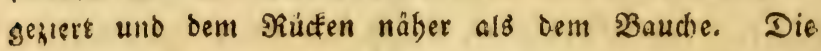
巨कuwpen find grofi, haben in ber Mitte des Mandes eis sell Eleinen 2lusifunitt. Die Bruffloffe ift gelbltcht, dic übrige floffen baben meiflifte Grrablen, eine blaulidte 3wijdenbaut und Finfaffung. Die rüctenfleffe ift bem (6) w)wange nâber ald bem siopfe. Die Jettfulfe rautbere. 
ano bie Schwanjfleffe gabelförmig. Sein Bewidtht batrïgt 1-1 $\frac{1}{2}$ Şfund. Er bensobnt bie Siefe Der Rords und Dffee, aus welder er vorn lluguft bis Dotober fiä) in Nienge an ben Niünoungen ber Slitfie zum Raiden eins

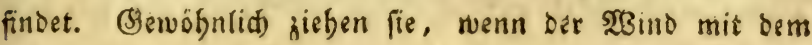
Cotrom geft, in 2 in einen $\mathfrak{S}_{\text {indel }}$ zufammenffopentoen Sieifhen. Sie fefren nad) ber Raidgeit shne Dronung wies Der in bie Gee zarück, uno defto frúfer, wenn ein bals

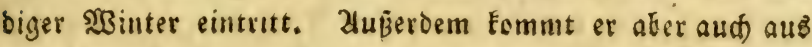
ber Siefe bes Meeres heroor, wenn er Den şering bę befien Raidjen verfolgt, um fich von feinen $\Re$ gogen zu näb=

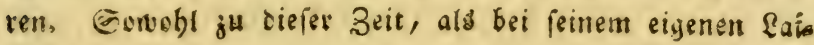

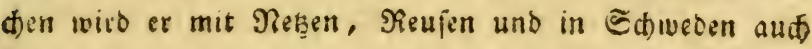
mit ber Eveere gefangen. Sein gartes, weip̌es, fohmacts baftes gleifd) If fefor gefdáat und gefud)t. Mian pflegt

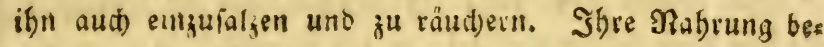

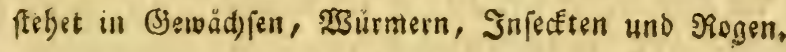

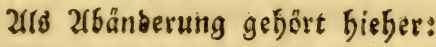

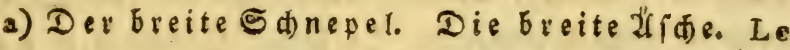
Large. Bonnaterre 165. n. 27. pl, 69. fig. 282. La Cepéde V.p. 253. Salmo Lavaretus var。 B. Linn, ed. Gmel. p. 1377. Bloch Fifite Deuticht. I. 170. t. 26. (I. 214.t. 26.) Salmo Thy. mallus latus,

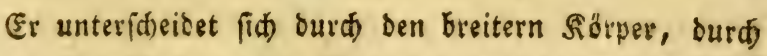

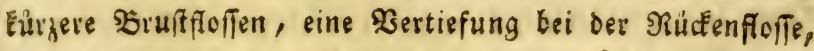

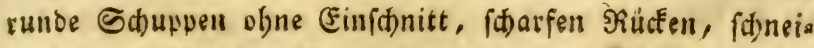

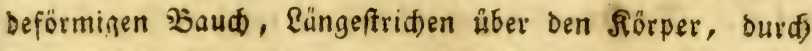

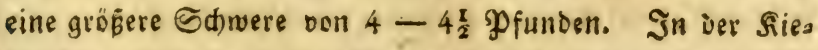

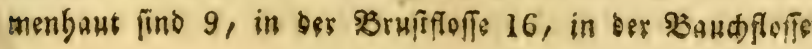


11 , in ser 2ffterflofie 14, in bet Sdwansflofie 20, and

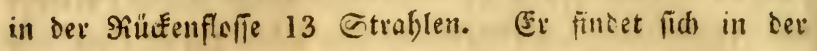
Diffee, ift in Danzig unter bem Tamen $\mathfrak{W}_{\mathrm{B}}$ is fifd), it

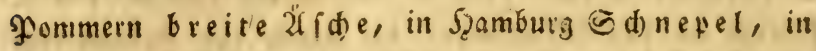

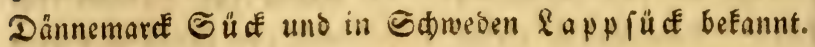

* 12) Die 2́fde. Die gemeine Üface. L'Ombre de $R$ iviere. Bonnaterre 167. n, 33. pl. 69. fig. 281, unt Lombre S. Thymus. 167, n, 32. pl. 53. fig. 202. Le Corégone Thymalle. La Cepède V. p. 253. Salmo Thymallus. Linn. Bloch Fifide Ieutid)! I. 158 t. 24. (I. 199. t. 24.) v. Meidinger. Pisc. Austr. tab 33.

(Tab, 89, Fig. 131.)

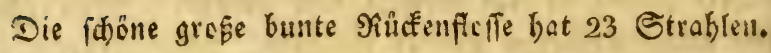

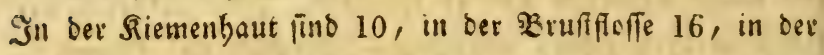
2audfleffe 12, in ber afterfeffe 14, in ber Stwwanjfoffe 18 Etrablen. Der Elcine ftumpfe $\Re$ wf ift mit fd)wargen \$uncten befprengt, oberbalb braun uno an ben Seiten weiß ins blaue foimmernd. In beiden ßinnladen iff eine Reibe Eleiner Eeilförmiger Зäbne. Der fowwarge Żugenftern febt in einem gologelben mit id)wargen Pundten beiprengs ten Ringe. Der geftrecfte Sörper ift mit grofien harten Sd)uppen umgeben. Der einen Eleinen Bogen biloente

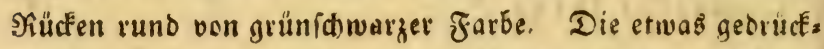
ten Seiten find grau = blaulıdt. \&ängg benfelben lauft vom Sopfe bis zum Sd)wanje über jebe Rerbe Eduppen eille gerabe Sinie, bavon bie mittelfe mit fdwargen Pundfen bea fezt iff. Der etwas ftarce Bauth ift weiß̄. Die Bruits folfe gerblid)t, Bauch = Sdwwans = uno 2(fterffoffe rötblict)t uno an ber saudffuffe eine Mittelfoffe, fidtbar. Die 


\section{Bierte Elafie. Fifde.}

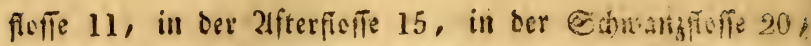

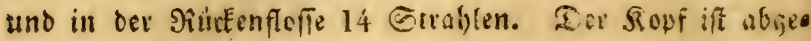
fumpft, Der Mind Elein und zabulos. Der Unterkiefer f(d)mäler und fürzer als Dev sbere. Zn bem Rande bes legtern fteben 2 Eleine runde D̈finungen, ఇaje uno Gtim

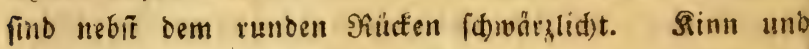
2̉aud) weis. Die greffen 2lugen baben einen fatwatgen

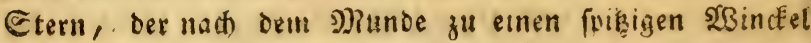
bifoet. Der augenrmg ift filberfarbig. Die Backen fint gelb, ber Siemendecfel iff blaulid)t mit weifer (Finfaffunge Die Geiten fine oberbalb ser sinte blaulid)t ins gelbe fifeo leno, unterbalb berieiben aber filberfarbing. Die mit 44 weižen गु)uncten befejte Gettenlinie marit nabe am Sopfe

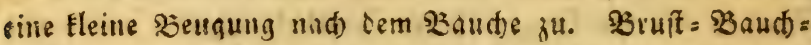

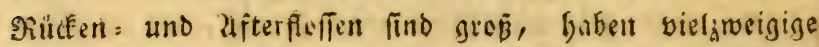
Strablen und an Grunde eine viofette fonft aber eine blatte

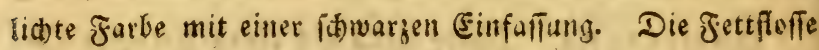

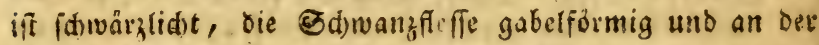

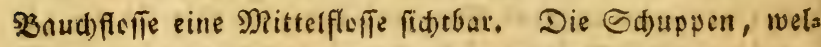

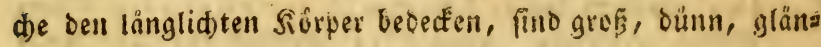

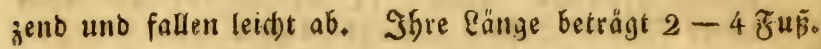
Sie finden fid in verid)tedenen brandelurgifden Secen, befonders dem Ma dui, See sfuneit Stargard in Şin

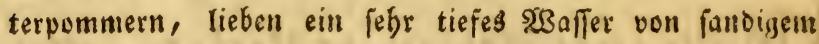

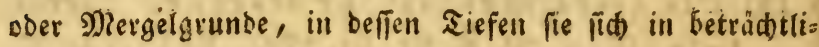
d)er 2fngabl aufbaltell, unb nur jut \&aidjeit, ble in No, vember fält, uno im Frủbjabr, um fid an ber Mufdel: uno ธdnecfenbrut zu fättigen, in bie Şöbe Eommen. 3u biefen Zెeiten werben fie mit einem 8 §! weldes mit weiten Mafijen verfehert, bamit bie jungen

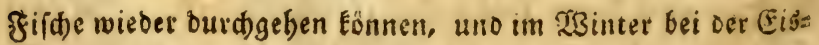

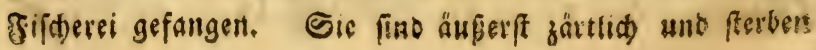




\section{Dั5แung. Pisces.}

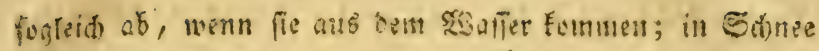

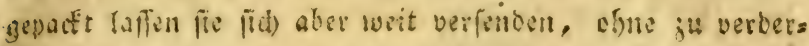

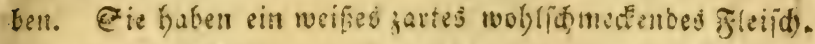

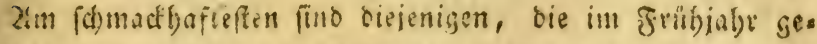
fangen warben, fls weldher zeit fie an fettifien finto.

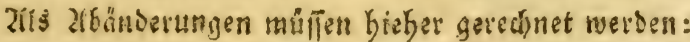

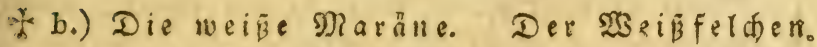

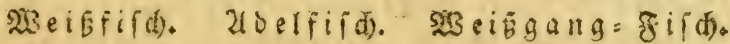
Salmo Muraena Ferra. Wartmann. Bes

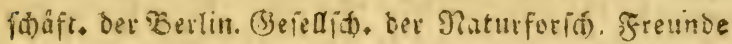
iII. p. 210. Bloch \&!ithe Deutifis, III. 148. 16 f. (III. 188. 208.)

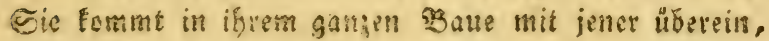

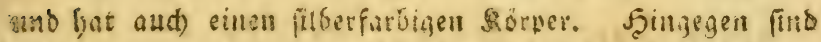

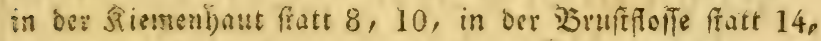
15, is ber sousfoffe ebenfalds 11, uno in oer afterfetie fatt 15, nut 12-13 Otrablen. Diefer Fifion Eommt int

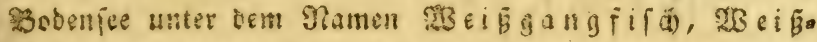

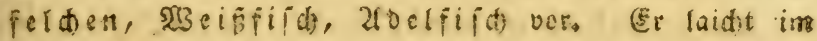

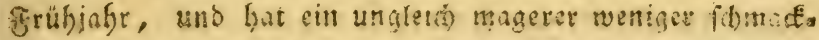

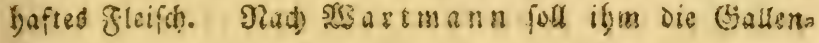
blape feblen.

f. c) Die Aropfomiaráne. Sandferden. Sropfo feichen. Salmo Muraena gutturosa.

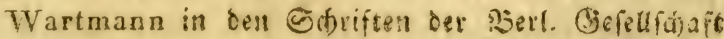
Maturf. Ereunbe IV. p. 431. Bloch Fif fise Deutidito III. 148. 164. (III. 188. 208.)

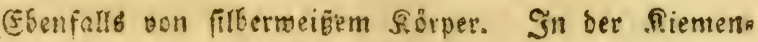

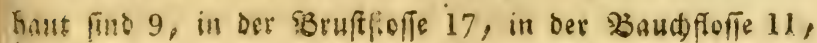


in ber Siŭcenfloffe 12, und in ber 2ffterfloffe 14 Etrab): len. Er Eommt ebenfalls im Bobenfee uno zwar vorzúg= lich in Unterfee bei (Sonitans vor, und erreid)t eine fänge

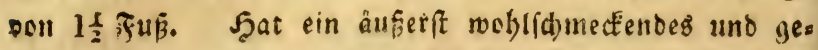

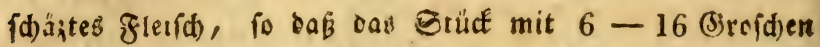
berkauft wiro. Sie werden im alugult, befonders bei ftils Iem Regenwetter oft fo bäufig gefangen, daßz die Conftane jer fifcher in einer Farth uber 40,000 erbalien baben. In ber Raicheit, die in September, Dctober fällt, ift iffr Sals mie eine Blafe aufgetrieben, zu weld)ev Seit lie Rropffelden genennt werben. Den ibren glänzenden (C)uwsen werden bie Eleinften nad) Francfeid) verfendet, um oen Perlfaft (Essence Orientale) womit Die unähten Ferlen überzugen werden, Daraus zu bereiten.

14) Die fleine Maráne. L'Able. Bonnaterre 166. n. 30. pl. 69. fig. 280. Salmo Maracnu 1a. Bloch fifthe Deutid)!. I. 176, t. 28, f. 3. (I. $222, t, 28, f .3$.

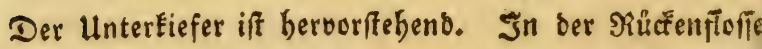
freben 10 Straben. In ter Siemenbaut find 7, in der Bruffifle 15, in ber Buuchflefie 11, in ber 2lfterfloffe 14, in ser Sdmaniflofie 20 Strablen. Der fpizig zus laufende Sicpi if balbourdfidtig uno oberwäts blaulid)t.

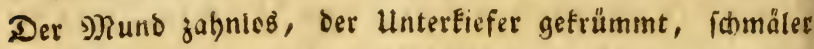
und länger als ber cbere. Die forwargen 2lugenfterne bas ben einen filberfarbigen $\Re$ ing. Die gerade nabe am $\Re$ iüs Een fitehende Seitenlinie if mit 58 Pundten bejezt. Dic Sduppen fino Dünn, filberfarbig, leid)t abjallend. Såñt= lide frloflen fino grau = weif, nur bie gabelförmige $S$ d)want $=$ floffe ift blaulidt. Sbre fänge beträgt $6-8$ 3oll. Sie 
fommen in Der Mark, in Ed)eflien, Preufen, Mommern wno Mertlenburg in Ceeen, die einen fandigen ocer mers gelidsten Boden baben, vor, leben gefelliduffllich beifams men, und gwar in bell tiefifen Gtellen ber Seeen, uno furmmen auß̧er Der Eaidjzeit, bie auf Murtini fällt, nid)t

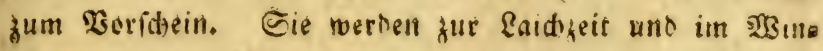
ter us +er bern Eife gefangent. Shre Nathrung beftebt in

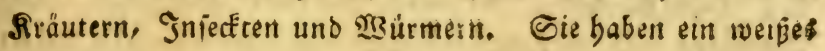
fartes woblíbmectendes zleiit).

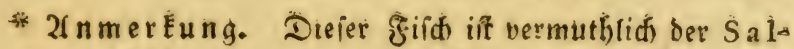
mo Albula. Linn.S. N. nie auth Bloct im 9ten Ehetle ver auståndifden Jifde pag. 59. (im $\mathfrak{N a d t r a g e ) ~ g l a u b t . ~}$

+ 15) Der Bianfelderi. Dever. Salbfeld. Sibenden, (sangfifd), Stuben, Steuben, Jeuerling, Maydel. Le CorrégoneWartmann. La Cepède V.p. 261. L'O inbre bi leu e. Bonnaterre 166. n. 28. pl. 68. fig. 275. Salmo Wartmanni. Slod Siide Deutidl. III. 161 t. 105. (III. 203 t. 105.) Wartmann in 3̇echåft. ber Serlinter (jefellf (क). Naturf. Freunde 1II. p. 184. Linn, ed. Grnel.' p. 1382.

$$
\text { (Tab. 91. Fig. 133.) }
$$

Die Oberkinnlabe if ab̆gefĩumpft. Fer ß̊örper b̆lau. In Der Siemenţaut find 9, in ber Bruffforfe 17, in bet

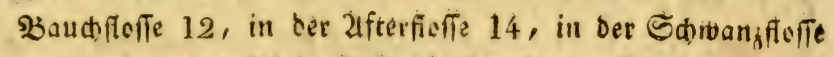

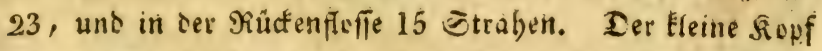
wie ber Baud) ut unter ser Stmie fitberfarbig. Betbe Sinnts Iaren fino von gleider Länize, ber gRuno it zahnloz. Die Zutgen baben einen fowarken Ëtern in einem fitberfurbie

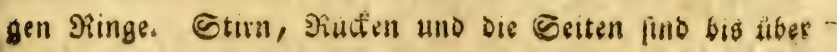




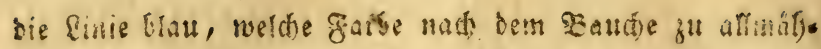

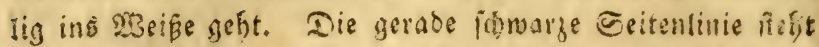

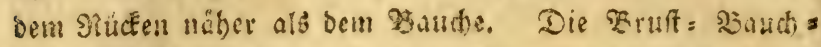

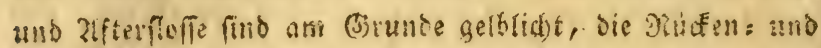

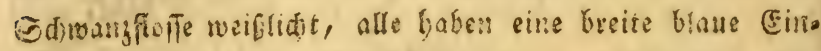

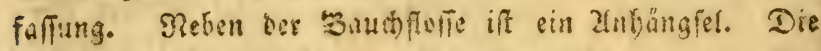

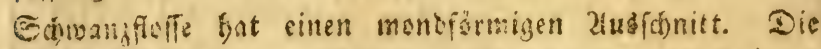
Echupen fino an ver Sible uno thber ben Bruiffoffll und

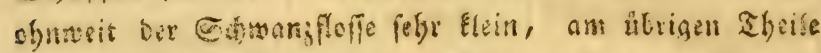
Des Sicrpers unaleich gröser. Sim erften gabr bat cr bie Ränge nen $1-2$, iin glweiten $3-4$, im britten $5-7$, im vierien $8-9$, in fefisten 13 uno im fiebenten $14-$

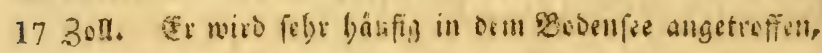

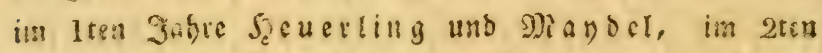
(btaben uno ङteuben, im 3ten (Sangfifd, im 4ten Brbencen, im 5ten Salbferch, im 6ten Dreyer

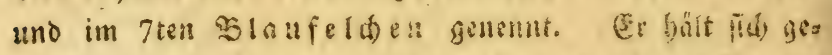
wobulid) in ser Riefe anf. erme Eurouzeit fällt in Dejents

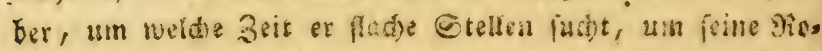
gen im rauken Eiefigen Grunbe abufezsn, nat) weliber Beit

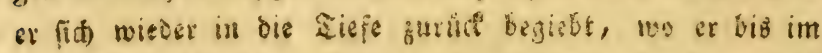
Srubjab: verbleibt. (Ex oermergrt fid) febre fratck, und ift für die fifiter des sodenfers das in Rleinen, was Der

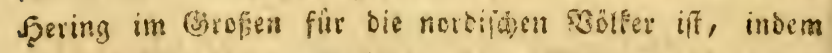
man im Mai bis im Serbfĩe mehrere Mialionen fängt unb nad) antere Ränber verführt. Snghemein geben im Som mex alle 2tbeno 20 - 50 sobte auf befien Jang aus, cill Eleines iff mit 2 und ein grö́s mit 4 Mann befejt. Die.

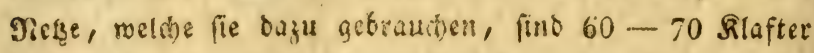
bod), indem der Fifich fid) gewebulith in einer Stefe von 50

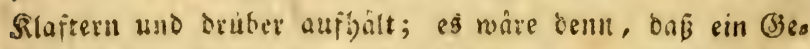
mittit in oer Euft wäre, toes bafs es regllete, in welders 


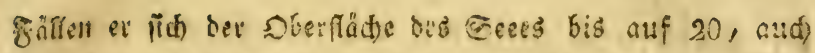

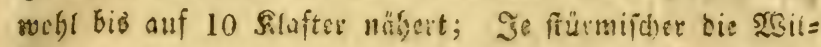

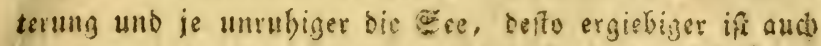
Der Fang. Ein jebes Sojiff éthit faft ben ganjen Sonmer binburd stidt felten mit einer seute von 2-400 Estiti gegen Morgen zुu Sanafe. Durdh ein Bjefeg ift es verbeten

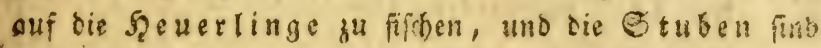

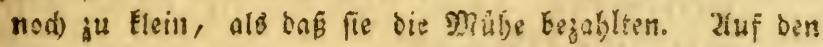
Bangfifch bingegen, ber im Erühjiafie bei 3citan aus

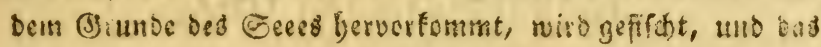
100 auf ber Stelle genioffntid) ntit $3-5$ Gulden, uno

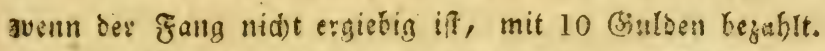

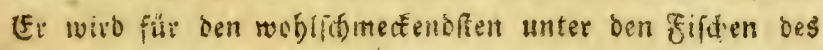
Decenfeets gefalten. Diejenigen, welde man verjendet, wersen entweber, nawbom man fie autgensmmen, frifo marinirt, oder aud juvse auf bem Finft gebraten, aldsenn

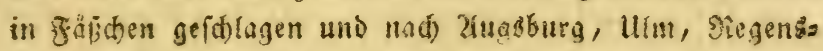

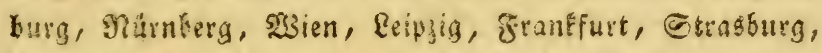

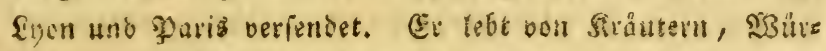
mern, Gufecten uno bern fogenannten zifobroo, einer etrionmant (vermuthliá) Spongia lacustris). Sie ba

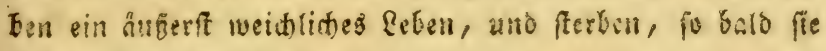
ละแ bem ş3affer fommen, ab.

* UnmerEung. Gesner Egierfud อ. 187 189 veeffeft unter feiner Albuld minima niches an= Ders als des einjáfrige, uno unter Albula parva dos

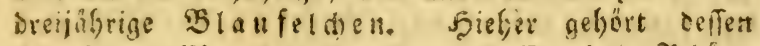
Albula nobilis, Albula coerulea, Bezola. Błáu. Iing, Bratfifd, Eelden, Blaufelden,

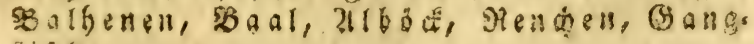
piip. 
D. Şalbforen. Nit 3-4 Strahlen in ber Ries ment)aut. (Characini.)

16) Der Sâgebaud. Diebreitleibige Sharbs. feren. Der S⿹\zh13一 rhomböide. La Cepède V.p. 284. Le R hombosde. Bosnaterre 170. n. 48. pl. 70. fig. 286. Salmo rhombeus. Linn. S. N. Bloch aưrle इुifde VIII. 113, t. 383.

\section{(T a b. 92. Fig. 134. 135.)}

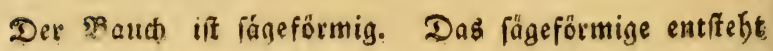

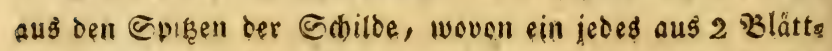
d)en hufammengeferst ift, fig. $135 . \mathrm{b}$, bie , wenn fie fid vereinigen, in eime Solse auklaufen. In der Riemenhaut

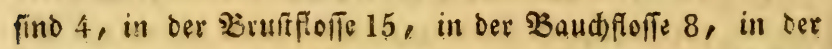

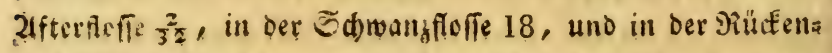
floffe 17, 0 strablen. Der fouppenlofe Siopf ift zujammena

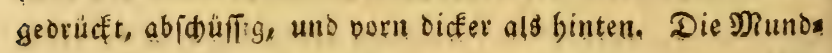
gffnumg weit. Die Unterkinulade herverffefend. Die Zăbne fino breit und iprigig. Die lugen haben einen idwarjen Stern

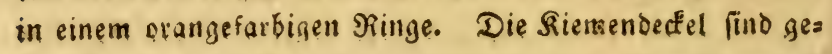

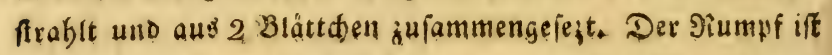

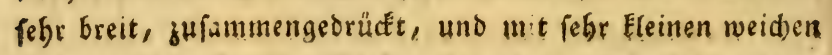

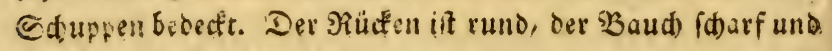
beide fino begig Die serace Geitentinie låuft an der Mitte

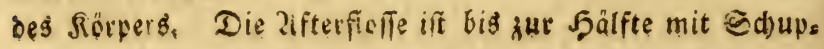
pen bedefft, und ibse erfien beiden Strablen find furz unt hat. Die mondförmige Éwanzfeffe hat eine fdrars

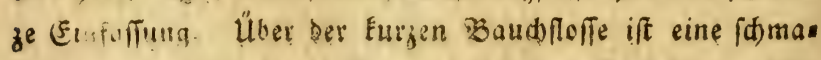

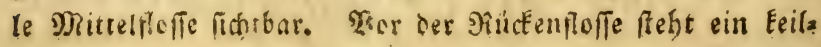

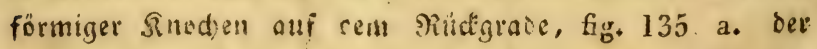

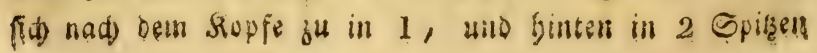


ensigt. Der Miúfent unb oie Seiten bis an bie Geiten.

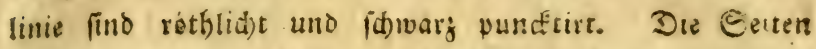
uno ber Bauch filberfarkia, uno die Fleilen grau. Er ers

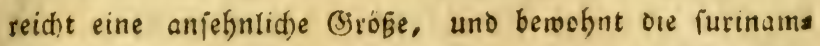

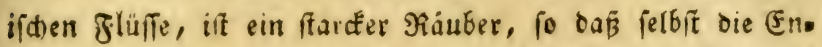
ten auf ben glüfien vor ifm nidst fider fint, hat ein

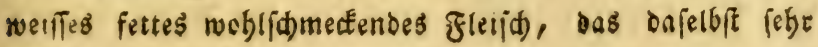
ge[chąat if.

\section{Das pfeifenfif(t): Befd ledt.}

\section{(Fistularia.)}

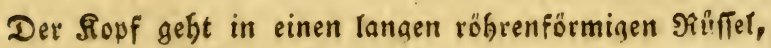
ber an ber Spize mit šinnluden verfehen iff. Die Tiobre beitebt aus 3 bünnen breitest ourdofitdtigen Snoden, wels (4) burch) eine pergamentartige burch fitdtige Şaut mit eints ander verbunden fino. Der obere Sinodjen in Beffalt eis

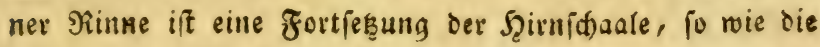

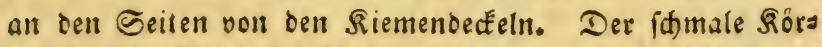
per bat 7 fleffen. Scierven find nur 4 2frten be Eannt, welde in ben ofts und weftindifden Biewäffern vortammen.

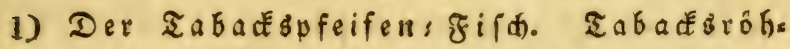
renfifd. La Petimbe. La Cepède V. p. 350. Bonnaterre 171. n. 1. pl. 71. fig. 289. Fis:ularia tabacaria. Linn, ed. Gmel. p. 138\%. Bloch

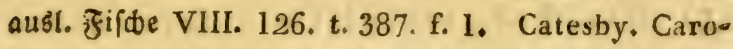
lin. II. tab, 17. fig. 2. Mus. reg. Adolph. Fridr. I. 80 . t. 26. fig. 2 .

(Tab. 93., Fig, 136.137, 138.)

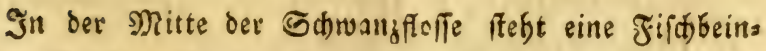
artige Borjee. In ber Riementaut find 7 , in ber siufta 


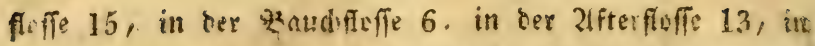

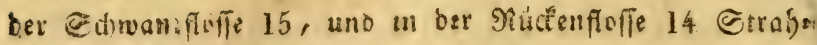
ren. Der fobl lange seaf if vierecting und an ben Gets ten gefrablt. Dis Miunisfinung iff fotief, weit, uno die. antere Simniuve herouriebent, beice find init febr vielen. Icisen Bäbnen bewaffiet. Die zunge ift glatt und frei. Fie Rufentader apsoupelt, iid)t an Den Zluggen, weld einen fifwwaren Gtern in eimem fllberfarbigen झilnge boo bon. Die siementetel befeben aus sinem eingigen büne

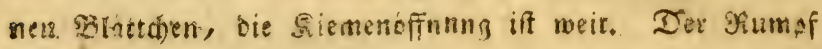
fámptenlos, voin fiach uab huten rund. Die Geitentinis Ianft gerase tifer den Siorper. Der Saut) tif lang. die

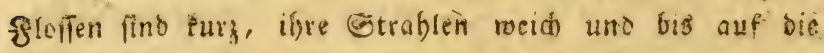

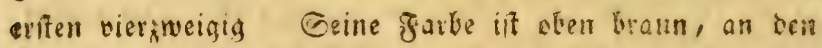

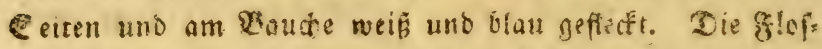
fin fub rotb. Geime Eänge beträgt $3-4$ \&ub. Er ber.

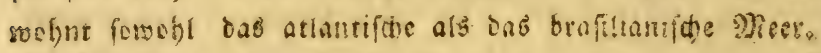
Dic \&raffianer nennen ifn Petimbuaba.

* 21 n mer

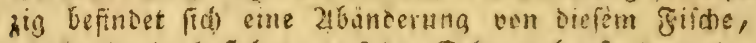

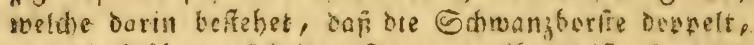
unt die Sióbre auf beiten Eerten gezabueit ift. fg. $13 \%$

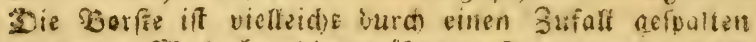
worden. 233as aker bie gezäbnelte Edinaule fig. 138.

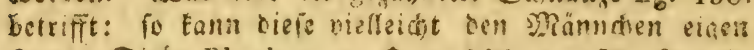
finn. Qiefje Bloch a. a. D. p, 130. 1. 187. f. 2.3.

2) Der Trompetenfift. Der dinefifde Ióbrfifo. L'Aulostome chinois. LaCepède V. p. 357. L'A iquille. Bonnaterre pa 172. pl. 71. fig. 290. Fistularia chinensis. Linn. cd. Gnel.p. 1387. Bloch augl. filide YM!. 131. t, 388

(Ta b. 94, Fig. 139.) 


\section{5040 thtig. Pisces.}

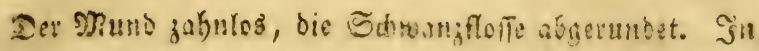

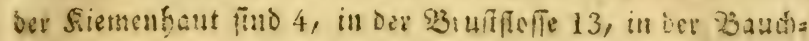

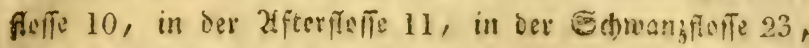

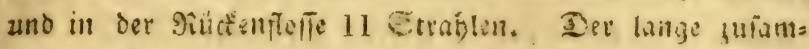
mengebrückte cten breitere und unten fharfe Stopf iff ithupe

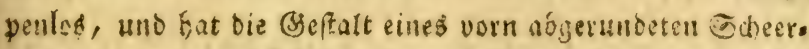

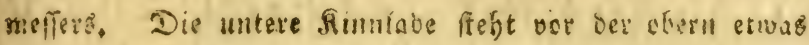

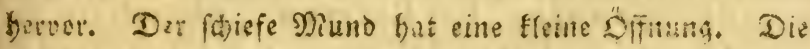

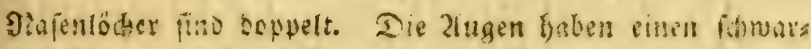
jell Stern in einem nitberfarbigen \$ainge. Der fidmate

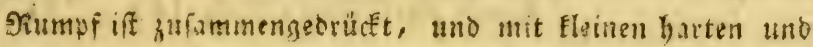

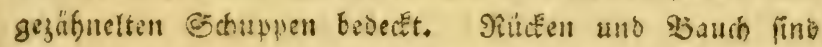
sunt. Die Seitentinie fängt an Gientice an, mad)t bas fet6ft eire seugung, uno lauft bann mitten über ben Rorra

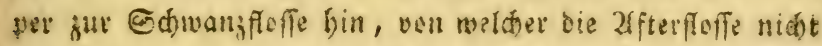
socir entiernt ir. Snom Bupfe bis binter bie afferflufie

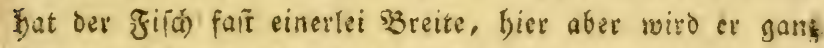
idomal. Eammtliche Fienten fino Eurg und ibre Etrablen sveid. Wor ber Siúcenflefie fieht man 9 weit ben einans Der entfernte, Eurge und nad) finten żl getrütmmte Stad)e(n,

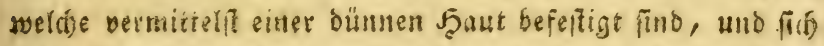

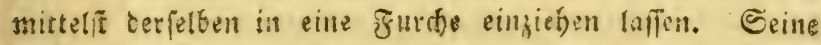

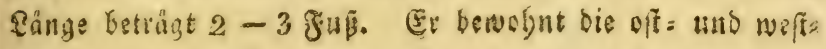
indifden Mieere.

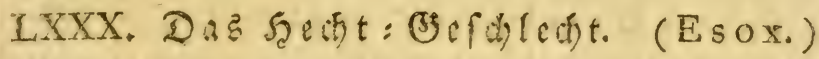

Der Sopf cben etwas flad. Miuno uns Piatifen weit. Die obere Silumlade meifeng Eürzer a!s oie untere, unt bein

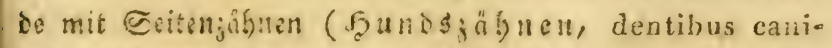

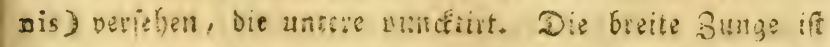

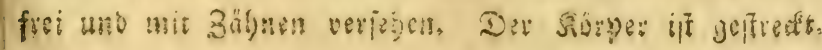




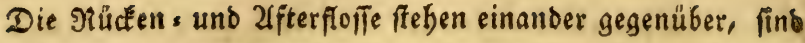
febr Eurg, unb exftere bat feine Fettfoffe. Davon find 14:

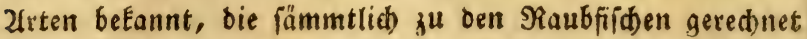
werben, und theils fich in Meeren und füßen श्ञaffern bes finden,

1) Der Sinodenfedt. Shilbbedt. Die 3 ans genfdinaze. Le Caiman. Bonnaterre p. 173. n. 2. pl. 71. fig. 292. Le Lépisosté e Gavial. La Cepéde V.p. 333. Esox osseus. Lina. S. N. Bloch aนฮ่. Fifate VIII, 140, t, 390.

Die obere Sinnlabe if länger als bie untere. Der Söbs: per ift mit bicfen Enodigen Sd)uppen belegt. In fanmmts liden floffen ift ber erfte Strabl von ben Spif̧en der Sduppen, womit ek belegt if, gezåbnelt. In der Brufto

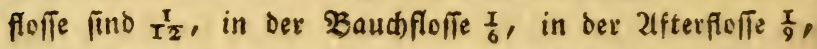

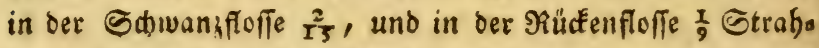
Ien. Der fauppenlofe Ropf lauft in 2 lange Sinnladen aus, welthe mit jpiłzigen Bâbnen bewaffnet find. Die 2(us gen baben einen fowarken Stern in orangefarbigem $\Re$ Rin.

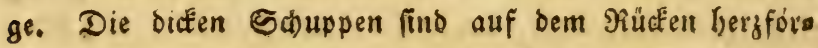
mig, an ben Seiten länjlid)t, vierectig, am \$3audbe raus

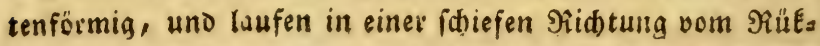
Een nach bein Baude bir. Siücken = uno Sd)wanjfolfe fins am Srunbe mit Sduppen belegt. Die Seitenlinie neigt fid) nad) oem 3 audbe bin. Die Floffen fino Eurg uno rött) lid)t uno die bintern fdwarg geflectet. Der Siücfen ift grün. liabt, an ben Seiten beagrün, unb ber Baud rötflicht. Seine Ränge beträgt $2 \frac{1}{2}$ bis über 3 Fußj. Er bewebnt bie Geren uno Flüle von Dits und 2 seftindien. Gein Fleifid tf fehr fett uno falmadfaft. (5r gefört unter bie febr gea

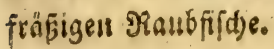




\section{V. $\supset \times ธ \mathfrak{n} \mathfrak{n}$. Pisces.}

2) Der gemeine f̧edt. Le Brochet. Bonnaterre p. 174. n. 6. pl. 72. fig. 296. La Cepéde V. p. 297. Esox Lucius. Linn. S. N. Bloch Sifife Deutíchl. I. 229. t. 32. (I. 291, t. 32) v. Meidinger. Pisc, Austr, tab, 10.

Die Sdnauze ift Greit. In ber Riemenlyaut fino 15,

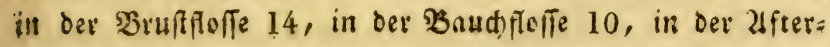

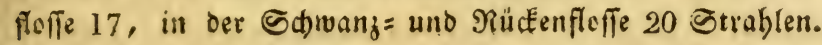
Der grefe Siopf iff an ben Bacten ven beiben Seiten jua

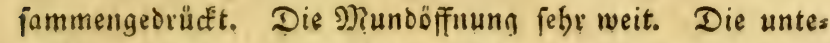
ye §innlade raget etwas übẹ bie obere hervor. Die alugen haben einen blaulidten Stern in einem goldfarbigen Ringe. Sopf uno ber langgeffrectite Förper fint marmorirt. Der

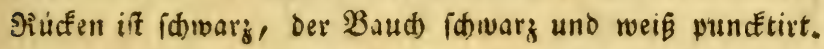
Die Geiten grau mit gelben Flecten uno Dueritreifen vera fefen. Im erfienn §abre bat er eine grůne Zarbe, baber

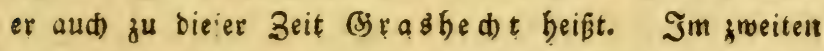
verwandelt fidd) Die grüne in eine graue, auf welder blaffe Elecfe ericheinen, die mit dem britten Jabr gelb werden. Die Seitenlinie if gerade, unb der Sörper mit Eleinen fängid)ten barten Sduppen bedeckt, Die Bruft, uno

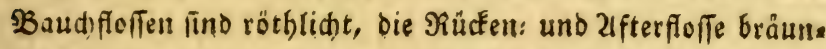
lidt, uno legtere nebif der braunen Sdiwangfleffe fatwar

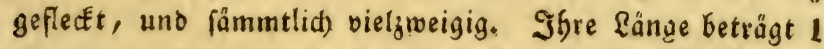

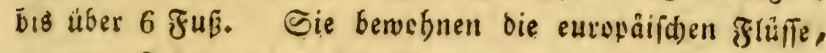

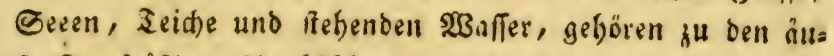

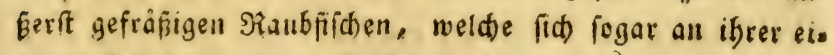
senen 21 rt vergreifen. Fildje, weldje er gefangen bat, be= bält ex fo lanze jwifhen feinen Zähnen, bis fie tobt finto,

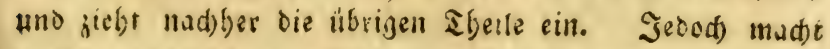

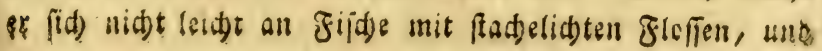




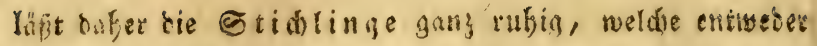
blos junge feste, ocer aud wobl âltere in Scunge: ers gieifen, uno bie man gumetles in ifrem Munde findet,

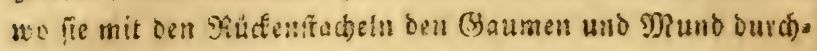
ftoden bafest uns fenfegen. 2luferbers fribt ex aud szöget,

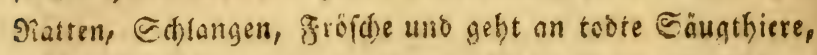

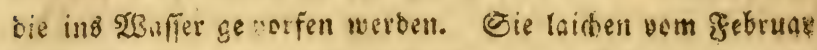

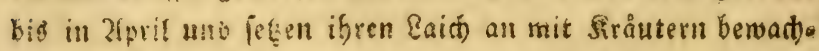
feneri Eteflen afy. Diejenigen, weldte im Eebruar laithen,

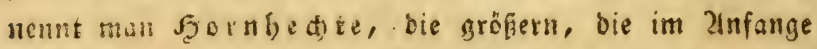
bes Merges Yaithen, beipen Mex zbechte, uno biejenigen, welate in Tprif cribeinen, werben

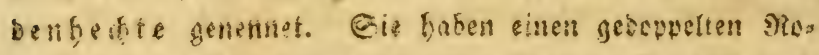
gen, wno entbilt nud Solod) ein 60 fünoizer feed)t 136500

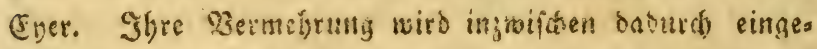

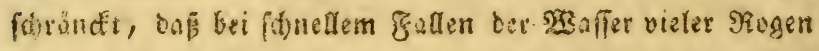

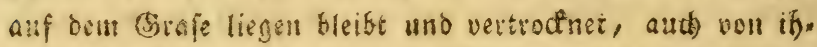

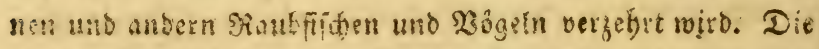

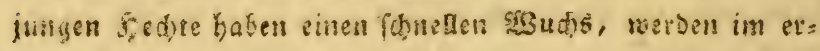
fian Tabre 8-10, im sueiten $12-14$, im oritten 18 - 20 3ofl lang, in pectoten gagre folden fie 3 , uno im

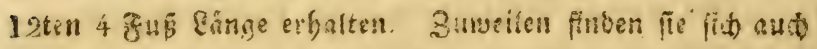

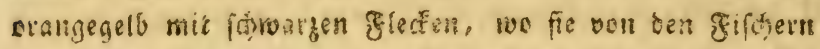

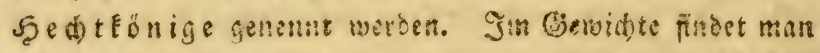

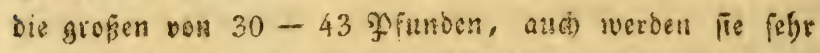
aft, wiz ter, welden nan nach Gesner 1497 in Setle

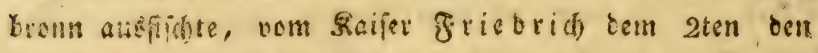
5ten Detoler 1230 eingefeft warten, แno 267 Jabre ers

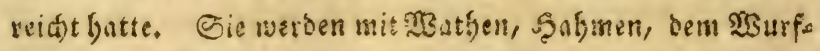

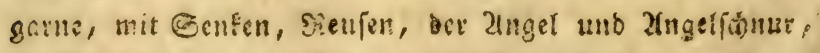
in 23 Bnter unter dem Eife, ober fonit bei Eacteln mit Spees

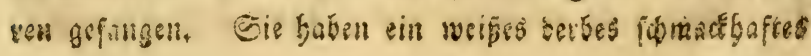




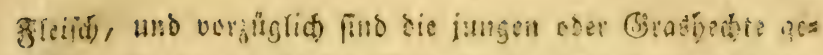

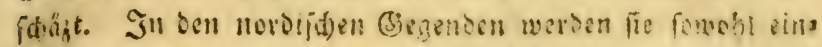
gefalzen als getrodinet ober geriudert in zâfer gesuct, ais

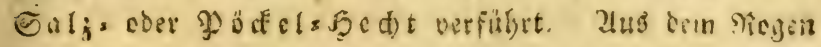
wiro aud sin Eaviar rereitet, uno in ber Clyumare sin

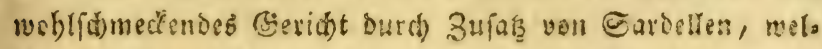

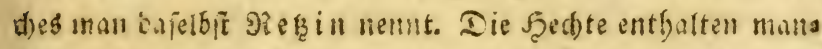
(d) ertai Fingeweites sisutrmer als: Ascaris Acus, Echinorhynchus Lucii, Die Fasciola Lucii unb Taenia nodulosa.

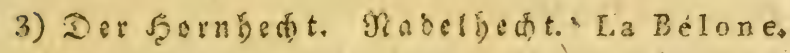
La Cepède V. p. 308.' Bonnaterre p. 175. 1.7. pl. 72. fig. 297. L'Orphie. Esox Belone.

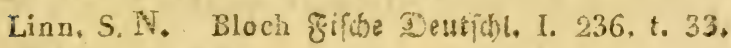
(I. 301. t. 33.)

( $\mathrm{Tab}$. 95, Fig. 140. 141.)

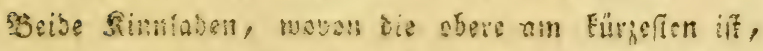

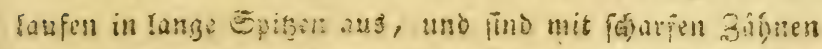

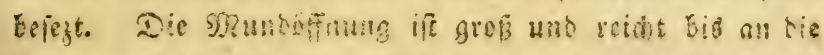

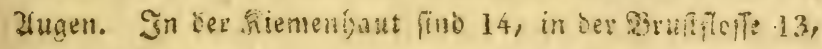

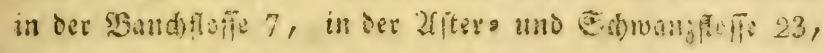

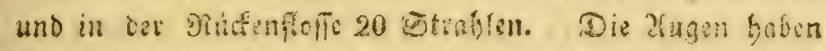

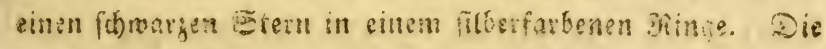

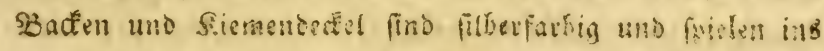

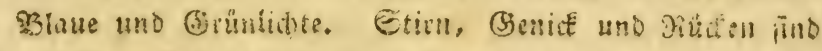

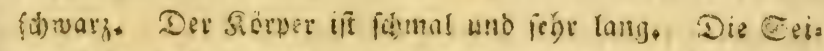

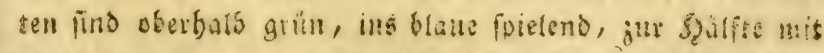

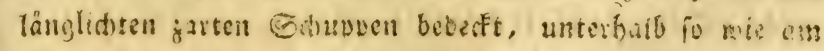

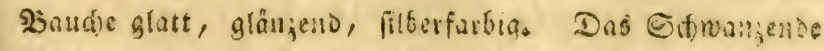
if sum, wirt an ber frate weder Ersit. Die whe ain

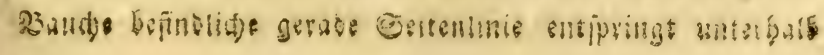


Dem Siementectel, lauft nahe am Bauche mit bemprlbet parallel, uno verliert fid) unter ber Edwanjfaffe. Diè Flefien find furg und bei ben qrauen Bruft: und Sauchflof=

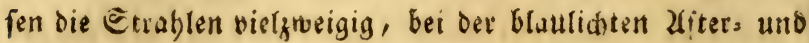
Rücfenflofte nur einfach. Die Sdwangflofte if etwas aus. geidnitten, bat eine blaue Finfafiung und an ben Spizen getbeilte Straflen. Sie erreiden eine \&änge von $1-4$

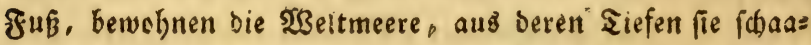
renweife an bie flachen Gtellen und אüften vom Măry bis in Suni bingezogen Eommen, um bafelbit zu (aid)ett. Gie gebören zu oen gefräfígen Naubfiiden. Man fängt fie mit befondern Epeeren, weld)e aus einer bölzernen Stange und einem daran befeffigten mit Exizen in (3jeftalt einer vier. zackigen Bjabel verfebenen Eifen befteben. Der Fang ges

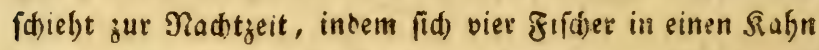
frgen, daven ber vorterfte eine aus Sol uno Gtrob vero

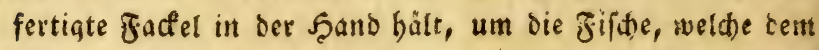
gidbte nađhgeben berbeizulocfen; Die hbrigen orei lauern mit ifren Epeeren auf bie berantommenten Fiftie, uns wents fie biefen nabe genug zu jeyn glauben: fo fabren fie mit ifs.

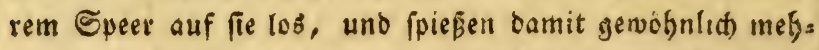
reve ;ugleid). So erbålt man auf bieje zirt, wenn ber Jang glüctic(t) von ftatten gel)t, in einer einzigen Nacht 12 -

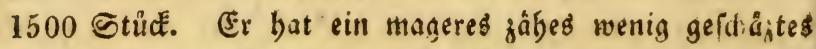

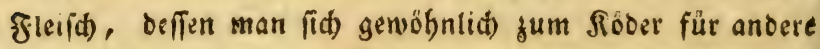
Jifde bedient. Seine Giäten nebmen brim Sodjen odet

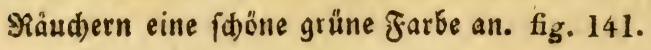

4) Der brafilianifde Sedt. Der Eleine Sd) werofifd. Die Elephantennafe. Le petit espadon. La CepèdeV. p. 313. Le demi Museau. Bonnaterre p. 175, n, 10, $\mathrm{pl}_{\text {。 }}$ 
72. fig. 298. Esox brasiliensis. Linn. ed. Gmel. p. 1393. Bloch ausl. Jifhe VIII. p. 145. t. 391.

(Tab. 96. Fig. 142, )

Der fd)mare lăngere Unterkiefer lauft in eine fefr lange Enize aus. In ber siementyaut find 14, in ber $\mathfrak{B r u f t =}$ fleffe 10, in Der Baudifferfe 6, in ber afterfoffe 12, in

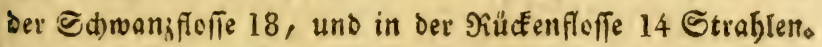

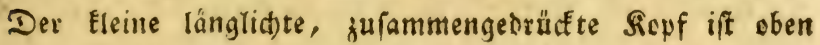
breit, unten fdarf. Die DherFinnlabe lauft in eine gans Eurge und fitumpfe Exitge aus. Die zugen baben einen

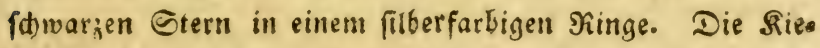

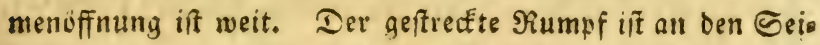

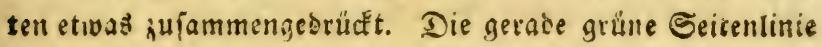

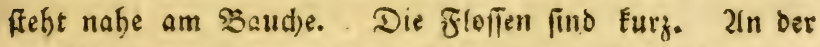
gabelförmigen Sotwaniflerfe ift eer untere Theil lánger als ber obere. Die Baudfifoten freben febr weit binten. Der Sopf und bie Seiten fino filberfarbig, an lejtern fieben

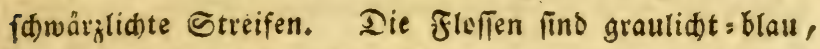

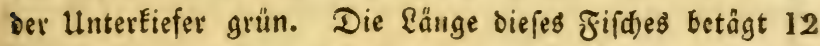
-15 3oul. Ere bewobnt das eft, und wefitindifde Mieer, wirb am reidteften bes Nactits betm Sahein bes Feuers gefangen. SWenn man nemlich etwas Şeu anzündet, fo follen fiidh biefetben gleid) zu taufenden um ben sarb bes Sodiffes verfammeln, und fo teidte in bie au\&geworfenen Siefse gernthen. Sie find jegr fett und fammadkaft.

LXXXI. Das (Endectenfifd: (5)efdedt. (Elops.)

Der Sopf iff glatt. Die אiemenhaut hat 30 uno mebrere Strablen. Der Särper it gefteckt, unD Der 
Sinmpf mit 7 froffen verfégen. Davon fino nur 2 Kuten betannt.

1) Der guinefifice Evoeáfenfifo. L.Êlope Saure. La Cepède V. p. 288. (Elops guine. ensiso) Elops Saurus. Blooch augl, Fifje VIII. 153. t. 393. f. 1.

\section{( $\mathrm{Tab}, 97 . \mathrm{Fig}, 143$.}

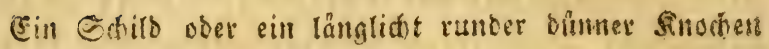
sern an ber Unterfinntode unb binten on Der Siemenbaut, we fie beide zufammenfofinen, beferigt. Sie SRüctenflofie

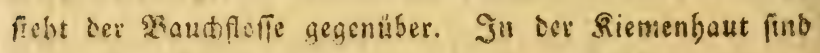
34. in Der Sirufficfie 18, in ser Bautgleffe 15, in ber

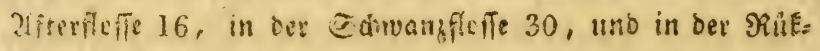
Fenfeffe 22 Ërablen. Sor foumpentafe fopf ift jufammens gesuldt, longlidt anb cben etwas flad). Die untere Rinno labe ift erwas linger als bie sbere, unb beite frub nebit

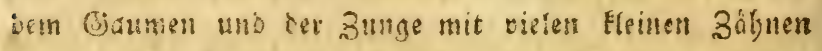
belezt. Sie Sofentodier find bonpelt. Die arugen baben cincn fdwarken Eten in einem theils gelfen theils rotfen

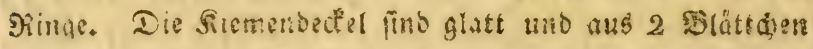
zufammengefezt. Die siomenfout liegt frei. Die Shups

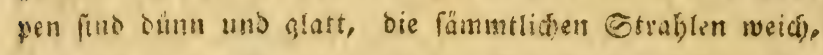

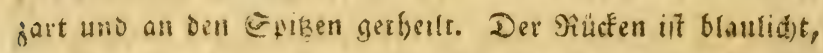
Die Eeiten und ber zanch funo nitherfarbug uno bie Gloffen

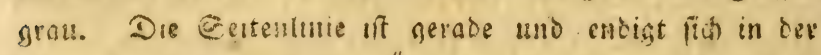

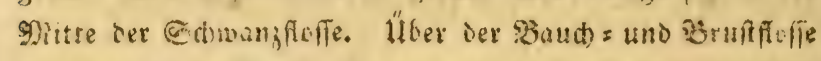
frebt eine Dittelficfie. In Der gabelfömigen Echwanzfoffe

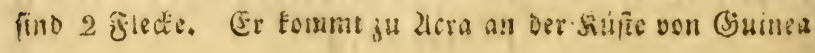
vor.

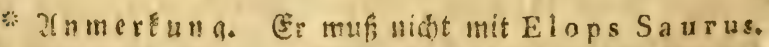
Linn, ed, Gasel. p. 1394. verwediffert werosn, we'der 
eine Sdwanifinfe bat, bie sben und unten mit einem lantietförmigen @tadel veriegen ift, unb in Carclina zu STaube fenn forto

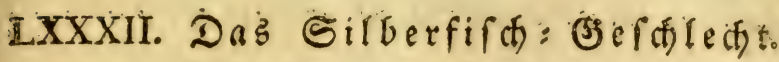 (Argentina.)}

Det Sopf ift breit, Die Etim niebergebrüct. Die Simntaden gleich) lang nebft der Bunge und dem (Saaumen

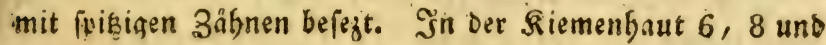
mehrere Strablen. Der alfter fteht nalje am Ed)wanie. Die Sauthfluften baben viele Strablen. Davon fino \& 21rten, bie gröftentheils Meeresbewubner fint, bekannt.

(1) Der Perlen= Silberfif L. L Argentine Sphyrène. La Cepède V.p 366. Le Hautin. Bonnaterre p. 177. n. 2, pl. 73. f. 301. A rge utina Sphyraena, Liun. ed, Gmel. p. 1394.

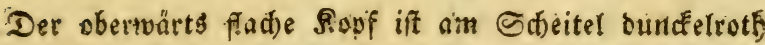

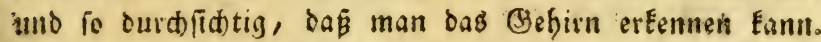

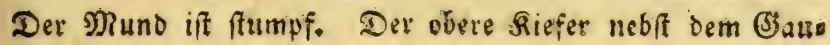

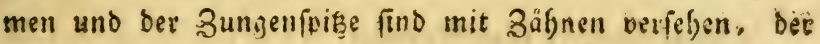

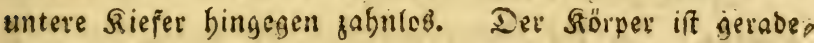
grau: grünlidt, an ben Fiemendeffeln, Geiten uno beîs S3authe fitterfarbig. Die গiúfenficite fangt etroas binter Der Mitte des Siörper's an, und fteht ber Dbaudi)fleffe gegers über. Die Eswanzfeffe if gabelformig. In oer Fies

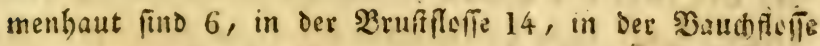

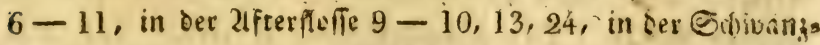
forfe 19, uno in Der Siuctenfiefie $10-13$ S̈trablen.

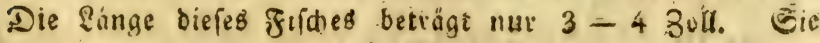

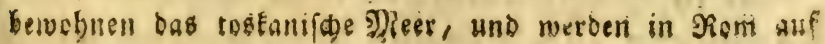


Den Mårcf́ten verÉauft, unb all verfaledenell Drtell aud wabrideinlid) unter die Sarbellent gemengt. Şbre an beis Den Enien Eegelförmige Gothuimmblafe glangt wie Gilber

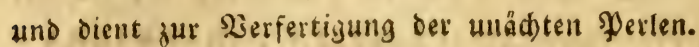

LXXXIII. Das Gornäbrenfifd): (5efdledt. (Atherina.)

Der Sapp ift oberwånts flad). Der obere Riefer ets

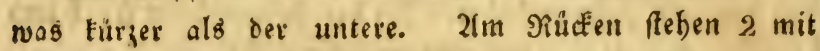
Etrablen verfebene floffen. Der Sörper if idmal, Elein mit dünnen filberglänzenden Sduppen belegt. Ein Silbers ftreif ziel)t fith von jeber Seite des Ropfs bis zur @dwanzs floffe bin. Ess find 4 2rten befaunt.

1) Der inittellandifipe Sornăgrenfifd Le Joël. La Cepède V. p. 372. Bonnaterre p. 178. n. 1. pl, 73. f. 302. Atherina Hepsetus. Linn. ed. Gmel, p. 1396. Bloch autr. Fifdhe VIII. 158. t. 393, f. 3 .

$$
\text { (T ab, 97. Fig. 144.) }
$$

Die Eduppen rautenförmiz. 13 Strablen in ber $21 f_{s}$ terforfie. In Der Riementhaut fino 3 , in oer Brufiffeffe 13, in ber Sbaudfleffe 6, in ber Edwandjfoffe 20, in ber Siudenflerie 8, 10 Etrablen. Der sopf ift ituppentis, Die Mruncéfinnung weit, ber Unterfiefer länger als ber cbes re, uno beide mit äunererf Eleinen Eaum fidjtbaren Bäbnen beiegt. Die 2lugen baben einen fdwargen Stern in einem

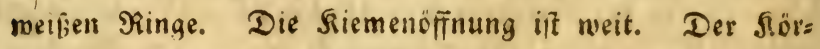

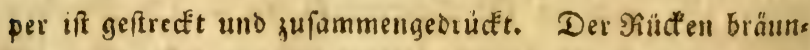
lidt, Die Eeiten blaulidt, Der Bauct) filberfarbig und oie Siefien grau, Dis Geitentunie an der Mhitte des siorpers. 


\section{Bierte Elaffe. Fifare.}

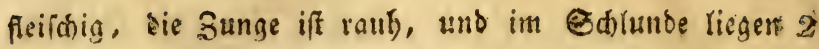
rasuelartige אnechell. Die Zlugen baben einen iffwargest Erern in cinem weinggelben ringe. Die Siemenöfnung if weit. alte weidfe Strablen fint vielgweigig. Die $2 \mathrm{f}=$

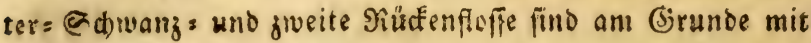
Eduppen bedect. Des SRüffen ift braun. Dis Setten

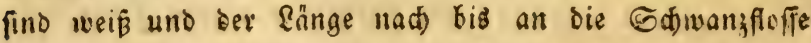
fitwory liniit. De: Baud) fitberfarben und bie floflen btau. (Fr erreid)t eine beträd)tlid)e (SröB̉e, und eine Śd)we= re von 25 Pfunden, unb Eommt beinabe in allen SNeeren, verzüglid) aber in bem mittelländifd)en und amerifanifd)en Me:re nox, und gefört zu ben Fifdjen, wetdie zu beftimm= ten 3eiten aus bem Meere in bie stüffe ftreid)en, er ers

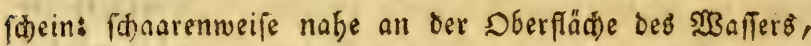
uno bält fict) unweit ben Ufern auf, wo fiá) bie früfie ins

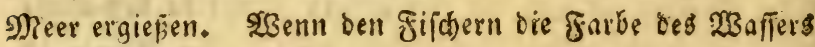
blaulid)t erfdeint, fo wiffen fie fogleict), ba仍 fid in biefer (3) gend eine grobe Menge derferben befinoet. Sie umzirg, len ibn osnn mit ifien গegen und indem fie dieferken zu= fammengleben, fo treiben fie ifn unter vielem Gisräufibe nad) unb nad) in Eage. In Sarbinien, wo bie Süften mit Seiden eingefaft find, fommen biefe fifd)e nebft mefs= reren ancern, aus Dem Meere in fold)e, und befonders băus

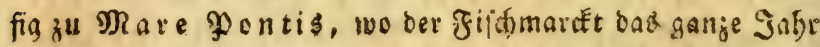

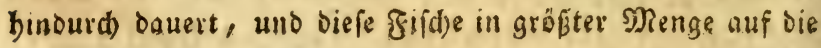
Infel verfübrt merden. Sie gebören zu den gefăäjten ano fomadfhaften Fifchen. M?an Iffegt fie gefocht mit

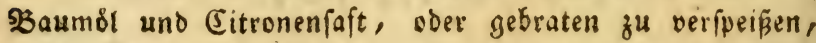
audb werben fie eingefalgen und geräuchert. 2lus beffen Rioo gen wirb eine vorłügfiche 2lrt Caviar, bie in Sarbinien unter bem Namea Bottarga, im füblid)en franctieid) Boufargue betannt ift, bereitet, weldes auf folgende alt gea 


\section{Dน นtutug. Pisces.}

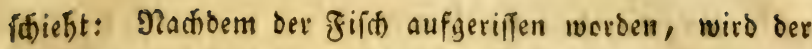

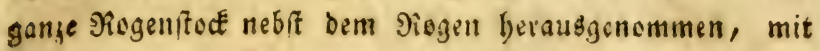
Ealz beftreut, und nadioem ex to 4 bis 5 Etunien gele: gen bat, zwifden 2 sietter gebrad)t, um bas 23 affer aus. gupreffen, worauf ex benn mit einer leichten Eacfe getwaidten

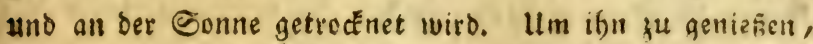

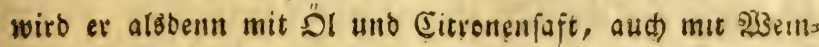
efiig jubereitet.

* 2 nmerEung. (E⿱ if Ser Mugil bes Doibs unb

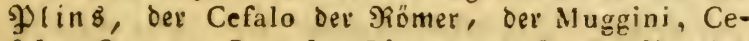
falo, Ozzane, Cunula, Lissa, uno Concordita bes Sarbinier.

LXXXV. Daz fliegende Fifか: Befめledt. (Exocoetus.)

Der Sopf ift iduppig, bie @tirn niebergebrůdet. Beis

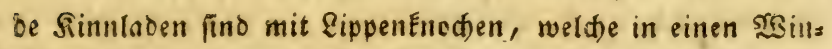

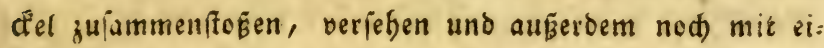

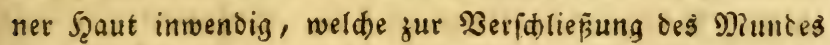
bient. In ser Giemenfaut ftehen 10 Strablen. Die alus gen baben Eeine Nisfffaut. Die Bruffluten fino ouffallemo rang, reiden bis an sie Sdwwangloffe, find fomit zum glunge

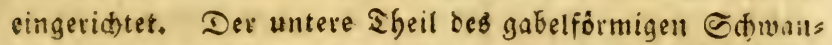

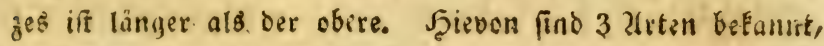
bie Necresbewefner find.

1) Der Epringfifd. Der Springer. Le Muge volant. La Cepède V.p. 402. Bonnaterre p. 181. n. 1. pl. 73. f. 306. Poisson volant. Hirondelle de mer. Du Hamel Tr. des peches. 
- Esocoetus exiliens Linn. ed.Gmel, p. 1399. Bloch augl. Fifde IX. 10, t. 397.

(Tab. 99. Fig. 146.)

Ennge R्auchfoffen nabe am 2ffter, weldie bis an ben Sruno ter Gomanifioffe reiden. In ber Riemenbaut fino 10, in oe: Bruftroffe 18, it ber Baudfoffe 6 , in ber

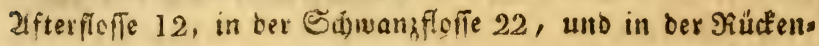
finf 11 Strablen. Det zufammengedrüte cben breite uns ten (d)male Sovf iff mit groben leid)t abfallenten $S$ dup. pen beseckt. Die Munsoffnung Elein. Die UnterFinnlade ftebt vor ber cbein bervor, und beibe find mit einer Sieife flenter fwişger Zåbne bewaffnet. Der bintere Riemendecfel if aนs 2 Blảttd)en zulammengefę̧t. Die febr grofien 2 (us gen feben nabe am Grbeitel und baben einen fowargen

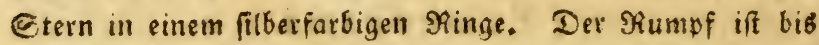
am @owwanse viereffig. Die Sduppen auf Der Seitenlinie baben in ber Matte einen Siel, uno bitoen auf treiben Geis ten oie fharfen ßänder am şauche. Die Geiten und bet Baud) fino filberfarbig, der अincten blau uno bie Floffer

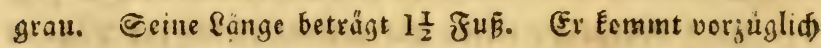
im mittellándifaten uno rotben Meere vor, bat ein fdomack:

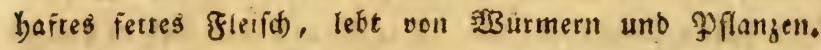
Sie tönnen 2-3 $\& u \tilde{B}$ bod in fendred)ter Stellung ibues

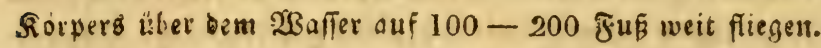

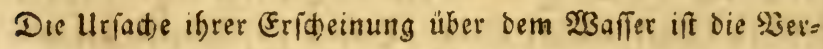
folgung oer siaubfiche uno Sbicre, denen fie Daburd) $j^{u}$ entemmen fudjen. L̈brizens baben fie aud) über vem 2 (3af fer ibre frince vorghglid an ben $2 B a f f e r=$ und Steñoos

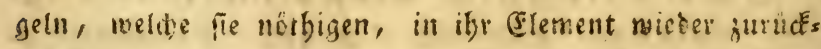
jufegren, coer wabl gat zu oen Mienfold ifre suphud ju nelymen, und fid) in bie voritsergebenden Ediffe nieder= 
gulaften, wo ithr Schicffal ebenfalls míflid), indem fie eine gute ভpeipe geben.

2) Der sodflieger. Le Pirabe. Bonnaterre p. 182. pl.100. f.409. Poisson volant. Traité de Pech. 11I. p. 17. pl. 1. f. 3. Exocoetus evol ans. Linn. ed. Gmel, p. 1400. Bloch auช̆. Fifide IX, 14. t. 398.

Er hat viele 2l(hnlideerit mit bem vorfergehenden, vart

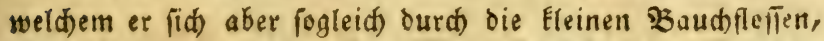

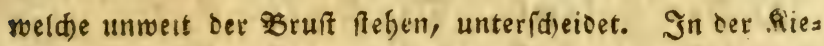

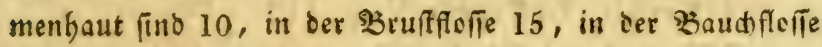
6, in ber afterforfe 13, in oer Edwwanzflute 20, uno in Der Miütenflofie 13 Strablen. Der Muns if zahnloż. Die Strablen Der Rücfens und 2fferffoffe find lünger als

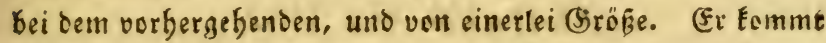
in Brafilien, bei ben 2fntillen und am Sorgebürqe ber gu= ten Syeffinung vor, und nach Du Hamel foll er fid aud) in Canale finben, aber nur einzeln. In feiner Rebensart uno (Eigenfidaften fornmt er mit ber vorigen 2frt überein.

* 2fnmertung. Die britte 2frt: Der Mittelo floffer. Exocoetus Mesogastor. Bloch audf.

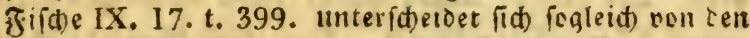
beiben vorkergetenden ourd) bie Baudfletien, welche mitten am Bumpfe ftehen. 2luch ift cie Piuffenflefie velel grö́per als bei jenen uno bat einen menoformigen Zluafidnitt. Er foll sas atlantifde Meer bei ben an. tillifden Injeln bewobnen.

LXXXVI. Das Fingerfifd : (3efdled t. (Polynemus)

Der mit Edappen bejegte Fowf lauft in eine gan: ftumpfe Splege aus. Die Mundeffinuty ift wett. Det 
Sinnlaben find mit Eleinen Zẩhnen befętt. Unter bel Sebs. Ie fiken zu betben Seiten frelliegende bünne Strablen. (Finger, digiti) weldhe borftenartig zu fevn fdeincs beren 2 nnahl fiab oon $5,-10$, auf jeber Seite belauft, Sie bången vermittelft einer gefalteten \$̧aut mit ben Bruft: floffen zufammen, uno fint ourch ein Sudglas genaues: betracter, aegliebert. Stievon find $4,-5$ ziten betannts.

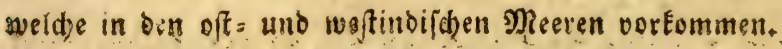

1) Der Salamin. Der Emoi. Röniggfift. L'Emoi. La Cepède V. p. 412, Bonnaterre p. 183. п. 4. pl. 74. f, 309. Polynemus pleb cjus. Linn. ed. Gmel, p. 1401. Bloch augl. §ifळe. IX. $22 . t, 400$.

(Ta b, 100, Fig. 147.)

In jeber Seite ber Siefle liegen 5 freie und Eurge Strabs. len. In ber Siementgaut fino 7 , ill ber siruffloffe 12, in,

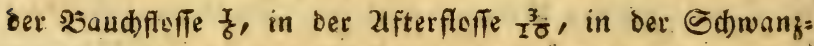

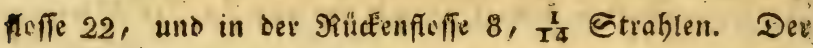
Ionglidte fopf: if oben breit. Die Najenlodber find ocp: pelt. Die grofen Zugen baten einen fowwargen Stern in.

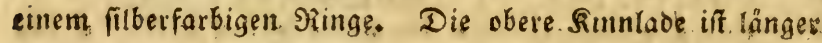
als Die untere. Die Sunge frei und glatt. Der Gaumers: sorn unb binten mit Elesnen fit)arfen వäbnen bejezt. Der

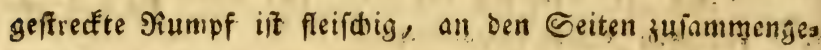
Drủcft, uno burdaus mit grö̌n Sdbuppen bedecft. Die

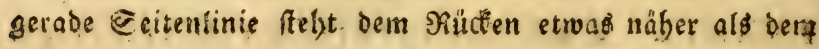
Saudte. Die Flaftn find mit Schupen bedeckt, uno ibre. Strablen vielgweigig, nur bie in ber erifen siucfenflufie fino cinfad). Sepf uno Siumpf find filberfarben und nur ber

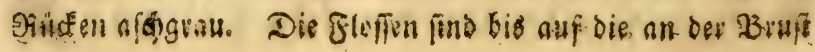




\section{V. \$ำung. Pisces.}

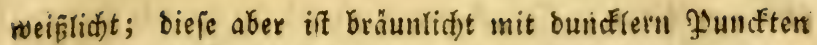
bejprengt, bergleiden auch an ben übrigen folvifen nabe

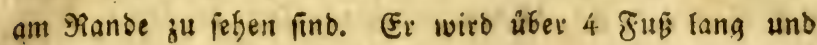

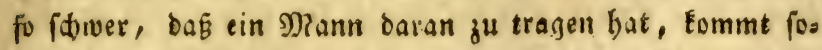
wofl in Dftinsien unb gwar im bengalifden Meere und in

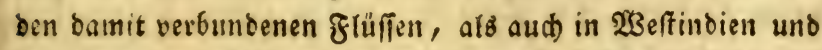
befonders im fïblidgen Zumerifa, aud) im ffitlen Meere bei bor Infer Otaheite vor. Er wiro in Nef̧en und mit bev

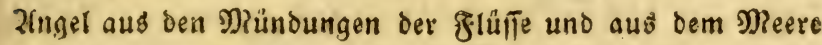
gefungen, uno gebört mit żu den fohmadf́lgaften uno beften Fifiden, baher ibm ber Namen אöniggfifd) von ben

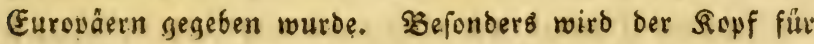
einen Eecferbifien gebalten. Er wirb getrocknet unb einges farzen, aud) wirb beer Rogen beffelben getreffinet und eirrs sefaligen als eine woblímmedfende Gpeise meit verfendet. Man geniefit diejen siích fowofi getod)t als gebraten, auch

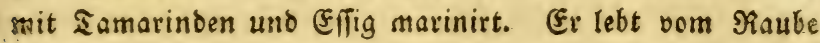
und feine Sieflffrablen dienen ifm zum 2(nloçen Eleines Fifde. Son Den Dtabeiten wirb er Emoi genennt.

2) Der Jarabisfifh. Le Poisson de Para. dis. La Cepède V. p. 412. Bonnaterre p. 182. pl, 74. f. 309. Poly yemus paradiseus. Linn. ed. Gmel. p. 1401. Bloch ausl. Fifide IX. 28. $t$, 402.

2n jeber Seite ter Reble fethen 7 freie Etrahlen. Die Sdwang folle if gabelformig. In ber Siementgaut finb 5,

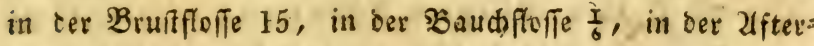

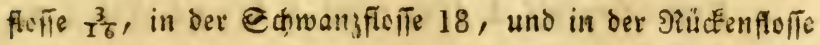
$\frac{1}{3}$, is Strahlen. Der greste Slopf ift you abgeftumptt. Iie Zlugen Faben eimen fdjwarjen Stern in einem fitbers 


\section{0 \\ Bierte Eraffe. Fifde.}

farbigen singe. Die Riemenbaut ift berbergen, unb ber vorbere fiementedel gezäbnelt. Die gerabe Seitenlinie liegt

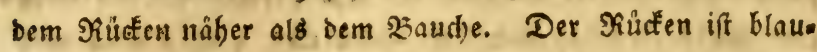
lid)t. Die Geiten unb ber $\mathfrak{B} a u d$ find filberfarben unb bie Floffen grau. Die Strablen in ber erften Rüfenflofie fino unten hart unb oben weids) bis auf ben erften, welder furs unb ourdaus hart iff. Siefer frifa) prreid)t eine anfefnli= de Gröbe uno wirb um Eurinam und bei ben antillifhen Inieln mit bem Rekge und ber 2lngel gefangen. Er bat

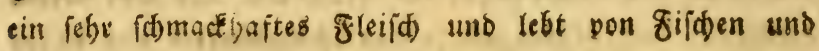
Shaalthieren.

* 2fnmer fden Siebenfingerfild. Le Mango. Bonnaterre p. 182. n. 2. Polynemus virginicus. Linn. ed. Gmel. p. 1400. verwechleft werten, weldher ebenfalls 7 Finger coer freie Strablen am Sinne, bins gegen Eeinen gabelförmigen Sd)wan bat.

\section{Dą Scering: (Befdiledt.}

\section{(Clupea.)}

Der Sopf ift an ben Seiten zufammengebrüč̆t unb mit einer nad)enförmigen ßertiefung oberwärts verjeben.

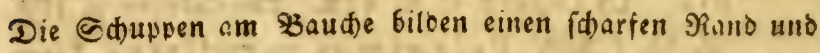
fteben fågeförmig beroor. Şievon fino gegen 20 arten bes Eannt, welde fämmtlid) Meeresberwobner find.

1) Der gemeine Spering. Le Hareng. La Cepéde V. p. 427. Bonnaterre p. 184. n. 1. pl. 75. f. 301. Clupea Harengus. Linn. Bloch Fiifhe Deutid)l. I, 186, t. 29, f. 1. (I. 235. t. 29, f. 1.)

(Tab. 101, Fig, 148.) 
Der UnterÉfefer if aefrümmt und fref́t vor bem obern bervor. In ter afferfleffe fint 17 Strahlen. Int Der Sies

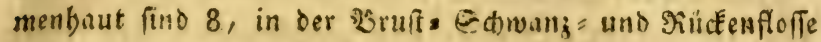
in jeber 18, unto in ber Baudgioffe 9 Strablen. Der Sopf if tlein. Die grofen zlugen baben einen fdwarzen @tern in einem filberfarbigen Minge. Die Mundêffnung if Elein und neb́ft Der fpitzigen Bunge inwendig mit Eleinen Zäbnen bejegt. 2ln ben Siemenbeckeln befindet (id) ein vieletter ooer rether

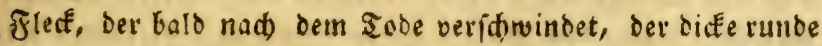

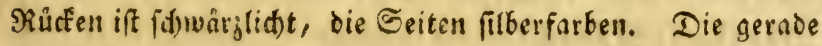

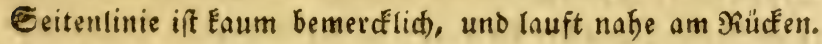

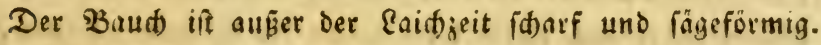
Sånttlide greften baben eine graue Farbe und find, bis auf die gabelförmige Sdbwangfloffe, Elein. SGre Lảnge betrågt 9-13 3or. Die Seringe balten fith in dem nôroliden Oceane, in ber mit ifm verbundenen Nords und Ditfee uno in bem attantifden Meere in ber Tiefe auf, uno ftreiden im Erübjabre, Sommer uno Şerbffe zur Qaidgzeit in uns

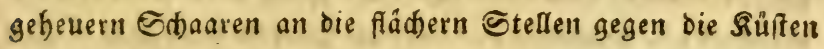

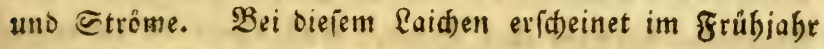

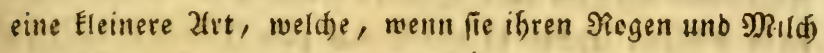
won fid) gegeten, von ben fadlänibern J̧ohtheringe ges nennt werden. Sm Sommer Eommen größ̄ere zum Bor=

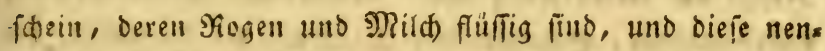

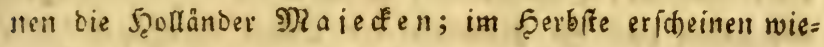
Der Éleinere, bie ned) mit Miogen uno Mild) angefúat fint, weltie in Salland 20 cllferinge genenut werden. In ber Sfffee find übrigens die Sartnge überbaupt Eleiner als in cer Torojee, uno heifit man jene Ströinlinge. Die

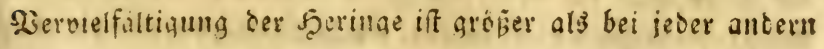

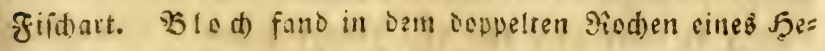

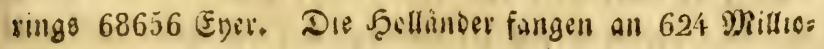


nen, unb blos bei sotbenturg in Sdrweden werben an 720 Millionen gefifict. Die Seeringe năhren fid von Sirats. ben, zijofregen unb einer nod) unbeftimmten 2frt rotber 23armer, welde in Norwesgen $\Re$ oe = a a t genannt werben.

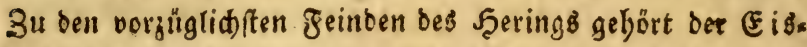
svallfifd ober fogenannte Norbfaper, welder burw

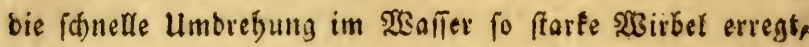

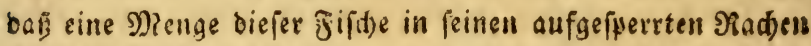
fiüzer. Llnter ben 2 sögehn geken ifnen aber bejonbers bie Sering : Miöven (Larus fuscus) in groferer Menge nact,

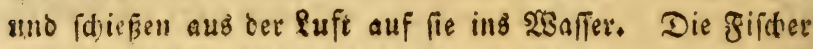
fonmen baher auth burd) biefe şöger bie Otellen erfennert, wo fich bie mebreften Seringe anfbalten. Sei bobem Flus ge Diefer Mröben befinten fich bie Sgeringe in ber Siefe, fie Emmen aber niebriger herab, fo wie bie fifdo bober fei= gen. Det Sering fang be/dáftigt fehr viele Nationen. Die

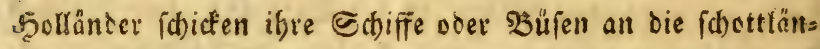
Difden sulften, und obnerad)tet ifre Fana nid)t mebr fo ftard als fonft ift, befdäftigt er bod an 20,000 Menichen. Die Frangofen foricten iffre $\$$ differ fonft theils an die engli=

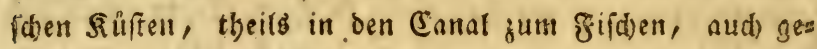
Genl fie an bett Süften ber Normandie uns Jicarbie im

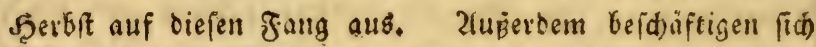
bie Englänber, Sdjottlänber, Irtänter, bie Norverger, bie Ediweden und bie Nactbarn ber Dffee farce mit biefet Fifherei. Der Fang ber Jeringe fortert cine geniffe Sol:

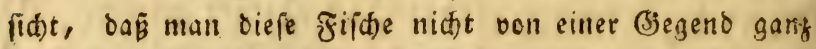

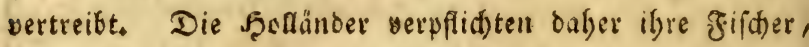
Die Neģe nid)e vor oem 25. Juni auğmuerfen, eamit bie ङrübjafrgberinge nicht in bem Raidjen geftort werben, aud burfen fie nidht über ben 25 . Jenner fijden. Ofne diefe 23orfidjt verlieren fich bie Şeringe mit ber Beit, wie biet 


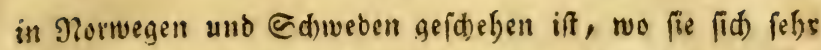

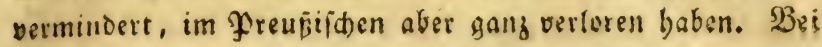

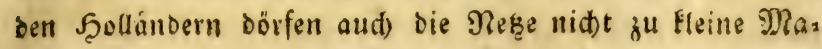
fithen haben, Damit bie Eleinern und iüngern Durd)Emmen uno lid) weiter vermehren Eönnen. Beei bern Fange bebient

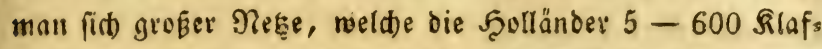
ter lang maden, und fie aus $50-55$ פ3ănben zुน fammeno fejen. Die Ediffe werben zugleiø) mit \&aternen befjangen,

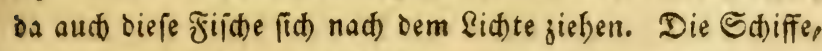

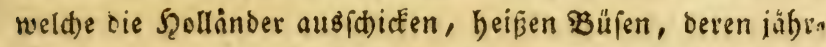
(id) $1000-1200$ abgefendet werben. Jè es biejer Edjifie ift augerdem mit 3-4 leid)ten Fabrzeugen verifhen, wels

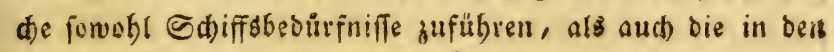

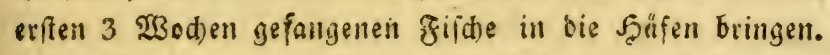
Die Büfen werben auf $25-60$ Saften, Die Saft ĭ 12 Eonnen gered)net, eingeridtet. Der Fang an Den ßüulfen

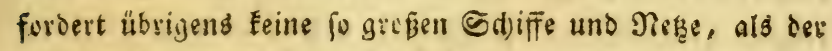
auf bem boben Mieere. Die Seringe werben auf manabers rei art benuit: 1) werben fie frifich gefotten und gebraters veripeiß̧t: 2) werden fie am hăufigften eingejatgen. Das

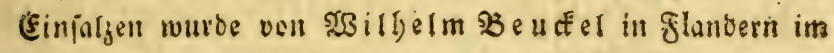

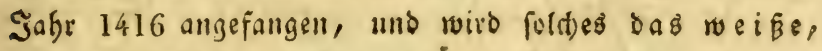
jum Unteridico von bem rothen Einfalzen genennt. Nachoem den Seresingen bie Riemen und Cingeneide bis auf ben Mogen und Mild) ausgenummen worden fitho, wers Den fie 12-15 Stunden in eine fo ftarffe Ealjtacte ges legt, oaß́ auf biefer ein (Ey fdwimmt, unt nadber in ₹on. nen gepact. 3) Das rothe Einfalzen, oder die Bes

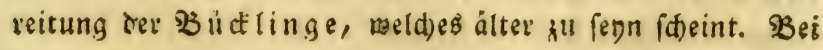
Diejer Bereitung bleiben Dis aแร̊genommenen Şeringe wes nigitens 24 Stunden in jener Salylacfe, werben bieraup

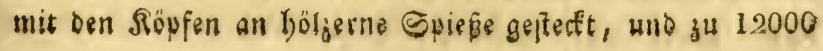




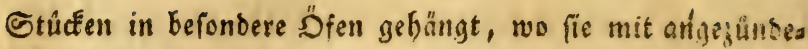

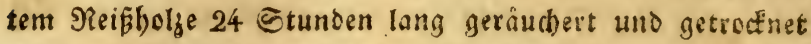
werden. Nadiber werden fie in Sonnen oder in Strob gen padt, unb beifen lejtere Strobbü linge. Die beften Sücflinge liefern Die Schlländer uno die Rieler. Daju wer=

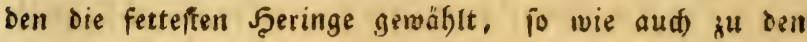

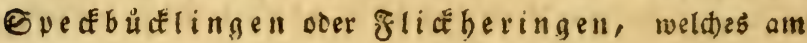
Rücf́en aufgeidnittene uno über Spane aufgefpannte uno geräucherte feringe fino. 4) Srocfinen aud) Die Saländee und (3rönlăncer ibre Seringe auf Felien und an Der $\mathfrak{E}$ uft. 5) In Sdweben und Norwegen verfertigt man auperbem Sauerberinge, inoem man fie mit fdwäd)erer Salglaffe entweter in verid)loffenen, oder mit Södern verfebenen Son=

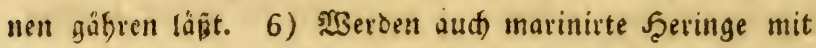
Eifig, Bervïge und Earberblätter zu Bjotbenburg bereitet,

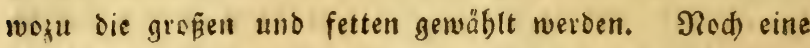

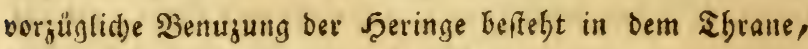
welden man aus ifuen zu dictbenburg gewinnt.

3) Der Breitling. Die Sprotte, La Sardine. La Cepède V. p. 444. Bonnaterre p. 185. n. 2. pl. 75. fig. 311. Lé Sprat. Clupez Spratt u s. Linn.ed, Grnel p. 1403. Bloch ₹rifite Deut(d)! I. 206.t. 29. f. 2. (I. 262 . t, 29, f. 2.)

Dex Unterfiefer berverftebent, 19 Strablen in bee 2 ffs terficfle. S̈ ber Siementiaut find 8, in oer Borreffoffe

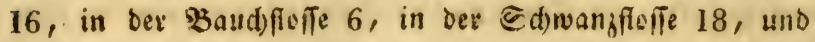
iit. Der Råfenfloffe 17 Etrablen. Der pipizige Sopf it gegen ben Sörper ziemlich grof. Die Ettirn fatwärlicht, Die Riemenbecfel geftrablt uno fllberfarbig. Die grobent Jugen baben einen fowmargen Stern uns fint in etrem 


\section{V. $\supseteq$ เฉung. Pisces.}

gelbweifliduten গinge. Die Eaum fidtbare Seitenlinie ift

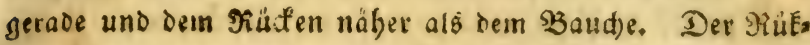
Fent if blaulid)t und bie Eeiten fillberfarben. Der গiumpf if an ben Geiten zufammengedrüaft, unt) der B̧auch endigk fid) in eine gefrümmte Sdmetioe. Die Sdhuppen fino grof̧, zart uno leidt abfalleno. Die floffen fino furs, zart, oun grauer zarbe. Die Édmangforfe iz gabelförmig. Die långe biejes fríches beträgt $4-5$ 3ou, bie Breite 1 3oul. (Ex wiro nid)t nur wie der f̧ering in 9loromeer und in ber Diffee allentbalben, fondern aud) im mittellansificen Reere angetrerien, bält fid in ber $\mathfrak{E}$ lefe auf, uno findet fid) in groferer Menge an Den Rüfen unb flachen Dotern in Şerbft zum Eaidjen ein. (E) Eommt in fo groger Mens ge jum Sorithein, dá man nidht fetrell auf einen 3 ug für 40 Sonnen binlängliden Borratb Davon Gefommt. 2 Benm man bebencti, wie viele 1000 Ettůa baģu gebören, um eine einjige Some bamit anjufülen; wenn man ferner auf bie Jienge 9iüctifict nimmt, in weldjer er in Norwes gen, Sd)weden, Saollitein, Jallano und Englant.vorEommt, un da 2 Millionen Siores eintringt, aud) juiveiten in Mreuisen und glommern beträdtlich feg, fo wie in Catabrien, Ppro= vençe, Bienua uno Iobcana, auf Der Infel Capraja foin

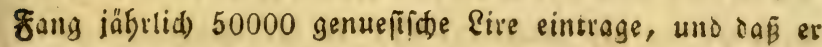
bäufig im corfichen Mieere gefangen werde, follte man

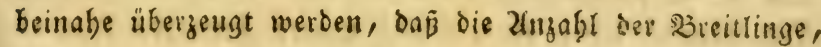
bie ber Şeringe beinabe übertreffe. Ste werben eben fo

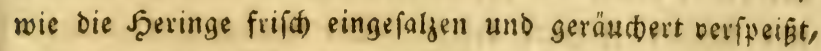
im erften falle beftreut man fie mit Mebl und bratet fie in Butter ober Baumöl, in zotweiten werden fie aber fratt ber Earbellen gebraudt. Da wo der gang frbe băufig ifi, merden lie geräudert, in Eennen verpactit und unter 


\section{$33^{6}$ Sierte Elafie. Fifde.}

Dem Namen Sprott verfendet, wie benn bie Englifíter uno Sieler Sprotte weit uno breit berúfint, uno als cille

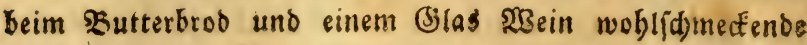
Speize betannt fint.

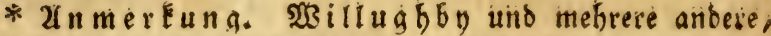
balten diefen filid) für einen jungen Şering. (fr un= tericheidet fidh aber von bemielben ourd) die $)(11$ affl ber sloffen = Strablen, aud if er bünner uno bretter als Der junge fering, ferner Eommt er blog im Sperbif als

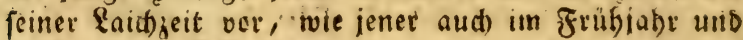
Sommer zum Borfhein Eommt, uno bat ber junge f̧ering 56, ber Breitling aber nur 48 risibelbeine, aud bat biefer eine ungleid) Eüraere $23 a u c b$ boble, uno Daber Eaum halb fo viel ßripwen al Jener. Ferner if ber Baud beim steitling (đärfer als beim ફ̧ering.

* 3) Die żlfe. Der Miaififd. ĹAlose. La Ced péde V. p. 447. Bonnaterre p. 185. n. 3. pl. 75. 312. Clupe a Alosa. Linn. ed. Gmel p. 1404. Bloch Ziide Deutidi. I. 209. t. 30. f, I. (I. 266. t. 30. f. 1.)

(Tab. 102. Fig. 149.)

Der Piand beb Bauthes ift mit Edjilden befegt. SIn

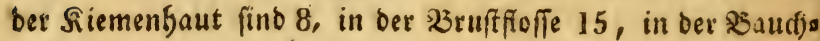
fleffe 9, in ber xifterfoffe 23, in ber Sdbwanfluffe 18,

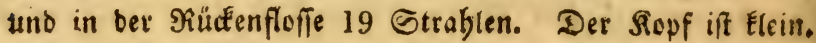
Die Munböfinang grop. Die untere Rinnlade ffelt vor Der obern etwas bervor, uno bie obere if nur am Tianie

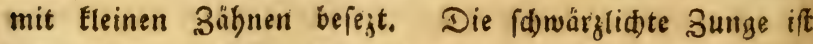
frei, glatt und endigt fid) it cine ftumpfe Epişe. Der idwarke 2(ugenftern bildet mad) unten ju cinen $2 B$ indel,

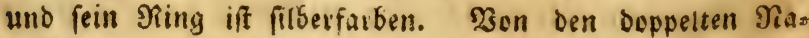

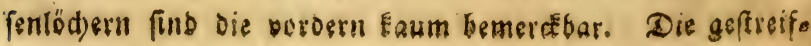


8en Riementecfel find in der Mitte blautitht anb am Piande

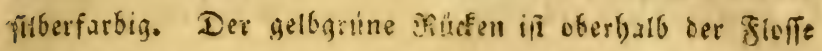
ein wenig fort, unterthalb seristben aliet rund. Die Ecis ten find w21

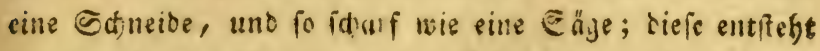
von ben barten Shurpen sder Sotitiben, welthe ba, wo fie gebogen fino, ente barte Epize bilben, die febr fidarf ift. Die Eaum fithtbare Seitenlinie iff Dem Siücfen näber als bem Saude, unb üter berfelben fépen $4-5$ fdwar=

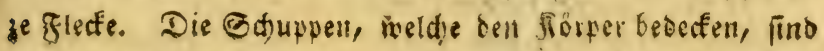
greś und falfen leidt abs. Die Fisfen fino grau, unb mit

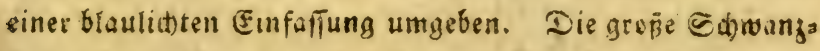
fefle if an Grunte mit 2 braunen Jlecten verfebit, unt am Bauche ftebt eine Sitteiftelfe. Seine Eange beträge

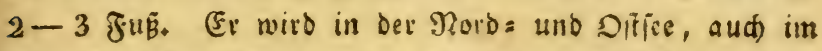
mittelländifchen Jjeere angetreffen, feigt im Erübjafr baus

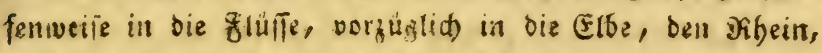
uno aus biefem in ben Peatat, worinn et im Mai unt Suni exidpeint, feinen Eaid) an den idnellften Gtellen im (5runde abjejt, uno genen bra feerbit wieder in bas Meee

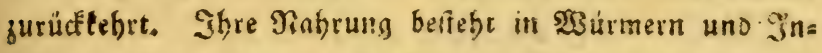

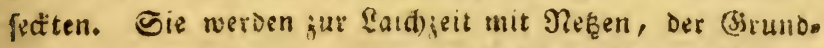
angel uno mit Seuien gerangen, baben ein weidtidbes $R_{e}=$ ben, und fteben auß̉er Dem 23 affer wie die Seringe balb ab. WBenn lie aus bem Mieere Fonmen, fino fie mager anb unidmactígaft, je länger fie fid) aber in ben flüfen aufbulten, je fetter uno fotmatfiafrer werben fir. alm beften werben biefe ffilde in ben Fihein, und Yiedargegen. den zugeridtet, menn man jie blau abjieden läbt, uno fole de nachber Ealt mit Citronenfafe oder gutem iueis̄t, aud weroen fie gebraten. Die draber troctnen uno 
Derfpeizen ifnn mit Datteln, und in Norbamerita werden fie fowobl frifh als geoôrt, gerâud)ert und eingejalgen, segeffen.

* anmere witter fdeurn, als bie Miujit lieben, Daber bie Fifider an ibren Neģen bölzerne mit (j)lecfen bebangene : Bugent

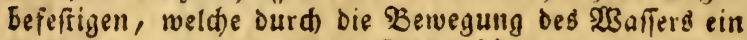
Giclăute macben, und die giiche bäufig in die Netze

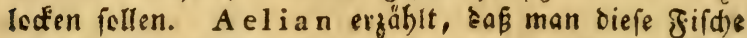
an ber maråotifiten See in Egyoten ourd) eine Sius fif von Rlappermufdeln mit Dem Biejange ber Fifder vereinigt fange, und $R$ on delet will beobactet has

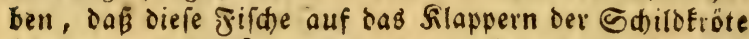
bäufig an bas Ufer geeilt wären; befonders trủge fid) biefes zur Nadtzeit zu. 2lud) follen fie ben Galdichif. fen nadgeben, uno ibuen bunbert Meilen weit nad) folgen.

4) Die Sarbelle. Der Anjouis. L'Anchois. La Cepéde V. p. 455. Bonnaterre p. 185, n. 4. p1. 75. 313. Clupea Encrasicolus. Linn. ed. Gmel. p. 1403. Bloch Fifide Deutial. I. 212. t. 30. f. 2. (I. 270.t. 30. f. 2.)

( $\mathrm{Tab}, 102 . \mathrm{Fig}, 150$ ) ,

Der DberEiefer ift Gervorragend. In Der Riemenbaut find 12, in ber Brufflofie 15, in ber Baud)fiefie 7, in

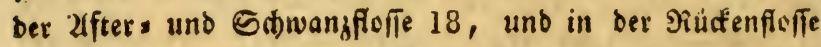
14 Strablen. Der lange Ropf ift oben breit uno endigt fid) in eine Spige, an welcher die getheilten Najenlö. der fteben. Die Munoöfnung ift grob, inwendig glatt, bie dugen baben einen idwarzen Stern in einem filbers farbigen Ringe. Die Siemenöfrnung ift groß̈. Den geo

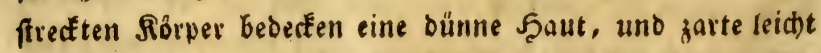

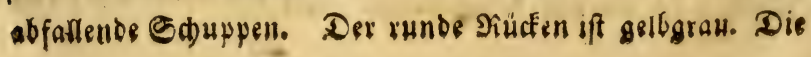




\section{Dronung. Pisces.}

serabe Seitentinie wiro mur nach bell abgefallenen (s)dups

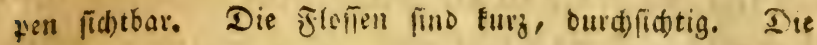

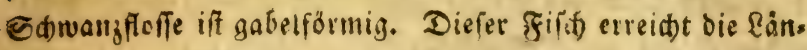
Be ven einer Epanme, uno if einell Ball breit. Fr wirt in ter Deffee, jeosd) nur felten, befite băufiger aber in Der Norbjee, im atiantifiden und mittelläbifden Meere angez troffen. Er Ecmmt wie Der Şering und Breitting aus bew Iiefen an ben אüften und fladen D̈rtern zum Boridein,

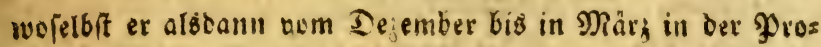
venje, staband und Catulonien fely băufig gefangen wird.

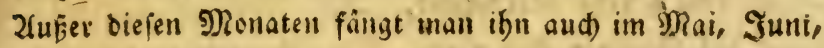
Sufi, um weldhe Zeit er vorghiglid) in ber Meerenge von (3ibraltar, in ber Biegeno-voil Senedig, Benua, Fiom uno

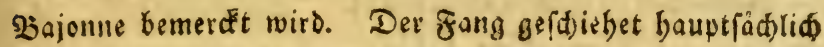

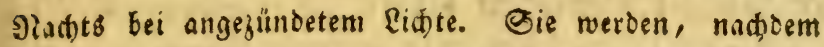
ibnen bie Söpfe abgeidnitten, unb bie Eingeweibe berauss

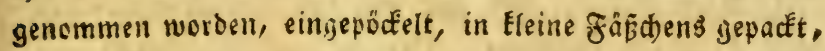
und weit unt breit/verfentet, unb zur Bereitung an alfers

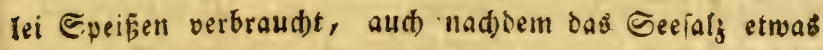
abgewajden iff, zum Butterbrod, oder mit Eifitg und oै als ein Sallat verfpeişt. Die Brabanter Garbellen bes baupten vor allen anbern ben Sorzag. Die Briedten unb

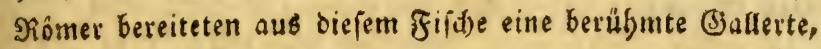
welde man Garon eder Garum nannte.

5) Der Pildard. Le Clupanodon Pilchard: La Cepéde V. p. 470. Clupea Pilchardus. Bloch augil. siffte IX. 40. tab. 406. Pennant. Brim tisch Zool. 111. p. 343. n. 161. pl. 68. f, 1.

(Ta h. 103. Fig. 151.)

Er unterfheitet fith ven allen übrigen Seringsaartel

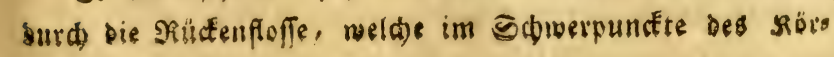




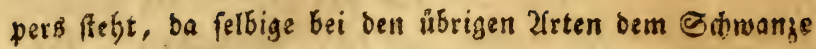

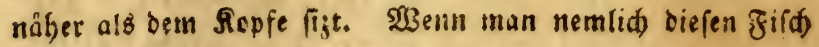

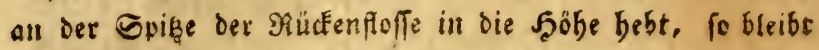

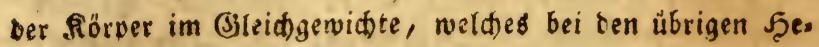

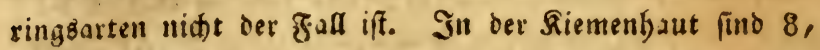
in ber 2 iuffloffe 17, in ber Baudfleffe 8 , in ber aftero

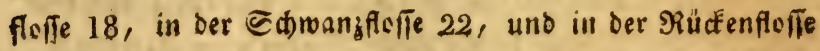
18 Strablen, Der fouppenlofe Repf ift zufammengetrüct. Die untere Finulabe ift Dit lñngfte, nach sben zุu gefrủmmt, mo in eine Spike auslaufent. Dev Munb if jabnlos, 3unge und Goumen fint glatt. Die Najenlöder einfach, bem Munde náber als ben Zugen. Die \&ippentüoden breit. Die Ritumendectel glatt unb geftrablt. Die Riemenoffrnung weit, uno Die Riementaut bebeft. Die nabe am Ed)eis tef febenden 2fugen baben einen (a)wargen Stern in einem filterfarbigen Ringe, unto find von ben Seitell mit einer

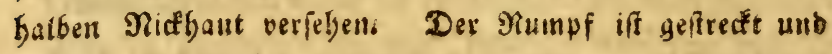

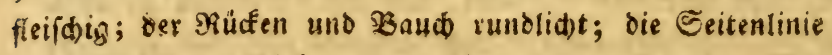

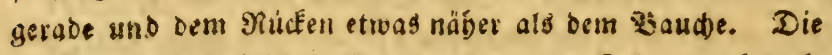

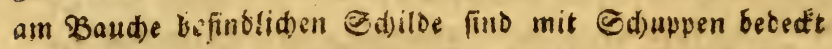

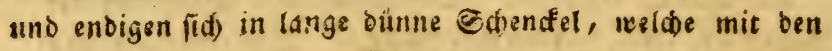
Gräten verbunben finb. Die Strablen fiito weich und bis auf bie exfen vielgmeigig. 116er ber Bauchfleffe ftebt ein anbong von einer Mittelfuffe. Der blaue Fituten fipit ins grüne. Der Sopf uno die Seiten fino filberfarben,

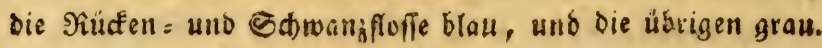
Geine Rånge beträgt $10-12$ 3oll. Ev erisheint an ben Süften von Cornwallis in ber sistte Suli in grep̄en Sdans sen, verliert fich im Sperbfie, uno fommt um SBeifnad)ten, iebod) nur einieln wieder sum soridtsin. Da ex burd Sturm łu Zeiten von Dem gewöbnliden trid)e abgereitet

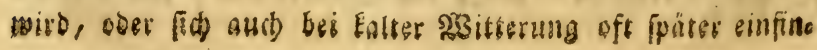




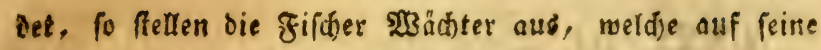

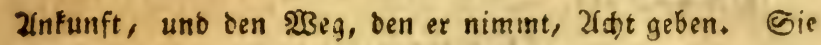
fiehen auf den Eelien, wo fie ifn beobud)ten. Die Zeidjen

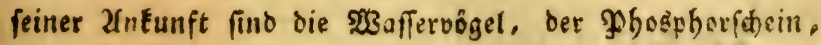
Der burdh feine Bewegung heroorgebradte wirt, ber eigene (Eerudh, relden ber Mildber verbreitet, unb ber blaue Eitberglanj bes Meeres an biejan Etellen. Er wirb ver, zuglid in ber Begeno von Fawy. Falmouth, Penzance und $S t$. Ives gefangen. Der Gang beffelben beidáftigt virle Meniten uno ift für Engeland pefre wid)tig. Dr. Borlase

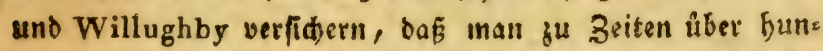
Derttaufend Strad in einem einzigen 3uge fange, uno jentet melbet an Szerrn Pennant, bá̈ in einer Eurgen 3 eit in St. Ives Budt), allein 700 Eomnen, bie Torne \&̆ 3500 Stüd gerechnet, mitfin $2,450,000$ fenen gefangen wordell. Co

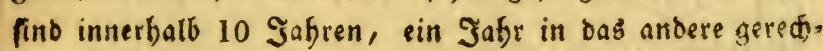

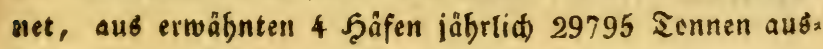
geführt worben $D a$ es nidft móglid) iff, ifn bei einem zu ftarcéen Zange ganz einfaligen żu Eônunen, fo wirb er auf bie Erbe geidüttet, uno darauf fadidtenneife mit Beefals in F̧aufen von einer bis andertbalb callen bod), gelegt. शsenn fie auf biefe 2art 15 bis 18 इage getegen baben, werben fie oom Galge burd XGbijüflen gereinigt, darauf in Faffer getban, und fefr fard mit Bewidit befonmert.

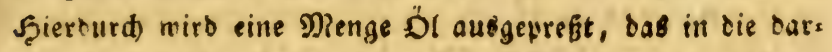
unter befintliden Bruben lauft, bernath in Sonnen sethan, and fewebl zum Brennen, als aud anfatt ces $\mathfrak{E}$ hrans ge: braudt nirb. Dat Zु! Des 5eringz, oaber er aud von vielen semiglben veraezegen nurd. Ü:rigenb wirb er, nie biefer, frifi, oerfpeist, uno Der grobite Ebell eimberádilt Er bat in Finglano ben 9? meil Piichard, welder fidi) pegre gut in antere Eparden übertivigen läpit. 
342 2zierte Eraffe. Fifde.

\section{IXXXVIII. Das farpfen: (sefdled)t. (Cyprinus.)}

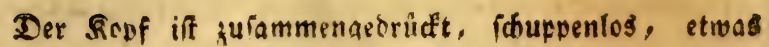

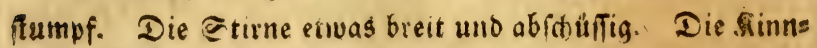

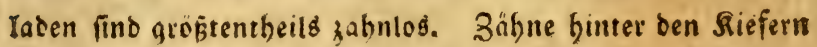
in einem bejontern gebogenen Snochen, und in Demi Batts men ein rauber Finoden. In oer Siemenhaut 3 Strablen. Der Siementectel beî́eht auß 3 Enỏdernen Blârtchen, woo ven bas oberfie bas grö́fefte if. Die Enorplichten Eippen find mit einer biffen 5̧aut übergogen, und bilben bei aufa gefpertem Miunde eine runde Öfinung. Der auf den Seia ten zufammengedrủfte Rörper if mit glänzenden weifen

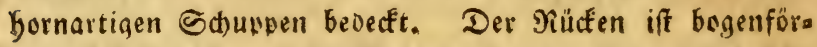

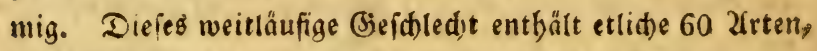
bie theil' Meeres: theils Subwaffer = Bemohner funt.

A. Nit $\mathfrak{B a r t f a f e r n}$ am Runoe.

* 1) Die Barbe. Glub́barbe. Bårble. Le Bar bea u. La Cepède V. p. 524. Bonnaterre p. 189. n. 4. pl. 76. fig. 317. Cyprinus Barbus. Linn. ed. Gmel. p. 1409. Bloch Fiíd)e Deutidir. I. 109. t. 18. (I. 138.t. 18.) v. Meidinger, Pisc. Austr, tab. 11.

( Tab, 104, Fi g. 152.)

Die Dberkinnlabe fteft weit heroor. 2(m Munbe 4 Bartfaiern. In ber Bruffforife fino 17, in der Baudfifolfe 9, in ber 2fferfloffe 8, in ber @dwanjillofe 19, unb in der Rüctenflefie 12 Strablen, baven ber britte fägeförmig iff. Der langlidte Sepf endigt fid in eine Epise und iff

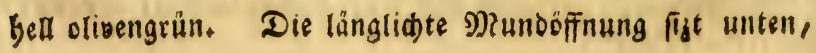


bat eine farde und rothe Dberlippe. Die Zlugen habent

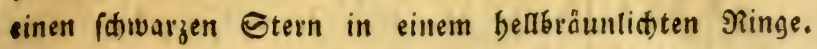
Der geftrectice fö̈rper if mit geftreiften uno gegăbnelten Couppen von mittelmáäiger Bröße be bęt. Der runce rüafen ift olivenfarbig. Die imit fowwarzen \$unatten bes Fegte Seitenlinie ift gerabe. Die Seiten fitto weisflid)t int

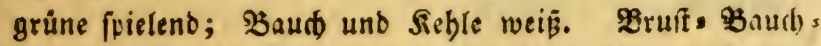
affer. und Gdwantifleffen find röthlidt, und über ber Baudfloffe ift eine Dittelforte. Die gabelförmige Edwallz.

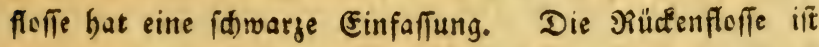

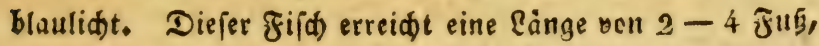
wiegt 6-8 Pfund, unb in unfern Ribeingegenden nidit felten $13-19$, und zुu 2(ffadjan an 30 Pfund. Eit wird vorgüglid in fdnell fieffenden Strómen als im Theine, im Nectar, ŞBejer, in ber Elbe und Doer gefunden, wo er fid gewöbntid im boglen llfer und unter Steinen ver. borgen bält. Seine Nafrung befteft in Sdöallkaut (Chelidoniurn majus) Conthylien, ȘSurmern unb Eleinen $\mathfrak{F}_{2}$

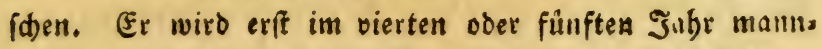
bar, feine Eaidjzeit fällt in Mai, zu weld)er 3eit er gegent ben Etrom jieft, und peine Nogen im Grunde an ben

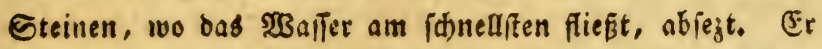
wiro bas ganz̧e Sabr bindurch mit Neşen, Barnfäcten, unb an ber alngel gefangen; hat ein weifes woblidimerfens bes flei(d), weld)es zu jeiner Eaidgeit am fetteften if. In affradan und am Eereft werden bie 3ungen biejes fis

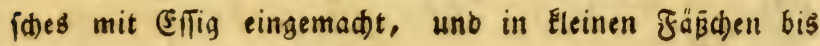
nad) Petersbuty verjendet.

- 2) Der Rarpfen. Der gemeine Sarpfen. La Carpe. La Cepède V. p. 504. Bonnaterre p. 190. n, 6. pl. 1. fig. 1. Cyprinus Carpio. 
Linn. ed. Ginel. p. 1411. Bloch Fifde Deutitht. I. $92 . t$ 16. (1.117. t. 16.) v. Meidinger. Pisc. Austr. tab, 6.

Der tritte Eiraht in ter after: und Rüdenfluffe if fägeformij. In ber Bruffiofle fino 16 , in ber Baud : sub Ufterfleffe 9, in oer Qdomanifiefle 19, und in ber Siuctenfiolie 24 Etrabien. Der Ropf ift grafa, die Stirne breit und blauidimara, bie Baten blaulioht. Das fdivars ge aluge bat eune gelbe Einfofiung. Die Kinnlaben fino

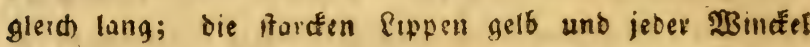
berfelben mit einer längern, am Dberfiefer aber mit 2 Eurzen Bartfajern verfeber. Die Eduppen am Sôruer

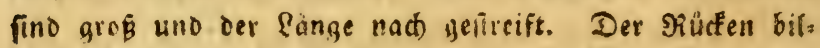
bet einen flactent zenen, uno if blaulidtgring, oberbalb bes Flofie fdarf uno unterbalb oerfelben rund. Die Spitentinie if finwaik funcftirt, macht cine geringe \$eugung. Dis Eeiten nad) bem Baud) zुน lind getb ing grüne uno fduwar= ze fpieleno; am Bauche weifficit und am Equange gelb.

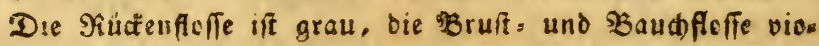
Keti, die afterfioffe braunreth, und die gabelförmige \$amang=

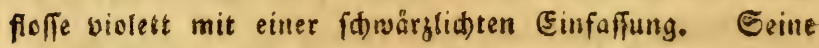
Cånge betrăgnt $1-4$ ₹uß̂, uno wiegt 1 bis $20-30-$ felten $70-80$ pfunb. Sie befinden fid) voriüglid in bere

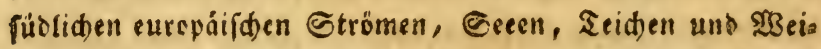
bern. Die sarpfen aus den Strömen uno Seen baben eine gelbe, bie aus ben ₹eiden aber eine mebr grünlid)te

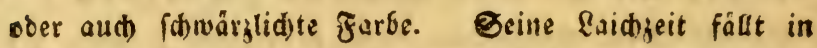

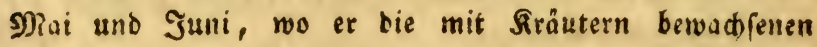
Etellen aufiud)t, uno gewóbnliab ein Rogener von 3 Mils dern begleitet mirb. Findet er bei feinen 3ünen श2Biders

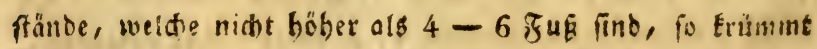
er fid wie oer Salm, uno fejt ourd) Sprünge über fols 


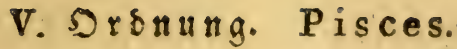

the Gintiber. Sie nermefren fị febre farce, und enthâlt

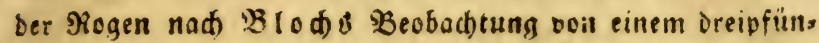
digen Fifiche 337000 Ener. Sie erreichell ein boheg lite ter, bab nad) Buffons Zangabe fich auf 150 Jabr belauft. Shre Nabrung befteht aus Rinatern, 20 urmern, Sniects

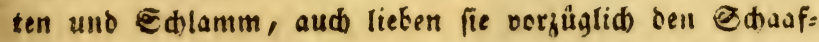

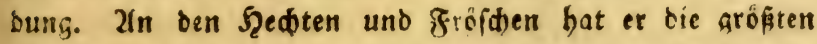
Sjeince. Sino Sarpfen mit Saraufacen uno Bsicbeln in

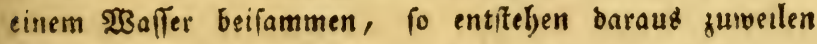

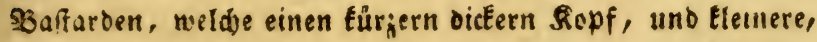
ter fänge nadb geffreifte feftere Ediuppen baben. In Eecen und glüffen werden bie Farpfen mit bem 3uggars

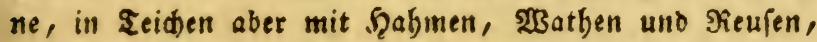
aud) mit ber Zlnget gefangen. Den Neşen fudit er ôfter baburd) aubsurweiden, baßj er ben Ropf in ben Sdlamm

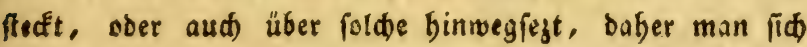
in Eleinen Seeen gebsppelter Şahmen bebient, um fie bei ifren Eprüngen in bem zweiten aufäufangert. Sie baben

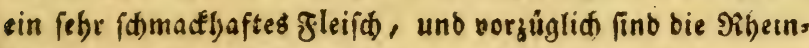
Earnfen geidhäkt. WSegen ihrem vortheilthaften Ertrag wers ben fie bäufig in इeiden oder $\mathfrak{B e i b e r n , ~ w o ~ f i e , ~ w e n n ~}$ biefe einen beftändigen 3ufluf von friftem $233 a f f e r$ haben, febr gut forttommen, ba fie bingegen in Ermangelung

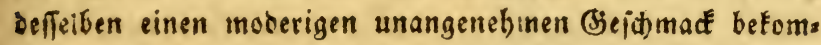

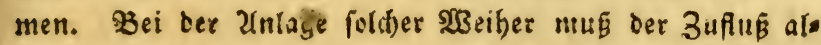
Ier vitriclifder sober fdwefeliger Grubenwaffer beitend vers

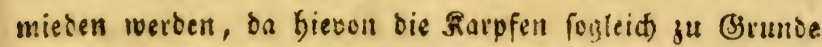
geflen. Dergleiden 2 Beifer soer Ieidje werden gewöhnlud treierlei angelegt, und z̧war 1) bie (Etreidjweiber oder Seide, in welde man 6 bis 12jafrige Rarpfen uno giwar 3 shilder ž einem Jiogner fejt. Man bringt die=

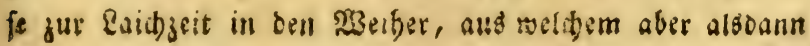




\section{Ficrte Elaffe. Fifde.}

Eein $23 a f f e r$ abgelaffen werden barf, bamit bie junge Srut

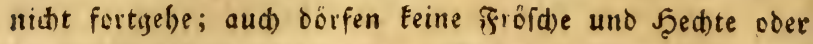
nnoere Raubfirde fid) in bem siseiber aufbalten, fo wie

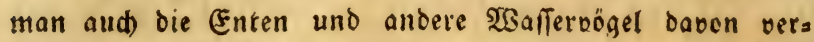
fideuden muß̧. Entweder im Serbft, wenn diefe Weiber, weld)e flach fern mülien, zufrieren Fönnten, oder wenn bieß; nid)t zu befürdren ift, in folgendem Frübiabre, láft

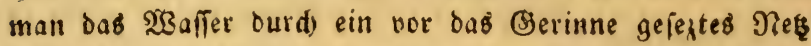
ab, Damit Eeine SBrut ourdigebe, und fich in bem Refiel

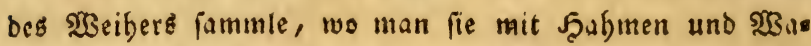
then berausnimmt, und in bie andern, námlid) 2) ben

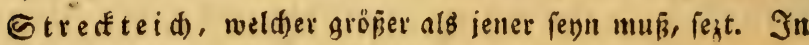
biefem bleiben fie nun 2 Sabre, und find bie fiiche von guter 2frt, fo milfen fie in biefer 3eit $6-8$ 3oll lang fenn uno $3-5$ Pfund wirgen. 2lutb Eann man bie Streidsteid)e entbefren, wenn man aus einem andern mit Sarpfeneyern befejte Fråuter gleid) in ben Strecteid) fezt.

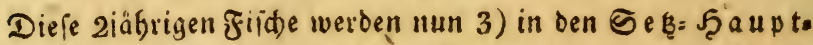
ober Fet $t$ : $\mathfrak{B}$ eifer ( $\$ e i d$ ) gebrad)t, worinn fie nad) 3 Jabren zum Serfaufe bienen, ie länger fie aber Darimn bletben, bei gurer Nabrung immer grö́cer und fetter wers oen. Injwifden ift ef bed) nid)t tatbfam, fie viel lönget ald 6-9 Jabre barinn zu lafien, ba fia) ber şandel nid)t biulänglid) Gelobnen wuirce. Mian füttert jie in biefen Ieio

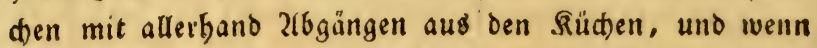
es die Rage zuläp̃t, fo ift es gut ben funifigen Dung oder

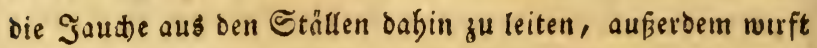
man Sdlamm voer fefm mit Sdaafoung burdEnetet,

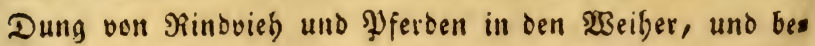
Dectit fie aud junefrobren mit Dung. Im $\mathfrak{B}$ inter müffen mit Etrel) susgefejte \&öd)er in oas (Eiş gुebauen, uno bas

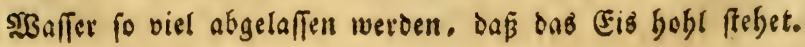




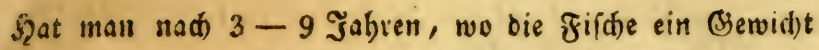
soin $6-9-12$ Pfunb erreidt baben, biefen 2 Beifer ab=

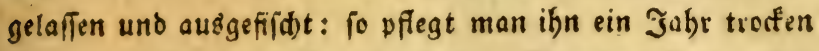

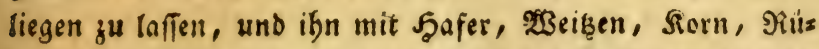

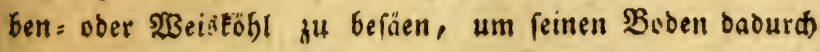
wieber mit Nabrung für bie Fifiche zu verfeben, uno bas

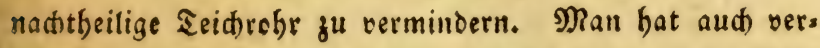
Futht bie Sarpfen ourd) (Saftriten fett gu maden, wo ifnen nad aufgefdnittenem Reibe ber Mild und Rogen genommen

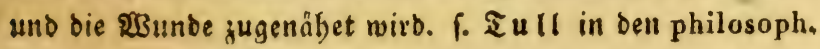
Transact. V. Zrrt. 48. 106. D e la Tou r Mem. de L'Acad. de Paris 1742. 31, fand, Daßs von 200 Stüffell, welde auf fold)e Z(rt verffonitten worben, Eaum vier farben. Der Sarpfen if aud einigen Srankfeiten auğgefęt, weld)e uns ter bem Namen Yyodéen und Moos betannt fint, erffere beo fteft in Blajen, bie fid jwifhen der 5̧aut und ben Edup.

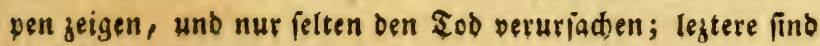

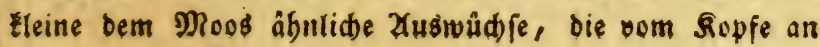

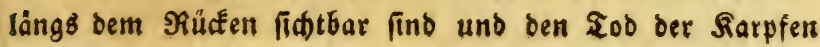
verurfachen. Diefe Sranklyeit entffeht vorgügrid, wenn

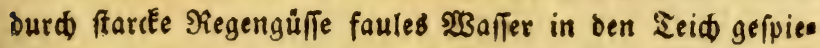
let wirb, verliert fid) aber aud ourd Bulafien von frifdem झूßatier.

"2f nerkung. In bem fogenannten Nonn, Mat to weiher, einem Eleinen See mit einer fonmimmenten

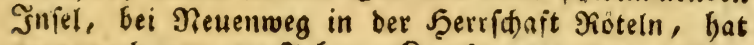
man nod vor 20 Jabren Rarpfen ven $50-70-$ 80 भfunb fdower gefunden.

Bei ben ältern Naturforidhern Rondelet, Gesner, Aldrovand finden fíd abbiloungen eines Sarpfen mit einer bem Sodtenfopfe, bei Richter bem Mopsfevfe, uno bei Meyer bem Delnhm äbnliden Bieftalt. Dlefe

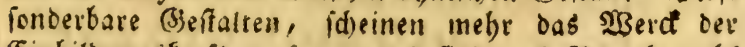
(Einbildungefraft ju fern; und find nad) 810 d) wohl 
nidts anters als vernarbte Greflen etner bermals ero littenen Bermunouna.

Nad) eimiaen, jeocd) wele es folleint, zur Beit nidit gee bërta verburgtell Madtititen, foll es aud 3 mitters farpfen, eder folche mit Ricaen und Mild in eirem Frifhe geben; auch unfrudtbare, obne Riogen und glild ; legtere foinen aber aud) leid)t burd) einen 3 us fall oiefes gemorten pern.

Das Etreichen ber Sarpfen aus bem Sibein in bie Gräben, इeidle uno jogenamurell zitwaffer, cienet ders Ffifdern zum Beichen einer baldizen beverfebenden - Lilheridheramung. EBenn fie bie Rarnfen in ben ftills ftebenoen 2 saffern idon im Mai bemerden, fo fino fie von ber boloigen llustretung beb Sibeins vergeniffert. Die Urfucte fowohf bes frübern faidiens diefes ficiches, als ier zeitigen Jinfoweflung Diefes Etroms, liegen zuverlâfin in einem warmen Grübjabr. Der Karnfer findet alsbenn reithlide NRabrung, feine Eyer werbert fruber entwiffelt, ber Scib aufgetrieben, uno er fudt

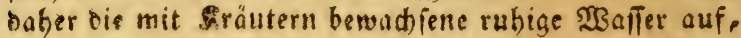
um fich ourch Das Reiben an benfelben von feinen Evern zu befreien. 2aker eben bie SWärme, bie cell Marps fen is frubzeitia frudt)tor madt, if aud) zugleich bie Urfade ber uberfowemmung, indem burd) fie bee Sanee ber böbern Beburge und ber Someizer

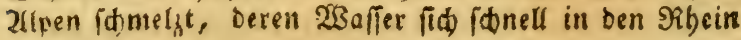
ergiepen.

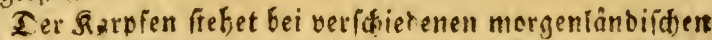
Bölfern im anfehen, wenn der greßze Mogel felbif gu selde geben, itep fonit enwas wichtiges unternebmen mill, fo lont er feine finger auf einen grofien starpien, mobei er ein (3ebet verridtet. fo allg. Neife 11 ter इb. 5.240.

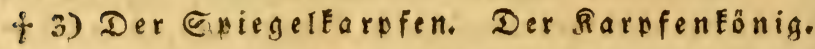
Le Cyprin spéculaire. La Cepédep. 528. La Carped miroir. Duhamel. Raine de Carpes. Bonnaterre p. 189. n. 2, pl. 76. fig. 318. (Cyprinus macrolepidotus.) Cyprinus Carpio macrolepidotus. Linn. 
p. 191. n. 9. pl. 77. fig. 319. Cyprinus Gobi o, Linn. ed. Gmel. p. 1412. Bloch. 仵ithe Deut\{d) I. 57. t. 8. f. 2. (I. 73. t. 8. f. 2.) v. Meidinger Pisc. Austr. tab. 23.

(Tab, 106. Fig. 154.)

2 Sartfafern am Munde. Der Rörper if famal unó geffecft. In ber Bruftfoffe find 16, in ber Baudfloffe 9, in. bet 2fferfloffe 10, in bet Sdywanjfleffe 19, und in ber Rücfenfloffe 11 Gtrablen. Der Sopf ift grob und grün. Gräunlid)t. Die Eleinen 2(ugen baben einen blaufdwwarzen Stern in einem golofarbigen Singe. Der gerabe Rutcen ift iawarjblau. Die Seiten find úber ber Sinie blau und unter berferben weî́ ins gelbe fdielend. Die gerabe Seis tenlinie ift mit blauen flecten gejiert. Die Floffen fino

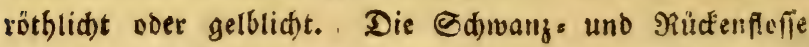
baben viele idjwarge flecte, uno legtere ffeht ber Baudifleffe gerabe gegenüter. Die \&änge beträgt 3-9 3oll. Sie wirb voriäglid) in fladen Seeen uno ftilleftebenden 2 affern und glüfen, beren Brund rein und fandig if, gefunden; ftreid)t im Frübiabr aus ben Eandjeeen in bie Flülie, gebt Strom an, unb fejt ibren Siogen im 2lpril uno gai an ben Steinen $a b$, uno bauert ifre Eaid)zeit, oa fie ifren Regen nad) und nach sbiest, 4 230 d)en, geft aldbenn wies Der jurücf, wo fie im September uno Detober in grofer Mlenge mit ber Rabbe, 3ute und ber 2lugel gefangen wers

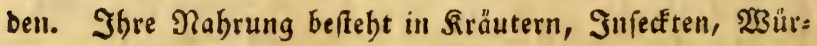

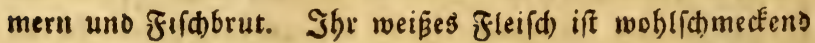
uno leidht zu verbauen. Nian pflegt fie in ben Nibeinges genden gewobntid) gebarfen zu verfpeisen. In ber f̧öle feines Unterleibes findet fid oft ber ffiect ligula abdominalis Gobionis. 


\section{$35^{2}$ Bierte Exaffe. Fijula.}

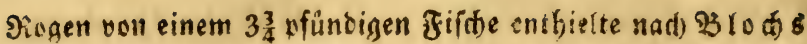
şeobadtung 297000 Eyer. Die MDitder baben megrens theils eine bellere Farbe, ein fetteres fleif uno am \$audje gripere uno ftôrdere flofien als bie Nicgner. Man pflegt

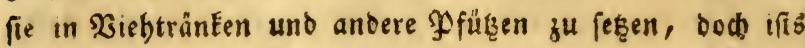
nidut rutblich, fie in Sarpfenweiber ž febsen, intem fie jes

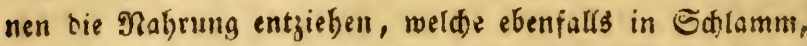

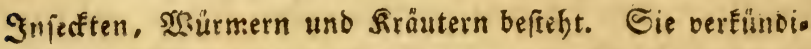

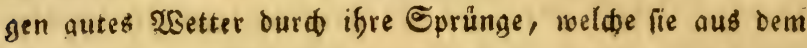

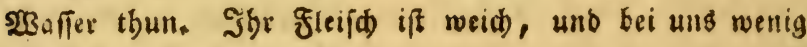
gejdåzt.

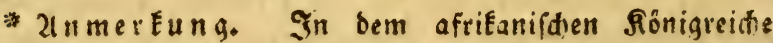

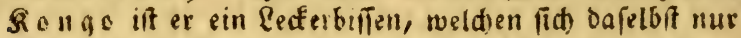
allein ber Şof antraabit, und es ifeht febensftrafe dars auf, wenn jemand einen Edlet fiidit, und ifn niats fegleith on bie funiglithe süde abliefert. S. 2tllges meine Reife 4 ter B. 3.693.

6) Die (3) lofdreibe. Der (5) doré e. Bonnaterre p. 191. n. 8, pl. 77. fig. 321. La Cepède V. p.541. Cyprinus Tinca $\beta . a$ u re a. Linn. ed, Gmel.p. 1414. Cyprinus Tinc a a ratus. Bloch Fifde Deutid) I. I. 90, $t, 15$. (1. 113, t. 15.)

(Ta b. 107. Fig. 155.)

Sie unterideibet fid) fogleid) burd) ben golbfarbigem Sörper und bie burdilitigen fleften von ber gemeinen Ed) eithe. In ber Brufffeffe find 16, in ber Bauchfoffe 10, in ber Afterfloffe 9, in Der Edwaniflofle 19, uns in

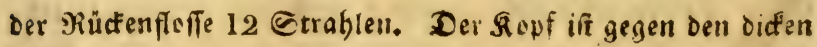
Sörver nur tlein. Sippen uno Naje fino Carminreth, Die

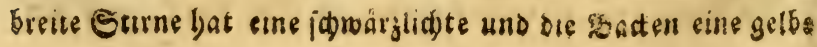




\section{4 sierte elaffe. Fifde.}

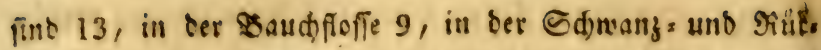

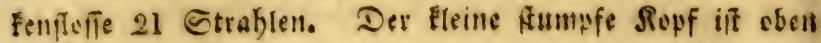
slirenfarbig und auf ten Eeiten gelb mit grün gemijd)t. Die fleinen zugen baben emen idwarjen Stem in cinetr fitberfarbigen 9iinge, weld)er mit ciner goldgetben Einie uma seben if. Der Rörper ift forb breit und mit Sdequpent

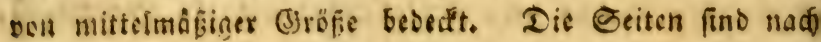

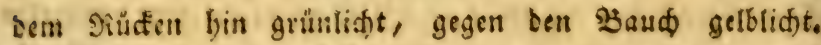
Der bugenförmige Piúfen if Duncfelgrủn umb bis an die STefle foncibeförmig, unter berfelben aber runolidt. Des

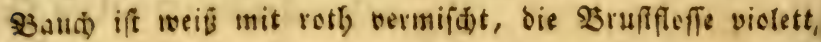
sie tibrigen glefien find am (jrunbe gelbfid)t am Miunbr grau. Shre Sånge beträgt gegen $10-14$ 3oll. Sie be: welgnt Sesen und febente şaffer ven leimigem Brunbe, unb wirb aud) in ben Tibein = unb Maingegenben in 2llt: waffern uno 23 seibern angetreffen. Sie laiden im 2tpril uno Mai. Şfre Mabrung beffelft in Sd!amm, Sxåutern, Injerfen und 23 ümern. Gie werben mit ber WBathe, mit rieujen und ber Zlngel gefaunger. In Piugland ant Sibiriegn trifft man fie in fladent mit Sodiff bewadienen Eteflen der Elüfe uns Eceen, fogar aud) in gefaljenten Geeen an, wo fie in grofer Mienge gefangen, autgenom men unb ungejalgen an ber fuft getroffinet werben, unb

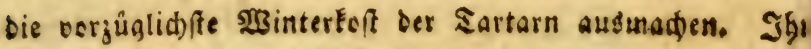

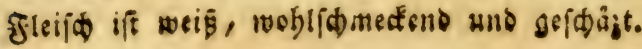

+ 8) Die Elte. IIat. Det Diaftopf. Le Cyo prin céphale. La Cepède V. p. 649. Le Cyprin cylindrique. Bonnaterre p. 192. n. 13. uno $L_{2}$ Cheranne. d. p. 195. n. 23. pl. 77. f, 323. Cypriaus Cephalus. Linn. ed. Gmel, p. 1417. Lina, Mus, Ad. Fr. p. 77, tab. 3Q, 
Stoffe frebt bem Sopfe näher als bie Baudfferfe. Die

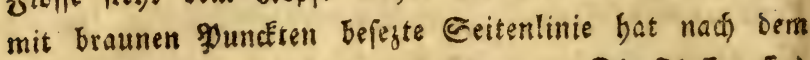

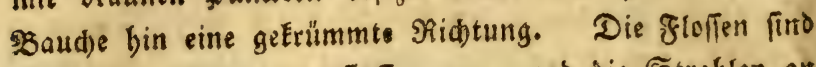
getb, nur bie Sdymanjfoffe grau, unb die Etrahten an

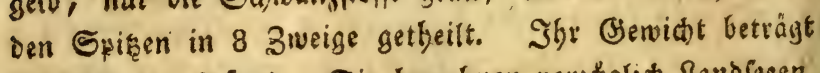
$\frac{1}{4}-\frac{1}{2}$ bis 1 ஒ funb. Sic betwobnen vor

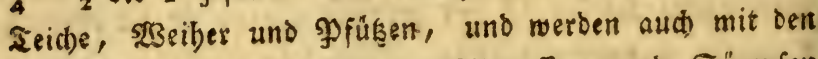
Saraulfen in den fogenannten zlltwaffern uno Cümpfen Des Sibeins uns bes sRainffromes angetroffen. SGbre Eaidso jeit bauert vom Mai bis in Suli, wo bie ältern juerff, Die jüngern aber fpäter ibre Rogen abjzzen. Sie vermefo

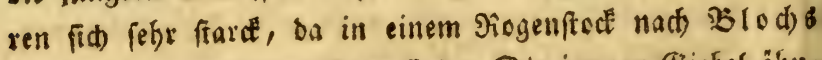
Bzeobactitung 300.000 Ener fino. Die iungen (Siebet älyn: Ien fefr ben Sarpfen, uno mus man fid) baber in zdd

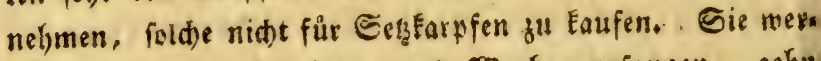

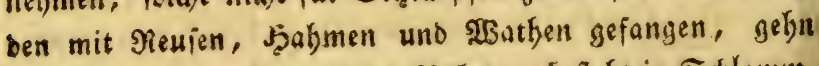

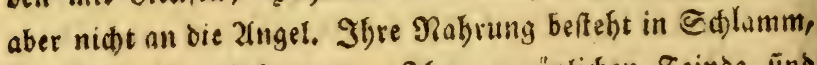

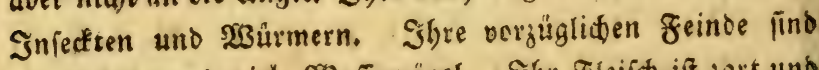

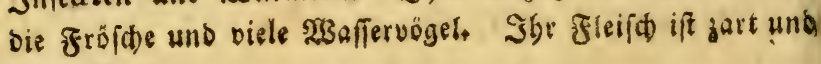
ímaxhaft.

2fnmer Eung. Mefreye Naturforidher balten fie blob

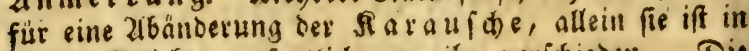
vielen (Stüaten wefentlid) bon inge berfadieden. Die Saraufde ift viel breiter, uno ibre Echuppen viel \#leiner. Die Gi iebel bat eine gektümmte Sestenlinie

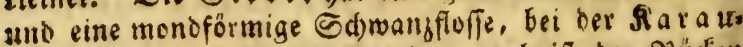
fite bingegen fino beibe gerabe, audb ift ber Piücfen

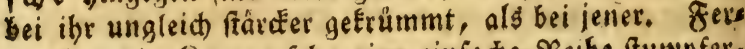
ner hat bie Siaraufde eine einfacte Reibe ftumpfer,

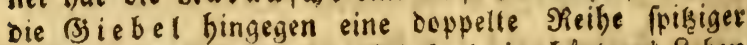
Zäbne. Enolich bat bie (s) iebel ein bârteres Reber

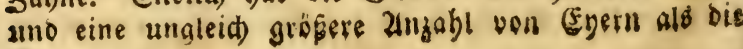
Sิara 


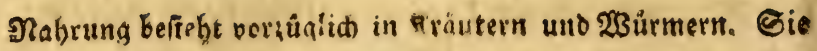
uverden mit ber ?ngel, aud mit feinen Nebुen zu allen SabrEzeiten, vorzualtch aber zur Raidzeit gefangen, baben

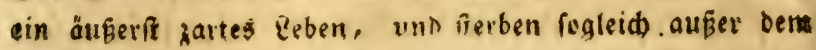

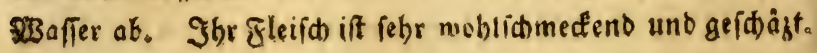

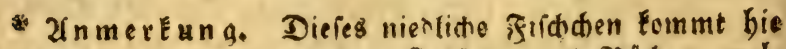

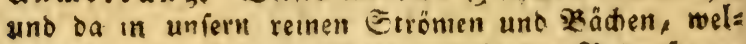
dhe fidh in ben Ribein, Main und in bell Bodenfee ers gieg̈en, vor, uno id fano eg var mebreren Jabren in

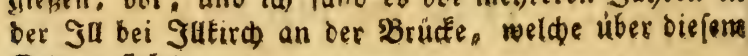
Etrom irebt.

4 11) Der Eauben. Die Secle. Binnfif́. Eaua gele. Vaudoise. La Cepède V.p. 570. Bonnaterre p. 196. n. 28. pl. 79. f. 331. Le Da r d. Cyprinus Leuciscus. Linn, ed, Gmel p. - 1424. Bloch Fifale Deutidl. III. 141. t. 97, fol. (III. 178. t. 97. f. I.)

(Tab. 110. Fig. 159.)

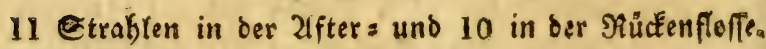
In ber Brufffoffe fino 15, in ber Baudflofie 9, uno in Der Sdwanzforfe 18 Strabletr. Der ßopf ift Elein, ber

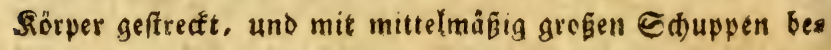

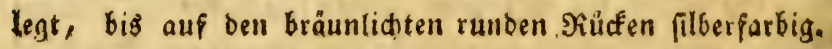
Die 2lugen baben einen fdrwarzen Stern in einem getblid)

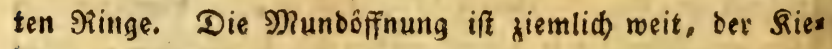

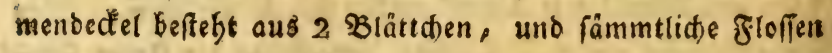
fino weifgrau. Die Seitenlinie if gebogen, unb lauft ame saudbe fort. Der Sd)wang ift gabelförmig. (Ev erreid

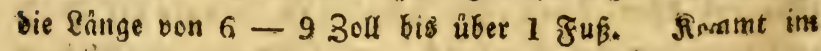
fiustidien Deutidlano, im Bobenfee, ber odbeis, in

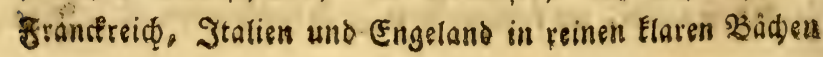


medhende Eeitentinie if mit gelben Pundten befegt. liber

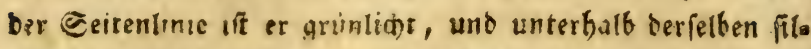
berforben ins blatue fmeleno. Die Brufflefte ift gelf, bie Bauch = uno afterfloffe rotb, bie Sommanifleffe blaulidt,

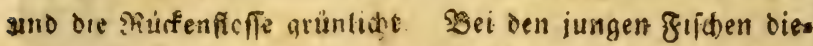
fer 2lit ober jiñ pie olle meí, baber fie auch in einigen fiegenien $g g_{3}$ eiffif

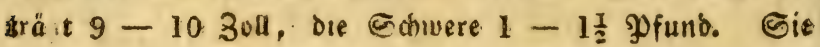
merxen in allen grosen flüfen Deutidinnis, und vorkugg

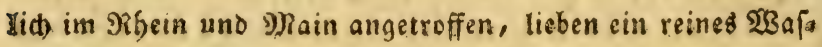
fer, emen fansigen Grund Im

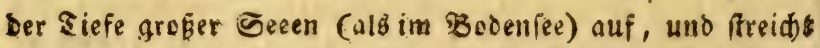

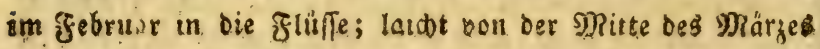

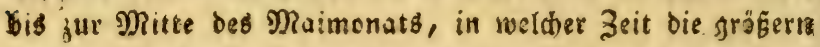
früber, die Eleinern aber ifren Eaid) fwäter an ben Steinen ber Jlüfie abjajer. Die Mannnthen ober Mild)er bstommen

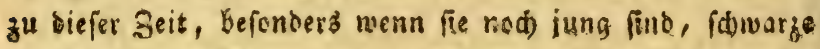
Slecte auf bem fiöper und ben floffen. Shre Nabrung ber

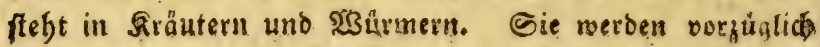

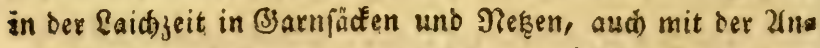
gel gefangen; baben ein zarteł feben uno ffehen auser berr

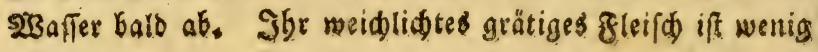
geadtet.

* 2fnmeriung. Eind fie now̉ jung, fo werdent fie

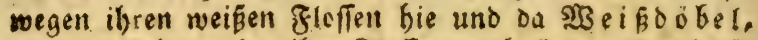

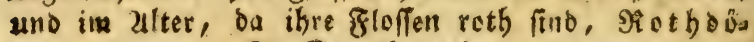
bel aenannt In Etrafburg beifien fie 5 wot to

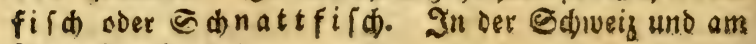
Bodentee Şafele.

+ 13) Das Rotbauge. Der Rothfloffer. Der Rotter. La Rousse. La Cepède- V. p. 570。 Bonnaterre p, 198, n, 34, gl. 80, f, 334. La Ross 
Cyprinus Rutilus, Linn. ed, Gmel. p. 1426. Bloch Jifide Deutfifl. I. 32. t. 2. (I. 41.t. 2.)

gothe zugenringe, rothe glofien, unb 14 Etrablen in Der 2lfterfoffe. In ber Bruffente find 15, in Der Bautho

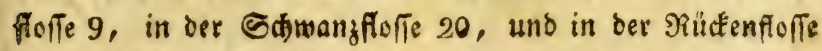
13 Strablen. Die Rimulaben funo gleid lang uno dre Sips pen roth. Der Gốrper if mit breiten Sduppen bebect', Der runbe গitcten grünlidtidgwarg. Seiten und Baud) fils berfarbig. Die nad) bem Baudje hin gebogene Seitenlinie

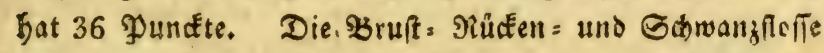
baben eine braunrothe, bie übrigen aber eine bluthrotbe

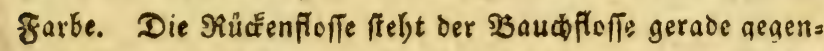

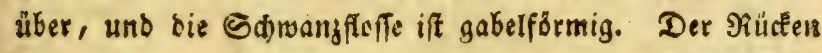
iff braum, ber Baud unb bie Geiten weif. Diejer ziich madjt ben Übergang von ben breiten zu ben fdinalen Sarpa fenarten, benn ber sopf ift fleiner als bei ben famalen, größer als bei bent breiten 2rrten, unb ber Sörper weber fo breit als bei legterer, nod fo ingmal als bei erfterer. Sie orreident ein (B)ewid)t von $1-1 \frac{x}{2}$ Pf fund, uno lommen in

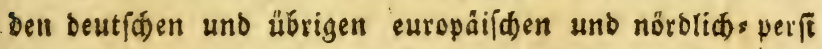
fthen flüffen uno Eeeen vor, laiden in ber Mitte bes Maieg, jut welder Zeit fie vor gugglid) mit bem (jarne, bent Porthe, ber Sabbe unb ber Zungel gefangen werben. Sie

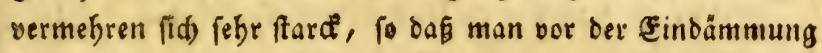
ber Doerbrůde baferbft bie Sđwweine mit ifnen mäffete.

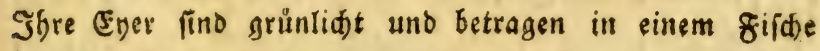
nact Blochs Beobactung 84570 und belonmen in Sübers eine rethe Farbe. Shre Nabrung befteft in Srậutern,

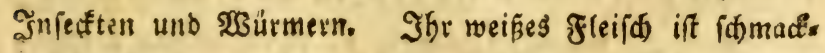
baft, aber wegen ben vielen gabelförmigen Giräten reenig

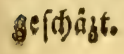




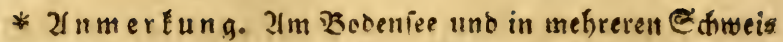
zer Eepen lif er unter bem Ramen $R$ ö te le befannt. Dieier frith wird fehe oft mir oer $P$ löBe, welde it

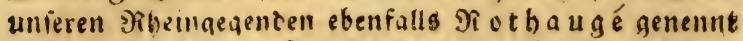
wito, nerwettelt. Sis plobe if oünner und breis ter, bat einen Eleinern sepf, und Eeine rothen, fors bern erangefaróne !luaenringe; bie sauch = 2after, unb ectwanjporfen baben eine ftarde Binneberrotbe, fo

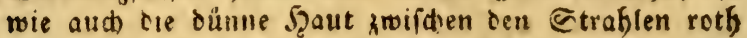
ifi. Beim Stothauge hinaenen if die Farbe ounder und bie Bnifhenfaut bräunlicht, bie Eduppen gröber uno beftehen auf jecer aus 36 Tietben, bei der Flöbe aber nur aus 30 , uno die eduppen jino Eleiner. Das Siothauge hat nur 12, bie P̧löge aber 15 Strab. len in ber zffterfieffe, audb frebt bie Stúcfenfleffe bei biefer entfernter vom Sopfe als Gei iener. Ferner bat bie Plöke eine boppelte, das Notbauge aber nue cine cinfade rieibe Zâbne.

絖 2 nmerEung. In Seeen bie man nur felten befifdt machen oie Rethaugen nach $\mathbb{E}$ uno Besbaditungen

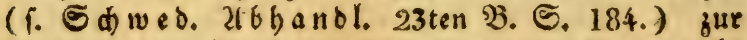
Eaichzeit einen 3ug in folgender Dronunt. Soran zieft ein Ibeil Derfelben, ein paar Taye frúber, als Sor. truppen, und biefer beftebt auछ lauter Milabuern, bier: auf felgen bie Biogner und alscenn wieier Mildner. Sie fino in (jiliebern, Siotten uno abtheilungen. Jes be Siotte entbält fridhe von gleicher Giröpe, bie bicht an einanter folwimmen, $10,20,50,100$ in ciner reibe. Bisiveilen wiro biefe ibre Didnung unters broden, weldes iesod) felten oer Fall ift. Indeffent ftellen fie oiejelbe in Eurjer Zeit wieder ber.

\section{+ 14) Die Próke. (Das Fotbauge.) Le Cyprin} Rotengle. La Cepède V.p. 570. La Sarve. Bonnaterre p. 198, n. 38. pl. 81, f. 337. (R osse derivières,) Cyprinus erythrophthalm us. Linu. ed, Gmel, p. 1429. Bloch fifide Dentifl. I. 28.t. 1. (I.37.t. 1.)

(Tab, 111. Fig. 160.) 
Der Sörper ift breit, bie afugenringe orangefarben,

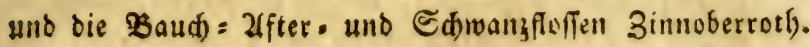
In ber Bruftloffe find 16, in ber Baudferfie 10 , in ber 21fterfolfe 15, in ber Edfwanzforfe 20, uno in ber Miülens flofle 12 Strabien. Der Eleine Sopf ift vorn ftumpf. Der

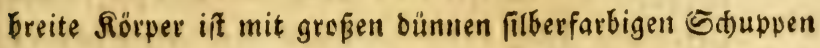
bebect. in eine Sdmeibe, unterhatb berfelben iff er runb unb fhwar grün. Die Bruft = und গiüdenfloffe find braunrotb, und reztere ftebt in einer größ̈ern Entfernung voin Sopfe, als bie SBaudfleffe. Die Eeitentinie fangt am Bsenticte an, uno madbt eine Beugung nacb bem $\mathfrak{B}$ audfe, entigt fid am Saywanje, uno hat auf jeber Seite 30 erbabene Punctite. Die Seiten uno ber Baut) finto von einer fómuşigen Boldo garbe. Sie erreidt eine fänge ven $8-10$ Zoll, unb eine Breite von 3-4 3oll. Diefer Fif Eommt vorgüglid) in ben glürien und Sreen vom nỏrbliden Deuridlano, jebud) aud in Mibein und Main vor, auserbem aud in Ungarn

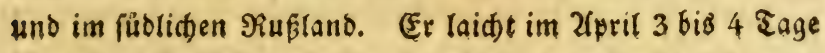
lang, und giebt feimen Rogen nad) uno nad) von fid), vers mebrt fid fo ftaré, dab man efedem an ben Doerbrủchen

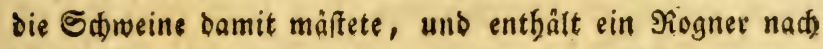

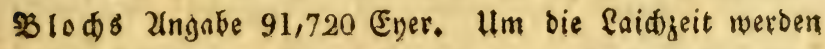
auf ben Eduppen ber Månndjen Fleine Garte uno fpirzige Zluşwüdfe fid)tbar, bie aber nad) ber Streidjecit wieber vers

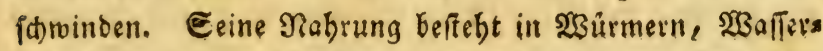
injecten und Brunstenautern. Er wirb das ganje Sabr Gin= burd, am bäufigften aber in ber Raid)zeit mit bem (sarne,

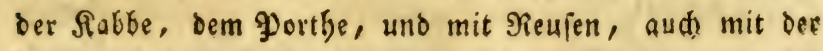

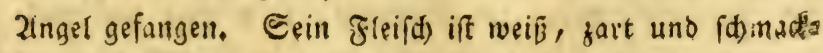
buft, aber wegen ber vielen biantin wenig geadqeet. 


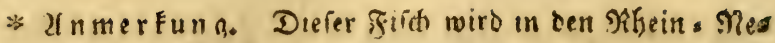
ctar, und shangegenden, fo me an mehreten andern Srten von Den fifdera Fotba uge genemt.

15) Der Sübling. Dex Spiffloffer. Der Nerflung. L'lde. La Cepède V.p. 570. Bonnaterre p. 198, n, 35. pl. 80, f. 335. Cyprinus Idus. Linn, ed. Gmel. p. 1427. Bloch Filde Deutid)t. I. 253, t. 35. (I, 323, t. 36. v. Meidin. ger. Pisc, Austr, $t, 36$.

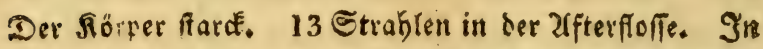
Ser Sismenbaut find 3, in ber $\mathfrak{B}$ rufffeffe 17, in ber Baudb.

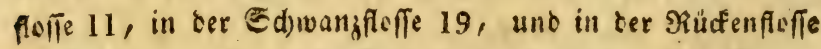
10 ङtrablen. Der bicke Sopf ift abzeizumpft. Die Jiund. bffnung Elein, ber Muns zafnlos. Die breite Etirn, fo

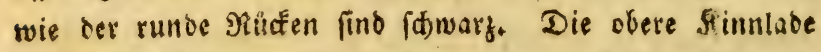
fteft etwas bervor. Der fdwarge Zugenftern ftebt in ei rem getbweiben Ringe. Die Bacten find gelb ins blaue fpieleno. Die etwas zufammengebrüften Seiten fino über Der Ente blaulidst, unter berfelben gelblidtweib. uno bes Ereite $\mathfrak{B a u d h}$ if weiß́. Sie Eeitenlinis madt nabe am

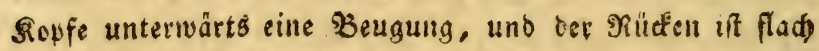
gebogen. Die Edupper fino grof. Die Brufffeffe ift gelbs lidt, bie Saudhfolfe in ber SPitte rath, an beiben Geitent und am Brunce weif, unb über cerfelben ftebt eine Mittels floffe. Sie 2lfterfolfe ift am Grunde weî̉ und übrigens

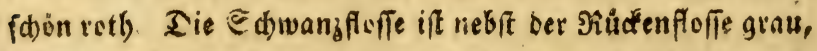
erffere iff breit, bat einen monbförmigen 2uB̈fdnitt, unb rez̧tere fteht ber Baud)folle gegenüber. Cämmtlide Strab. lell, ur bie exfteren ausgenommen, fino breit uno viels

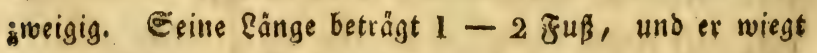
- 8 sfund, Er bewobnt vorgugglid bie grofen füpen 


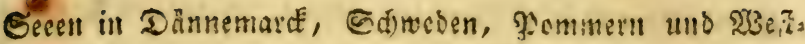
whalen, wiro aut) in ber Donau, Reitga und antern Jlúfo fen in Ditreich) angetroffen, we er unter bem Slamen Derfa Iing, Exfling, SBratfifd betunnt iff. Eeine Enithjeit

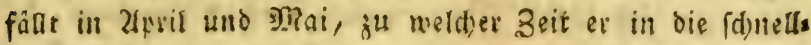
fleffenien Errëne ftreidst, uno feine Eyer an Cteinen ab= Fezt. Seine Pabrung keffeht in Siräutern, Sifecten und

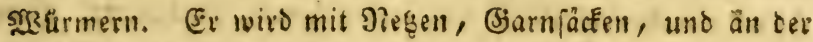

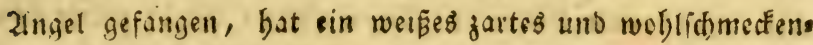
Des fleifa), bas̆ aber mit vielen Eleinen Brăten verféfen iff.

+ 16) Die Drfe. Urfe. Nerfling. Der Frau. enfifक. L'Orfe. La Cepéde V. p. 563. Bonnaterre p. 198. n. 37. pli 80. f. 336. Cy prinus Orfus. Linn. ed. Gmel, p. 1428. Bloch Fiffte Deutid)1. III. 138. t. 96 . (III. 175, t. 96 ) v。 Meidinger. Pisc. Austr, tab. 28.

(Ta b. 112, Fig. 161.)

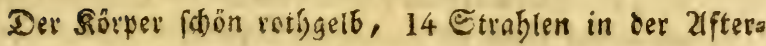

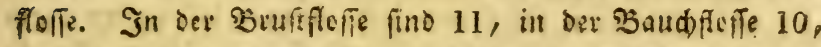

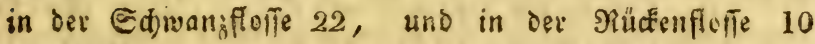
Etrablen. Der Eleine Ropf if oben nebft bem Siúcen uno ben Seiten nngenebm geltbrotf. Der fdiwarje 2us genitern fteft in einem gelofarbigen $\Re$ Ringe. Die obere Sinnlade frellt ver ber untern etwas herver. Die Baçen uno ber "Baud fin fitberfarbig. Die Ectuppen fino

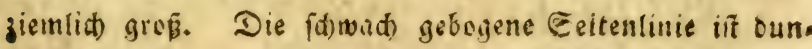
Eerroth pundétirt. Eammtlidte flefien find angenefm roth,

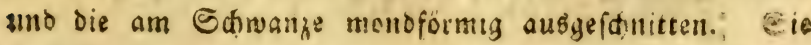
orreidt eine fänge ven $10-1530$ all, wiro jebod) fets

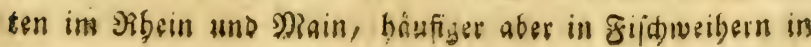


ben Mifeill = unb Maingegenben, vorjüglid) abet in Fratiett in ber Segend von Bamberg, Erlangen, Nủnberg uno

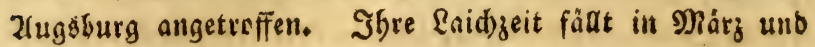

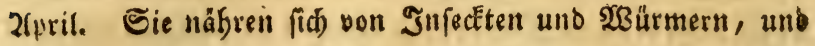
vermefren fid in ben 2 beibern und Seiden febr ftarf, bae

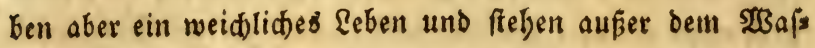
fer fogleid) ab. Gie werben verzüglid) zur Bierbe gebalten,

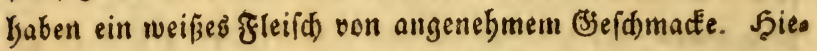
ber gebört au(b) eine weifie 2abảnberung, weld)e einige unts ter bem Namen weí̈e Drfen befdrieben baben.

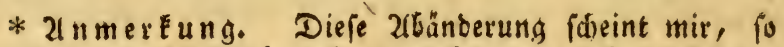
wie id) Belegenleit batte mebrere berfelben in einem Isid)e dhmweit Errlangen mit ben übrigen angenefm orangefarbigen Drfen zu beobadten, niats anders, als ein EranEbafter Buftand zu fern. Mebreres Darüber werbe ith bei bem d) inefifden (j) ol ofifa fagen.

** 2l n me $\mathfrak{E}$ ung. Die ăltern Saturferfther gaben un.

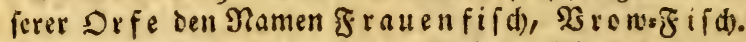
Orphus germanorum. Vrow-Fish. Wil. lugyby Jchth. p. 253. Raj. Synops. pisc. p. 118. n. 15. Dermutblid) Gaben bamals bie bentiden fraus en biefen sijh als Jierde in ibren Bimmern in befert. bern (siefäken gebalten, wie es nun bei unfern beut. fhen Damen ber fall mit bem d) inefifd)en (5) 10. fifde ift, welder feit ber 3eit bie Drfe verbrängt bat.

* 17) Der zrand. Die Göp. Jefe. Der Jellt. ling. Gengling. Sratfifd. La Jesse. La Cepède V. p. 585. Bonnaterre p. 199. n. 39. pl, 81. f. 338. Le Meunier. Le Vilain. Cyprinus Jeses. Linn. ed. Gmel. p. 1430. Block Fifdue Deutidl. I. 45. t. 6. (I. 58. t. 6.)

Der Ropf Did, abaeftumpft, ber Siörper ftard", unb bie afterforfe mit 14 Strablen verfeben. In Der \$rufflofte 


\section{Droung. Pisces.}

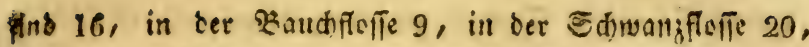
unb in ber औibtenfleffe 11 Etrablen. Die breite Stirn ift

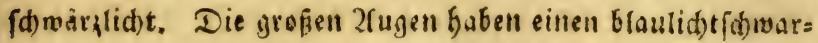

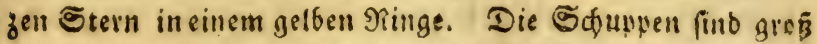

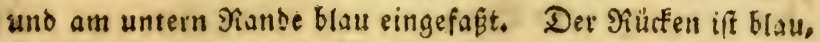
die Seiten blautid)t, aberbalb der Sinie ins getbe, uild una terbalb berfelben ins filberfarbige fpietent. Die giemticts ges rade Seirentinie if mit 58 gelbbraunen Pounctin befejt.

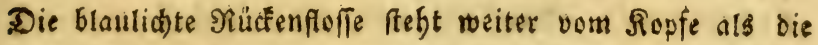
3audfleffe. Die breite Gdwanjfolie ift wenig gabelfôns

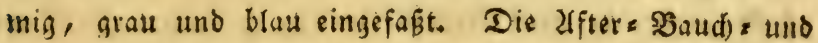

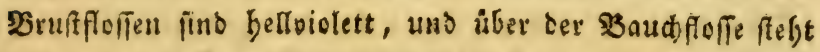

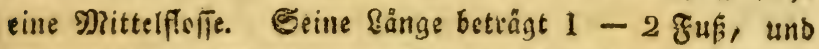

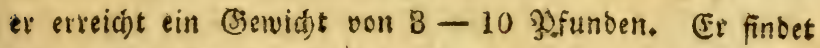

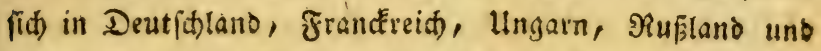
mebreren andern Begenben in 伍nell fiefienton Strömen, vorgüglid) bei Müblen und Sandbủgeln. Seine Raidgeit fállt in Mrảz unb 2april, unb bauert gewöfntid) 8 Tage.

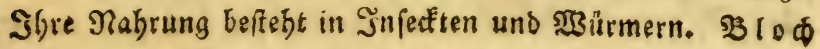
fanb in einem $1 \frac{1}{2}$ pfünbigen 92720 Ever. Sie werben

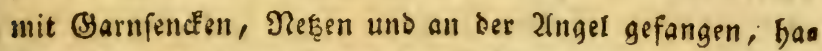
ben ein zartes fettes mit vielen Giråten berwebtes, 他mact. bafteb Jieifo.

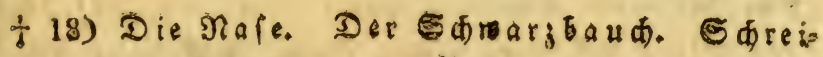
ber. Näfting. Le Nase, La Cepède V. p. 585. Bonnaterre p. 199. n. 40. pl. 81. f. 339. Cyprinus Nasus. Linn, ed, Gmel. p. 1431. Bloch Fi (d) Deutid). I. 35. t. 3. (I. 45. t. 3.) v. Meidinger. Pisc. Austr. t. 12.:

Der obere Fiefer fteft vor Dem untern Gervor, uno en. higt fich in eine ftumpfe najenartige Spige. Die afterforlis 
bat 15 Strablen. Das $23 a u b$ fell (peritoneum) if fowwargs In Dex Rrufforfe fino 16, in ber S3auchfleffe 13, in Der Edwanjloffe 22, unb in ber Nüctenfloffe 12 etrablen.

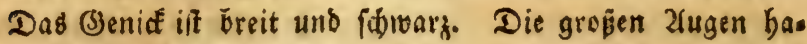
ben einen fonwarzen Stern in einem filberfarbigen ing golds gelbe jpielenten ringe. Der idmale lange Soorper ift mit

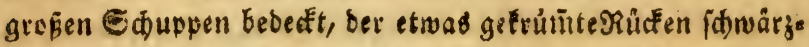
lid)t. Die Seiten find unter ber Seitenlinie nebft bem 3 Baus

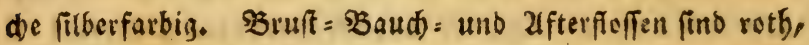

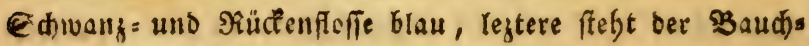

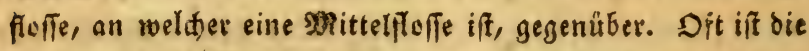
Edowanifoffe oberwäts blau, ber untere \$beil aber rótb.

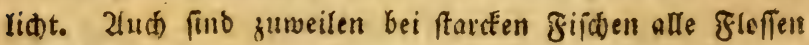
grau. Sie erreiden ein Gewidt ven $1 \frac{1}{2}-2$ Pfunden. פ)

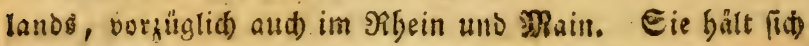
genoclyntich in ben Siefen greßeer Eeeen auf, unb ftreidbt

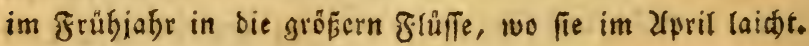
Die Mannnd)en beÉtumen in ber Raid)jeit auf bem Sörper und ben flufien fáwarge flecte, in beren Nitte man bie uni ba Eleine erbabene Punckte, jebod) nur bei ben jungen,

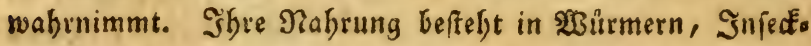

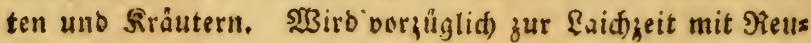
fen, Neģen und 2ngeln gefangen. Şat ein weiches füpes und fettes, mit vielen Eleinen Giråten Durdwebteb wenig geactitetes fleijh.

* If nmerEung. Die Na fe untericheibet fidi von den

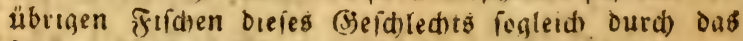
formarze $B$ aud)fell, unb megen biefer auffallenden id)wat. gen şarbe bat fie aid) an entgen Drten ben Yamen

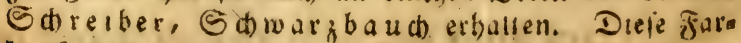
be uit aud Urfache, oas man an manden Srten einen 2hicheu oor Diejem silice bat. 


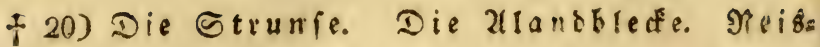
la иbc. Le Spirlin. La Cepéde V. p. 585. Bonnaterre p. 200. n. 42.pl.82. f. 340, Cyprinus bipunctatus. Bloch Fiide Deut(d). I. 50. t. 8. f. 1. (I. 64, t, 8. f. 1.) Linn. ed. Gmel. p. 1433. v. Meidinger. Pisc. Austr. tab. 16. (T a b. 110, Fig. 162)

Ifn ber rotben Geitentinie ftebt eine toppelte Siribe (d)waizer Slundfe; In ber 2lfterfiefie 16 Etrablen. In oer Bruffleffe 13, in ber Baudifleffe 8 , in ser gabelförmis gen Sibramaflete 20, uno in oer Sillenflufe 10 Strab= Jen. Dee Dberkiefer fteht etwas Gervor. Die grefien lus gen baben einen fdwargen Gtern in einem gelben Minge. und cberivants einen grünen Flect. Sie b!auen Bacfen

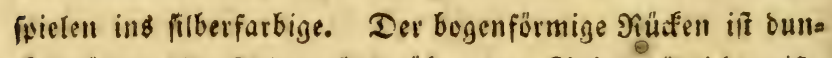

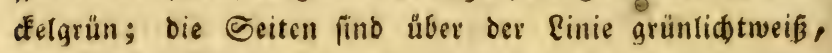
unb unter berfelben, fo wie am Basude filberfarbig. Det breite Rörper if mit Eleinen fdwarzpundfirten S(buppen bejezt. Die Seitenlinie martit sine Beugung nath bem

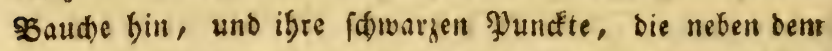
weipen (5runbe und ber rothen Rinie ffeben, geben bem fri fde ein reijentes 2(njeben. $\mathfrak{B}$ ruft , Baud) = und 2(fterfloffe

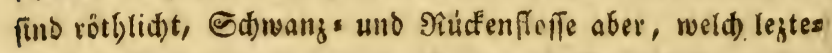
re vom Sopfe weiter entfernt ift, als bie SBauchfolfe, grün. lid)t. Eer gebört unter bie breitern Sarpfenarten. Seine fånge betrỉgt nur 3 3olr. Diejes nieblide gijd)den fine. bet fid) in Fandigen Eiefigen flüfen, vorjugliti in bee 23efer, uno audb im Sibein, uno jwar in regterem bes fonders an Biegenden, wo łreifber Gebanrme ausivaíhen. Sie laid)en in Mai, zu weldfer Zeit fie fith in ben Ttes fen ber zluffe aufbalten, nadber fidd aber mebs an bis 


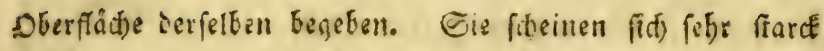

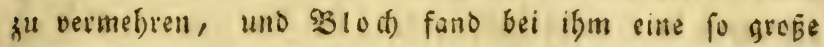
Menge Eyer, daf ber Miogen beinate fo viel weg, als bee

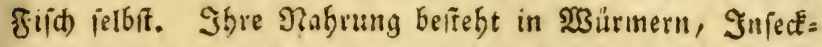

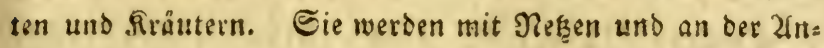
gel gefangen. Shl Eleijh) if weis und woblidgmedtent, fie werden var gughld gebraten veripeisit.

21) Der 3 itterling. La Bouvière. La Cepéde V. p. 585, Bonnaterre p. 197. n. 30. pl. 80. f. 333. Cyprinus amarus. Bloch छifde Deutiका. I. 52. t, 8. f. 3. (I. 67. t. 8. f. 3.) Linn. ed, Gmel. p. 1433. v. Meidinger Pisc, Austr。 táb, 37.

(Tab, 111, Fig, 163,)

" Etrablen in ber Bruft s und Baudforfe. In bet 2afterfelfe find 11 , in ber Sd)wanjflefte 20 grofe 10 Eleine,

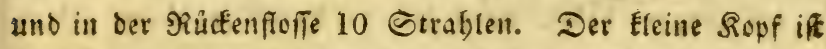
Eeilförmig, Die Finnlaben fino gleid)tang. Die f́einen 2lus gen baben einen fdrwarzen Etern in sinem oben rothen unb unten gelbell গiinge. Die Siemenbeckel find gelblicht, Die

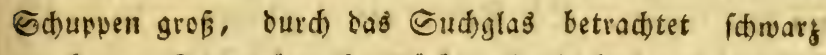

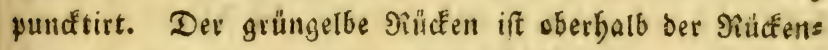
forfe idharf, uno unter berfelben runblidst. Die Eeiten fino äber Der Sinie getb, uno unter berfelben uno ain Baudbe jitberfarben. Die Geitentinie madt nabe am (Bjenicfe eins Beugung, nad) bem Baude zu ift fie fidwắnglidft, am Sdwange ftabrblat. Bruft: Sand = uno zifterfleffen finb

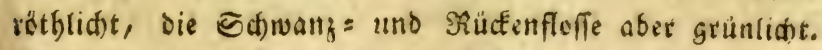

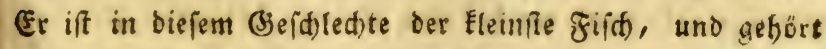
bu Den breiten Garpfenarten, wirb niwt ùber 2 3oll lang, Dnbei aber über $\frac{1}{2}$ Soll broit; Eoumt in reinen fleffenoen 


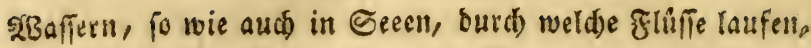

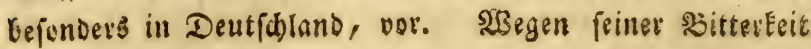
ift er wenig gead)tet.

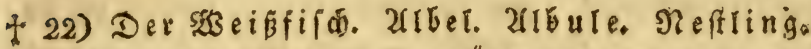
Sdneiberfifd. Der ütétei. Der spiţa laubeit. L'Able. LaCepède V. p. 585. Bonnaterre p. 201. n. 48. pl, 83. f. 343. Cyprinus Alburnus. Linn. ed. Gmel, p. 1434. Block Gifale Deutid)!. I. 54. t. 8. f. 4. (I. 69. t. 8. f. 4. ) v. Meidinger. Pisc. Austr. tab, 30.

Der UnterËEfer berworffetjent; 21 Strabien in ber 2ffs serforfe. In ber Brufffoffe fut 14, in ber Baudfoffe 9, in ber Edrwangforte 18, und in ber Mituenforfe 10 Strablen. Der Ropf ift zugeipięt, bie Stim flad), sli= venfarbig unb idwwarz punctirt; bie Battell blau. Die greß̧en 2ugen baten einen blauen Etem in sinem folbers farbigen Range. Der Sörper ît mit bünnen glänjenten (5)

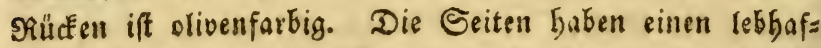
ten Gitberglang. Die Seitentinie if gebugen. Die \$Brufta

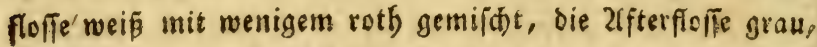

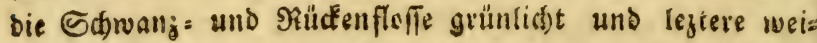
ter als bie Baudfifolfe vom aopfe entfernt. Seine \&änge

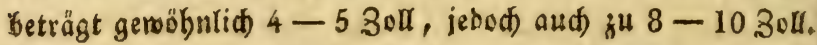

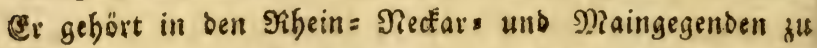

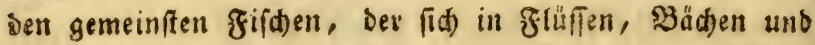
Seeen aufbält; laidt im Iuni, uno wirb bas ganje Jafge

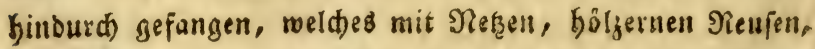
ber Zngel, und unter dem Eife mit den grofen (5arme

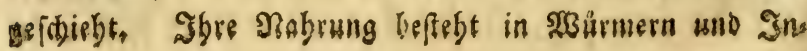




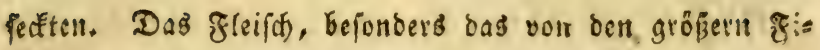
fden, bat Eeinen unangenebmen Beidmact. Sie werten äbrigens vorzüglid wegen ibrer Sduppen gefangen, bie

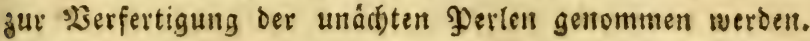

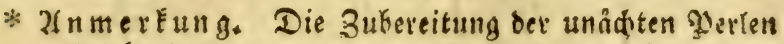
gefthieht folgenoer mafien: Mlan fduppt biefe Fifiche ab, bringt die Ed)uppen in ein mit reinem $23 a f f e r$ angefülttes (Befäá, unb nachbem man fie eine Seitlong

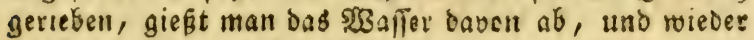
frifdes darauf; reibt alobern von neuem und wieders

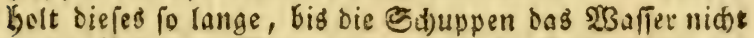
mehr färben. sersenn fich nun bie Silberfarbe ber

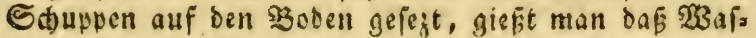
fer behutfam ab. Der jurücfigebliebene Eaft, Dier Die fogentunte Essençe d'Orient, wiro alsoenn mit etwas Saufenblafe vermifót, uno zum fernern Bes braud) aufberwafit. Son biefer (Effen thut man ein

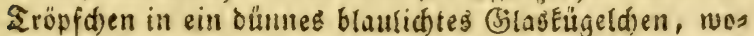
felbft es nad) allen Seiten verrieben wird, modurch Die Glasperle ben Glang erfült. Damit fie aber eme ges soiffe Edtwere betommen und bauergaft werben ing̈ge,

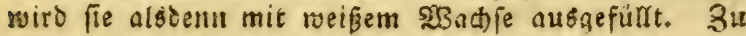

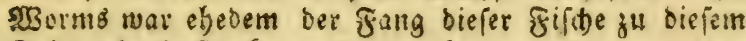
Gescrauche fo ftarck, dos man inn unterfagen muste,

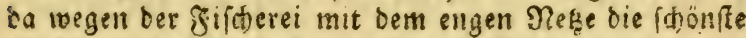

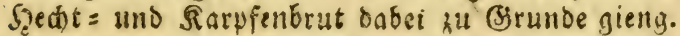

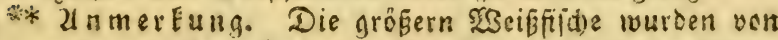
mehreven Epeculanten im Elfá, uno läthg bern Sibzin uno Nectar, vor einigen Jabren eingefaljen, uno frate

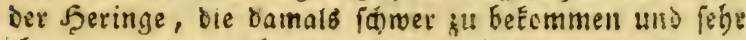
theuer varen, verEauft uno beripeist.

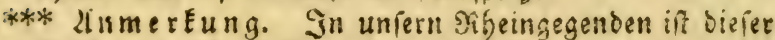

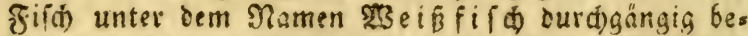
funnt, jedeco nennen die Fifá)er in diefen Gegenden beinabe alle Eleinen Sarpfenartan, welde meipe filber:

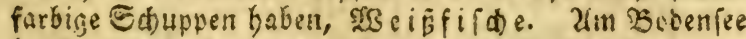

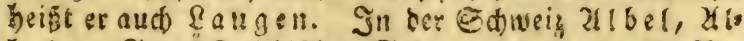

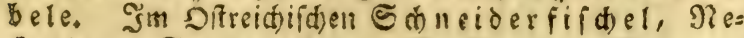

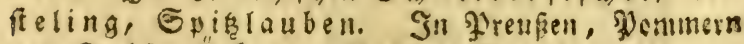

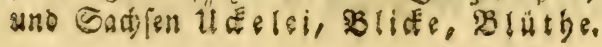


23) Die 3ärtbe. Meernafe. Elbnafe. Die 2 imba. La Vimbe. La Cepède V. p. 585. Bonnaterre p. 201. n, 49. pl. 83. f. 344. Cy prinus Vimba. Linn, ed. Gmel. p. 1435. Bloch Filidue Deutidt. I. 38. t. 4. (I. 49. t. 4.)

Der obere Siefer fiebt in (5eftalt einer Naje oor bem untern bervor. 23 Etrablen in ber afterfloffe. In ber

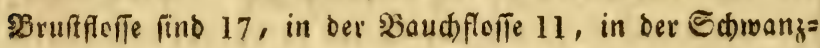

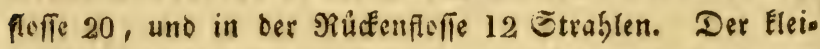
se Siopf iff Eeilformig. Die greß̧en 2ungen baben einen fdwarzen Stern in einem oberwärts ftrohgelben unb uns ten gelben Singe. Der Siucken ift zwifhen bem Siopfe und ber Floffe f(d)arf, ber üfrige Ifeil aber rund, etwas gefrümmt und vou blaulifjter Farbe. Die nad) Dem Baua do bin getrümmte Ceitenlinie if mit gelben Puncten be: feit. Die Seiten fino über ber Sinie blaulicht, und unter berfelben, fo roie am Baudse, filberfarbig. Die গiüéen =

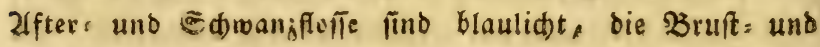
Bauchfleffe aber geiblid)t. Die Eänge diefes Fifdes be. trägt $1 \widetilde{\mho} u \tilde{B}$. Ev if ein 3 ugfiff, der aus ber Dftée in sie benadbarten fluffe im Suni freid)t, um feinen said

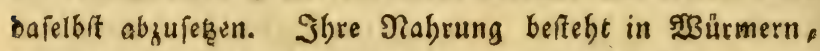
Injećten uno siråutern. Sic werben vorzüglid) zur faich)=

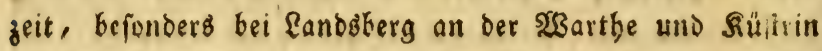
mit Senfen, Zugnesen und ber angel gefangen. Şfr Sleifh) ift febr fdmadbaft unb gefdázt, unb werben fie

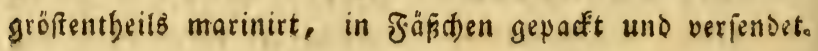

* 2f nmerEung. Diefer fFifa, weldber in unferen rbeis nifden (Segenden nid)t borfommt, mußj nioht mit bet Jiafe verned)felt werben, mit ber er nid)ts als den nafenformigen frumpfen Oberkierer gemein bat. Bei oet Naje figt ber Mund in bie suere, uno bei tę 


\section{Sronung. Pisces.}

3 arthe in bie Pange, enfere bat in ber afferfinte mur 15, leztere bingegen 23 Strablen. Die Siafe if innerbalb bes Baudtes fotwar, sie 3 ărtbe hinges gen filberfarbig. Fermer find die Sodupsen bet eriferer gróper. f. mebreres bei Bblo d) a. a. D.

f 24) Der Blei. Der Brefen. Sradien. Srap fent. Braben. Sleiģen. La Brème. La Cepède V. p. 585. Bonnaterre p. 202, n, 52. pl. 84. f 346. Cyprinus Brama. Linn. ed, Gmel. p. 1436. Bloch Jijete Deutid)!o I. 75. t. 13. ( I. 95. t. 13)

Die freflen fow floffe. In ser Bruffleffe find 17, in ber Bandffuffe 9.

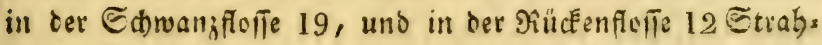
len. Der Sepf if abgeftumpft, ber Flund Elein, der

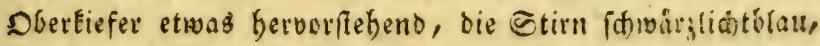
Die Bacfen gelbblau. Die fowwarjen Zugenferne baben einen gelbweifen mit id)war;en f̧unkten befezten Siing, über weldem ein fowarger halbmentförmiger flect ffeht.

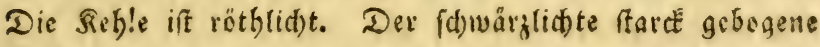

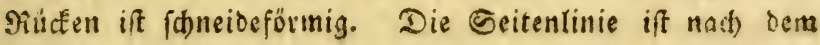
Baude zu geftümm und mit fitiwarzen Pुuncteten befejt.

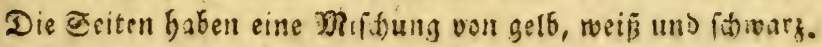
Die Bruffferfe iff oberwärts violett, unterwärt getb unb

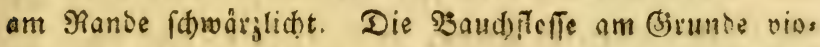
lett, und über berjelben fteft eine Mittelfuffe. Die ufs

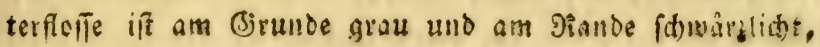

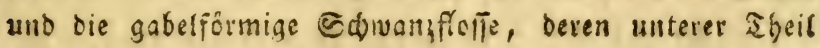

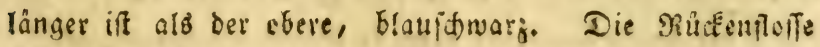
feht uam Sopfe weiter ab als bie Bandfflefile, und it

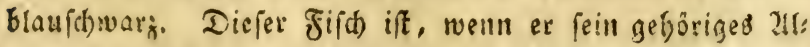
ter erreict)t bat, fefre beeit und jiemlid bisk; jung binge= 
gen neffrefít und cunne. Er erreidit eine Rảnge ven 2 -

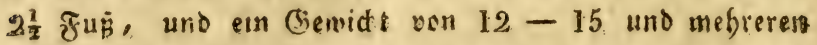

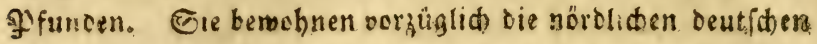
fonft fliefienden flüre und grefen Eantieeen, Ermmen aber aud un Shem, im Main und der Donalu, im Bobenfee, थn in mebrexen Soweizer. Eseen vor. Sle begeben fid grwobnlid im loril ooer Mai in cie Flüte, um zu laicher. Giemóbnlid ziebt eill Rogener wit 3-4 Mildnern uno

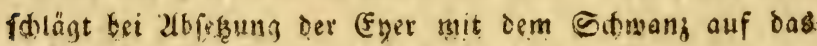
23affer, wo arbienn reztere tie Mild) von fids geben. Bea

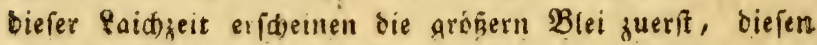
folnen bie mitlern und enolich ore Eleinern. Fin Rogenes. enthält nach $\mathfrak{B} 10$ d $\$$ Bevbadtuna, bie or an einem 6 vfủn. bigen anterute, obngefabr 167000 röthliche Eyer. Sic vermebren fidh troj der vielen Madufteffungen der Sechte Bariche, Selfe, Banter, 2lale uno Suappen, uno oes. S23afferoigel febr ftaré. Bur Eaitizeit beformmen die Millda net weige barte fpizige Snotchen auf ben Couppen, unto werben aldenn Dorn= Deer Steinbrach fen genennt.

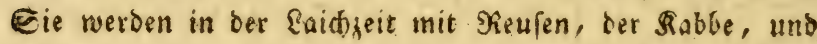
im Winter unter bem Elfe mit bem grofen Garne, außets

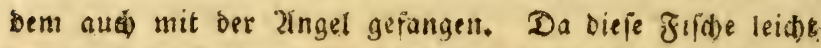

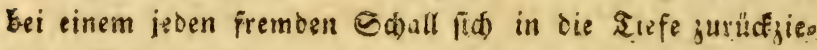
ben, if in Edweden in ben Dorfern, welde nabe an ben Fraffenfifdereien liegen, du biefer zeit, aud) fogar an ben fefltagen, Das Hocfengefăte unterjagt. Sei ber Fiba fifthere if ibr Sang am vortbeillgafteftel, intem man fie 8"l 5-50000 Stüc in einem Buge fangen fann. Ev wächit bei guter Nabrung eben fo fonmell als ser Sarpfen,

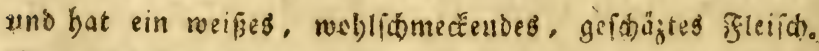
22: o er baufiz gefargen wird, pregt man ibn aur eingefals. zen unb gerâudgert ơ verfpeisen. 


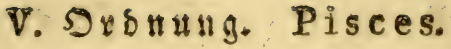

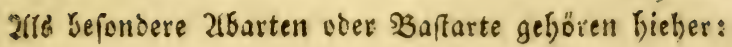

a) Der Eeit $=\mathfrak{B}$ lei. Cyprinus Brama Ductor:

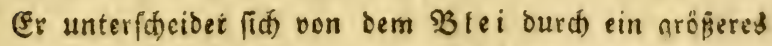
Zuge und ben blautithten 2lugenring; Fopf und oer Brund ber Eloffen fint von einer fitönen Purpurfarbe und am Siande röthlidt, bie Schuppen fleiner uno bichter, ourd) viele Elaßgrothe şundte von unbeftimmter. Beffalt an feis nem ganzell förper, ferner ift er mit enem Sdleime bes

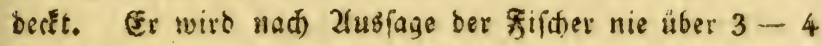

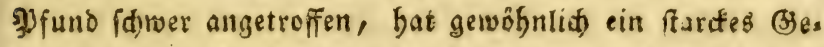
felge von siteien binter fidf, baber er wen ben frifdern

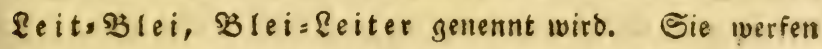

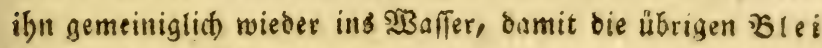
dieiem ifrem züfrer folgen, und ar ifnen einen ergiebigen

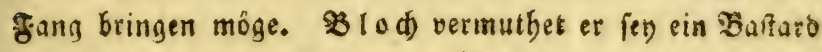

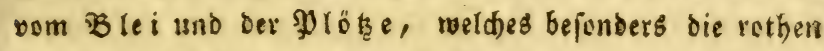

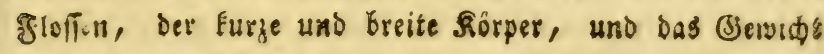

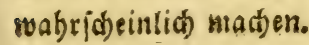

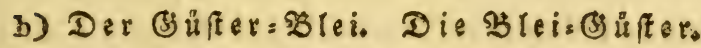

Der Repf fo Elein, uno der אörper fo breit als bei be\&

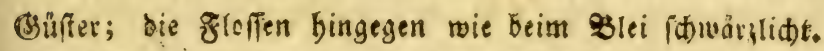
Sie foll nam zturfage ber giider now) einmal fo fowwer als

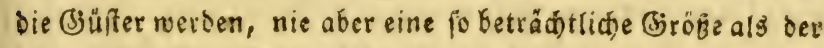

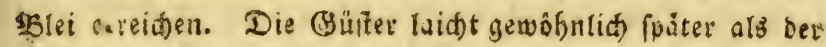

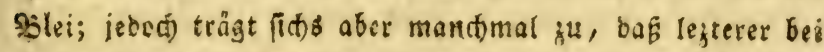

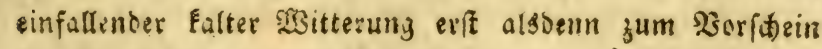
fommt, wenn bie (s)üler bereits angefangen hat zu laidert. 223enn mun beibe in den Neţen soer Reupen julammen gea rathen, fo geichieht es met) fetten, Daß̉ oer giugen dez eis

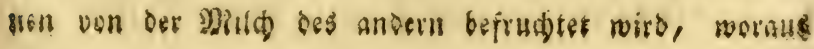




\section{Bierte Claffe. Fifde.}

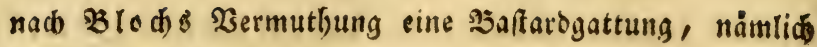

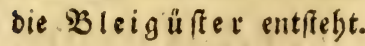

†25) Die (Giffer. Die Maffel. Die 2slide. Le Cyprin large. La Cepéde V. p. 604. La Plestie. Bonnaterre p. 202. n. 50 pl. 81 t 345. Cyprinus latus. Linn. ed. Gmel. p. 1438. Cyprinus Blicea. Bloch Filde Deutidhl. I.65. t. 10. (I. 83.t. 10.)

Der Siörper febr breit uno bủnn, 25 Etraflen in ber

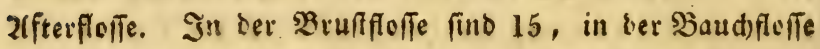
10, in ber Sdwwamjleffe 22, uno in ber গiücéenflefie 12 Strablen. Der Eleine Sopf if̃ jugefpirgt. Der DberÉefer ftebt bei gefdleffenem Diunbe vor bem untern etwas berver. Die Minnobffung febr Elein. Die Augen baben einen pdwarjen Stern in einem gelben mit id)warzen Puncten bejprengten ringe. Der Siörver ift mit mittelmázig gropient bünnen (e) duppen bedecf́r, das Gieniá uno ber oberbalb feis

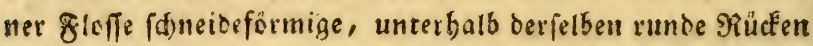
blaulid)t; lezterer ift febr ftarck gebogen. Über ber getrünts ten uno mit getben Spuncten befegten Seitentinie find bie Geiten weï ins blaue fdillernb, unter berfelben und am Baudbe weiß. Die Bruft. und Baudfifien find reth, bie

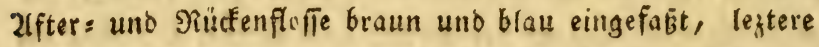
fteft vom Repfe weiter $a b$ als bie Baudfolle. Die gae belförmige Sthwangflefte ift blau uno bie untere Spize län

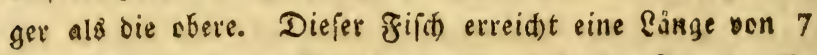
- 10 3oll, uno ein Gewidt von einem balben झुfund. Fr bewobnt bie Randjeen und fanft fieffenben $23 a f f e r$ von Ěu repa, uno wirb oorjüglid) in bem mittlern und füblicten Deutfdrland, aud) in ben Sifein = und Maingegenden ges funden, laid̨t im Mai und Jัuni in fladen Stellen, ju 
welcher 3cit bie gröEten guerf́t mit ber Blei soer $\mathfrak{B}$ rad) fen, und nach 9 Eagen bie fleinem, und binnen siner gleis ()en Frift bie Eleinfen erichenen. Bei bem Raiden felfif madjen fie viel (Sieplätider und (jeråuich. Sie vermebren

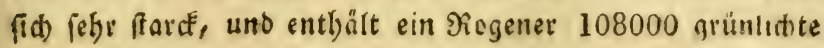

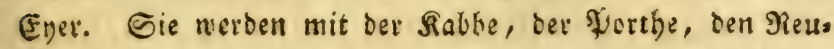
fen uno ber zinget gefangen. SGhre Nabrung befteht in

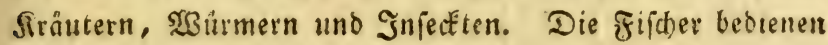

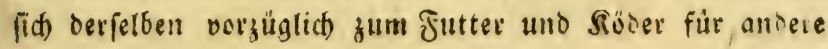

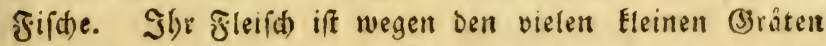
wenig gead)tet. Soorjüglid) bei Den jüngern Fichen dicfer 2(rt trifft man im Sommer, jesed) jelten zur Eaidgeit,

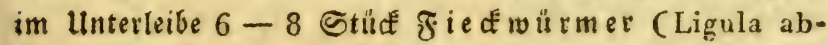

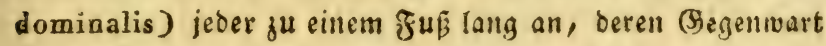
man fabon reidyt an bem aufgetriebenen lunterleibe biefes Bifhes erEennen fann.

26) Die 3ope. 3ophe. Strope. Le Cyprin Sepe. La Cepéde V.p. 604. La BordelièreBonnaterre p. 203. n. 55. pl. 84. f, 348. C y prinus Ballerus Linn. ed. Gmel. p. 1438. Bloch Fifthe Deutífil. I. 62. t. 9. (1, 78. t. 9)

In ber 2(fterforfe felgen 41 Strablen. In ber Bruff= flufe fino 17, in ber Baudfloffe 9, in ber Schwangforfe

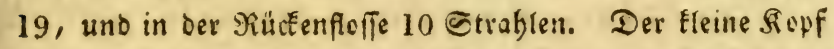
if ftumpf, Die Sinntaden gleid) lang und bie untere getrutmit und bei offenem Munde etwas bervorfegend. Die Stirn ift braun, Die grop̧en alugen baben einen fajwargen @tern in einem gelben mit 2 idwarzen flecten verjegenen গinge.

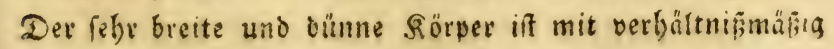
Eleinen Sduppen befę̧ t. Dis Ceiten fimo am Miúfen blaus Jid)t, weitet unten getbitid)t, untergalb oer Eeitentinie fils 
berforbig und am Bauthe retslidt. Die Seitentinie if getace und mit hrounen Flecten beiegt, Der fowivarie Sillts

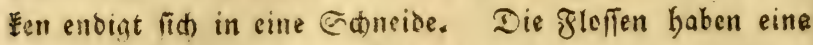

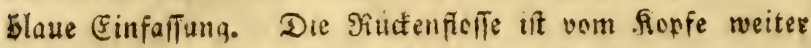
als sie Baudfonfe entfernt, die Xlfterfoñe fehr breit, bie Cdwangforfe menbförmig ausgeídynitten unb bie untere

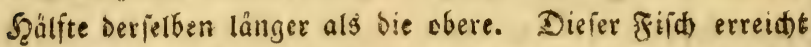
sine Rănge von $1-1 \frac{1}{2} \& u \dot{B}$, unb ein (Biwid)t von $\frac{1}{2}$ bis 3 Şfuns. Er finder fid vorğghtid in Randieeen und glüps

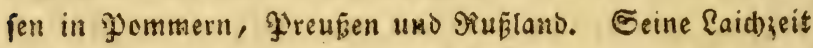
fäat in 2(pril uno Miai, un cin Nogener entbält nad) B

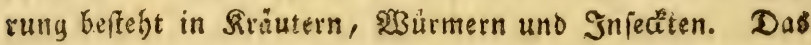
mit vielen (Sräten burdwebte fleifd ift wenig gead)tet.

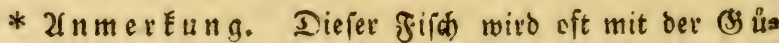
fier verwed)elt, ift aber burd) oie 41 Strablen in ber afterfoffe, ourd ben abgeftumpfren Sipf, uno bie übrisen angegebenen Sennzeiden von ibr wejents lid) verífieden.

\section{c.) Dit breitlysiliget Eshtwanfloffe.}

27) Der (3olberpfen. Der dinefifde Bolba fifd. Der (3olofifd. Le Cyprin deré. La Cepède V. p. 553. Le poisson doré de 1a Chine. Bonnaterre p. 193, n. 14. pl.76, f. 326. - pl. 78. f. 324. 325. - pl. 79. f. 327. Cyprinus a uratus. Linn, ed. Gmel, p. 1418. Bloch Eiifhe Deutidil. III. 132. t. 93. 94. f. 1-3. (Tab, 113. Fig, 164.)

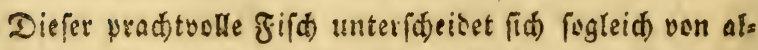
Ven übrigen Sarpfen burd) feitie eigene glänzeno rethe Gorido forbe. Sull ber \$rufflefte find 16 , in ber \$awd: und 21 fo 


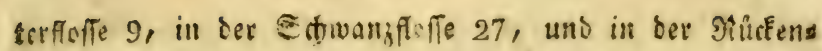

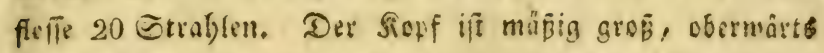
rath, an sen Seiten gerbfarbig. Die coppeltent uno meis

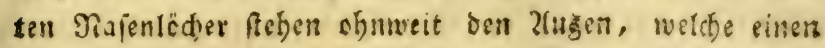
fdowargen Etern in eincm gotbenen Hinge babin. Die

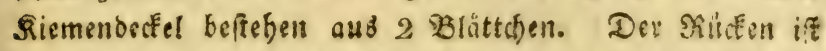
runt. Der Sörper ift mit grepent Souppent kepejt. Die Ceitenlinie bat bei bem rilfeen eine gerabe Siafit:mg,

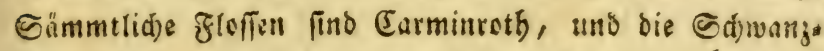
forfe 3theitig, febre oft aber aud) nur 2theilig, übrigen fino bei biefent Fifde bie Floten in BBetrad)t iflere Eage,

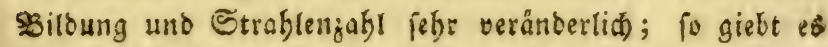

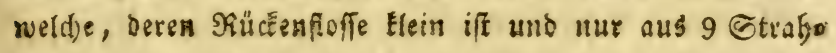
Ien befteft, anbern feblt fie gänglid), nech ardere babera ftatt ber Elofie nur eine (Erböbung, andere 2 Dergleid)en. Bei einigen if bie 2fferfoffe boppelt, unb bie Getfwand. flefte mie sine Dreizactige (sabet gebilbet, bei andern if - legtere floffe feffr lang, unb aud) bie übrigen fleffen ver.

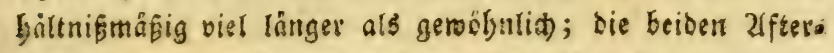
floffen fethen neben einander, bas überfluffige an Dez Ed)wangforfe aber wäd) gewöbntif) auf ben Geiten in Der Mritte. Die Farben ändern nad) bem veridierdenen zltter berfelben ab. In ben erften 3 Jabren ift biefer zilide

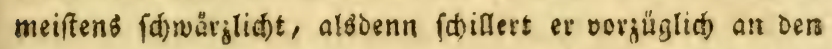
Geiten unb am sauche ind filberweise, Darauf wirb er

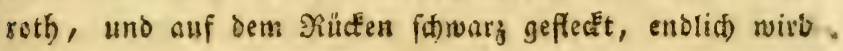
er über uno utber angenehm roth, auch if er zu Seiten gleid) im anfang roth. Seine rotbe garbe verifononert ficty

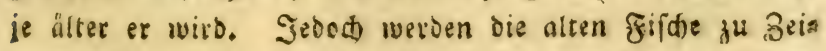

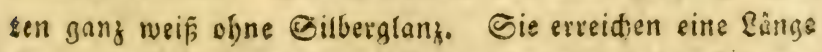

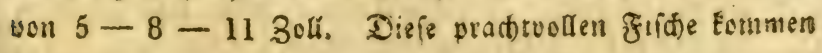

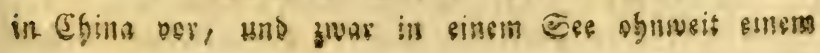




\section{Biexte Eraffe. Fifde.}

beben serge bei ber (atabt $\mathfrak{S} d$ anghou in ber Sroving

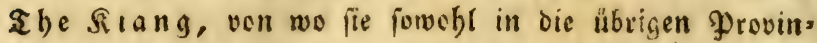

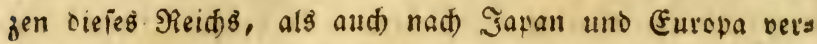
yfangt worben find. (Er ift bermalen nidh nur in Enges

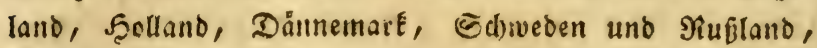
fonsern aud an vielen orten in Deutichlano uno bet

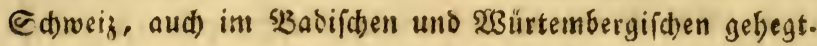
Nad) Engeland wurbe er im Jabr 1611 gebradt, und mar bafelbit 1728 allgemein befannt. Cie werben bie und ba in Eleinen $\mathfrak{3 e i b e r n , ~ B a f f i n s , ~ u n o ~ g r o ß ̧ e n ~ E u g e r = ~}$ förmigen (Gläfern gebalten, uno vermebren fid) in exfteren

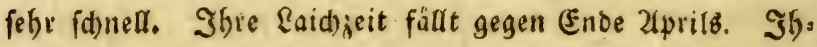

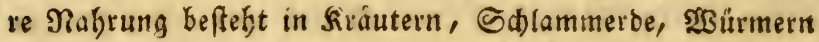
uno Infecten. In Gröfern werben fie mit Elein gerftüt elten Oblaten, feinen eemmelErummen gefủttert, aud) bes bagen ifnen bie ju 3eiten bineingenorfenen lebendigen fliegen, nad) welden fie begierig haiden. Im Sommer muß man fie die 230 d) 2 mal und bei beizer Sitterung nod) öfter mit frifa)em S్Şafier verfebert. In 23 seibern

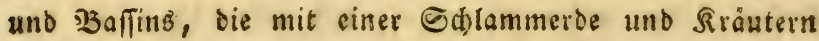
verieben fins, bebủfen fie feiner weitern Fütterung; o fie aber ben Schatten lieben, thut man wobl, biefe $23 e$ is ber unb Baffins mit vorzủglid) breitblättrigen झुflanjen, als bev reiz̄en und gelben Nymphea zu bepflanzen, unter welde fich biefelben verbergen Ënnen. Sorzüglid bat man

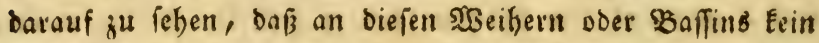
breitbeiliger 3 weijabn (Bidens tripartita) wadble, indem beffen Saamen, da fie fid) in Dem (jaumen bers felben fertbängen, ibuen tödid) fino.

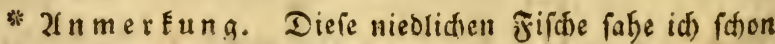
vor etra 12 Jabren in oem fidonen ग) erian= $\overline{5} u t$

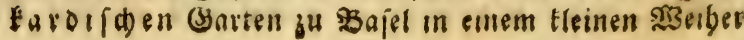


in Menge. STieher nach Cartgrulge wurten fie burd) Şbro Röniglide Scheit die Fraut Marggrâin (5a so. line Euife, Eantgraf \&uswig VIII. von feeflen.

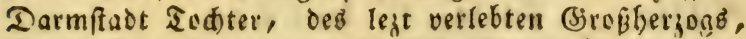
Carl Eriederid, erfte (Bemablin gebradt, wo. felbff fie in einige Eleine Baffing gefegrt murben, wo fie fid vermefrten. Nun fieft man fie Dafelbif, in Mannbein und in andern benadbarten @täbten bie

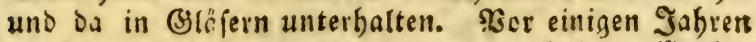

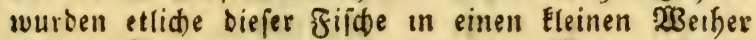
ohnweit $\mathfrak{B}$ a Denweiler in ber oberen Marggrafidaft gacen eingefejt, welde fich bajelffit feit biejer Seit rebr vermebrt baben.

** If nmerkung. Die ganz weifen gifide bicier frrt börften Eaum als eine befondere 2Gänderung, fontern vielmehr als ein FranEer Buĩand betradbtet werben. Die faöne rethe Farbe hat ibren Siç in bem oberfädlictens Edleime. Daber laffen fid diefelbe im 2 Beingeift, welder ifnen rogleids bie garbe aubgieft, nidst gut aufberwabren. 


\section{II fe}

Seite

Seile
oben. unten.

repe man

1.

4.

5. Iăngliđtrunto

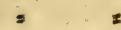

9. Ossicula.

$5 . \quad 12$.

7. Siefen.

28. =

29. 6 .

5.

Plattleiber.

$77 . \quad 10$.

Notocanthus.

104.

$=12$.

aculeatus.

122. 1.8. 13.

122.

6.12.

Gymnothorax.

123. 4.11.

$=$

Edwertiid. iduertformiges.

128. =

143. 4 .

5.

152. 10.

s

Edowert.

160.

178. =

191.

231. 3.

240 . =

$=$

6.

7.

Sdwwert.

248.1.

249.4.

Callionyme.

Fig.

380.

250.

$258 . \quad$

263.

8.

270.

15.

289.

9.

3.

pentadactyla.

291.

12.

307.

312.

319.

343.

16.

6.

.

13.

5

4.

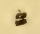

.

7.

5.

$=$

is

,

,

:

$\therefore$

b.

。
Fig.

Pleuronectes.

Fig.

296.

Sdwert.

Sd)werte.

Die Rotbbarbe.

Le

78.

Fig.

Salmone

baben einers

Corégone

tleinen

Nekze.

ditractan. 


\section{Detutide segliter.}

䍂

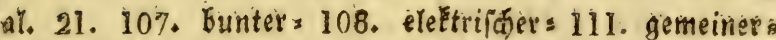
109 Tab. 21. Fig. 38. = Şaut, 111. Meer = 108. T. 20。 F. 37. = Niutter. 150, T. 36. F. 59. Natters 108. S. Suppe. 142. Sand $=22.118, T, 25$. F, 42. Bitter $=111$. T. 22. F. 39. - 2(id)e. 302. T. 89, F. 131, breite $=301$. getneine $=302$. Neer 30.323 . - 21fter. 7 . = floffen 11 . Zgenen 359. - 2llano. 366. - Blecfe. 370. - Ulat. 354. zilbel. 2llbule, 372. 2arie. 336. T, 102. F. 149. 21muhis Dien ichrommence 1. 18. 31. 26njovis. 338. 2unfauger. 156. 21rgus. 196. T. 50, I.,77. 26pe. 369. 2ugen. 6. = wimper. 147 .

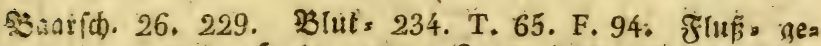
meiner $=229$. Sredt $=230$. Staul, 233. Sand $=230$.

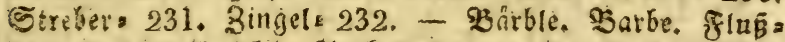
342. T. 104. F, 152. Foth: 250, - Baub. 7. = fliter。 260. =fleffen 10. Belunenftein 69. SBittertina. 371. T.111. F. 163. Blaufelderi. 307. T. 91. F. 133. Sblatovf 235.

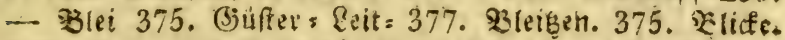
378. Bobian 226. T. 61. F. 90. B3d (t). 136. Borftene fleffer. 222. - B $r$ a d) Durn: 376. (5ieifl 212 . Biclo $=210$. T. 54. E. 82. guld:

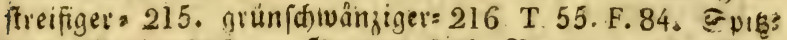
213. Gtein=376 - Braden. 375. Breitlutg. 334. Bres feri. 375. SBrummer. 171. Sruft. 7. s fleffe. 910 ร̧us

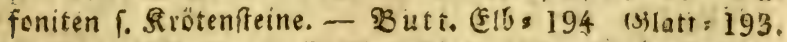

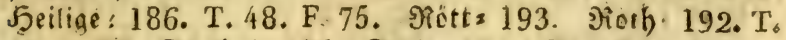
49. F. 76. Stad)el = 195. Ctein=194. Struffa pertegrtes E:lb = 196. Sitte, 189. Buttifecten. 188.

Savint. 63, 66, 68, 317, 324. 329. 


\section{Deนt}

Didfhals. 146. Eopf. 173. 354. - Döbel 359. Rotho S2Beí, 360. DonnerEröte. 171. DopuelbulsEieme. 18.36. fănabeltópfige = 36. T. 2 F. 5. Doppellinie, 191. Doraden. 24.157, S3indens 161. gemeine $=157$. Pfous 158. Segel=162. - Dorníd)weill. 175. Doridh. 136. - DradenEepf. 25. 175. fiegender. 178. T 46. F.

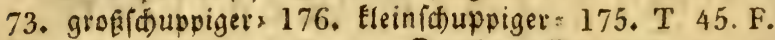
72. fduppenlofer= 177. - Draden: Seepferd. 83. T. 14. F. 24. - Dreiedf, geperlteb. 100. vierftad) vierbôrniges. 101. - Drever. 307.

Einbornteufel. 71. Eyerfted 12. Erribe, 357, T, 106, F. 158. Elte. 354. Erfling. 365.

Eafern. 11. Finger. 11.

Fijde. 13. 2ibtheilung ber $=18-30$. 26 belf. 305. 2fltet ber $=13$. 2lufentfalt ber's 13. Banof. 22. 12\%.153 T. 39. F. 63. geffridgelter $=125$. T. 28. F. 49. - Bart $=73$. - Baudfliemenf. 19. Glinder $=37$. T. 4. F. 7. - SEedez ciung ber: 2. Beinf. 98. - Blöbaugenf. 27. afrif́anis forer $=237$. T. 68. F. 97. - Bodianf. 26. 225. Bogenf. 198. Siratf. 365. 366. Brufffaltenf. ourdfidtiger. 22. 123. T. 28. F. 47. S5utterf. 149. Dectf. 22. 120. De: genf. 115. Dornf. 241. (Eided) fenf. 29. 319. guinefifders 320. T. 97. F, 143. - Eintornf. 75, T. 13. F, 22. - fang. 14. Fellenf. 29.281. geftachelter $=282 .-$ Fingerf. 30. 327. fliegender 30.325 . Frauenf. 365. Frofdff. 19. grofier= 69. T. 11. F. 19. - Fủnfïngerf. 160. Babelf. 253. Bangf. 307. $\mathfrak{N B}_{\text {ei }}=305$. Sertenf. 24. 164. Filber. farbiger, 165. 'T. 43. F. 68. Gold F. 158. 380. Đlümiers fdeers 206. T. 51, F, 80. SaaldÉlemenf. 18, 35. marmos rirter $=36$. T. 3. F. 4. 5马ammerf. 50. S2ainifdf. 29.283. getippter $=284$. rungelmauliger $=283$, T. 86. F. 128. Şornf. 19. 75. Bauci)gabel $=76$. geflecter: 79 . igels fobwangigers 77 . fowarzer $=80$, violetter $=79 .-$ Igelf. 20.89. Theibenförmiget $=91$. - Jobnf. 26. 236. Rats utt $=236$. T. 67. F. 96. Saiferf. 204. T. 52, F. 79, Slipp f. 136, 25, 197. adtbantigers 205. 2lrgus s bans,

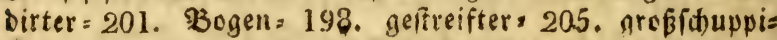

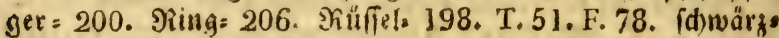
lid)ter = 199. ítwargers 207. - Slumpf. 91. Sinorwels artige f. 18.31. Sinorvelf. 6. Snotenf. 19. 72 ringflof. figer $=73$. Soniggf. 328. Sofferf. 20. 98. Dreiectigers 


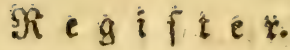

99. Rornábrenf. 30. mittelindiłary 322. T, 97. F. 144. Sugelf. 90. berftiger $=96$. Ransfidmarzf. 113, 24. 163 . T. 42. F. 67. Eanzetfówan; ;. 28. bärtiger $=258$ T. 76 . F. 107. - Lip p f. 26. 218, grinter $=219$. Sienenbonens 220. rether 221 . visletter $=219$. T. 58. F. 87. Eurjanf. 26. 228. T. 63, F. 92. Maif. 336. MRenfert. 20. 83.

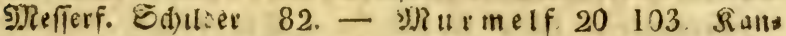
num: 104. - Nabelf. 85. zueiffadeliditer: 85 - NA. fenbeinf. 103. Rafenfaferf. 28. Eablets 267. T. 79. F. 113. Diugen der $=14$. Dronung Der $=18-3 \mathrm{C}$. Pamzerf. 98 . गुapageif. 26. grúner 218 . T. 57. F. 86. - 220. rothers 217. T. 56. F. 85. Paradiesf. 329. 5t. Peterf. 182. Dुfeifenf. 29. Subacks=311. T. 93. F. 136. - Biegents bogenf. 221. গiiemenf. 24. 153. アRiterf. 25. 208209.

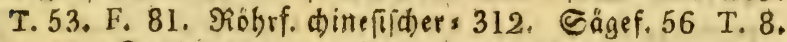
F. 14. Eantf. 118. - Eaugef. 24.154. greser: 155. Fleiner: 156 Edillf. 23. 133, 134 T, 32 F. 55.

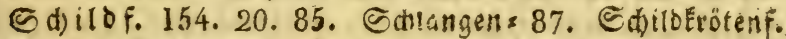
93. - Sdlangenf. 22. 3art= 119. T. 25 F.43. (5d) leimf. 23. 144. (5irunbel = 148. - Sthmalif. 73. Sthnabelf. 198. Sdunttf. 359. Sdineiberf. 372. Sdnepfenf. 20,81, T.13. F. 23. Fouppiger, 81. Cdnutt. 359. Sduertf 22 122. T. 27. F. 45. Eleiners 318. Siebenfingerf. 330. - Silberf. 180. 29. sjerten $=321$. - Sogof. 26. 227. T. 62.F. 91. Eotbaterf. 202. Sont nellf. 182. Epiegelf. 25. 179. liffiger $=181$. Epinnenf. 23. fliegenber: groß̈ers 128. T. 29. F. 50. Eleiner, 129. Epiziduan. 115. eleftrifor $=116$. filberfarbiger $=115$. T. 23. F. 40. Epring?. 325. T. 99 F. 146. Epribf. 198. - Sta delbaud) 20.93. geflecter* 96. T 17. F. 33. geffreifter $=95$. getiegerter $=97$. Sattels $27 \cdot 249$. Sta delf. 20. 27. eleftrifder $=98$. Ianger: 89, runbers 90. T. 16. F. 31. Etielaugenf. 23. 126. fabenförminer: 127. T. 77. F. 108. - Etindff. 299. Strdef. 136.

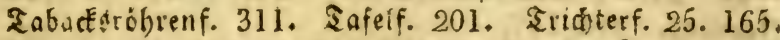
Irompetenf. 312. T. 94. F. 139. Umberf. 26. 223. Bart $=224$. gemeiner $=$ fd) war $=223$. T. 60. F. 89. siseiff.

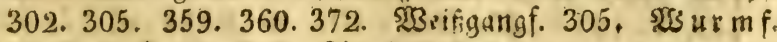
22 125. Faier. 125. 3innf. 358.

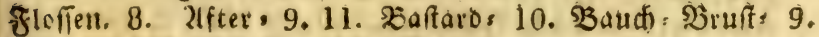
10. búfjelförmige, 10 . Fett = 8. 11, gleidformige: 8 。 


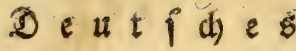

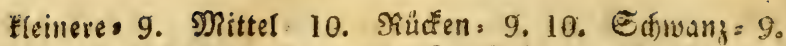
11. jufatuengefezte: 8. - Floflen Gräten. Etrablen. 8. Flonder. Flunoer. 189. linte Stad)el, 195. - Eos vellen. 286. 2lipen = 295. T. 87. F. 129. Bad) $=293$. Serigs 295. braune $=294$. gemeine $=293$. (jenferfe 297 .

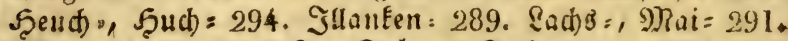
Mibeinanten = 289. See: Salm=, Sitber: 290. Stein",

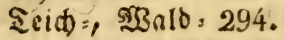

Barum. 243. 339. Baumen. 6. = Sined)en. 4. Bebörwetd" geนg. 7. (3engling. 366. (J)iebliden. Gietel, 355, T. 109.

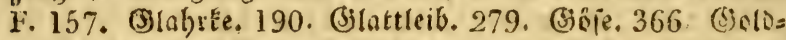
decfe. 120. T. 26. F. 44. = Strid). 215. (Sinäte. 5. (Sirnu= bart. 119. Sirimpel. 357. Brevpen. 25 169. gepangerter = 170. (3roffepf. 323. Bründing. 263. 349. Brün (d)wan. 216. (3) run е el. 25. 165. 263. इ3art: 263. Silau $=167$. geaugte $=168$, \&anget $=167 .-$ Gufte:。 378. 380. 5 Blei $=377$.

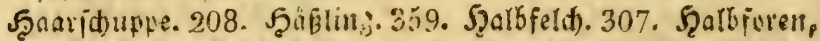
breitleibige. 310. Jaarber. 323, T. 98. F, 145. . 5afel. Sapele. 359. Jafentopf. 94. 5aufen. 67. = Blafe. 64. 68. 139. 142. $-5_{5} a \%$ 19. 46. Gancirter $=49$. Elauers 51. Dorn $=57$. Engel $=58$. netizgerter $=47$. Sammer $=50$. T. 6. F. 10. Şund $=47$. Jonas $=52$. ifabellenfarbener $=$ 47. Reken $=50$. Eleiner Jyunds = Fleingefteder: 48 . Sieuk $=50$. Siröten $=58$. Mieerfau $=50$. Tiiefen $=52$.

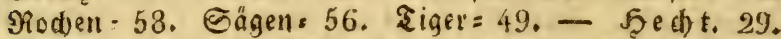
313. braftianifcher $=318$. T. 96. F. 142. Frufa $=316$. gemeiner $=$ Firas $=315$, forn $=317$. T. 95. F. 140. Sno dells 314. = Mönig. 316. Mer $=316$, 9labs $=317$.

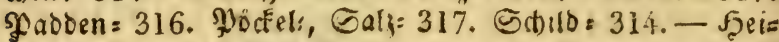
ligebutt. 186. T. 48. F. 75. - 5ering. 30. 330. Flict, 334, gemeiner: 330. T, 101. F. 148. 55obl=331. Eater $=334$. 2oll 331 . - Senerling. 30\%. Sacdpties ger. 327. STadrủcken. 24. 151. T. 37. F, 61.

Jentling. Jere. 366.

Sabeliou. 136, T. 33. F. 56. Sablafter: 24, Shawenifdev: 152. T. 38. F. 62. - S ab!b ruft. 21. 04. शgurenen=

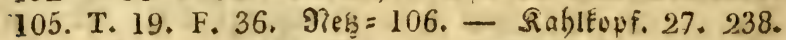
Sinhlrüten. 21. 111. Stalamin. 328. T. 100. F, 147. Sarauid)e. 353. T. 108. F. 126. - 356. Steins 355. Raryfell, 30, 342,343, Baftards 345.347, gemetnes 


\section{negifter}

343. (3) $18=380$, T.113, F.164. = אönig. 348. Epiegel= 348. T. 105. F. 153. 3ritter $=348$. - Saubaarid. 173. 233. Siaultepf. 173. Selyle. 7. Sehlenbaut. 4. Site fe 11. 4. = Decfel. 4. 5 = 5aut. 5. s Sautgräten. 5. 3. Ofinung. 4. 6. - Sieferm. Siemen. 4. Sinnlacen. 3.4.

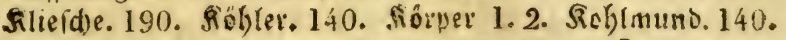
Sopf. 2. Throimmender $=91$. T. 17. F. 32. Sopple 173. Freffe. Sicksling 349. T. 106. F. 154. Sirötenteine. 11\%。 212. Srepffe!d)en. 305. Sirumbiefer. 369. אübring. 364. Rurzídwank. 114.

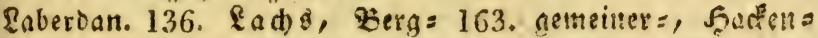
286. Ragenen. 359. Eamurete 32. Eangbart. 273. Eaue ben. 358. T. 110. F. 159. \&augele. 358. \&auqell. 373. Seim. 230. Reng. 141. Rippen. 3. Roetsmann. 246. Eufts röhren. 6. Sump. 72. T. 12. F, 21.

Maufel. 378. Majedien. 331. - Ma a r ele. 27. 242. Baffaro $=245$. Beutelaugen $=247$. gemeine $=242 . \mathrm{T} .70$. F. 100. Reots $=246$. Edwert= 248. T. 71. F. 101.

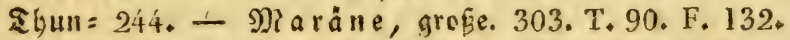
Heine $=306$. Siropf:, weife $=305 .-$ Ma goe1. 307. Meer = abler. 44. =nffe. 59. = barbe. 27. 250. gelbne= ftreifte: 251. T. 72. F. 102. = brad)e, 19. Morblichers 59. =engel. 58. iglundel. 166. T. 44. F. 70. = Girid). 146. = juncfer. 220. T. 59. F. 88. =lerche. 148. =nafe 37.4. = pavillen. 145.T. 35. F. 58. =pfau. 158. =(đ)!ange. 87. - פRenidenfreffer. 52. T. 7. F. 12. Mieferidmiot. 182. Mild. MRildner. 12. Mlitte! wieber Die Flecten ber Jouna baut. 144. Mgeluafijate 52erzog, 205, Mi un $0=1$ leim. 64. $=$ Offrung. 3. Murene 105 .

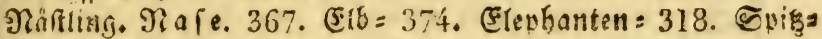
41. - Nafenlëd)er. 6. Nerfling. 364. 365. গieftungs 372. Neunauge, grefes $=33$.

öl. 242. 303. 341. Dife. 365. T. 112. F. 161.

3erten. 306. 322. 373. Perfide. 229. Ferfer. 193. Peters

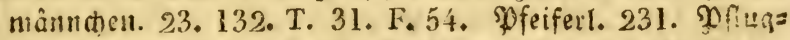
(d) aar. 180. T. 47. F. 74. Dildard, 339. T. 103. F.151. Wlatais. 187 - PlattEonf. 29. 279: rouber $=280$. Edi)aufel $=280$. T. 84. F. 125. - Flattleter. 28. 278.

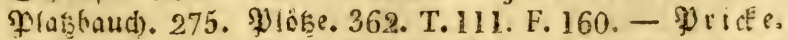
Fluf., gemelne $=33$. T. 2. F. 3. Sicefin $=34$. Eampratens 32, T. 1, F, 1. IJlanerifde:=, Silber $=35$. 


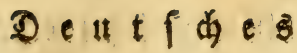

Quarke, 142. T. 34, F. 57.

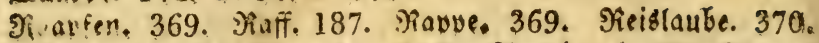

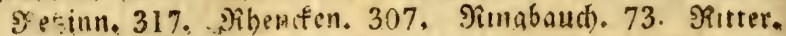
297. - Nochen. 19. 38. abler $=44$. Torn $=42$. Bifts 45 (i)tart $=40$. Siranuf $=39$. Nagel $=43$. Epiegel $=42$. Gribfont: 41. Sted $=45$. T. 5. F. 9. Bitter $=39$. T. 4 . F. 8. - Troffer. 187. Fiotele. 362. Siötbele. 296. গiöth= lina. 26. 234. 235. 297. Siggener. 12. - Rothsauge. 360. $362 .=6$ urt nefireifter, $25 \mathrm{l}$. Fleiner. 250 . = muno.

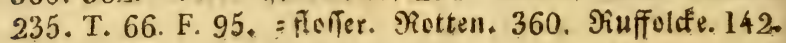

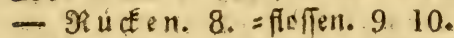

Sactflefler 214. Söqubauth. 310. T. 92. F. 134. Sälbling. 296. T. 88 F. 130. - a!m. 29. 285. Forellen $=286$. 289. nemeiner $=286$. Eee $=290$. SEBurfel $=310 .-E_{A L}$ maru. 29\%. Eaturlin. 296. Eander. 230. Sandelder. 305. Sarcelle 338. T. 102, F. 150. Ediffshalter. 155. T. 40. F. 64. Sdhlamninizaer. 265. - Seblangentopr. 27. punftirter $=257$. T. 75. F. 105. - Ed) lei. 351 . Gald : 352. T. 107. F. 155. - Shlund, = baut. 6. (s) inerle. 28. 260. gemeine $=263$. T.178. F. 111 . Sd) lamm=265. T. 78. F, 112. Stein $=264$. Furinamift)ea 260 T. 78. F. 109. Sdhnepel. 300. breite $=301$. Sd) ols le. 25. 184. gemeine $=187$. Seeiligebut $=186$, T. 48, F. 75. Bauten, 193. Zebra $=185$. Zungen $=190 .-$ Edrätz fer. 238. T. 69. F. 98. Sdreiber. 367. Sduppen, =rand. 2. Sdiwärmer. 203. Sd)wanz. 8. = fleffe. 8. 11. Sthrariz baud). 367. Sdwuliblaje, 11. Sdwoimmer, 84. Sdwope. 379. Eedsauge. 160. - See=bell. 72. = bradbe. 60 . 129. 83. =fledermau8. 71. = baafe. 72. =ba b n. 60. 27. 252. fliegender $=256$, T. 74, F, 104. gepanzerter $=253$. tother $=254$. Sd)walben $=255$. - stöpfer. 96. = Füflen. 39. Seele, 358. Gee =măule. 39, = nabel. 86. T. 15. F. 26. = pferodben. 87. T. 15, F, 30, =ratte, nörliche $=59$. T. 9. F. 16. püblides 60 s =rafsen. 59. sfecrpion. 171. T. 44. F, 71. sftier. 101. =teufele = wolf. 69. 21. 116. T. 24. F. 41. - Eifberbede. 121. Sole. 190. Spetf=

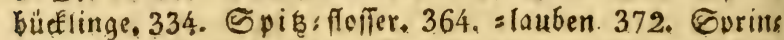
ger. 325. Sprotte. 334. Stad)el=nadel. 85. = rüfert. 29. 280. शafenftad)elrüfen. 281, T. 85, F, 127. = fal. 176. = fámani. 77. - Ste in=beifer. =grunidel. 264. spicter, 170. =pizger, 264. - Stern, 7. =6aud. $44_{4}$ 


\section{Fegifter.}

seber. 23. 130. rauber. 131. T. 30. F. 52.'- Stitss Iin n. 27. 239. 316. gemeiner $=239$. T. 70. F. 99. gros Ber See $=241$. Eleiner Gee $=240$. - Stint. Froger = 298. See = 299. - Stöder. 245. - Etöbr. 19. ge= meiner $=61 . T, 10 . F, 17$. Saufen $=67$. Saidefterlet, 66 . Sterlets 65. - Strablen. 8. Streben. 231. Strômlinne. 331. Strobbuttinge, 334. Strunfe.370. T. 110. F, 162. Stuben. Stueben. 307. StuB Éopf. 24. 157. Findens 161. Blauer $=159$. geflecters 157. T, 41. F, 66. Gegel = 162.

Sellertráaer. 278. T. 83. F. 123. Sheerbott. 196. Ibran. 92. 139. 141. 142, 177. 240, 334. 341. इ5un. 244. Iburmtråger, vierecfiger. 102, T. 18, F. 35. Torge. 144, Srompete. 86. Truiche. 142.

Utuéelei. 372. Urfe. 365 .

Sierauge, 260, Biereck, vierhörnige\&, 101.

Weib, altet. 78 W̉eisfeldhen. 305. 25 el 8. 28. 268. bitfe baudiger $=275$. T. 82 F. 118 . eleftrifder $=272$. frof $=$ 277. gebörnter $=268$. gemeiner $=271$. langbårtiger $=273$. T. 82. F. 117. Meer $=270$. T. 81. F. 115. rauber $=278$. fteifbartiger $=268$. T. 80. F. 114. ungebörnter: 269. -

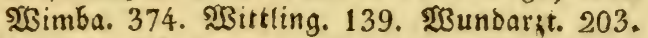

Bäbne. 4. 3ärthe. 374. 3anter. 230. T, 64. F. 93. 3an nenid)naube. 314. 3innel. 232. 3ove. 3opbe. 379. $\rightarrow$ 3unge, 6. 190, banditte $=185$. Barten, $345 \%$ 


\section{Régistre françois.}

Able. 306 372. Acanthure chirurgien, 203, noirauds 199. Theuthis, 282. Achire deux-lignes. 191. A c ifénsere Esłurgeon. 61. - Huso. 67. -Strelet. 65. Agénẹiose armé. 268, - désarmé. Aiquille. 312 a Alose. 336. Amie chauve. 267. Ammodyte appat. 118. Anablèps Surinam. 260. Anarhique Loup. 116. Anchois. 338. Apron. 231. Argentine Sphyrène. 321. Argyréiose Vomer. 180. Armé. 268. Ascite. 275. Aspe. 369. Aspidophore armé. 170. Asprède, 278. Aulostome chinois. 312.

Bagre. 270. Baliste épineux.77. -Monoceros.75. -noir. - sillonné 80. - tacheté. 79. - vieille.78. Barbeau. 342. Becard. 286. Bécasse. 81. Békone. 317. Bergfurelle. 295. Blennie Gattorugine. 146. - Gunnel. I49. - ovo vivipare. 150. - Pholis 148. - sourcilleux. 147. -Torsk. 144. Bodian Bloch. 2\%6. Bordelicre. 379. BouclierLiparis 74. -Lompe, 72. Bouvięre. 371. Brème. 375 a Brochet. 315.

Caesio poulain. 249. Caimann. 314. Callionyme Dragonneau. 129. -indien. 280, -Lyre. 128. Caranx Trae chure. 245. Carassin. 353. C a r p. 343 . - a miroire. Raine de-348. Centrisque cuirassé. 82. Centronote Pilote 246. Centropome Sandat. 230. Cépole Taenia. 153. Chét od on Argus. 201. - bridé. 202. sgrand écaille. 200. = huit-bandes. 205. museau-alongé. 198. Chevalier américain. 209. Chevanne. 354. Chien de mer barbu. 49, -isabelle. 47. -maricau. -Milandre. 50. - Rousette. 47. Chimère antarctique. 60. - arctique. 59. Clupanodon Pilchard. 339. Cobitc Loche, 263. Taenia. 264. Coffre a bec, 10,3, - trian- 


\section{R ếg is t r e.}

gulaire. 99. - triangulaire tuberculé, 100. Colli. branche. 36. Corégoue Thymalle 302. - Vartmann. 307. Corp. 224. Coryphène bleu. 159. - Hippurus. 157. - ondé, 161. - Plumier. 158. Cotte Chabot. 173. - grognant. -Scorpion. 171. Crin. 222. Croissant. 219. Cycloptère Lomp. 72, Cyprin céphale,-cvlindrique. 354. - doré, 380. - large. 378. -Rotengle. 362. - Sope. 379. - spéculaire. 348.

Dactyloptère pirapède. 256. Dard. 358. Désarmé. 269. Diodon atinga. 89. - Orbe.90. Diptérodon apron. 231. -Zingel. 232. Dobule. 359. Doras côte. 284.

Échénéis naucrate. 155. Écureuil. 235. Élope Saure. 320. Émoi. 428. Éperlan. 298. Épinoche. 240. Espadon le petit. 318. Essence orientale. 306. 373.

Filou, 213. Franche-Barbotte, 263.

Gade aeglefin. 134. - Callarias. 136. - Lote. 142. Merlan, 139. Molve. 141. - Morue. 137. Gascon. 245. Gasté。 rostée épinoche. 239. - épinochette. 240. -Spinachie. 241. Gastrobranche Aveugle. 37. Gibèle. 355. Girelle, 220. Gobie awaou. 168. - jozo. 167. -noir. 166. -Lanceolé. 16\%. Goujon, 349. Grenouiller. 277. Gros-yeux, 260. Guacari. 283. Gymnètre Hawken, 152 Gymnote Carape. 113. -électrique. 111. Gymnothorax reticulaire. 106.

Hamburge. 353. Hareng. 330. Hautin. 321. Hémiptéronote cinq-taches. 160. Hirondelle de mer. 255. 325. Holacanthe anneau. 206. - cilier, 208. - Duc. 205. -Empereur. 204. Holocentre Post. 233. -Schraitser. 238. - Sogo. 227. Humble Chevalier. 297. Huch. 294. Hypostome Guacari 283.

Jarretière. 165. Ichthyocolle 67. Ide. 364. Jesse, 366。 Joël. 322. Istiophore porte-glaive, 248.

Kurte Blochien. 151,

Labre barbier, 235. -verd. 219. Lamproie branchiale. 34. - marbrée. 32. Large. 301. Lavaret. 300. Lépidope Gouanien, 165. Lépisostée Gavial. 314. Leptocéa phale Morrisien. 125. Loehe. 264. Lenchure dianémea 258. Lophie Baudroie. 69. - Chauve-souris. Vesper. tilion. 71. Lutjan Anthias. - Écureuil. 235.

Macroptéronote Grenouiller. 277. Macroure Berglax, 463. Mal 271, Malaptérure élcctrique. 272. Malare 


\section{R ég is tre}

2nat. 253. Maquereau, 242. Marène. 303. Meuniex, 366. Misgurue fossile. 265. Mormyre Kannume 104. Morue en breton. -frais, - seche. 138 . Muge céphale. 323. volant. 325 . Mulet. 323. Mulle rouget. 250. Murène Anguille. 109. - Congre. 108. Murénophis Héléne. 105. Museau, le demie. 318.

Nase. 367 Notacanthe Nez. 281.

Oligopode vélifére. 162. Ombre bleue. 307. - de Riviere 302. Ophicéphale Karruwey. 257. Ophidie barbu. 119. Ophisure Ophis 108. Orfe. 365. Orphie. 317. Os racion Drumadaire. 102 = Museau-alongé. 103. -quadrangulaire. squatre -aiguillons. 101. - triangulaire, 99. - trigune. 100.

Pagre 214. Papou. 282. Pegase Dracon. 83. - Spatule, 84. Péristédion Malarmat 253. Perlon 254. Petimbe. 311. Persèque Perche 229. Umbre.224. Petrom yzo n Bricka, 33. -Lamproyon. 34. -Lamproie. 32. - Planer. 35. Pilote. 246 Pimélote Ascite. 275. Bagre. 270. Pirabe, 327. Pirapède. 256. Planer. 35. Plestie. 378. Pleuronecte Argus, 196. - carrelet. 193. - Fletan. 186. -Flez.189. -Limande. 190, moineau. 195. - Plie. 187. -Sòle. 190, -targeur, 192. - turbot. 194. -Zèbre. 185. Poison coq. 60. - doré de la Chine 380. - de Paradis. 329. - rayè. - à Rubans. 209. -volant.325.327. Pomacanthe arqué. 198. -doré 206. - Paru. 207. Post. 233.

Quinze-épines. 241 .

Raboteux, 280. Raje Aigle. 44. -alêne, 41. -Batise 40. - Bouclée. 43. - coliart. 40. -Miraillet. - Miralet. 42. - oxyrinque. 41. - Pastenaque. 45. - Ronce, 42. - Torpille 39. Régalec Glesne. 125. Rhomboïde, 310. Rosse 360. de rivières. 362. Rousse. 360. Rousette tigrée. 48. Roy des harengs du Nord. 59. -du Sud. 60. Salmarine, 296. Salmon e lllanken. 289. - Salveline. 296. - Sieffermuller. 290. - Truite. 293. =TruiteSaumonée. 291. Sandat. 230. Sanguinolente 234. Sardine, 334. Sarve. 362. Saumon argenté. 290. Scare rouge, 217. - verd 218. Schraitser. 238. Sciène umbre. 223. Scombre la petite jumont. 249. -Thon, 244. Scorpène horrible. 177. -volante. 178. Serrasalme rhomboïde, 310 . Seuruga, 66. Sheilan, 273a 


\section{f $r$ a n g o is.}

Silure cole. 284. - Glanis. 271. Spare Dorade. 210. =queue-verte. 216. - Sargue.212. -Saupe 215. -trompeur. 213. Spirlin. 370. Sprat. 334. Squale ai. guillat. 57. -Ange, 58. -glauque, 51. - Isabrlle, 47. - marteau. - Milandre. 50. - Requin. 52. - Roussette. 47. - Roussette tigrée. 48. - à Scie. 56. -très grand. 52. Sternoptyx Hermann. 123. Stromatée Paru. 120. Styléphore argenté. 127. Surmulet. 251. Synbranche marbrée. 36. Syng $\mathbf{n}$ athe aiguille, 86. - Hippo. campe 87.

Tanche 351. - dorée. 352. Tête-nue. 367. Tét rod on hérissé. 96. - Lune. 91. - Perroquet, 93. -rayé. 95. Thon. 244. Torsk. 144. Trachine vive. 132. Trembleur. 272. Trichi u r e électrique. 116. -Lepture. 115. Trichopode trichoptère. 222. Trigle Grondin. 254. Triple-tàche, 221. Trois-épines. 239. Truite. 291. - brune. 294. - Saumonée. 289.

Umbre. 223. Unibranchaperture marbrée. 36. Urano. scope rat. 131.

Vagabond. 203. Véron. 357. Vilain. 366, Vimbe, 374 。

Vaudoise. 358. Voilier, 248.

Xiphias Espadon 122.

Zée Forgeron, 182, - rusé, 181, Zingel, 232 。 


\section{Lateinisches $\mathbf{R}$ egister.}

Abdomen. 7. Acipenser. 19.61. -Huso.67. - Ru thenus. 65. -Sturio. 61. Tab. 10. Fig. 17. A mi a.28. - calva. 267. T. 79. F. 113 Ammodytes. 22. -Tobianus. 118. T.25.F.42. A m ph ibia nantes. 1.31. A nableps teirophthalmus. 260. An arhich as. 21. - Lus pus. 116. T. 24. Fig 41. Anthias, 26, 234. -formosus. T. 66. F. 95. - sacer. 235. Anus. 7. A pertura branchialis 4. 6. Argentina. 29. - Sphyraeva.321. A therina. 30. - Hepsetus. 322. T. 97. F. 144.

$\mathrm{B}$ a list es. 19.75 . - aculeatus. 77 . - maculatus. 79. - Monoceros. 75. T. 13. F. 22. - ringens. 80 . - Vetula 78. Blennius. 23 144. -Gattorngine. 146. -Gunnellus. 149. -ocellaris. 145. - Pholis, 148. -superciliosus 147. - viviparus. 150. T. 36. F. 59. Bod i a n us. 26. 225. - Bodianus. 226. T. 61. F. 90. Branchiae. 4. Bufonites. 118.

Callionymus. 23. 128. - Dracunculus. 129. - indicus. 280. T. 84. F. 125. -Lyra. 128. T. 29. F.50. Callo. 123. Caput. 2. 3. Cataphractus costatus. 284. Cauda. 8. Centriscus 20.-Scolopax. 81. T.13. F. 23. -scutatus. 82. Centrog ast er. 27. -Equula.249. Cepola.24. -Taenia, 153.T.39. F. 63. Cha et od on 25. 197. -annullaris 206. -arcuatus. 198. -Argus. 201. - aureus. 206, T. 52. F. 80. - capistratus. 202. - Chirurgus. 203. - ciliaris. 208. - Dux. -fasciatus, 205. -Imperator. 204. T.52. F. 79. - lanceolatus. 209. -macrolepidotus, 200. -nigricans 199. octofasciatus. 205. Paru 207. rostratus, 198. T.51.F. 78. -striatus. 201. - vagabuidus, 203. Characini, 310. Chimaera. 


\section{$R \odot g i s t$ e $r$.}

19.59. Callorhynchus, 60. -monstrosa. 59, T.9. F.16。 Cl u pea. 30. 330. Alosa. 336. T. 102. F. 149. Encrasicolus, 338. T. 202. F. 150. Harengus, 330. T. 101. F.148. -Pilchardus. 339. T. 103. F. 151. Sprattus. 334. Co bitis. 28. -Aaableps, 260. T. 78, F. 109. - Barbatula. 263. T. 78. F. 111 - fossilis, 265. T. 78. F. 112. - Taenia, 264. Coregoni, 300. Corpus. 1.2. Corypha ena. 24. 157. coerulea, 159, -fasciolata, 161. -Hippurus. 157. T.41. F. 66. -Plümieri. 158 - pentadactyla. 160. -rupestris. 164. T. 42. F. 67. - velifera. 162. Cottus. 25. 169. - cataphractus. 170. -Gobio. 173. -grunniens, 171. -scaber. 280. -Scorpius. 171. T. 44. F. 71. Cyelopterus. 19. -Lumpus. 72. T. 12. F. 21. Cyprinu s. 30.342 . Alburnus, 372 . - amarus. 371. T. 111. F. 163. -Aspius, 369. - auratus. 380. T. 113. F. 164. - Bsllerus. 379. -Barbus. 342 T. 104. F. 152. -bipunctatus, 370. T. 110, F, 162. -Blicca. 378. - Brama. 375. - Brama Duetop, 37. - Carassius. 353. T. 108. F, 126. - Carpio. 343, - Cephalus. 354. -Dobula. 359. - erythophthalmus. 362. T. 111. F. 160, -Gibelio. 355. T. 109. F. 157. -Gobio. 350. T. 106. F. 154. -Idus. 364. -Jeses. 366. -latus. 378. -Leueiscus。 358. T. 110, F. 159. - macrolepidotus, 348. T, 105. F, 153. - Nasus. 367. - Orfus. 365. T.112. F, 161, -Phoxinus. 357. T. 106. F. 158. -Rutilus. 361. - Tinca. 351, -Tinca auratus. 352. T. 107, F, 155. - Vimba. 374.

Dentes. 4. Digitio 11. D iodon, 20. -Atinga. 89. -Hystrix, 90. T. 16. F. 31. -Mola 91. T. 17. F. 32, -oblongus, 89. -rotundus. 90, T, 16. F. 31. Dors u m. 8.

Echeneis. 24. 154. -Iveucrates, 155, T. 40. F. 64. -Remora. 156. Elops, 29. 319. -guineensis. -Saurus. 320. T. 97. F. 143. E pinephelus. 27.-afer. 237. T. 68. F. 97. Eques. 25. 208. - americanus. 209. T. 53. F. 81. Es ox, 29, 313. -Belone, 317. T, 95. F. 140. - brasiliensis. 319. T. 96. F. 142, -Lucius 315. -osseus. 314. Exoc oetus, 30, 325. -evolans. 327. - exiliens. 326. T. 99. F. 146. - Mesogaster. 327.

Fistularia, 29. 311. - chinensis, 312, T. 94, F, 139. - tabacaria, 311, T, 93, F, 136, 


\section{Lateinisches}

Gadus. 23. 133. - Aeglefinus. 134. T. 32. F. 55. - Cale 1arias. 136. - carbonarius. 140. - Lota 143. T. 34. F. 57. - Merlangus. 139. - Molva. 141. -Morhua. 137. T. 33. F. 56. -Torsk. 144. Garon, Garum. 339. G ast erosteus. 27. - aculeatus, 239. T. 70. F.99. -Ductor. 246. - pungitius, 240. -Spinachia. 241. Gastrobranchus. 19. -coecus. 37. T.4. F. 7. Glossopetrae.52. Gobius, 165. -jozo.-lanceolatus. 167. -niger. 166. T. 44. F. 70, oceanicus, -ocellaris, 168. Gula.7. Gymnetrus. 24. -Hawkenii, 152. T. 38. F. 62. Gym nocephalus, 27. -Schraetser. 238.T. 69. F. 98. Gymn ot hor ax. 21. 194. -Helena. 105. T. 19. F. 36. - reticularis. 106. Gy m n ot u s. 21.111. - Carapo. 113. -electricus, 111. T. 22, F, 39, -fascia. tus. 114.

Hol ocentrus, 26. -Sogo, 227. T. 62. F. 91.

Johnius, 26. - Carutta, 236. T. 67. F, 96.

Kürtus, 24, -indicus, 151. T, 37. F, 61.

Labia. 3. Labrus.26.218. -A n thi as. 235. -earneus, 221. - julis. 220. T. 59. F. 88. -lunaris. 219. T. 58. F. 87. - trichopterus, 222, -viridis. 219. Le pidopus. 24. 164. argenteus. 165. T. 43. F, 68. Le ptoce phalus. 22. 124. - Morrisii. 125. T. 28. F. 49. Lonchurus. 28. - barbatus. 258. T. 76. F. 107. Lophi.u s. 19. - piscalorius. 69. T. 11. F. 19. -Vespertilio. 71. Loricaria. 29, 283. - costata. 284. - Plecostomus. 283. T. 86. F. 128. Lu tian us. 26. -Lutjanus. 228. T. 63. F. 92.

Macrourus. 24. -rupestris. 163. T. 42. F.67. Mandibula. 4. Maxillae, 3. M embrana branchiostega s. branchialis. 4. 5. -palati, velamen, 6. Mormy* ru s. 20. 103. -Kannume, 104. Mugil, 30. - Cephalus. 323. T. 98. F. 145. Mullus. 27. - barbatus. 250. - Surmuletus. 251. T. 72. F. 102. Muraena. 21. 107. - Anguilla, 109. T. 21. F. 38. - Conger. 108. T. 20. F. 37. - Helena. 105. T. 19. F. 36. -Ophis. 108. Mures marini. 39. Myxina glutinosa. 37. T.4. F. 7.

Notocanthus. 29. 280. - Nasus. 281. T. 85, F. 127, Novacula coerulea. 159. 


\section{Re $g$ is t e r.}

Oculi. 6. Opercula branchialia, 4.5. Ophicepha. 1us, 27.-punctatus. 257. T, 75. F, 105. O phid is u m. 22. - barbatum. 119. T. 25. F. 43. Os. 3. Osmeri, 298. Ossicula palati. 4. Ostracion. 20. 98. - bicaudalis, 100, - cornutus. 101, - Nasus. 103. =quatri-cornis. 101. - trigonus. 100. - triqueter. 99. -turritus, 102. T. 18, F. 35. Ovaria. 12.

Pogasus. 20. - Draconis. 83. T. 14. F, 24. - natans. 84. Perca, 26. 229. - asper, 231. - cernua. 233. - fluviatilis, 230. -formosa. 235. T, 66, F. 95. - guttata. 234. T. 65, F. 94. -Lucioperca, 230. T. 64. F. 93. -Schraetser. 238. T. 69. F. 98. -Zingel. 232. Petromyzon. 18. 31. -argenteus. 35 , -branchialis. 34. - fluviatilis. 33. T. 2. F. 3. -marinus. 32. T. 1. F. 1. - Planeri. 35. Pinn-a-ae. 8. - adiposa. 8. 11. - analis. 9. 11. caudalis, 9. aequalis. anexa, bifida, coalita. distincta. emarginata, rotundata, trifida. 11. - dorsali s. 9. coalitae, distinctae. longitudinalis. lumbaris, media aequilibris, occipitalis, re* mota. scapularis. semilongitudinalis. 10. - mediac. 10. - pectorales, 9. acuminatae, falcatae, geminatae, inae, infimae. longissimae. mediae, rotundam tae. solitariac, supremae. 10. -s p u ria e. 10. -venirales. 9. abdominales. coadunatae, coalitae, jugelares, remotae, thoracicae, vicinae, 10. Pinnulae fasciculatae, 10 . Pisces. 13. - abdominales. 28. 260. -Apodes. 11. 21. 107. -chondropterygii. 18. 31. - diurni, fluviatiles, gregarii. 13, -jugulares. 23. 128. - lacustres. 13. - malacopterygii, 8. -marini, nocturni, solitarii. 13. -thoracici. 24. 153. Pl at yce pha. 1 us. 29. 279. -scaber. - spathula. 280. T. 84. F. 125. Plat y $\mathbf{t}$ a cus. 28. - cotylephorus. 278. T. 83. F. 123. - laevis. 279. Pleuronectes. 25. 184. -Argus. 196. T. 50. F. 77. -bilineatus. 191. -Flessus, 189. -Hippoglossus. 186. T. 48. F. 75. -Limanda. 190. - maximus. 194. - Passer. 195. -Platessa. 187. - punctatus 192. T. 49. F: 76. - Rhombus. 193. -Solea. 190. -Zebra. 185. Polynemus. 30. 327. - paradiseus. 329. - plebejus. 328. T. 100. F. 147. - virginicus. 330. Radii, aculei, malacopterygii, spinosi. 8. Raja. 19. 38, -Aquila. 44. -Batis, 40, - clayata, 43, -Mirz- 


\section{Latein is ches}

Irtus. 42. - Oxyrinchus. 41. - Pastinaca. 45. T. 5. F. 9. - Past. Altavela. 46. -Rubus 42. -Torpedo, 39. T. 4。 F. 8. R a menta. 11. - Regalecus. 22, - Glesne. 125. Rictus. 3 .

Sal m o. 29. 285. -Albula. 307. -alpinus. 295. T. 87

F. 129. =Eperlano-marinus. 299. -Eperlanus, 298. -Fario. 293. - Far. sylvaticus. -Hucho. 294. -Illanca. - lacustris, 289. - Lavaretus. 300. 301. - Maraena. 303. T. 90. F. 132. - Maraenula. 306. - Muraena Ferra, gutturosa. 305. . rhombeus. 310. T. 92. F. 135. -Salar $\beta$. Illanca. 289. -Salmarinus. 297. - Salvelinus. 296. -Schieffermülleri. 291. -Thymallus 302. T. 89. F.131. -Thymsllus latus. 301. -Trutta. 291. -Umbla. 298. - Wartmanni. 307. T. 91.F.133. Scarus. 26. -Croicensis. 217. T. 56. F. 85. -viridis. 218. T. 57. F. 86. $\mathrm{S}$ c i a e n a. 26. 223. - cirrosa. 224. -nigra. Umbra 223. T.60.F.89. Scomber. 27. 242. -Crumenoph thalmus. 247.-glaclius. 248. T. 71. F. 101.-Scomber。 242. T. 70. F. 100. - Thynnus. 244. - Trachurus. 245 . Scorpa e a. 25. 175. -horrida. 177. -Porcus. 175s T. 45. F. 72. -scrofa.176, - volitan3-178. T.46, F.73。 Silurus. 28. 268. - Ascita. 275. T, 82, F.118, -Aspredo. 279. - Bagre. 270. T. 81. F. 115. - Batrachus 277. - Clarias. 273. T. 82. F. 117. - costatus. 284. - electricus. 272. - Glanis. 271. -inermis. 269. - militaris. 268. T. 80, F. 114. Sparus. 25. -aurata. 210. T. 54. F. 82. -Insidiator. 213. -Pagrus. 214. - Salpa. 215. - Sargus.212. S phagebranchus. 18. - rostratus. 36. T. 2. F. 5. Sp irá eula. 6. Squa Ius. 19.46. - Acanthias. 57. - canicula. 48. - Carcharias. 52. T. 7. F. 12, - Catulus. 48. -fasciatus. 49. -Galeus. 50. -glaucus. 51. -Isabella. 47. - maximus. 52. - Pristis. 56. T. 8. F. 14. -Squatina. 58. -tigrinus. 49. -Zygaena. 50. T. 6. F. 10. Squamae. 2. St ernopty x. 22. - diaphaná. 123. T. 28. F. 47 . Stro$m$ at e us. 22. 120. -argenteus. 121. - Paru, 120. T. 26. F. 44. Stylephorus. 23. 126. - chordatus. 127. T. 77. F. 108. Synbranchus. 18. 35. - marmoreus. 36. T. 3. F. 4. Syngnathus. 20.85. -acus 86. T. 15. F. 26. - biaculeatus. 86. - Hippocampus. 87. T, 15, F, 30. - Ophidion, 87, - telxagonus, 86. 


\section{$R$ e $g$ is $t$ e $r$.}

Tetrodon. 20. 93. - electricus. 98. - hispiảus. 96. -Honkenii. 97. -lagocephalus. 94. lineatus. 95. - Mo1., 91. T. 17. F. 32, -ocellatus. T. 17 F.33 -testudineus. 93. Teuthis. 29.281. - Hepatus 282. Thorax. 7. Trachinus. 23. -Draco. 132. T. 31. F.54. Trichiurus, 21. 115. - indicus. 116. - lepturus. 115. T. 23. F. 40. T'rigla. 27. 252, -cataphracta. 253 T. 73. F. 103. - Cuculus. 254. - Hirundo. 255. - volitans. 256. T. 74. F. 104. Truttae. 286.

Uran os copus. 23. 130. -scaber, 131. T, 30. F, 5\%, Velamen, vid. Membrana palati. Vesica aërea. 11 . $\mathrm{X}$ ip hia s, 22, -Gladius. 122. T. 22, F. 45. Z e u. 25. 179. - Faber. 182, -Insidiator. 181. - Vomer。 180, T. 47, F. 74.

গEDDECE. 


\section{$\Re \mathfrak{R} \mathfrak{g}$ iff $\mathfrak{f}$ \\ ow}

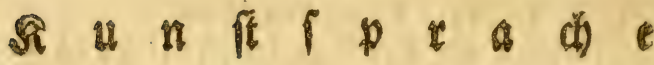

$5 e$

ben fifden.

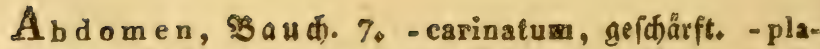
num, flach. - serratum, von Sduppen gefögt. - tumidum, aufgetrieben. - rentricosum, baudig.

Aculei, gloffenftacheln. vid. Radii.

Anus, Xfter. 7. -anticus, prope caput, nabe am fiopfe. - gularis, bei ber Fiefle. - medius, mitten am

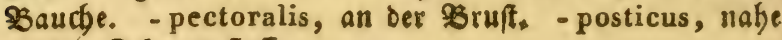
an ber Sdwangflofie.

A pertura branchia lis s. branchiarum, Siefenoff? ทи nq. 4. 6. - arcuata, gebogen. -cervicalis, im Nacéen. -gularis, unten in ber Reble. -lateralis, an ben Sei= ten. - nuchalis, im Senič. - ovata, eyförmig. - pectoralis, gegen ber $\mathfrak{B} r u \mid$ bin. - tubulosa, röbrig.

Caput, $\Re$ ○pf. 2. 3. -aculeatum, mit Stadeln. -acuminatum, ługépipiçt. - angulatum, eč́tig. - attenuatum. ăugeipikt. - cataphractum, mit einem Sthilde bes becft. - cirris instructum, mit langen berfenförmigen 2 Infăzen befę̧t. - clypeatum, mit einem Sdilbe. - cryo statum, mit einem Siamme. - declive, walzenförmig, abbângıg. - depressum, plattgedrủf́t. olevato-punctatum, erhaben - punttirt. = excavato-punctatum, aus: gebolt a punEtitto -glabrum, glatt, - loricatum, bepans 


\section{Kegiftet.}

jert. - malleiforme, hammerformig. nudum, nact. - papillosum, wetdwarin. - pingue, mit einer $\xi 5 e t h a u t$ bedecft. - plagioplateum, plattgeorücțt. s radiato-stria. tum, frablicht. - retusum, zurüctgeftumpit. -rostrasum, in rostrum porrectum, in einell अiúffel berluns gert. rugosum, rungelid)t. -scabrum, raub). - simum, cingebogen. -squamatum, befduppt. - sulcatum, nes furcht. - transverse sulrato-serratum, mit fägeförmis gen Suerfurchen。 - truncatum, abgeftumpft. - verruco. sum, bartwargigo

Cauda, Sdwang. 8. -apterygia, ofne Flofien.

Corpus, fírper. 1. 2. -aculeatum, g. вitadelidt. - alepidotum, obne Sduppen uno Sthiloer. - anceps, aneifóneioig. - angulatum, ecfig, Eantig. - carinatum, Eielformig. - cathetoplateum, compressum, von den Seis

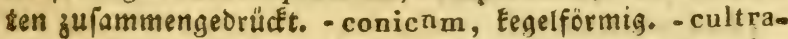
tum, mefterförmig. - cylindricum, länglichtruno. - depressum, niebergebrůct. - fusiforme, fpindelformig. -gibbum, buckeltajt. - glabrum, glatt. -globosum, Eus gelförmig. -laeve, glatt. - lanceolatum, lanzetförmig. -lubricum, mucosum, føllthpfrig, f́leimig. - murica\&um, Eleinftad)elid)t. - nudum, nacfend. - orbiculatum, Ereišrund. - ovatum, evfórmig. - papillosum, ivetd)war fig. - plagioplateum, von cben platt gebrücte -scabrum, raub. - setaceum, borf́tig. - sphaericum, Eugels formig. - squamis tectum, mit Sd)uppen verfeben. - teres, länglidtrund. - tuberculatum, finöpfig. -ventricosum, mit Gerosrftebendem 3 audbe. - verrucosum, bartwarzig.

Dentes, 3 åkne. 4. - rotundati, abgerundet. - sagittac ti, pfeilförmig.

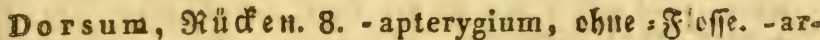
cuatum, bogig. - carinatum, gefdârft. - convexum, erbaben. - dipterygium, mit 2 sfleffen. - excavatum, mit Siruben. - monopterygium, mit I sflofe. -planum, flaळ). - rectum, gerade. - serratum, gefást. - sulcatum, mit surchen. - tripterygium, mit 3 = fleften.

Gula, Reble. 7. - carinata, gef̣ảrft, -plana, floç. - Featricosa, baudig. 


\section{Segifter ber Rutuffprade}

Iris, Stern. Zugenitern. 7.

Labia, Eıpen 3. 4. - hifida, gefpalten, -biloba sroclupptg. - carnosa, fleifhig. - ciliata, am गanie gez franjt. - duplicata, Dopvelt. - fissa, sefpaltert. -integra, gan. - membranacea, băutiq. - quinquepartita, finfo theilig. - rostrata, in cinen Siüfer verlangert. - simplicia, einfad). - tentaculata, mit Jüblfäben vcrieberr.

Mandibula, $\operatorname{Rinnlabe.~-~ensiformis,~bie~sbere~län~}$ ger alb oie untere, fdwertformig. -integra, auf berder Eeiten gall. - serrata, mit fägenförmigen Exizen.

Margo, $\Re$ ant. 7. - orbitalis, am Zugentreife, 7. -pua pillaris, an ber Dffnung bes Sterns.

Maxilla e, Rinnladen, 3. 4. -aequales, gleithlang. -inaequales, ungleid). - labiatae, mit Rippel bedect. enudae, unbebectit.

Membrana branchialis s, branchiostega, Fiefent

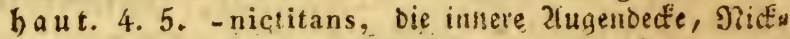
baut. 70.-oceulta, oom Riefendectel gan bedectit. -palsti, Edlunchaut. 6. - patens, gan frei, -semipatens, balo bedectit.

Oculi, 2f ugen. 6.7. - binati, nar allf ciner Eeite bes Sopfer. Iris, Stein. Margo pupillaris, Det গiano an ber S̈frinng bes Sterng. Margo orbitalis, ठ. 9i.

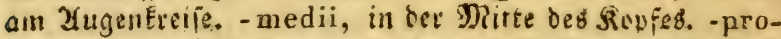
tuberantes, Gervorragent. -supremi, sben an ben Geis

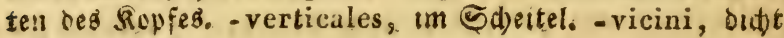
neben einander.

Opercula branchialia, Riefenbeder. 4.5. -acuk leata, ftactolict)t. -acuminata, zlugefpizt. -adnexa, fraenata, sten und uitten an bie Şaut angewadjen. - alea pidota, obne Sauppen. - angulata, effig. - arcuata, benenförmig. - carnosa, mit einer fleifdoigen 5̧aut übers zogen. - ciliata, gefirant. - crenata, geferbt. - dentata, am Fanbe gezä́nt. - diphylla, ineiblätterig. - emargisata, augeranbet. - flexilia, bieglam. - fraenata vid. adnexa, -glabra, glutt, -integra, gank. -laevia, eben. - libera, frei. - mollia, neió). - nitida, slen;ent. - ossea, fnödern. - patens, frei, -radiata, gefireift.-ro- 


\section{beisen Fifden.}

tundata, runb. -scabra, raub. -screrata, sqiâgt. -sim. plicia, einfad). - squamata, gefduput. - tetraphylla, vierblätrig. -triphylla, oreibláttrig. -truncata, abs geftumpft.

Pinn-a-ae, $F l o f f=e=e n .8$. - adiposa, 8. 11. - a nalis, 2ffter = 9. - caudalis, Gd)wanzs 8. 9. - compositae, zufammengefezt. 8, - coalitae, verwadien. 10. - distinc tae, abigefonbert. - dorsalis, Miuctenflelle, 9. -geminatae, zroei anf jeder Seite. 10. - longitudinalis, fo lange

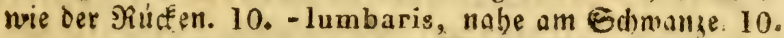
- media aequilibris, in Der Mitte beș ’iuctens. 10. - mediae, Mittel $=$ oder 23aftard flofien. 10. -occipita. lis, nabe am Sopfe. 10. - pectorales, Bruft $=9$. - remota, nabe am 5ळmange 10. -scapularis, auf bett

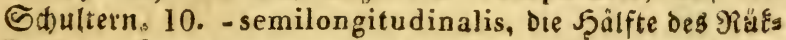
Eens cinnebmend. 10. -simplices, gleidförmig. 8. -spu. riae vid, mediae, - ventrales, Baud)fofien. 9.

Pisces, abdominales. Fुiffe mit Bounfoffen binter den Bruffifofien. 28. - alepidoti, solne Gd)uppen uno

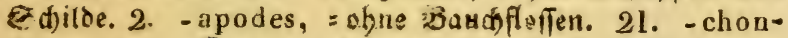
dropterygii, fincrpelfídie. 31. -jugulares, mit Băatts: ficfien, meldie vor ben Srufffoffen fteben. 23. - malacopterygii, = deren floffengrâte ober Srrablen bieg: fam, aus 2 neben emander liegenden jufammengefest find, bie (id) an Der Epije tbrilen. 8. - thoracici, mit $\mathfrak{B} a u(4)=$ floffen gerade unter ben şrufffoffen. 24.

Radii, (5iráten, Strablen. 8. - aculei, -spinosi, einfad), Gart, fvizig.

Rictus, NRunbỏffnung. 3. - inferus, unterwărtฬ. - obliquus, fdief. -superus, obermärts. - terminalis, vorı an Der Eyize bes Ropfer. -transversus, borizontal. - verticalis, fenfredit.

Spiracula, \&uftröbren. 6. - ante oculos, vor bet? 2fuger. - pone aculos, binter ben 2 fuger - solitaria, einjeln.

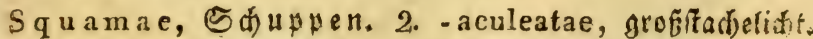
- acuminatae, - acutae, fugefpigt. -amplae, grob. - cartilagineae, Enotpelattio. - ciliatae, geflangt. - cre 


\section{Regiftet。}

natae, geferbt. - deciduae, leicht abfallend. - fasciatae, banoirt. - glabrae, glatt. -integrae, am Rande gam. - lamellosae, blättrig. - maculatae, gefiecft. - magnae, vid. amplae. - minimae, Eaum fid)tbar, febr tlein. - oblongae, lânglicht = runo. - orbiculatae, runo. - ossae, Enöbern, hart. - ovatae, eyförmig. - parvae, Elein. -punctatae, punttirt. -quadrangulatae, vierectig. - radiatae, frabliabt. - rotundae, runb. -scabrae, raub. - serratae, gefägt. - sexangulatae, fedssectig. - striatae, geifreift. -tenaces, feit angeroacien. - triangulatae, breiectig. -truncatae, abgeftumpft. -tuberculatae, enoppig.

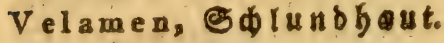

NEY DECE. 
Tref. 1.

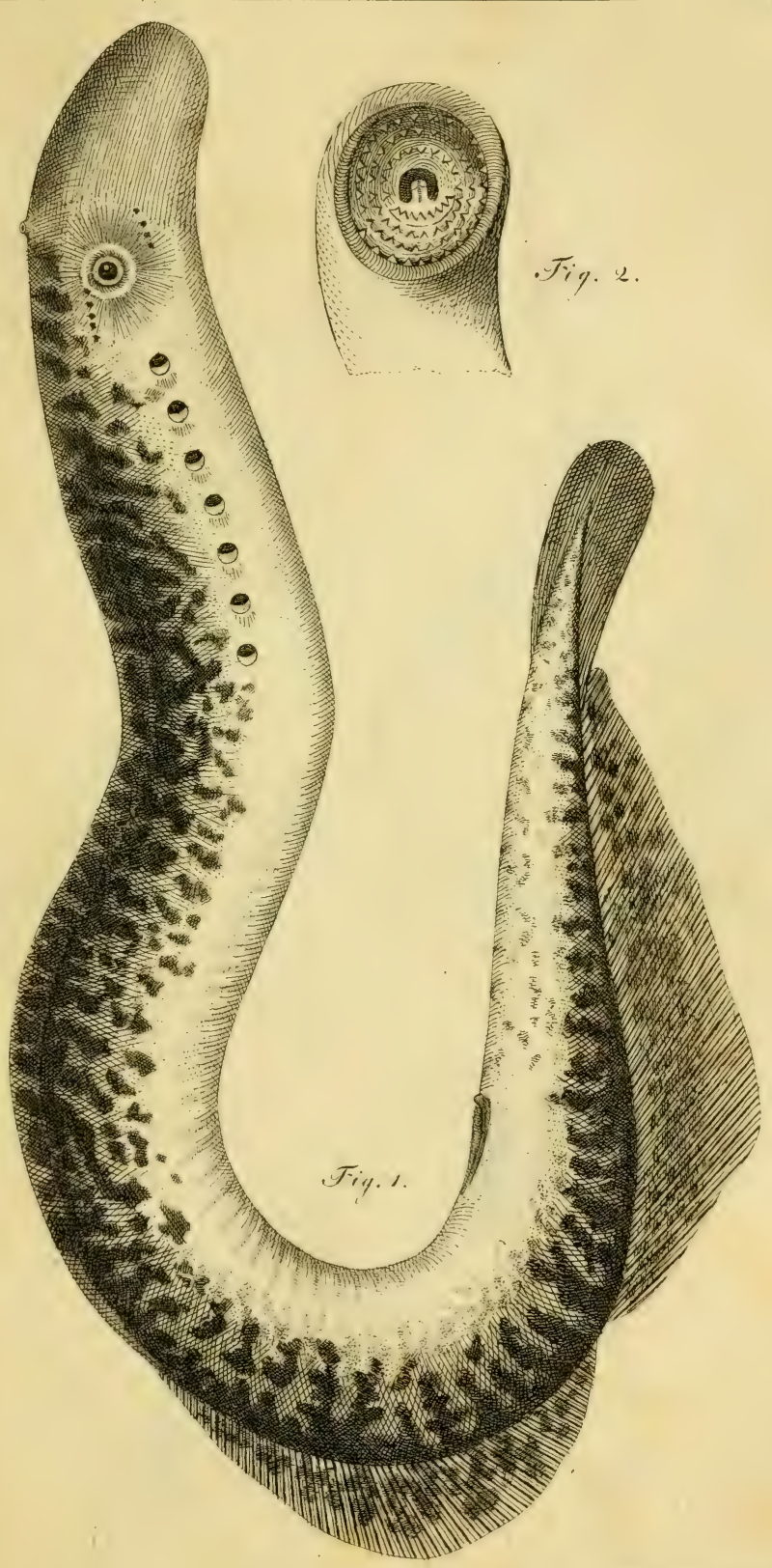






$$
\frac{1}{0}
$$



. Fort: के

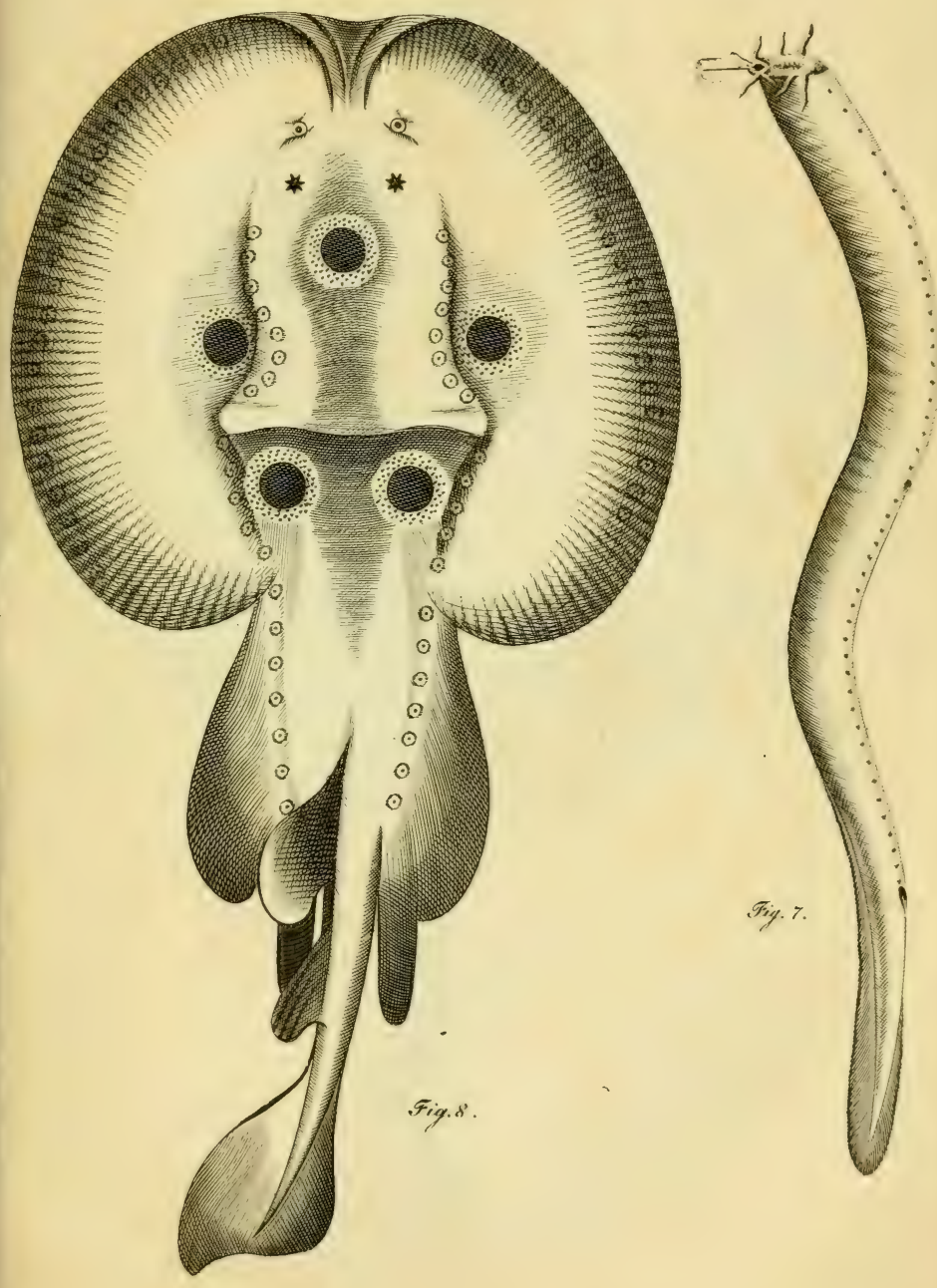




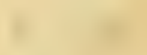

$$
\text { v. }
$$

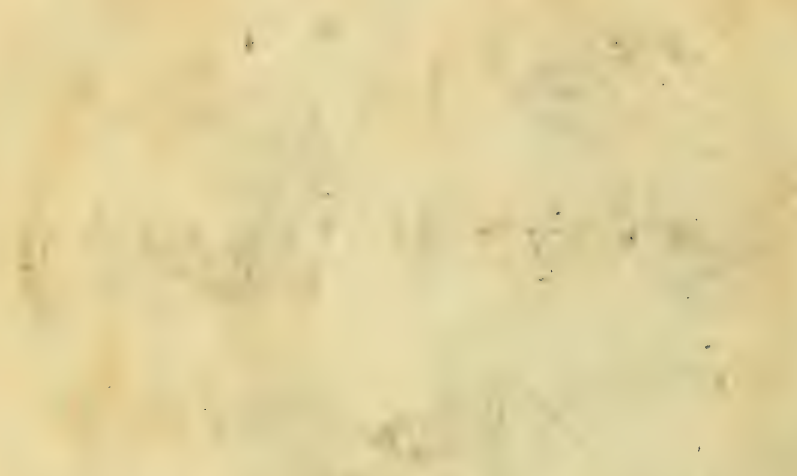

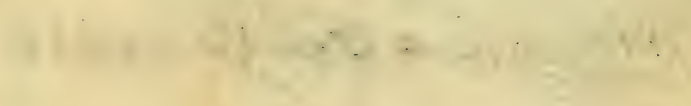
br 
Taf.5.

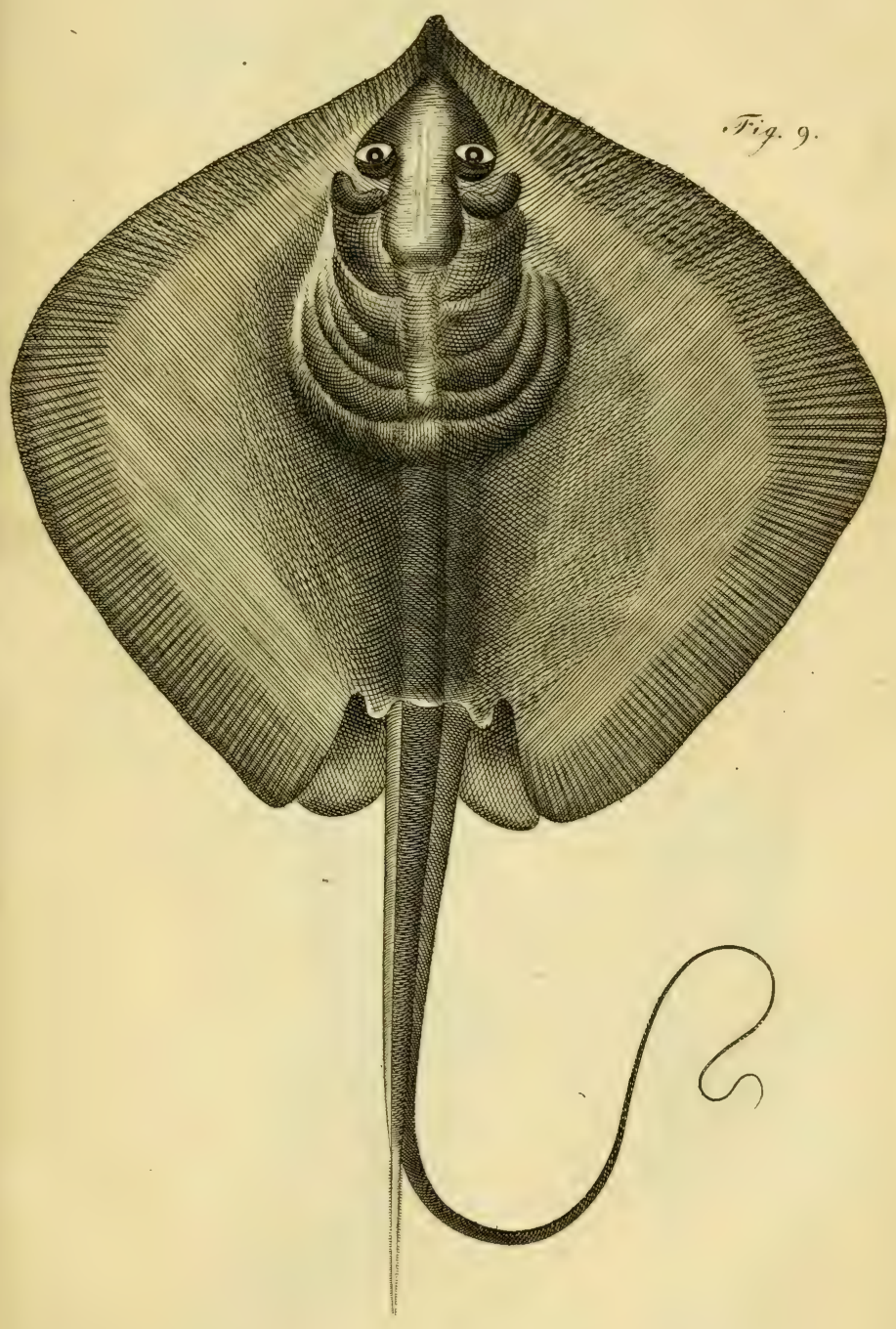




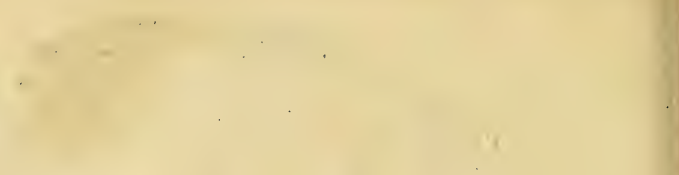

$$
\therefore
$$

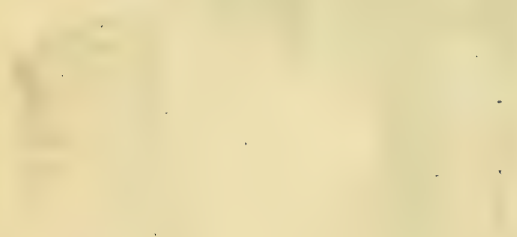


Try). 6

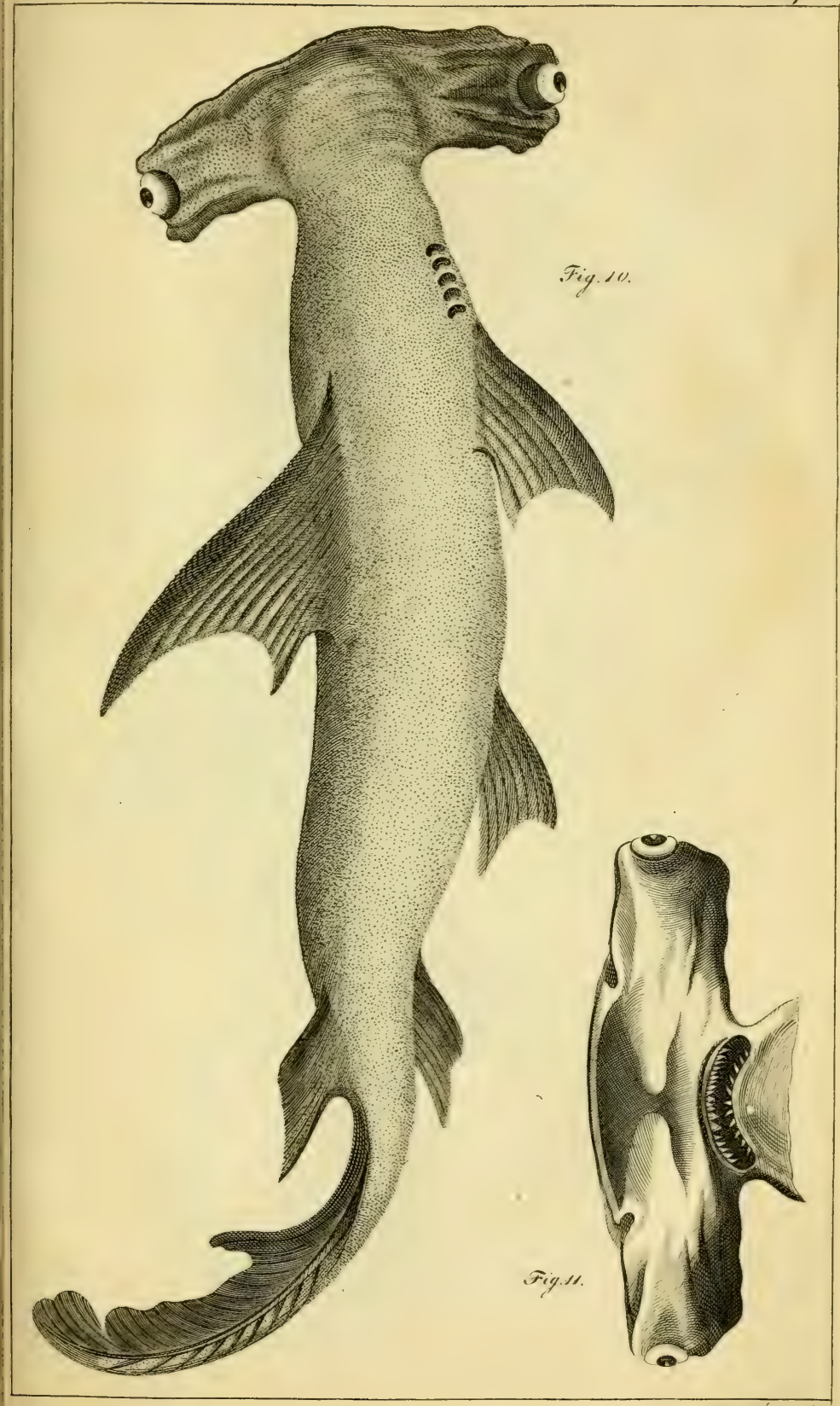




Tal. 8.
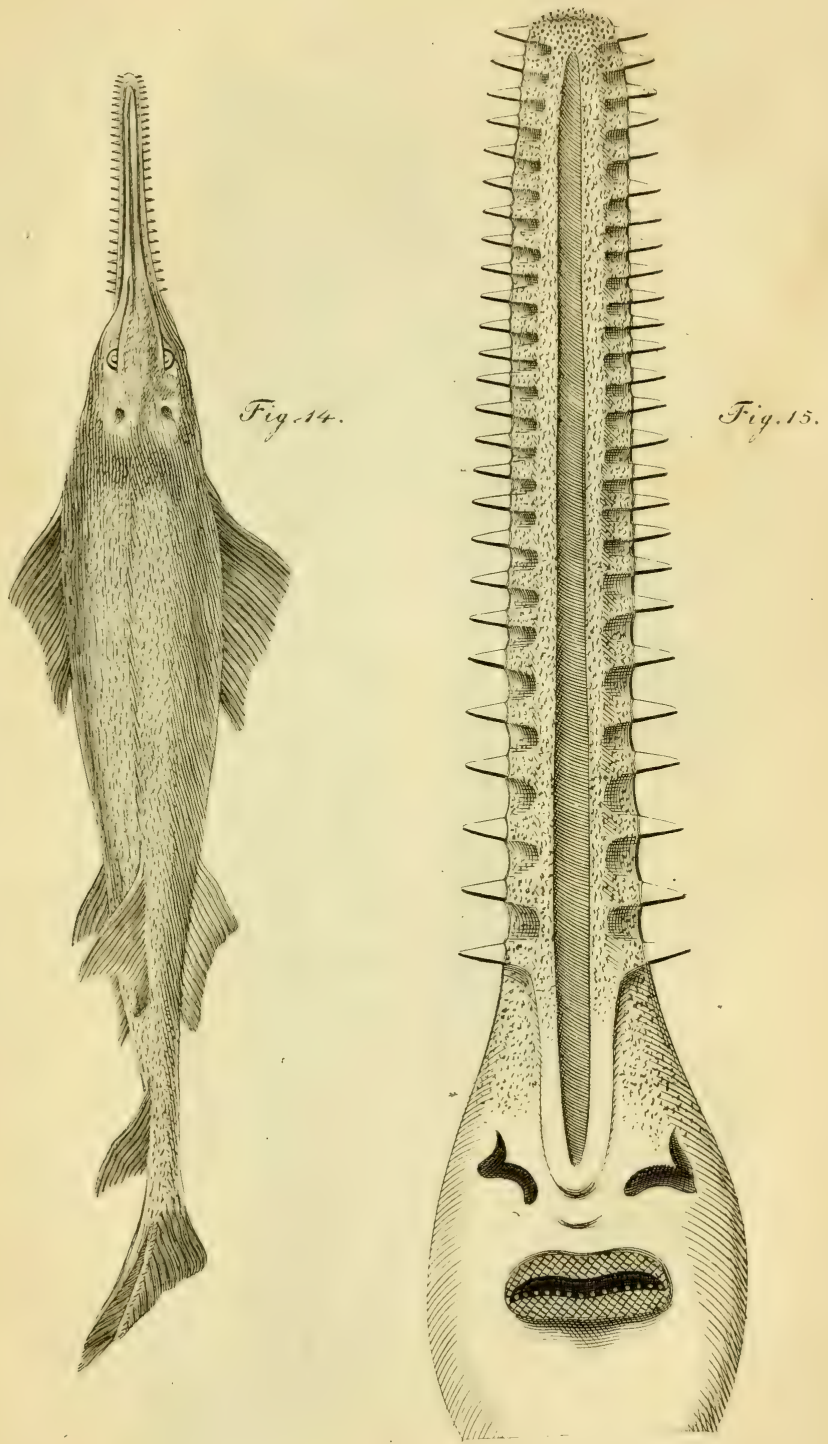

. Tol. 9

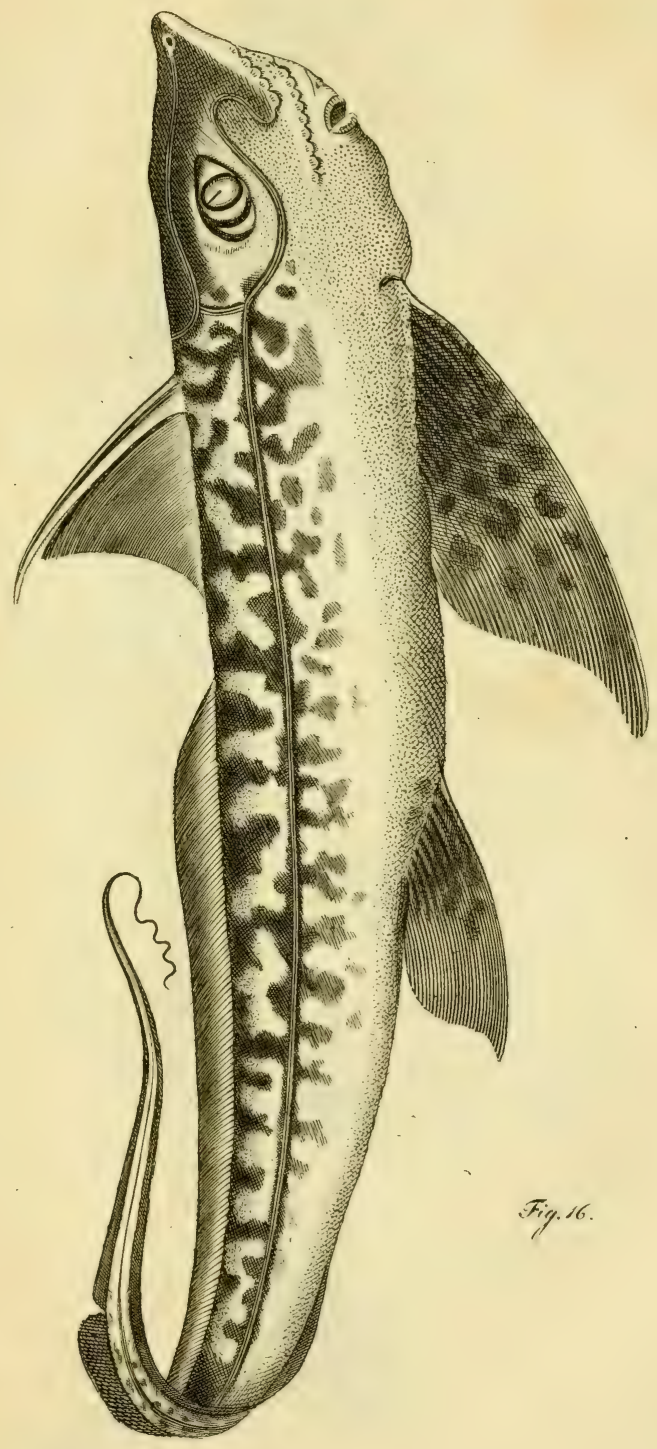



Tr1. 10.

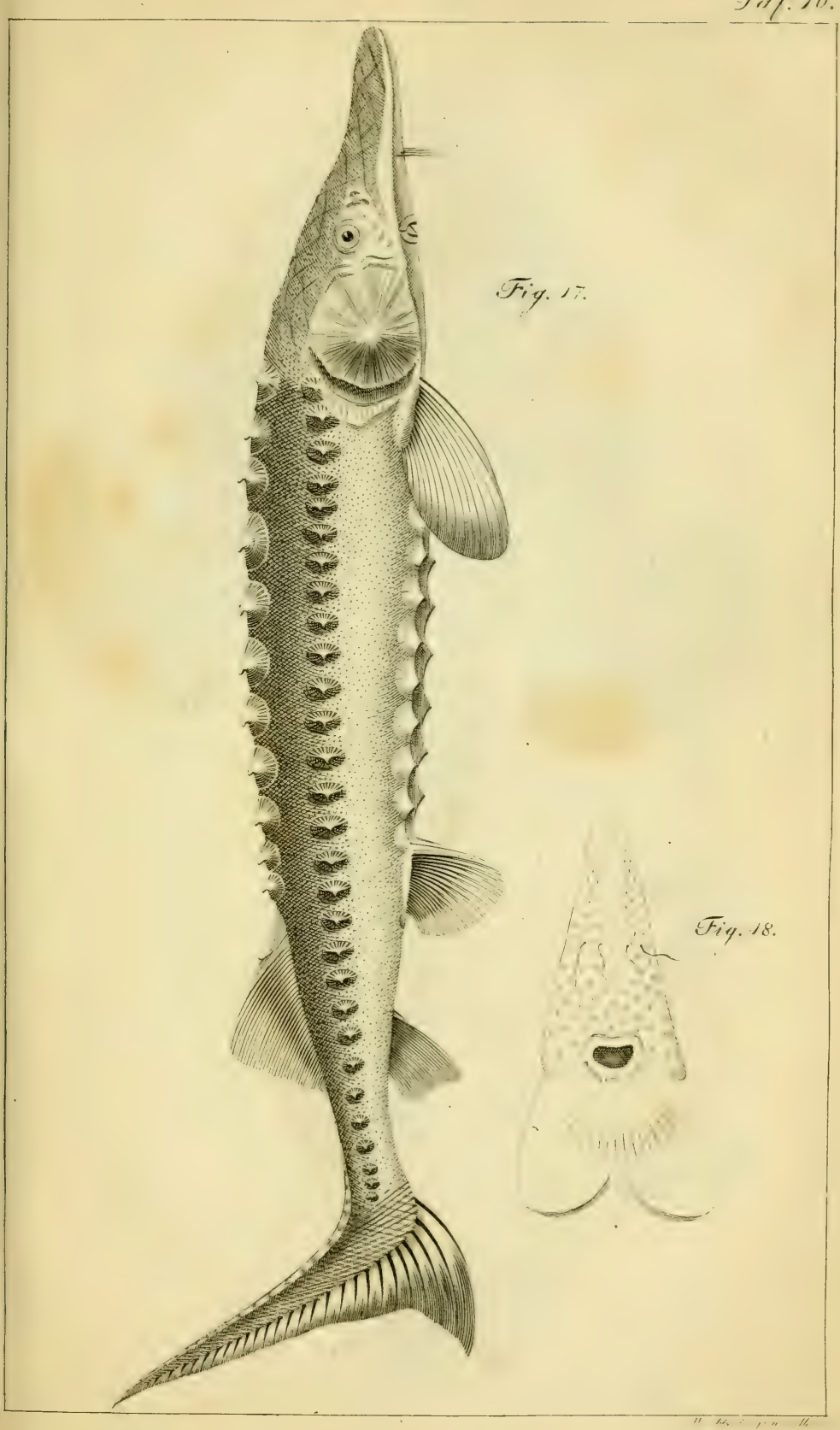





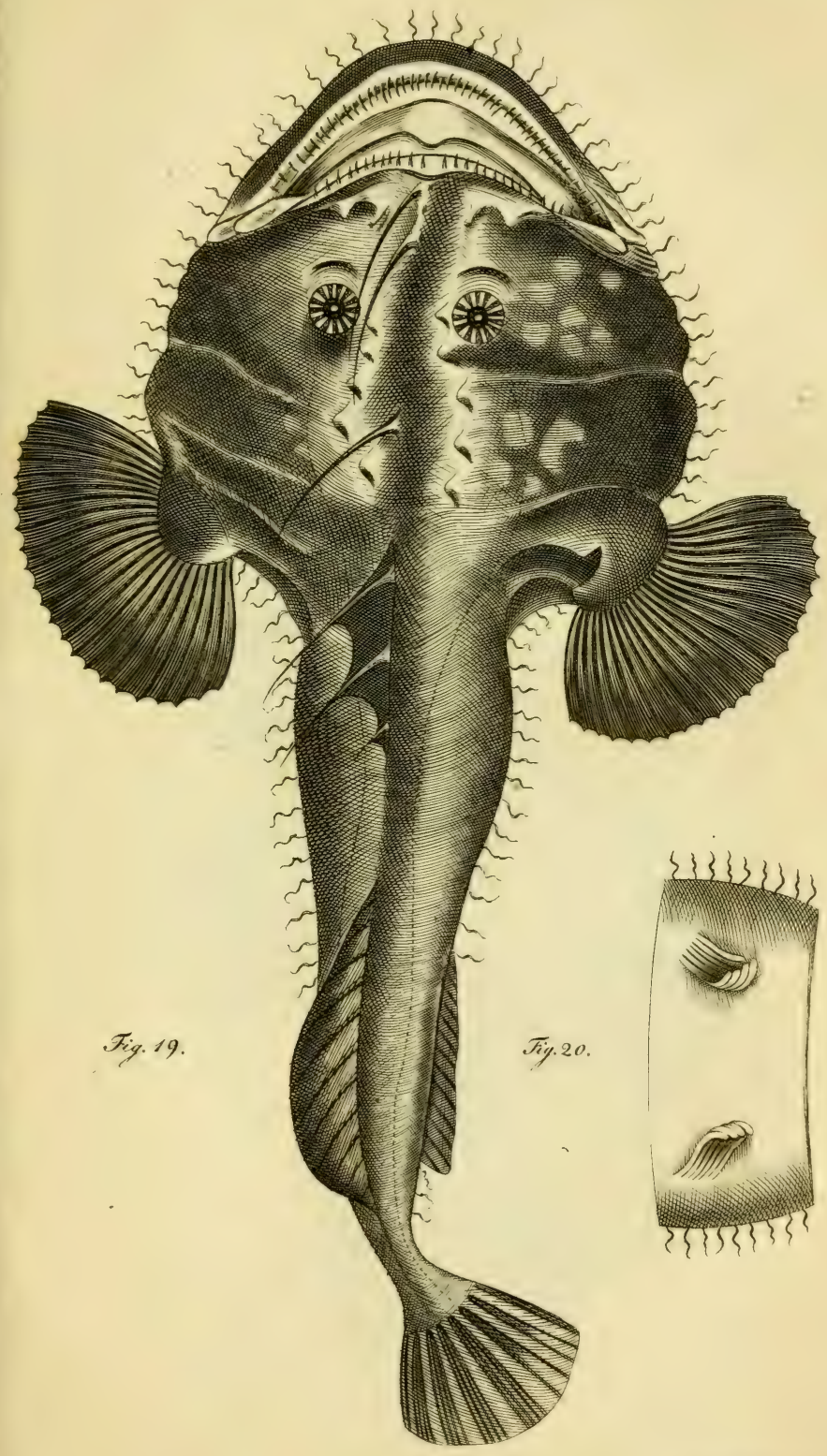



. TII I 12

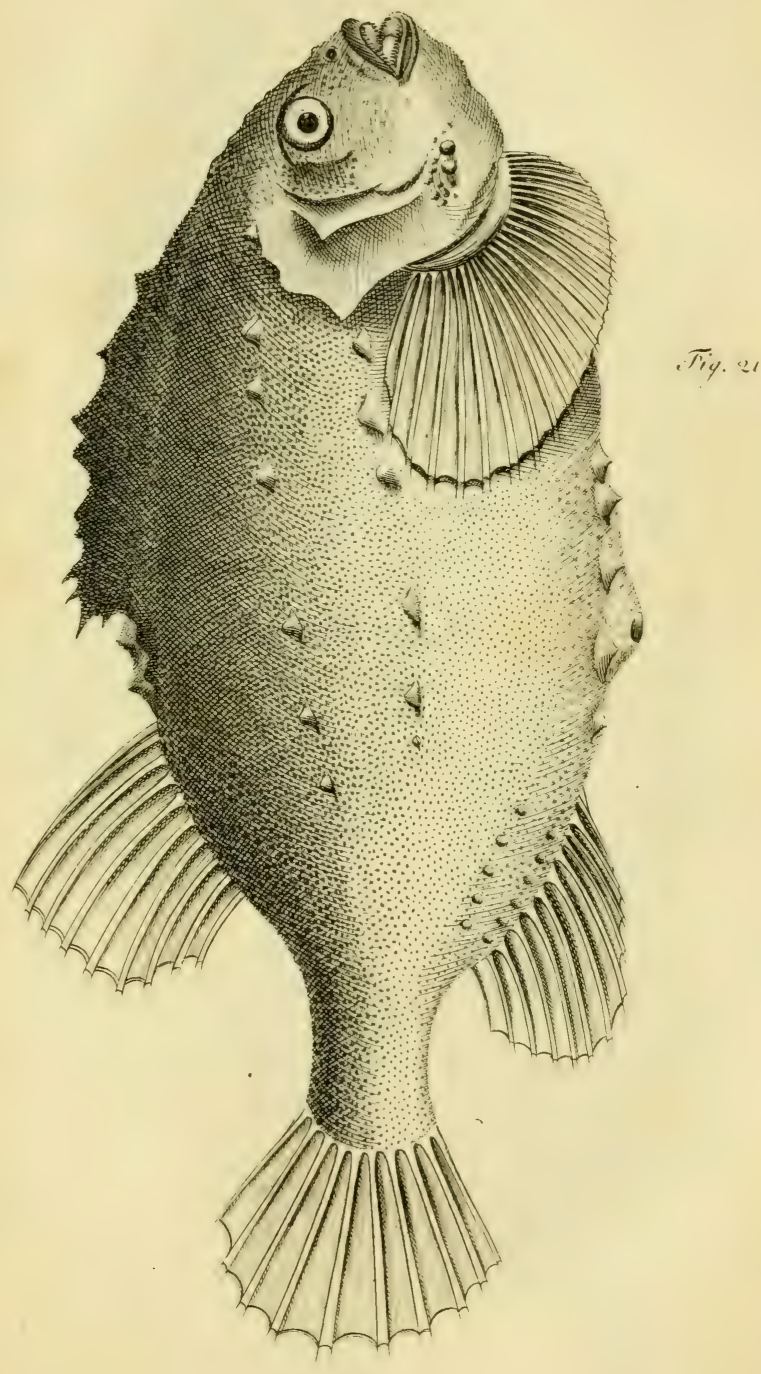


त्रण.ं3.

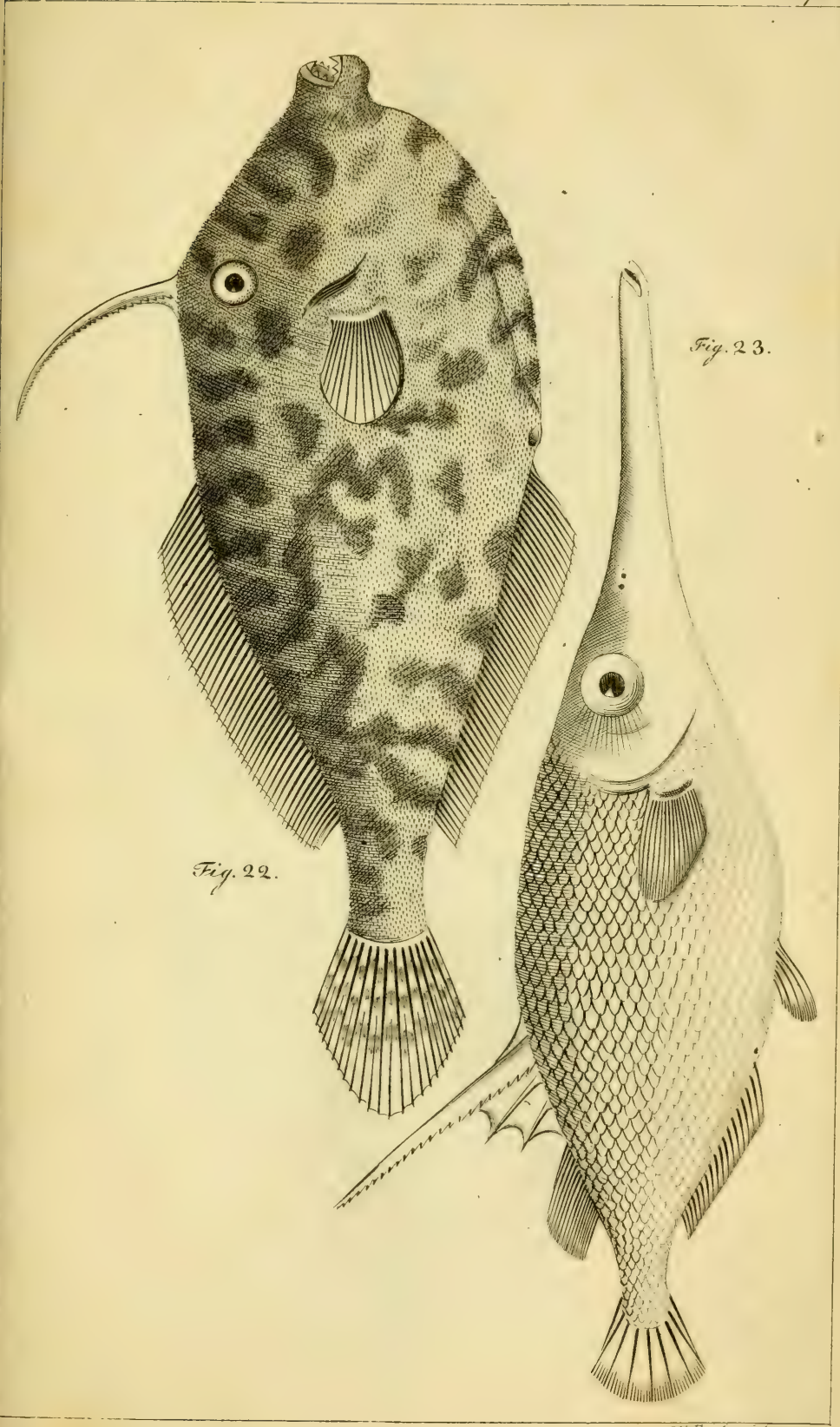



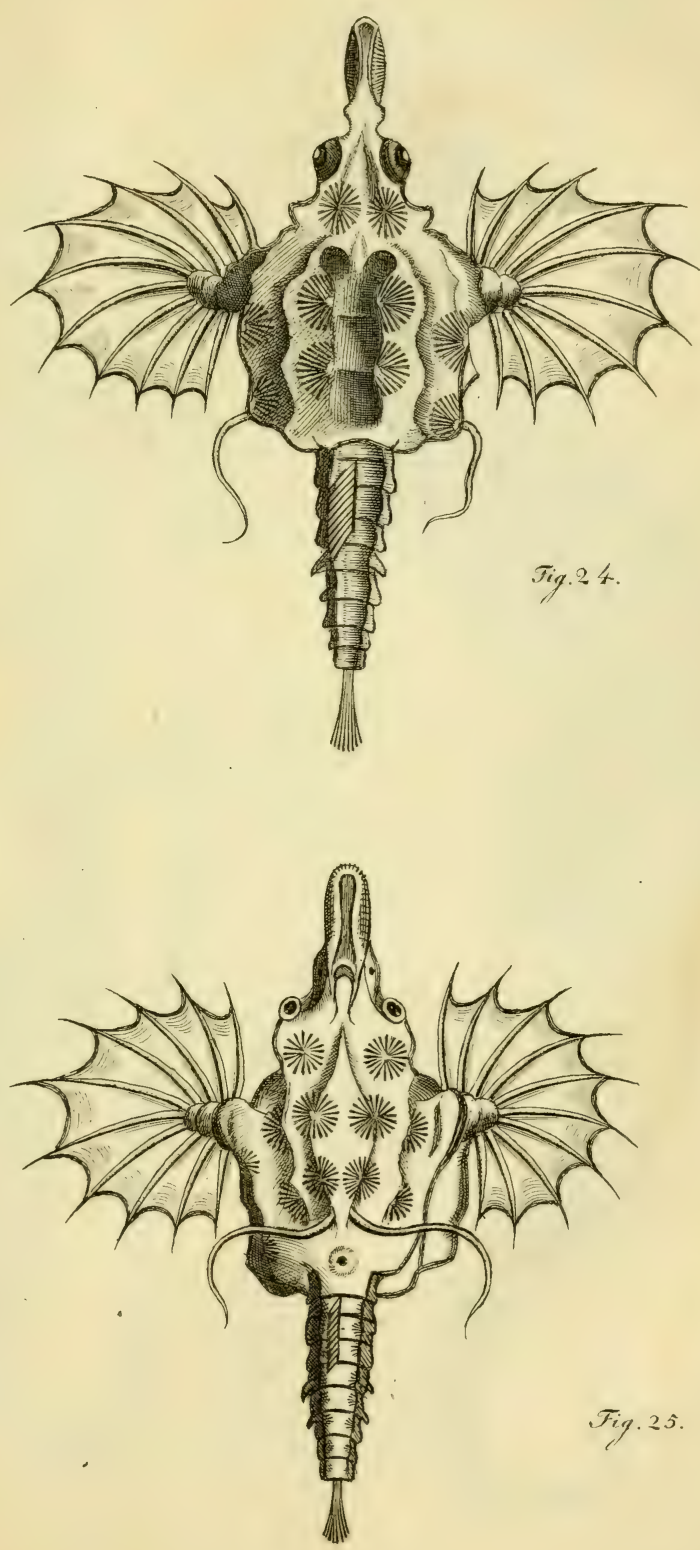


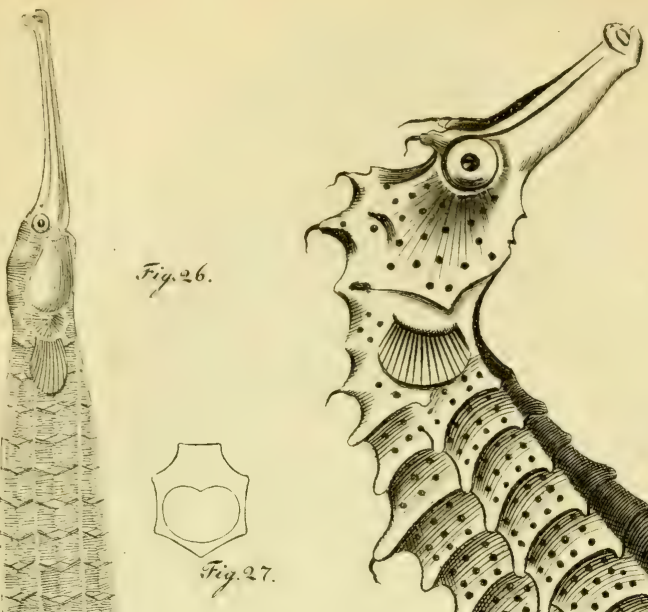

Fig. 30.

$<x$

ce t x

rex

lit $=x y-$

24

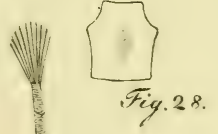

$\left\{\begin{array}{l}\cdots \\ \vdots \\ \vdots\end{array}\right.$

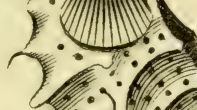
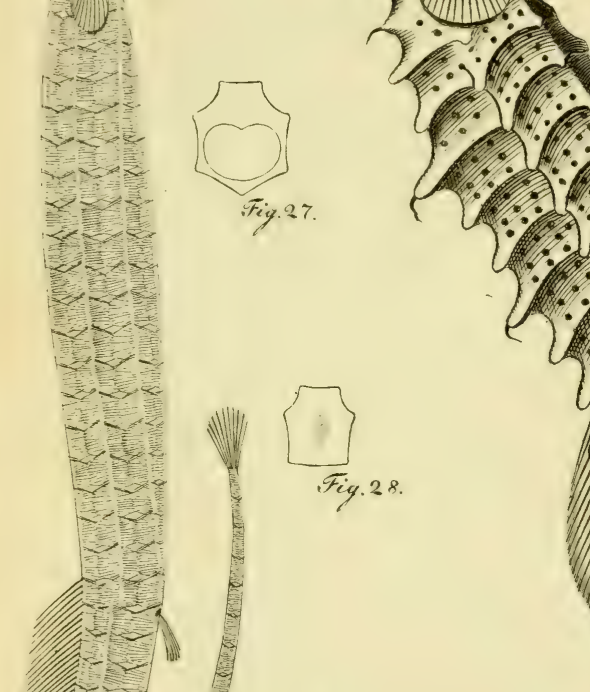

Fig. 28.

Fig. 29.

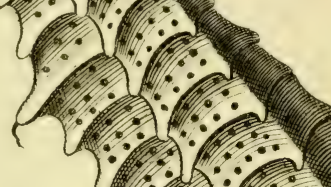

- 0.0

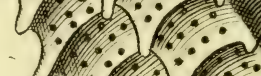

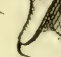
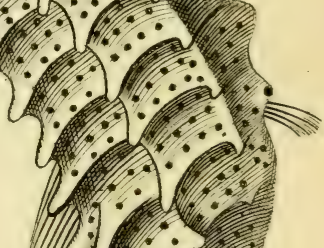



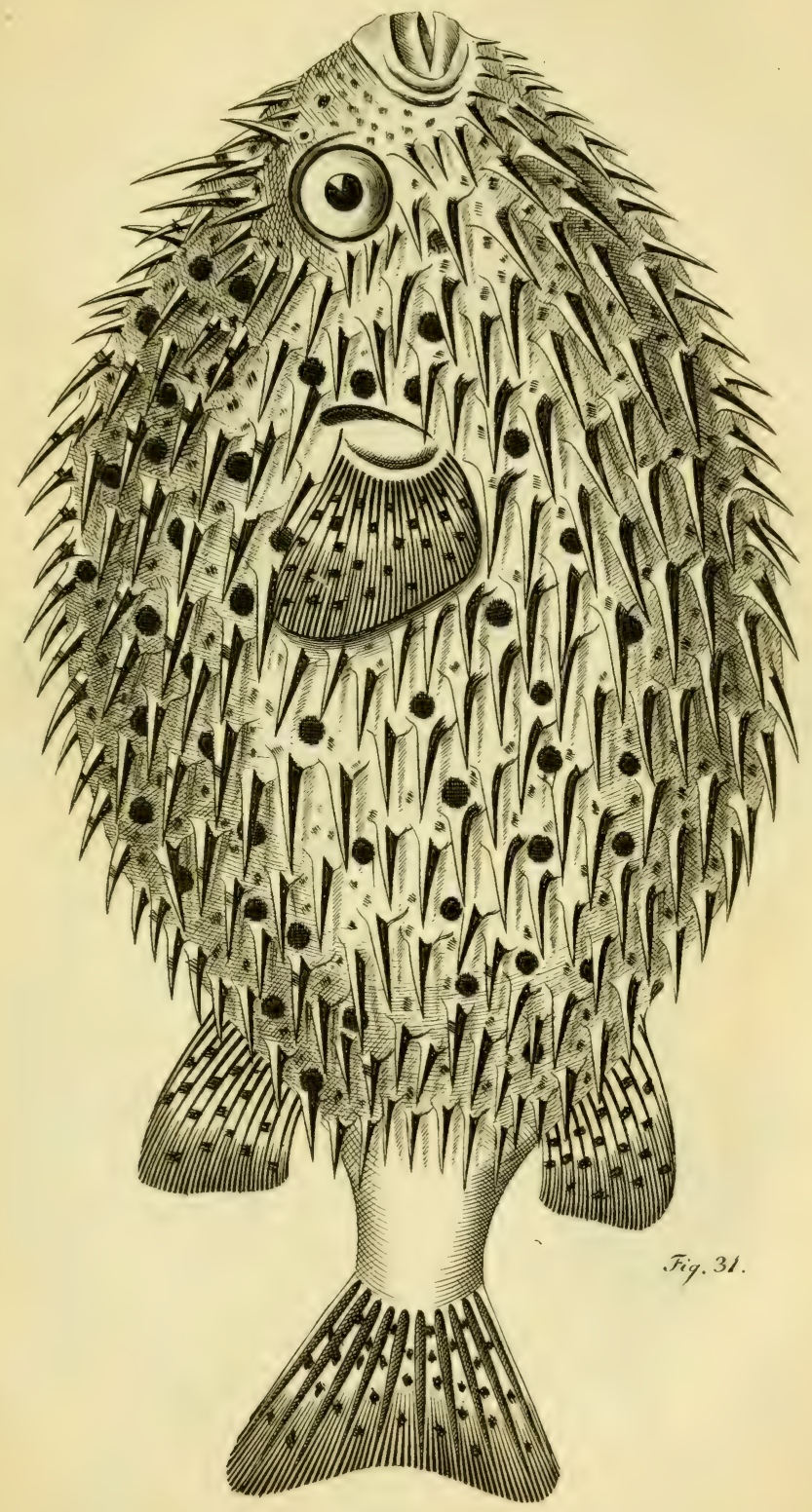



irrlit
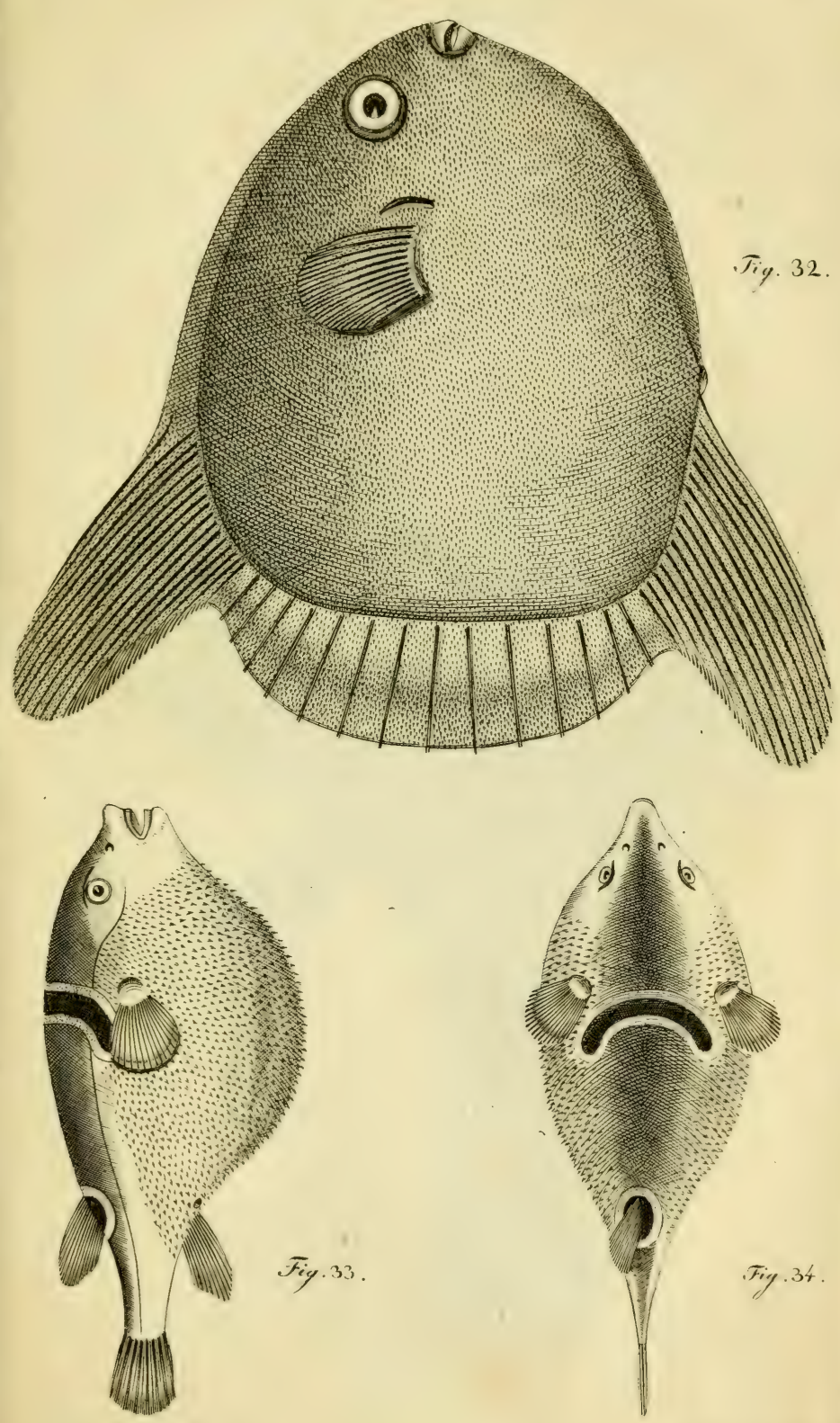

Tnt.13.

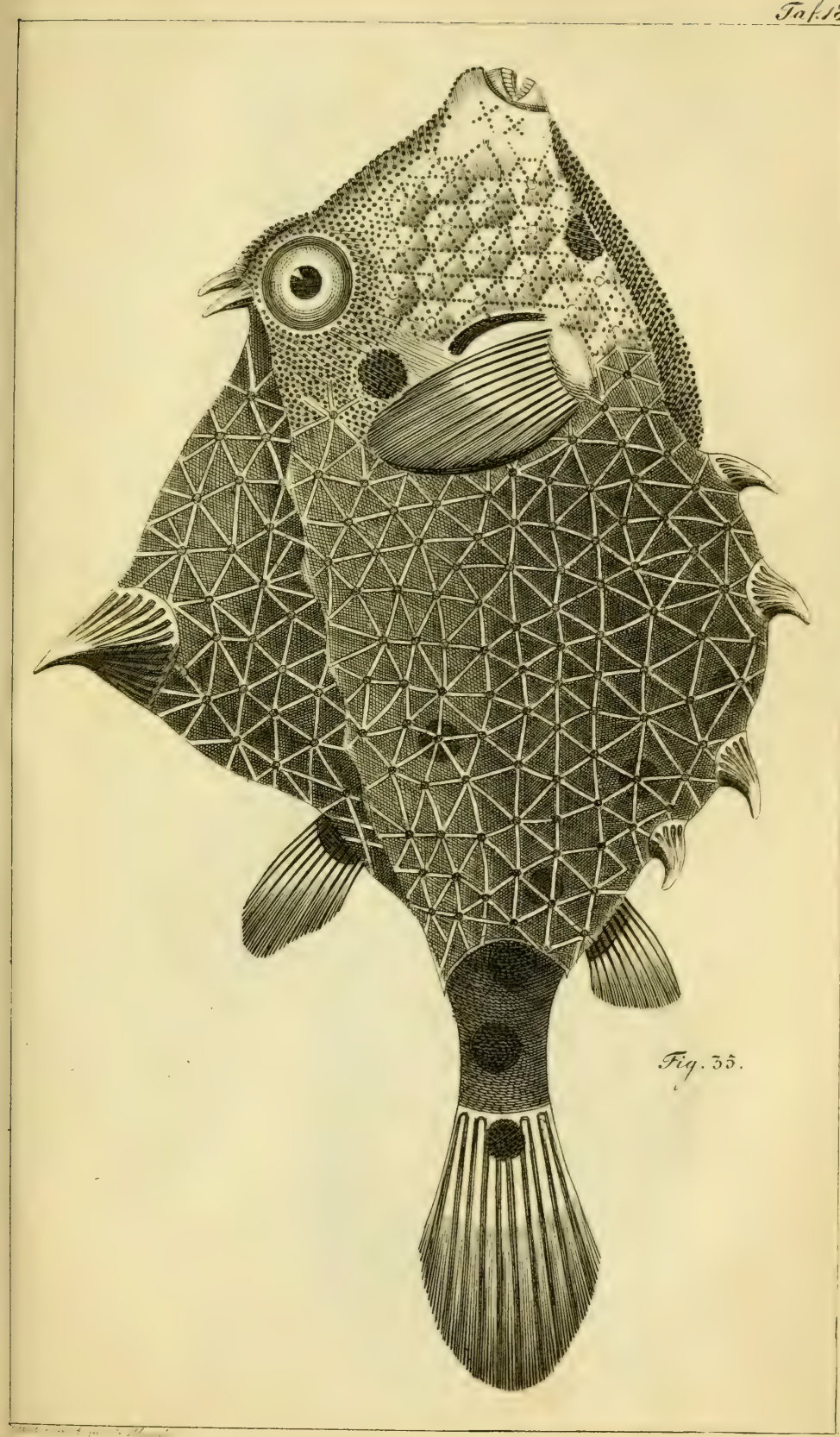



Tef.19.

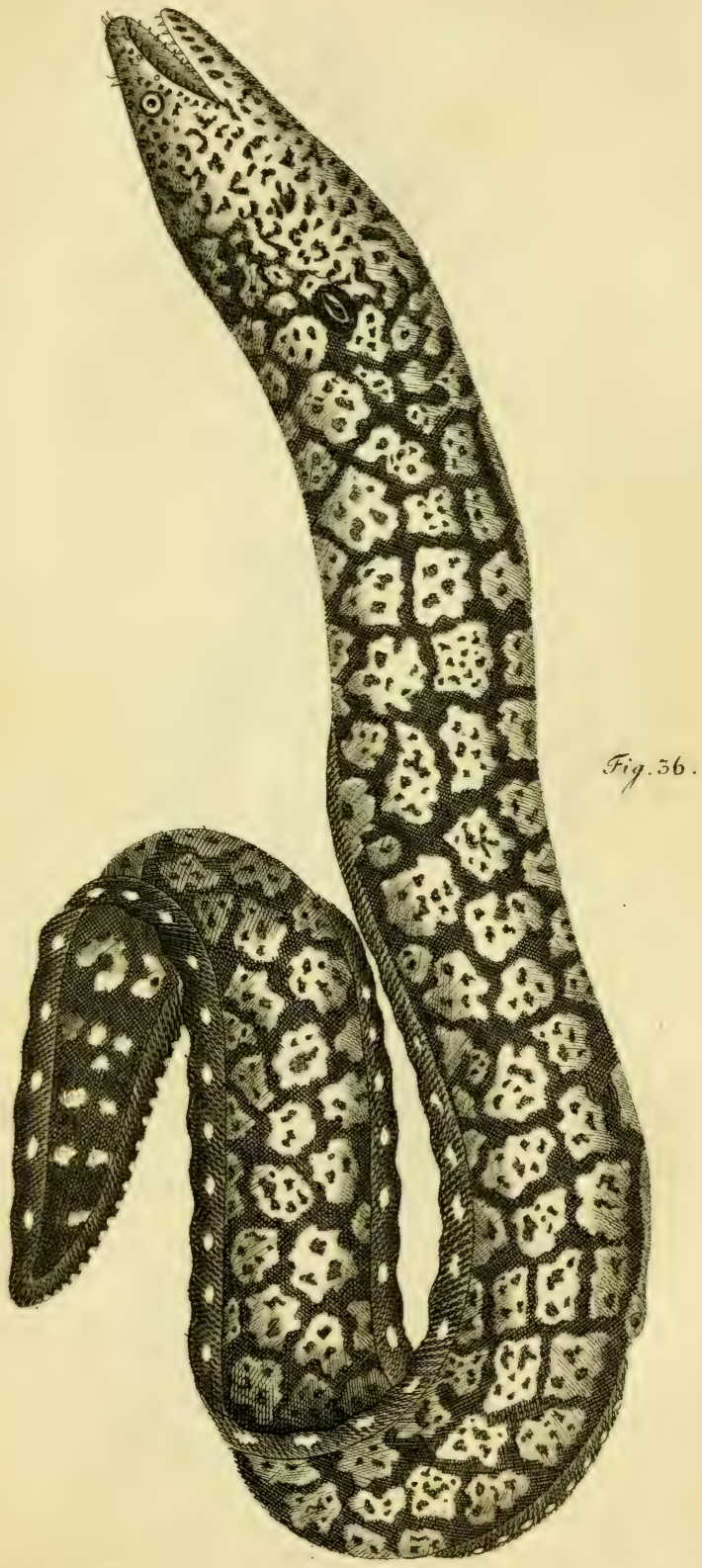





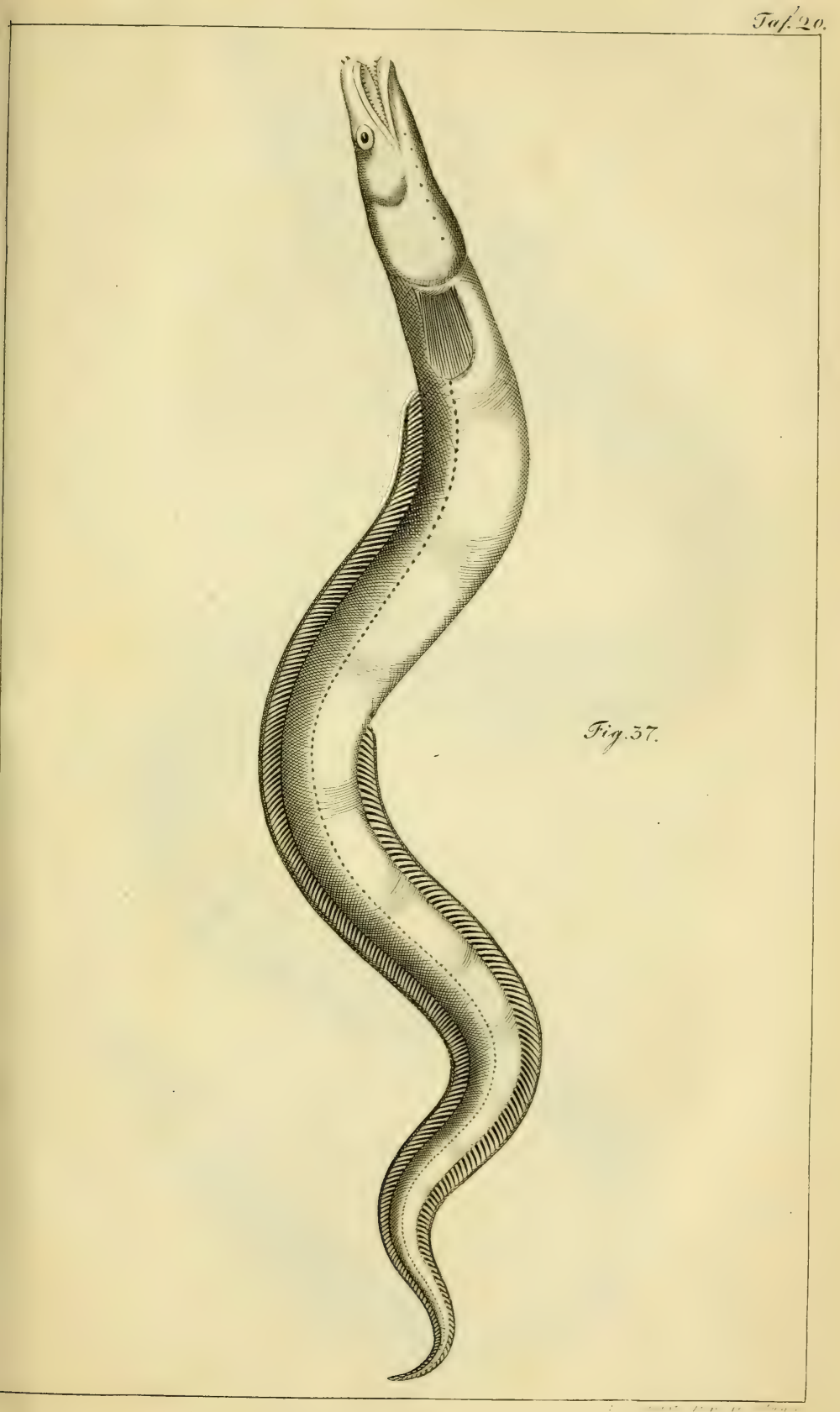





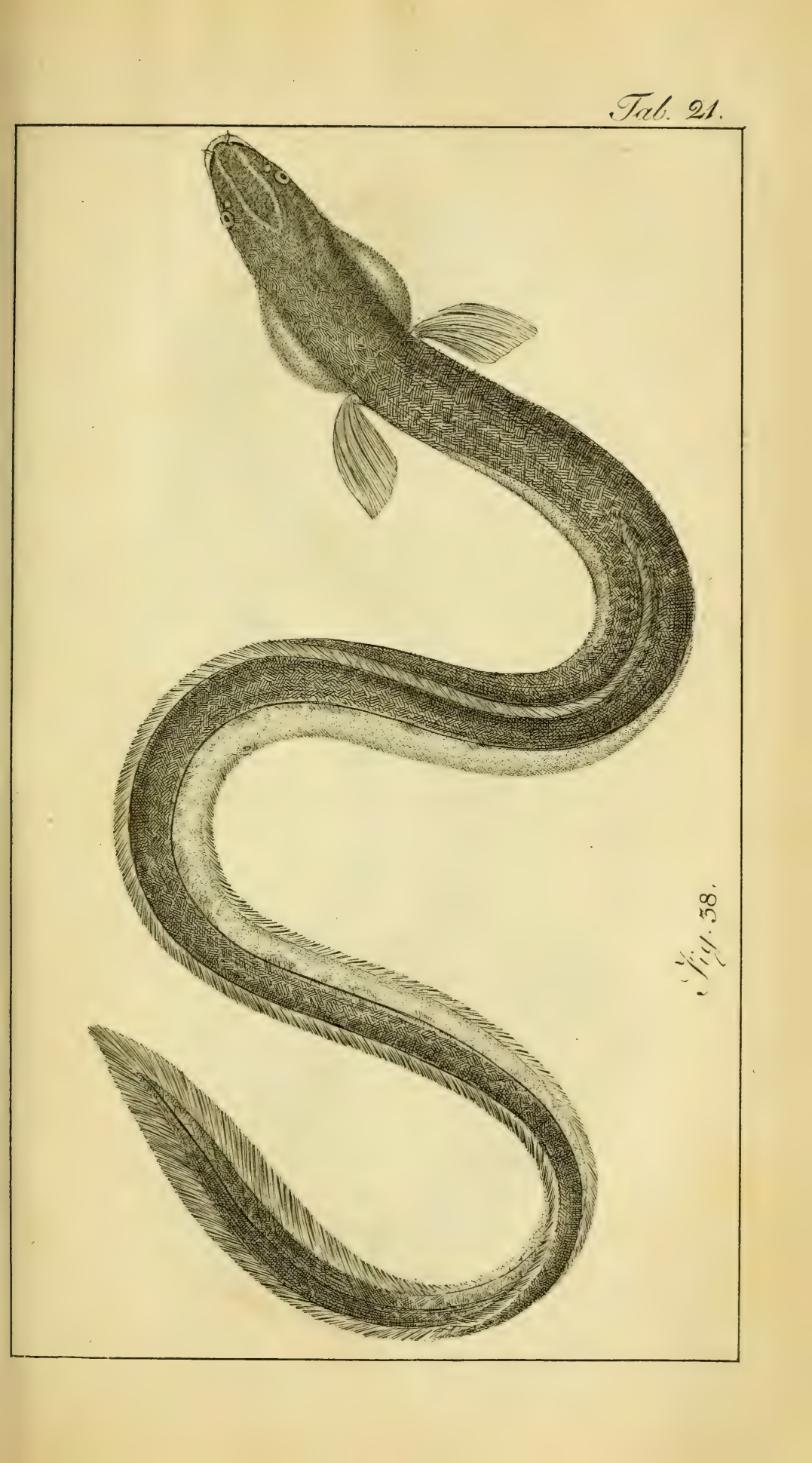





$$
\mathbb{S}
$$



Trl' 25.

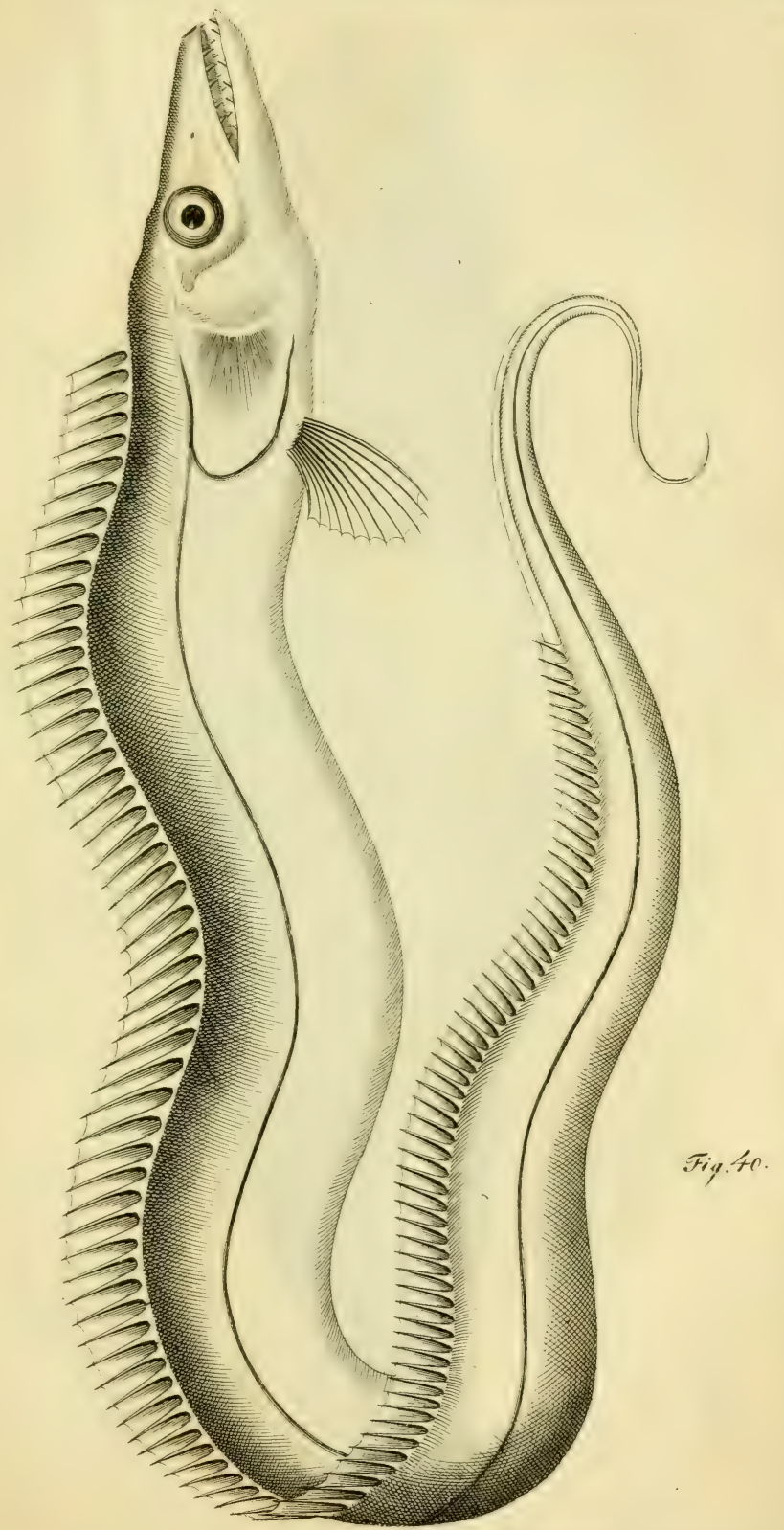



. Trel.'2-4

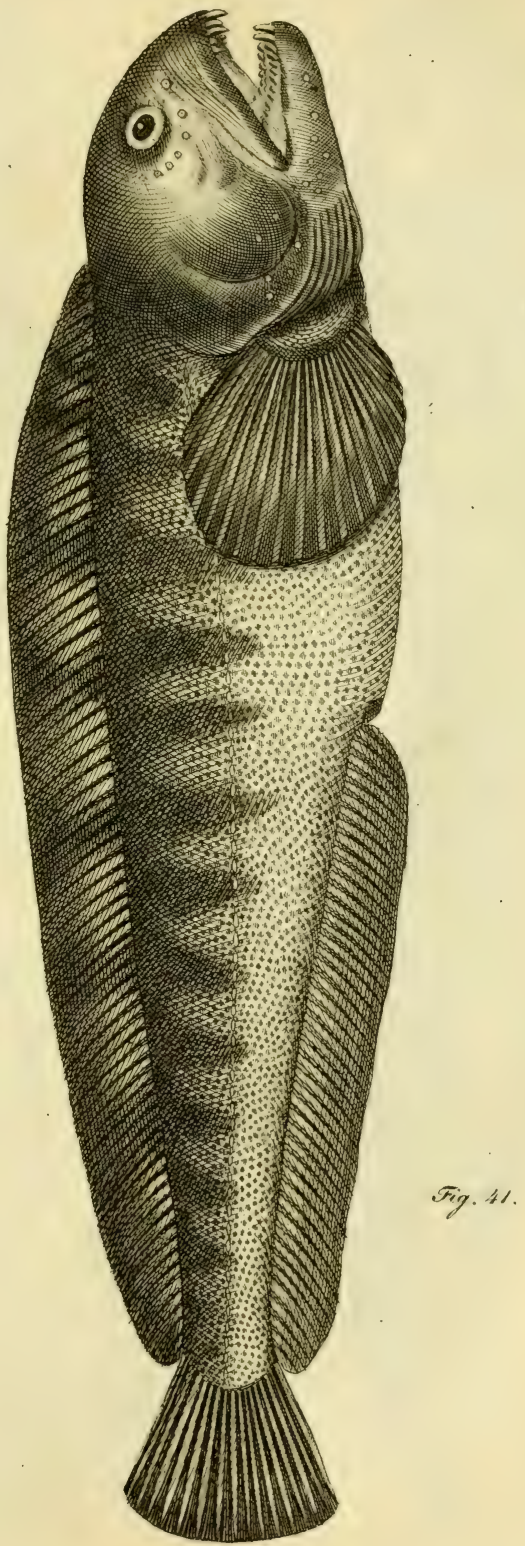



Terf. 25
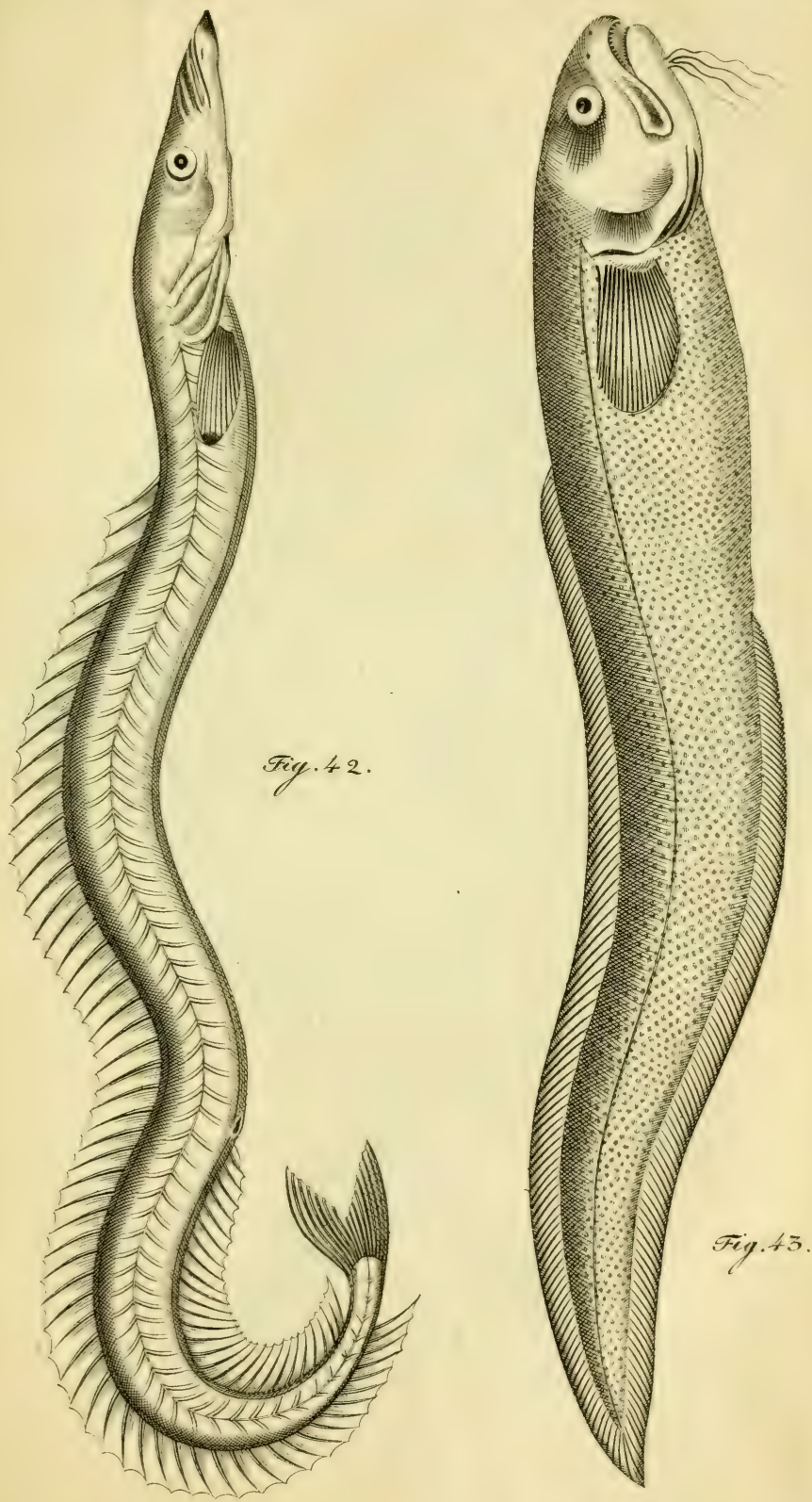

Tut:26.

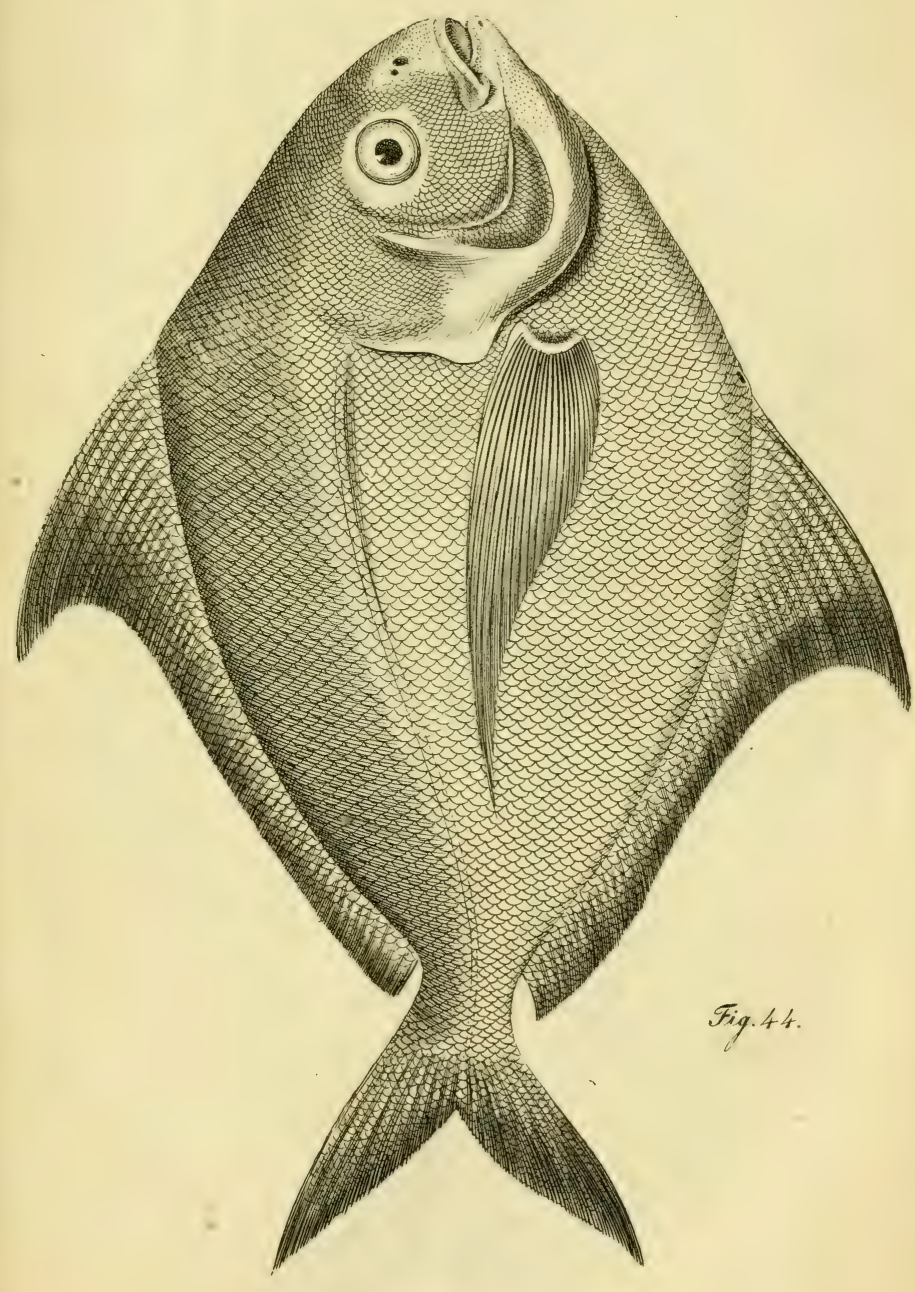





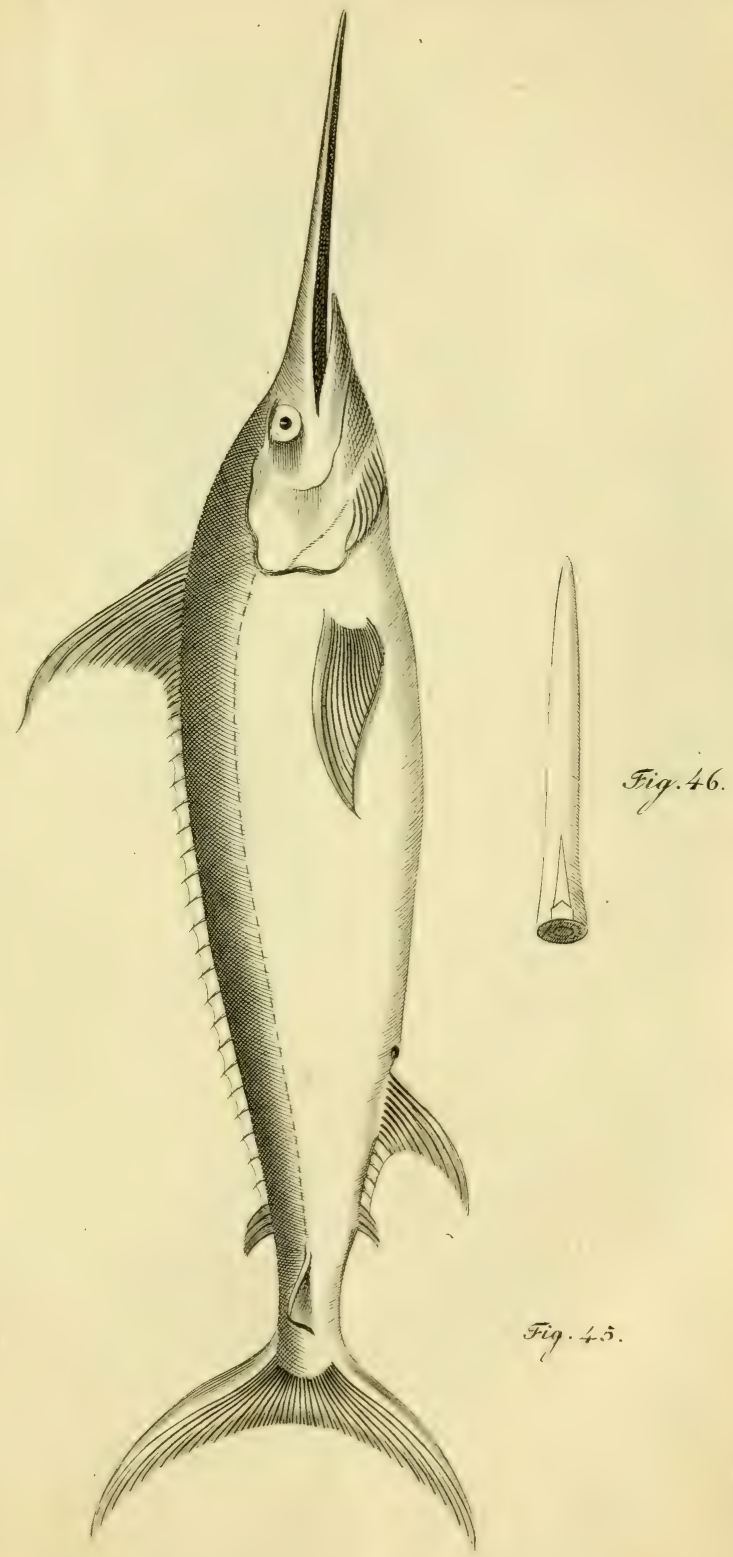



Taf. 28

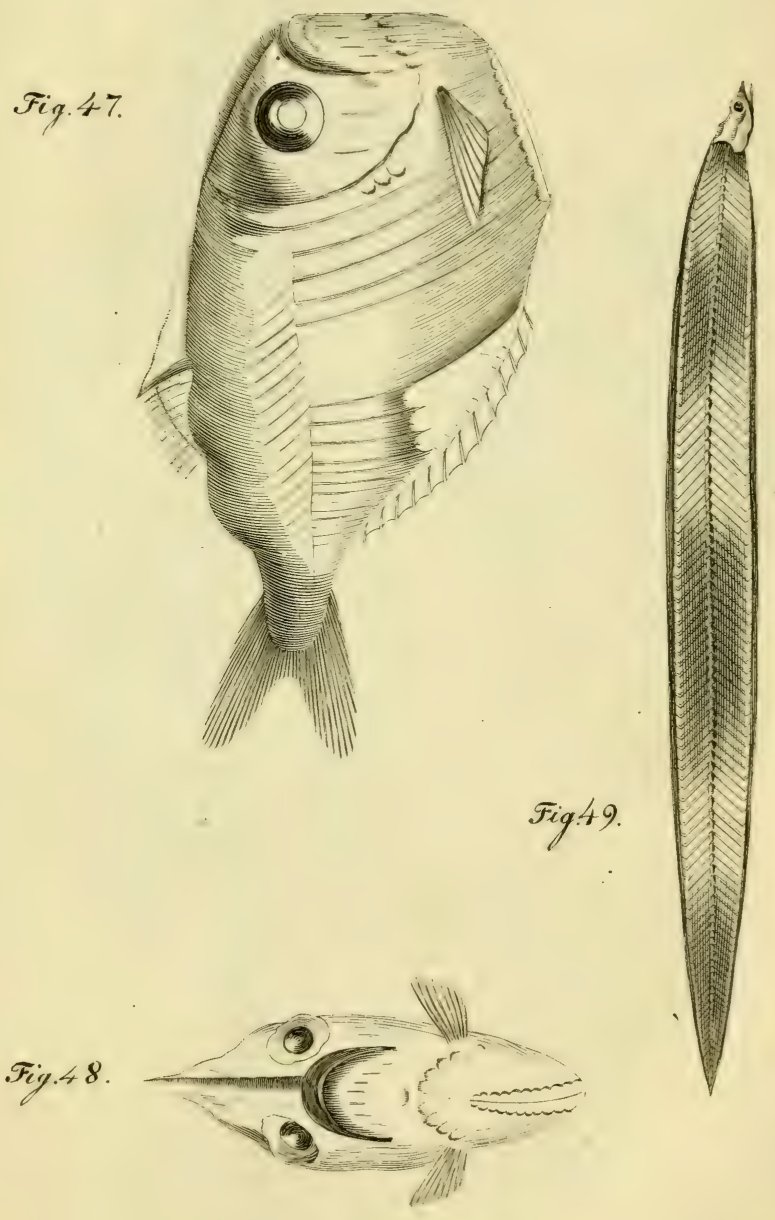



T(1):29

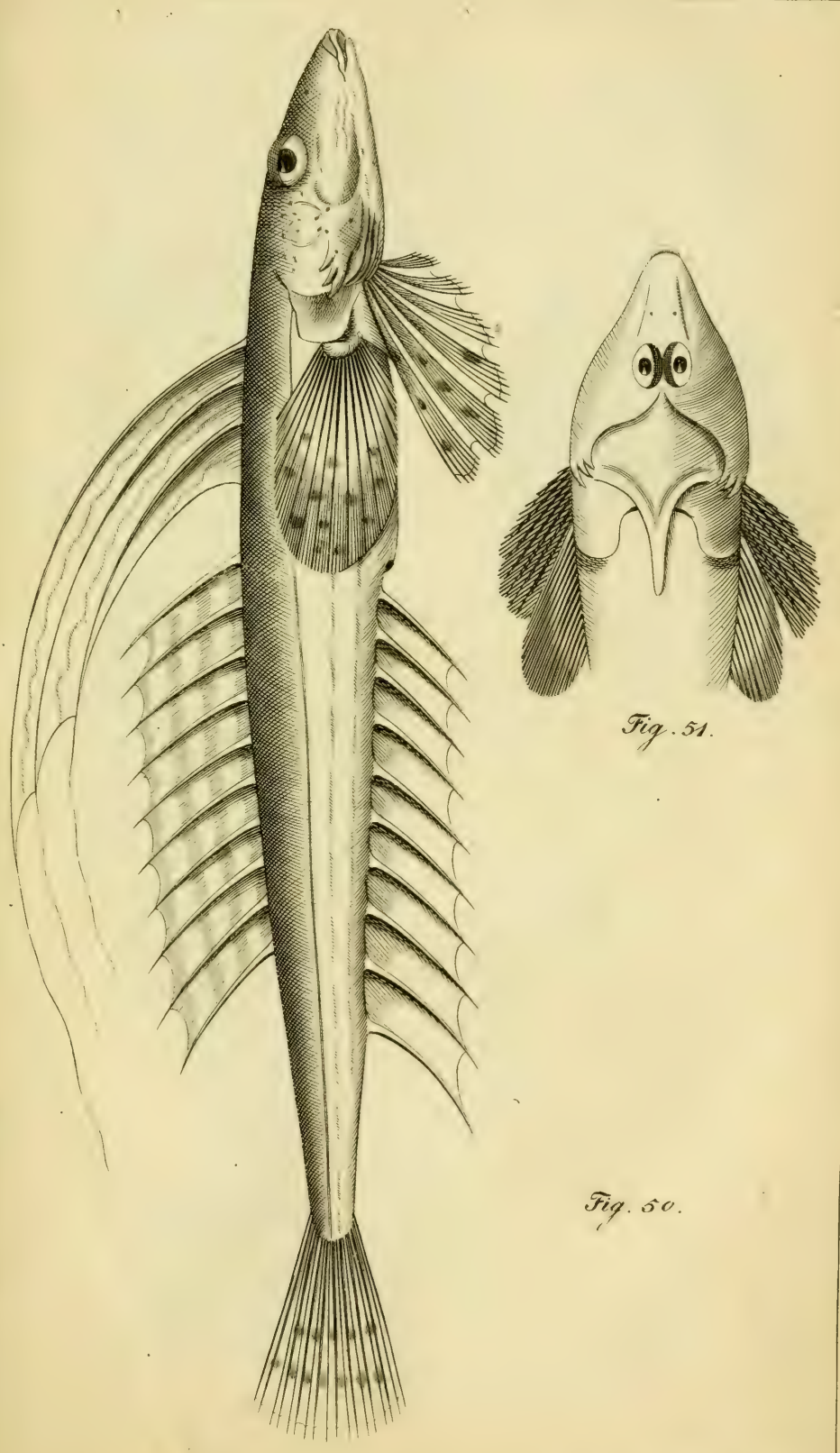




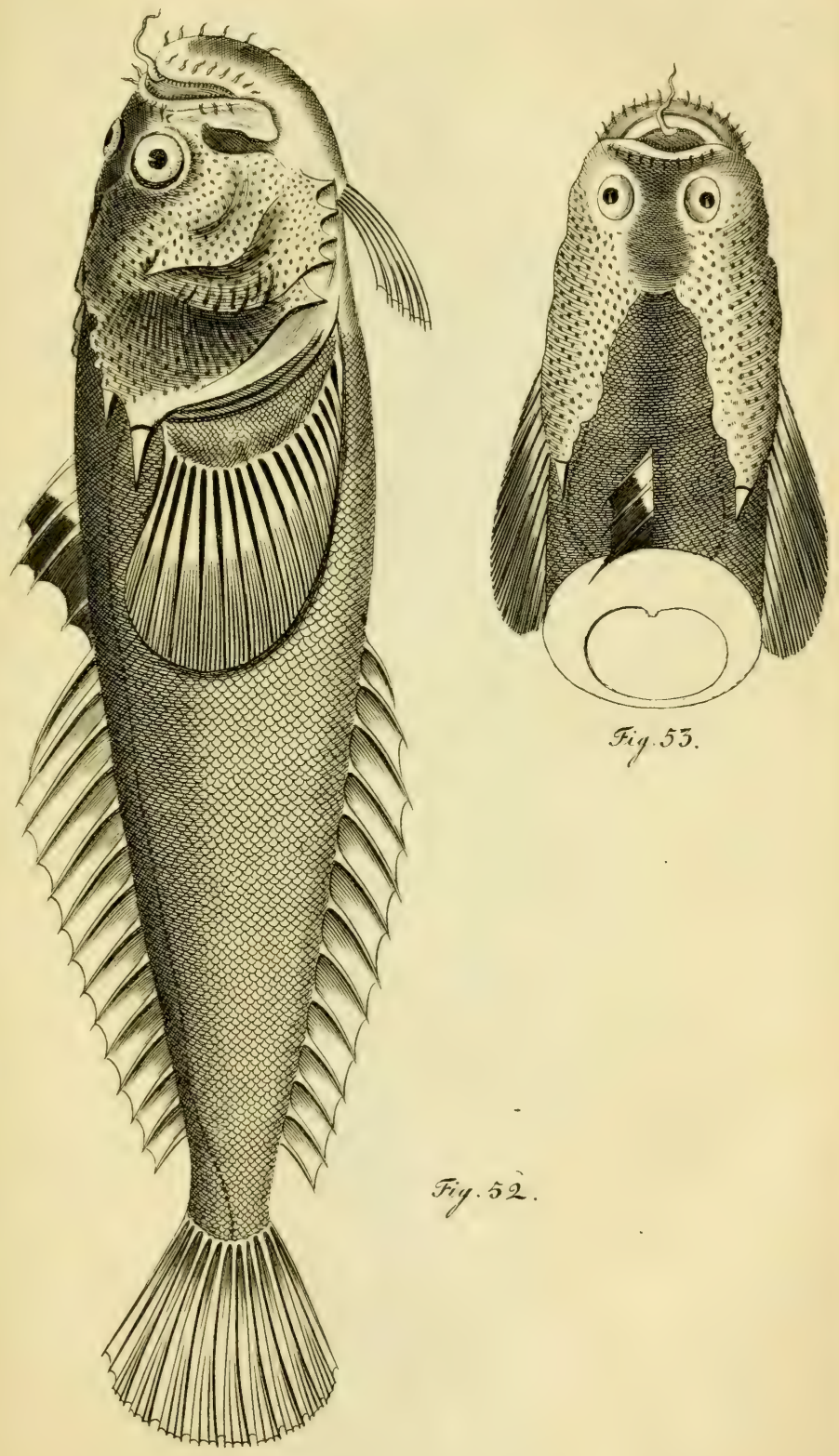

Fig. 53

Fig. 52. 



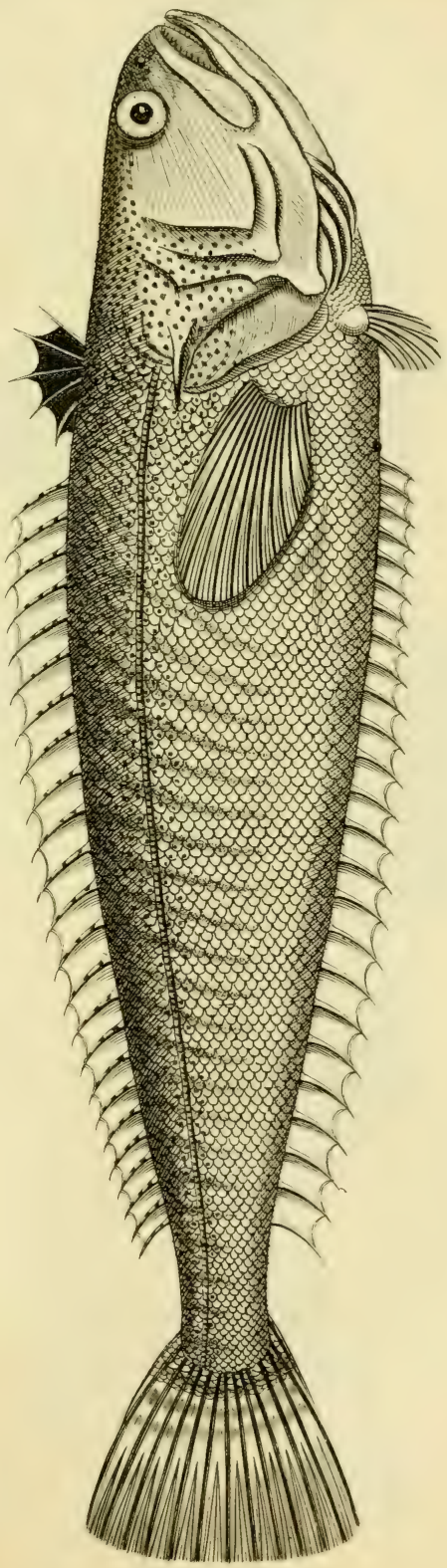

Tig. 54 . 

Tel's2

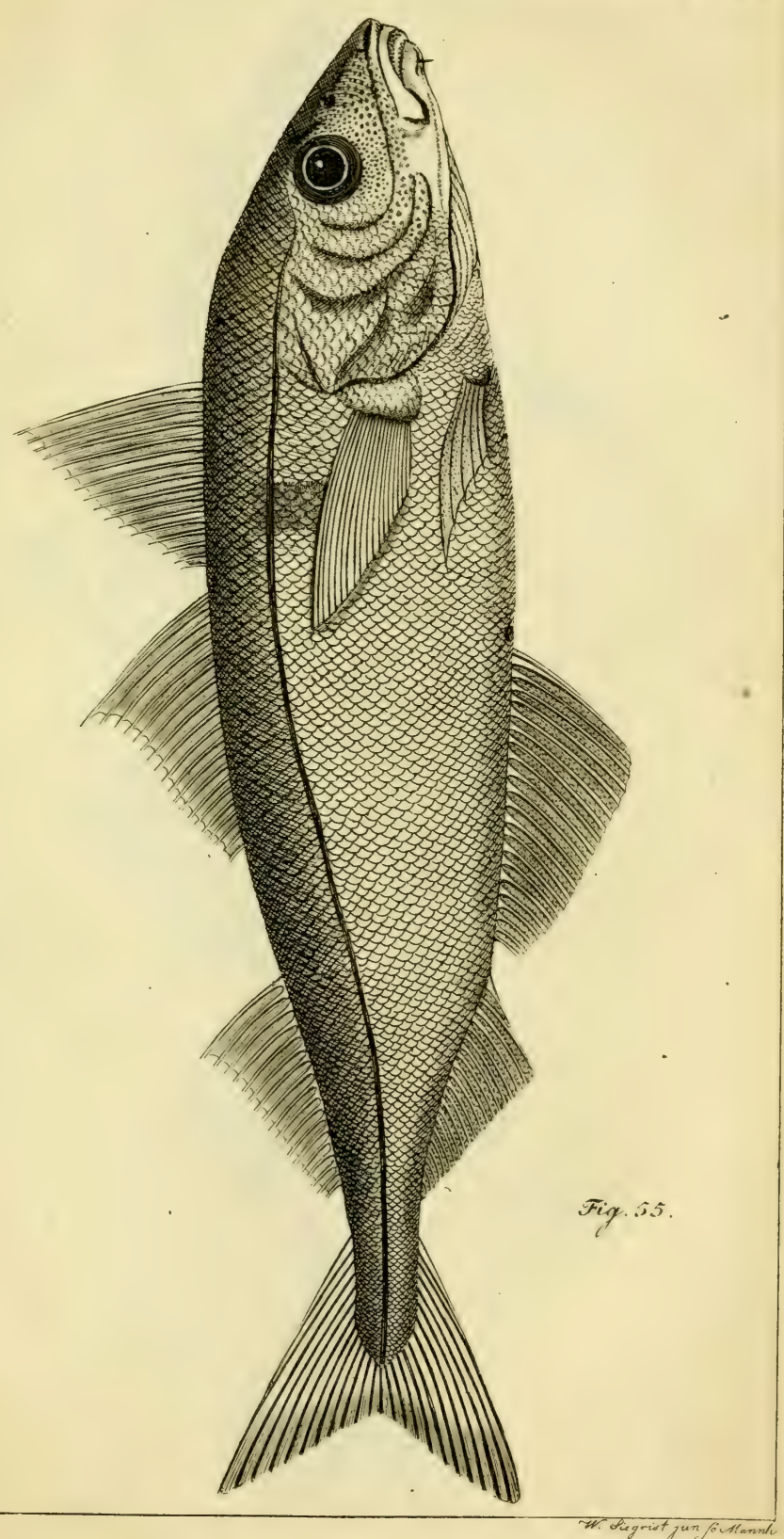





Tा/ड़

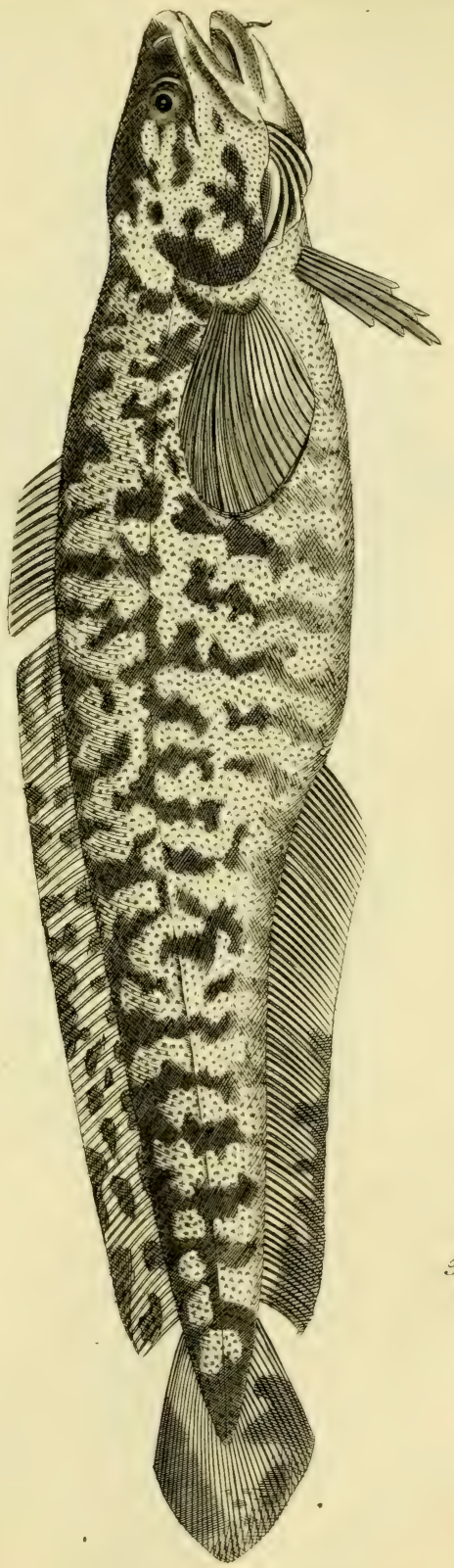

Fig. $0 \%$ 

. Tort.5.5.

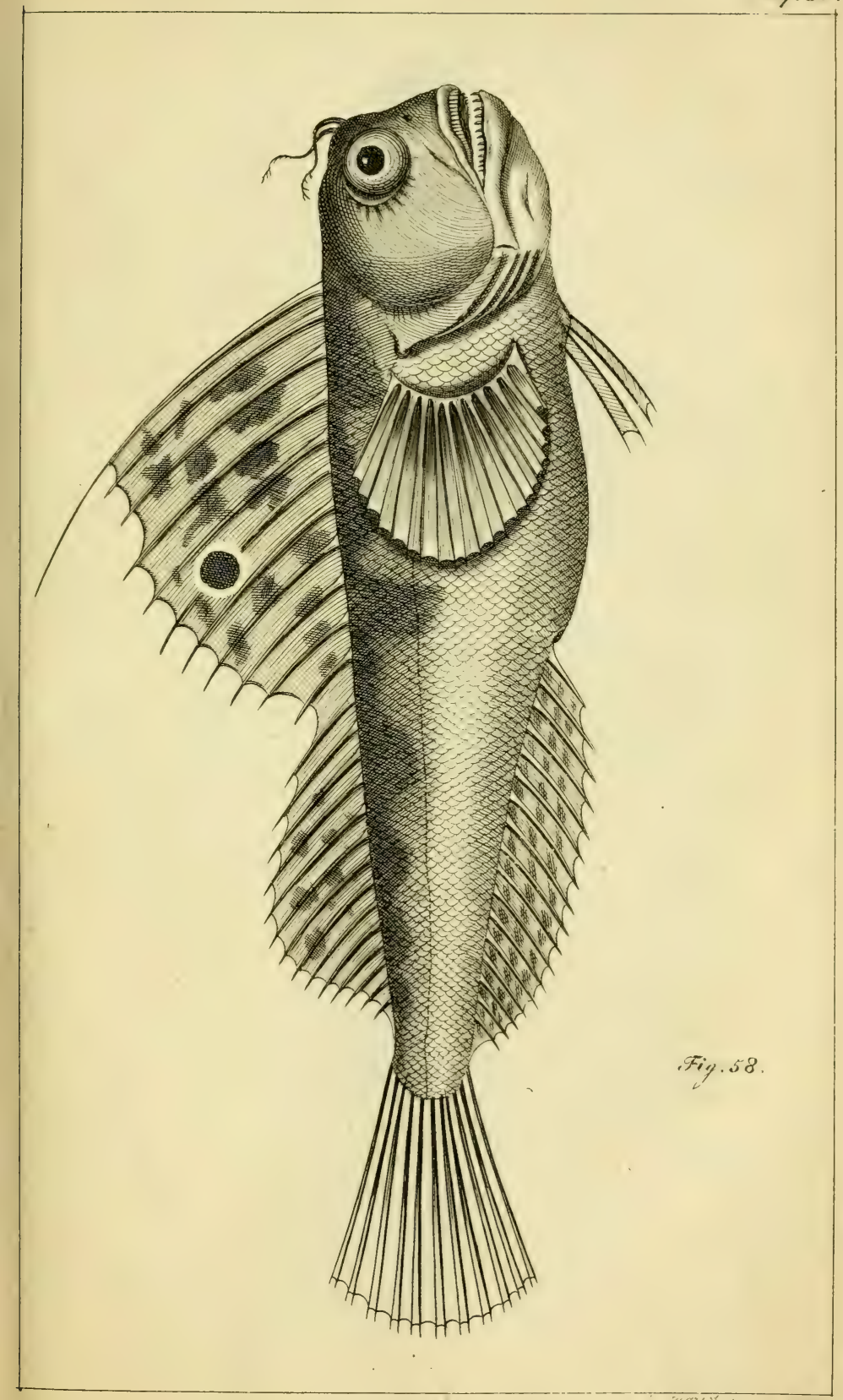



Trry.56.

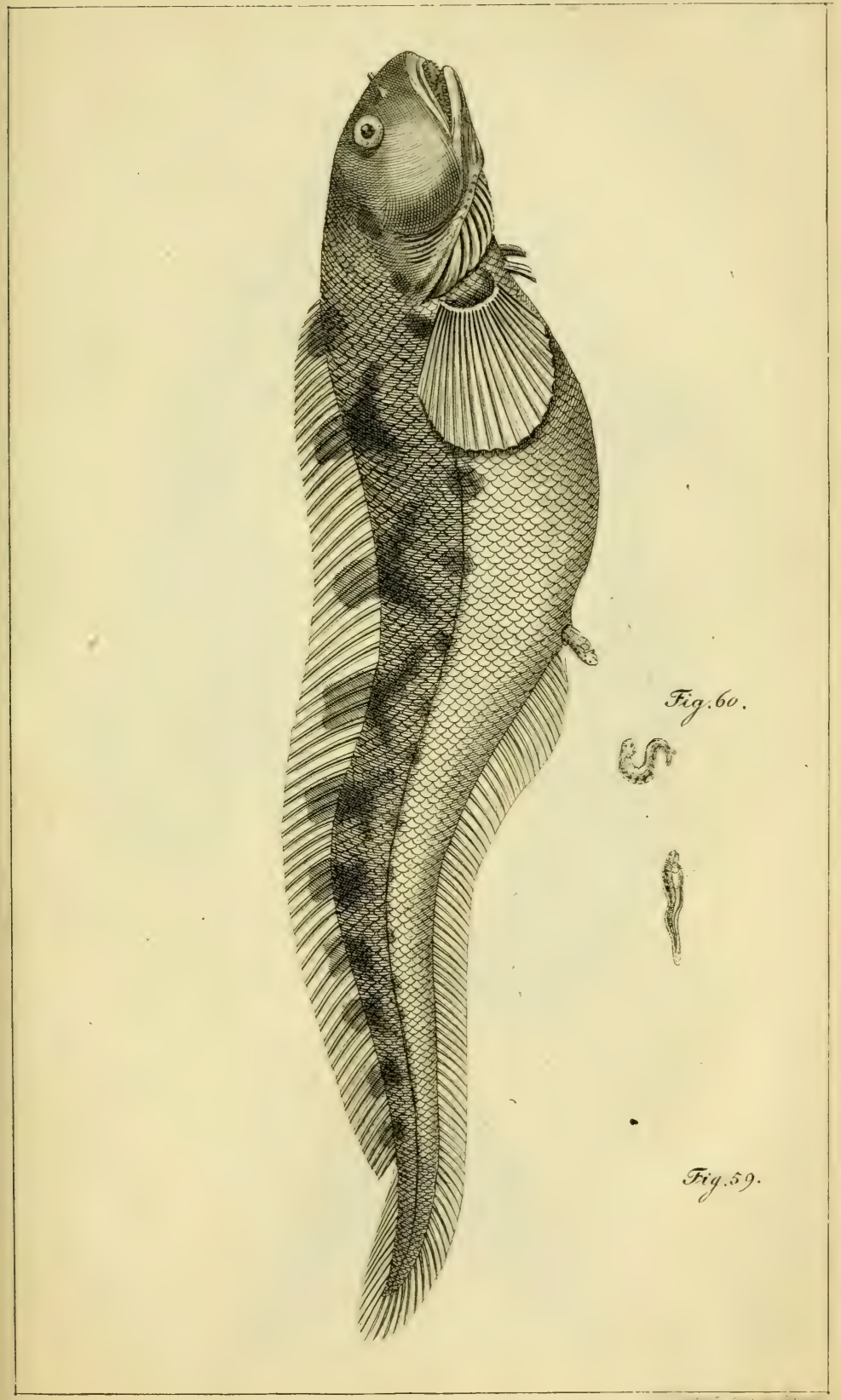




Tref. 58

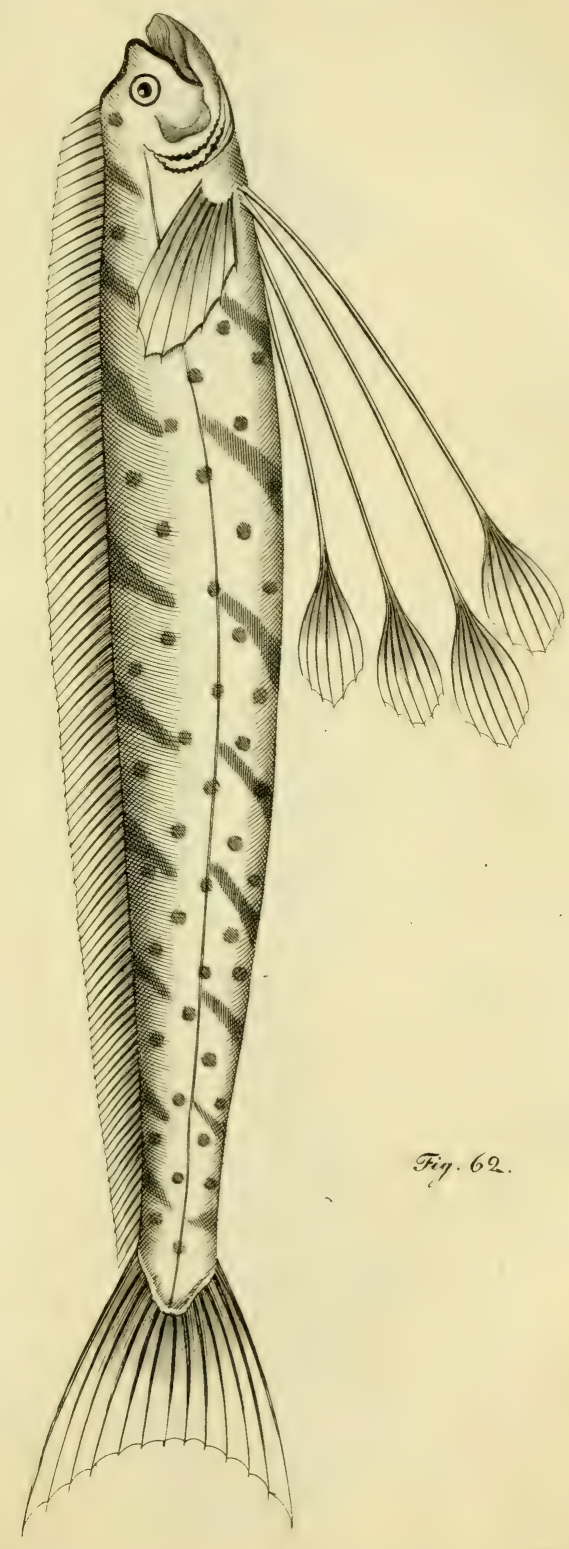





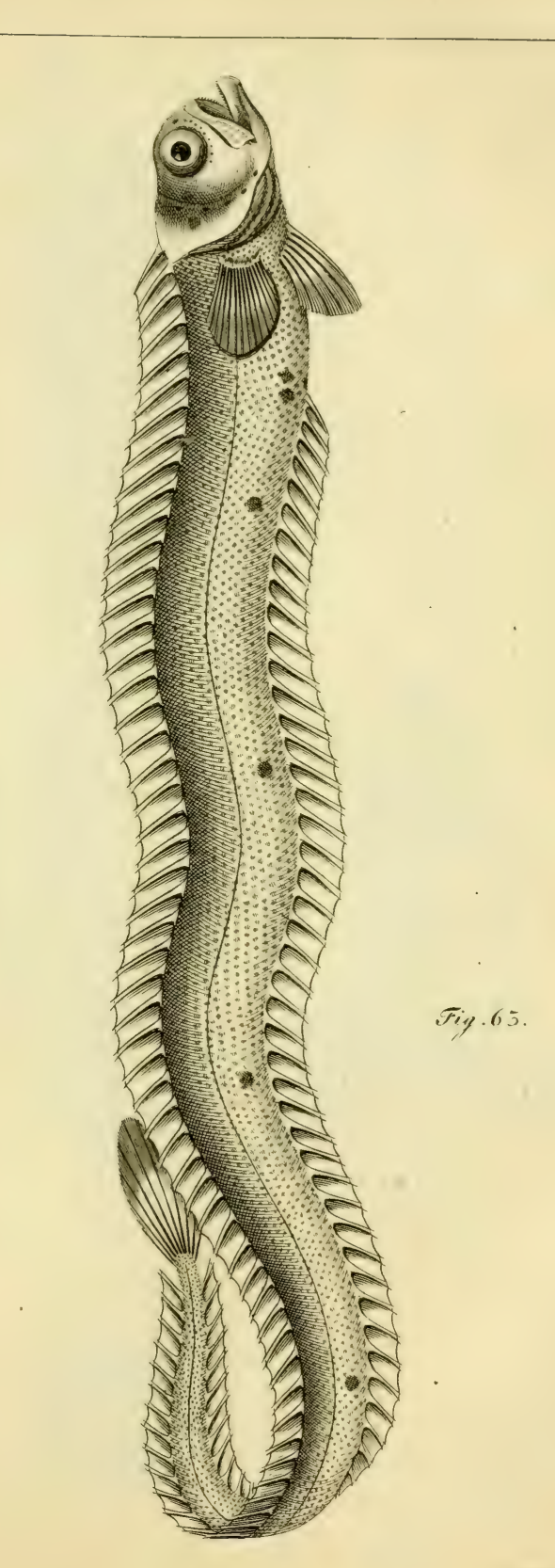





$$
\int
$$



Tref.47.

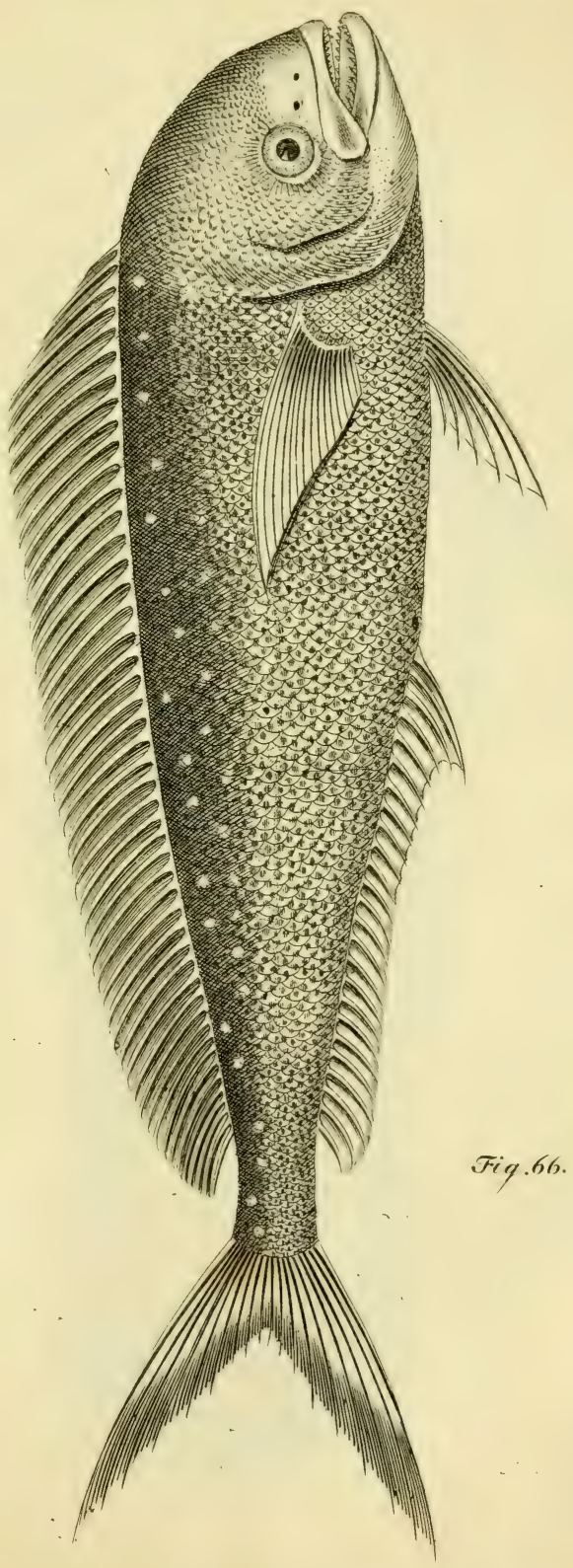



Tref 42

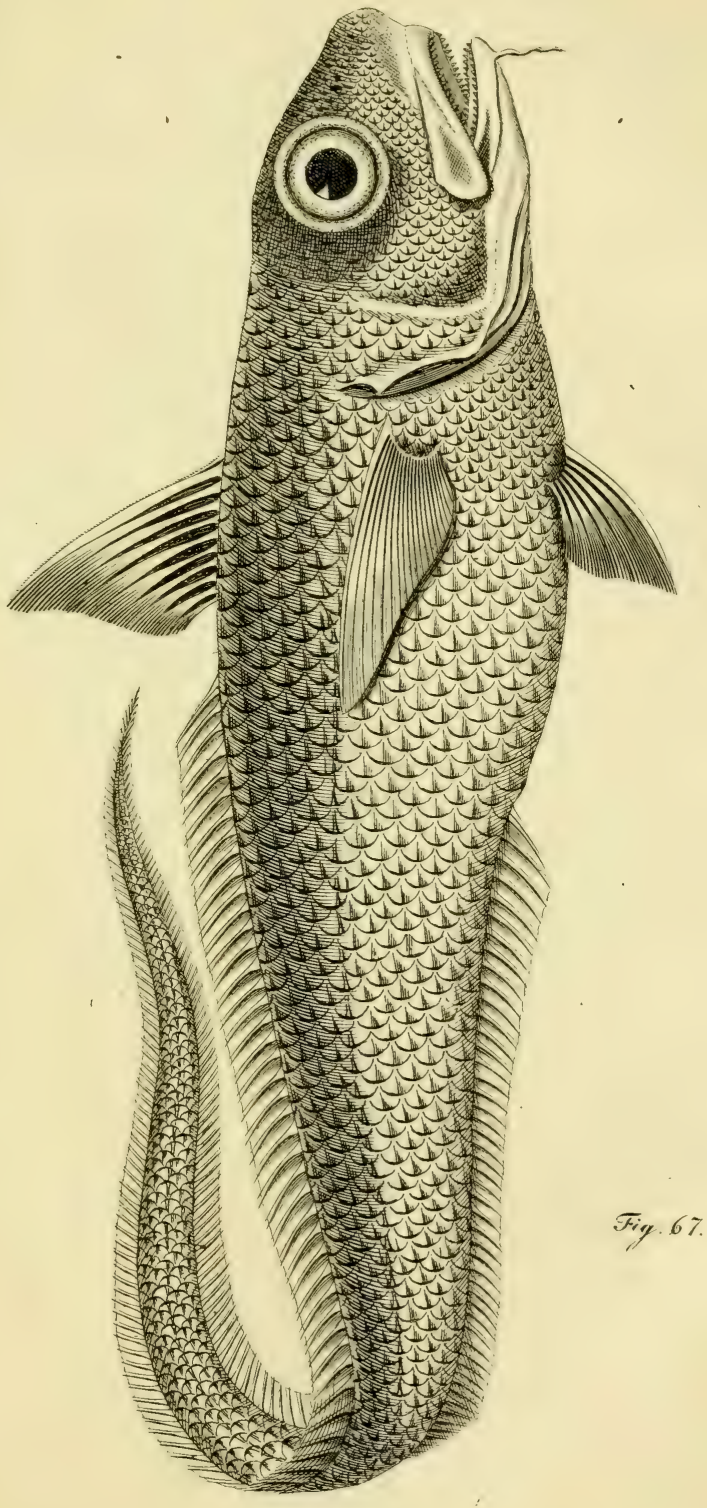



Teffits 5

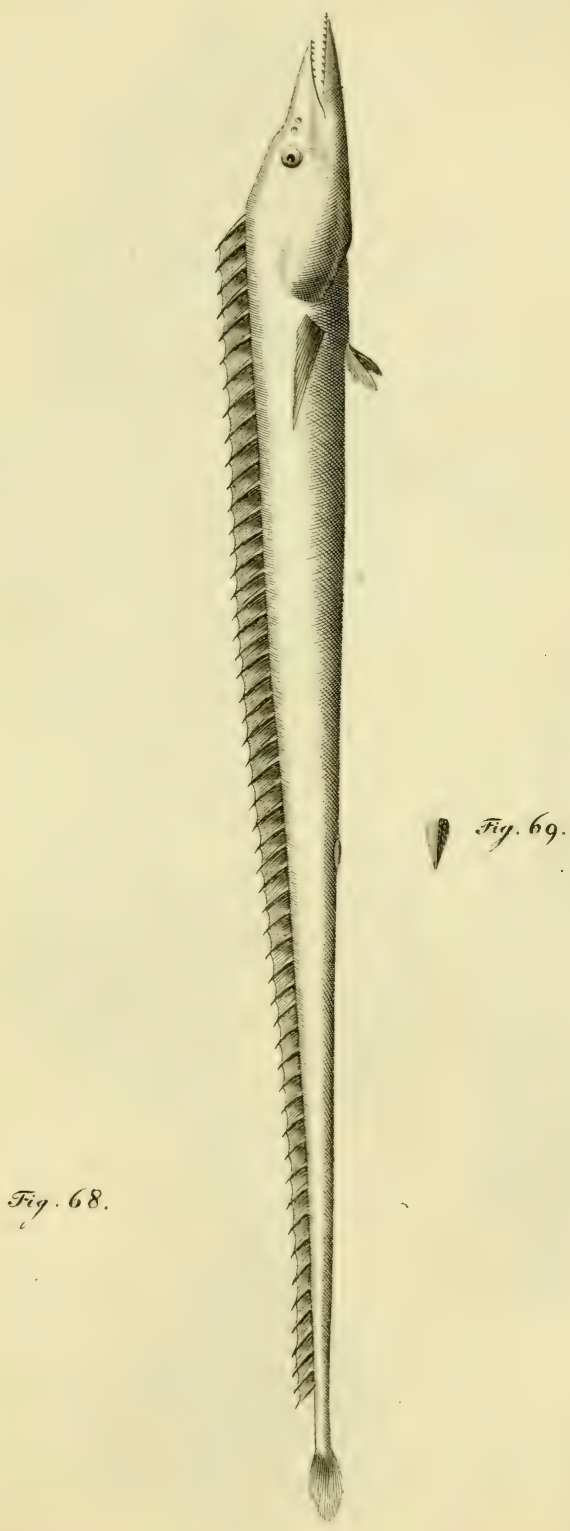



Taly4

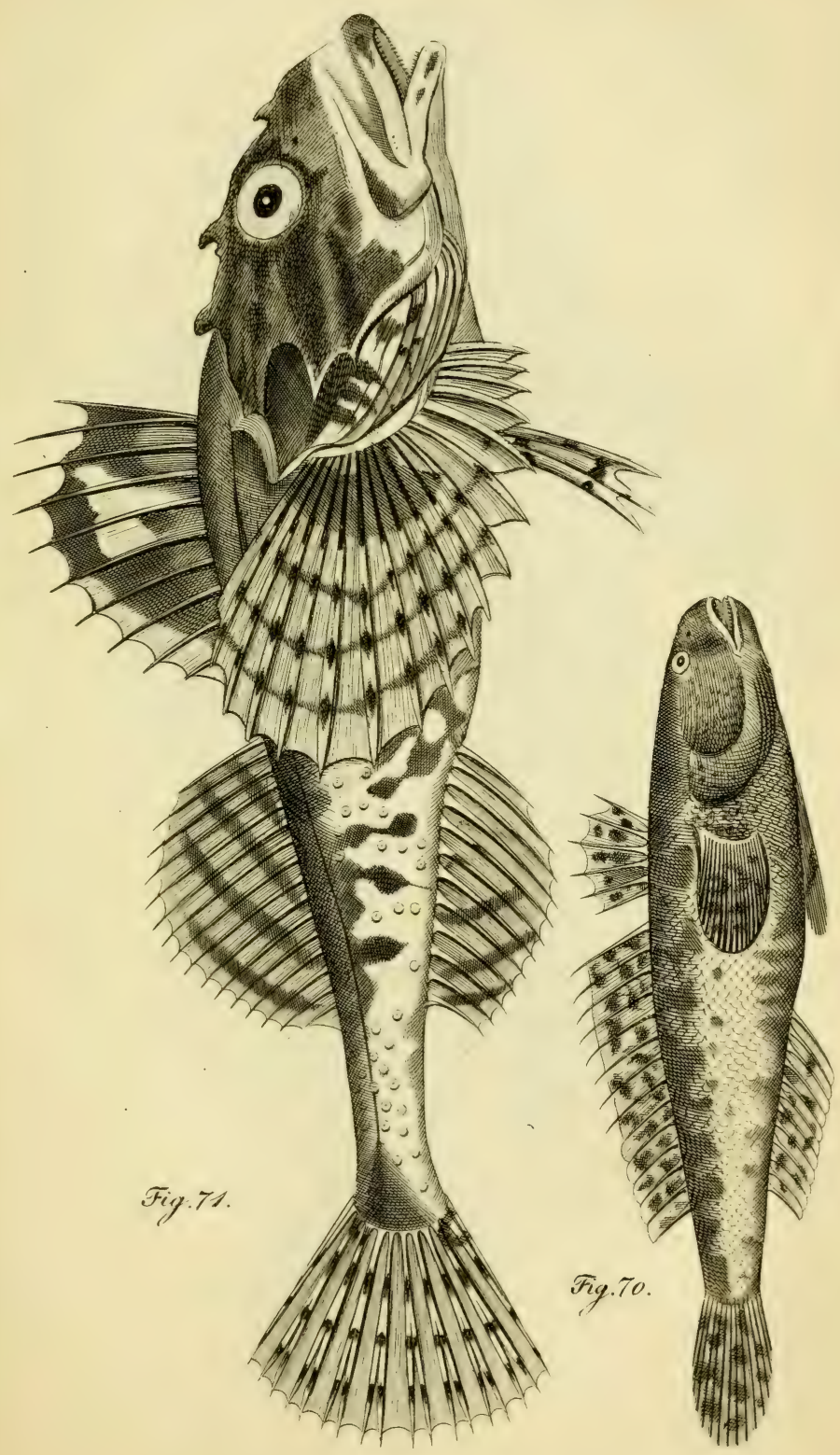



Trf. \&5.

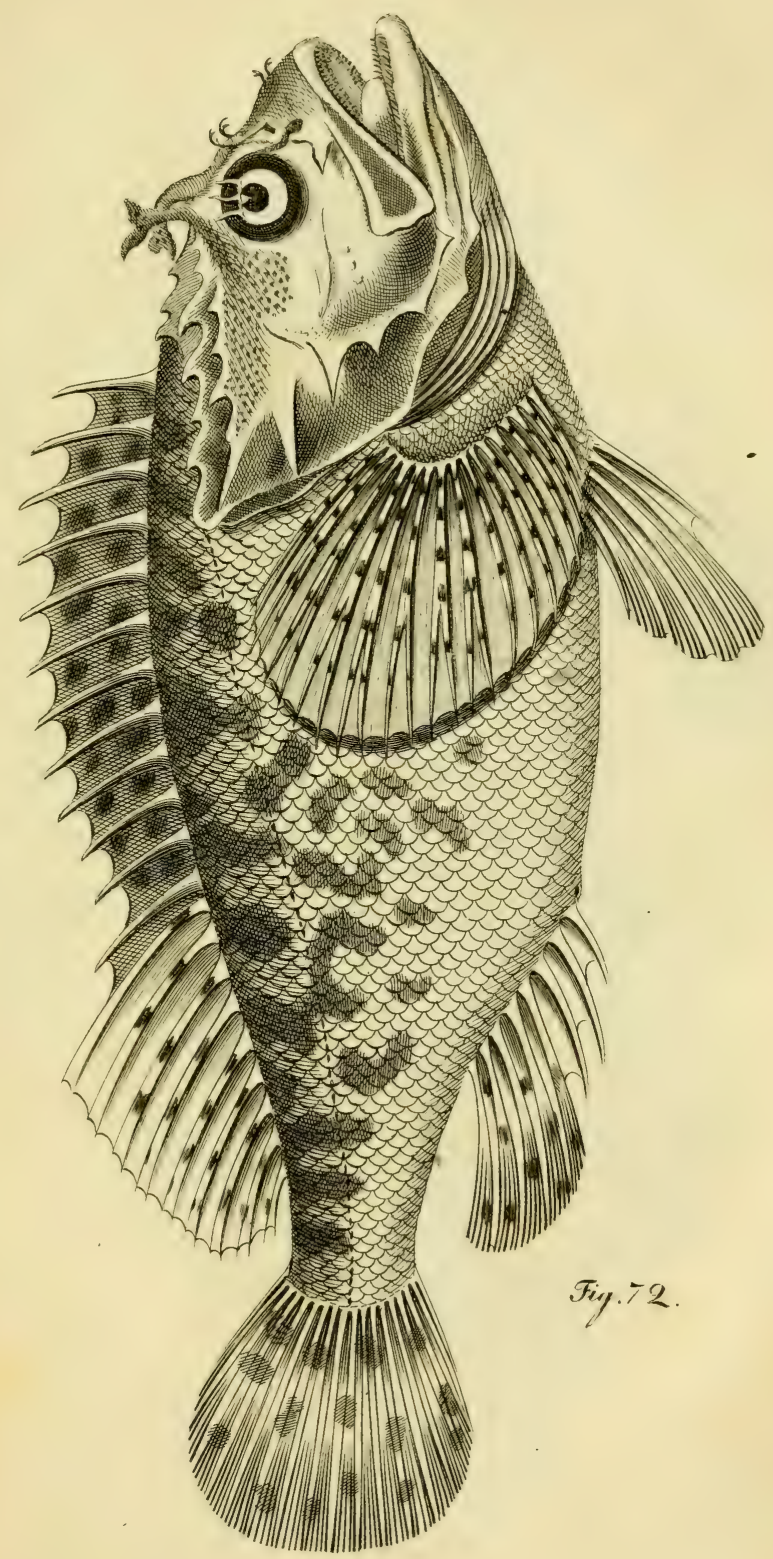



Txe +6.

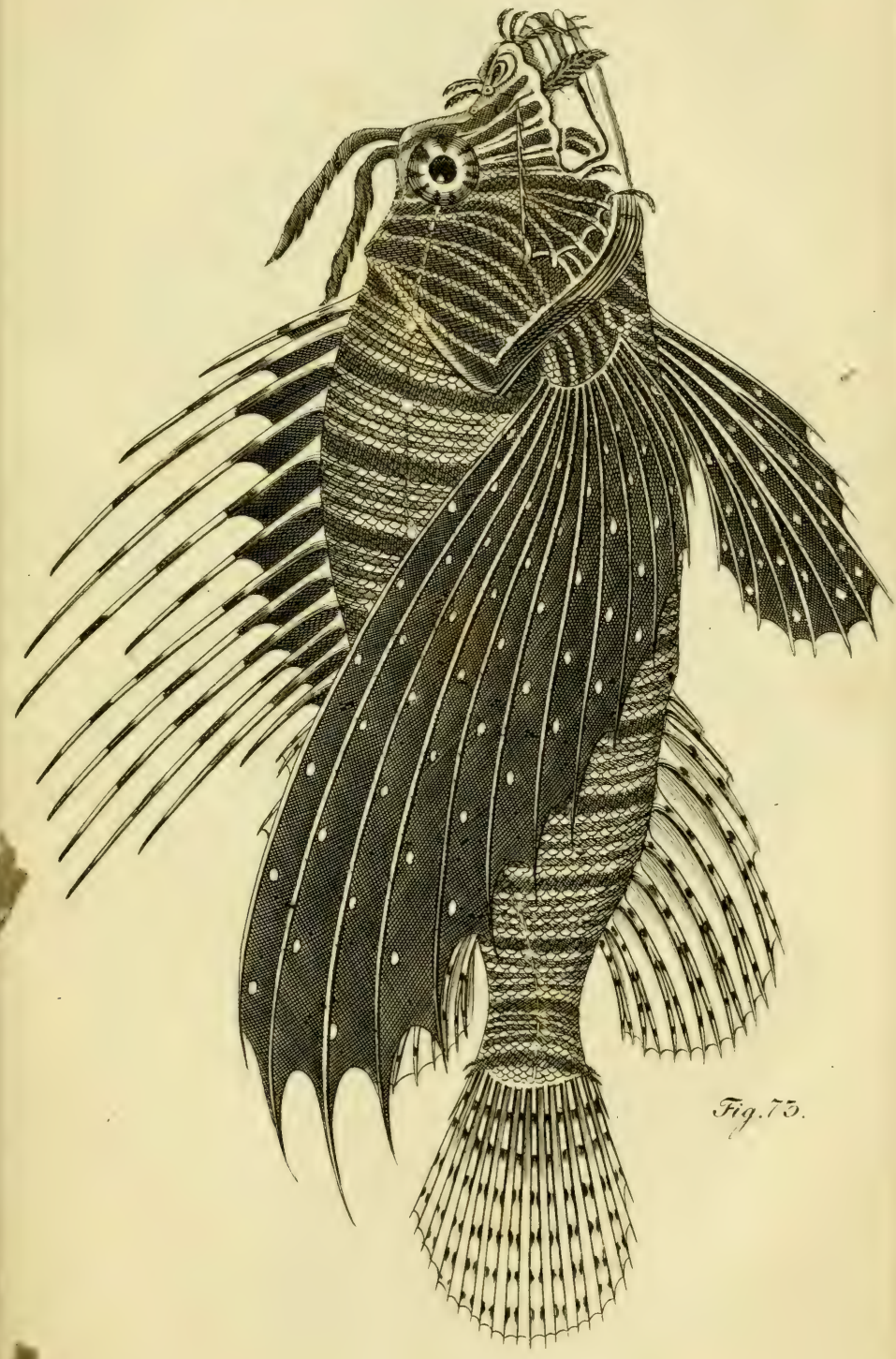



Tret-it.

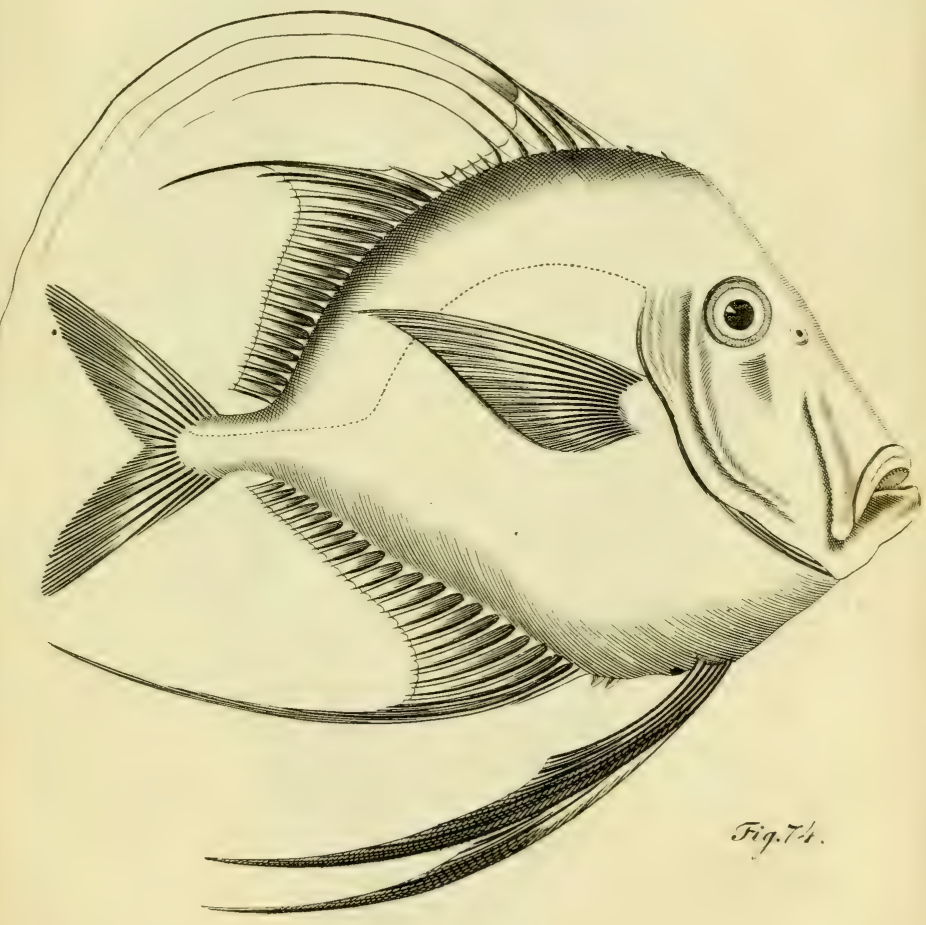



Tref - 8.

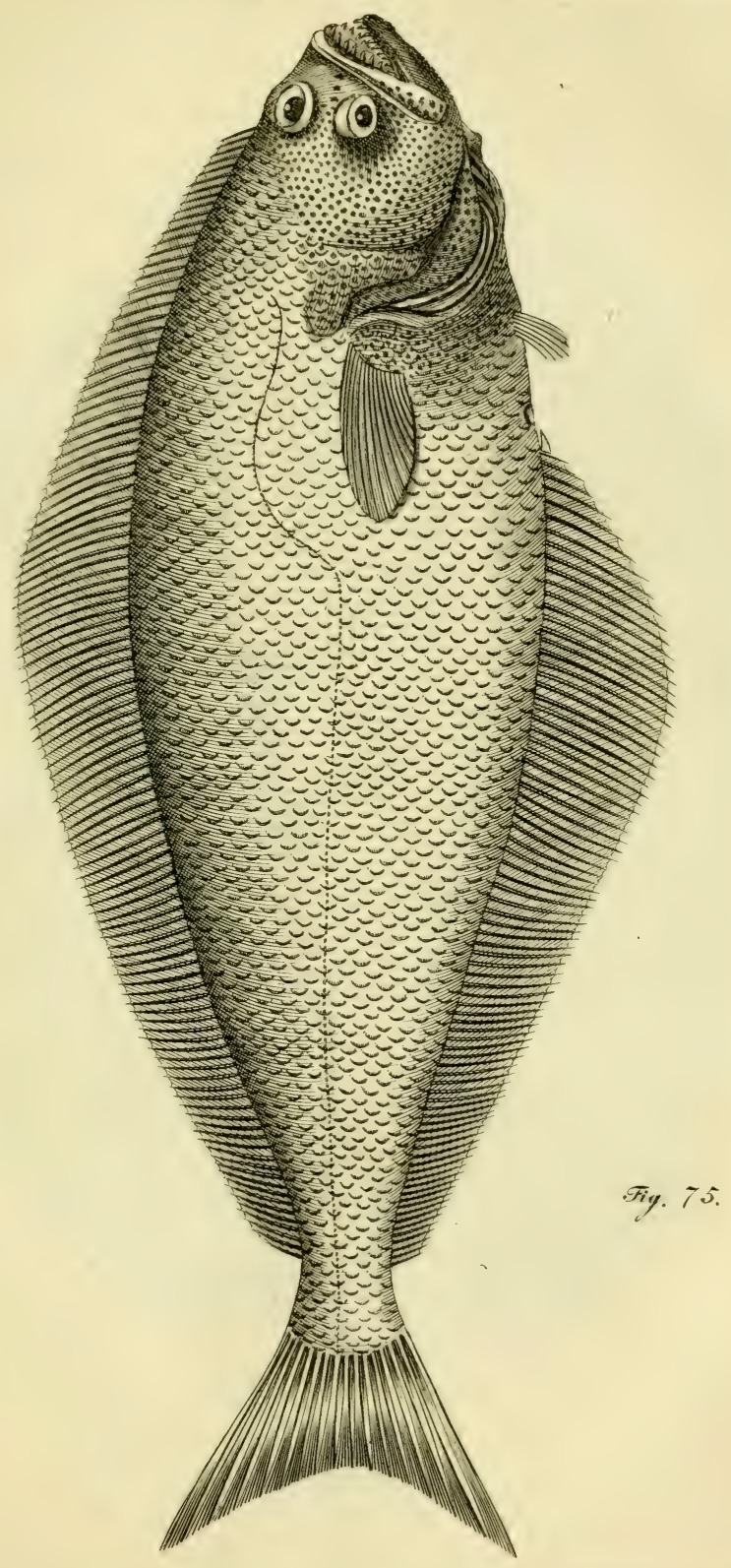





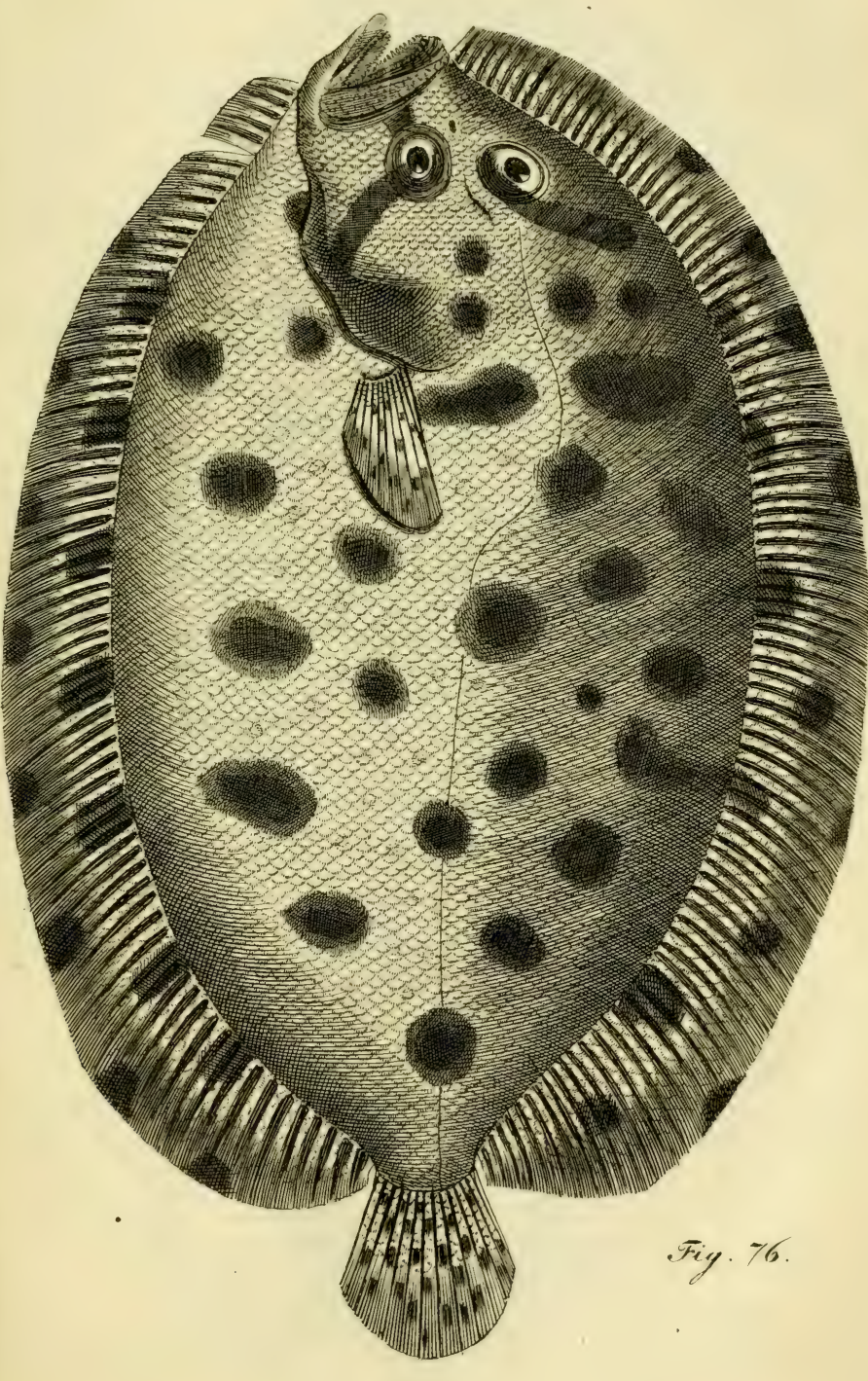





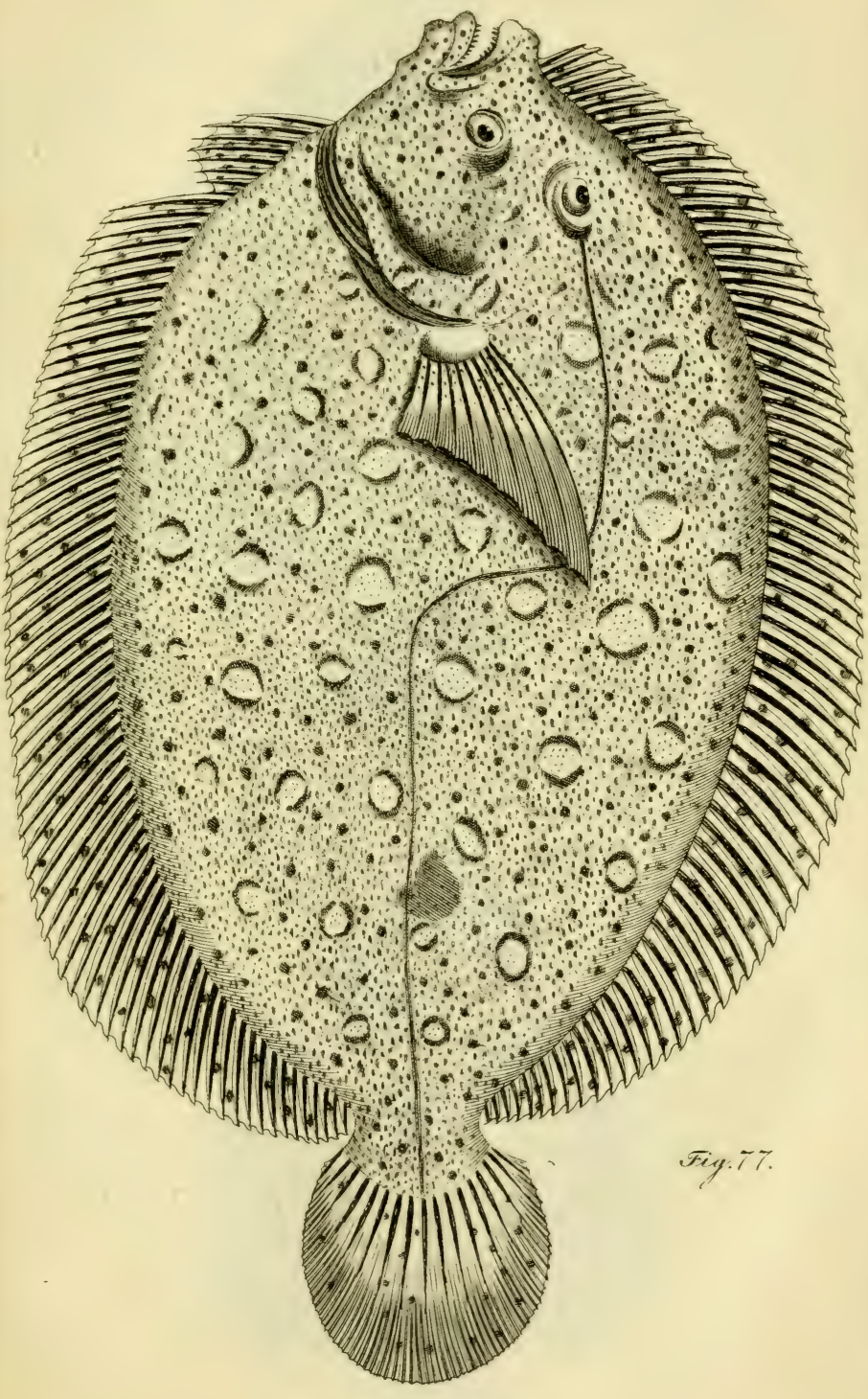



Toyt. 51.

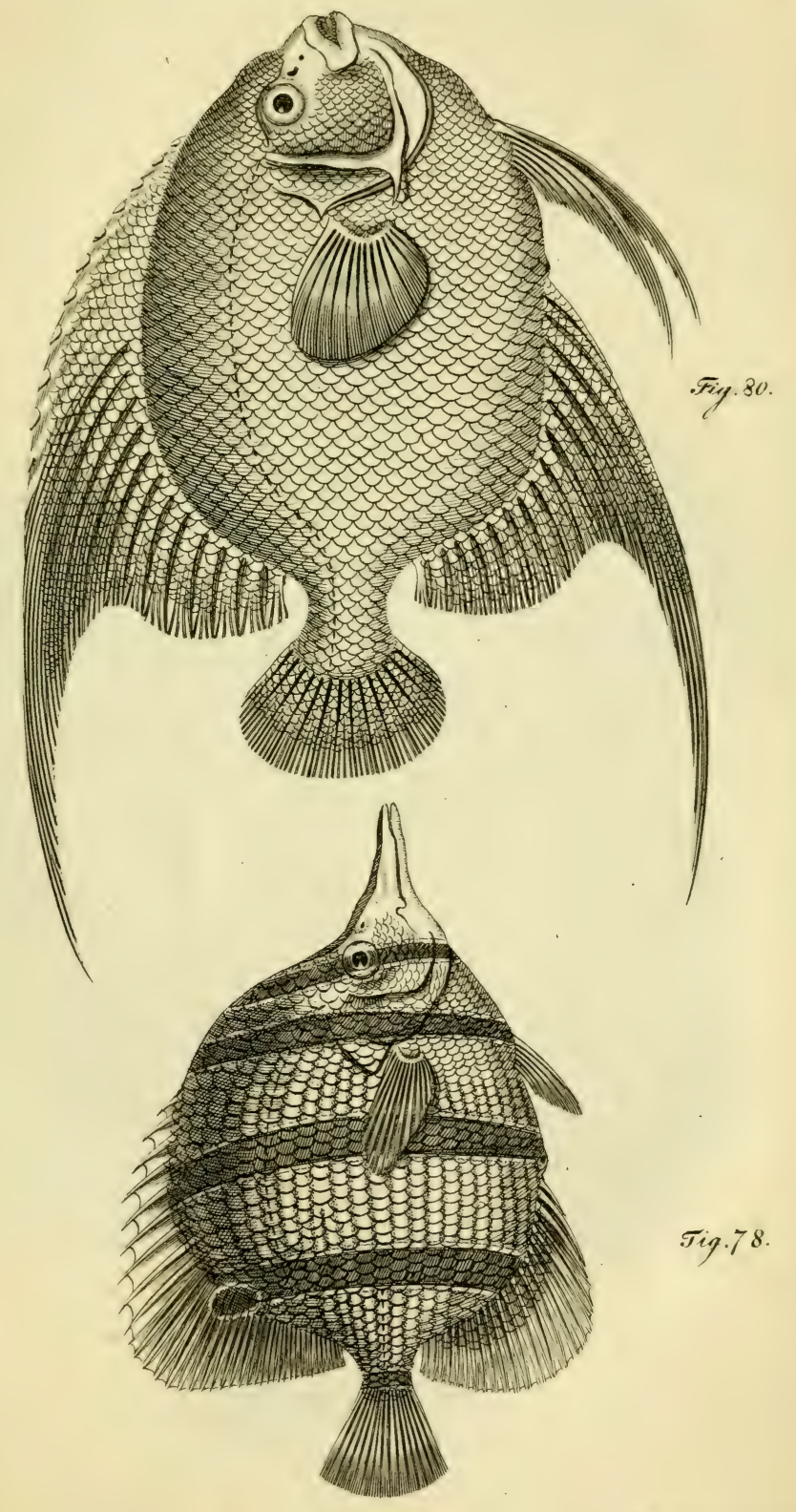



Tal.52.

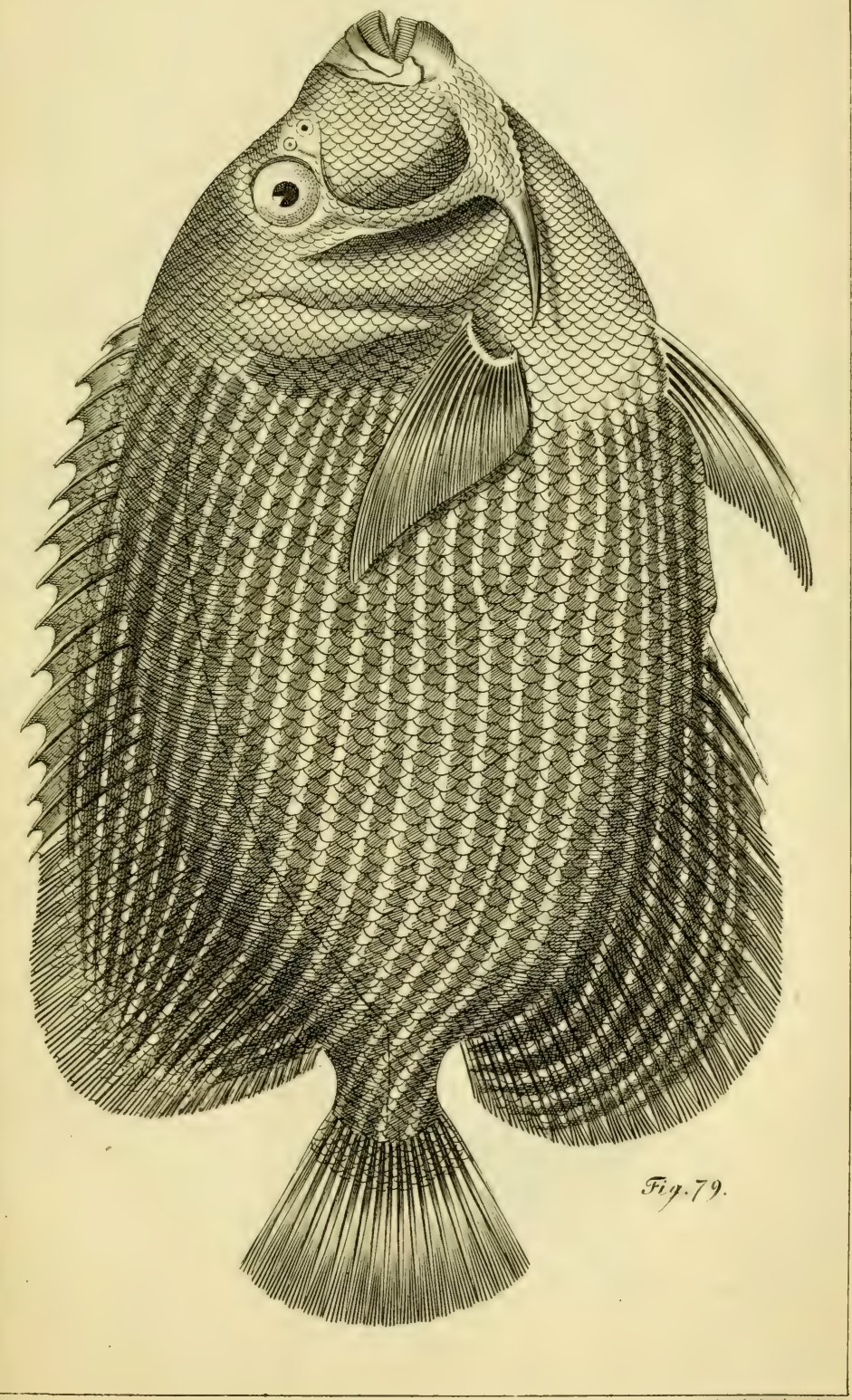



Tafis

1

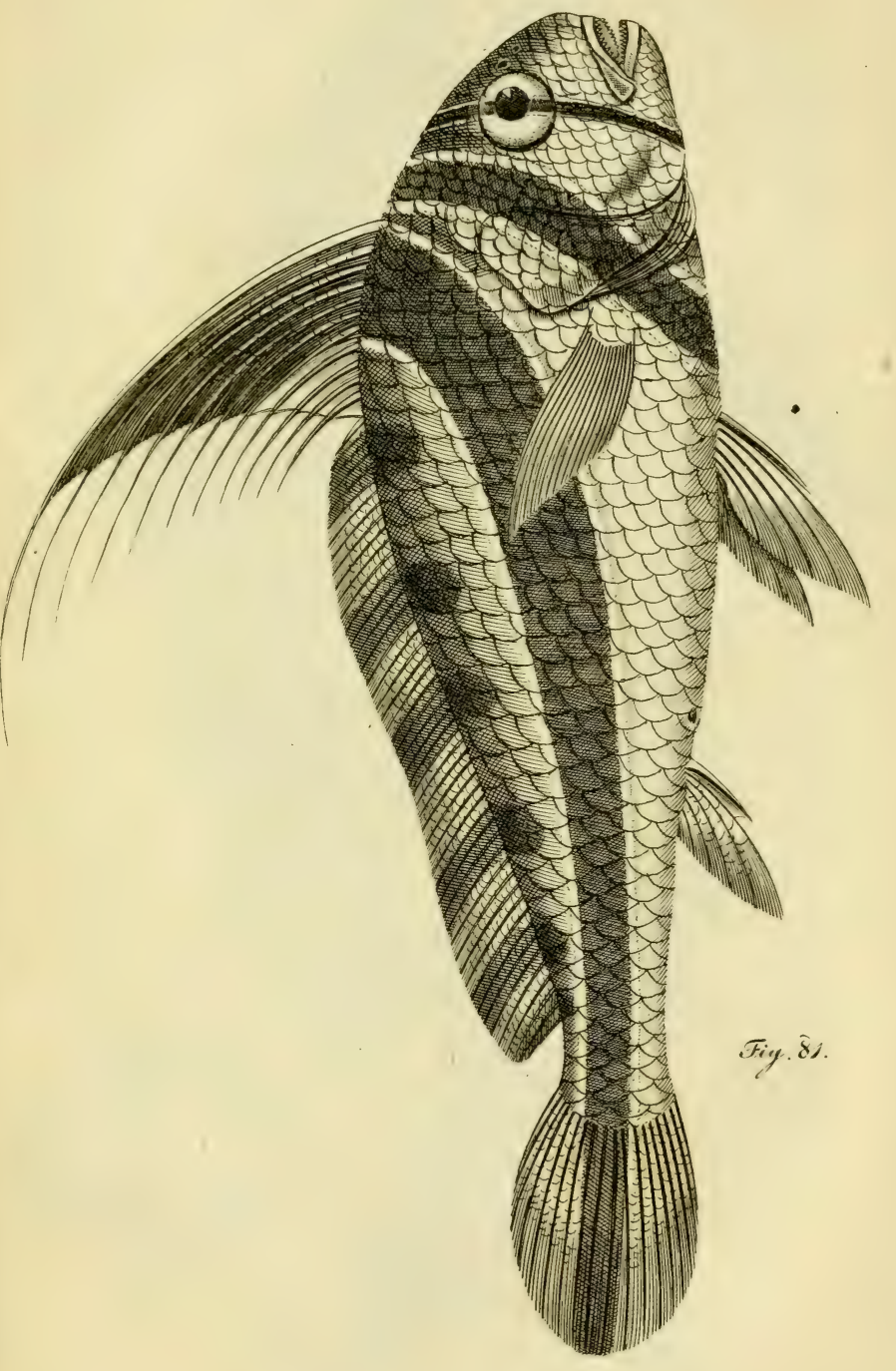



Tef.5\%

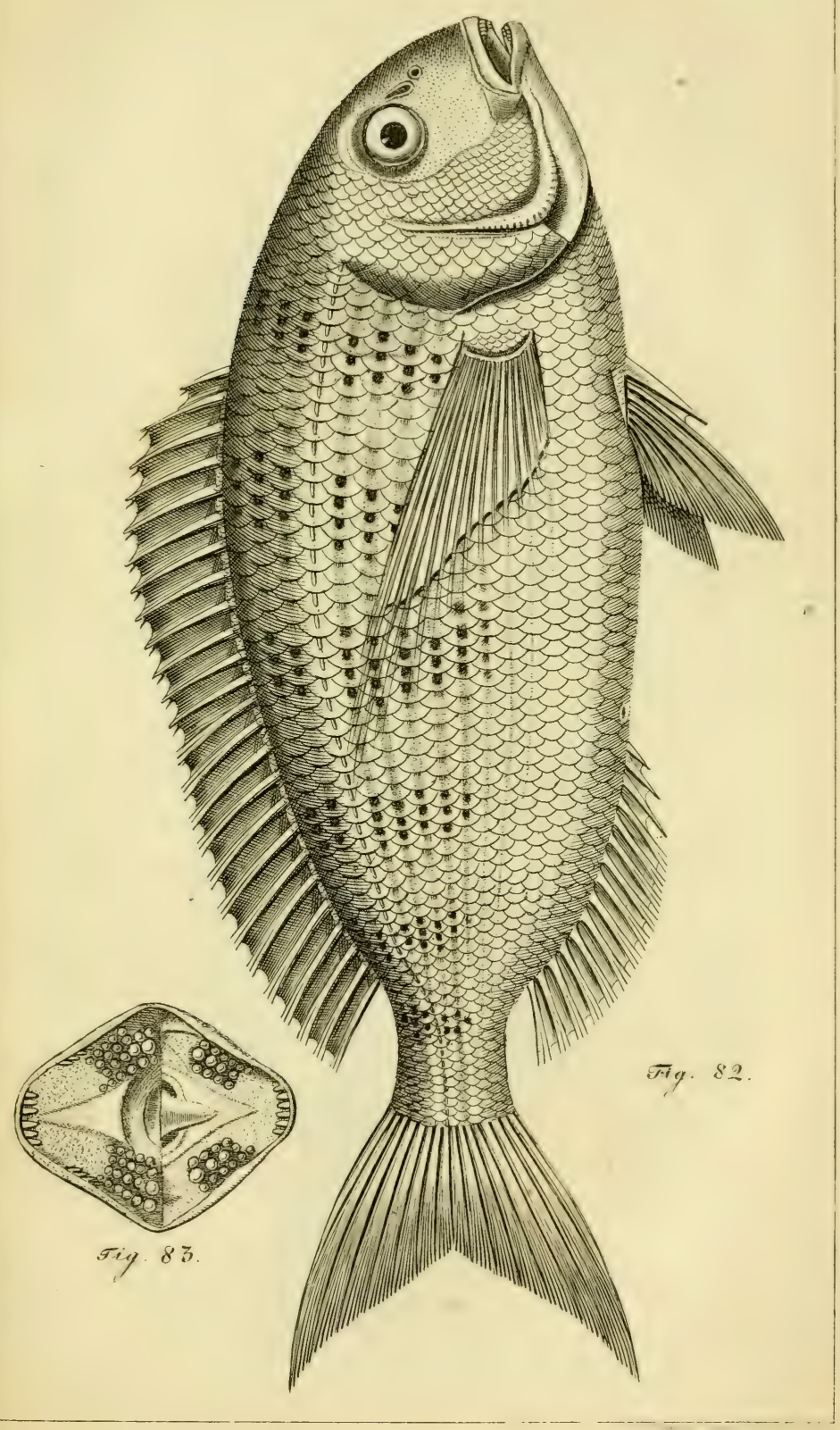





$\pi$ Tif. 56.

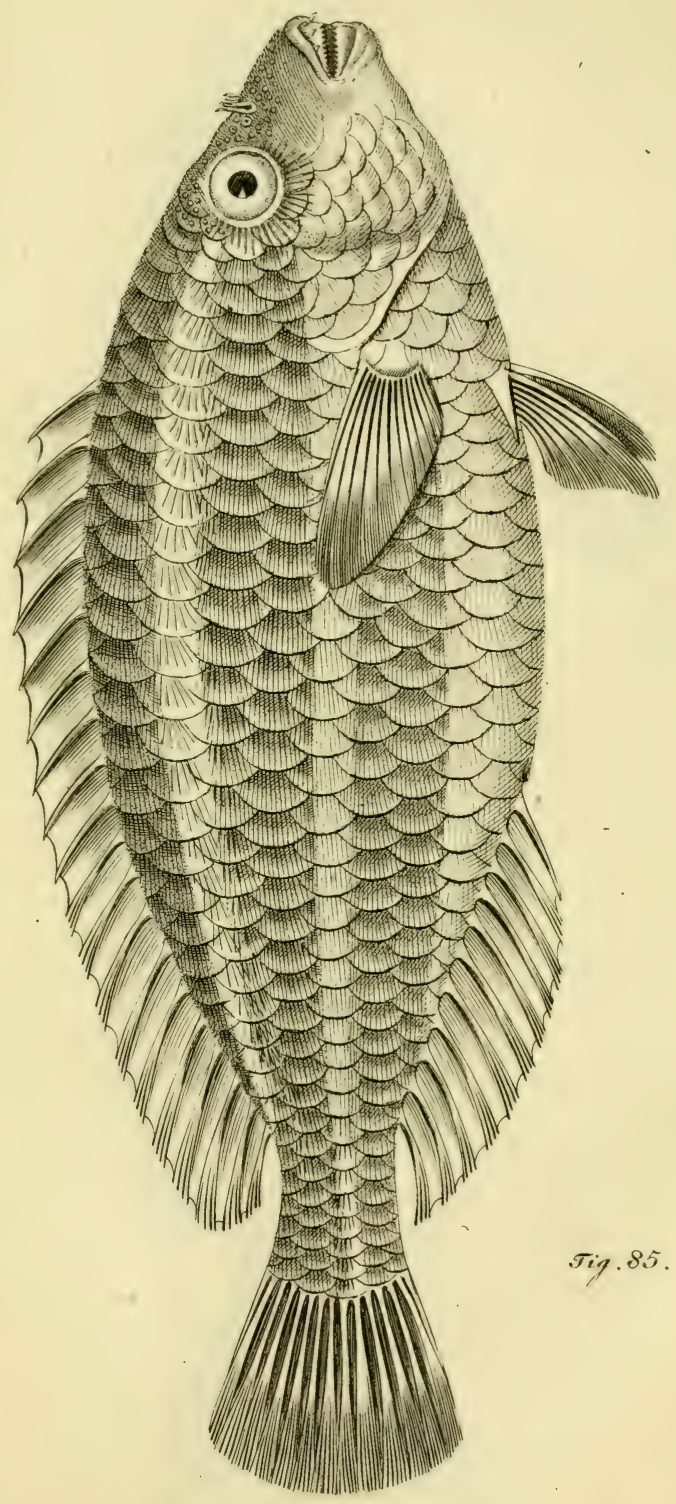



TII).57.

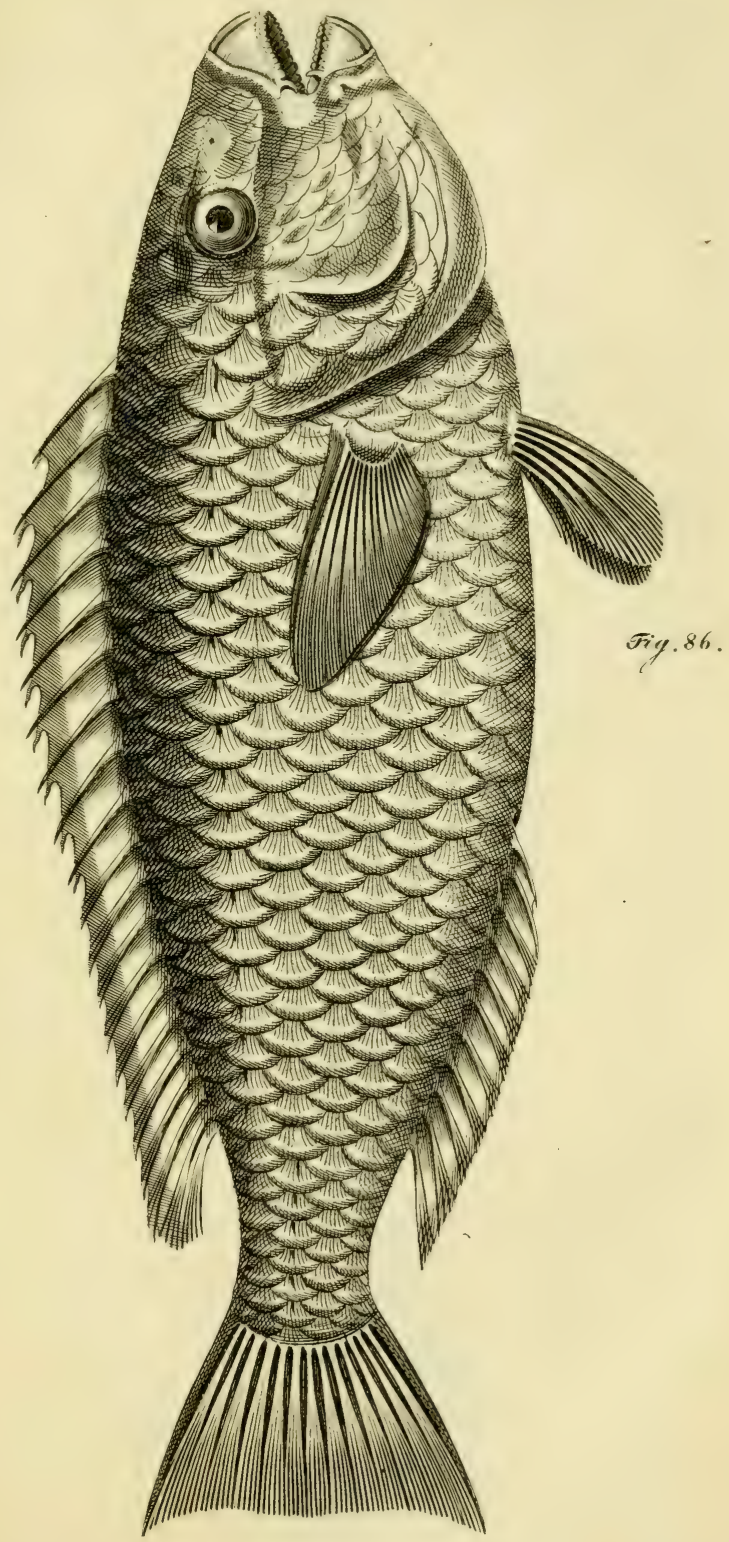



Tief. 58 .

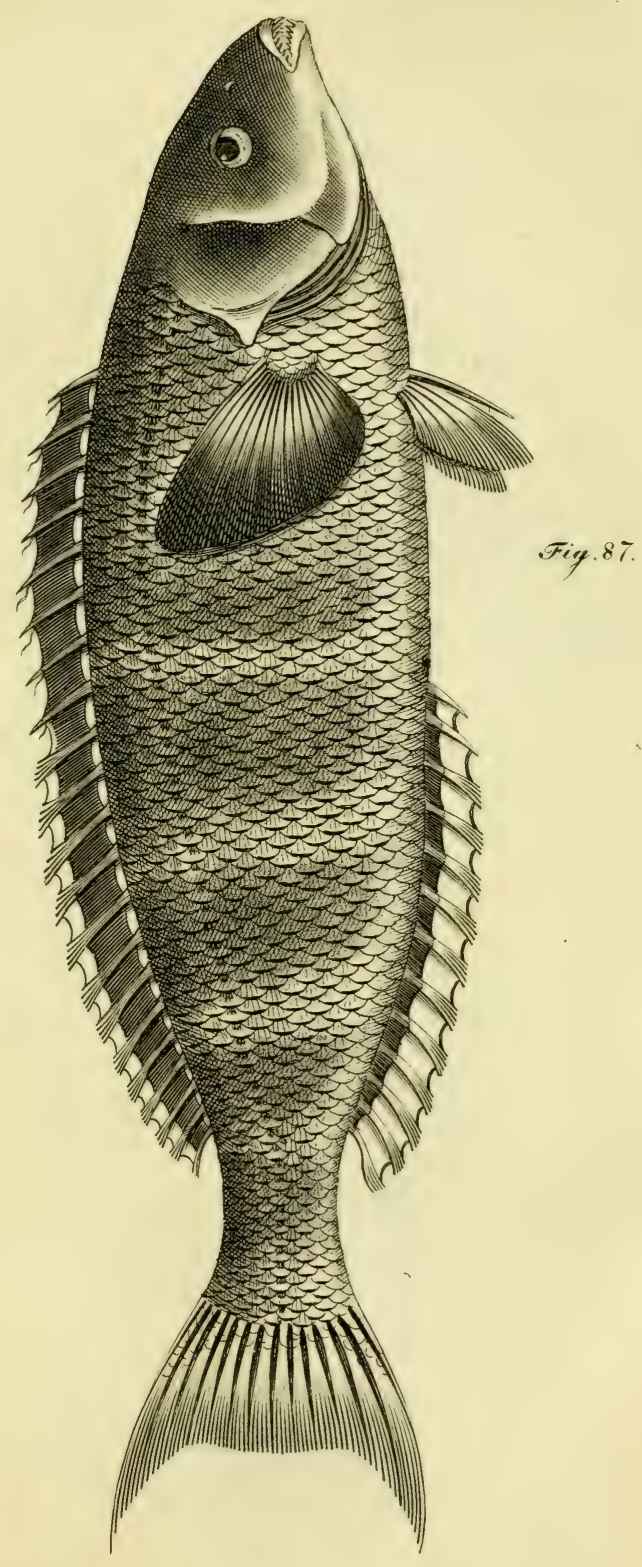





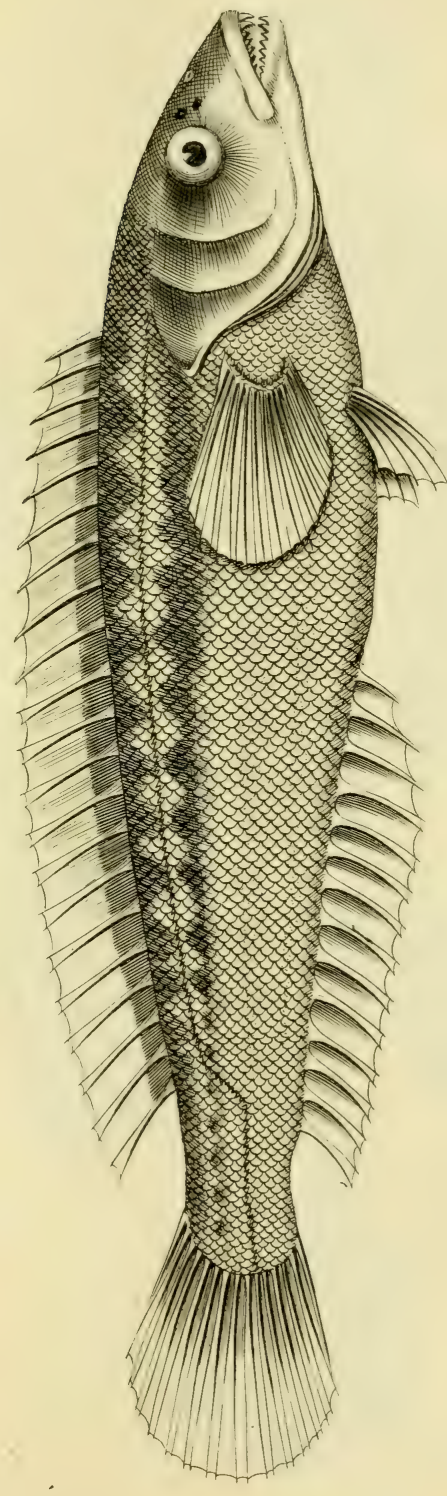



Tref. 60

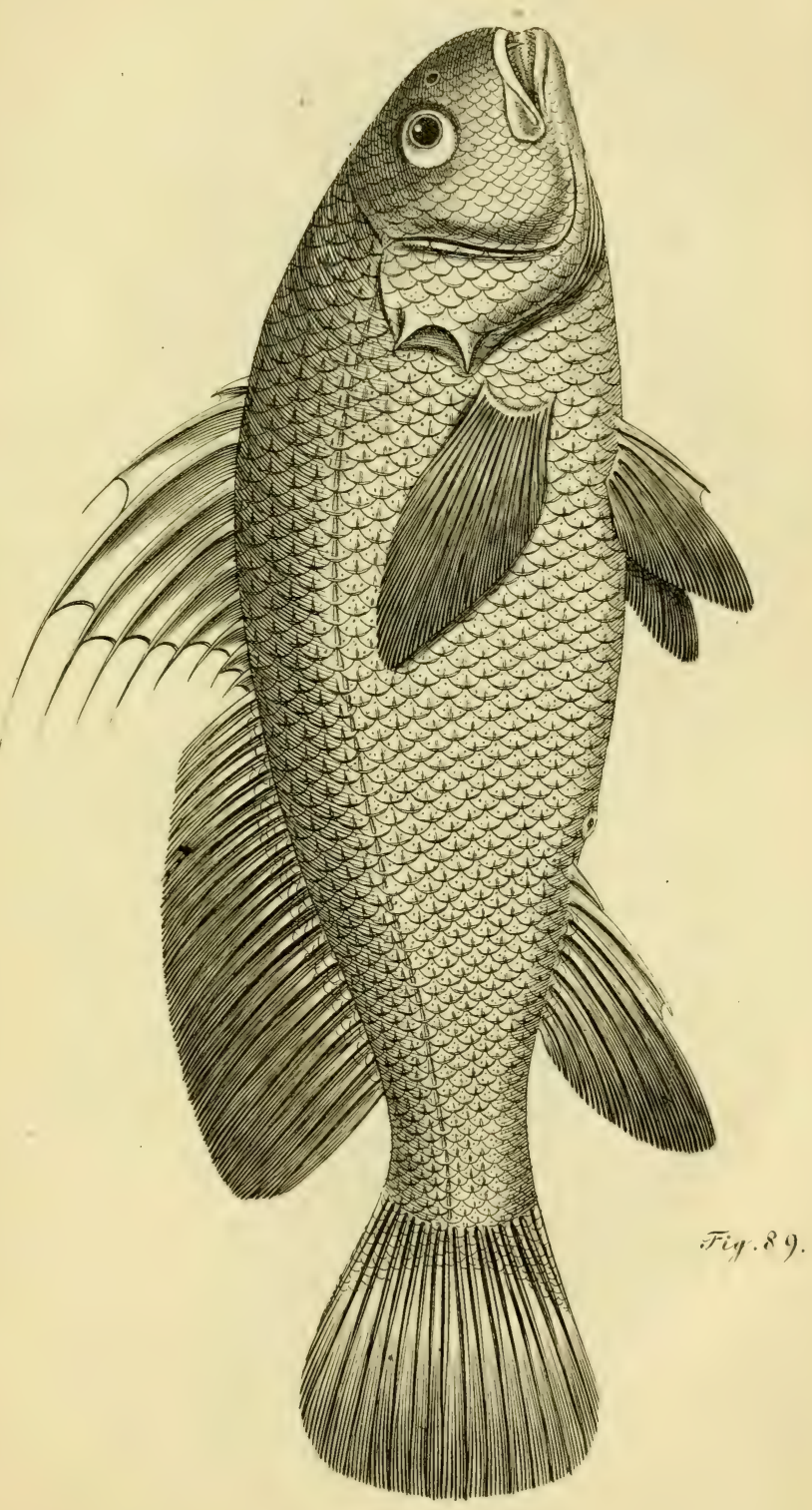





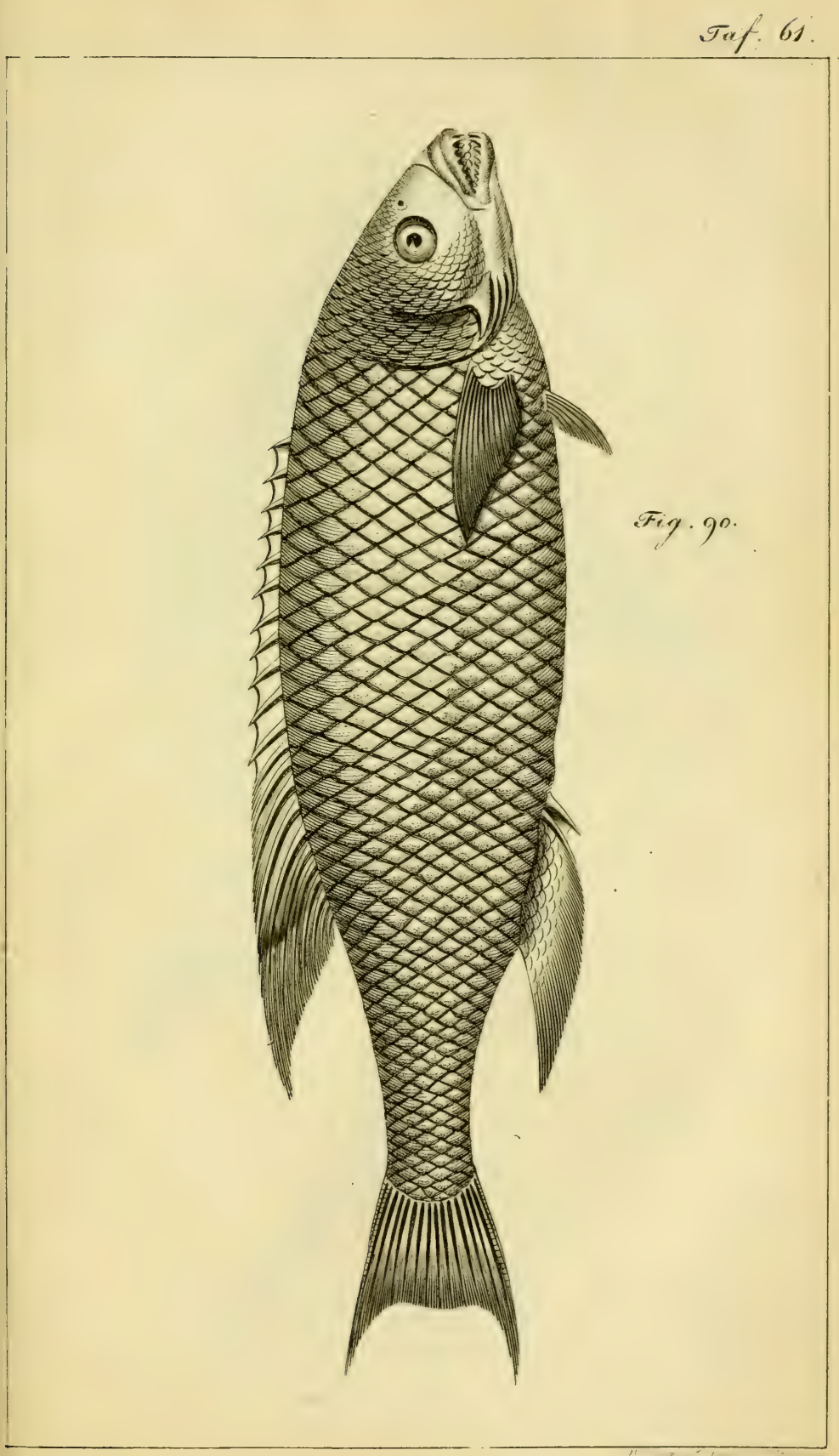



Til) 62.

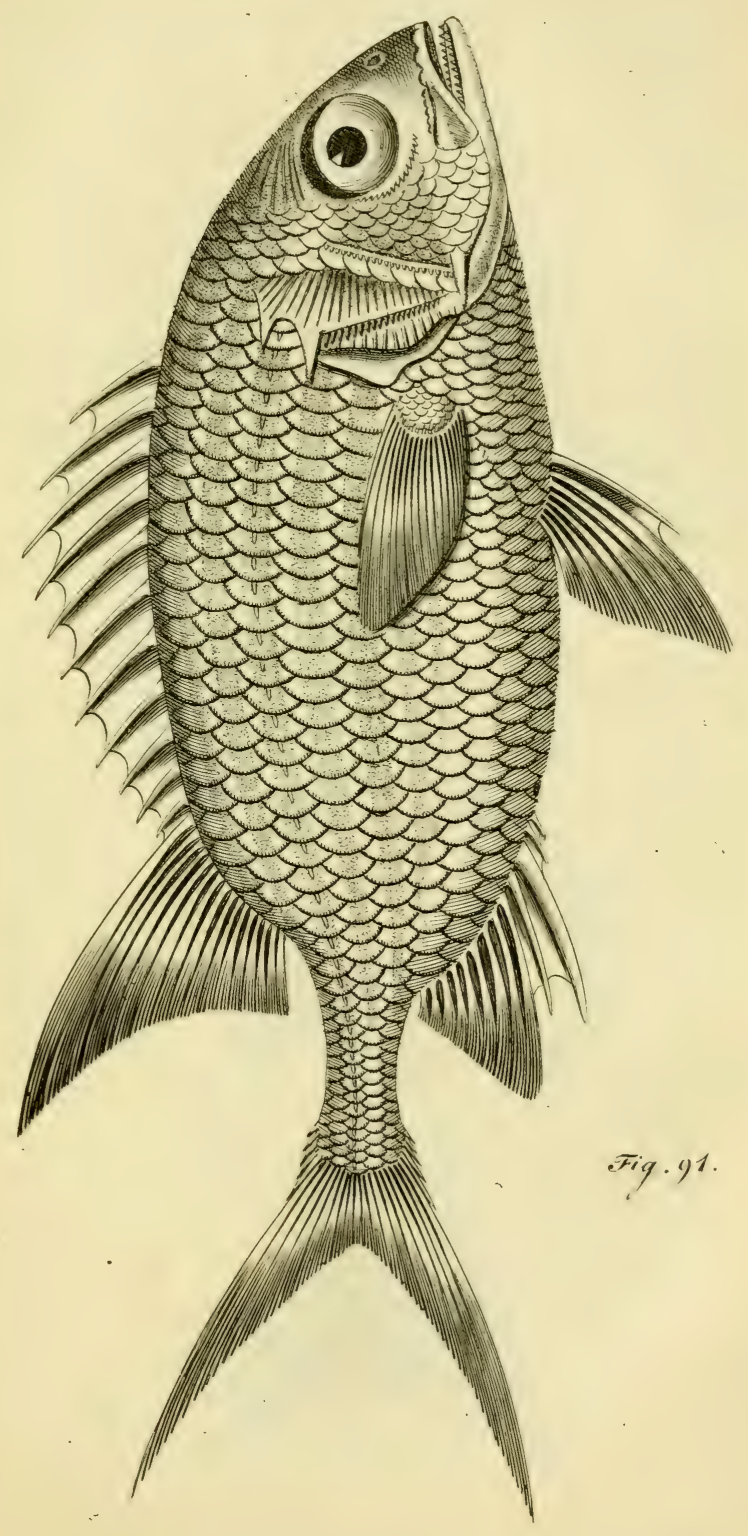



Tref.6.5.

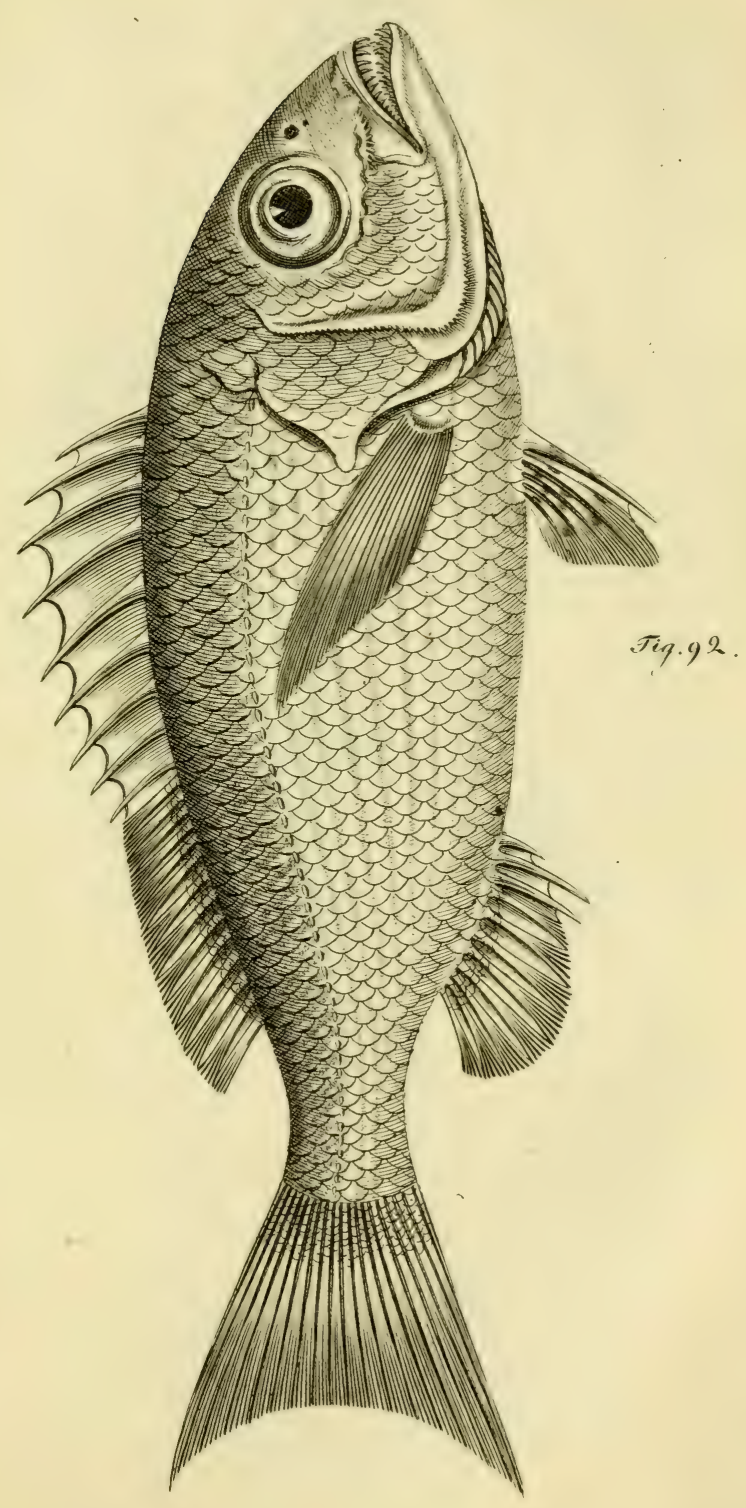



$\operatorname{Trr} / .6 \%$

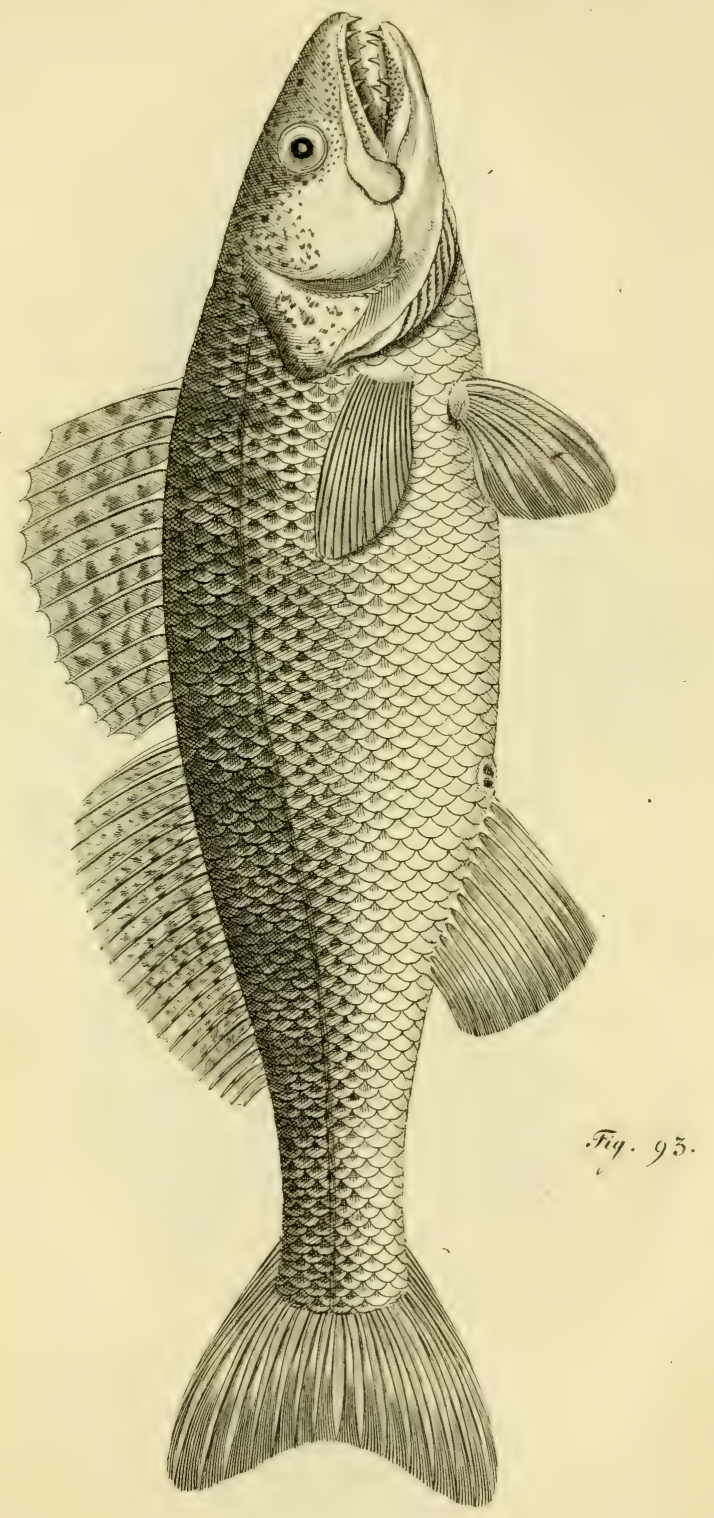



50 f. 65.

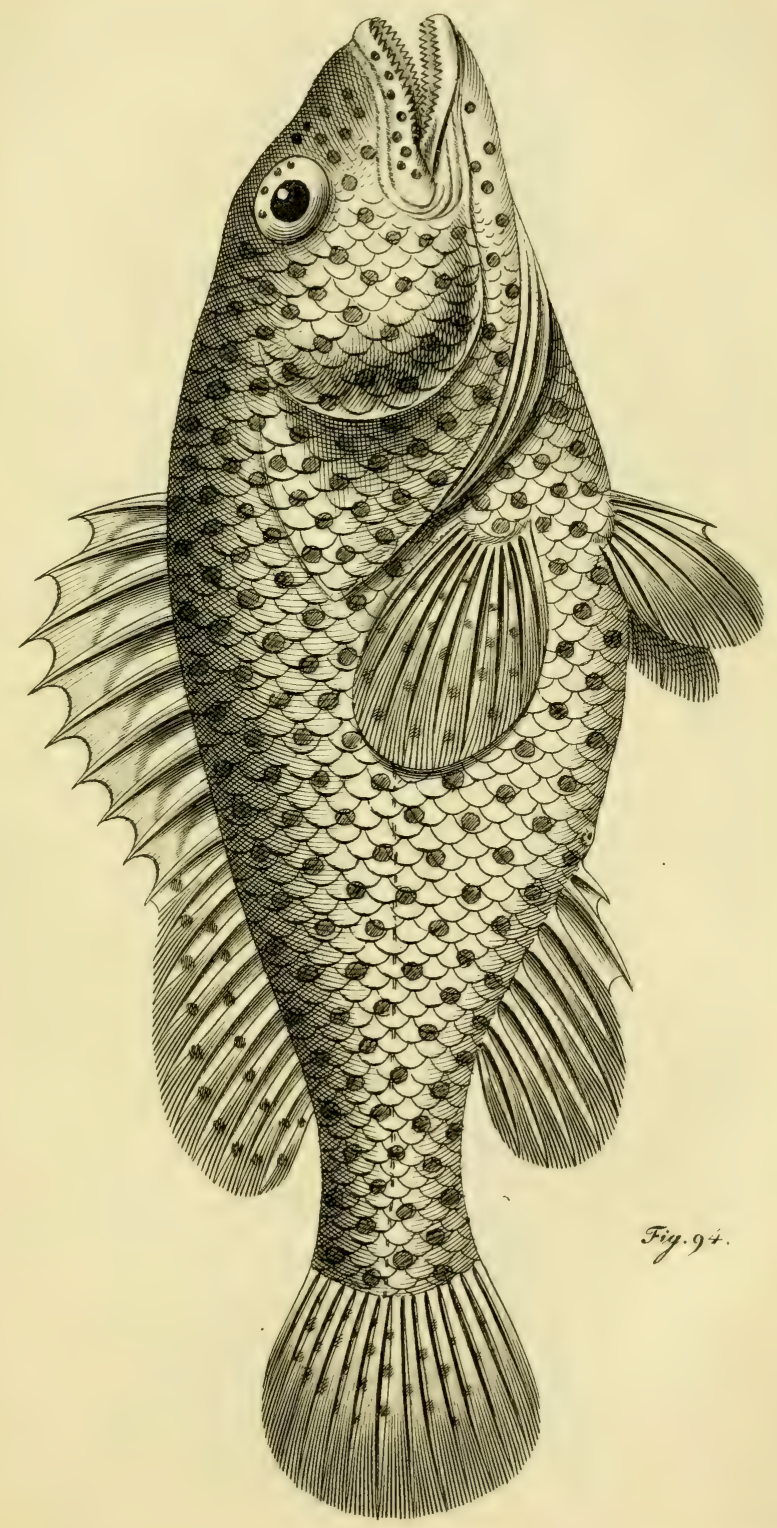



. Tre 66 .

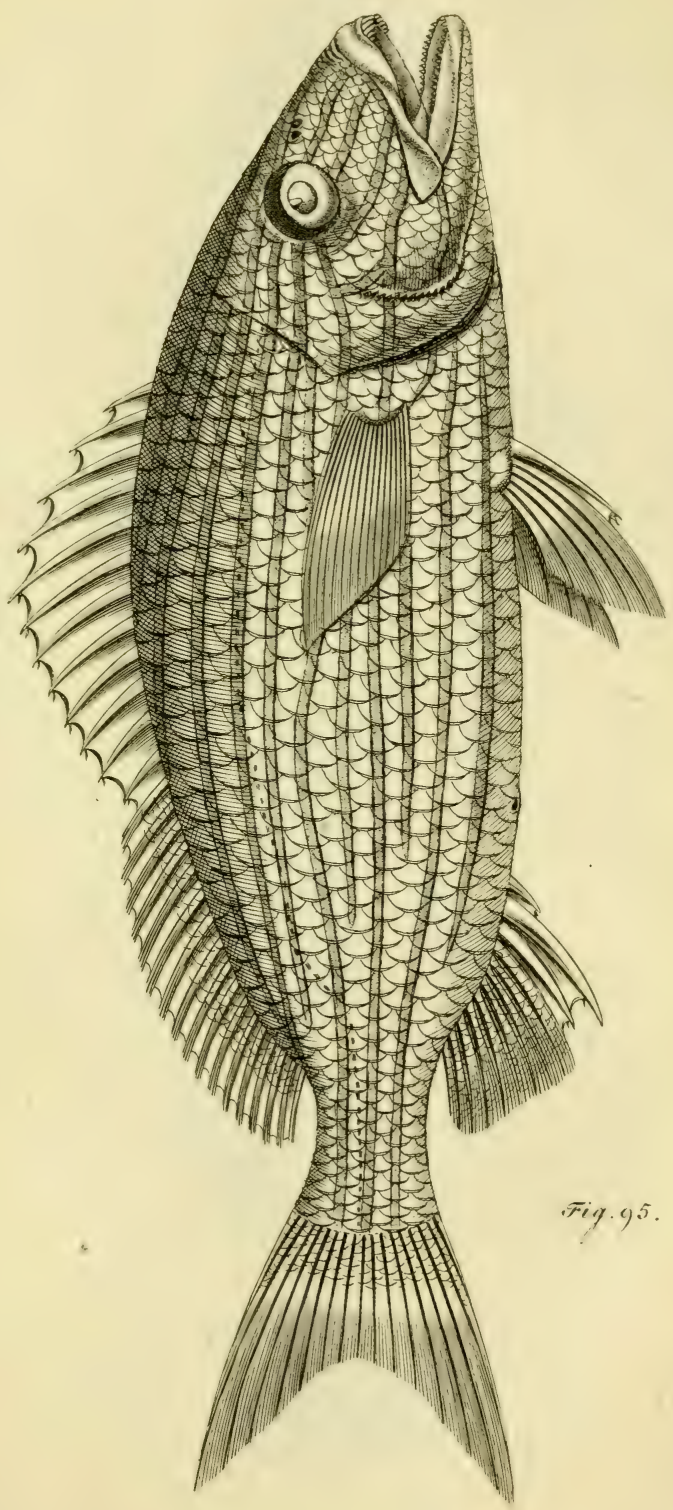



Terf.65.

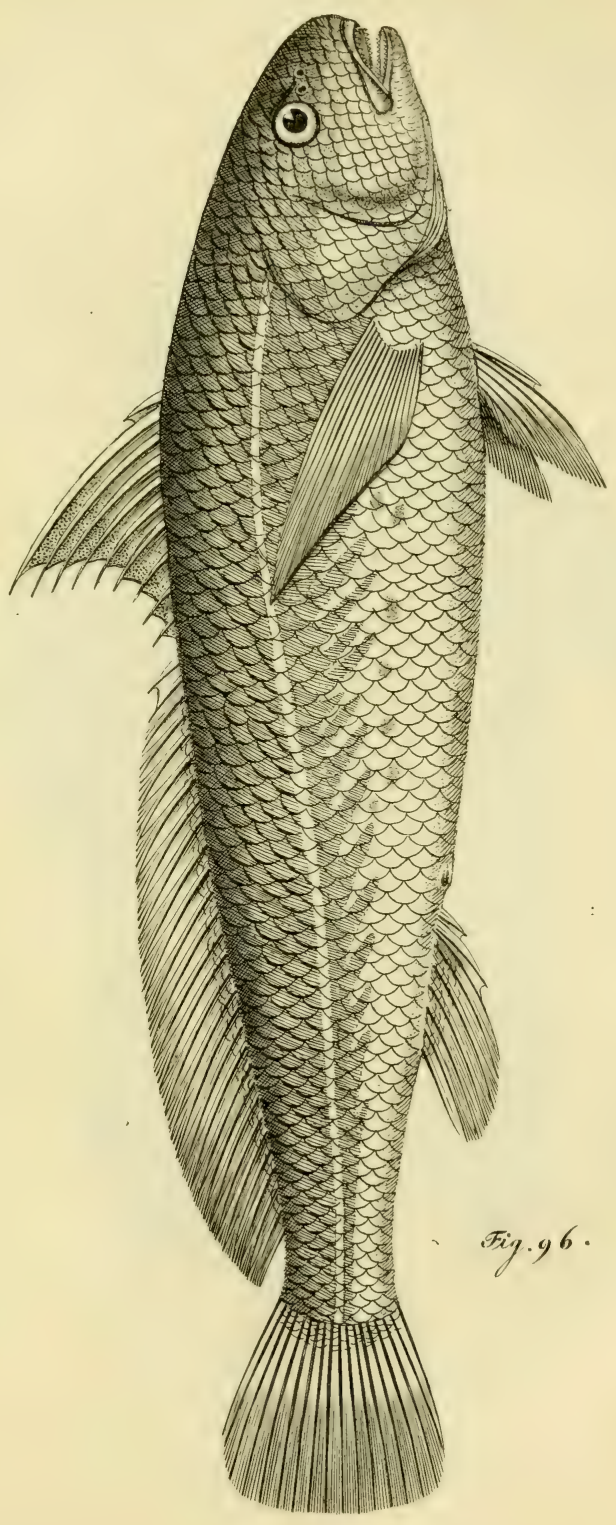



Tef: $60^{\circ}$

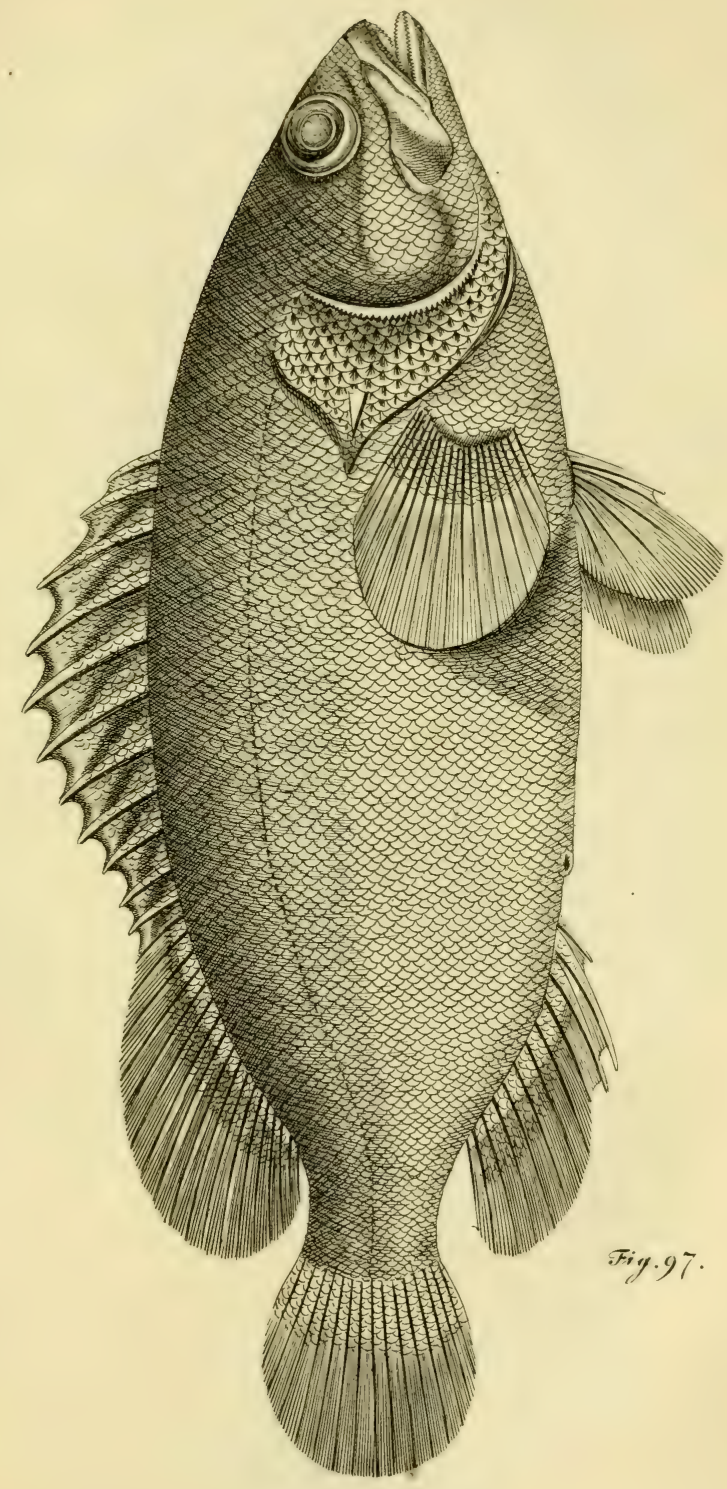



Tref. 69 .

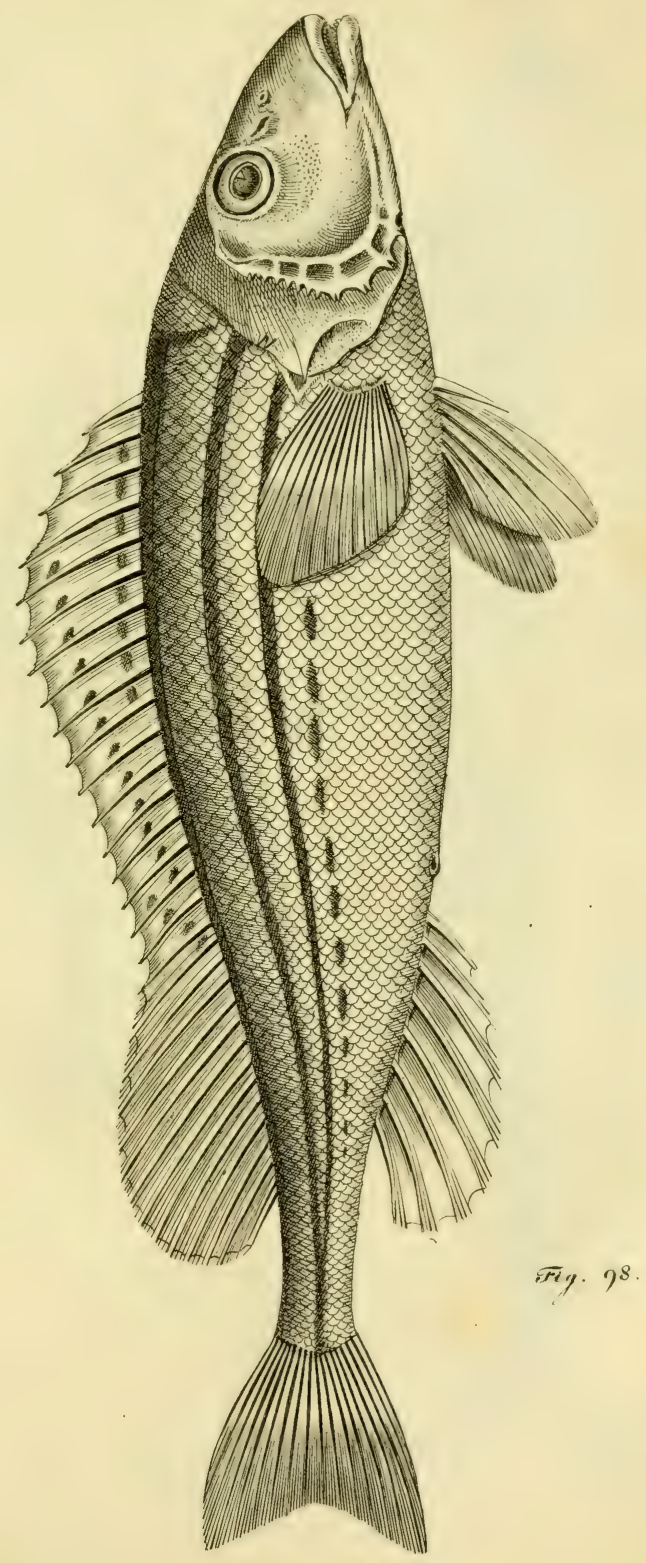




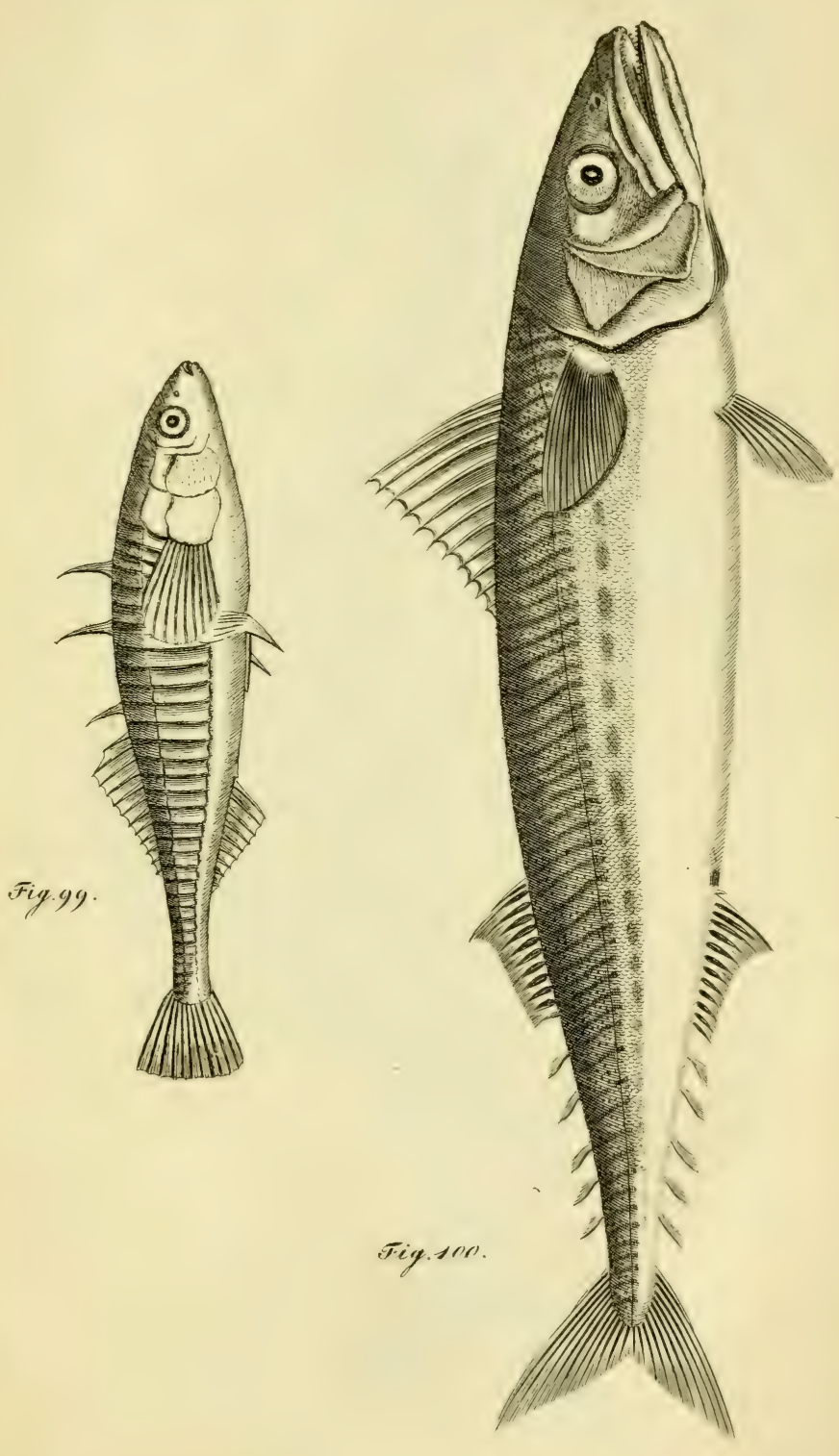



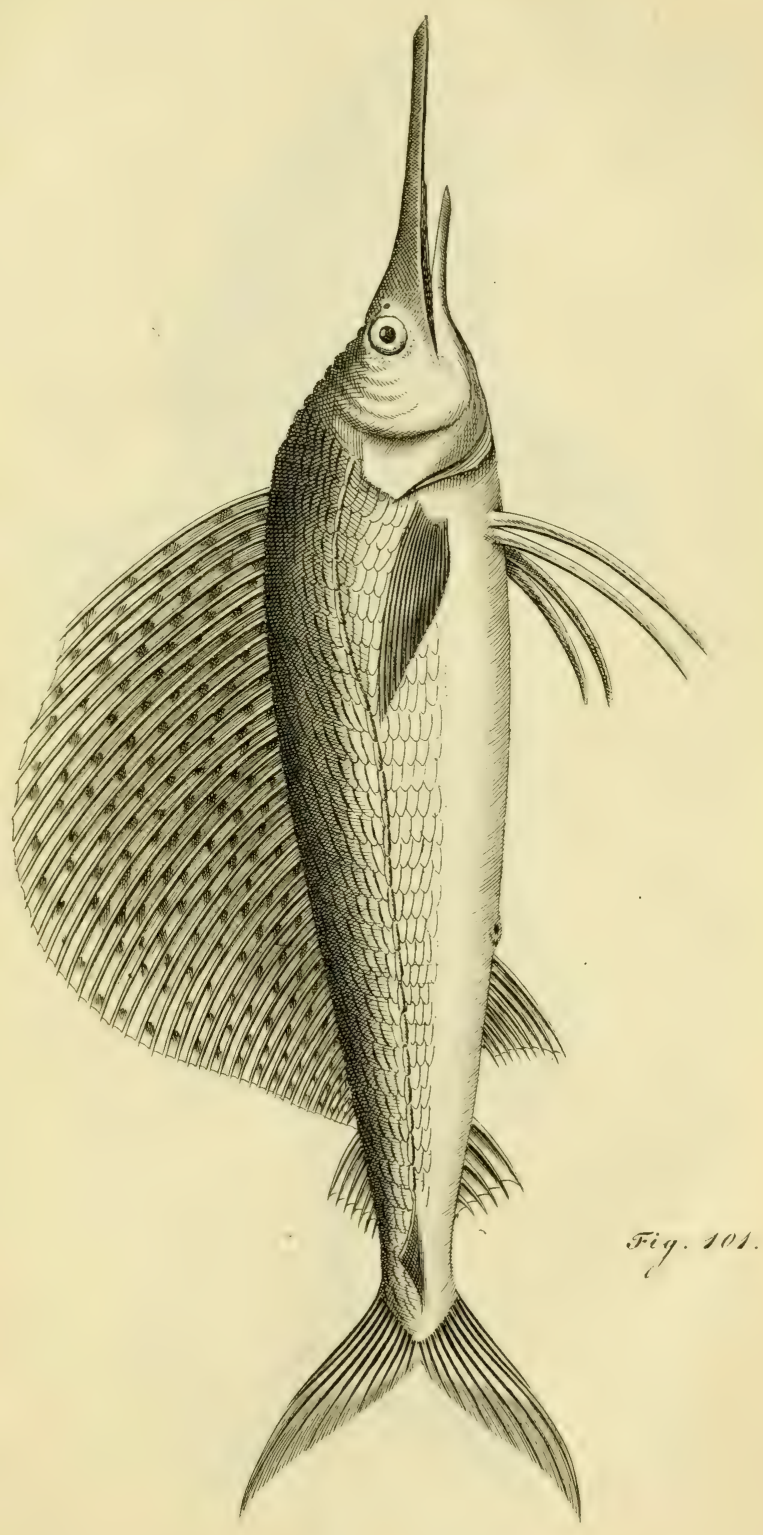



$\therefore$ Trt.72

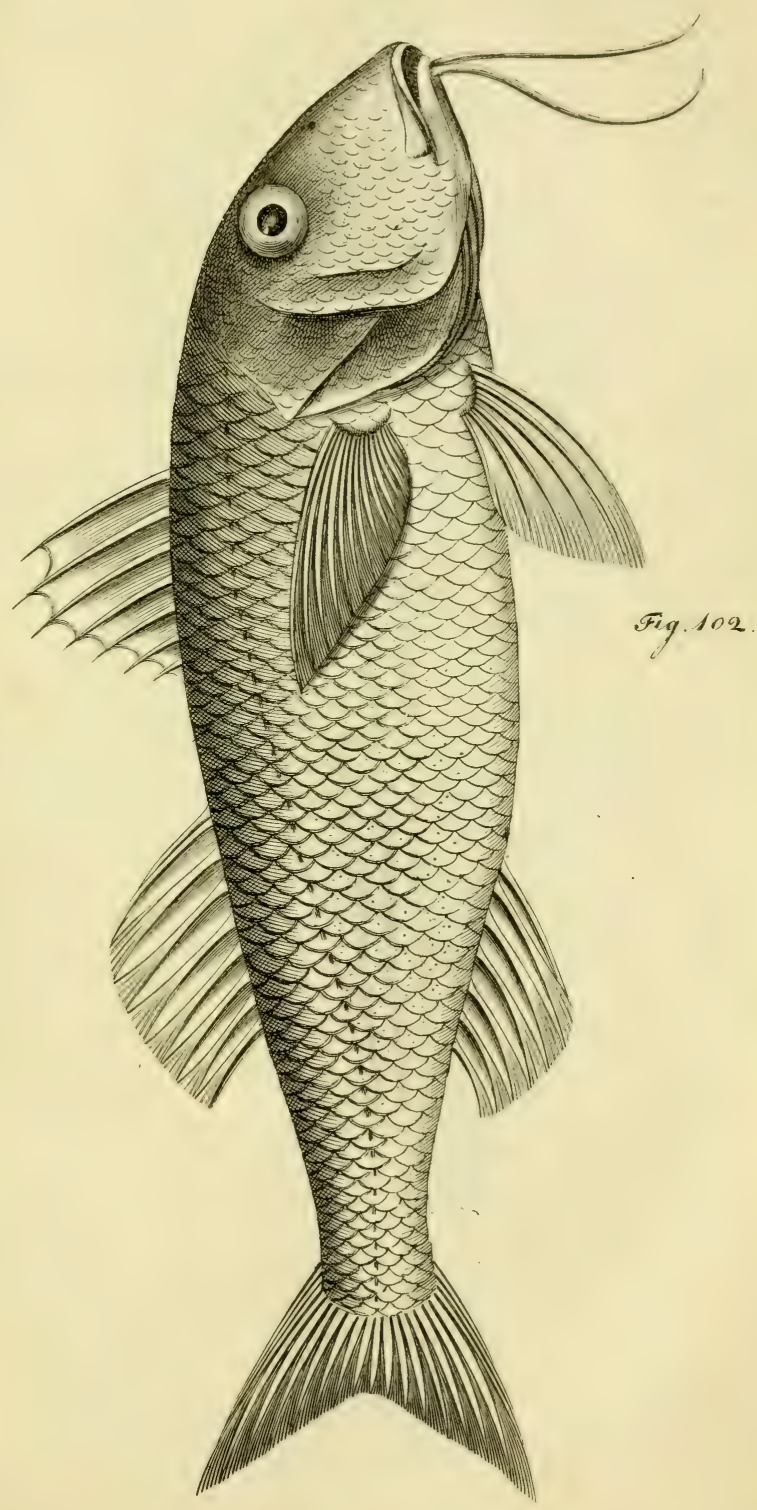





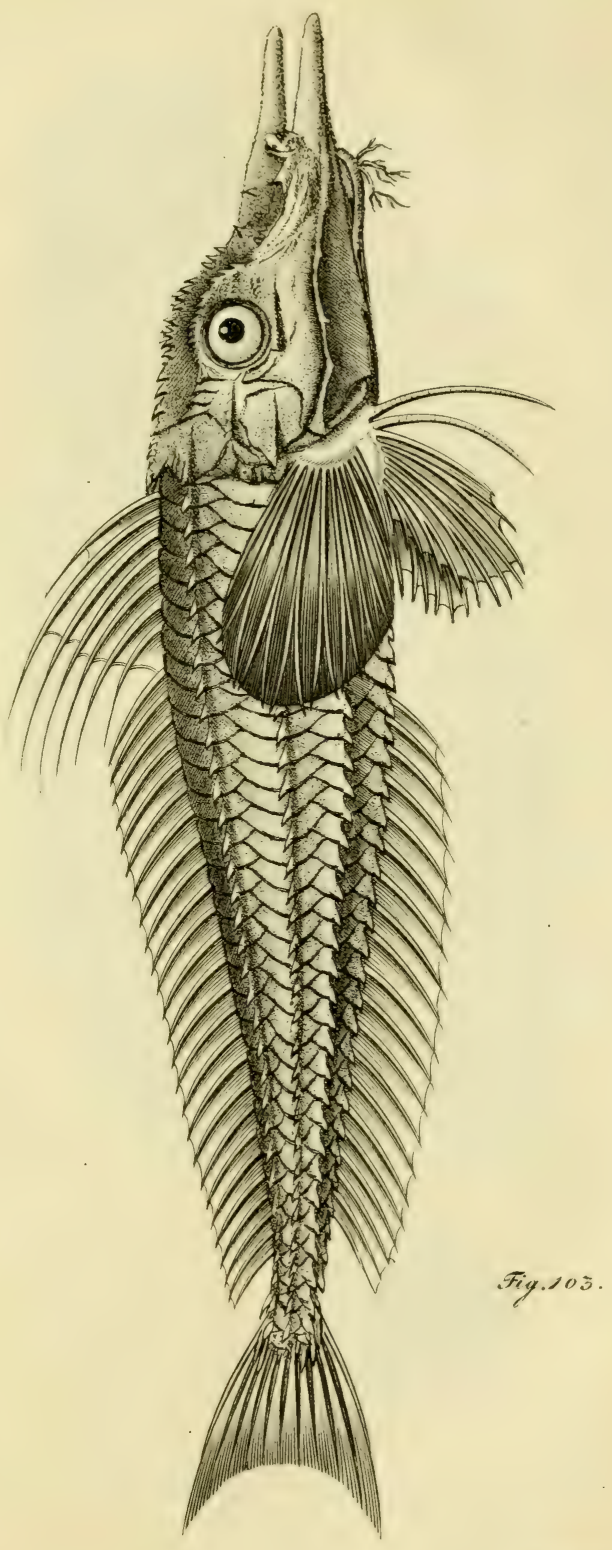



Try? Tr.

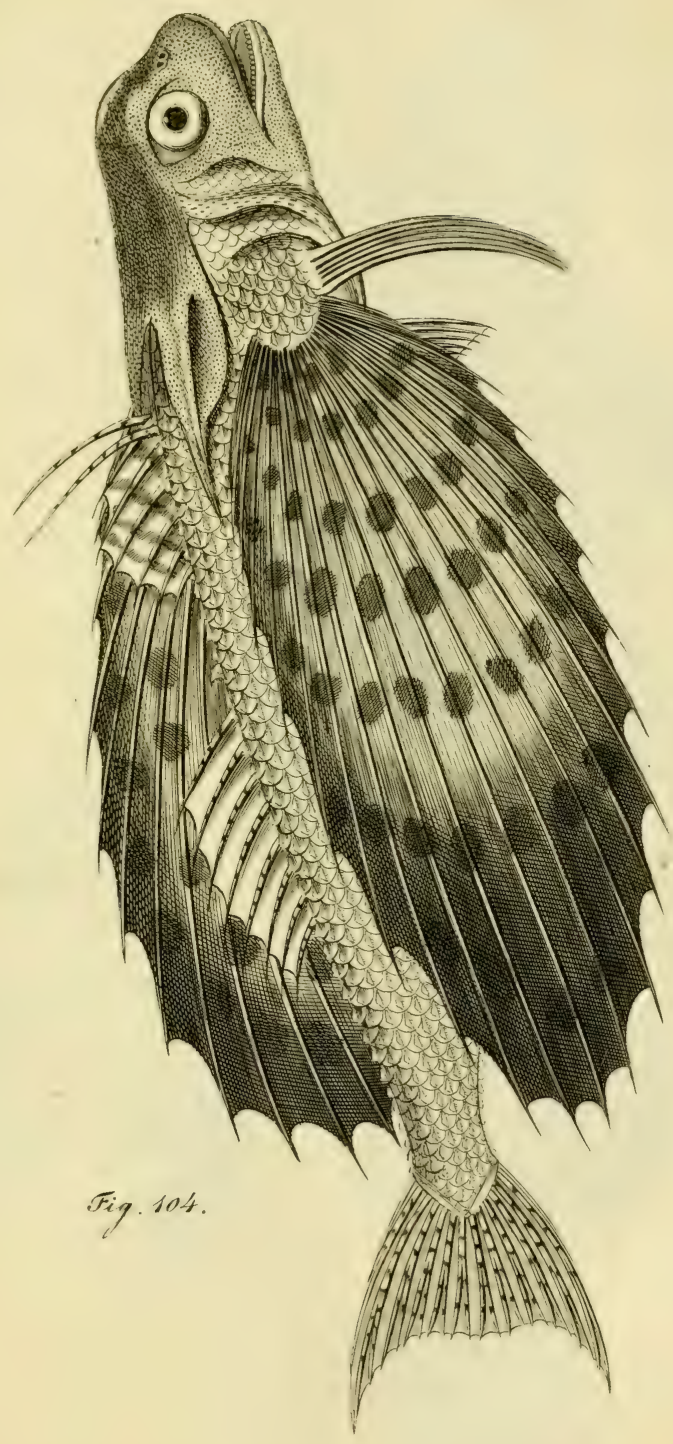



Trif 75.

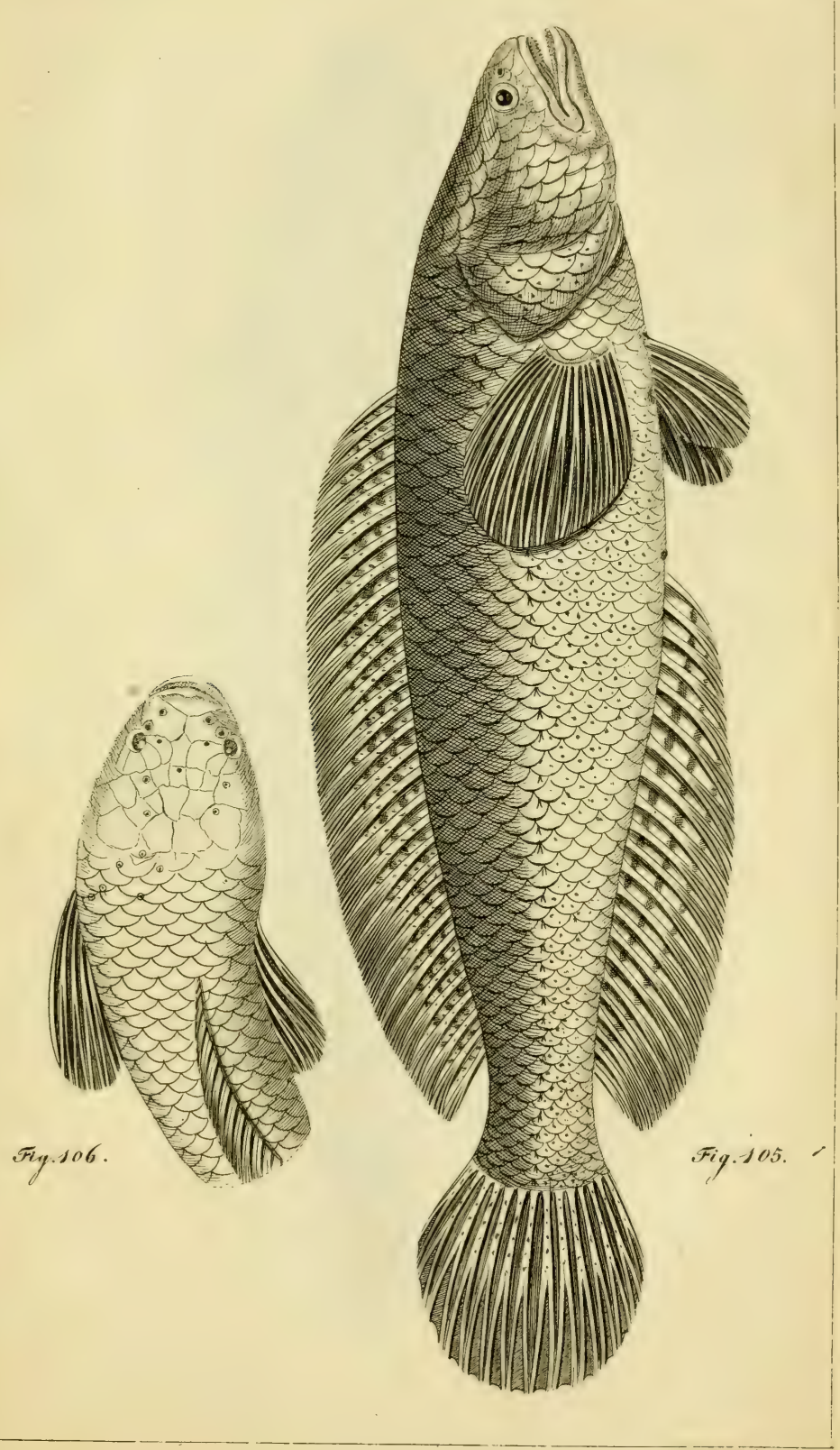





Tef $7 \%$

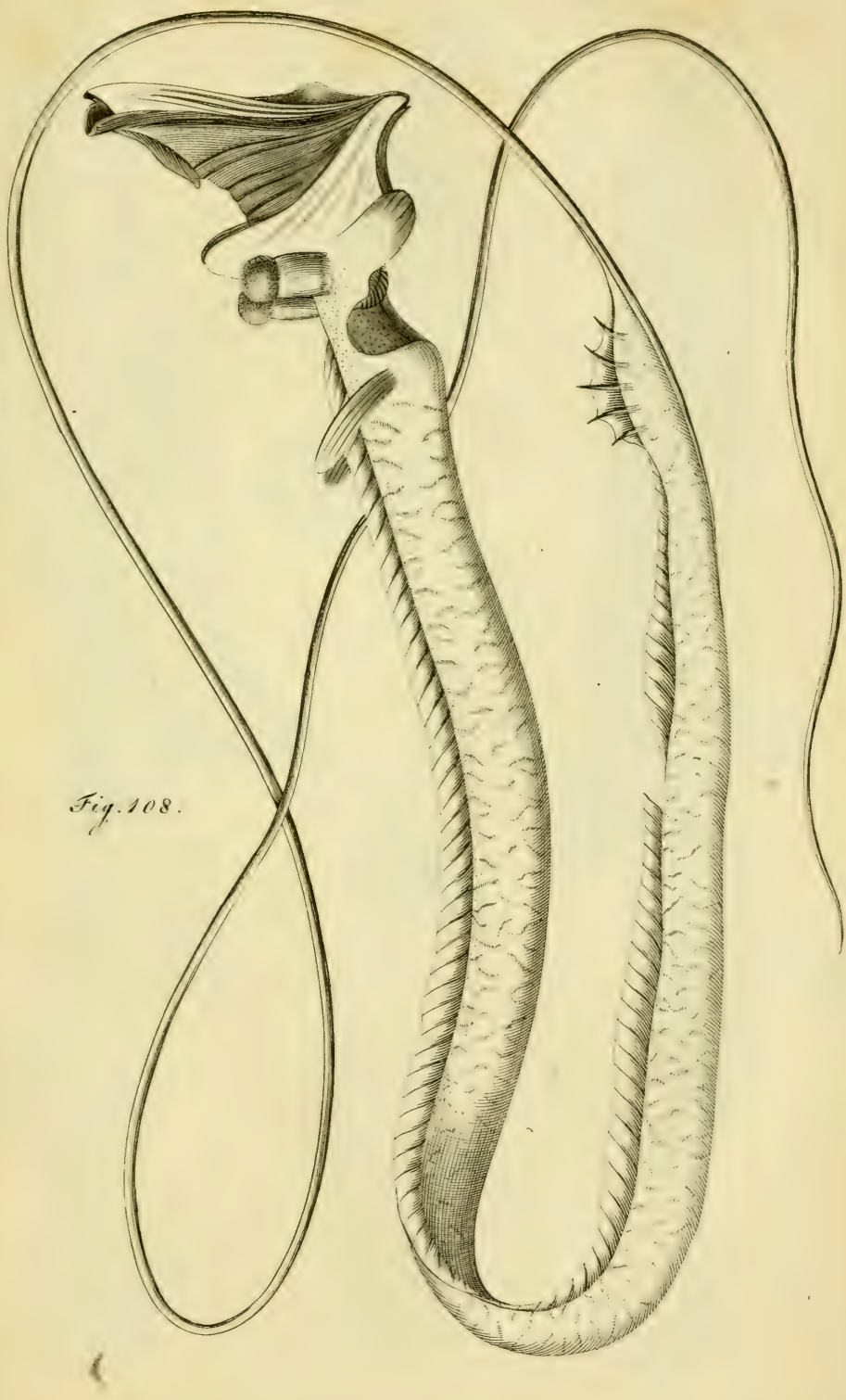



Tref. 78.

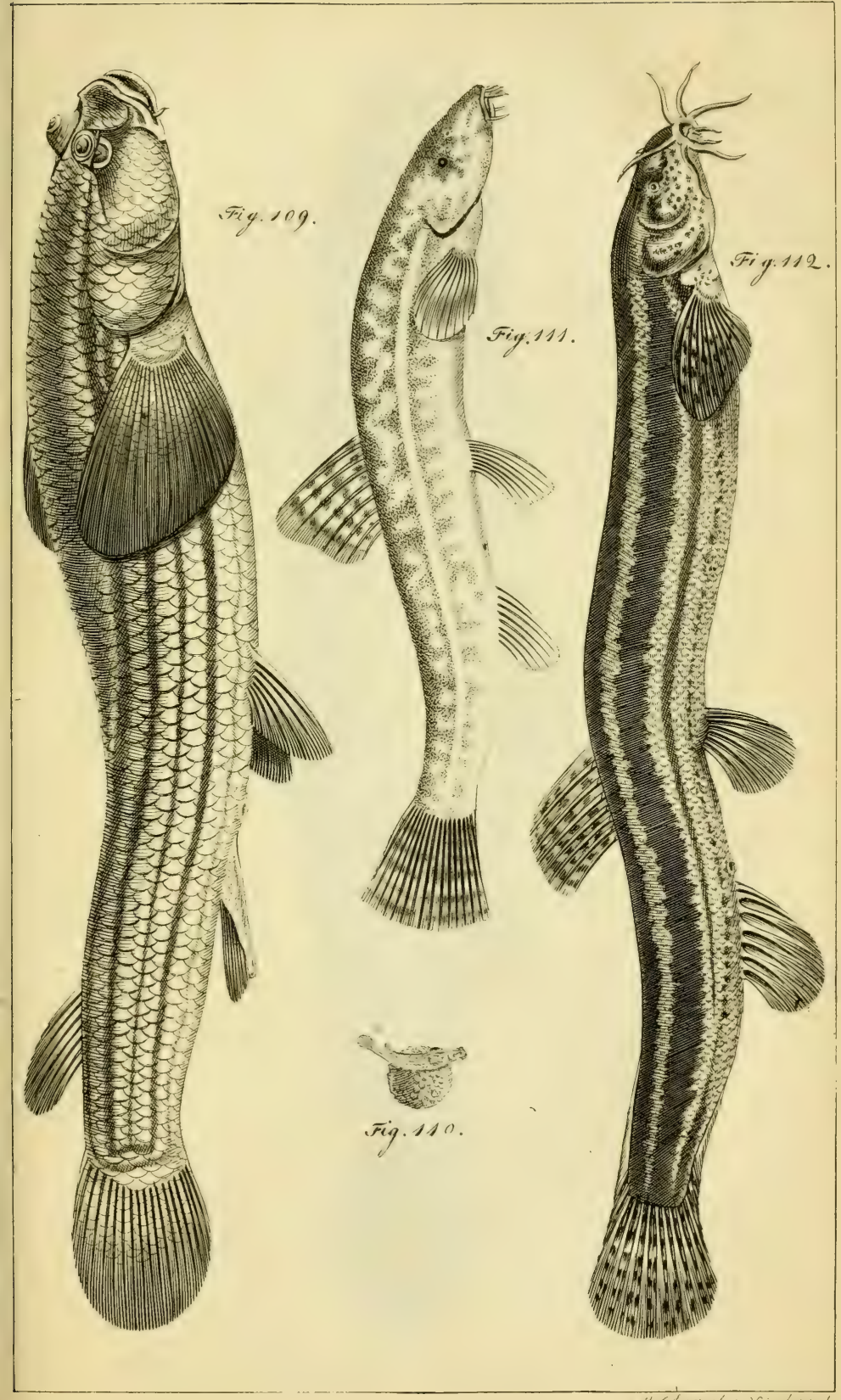







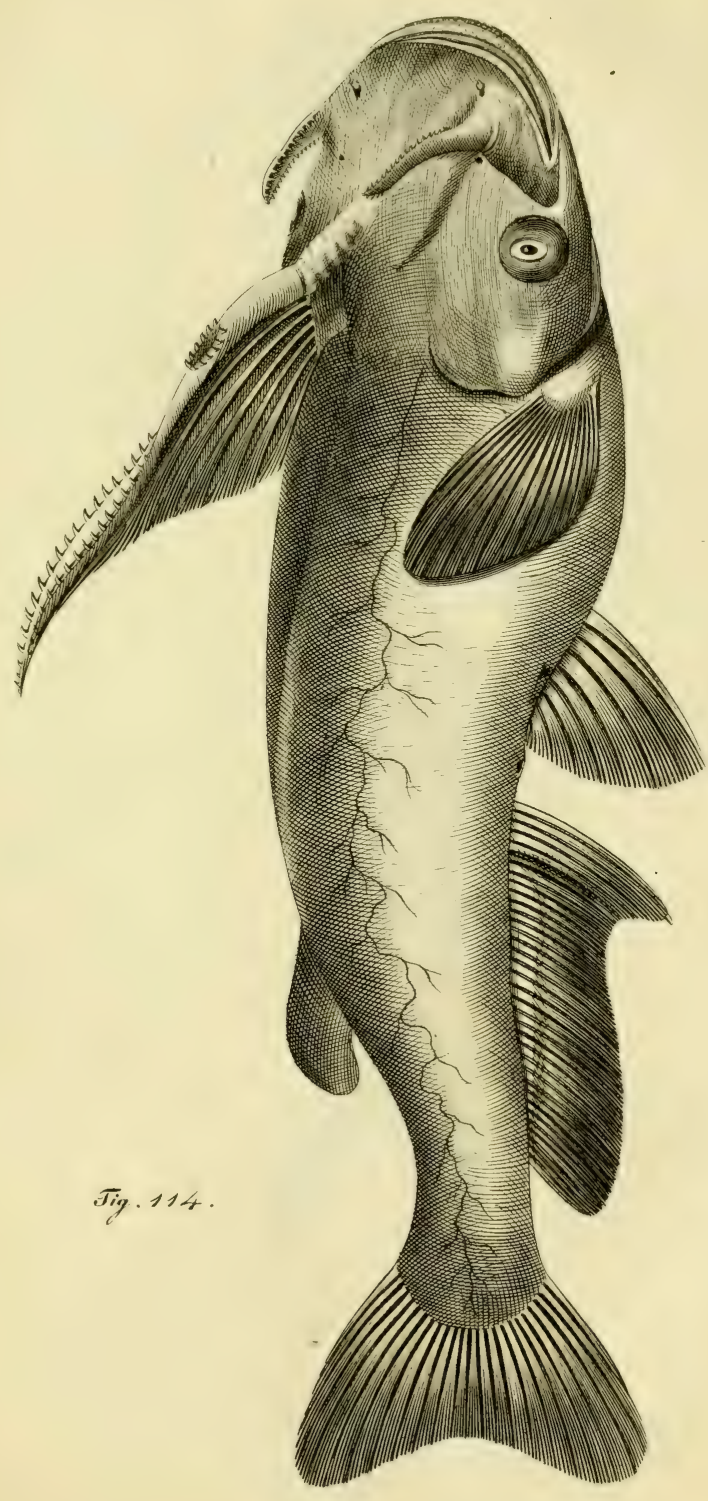



Tef. 81

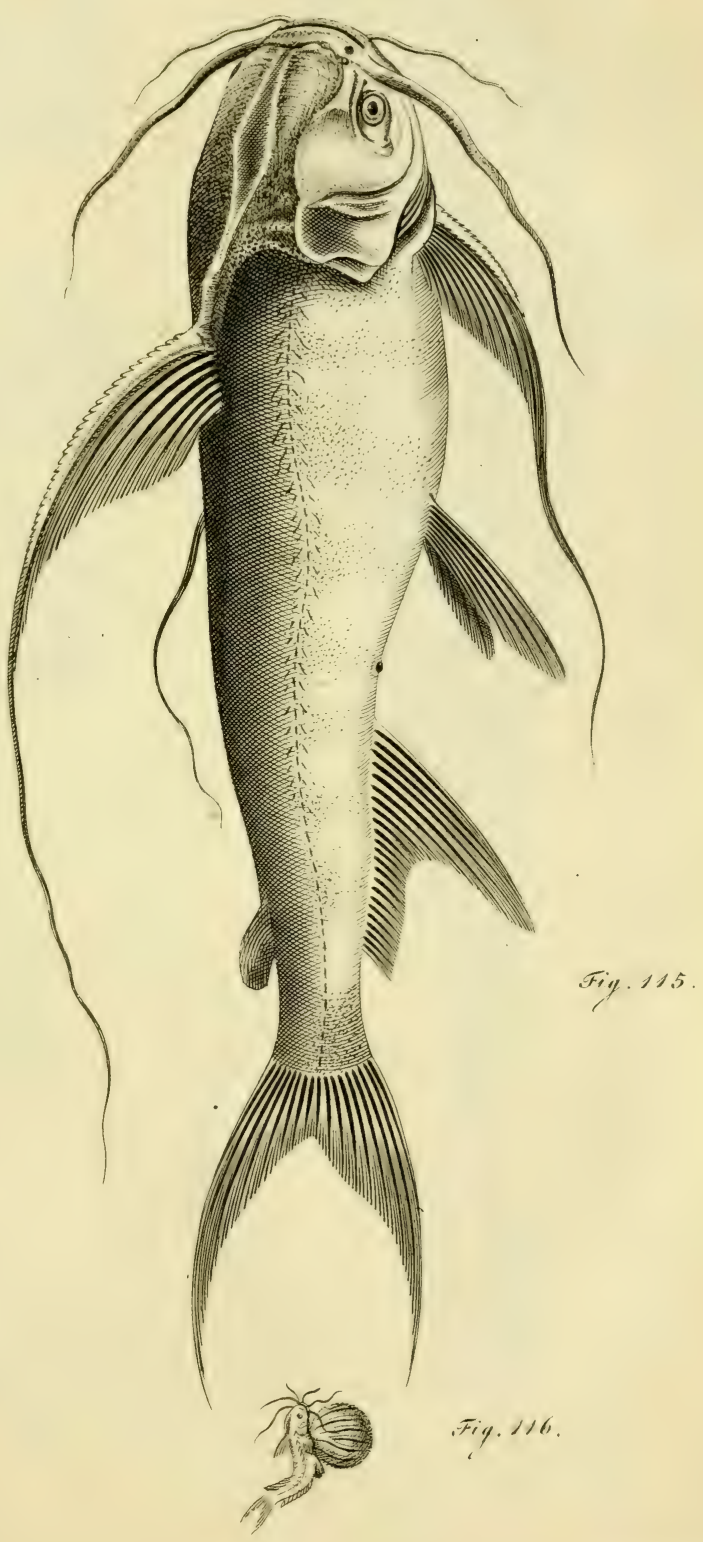



Tref. $8 \subseteq$.

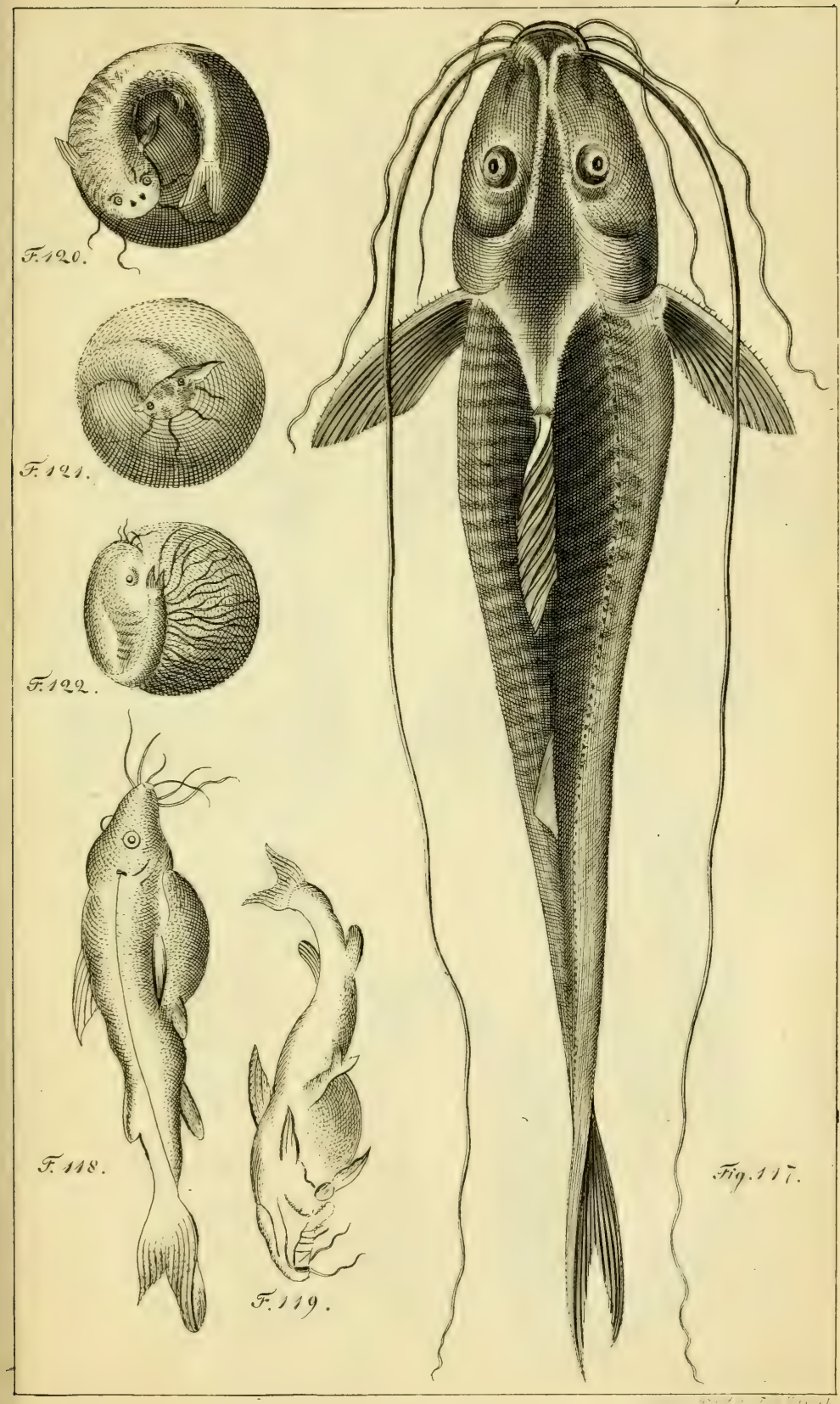



- Tre. 83.

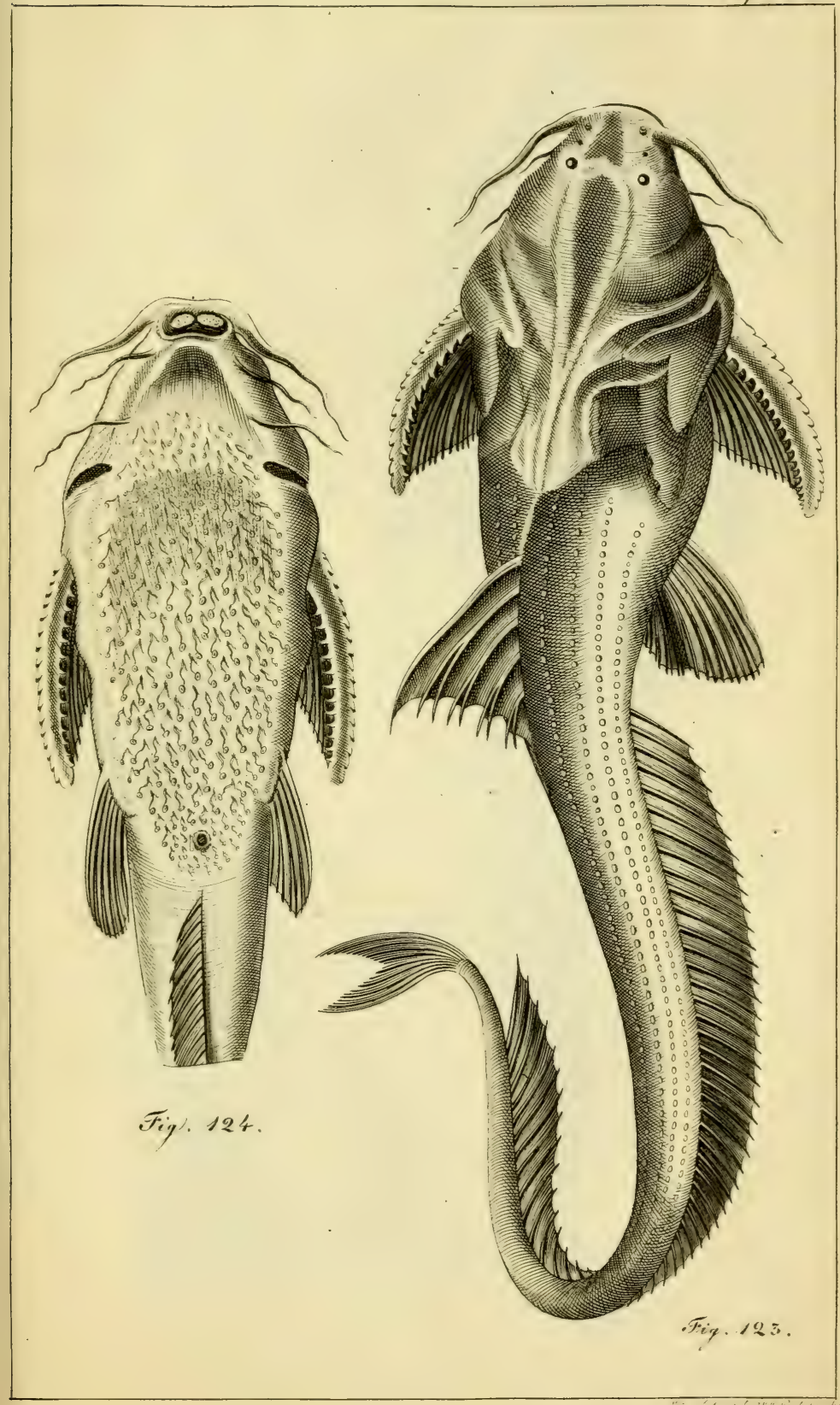


गान है
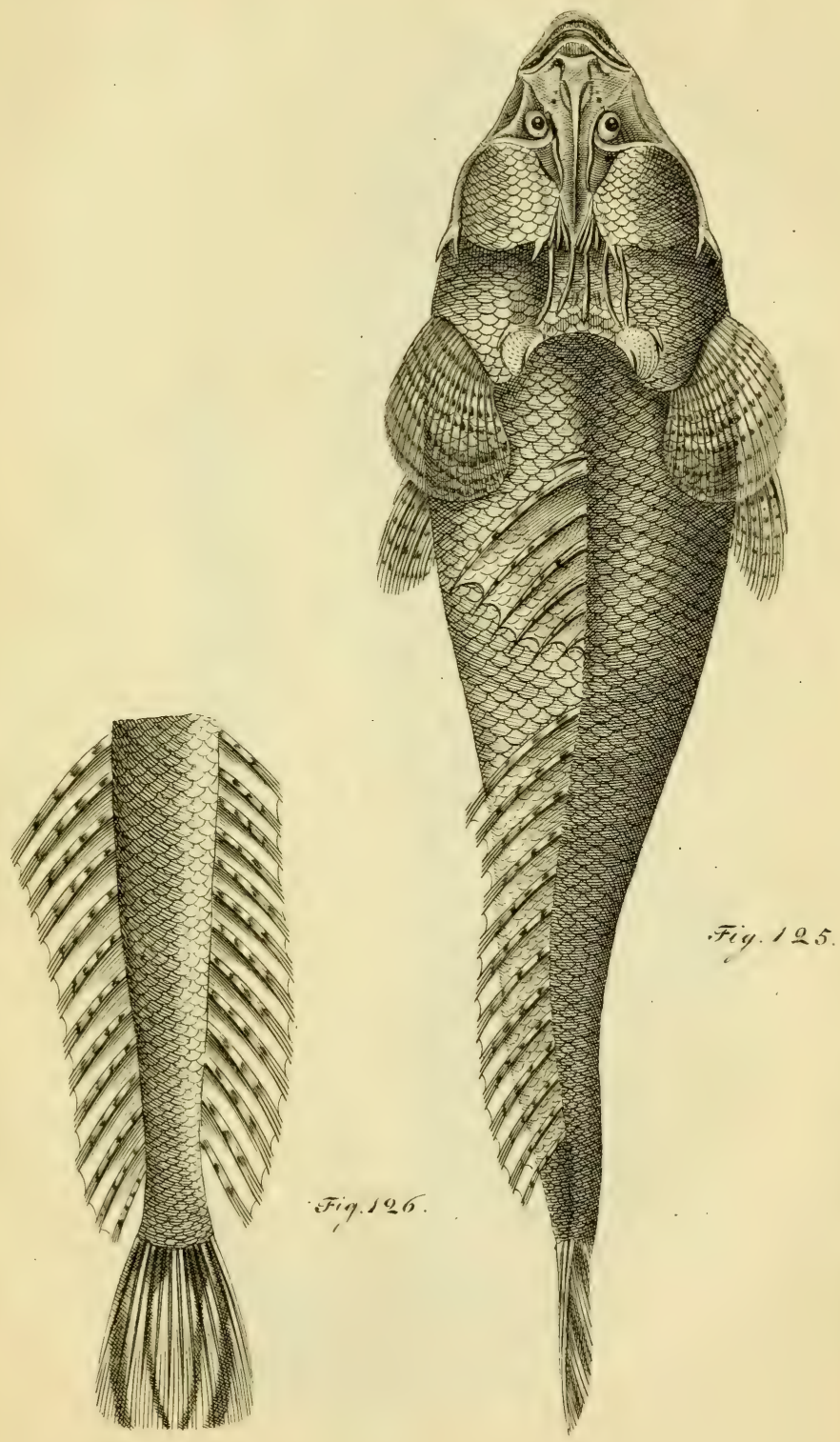

Taf: 85.

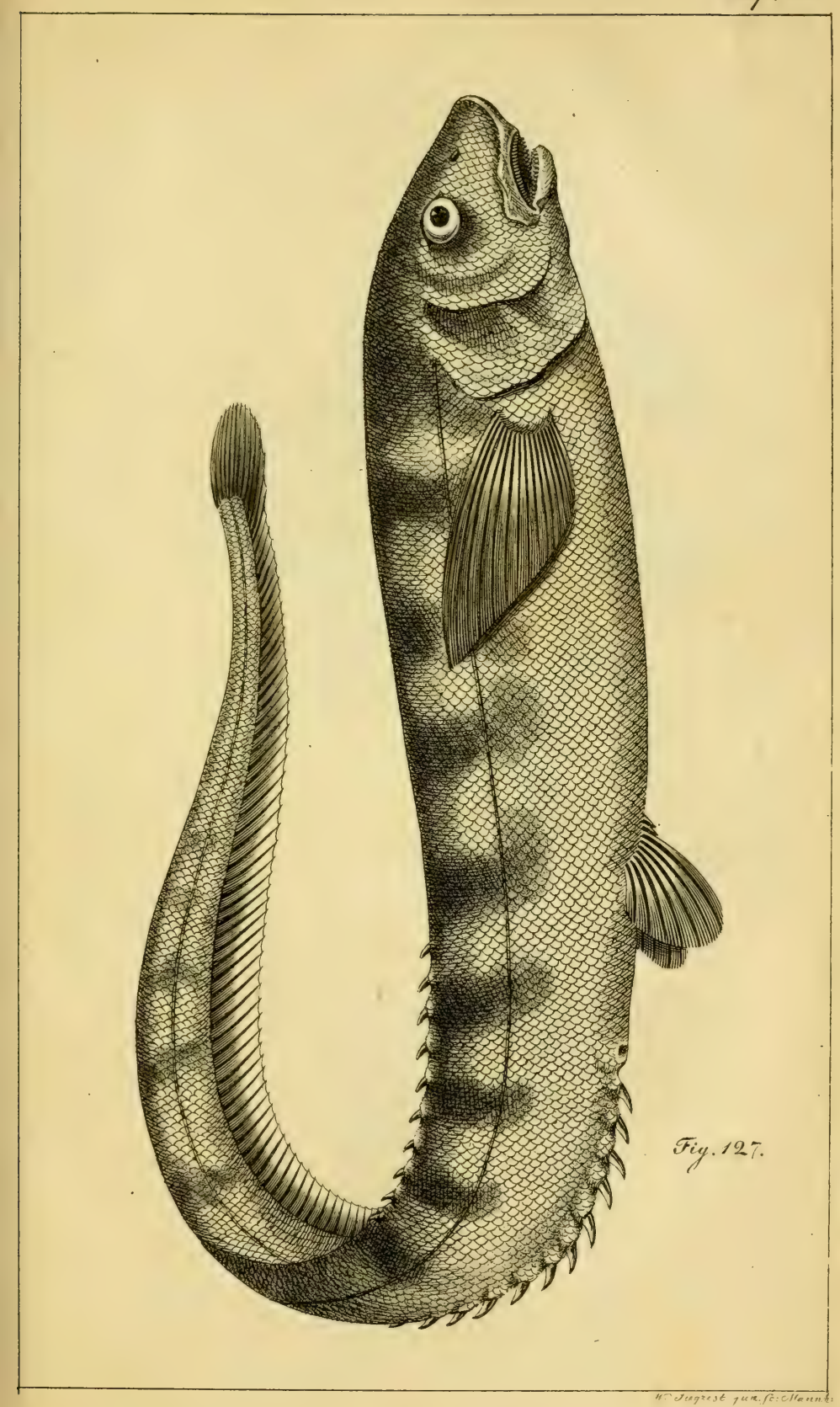



Tref. 86.

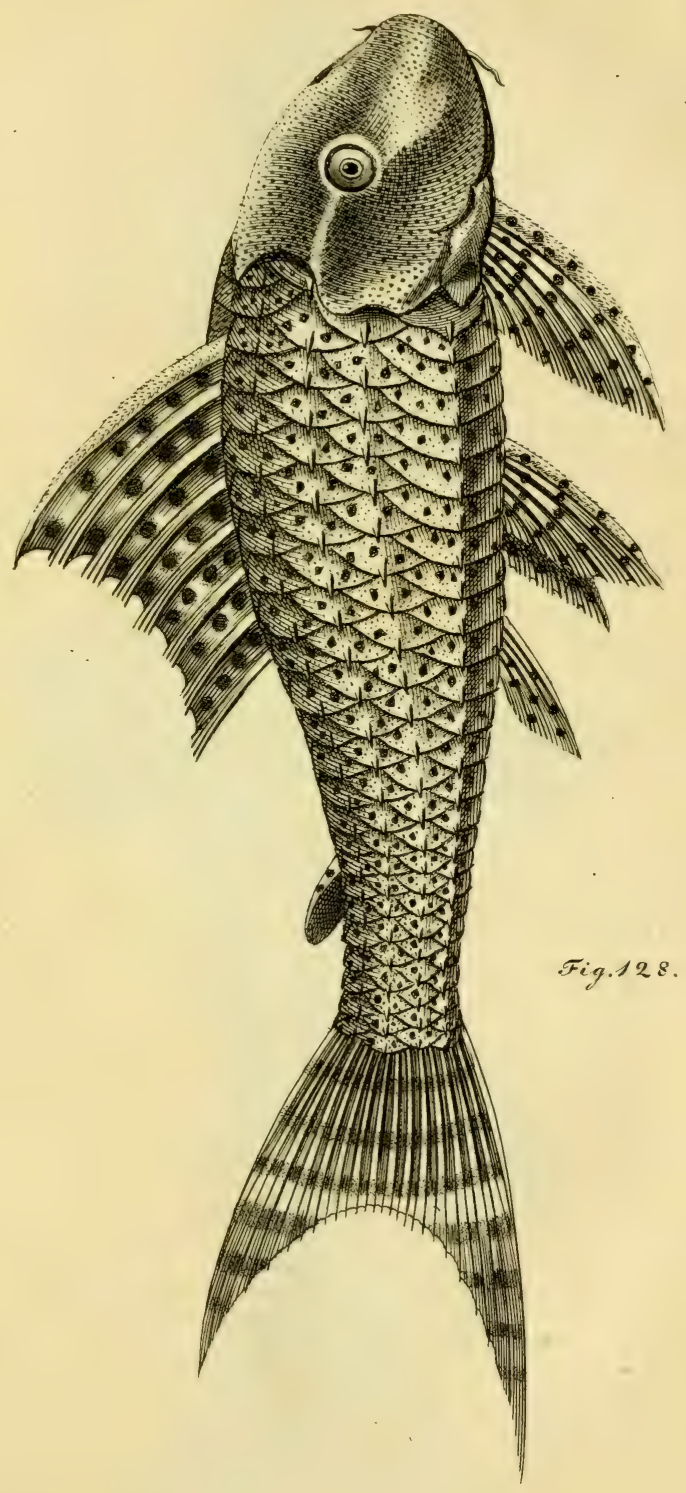







$$
\int
$$



Tref. 89 .

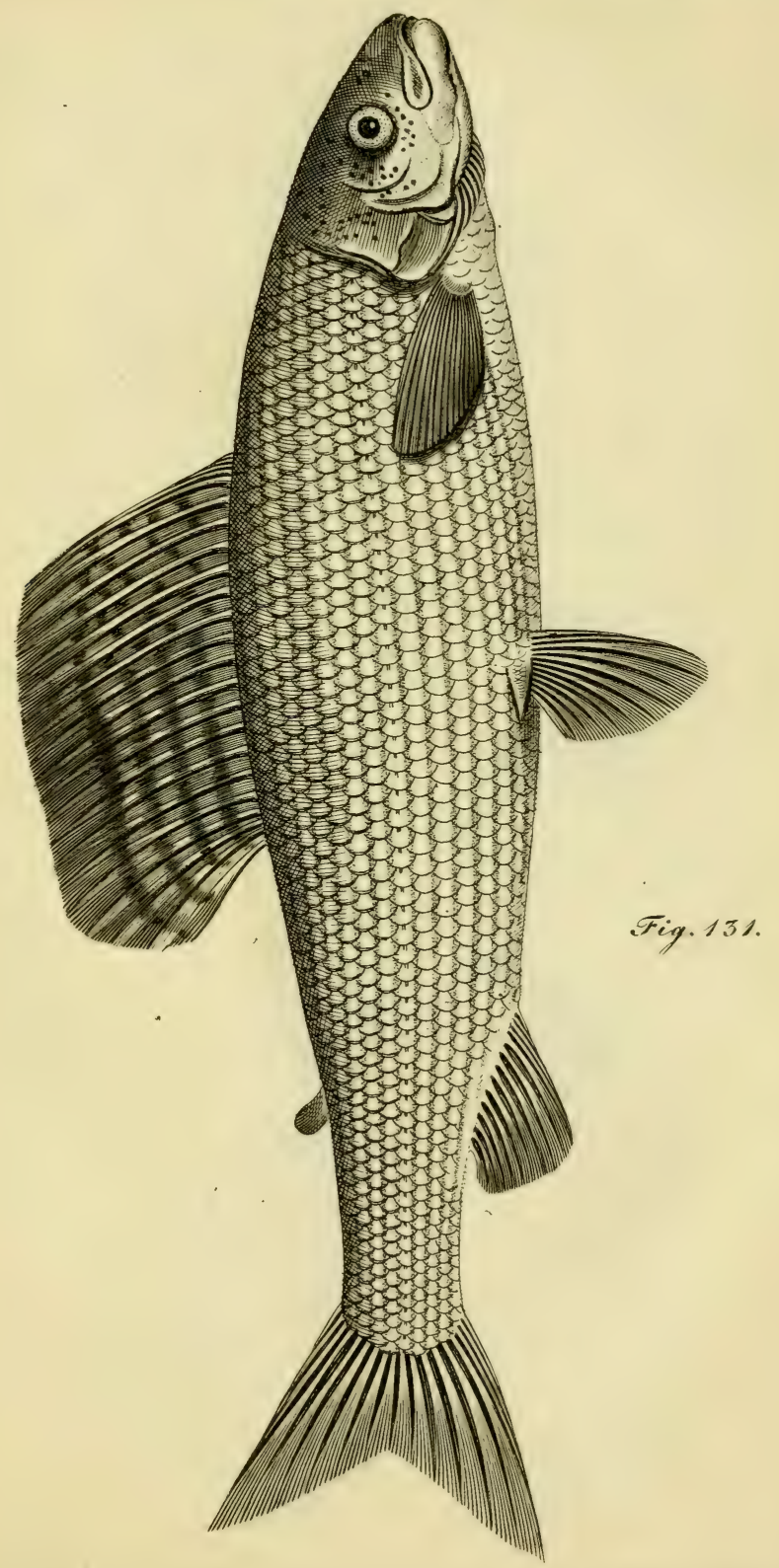





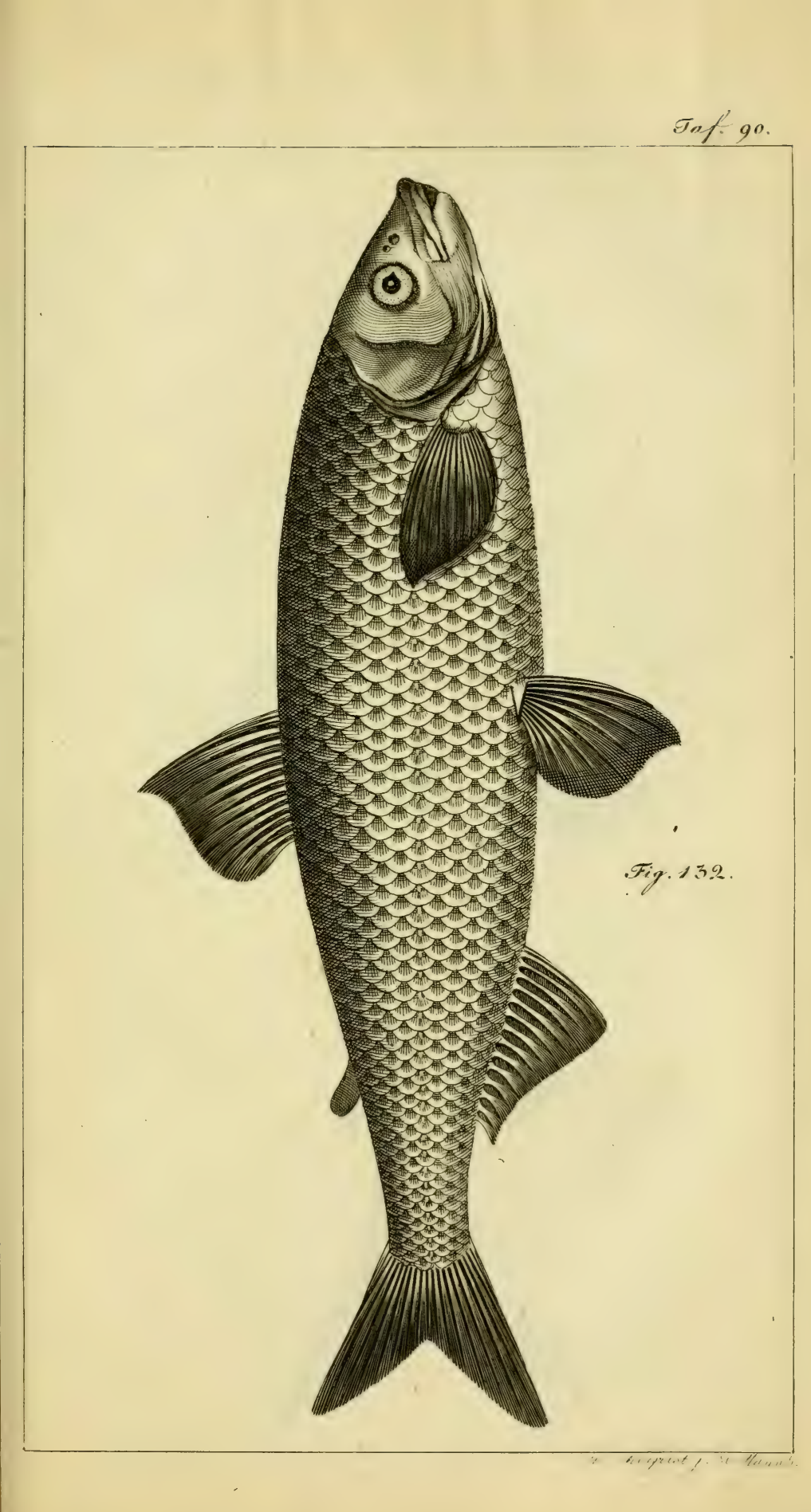





$$
\delta_{0}
$$



Tilt. 92.

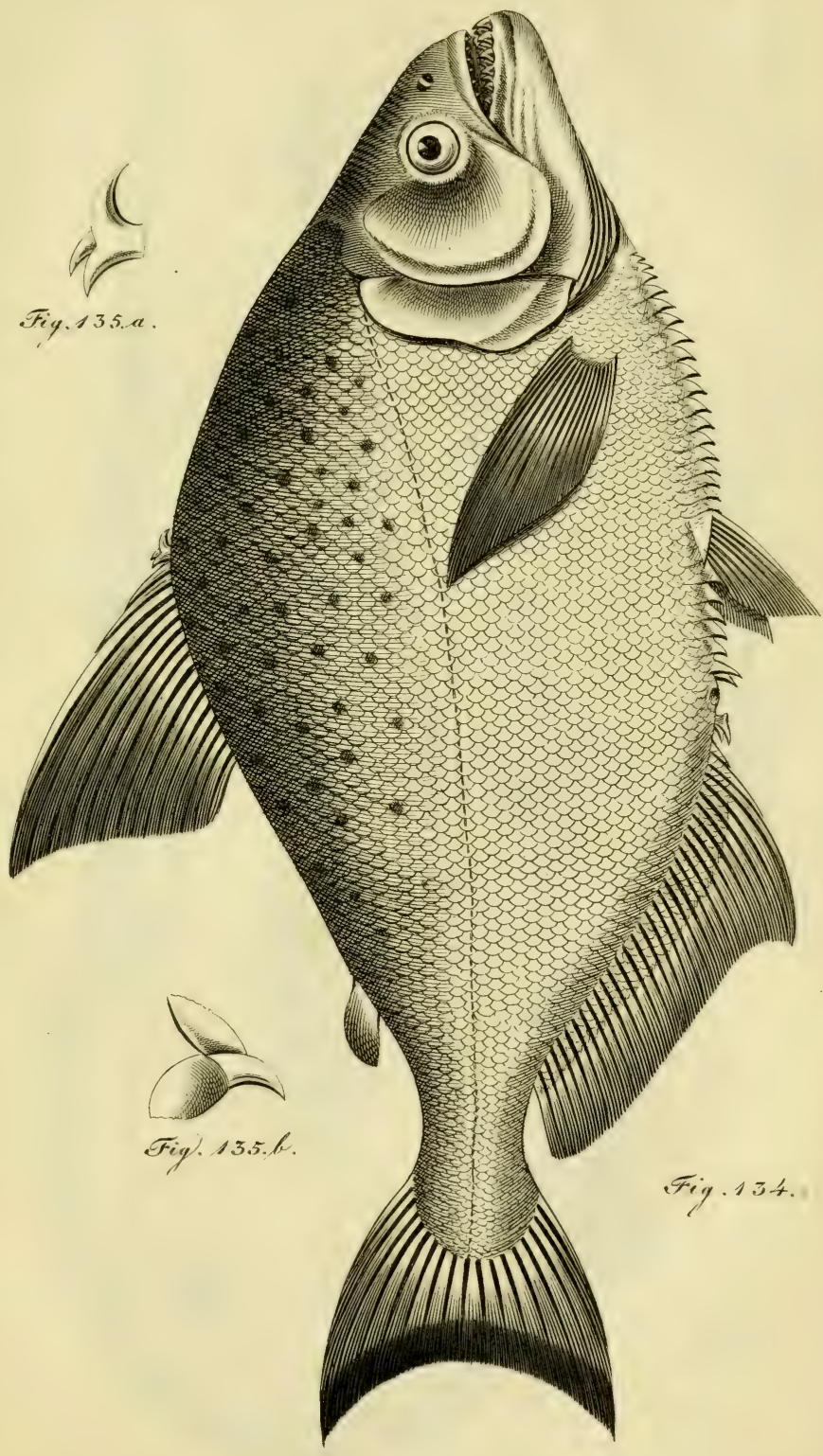



Ta/. 95.
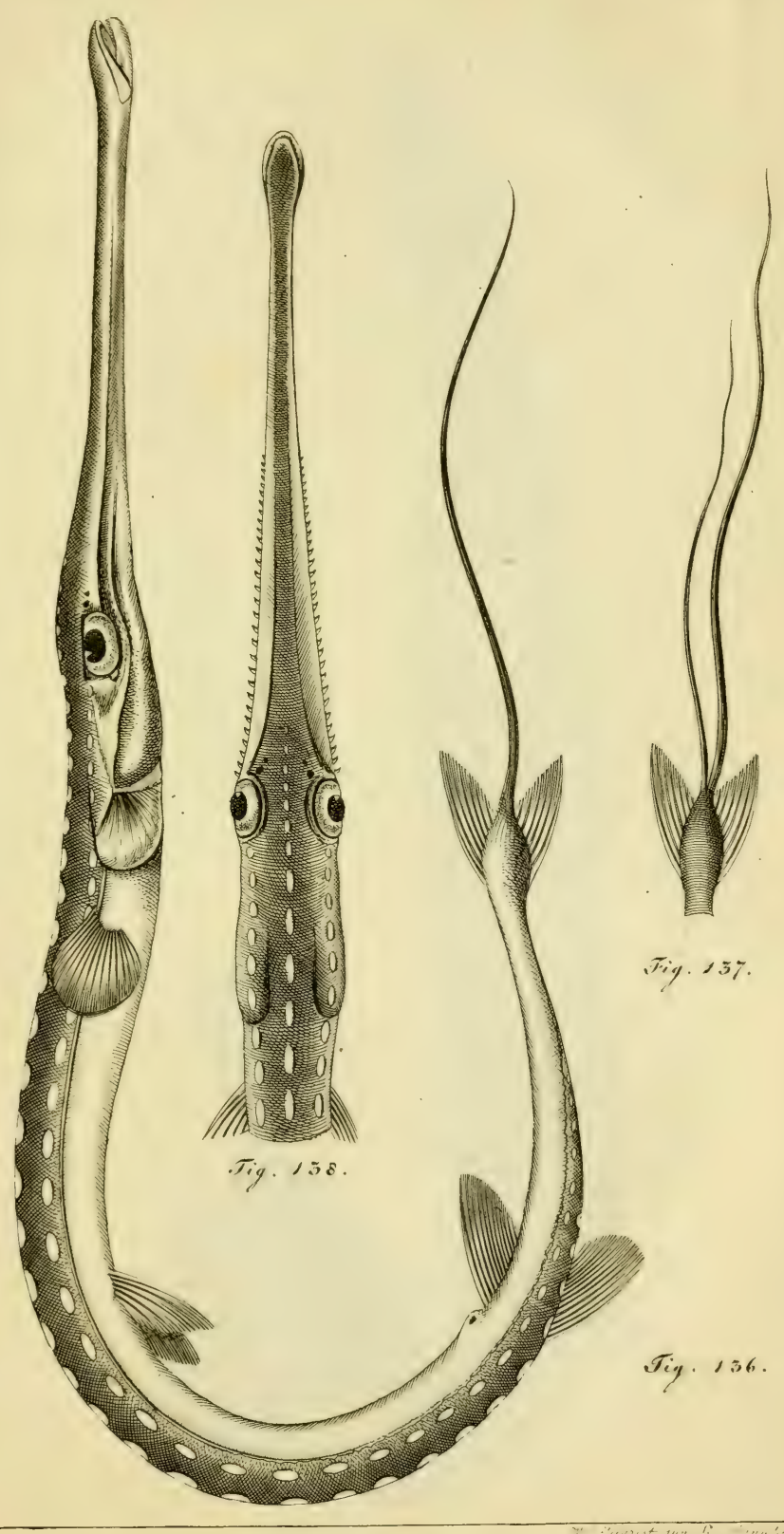

Tral. 94.

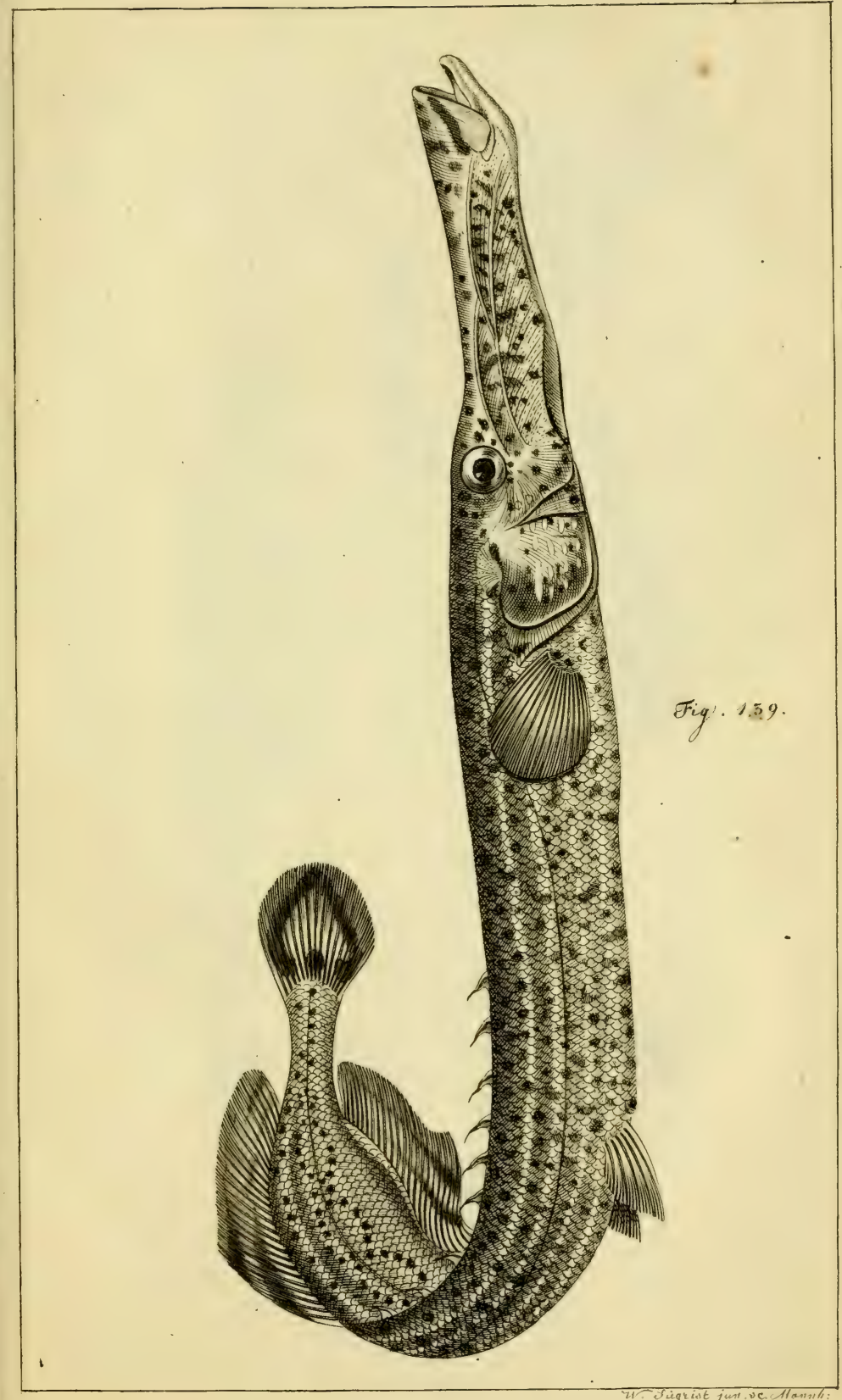



Trif. g.5.

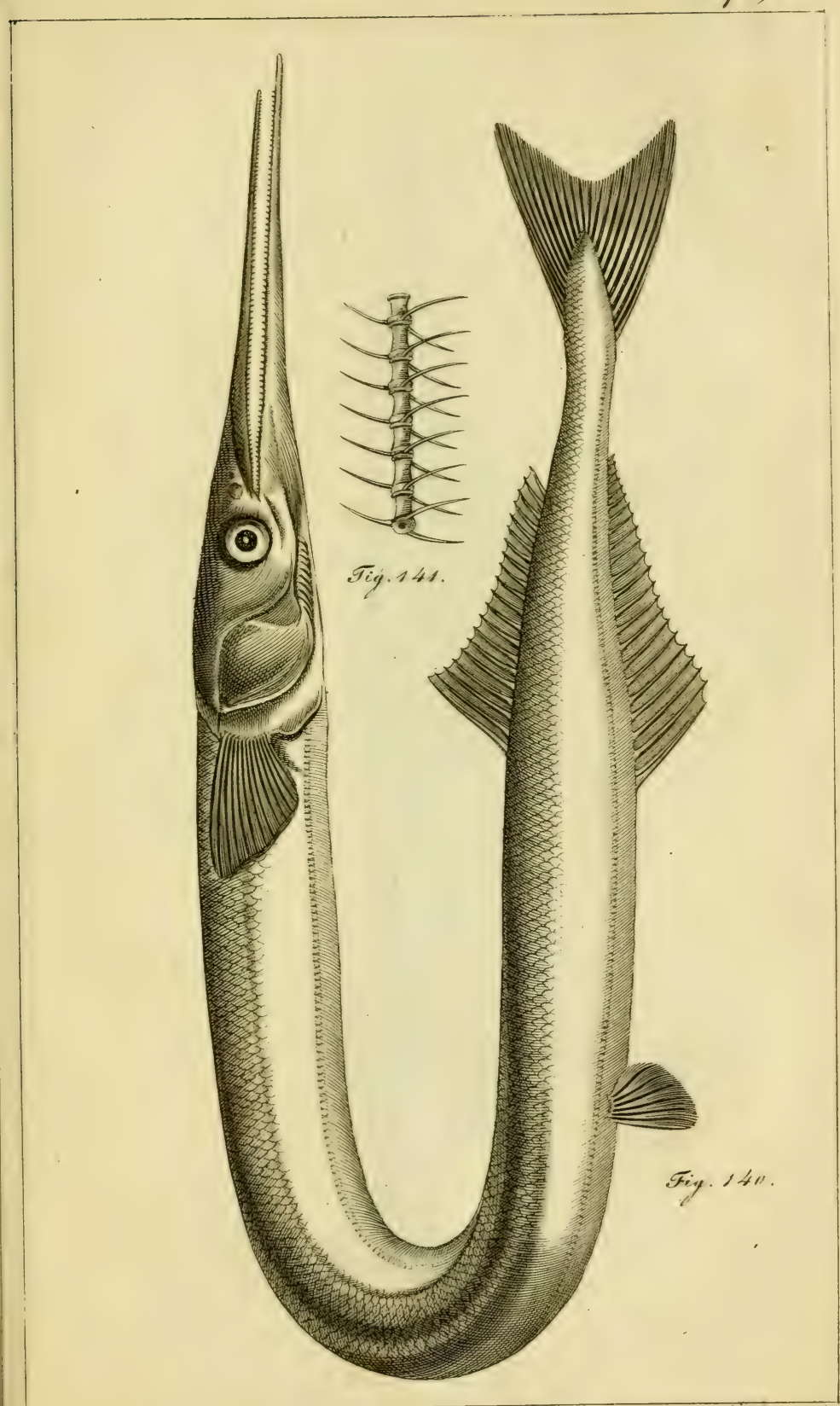









Tat: 99.

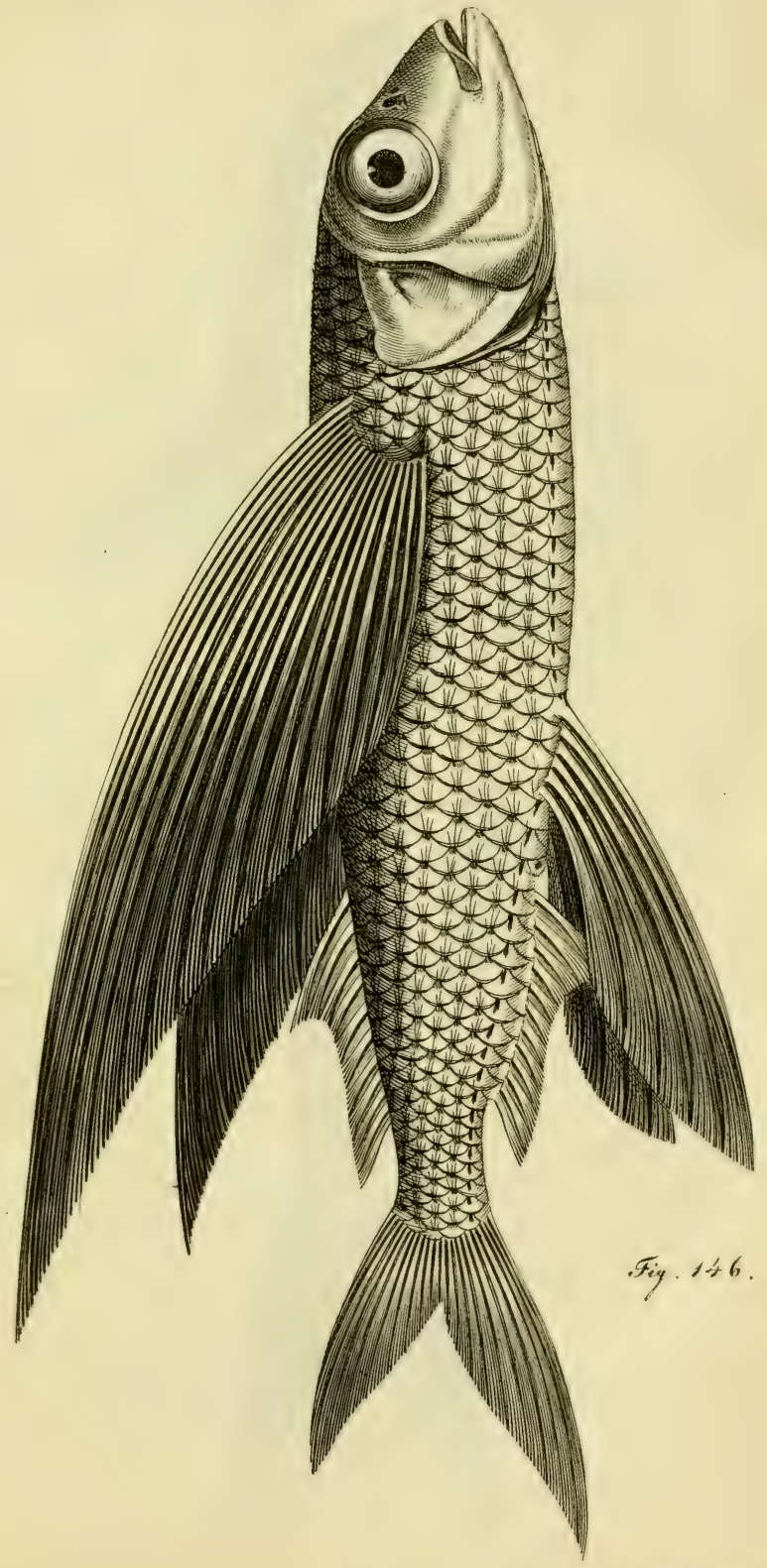





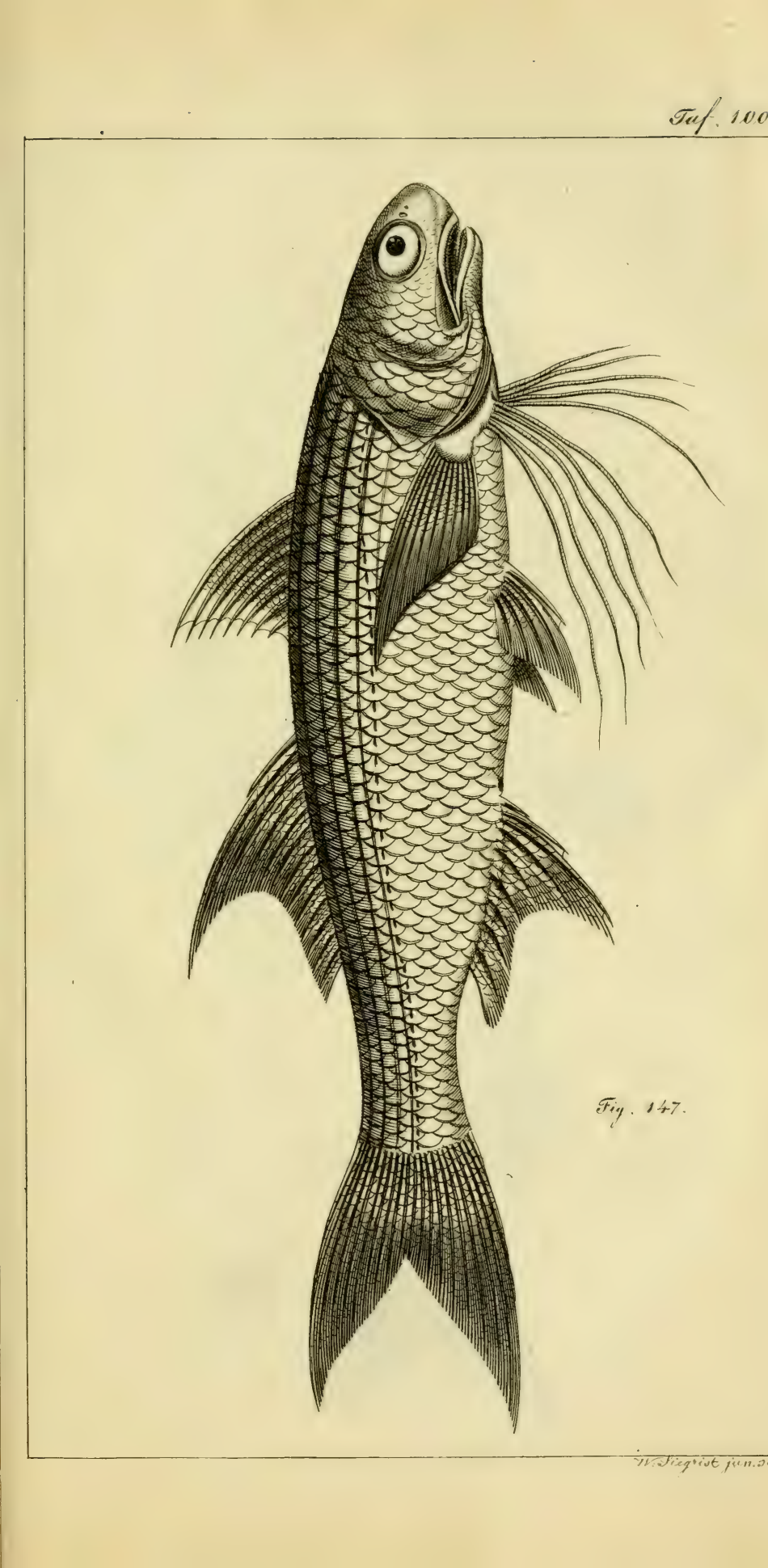





$$
\int
$$



Trfisor.

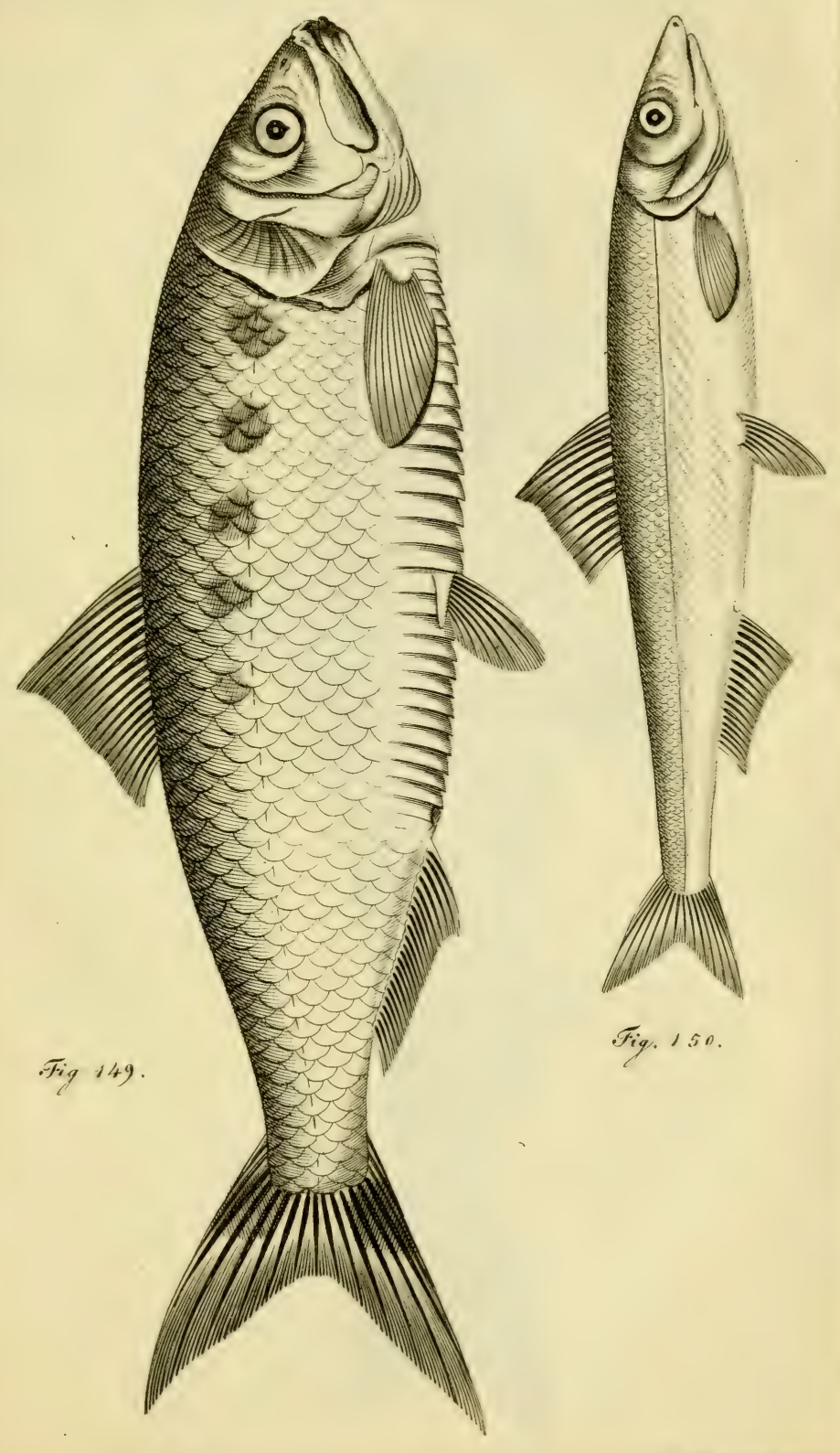





Taf. Iot.

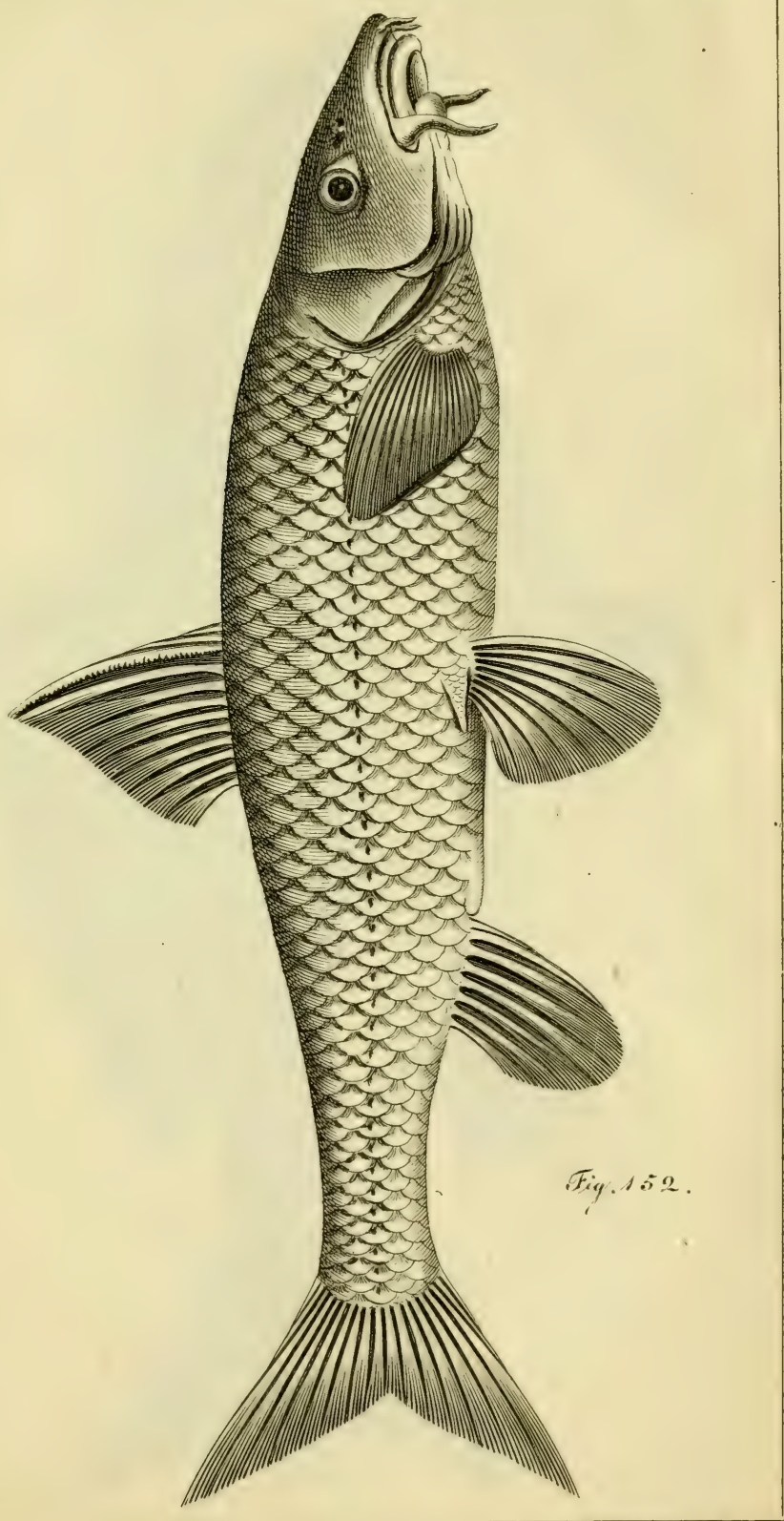





T"i, , "16

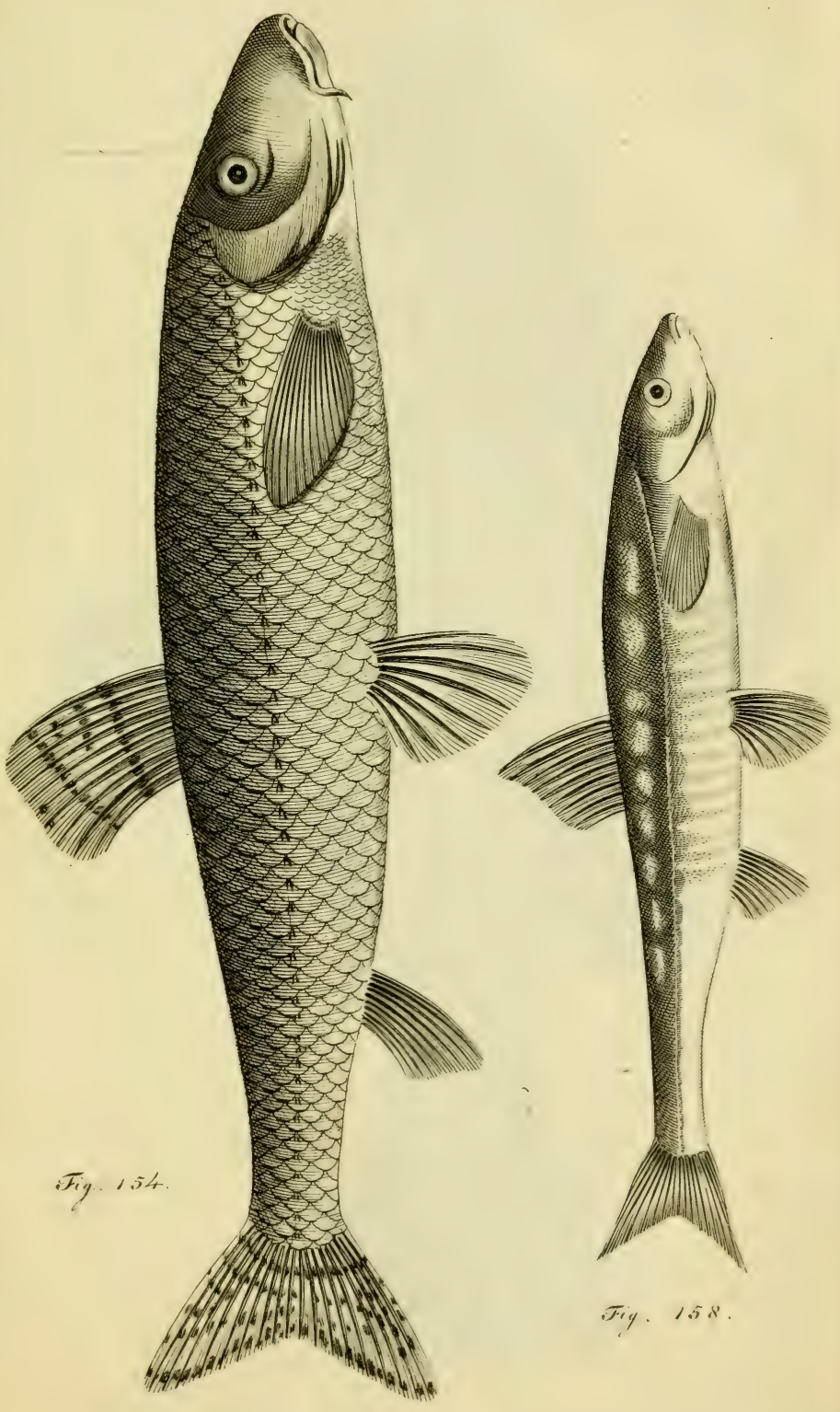





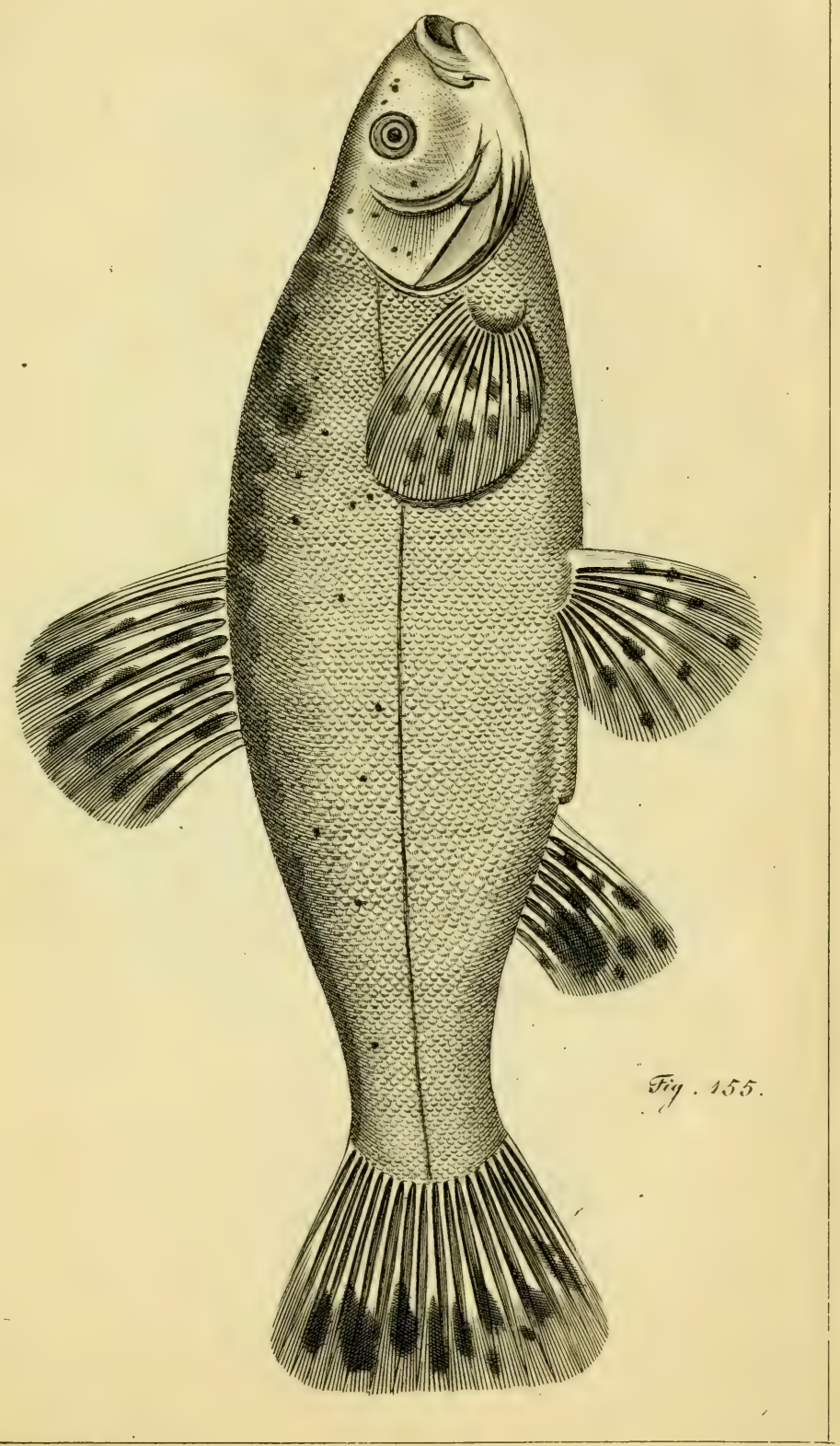



$\pi / 108$

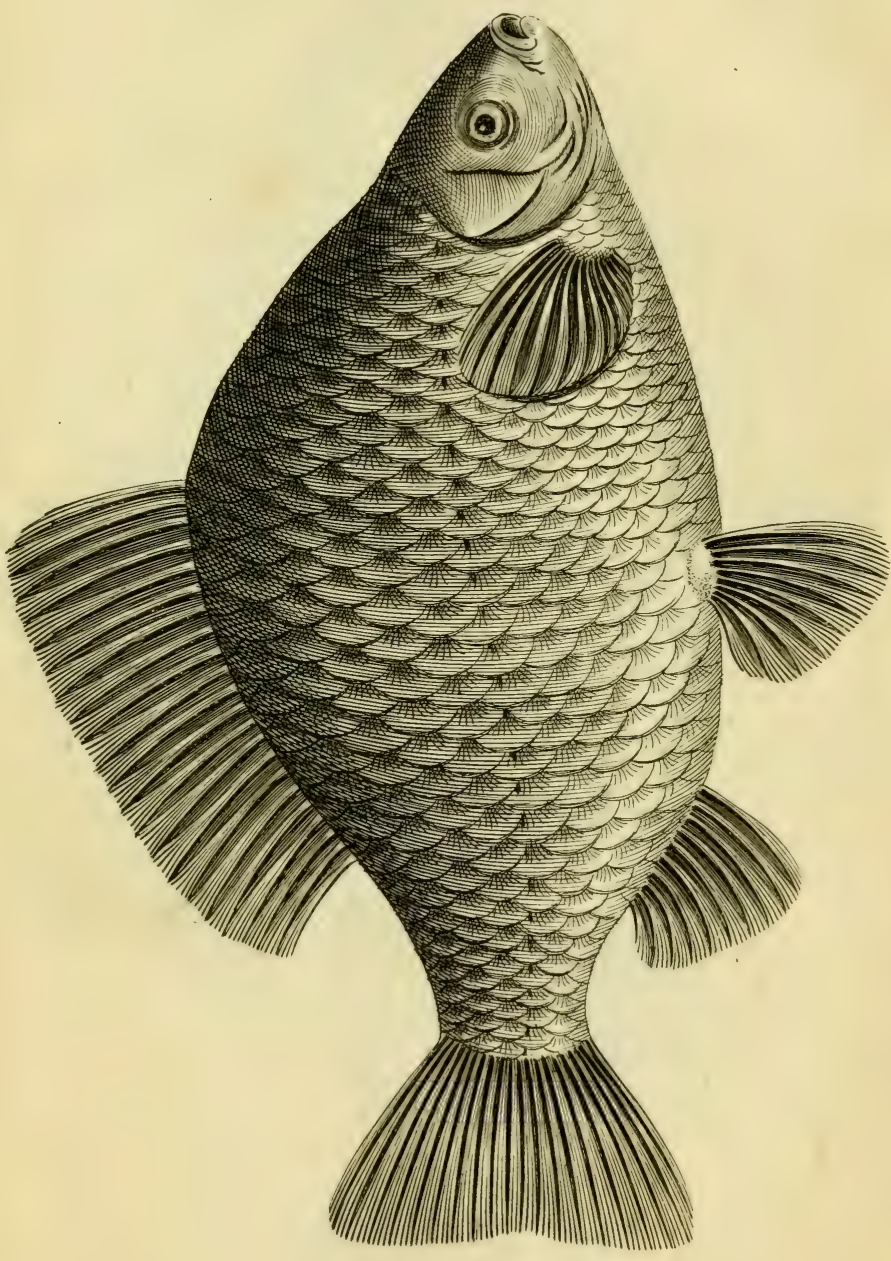

Fig. 156. 



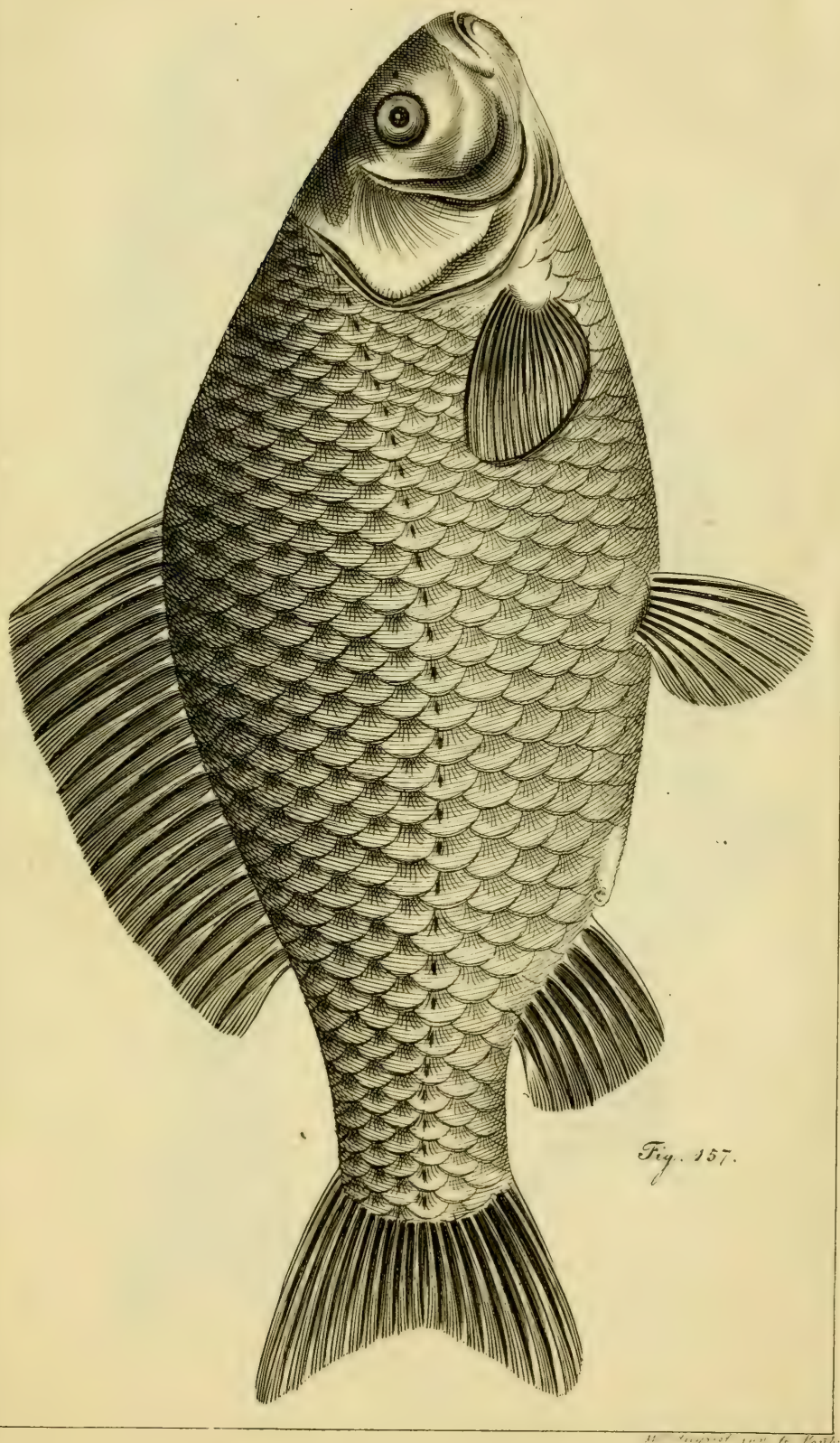


. 
Taf. 1100.

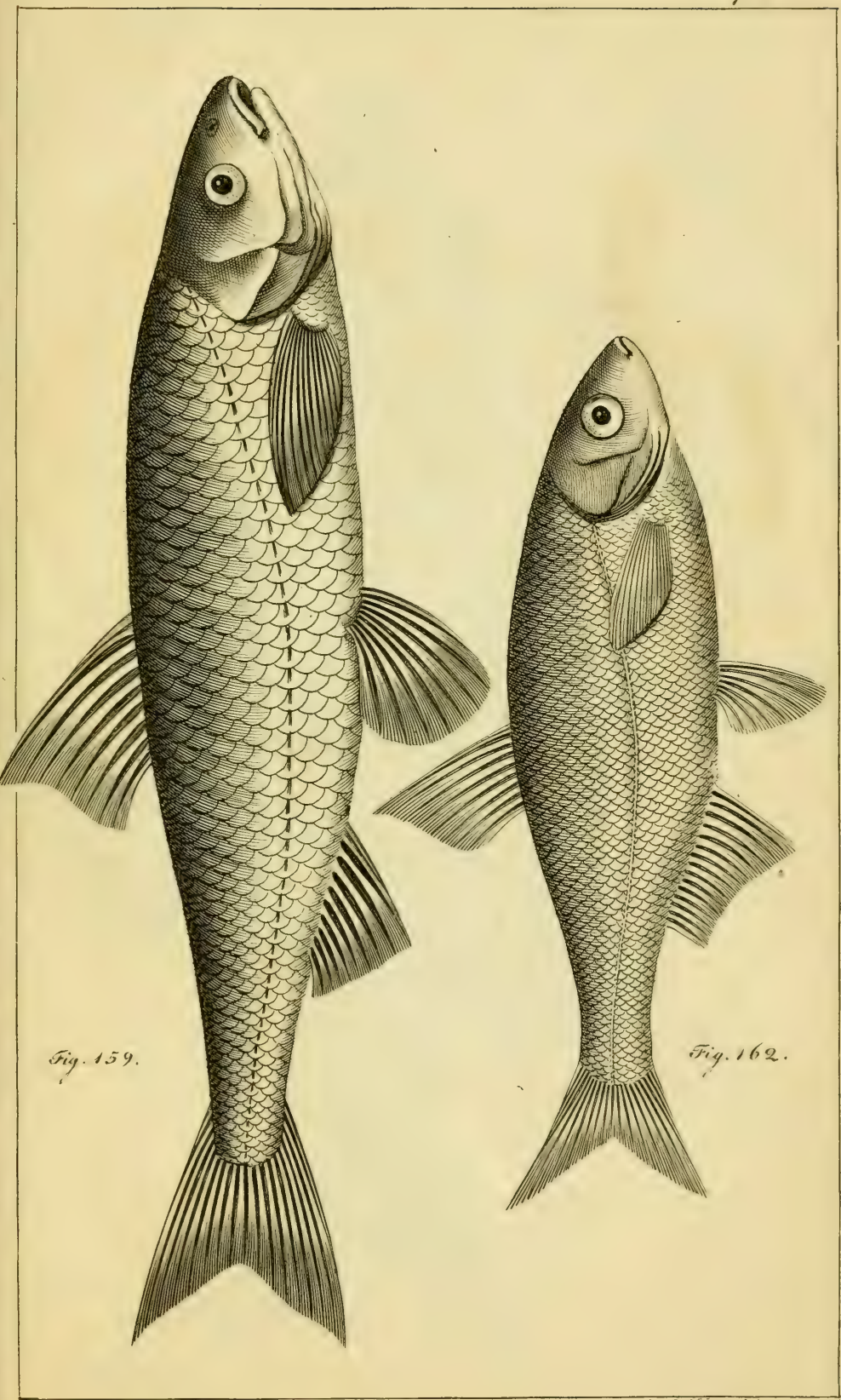



F F $/ 111$.

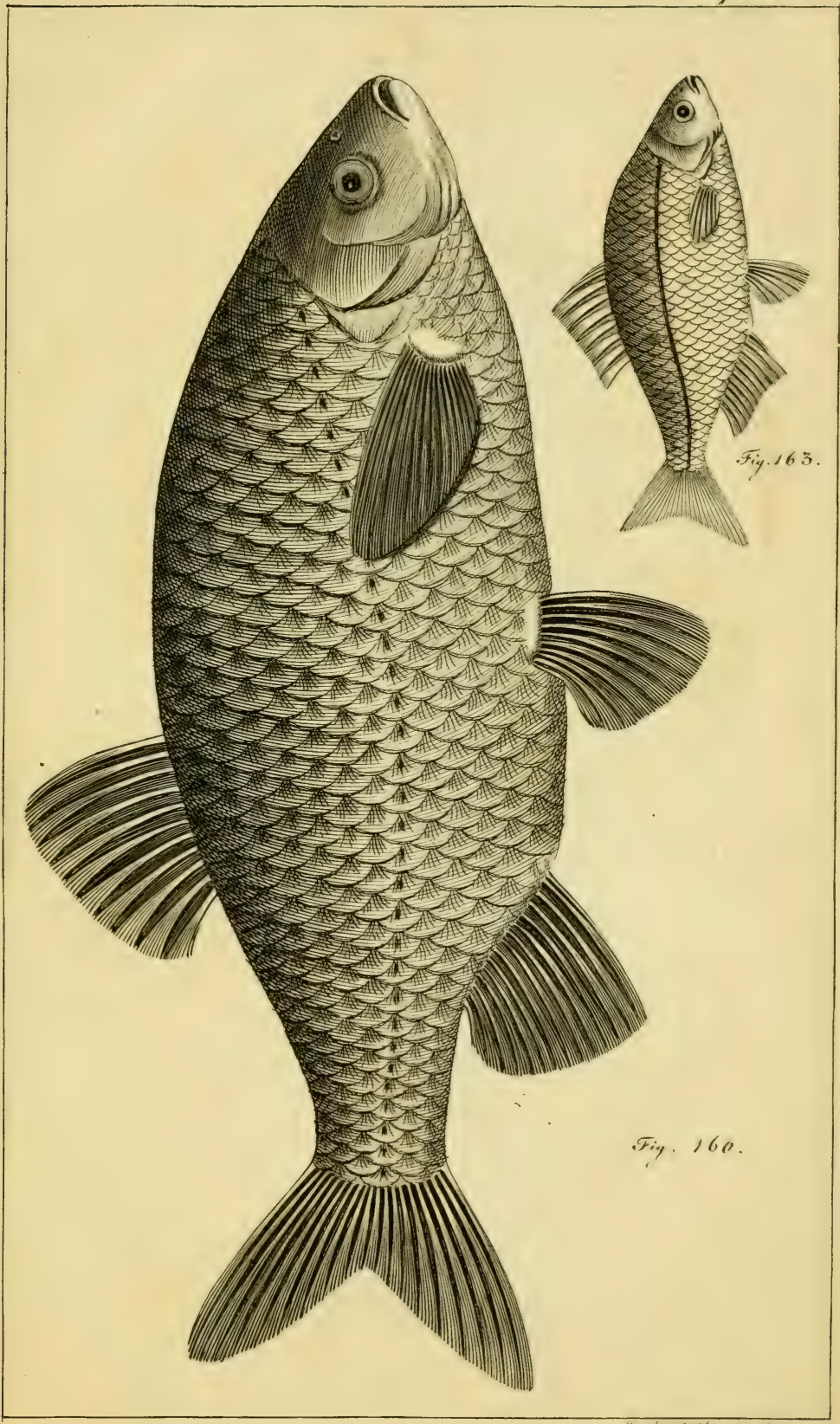




Tal. 11.3.

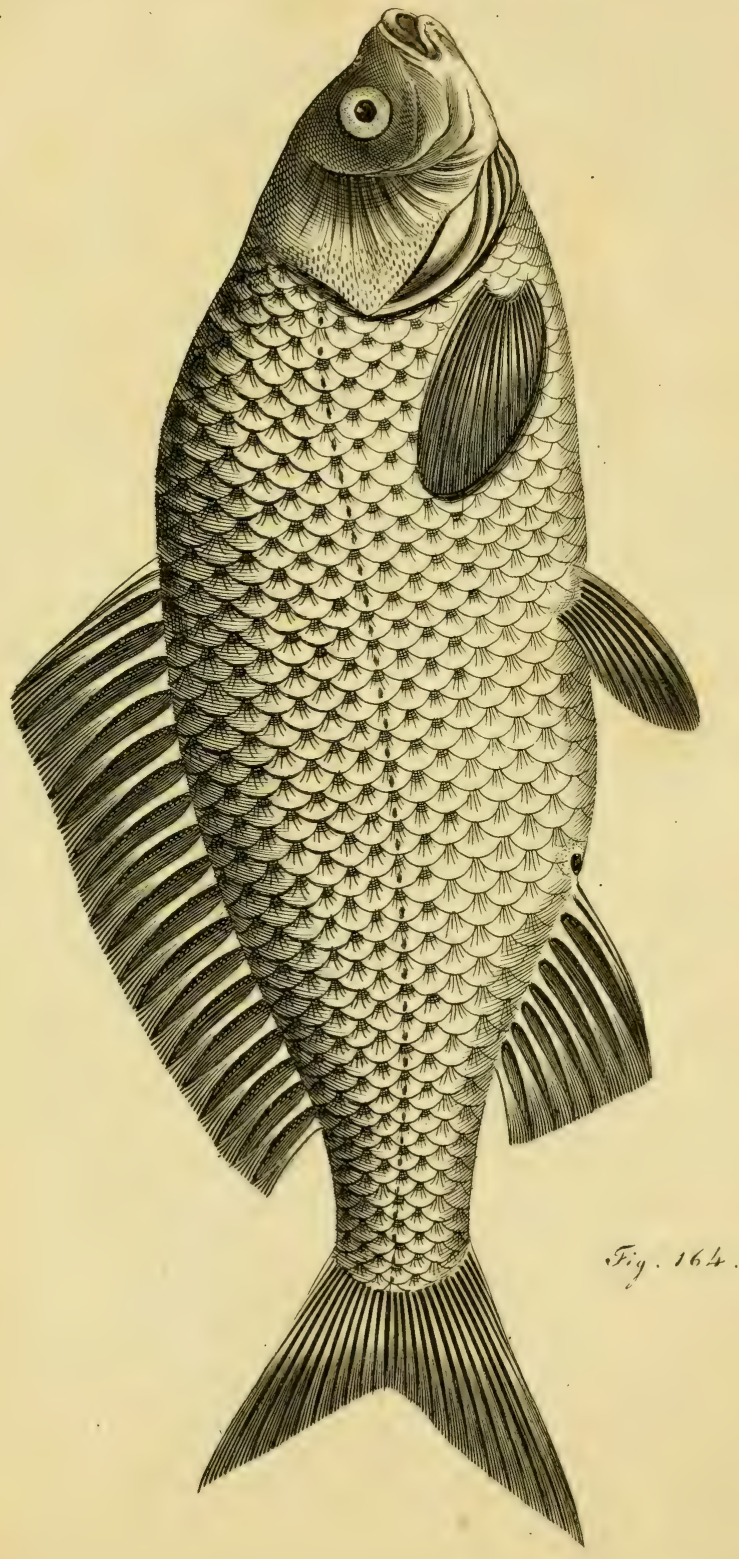







